GIANCARLO DE FILIPPI

\title{
MÉTODO PARA PLANEJAMENTO DA PRODUÇÃO E GESTÃO DE PRAZOS DE EMPREENDIMENTOS IMOBILIÁRIOS
}

Tese apresentada à Escola Politécnica da Universidade de São Paulo para a obtenção do título de Doutor em Ciências.

SÃO PAULO 


\section{MÉTODO PARA PLANEJAMENTO DA PRODUÇÃO E GESTÃO DE PRAZOS DE EMPREENDIMENTOS IMOBILIÁRIOS}

Tese apresentada à Escola Politécnica da Universidade de São Paulo para a obtenção do título de Doutor em Ciências.

Área de concentração: Engenharia de Construção Civil e Urbana.

Orientador: Prof. Livre-Docente Silvio Burrattino Melhado.

SÃO PAULO 
Este exemplar foi revisado e corrigido em relaçāo à versāo original, sob responsabilidade única do autor e com a anuência de seu orientador.

Sāo Paulo, de de

Assinatura do autor:

Assinatura do orientador:

Catalogação-na-publicação

De Filippi, Giancarlo Azevedo

Método para planejamento da produção e gestão de prazos de empreendimentos imobiliários / G.A. De Filippi -- versão corr.--- São Paulo, 2017.

$295 p$.

Tese (Doutorado) - Escola Politécnica da Universidade de São Paulo. Departamento de Engenharia de Construção Civil.

1.Construção civil 2.Planejamento da produção I.Universidade de São Paulo. Escola Politécnica. Departamento de Engenharia de Construção Civil II.t. 
Dedico este trabalho ao meu pai, José Antônio De Filippi, que me inspirou como profissional, professor, pai e amigo, e me ensinou a importância da retidão, a valorização da educação e a necessidade de sempre fazer o meu melhor. 


\section{AGRADECIMENTOS}

Ao meu orientador, Prof. Dr. Silvio Melhado, por acreditar no potencial do trabalho, por me inspirar e incentivar a continuidade do meu envolvimento com a academia, pelos conselhos nas horas mais difíceis. Pela parceria, não apenas no desenvolvimento desta tese, mas na elaboração dos artigos, apresentações em eventos, e por me indicar os melhores caminhos, sempre preservando meu ponto de vista sobre os pontos tratados nas pesquisas que desenvolvemos.

Aos meus pais, Maria Christina e José Antônio, pelo amor e dedicação durante toda a minha vida, por me ensinarem sobre respeito, igualdade, amizade, sobre o certo e o errado, a ter confiança, sobre limites (e que podemos superar os limites), e principalmente por nunca me cobrarem que eu fosse melhor do que os outros, mas sempre o melhor que eu pudesse ser, sem prejudicar ninguém.

À minha esposa Rosana, pelo carinho, incentivo e cumplicidade. Por sua determinação e valores, por acreditar e defender seus princípios e por nunca deixar que eu desistisse das coisas que eram importantes para mim. Por estar a meu lado em todos estes anos, me ajudando a ser mais crítico, por entender meus defeitos e me ajudar a crescer como profissional, marido e pai.

À minha querida filha Beatrice, por entender a importância desta etapa para mim, e aceitar as muitas noites que o papai não conseguiu dar a atenção devida que ela merecia por conta desta jornada acadêmica.

Aos meus irmãos Graziela e Gianflávio, e demais familiares, por fazerem parte da minha vida, da minha formação, pela força nos momentos de ansiedade e pela vibração das minhas conquistas.

Aos colegas de doutorado da POLI e da FEA, que compartilharam conhecimento, angústias, trabalhos, seminários, referências, livros e um pouco de suas experiências profissionais e educacionais, que me ajudaram a ver as coisas de formas diferentes.

Ao engenheiro e visionário Roberto de Souza, por suas lições de empreendedorismo, e por suas diversas facetas como pesquisador, empresário, consultor, chefe, sócio, doutor, palestrante, surfista e ator. Por me mostrar que é possível se reinventar sempre, ser ao mesmo tempo técnico e artista, competente e irreverente. 
Aos demais colegas e ex-colegas do Centro de Tecnologia de Edificações, começando pelo Geraldo Mekbekian, que me lançou no mundo do planejamento e do gerenciamento, estendendo-se por todos os profissionais de alto nível que conviveram comigo nestes muitos anos de empresa. À toda minha equipe de Unidade, em especial Rodrigo Quadrado, Juliana Pasotto, Breno de Oliveira e Thiago Gomes, pelo apoio no trabalho e ajuda no desenvolvimento dos estudos de caso.

Aos membros da minha banca, professores Sheyla Baptista Serra e Mauricio Bernardes, pelos elogios, críticas e sugestões. E em especial, aos professores Ariovaldo Denis Granja e Luiz Reynaldo Cardoso, por suas contribuições enriquecedoras durante minha qualificação, e que permitiram elevar o nível do trabalho, deixando-me mais confiante com o resultado final.

Aos colegas de planejamento Francisco Santos, Carlos Eduardo Oliveira, Rafael Almeida, Marcos Baptista, João Kleber da Silva e Alexandre Basile, pela dedicação de parte de seu tempo na análise do trabalho e pelas contribuições para a melhoria das proposições da tese.

Às meninas da secretaria, em especial Wandrea Dantas e Eliany Funari, pela força nas questões burocráticas e no entendimento das questões internas do programa, $\mathrm{e}$ à Cristina Borba, pela sempre disposta ajuda nas revisões.

Às empresas construtoras que participaram das pesquisas, em especial seus diretores, gerentes e equipes de planejamento, que colaboraram com o trabalho, abrindo informações importantes que possibilitaram a realização da pesquisa. 


\section{RESUMO}

Os atrasos de obra têm se tornado comuns na indústria da construção, afetando o desempenho dos empreendimentos e causando prejuízos consideráveis para todos os envolvidos.

Este trabalho analisa as principais causas de atraso em projetos de construção e propõe um método estruturado que auxilie o uso efetivo de ferramentas de planejamento físico, bem como boas práticas e instrumentos de controle de prazo.

Inicialmente, realizou-se uma ampla revisão bibliográfica sobre o tema. Em seguida, uma pesquisa de campo em 50 obras relacionadas a empreendimentos imobiliários (construídos em um período de cerca de nove anos) para se identificar os principais fatores que influenciaram seus atrasos.

Com base neste estudo inicial, propôs-se um primeiro referencial estruturado de práticas de planejamento e gestão de prazos que evitem a ocorrência dos vários problemas ou causas de atrasos levantados na pesquisa anterior.

Estudou-se a viabilidade destas práticas através de uma segunda pesquisa de campo detalhada, em outras 8 obras mais recentes de mesma tipologia. Além disso, buscouse uma validação das práticas por profissionais que atuam nos processos de planejamento de construtoras.

Finalmente os resultados de todas estas análises são utilizados para refinar e consolidar um método que evite a ocorrência de atrasos e que apoie uma boa gestão de prazos de obra em projetos imobiliários.

Palavras chave: atraso, planejamento, projetos de construção, gestão de prazo. 


\begin{abstract}
Delays are common in the construction industry. They create many concerns for project performance and cause considerable losses to project parties.

This research analyze the main causes of delay in construction projects, and it propose a structured method to improve the current use of time planning tools and control instruments.
\end{abstract}

Initially, a literature review and a field survey with 50 real estate construction projects in Brazilian cities (built in a period of nine years) are conducted to identify the main factors influencing the delays.

Next, tools and assumptions to improve the control of project deadlines are identified, thus avoiding the occurrence of various problems raised in the previous survey. This study also proposes a time management framework that consolidates these practices and tools studied.

The viability of the practices is measured in other recent projects, by a second field survey in 8 recent construction projects. In addition, validation of the practices by professionals who work in planning processes in construction companies was done.

Finally, the results of all these analyses are used to consolidate a method to avoid delay occurrence and to support good time management in real estate projects.

Keywords: delay, planning tools, construction project, time management. 


\section{LISTA DE ILUSTRAÇÕES}

Figura 1 - Estrutura do planejamento da pesquisa .................................................13

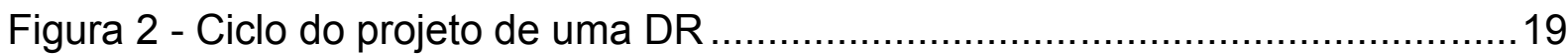

Figura 3 - Modelo do processo de uma Design Science Research .........................20

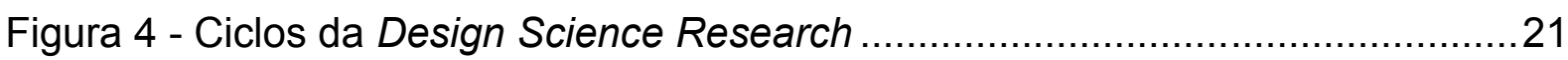

Figura 5 - Passos para a implantação do Grupo Focal em DSR ……......................24

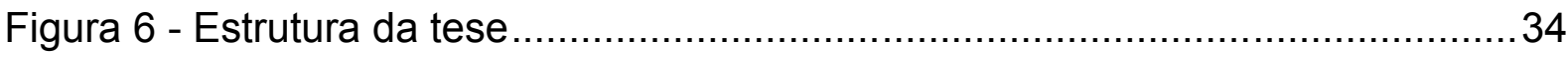

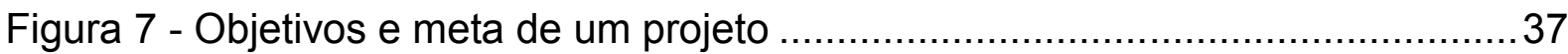

Figura 8 - Grupos de processos de gerenciamento de projetos............................... 39

Figura 9 - Interação entre os processos de gerenciamento de projetos....................40

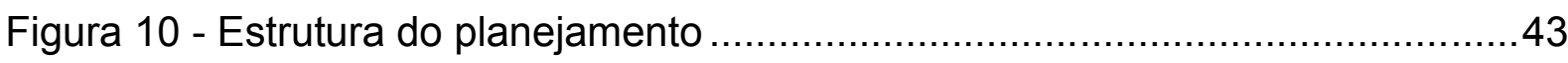

Figura 11 - Conceituação de Planning e Scheduling..............................................4

Figura 12 - Processo de decisão: da ideia ao empreendimento..............................45

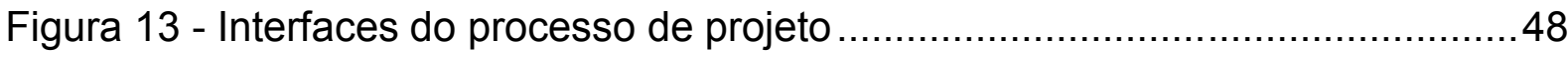

Figura 14 - Evolução do planejamento e níveis da gestão .......................................50

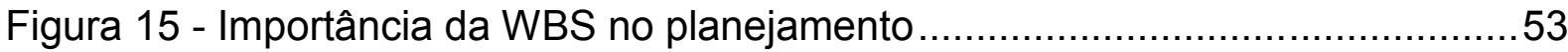

Figura 16 - Exemplo de Harmonograna de Adamiecki .........................................59

Figura 17 - Programação de construção de uma ponte em 1912 ............................59

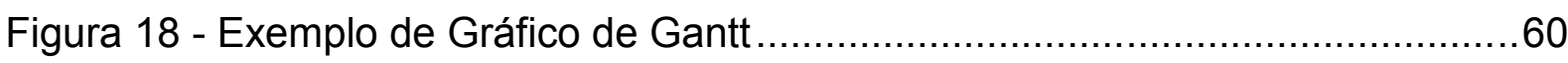

Figura 19 - Exemplo do mesmo Gráfico de Gantt com conexões ...........................61

Figura 20 - Exemplo do mesmo Gráfico de Gantt com progresso de atividades.......62

Figura 21 - Exemplo de Diagrama de Redes pelo método ADM ..............................63

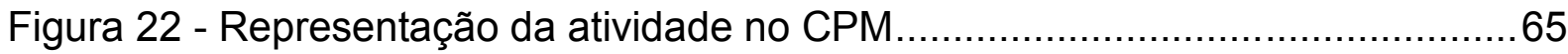

Figura 23 - Exemplo de cálculo de rede pelo CPM (método PDM) ………...............65

Figura 24 - Estimativas de tempo (durações) pelo CPM e pelo PERT .......................67

Figura 25 - Exemplo de cálculo de rede pelo CPM com MS Project .........................68

Figura 26 - Ramificações (a) determinísticas e (b) probabilísticas na GERT ............70

Figura 27 - Exemplos de três ramificações possíveis procedentes da Atividade A...71

Figura 28 - Exemplo de uso de buffer de controle na CCPM ...............................73

Figura 29 - Exemplo de rede com buffers de projeto e alimentação (CCPM) ............73

Figura 30 - Uso de buffers de controle com probabilidades (PERT) ………...........75

Figura 31 - Diagrama tempo-caminho (a) não balanceado e (b) balanceado ...........76

Figura 32 - Exemplos de variáveis de produção identificadas na linha de balanço...78 
Figura 33 - Exemplo de LOB com indicação de equipes para balanceamento .........79

Figura 33 - Redução do lead time pelo balanceamento das atividades ................... 80

Figura 35 - Redução do lead time pelo efeito aprendizado ................................81

Figura 36 - Comparação entre planos de ataque com uso de linhas de balanço......82

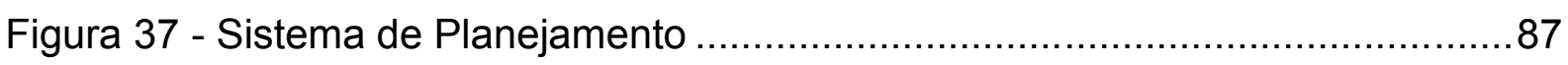

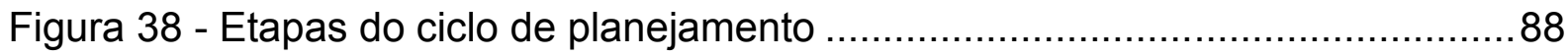

Figura 39 - Modelo básico de Planejamento ...................................................... 89

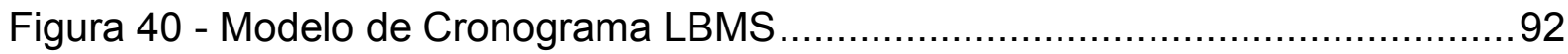

Figura 41 - Linhas de fluxo balanceadas, impactadas por instabilidades.................93

Figura 42 - Implementação da estratégia de estabilização de fluxo de produção .....97

Figura 43 - Exemplo de planilha de análise de restrições ...................................98

Figura 44 - Exemplo de planilha de planejamento semanal .................................99

Figura 45 - Exemplo de planilha de planejamento semanal com cálculo de PPC.....99

Figura 46 - Exemplo de uma análise de PPC de produção de uma obra................100

Figura 47 - Estrutura do processo Last Planner................................................. 102

Figura 48 - Modelo 5 Week Lookahead Schedule conforme LPS .........................103

Figura 49 - Modelo de Weekly Work Plan conforme LPS .................................103

Figura 50 - Representação do Shielding Production ........................................ 104

Figura 51 - Representação dos processos do LPS ......................................... 106

Figura 52 - Modelo básico de Bernardes .................................................. 110

Figura 53 - Modelo completo de Bernardes ...................................................111

Figura 54 - Exemplo de planejamento de curto prazo ........................................112

Figura 55 - Integração do planejamento tradicional, LBMS e LPS .......................113

Figura 56 - Diagrama de Ishikawa para identificação de causas de atraso ............126

Figura 57 - Protocolo para realização da primeira pesquisa de campo ...................135

Figura 58 - Estruturação do artefato (método) .............................................. 145

Figura 59 - Protocolo de estudo para a segunda pesquisa de campo ....................165

Figura 60 - Fotos do Empreendimento I (Set/15 e Jan/16) .................................170

Figura 61 - Cronograma com 2 calendários de dias úteis (padrão e chuva) ...........172

Figura 62 - Cronograma de contratações do empreendimento ............................174

Figura 63 - Tabela de pesos com índices de restrição .....................................176

Figura 64 - Ata de reunião de planejamento com metas de produção ...................177

Figura 65 - Projeto de canteiro dinâmico..................................................178

Figura 66 - Exemplos de comunicação visual sobre itens do planejamento ...........180 
Figura 67 - Fotos do Empreendimento II (Fev/16 e Mai/16) .................................183

Figura 68 - Curva $S$ dos 2 cenários de planejamento (realista e otimista) ..............184

Figura 69 - Exemplo de memorial de cálculo dos serviços ...................................185

Figura 70 - Recorte da planilha de datas marco da obra .....................................186

Figura 71 - Exemplos de comunicação visual sobre itens do planejamento ...........187

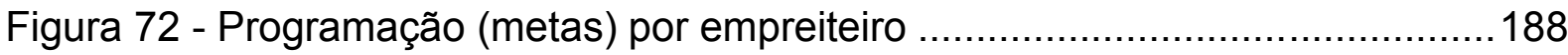

Figura 73 - Exemplo simples de análise de restrições para início de serviços .........189

Figura 74 - Linhas de balanço com incompatibilidades (destacadas em vermelho) 190

Figura 75 - Fotos do Empreendimento III (Set/15 e Abr/16)..................................192

Figura 76 - Premissas para planejamento do serviço de contrapiso ........................193

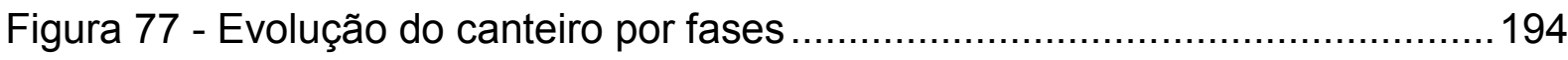

Figura 78 - Referenciais contratual, desafio e real, em 2 momentos da obra .........196

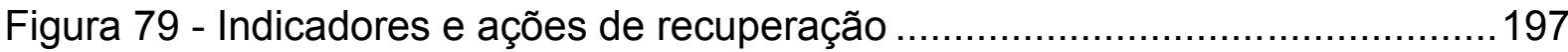

Figura 80 - Micro planejamento do ciclo da estrutura (5 dias) ............................198

Figura 81 - Definição de distribuição das equipes por setor (pavimento tipo) ..........199

Figura 82 - Exemplos de representação gráfica do micro planejamento..................199

Figura 83 - Planejamento por serviço (abastecimento e execução) - alvenaria ......200

Figura 84 - Croqui de abastecimentos do andar - pallets de blocos.......................200

Figura 85 - Exemplo de programação por pavimento ......................................202

Figura 86 - Aplicação do conceito de aprendizado no cronograma da obra ...........202

Figura 87 - Controle de solicitação de alterações de escopos e aditivos ................203

Figura 88 - Comunicação visual do planejamento da obra ....................................204

Figura 89 - Fotos do Empreendimento IV (Jun/15 e Jan/16).................................207

Figura 90 - Programação mensal do Empreendimento IV ....................................208

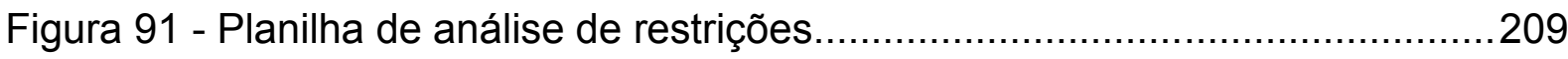

Figura 92 - Planilha de análise de cumprimento e cálculo do PPC .........................209

Figura 93 - Inserção de pulmão no cronograma desafio .....................................210

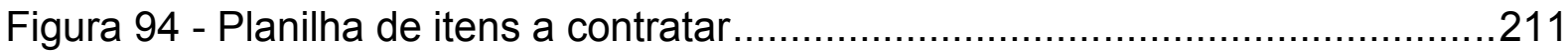

Figura 95 - Planilha de acompanhamento das contratações..................................211

Figura 96 - Exemplo de planejamento específico de insumo de suprimentos.........212

Figura 97 - Destaque para indicadores de qualidade .........................................213

Figura 98 - Fotos do Empreendimento V (Out/15 e Mai/16).................................216

Figura 99 - Aplicação de curvas de aprendizado na (a) estrutura e (b) caixilhos ....217

Figura 100 - Cópia de parte do cronograma inicial de suprimentos da obra ...........218 
Figura 101 - Fotos do Empreendimento VI (Out/15 e Jan/16).............................220

Figura 102 - Estudo de fachada com destaque para o caminho crítico....................221

Figura 103 - Exemplo de planejamento de médio prazo (trimestral) ......................222

Figura 104 - Exemplo de planejamento de curto prazo por equipe .......................223

Figura 105 - Formalização de problemas e ações de recuperação..........................225

Figura 106 - Planilha de datas marco do empreendimento ....................................226

Figura 107 - Conjunto de datas marco do processo de elevadores .......................227

Figura 108 - Monitoramento de precipitações reais no local da obra ......................228

Figura 109 - Fotos do Empreendimento VII (Set/14 e Ago/15) .............................229

Figura 110 - Cronograma individualizados por serviço (exemplo da fachada) ........230

Figura 111 - Controle de execução de fachada (com projeto adaptado).................231

Figura 112 - Práticas de organização: (a) circulação e (b) limpeza.........................231

Figura 113 - Painel gerencial com datas de término previstas ............................232

Figura 114 - Práticas de comunicação: (a) visual e (b) programações semanais ...233

Figura 115 - Fotos do Empreendimento VIII (Jan/15 e Jan/16)............................235

Figura 116 - Recorte de estudo de levantamentos quantitativos...........................236

Figura 117 - Cronograma de entrega da obra (parte ref. AVCB)...........................238

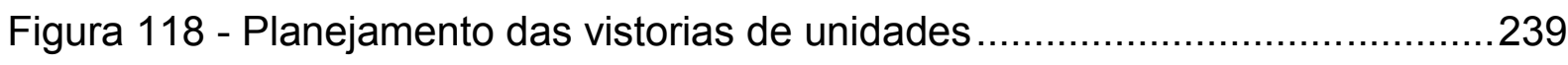

Figura 119 - Resumo esquemático do método proposto......................................258

Figura 120 - Detalhe da etapa de planejamento preliminar do método ...................259

Figura 121 - Detalhe da etapa de planejamento operacional do método .................262

Figura 122 - Detalhe da etapa de controle e reprogramação do método .................265

Figura 123 - Detalhe do grupo de práticas de suporte ao planejamento .................269 


\section{LISTA DE QUADROS}

Quadro 1 - Síntese das ciências naturais, sociais e Design Science .......................15

Quadro 2 - Síntese dos métodos de pesquisa e os objetivos da pesquisa .............17

Quadro 3 - Métodos de avaliação de artefatos em DSR ......................................23

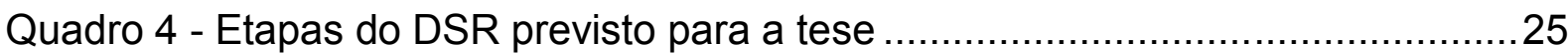

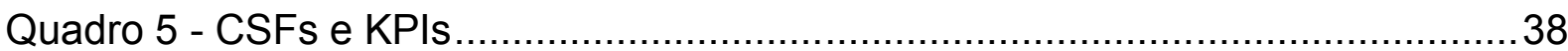

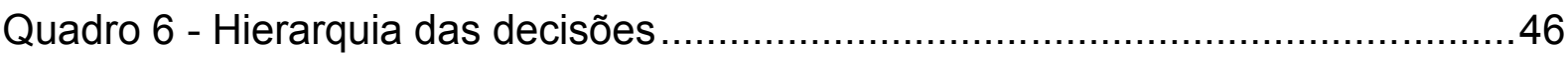

Quadro 7 - Níveis de hierarquia no gerenciamento da construção .........................49

Quadro 8 - Processos X Áreas de Conhecimento em gestão de projetos; ...............57

Quadro 9 - Comparação entre formas de representação de Diagrama de Redes ....62

Quadro 10 - Vantagens e desvantagens do uso da LOB ................................77

Quadro 11 - Boas práticas de planejamento ............................................ 124

Quadro 12 - Classificação e identificação das causas de atrasos..........................130

Quadro 13 - Grupos de diretrizes e referência às causas pesquisadas .................163

Quadro 14 - Características do processo de planejamento nas obras .................167

Quadro 15 - Resumo das avaliações das diretrizes orientativas nas obras ............241

Quadro 16 - Perfil dos participantes do grupo focal .......................................250 


\section{LISTA DE TABELAS}

Tabela 1 - Exemplo de lista de atividades para Diagrama de Redes ......................63

Tabela 2 - Características das obras pesquisadas.......................................137

Tabela 3 - As causas mais frequentes, compiladas na pesquisa .........................141

Tabela 4 - Resultados do workshop sobre as principais causas de atraso ............251

Tabela 5 - Resultados da identificação das diretrizes pelos participantes ..............254 


\section{LISTA DE ABREVIAÇÕES E SIGLAS}

ABC - Associação Brasileira do Consumidor

ADM - Arrow Diagramming Method

AVCB - Auto de Vistoria do Corpo de Bombeiros

CCPM - Critical Chain Project Management

CDM - Conditional Diagramming Method

CPM - Critical Path Method

CSF - Critical Success Factor

DSR - Design Science Research

DR - Design Research

EAP - Estrutura Analítica de Projeto

EVA - Earned Value Analysis

GERT - Graphical Evaluation and Review Technique

JIT - Just In Time

KPI - Key Performance Indicator

LBMS - Location-Based Management System

LOB - Line of Balance

LPS - Last Planner System

MDO - Mão-de-obra

PA - Pesquisa Ação

PCP - Planejamento e Controle da Produção

PDM - Precedence Diagramming Method

PERT - Program Evaluation and Review Technique

PMBOK® - Project Management Body of Knowledge

PMI - Project Management Institute

PPC - Percent Plan Complete

SPE - Sociedade de Propósito Específico

TOC - Theory of Constraints

WBS - Work Breakdown Structure

WWP - Weekly Work Plan 


\section{SUMÁRIO}

1. INTRODUÇÃO

2. DEFINIÇÃO DOS OBJETIVOS E MÉTODOS DE PESQUISA …………......................12

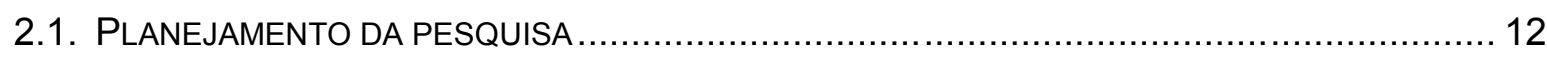

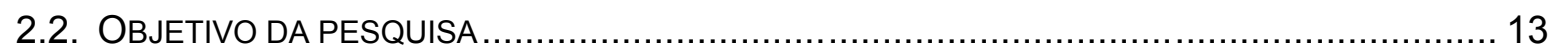

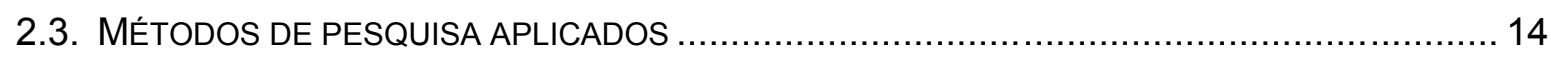

2.4. DESIGN SCIENCE E DESIGN SCIENCE RESEARCH .............................................. 15

2.5. A APLICAÇÃO DA DSR COMO MÉTODO DE PESQUISA PRINCIPAL DA TESE. ...................... 25

2.5.1. Etapa de Entendimento do Problema (primeira parte) .................................... 26

2.5.2. Etapa de Entendimento do Problema (segunda parte) .................................... 26

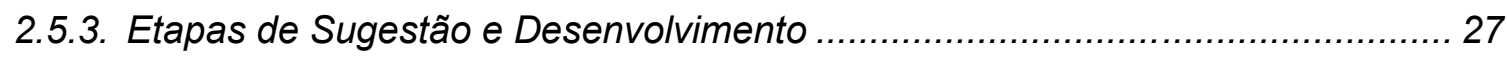

2.5.4. Etapa de Avaliação (primeira parte) ............................................................. 28

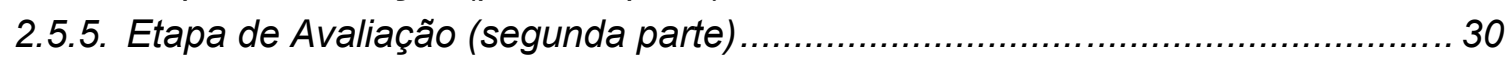

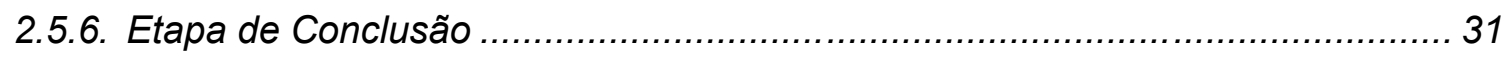

2.6. ESTRUTURAÇÃO DA TESE COM BASE NOS MÉTODOS DE PESQUISA PROPOSTOS.............. 32

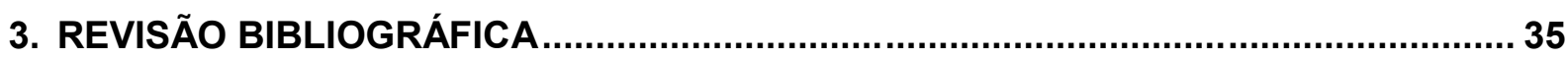

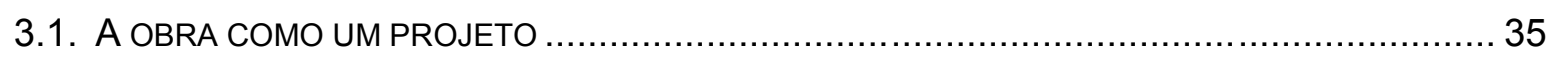

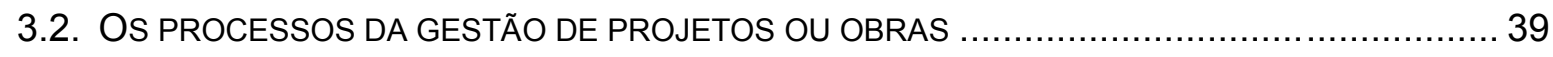

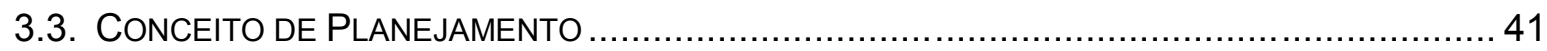

3.4. HIERARQUIAS do PLANEJAMENTO DE PROJETOS OU OBRAS ..................................... 44

3.4.1. Hierarquia vertical do planejamento e da estrutura de decisões ........................ 44

3.4.2. Hierarquia horizontal dos processos de planejamento.................................. 51

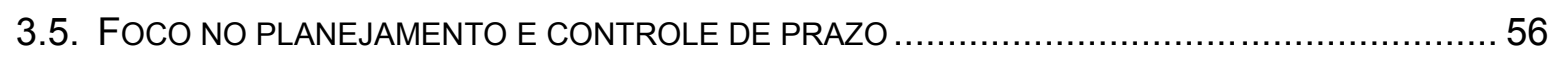

3.6. FERRAMENTAS DE PLANEJAMENTO FÍSICO DE OBRAS ............................................ 58

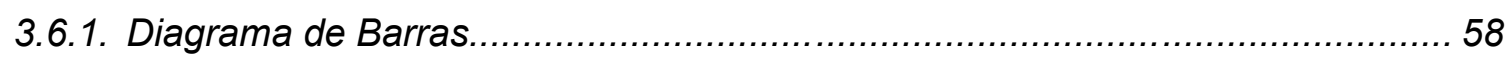

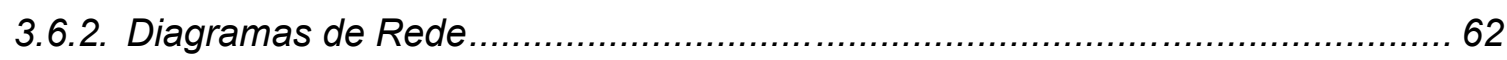

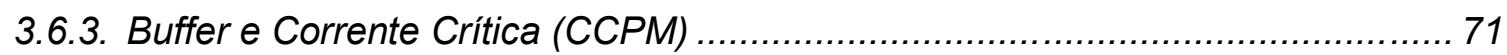

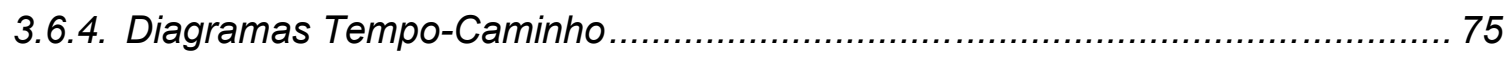

3.7. UTILIZAÇÃO ADEQUADA DAS FERRAMENTAS DE PLANEJAMENTO FÍSICO ......................... 83

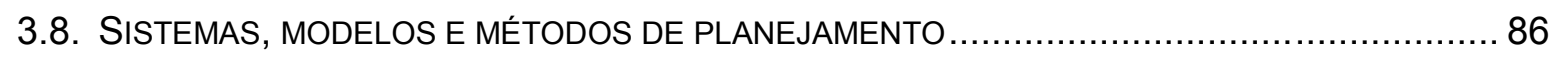

3.8.1. Sistemas de planejamento tradicional ........................................................ 88

3.8.2. Location-Based Management System ....................................................... 91

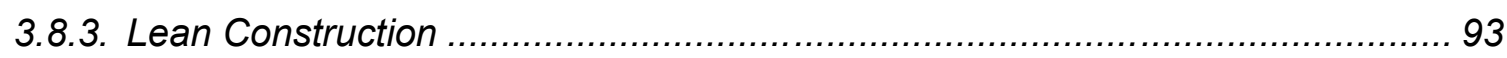

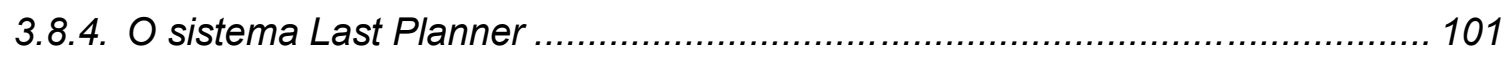

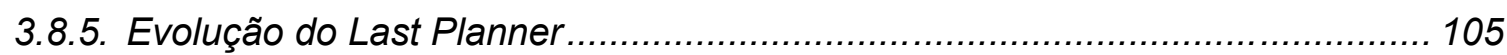

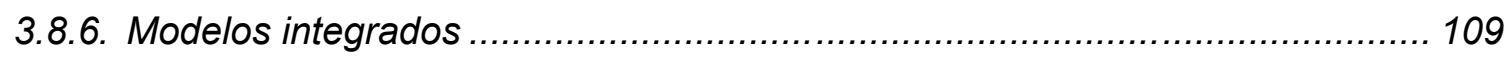

3.9. ASPECTOS QUE INTERFEREM NO PRAZO DAS OBRAS........................................... 114

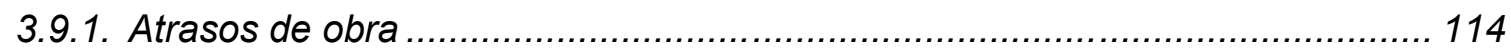

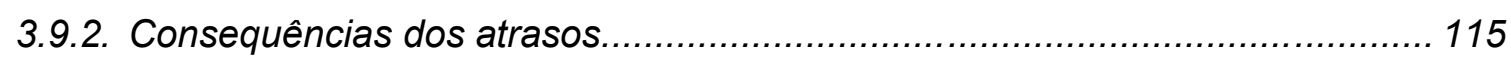

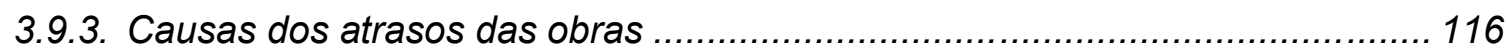

3.10. ASPECTOS QUE INTERFEREM NA GESTÃO DOS PRAZOS E POSSÍVEIS MELHORIAS ......... 121

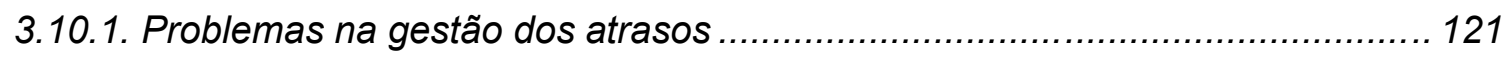

3.10.2. Ações para se evitar atrasos e melhorar o controle de prazos ...................... 121 


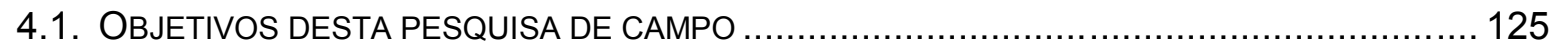

4.2. PREPARAÇÃo dA LISTA DE REFERÊNCIA DE CAUSAS DE ATRASO .................................. 125

4.3. CARACTERIZAÇÃO E PLANEJAMENTO DESTA PESQUISA .......................................... 132

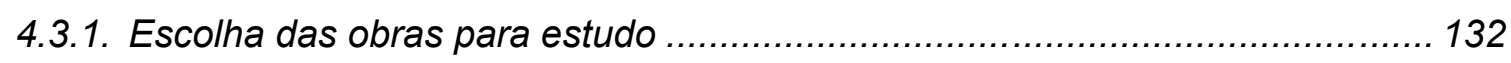

4.3.2. Elaboração do protocolo de estudo ................................................................ 134

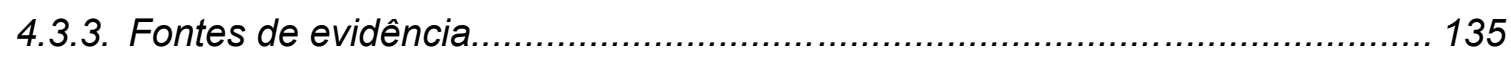

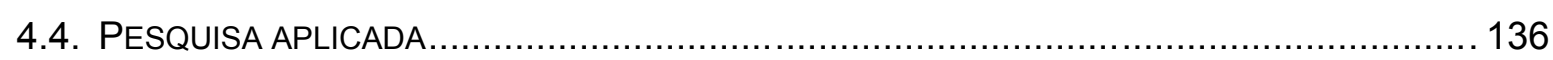

4.4.1. Análise das obras piloto e validação do protocolo de estudo ........................... 136

4.4.2. Amostra obtida na pesquisa de campo.......................................................... 136

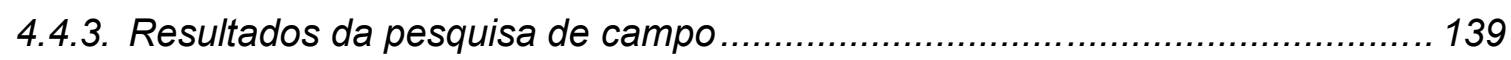

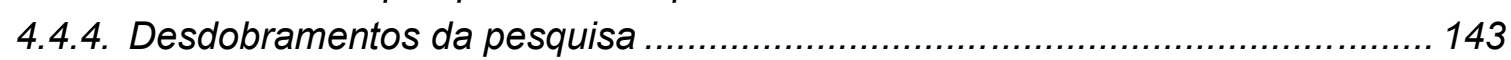

4.5. CONCLUSÕES DA PRIMEIRA PESQUISA DE CAMPO .............................................. 144

5. INÍCIO DA ESTRUTURAÇÃO DO MÉTODO........................................................... 145

5.1. TRATAMENTO DOS RESULTADOS E ESTRUTURAÇÃO INICIAL DO MÉTODO ....................... 145

5.2. DESCRIÇÃO DAS DIRETRIZES DE PLANEJAMENTO E GESTÃO ....................................... 146

5.2.1. Planejamento com definições de equipe e sua mobilização ........................... 146

5.2.2. Planejamento com premissas monitoráveis............................................ 147

5.2.3. Sistemas que assegurem a terminalidade dos serviços .............................. 148

5.2.4. Sistemas de produção puxado, que evitem desperdícios............................. 148

5.2.5. Gestão à vista (comunicação nos locais de produção) ................................... 149

5.2.6. Foco em continuidade de serviços e cadência de obra ................................ 149

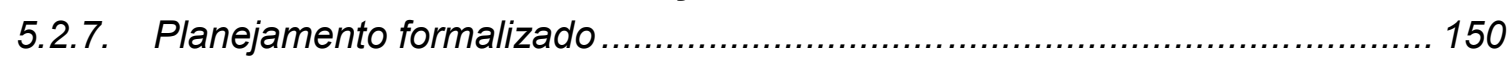

5.2.8. Participação das equipes de produção na definição de metas ...................... 151

5.2.9. Utilização de metas realistas, sem folgas arbitrárias ................................... 151

5.2.10. Métodos que busquem menor variabilidade ................................................... 153

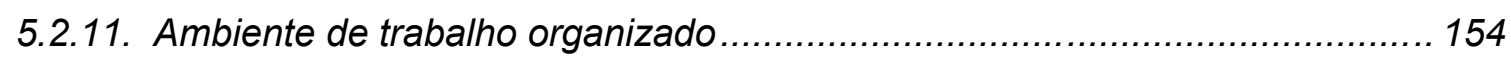

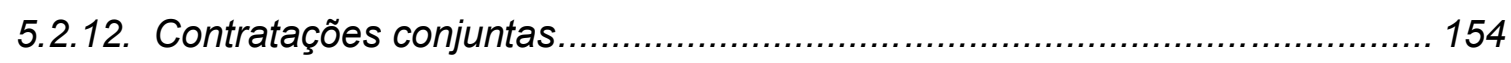

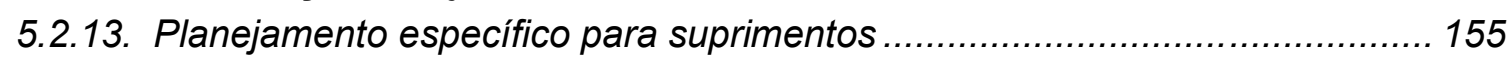

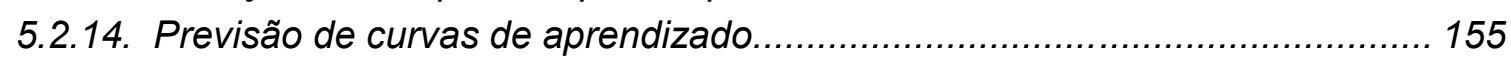

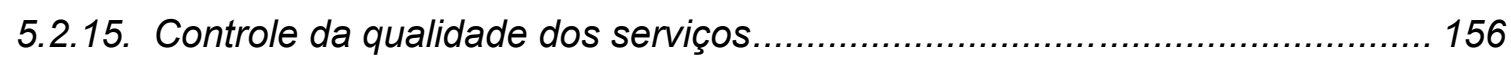

5.2.16. Logística de canteiro com condições especiais ............................................ 157

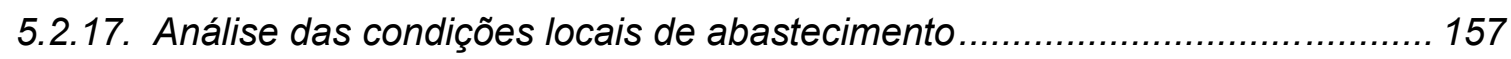

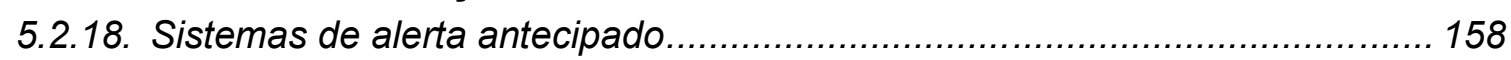

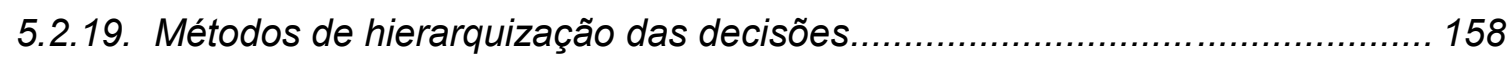

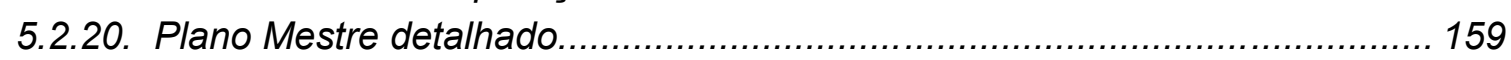

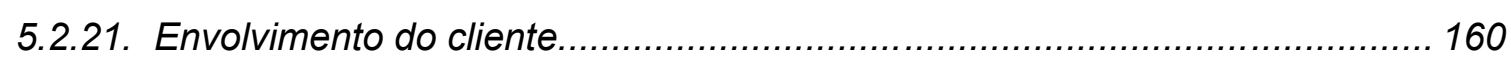

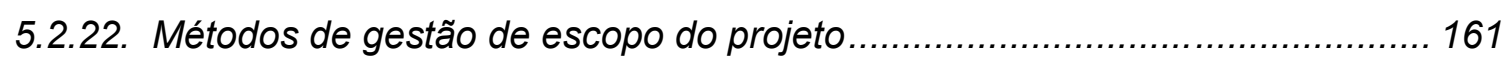

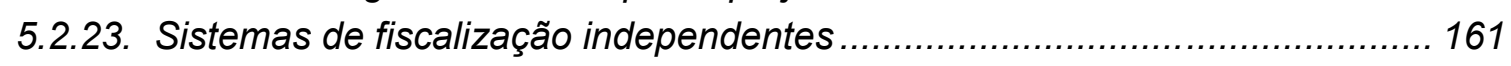

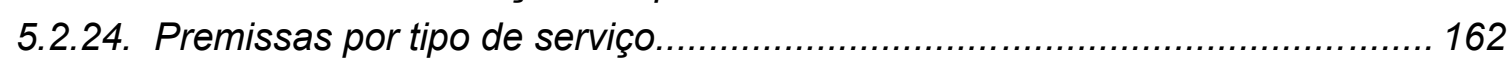

5.2.25. Resumo dos grupos de diretrizes e inter-relações..................................... 162 


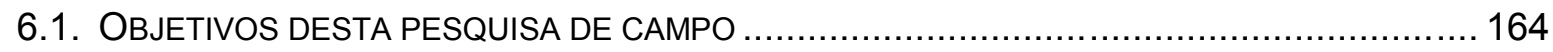

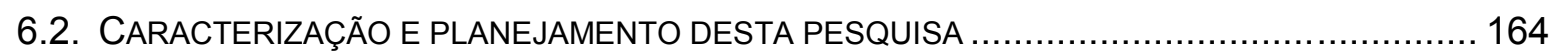

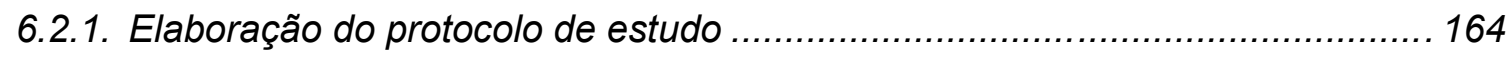

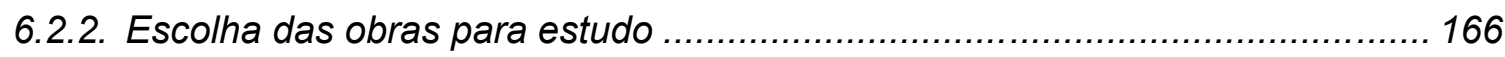

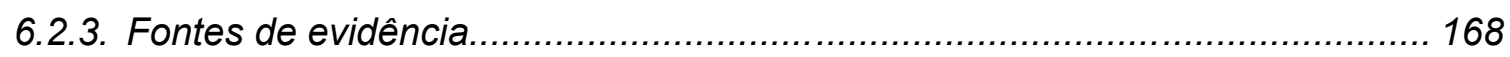

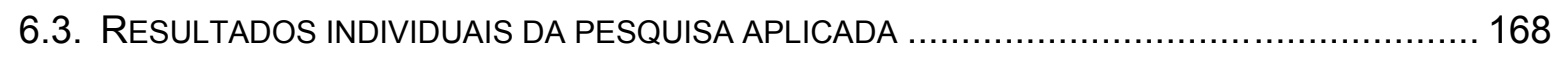

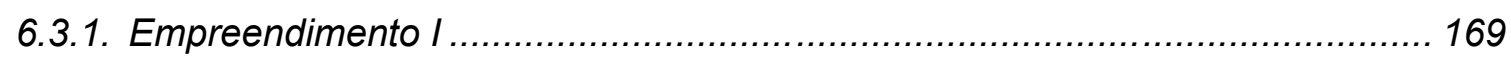

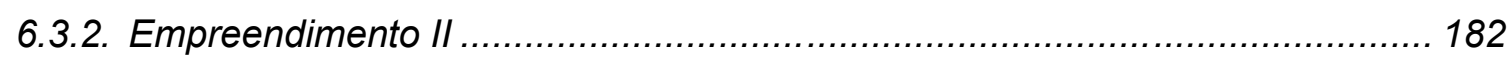

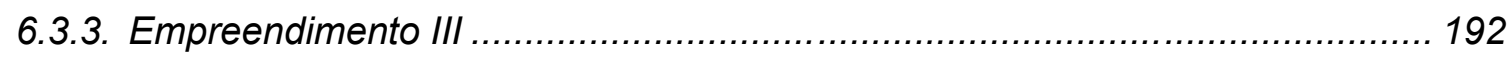

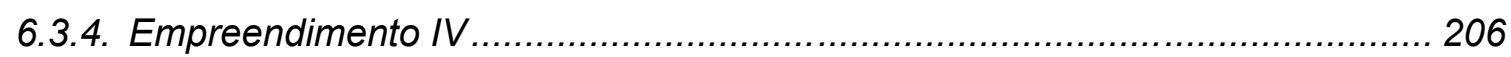

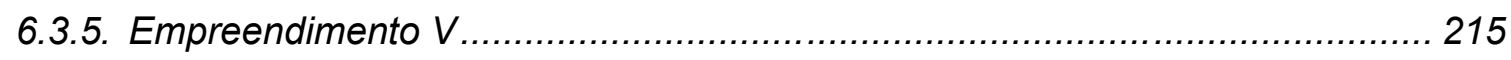

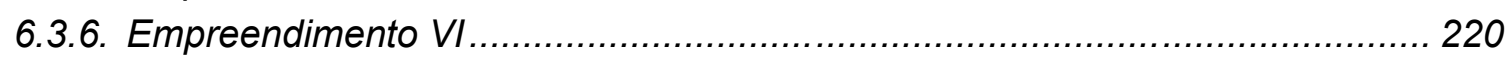

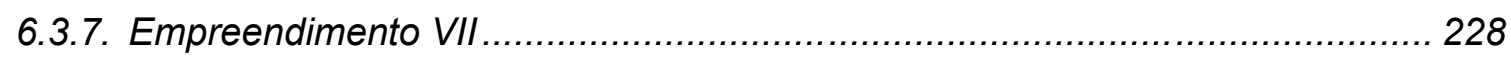

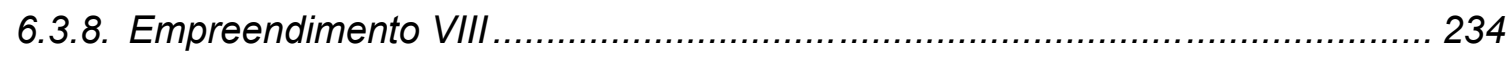

6.4. COMPILAÇÃO DOS RESULTADOS DA PESQUISA APLICADA ...................................... 240

6.4.1. Análise de aderência das práticas ao objeto de pesquisa.............................. 240

6.4.2. Práticas mais adotadas ....................................................................... 242

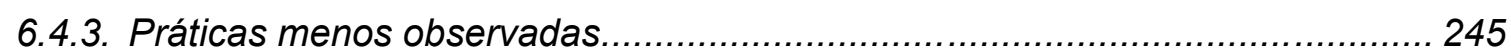

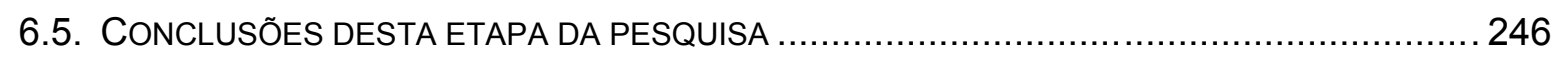

7. CONSOLIDAÇÃO DO MÉTODO E SUA VALIDAÇÃO ........................................... 247

7.1. CONSOLIDAÇÃO DOS RESULTADOS E ESTRUTURAÇÃO DO MÉTODO ............................... 247

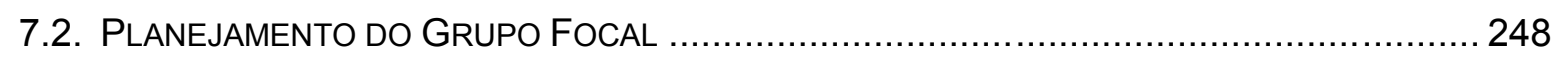

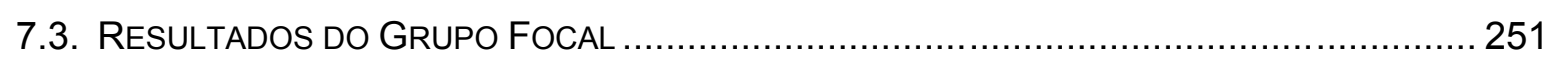

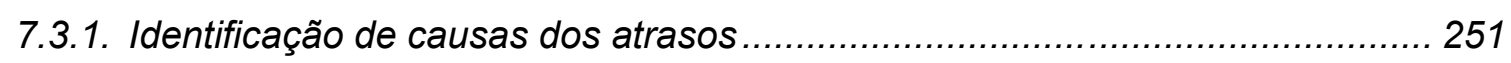

7.3.2. Sugestões para tratamento das causas identificadas .................................... 252

7.3.3. Validação de diretrizes para a definição das práticas que evitem atrasos........ 253

7.3.4. Análise crítica ao método proposto........................................................... 255

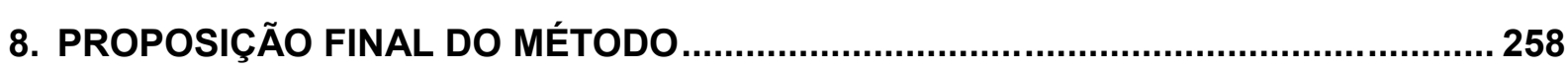

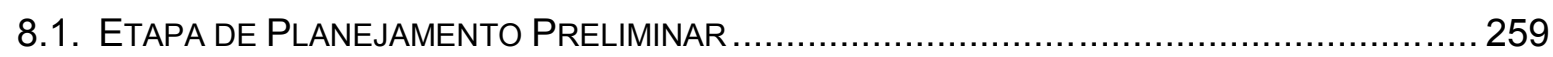

8.1.1. Fase I - Estudo de cenários realistas............................................................ 260

8.1.2. Fase II - Definição da cadência dos serviços................................................ 260

8.1.3. Fase III - Definição da logística de abastecimento......................................... 261

8.1.4. Fase IV - Formalização do plano mestre da obra ........................................... 261

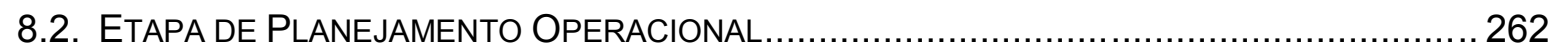

8.2.1. Fase $V$ - Definição de metas de produção realistas...................................... 263

8.2.2. Fase VI - Formalização da linha de base...................................................... 263

8.2.3. Fase VII - Programação por equipe ............................................................... 264

8.2.4. Fase VIII - Programação de suprimentos...................................................... 264

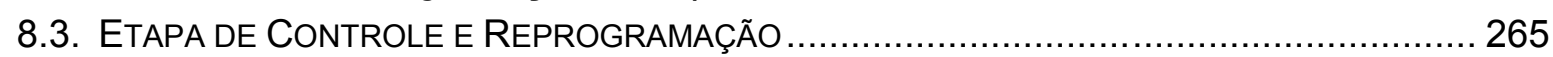

8.3.1. Fase IX - Análise de restrições de serviços ................................................... 266

8.3.2. Fase $X$ - Medição de serviços e análise de premissas................................... 266 
8.3.3. Fase XI - Estudo de ações de recuperação ................................................. 267

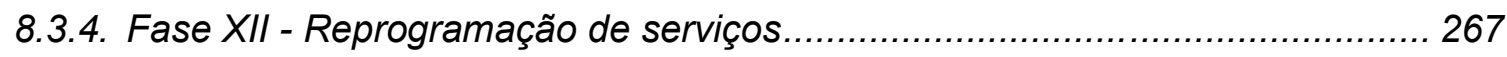

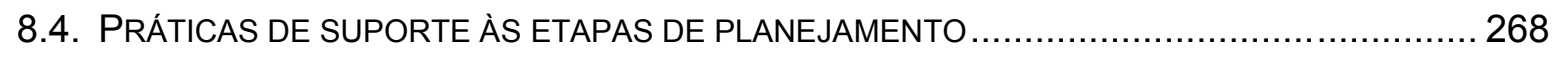

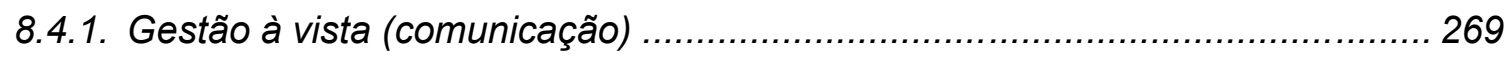

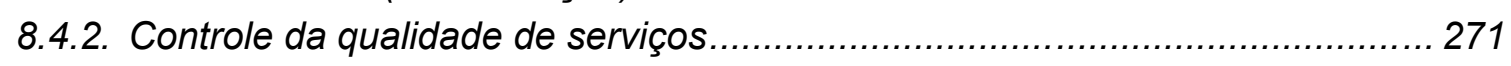

8.4.3. Participação do cliente e sua comunicação ................................................ 271

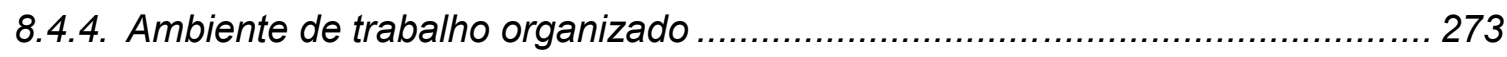

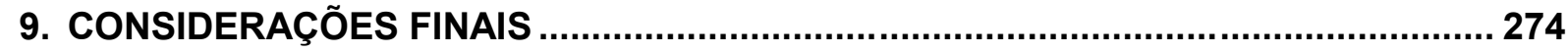

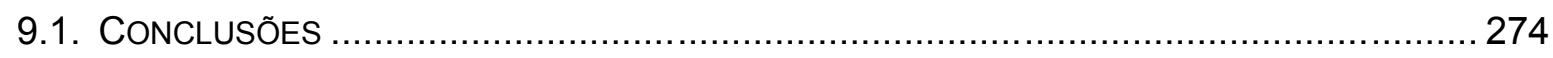

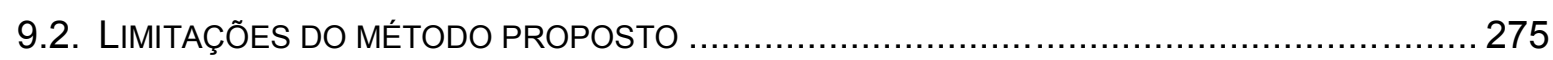

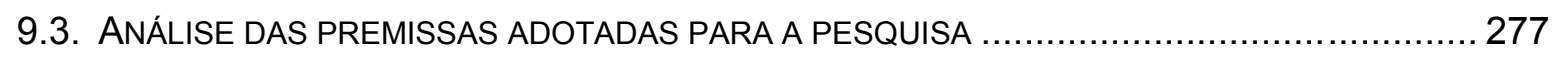

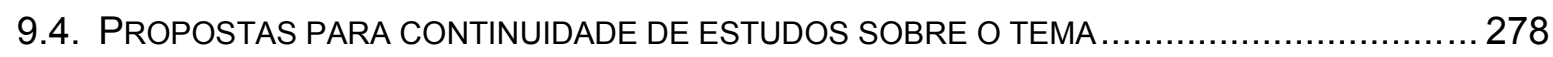

REFERÊNCIAS BIBLIOGRÁFICAS................................................................... 281

APÊNDICE A - RESULTADO COMPLETO DA PRIMEIRA PESQUISA (50 OBRAS) ...... 290

APÊNDICE B - COMPILAÇÃO COMPLETA DA PRIMEIRA PESQUISA ......................... 294 


\section{INTRODUÇÃO}

O mercado da construção civil passou nas últimas décadas por várias transformações. E a cada novo ciclo econômico, político e social que o país atravessa, a indústria da construção descobre novos movimentos empresariais, filosofias acadêmicas, ferramentas de gestão ou simplesmente de técnicas que auxiliem as empresas a atravessarem os desafios que tais ambientes trazem para seus negócios. Apesar de diferentes conjunturas, todas elas obrigam uma atitude cada vez mais proativa do empresário da construção.

Como resultado, muitas propostas de melhoria surgiram em todo este período. Já foram vivenciadas as fases da reengenharia, do downsinzing e da terceirização. No final dos anos 1990 e início deste século, as propostas foram estruturadas como programas de melhoria de ambiente de trabalho e melhoria de produtividade, como o 5S, programas de qualidade, certificações ISO 9001 (e seus derivados, QUALIHAB e PBQP-H), programas de produção enxuta (Lean Construction) e metodologias de melhoria de processos produtivos (como o Six-sigma).

Todas estas propostas são, em sua essência, bons modelos ou ferramentas de gestão, mas da forma como vêm sendo implementadas em empresas construtoras, para a gestão de seus empreendimentos, não vem alcançando os resultados esperados.

Várias causas podem ser apontadas. Uma delas relaciona-se à falta de comprometimento da alta direção, focada geralmente em resultados de curto prazo, mesmo utilizando-se de práticas de gestão inadequada. Seguem tendências e empresas líderes, sem, no entanto, verificar a adequação da proposta e possíveis adaptações, baseadas em sua necessidade principal, ramo de atuação, infraestrutura disponível, cultura organizacional e metas empresariais.

No entanto, talvez a causa principal esteja no fato da formatação dos programas buscarem modelos operacionais, que necessitam de ambientes ideais e constantes para sua implementação. Normalmente os resultados são procedimentos operacionais padronizados para toda a empresa. Isto porque, a maioria dos programas citados no segundo parágrafo foi desenvolvida inicialmente para atender 
às necessidades da indústria, estruturada funcionalmente e departamentalizada, considerando demandas constantes e produtos com as mesmas complexidades. Com o sucesso de tais modelos em empresas com estas características, os mesmos são transportados de forma similar para outros setores de atividade.

Numa empresa construtora, as demandas sempre são sazonais e os empreendimentos são diferentes, obrigando uma gestão flexível e uma estrutura adequada à realidade do momento. Desta forma, é muito difícil conseguir a implantação de programas baseados em padrões operacionais e equipes permanentes.

Os problemas de flexibilidade e comprometimento se agravam em empresas que realizam obras mais complexas, com vários parceiros comerciais (geralmente com interesses distintos) e/ou diferentes possibilidades de tecnologia construtiva.

$\mathrm{Na}$ busca das melhores práticas para tentar diminuir estes problemas, não apenas construtoras, mas empresas de outros setores que apresentam condições similares (como tecnologia de informação, consultoria, eventos, dentre outros) adotam modelos de gestão focados em projetos.

Alguns autores têm estudado esta questão, como Melhado (2001), que identifica a carência de métodos que avaliem o empreendimento de modo semelhante aos projetos de novos produtos na indústria seriada. Tais métodos consideram a necessidade de planejamento para adequação do sistema de gestão em cada agente do processo e para a integração entre esses sistemas.

Nas últimas décadas, o Project Management Institute (PMI) vem estudando as melhores práticas em gerenciamento de projetos e dando subsídios para estas empresas. As principais áreas de conhecimento em gestão de projetos foram agrupadas e organizadas em um documento, denominado PMBOK®, de maneira a abordar de forma organizada estes conceitos.

A grande aceitação desta abordagem no mercado vem também gerando interesse de vários empresários da construção em implantar em suas empresas, modelos de gestão baseados nos conceitos do PMI (2013). 
Como na indústria da construção civil cada produto é único, todos os conceitos de gestão são aplicáveis em cada obra de forma particular, trazendo a flexibilidade exigida para o setor e ampliando os adeptos a esta abordagem.

Apesar de uma alternativa atraente para construtoras, recomenda-se cautela para que estes modelos também não se tornem programas "mágicos", gerem burocracias desnecessárias, desgastes das equipes e acabem por se tornar uma nova decepção para a empresa. O próprio $\mathrm{PMBOK} 囚$ não é um programa, e sim um guia para que a empresa elabore sistemas de gestão organizados e completos, com todos os critérios e a documentação necessária para garantir o sucesso de um empreendimento.

Esta tendência também foi seguida por outras instituições, tais como o BSI (2010) e no Brasil a própria ABNT (2006), com guias próprios, porém bem menos complexos e abrangentes.

Dentre todas as áreas de conhecimento abordadas por todas estas instituições, uma delas apresenta destaque: a gestão dos prazos.

A dificuldade de se gerenciar empreendimentos no Brasil é grande, em especial o cumprimento dos prazos. Sempre foi uma tarefa árdua, dadas as conjunturas nacionais que em nada incentivaram os empreendedores brasileiros, tais como dificuldade de financiamento, juros altos, riscos jurídicos, inadimplência, complexidade regulatória e mão-de-obra desqualificada.

A realidade do mercado foi sendo alterada nos últimos vinte anos, principalmente após 2005, com a abertura de capital de grandes empresas incorporadores e construtoras, aliada à melhoria das condições de compra e financiamento dos mutuários. Viveu-se um período de verdadeira euforia e crescimento que não era previsto, com aumento muito forte de lançamentos, tanto comerciais, como residenciais.

Com o capital disponível e situação econômica favorável, o lançamento de novos empreendimentos neste período triplicou em apenas 4 anos, conforme informações do Sinduscon-SP (2014), gerando nova instabilidade, mas agora provocada pela falta de estrutura técnica e produtiva das empresas.

Assim, paralelamente a este quadro positivo, verificou-se um aumento igualmente importante de atrasos destes empreendimentos. 
Entre 2005 e 2010, segundo a Associação Brasileira do Consumidor - ABC os atrasos em obras no estado de São Paulo cresceram cerca de $65 \%$.

O despreparo de toda a cadeia produtiva para sustentar este crescimento talvez tenha sido a base dos problemas que foram encontrados para a efetiva entrega de tantos projetos.

Mesmo com todos estes problemas, verificam-se hoje poucos estudos estruturados para análise das causas de todos estes atrasos no Brasil.

Segundo Muianga et al. (2015), um volume considerável de estudos primários sobre desvios de custos e prazos em empreendimentos de construção foi publicado, mostrando o interesse da comunidade científica global neste tema. Mas de acordo com os autores, especificamente no Brasil, poucos deles se propuseram a categorizar e classificar os fatores que influenciam os desvios. Os autores citam alguns trabalhos, mas essencialmente relacionados ao setor público e ou de infraestrutura.

É o caso de Ricardino et al. (2013), que apresentam em seu trabalho as causas mais frequentes de reivindicações em contratos para execução de empreendimentos de infraestrutura e obras de grande complexidade técnica no Brasil.

Ou também de Santos et al. (2015), que apresentam um estudo diagnóstico sobre o aumento de custos e prazos de obras públicas de edificações em Belo Horizonte. Os autores ainda estabelecem um ranking de possíveis causas, que neste caso, estão relacionadas a falhas no processo de projeto nas fases iniciais dos empreendimentos.

Talvez a pesquisa nacional mais estruturada que se propôs a analisar as causas dos atrasos de empreendimentos imobiliários privados seja de Pereira (2012). O autor identificou os fatores associados à ocorrência de atrasos de empreendimentos na região de Camboriú e Itajaí, no Estado de Santa Catarina. A pesquisa identificou que no período em que foi realizado o acompanhamento, mais da metade dos edifícios das 31 construtoras pesquisadas $(53,8 \%$ das obras) foi entregue com atrasos.

Segundo o autor, a melhor forma de combater a ocorrência de atrasos é utilizar processos e métodos de planejamento. A falta de gerenciamento e planejamento das atividades faz com que as empresas não consigam visualizar os problemas do projeto com um todo. Elas observam somente a necessidade momentânea de maior 
quantidade de trabalhadores para a recuperação dos desvios verificados ao longo da execução do empreendimento.

Fora do país, no entanto, este tema é recorrente e merece maior atenção do mundo acadêmico.

Marzouk e Al-Rasas (2014) descrevem que os atrasos são problemas comuns em obras de engenharia civil e que ocorrem com frequência durante o tempo de vida do projeto, levando a disputas e litígios. Os autores defendem a necessidade de estudos mais aprofundados sobre o tema e identificam inúmeras pesquisas que buscam o entendimento das causas de atraso, em diferentes países, o que demonstra o esforço dos pesquisadores na busca de respostas sobre estas questões.

Gündüz et al. (2013) também destacam que os atrasos são comuns em vários projetos de construção e causam perdas consideráveis para todas as partes interessadas. Os resultados frequentes dos atrasos são: aumento de custos, interrupção do trabalho, perda de produtividade, reclamações de terceiros, disputas e até abandono ou rescisão de contratos. Por conseguinte, os atrasos nos projetos de construção suscitam insatisfação para todas as partes envolvidas.

Como o processo de desenvolvimento de projetos de construção é complexo e combina a programação de muitos intervenientes na obra, compreendem muitas etapas de trabalho, e implicam um longo período até a conclusão; muitos fatores contribuem para os atrasos. Vários pesquisadores examinam e identificam as causas dos atrasos nos projetos de construção.

Em alguns países, notadamente menos industrializados, segundo Fugar e AgyakwahBaah (2010), o atraso chega a ser o principal problema da indústria da construção local. Muitas vezes são problemas tão tradicionais, que são considerados por muitos engenheiros e empreendedores destas regiões, como uma questão endêmica à cadeira da construção.

Para agravar esta condição, conforme descreve Doloi et al. (2012), em alguns destes países em desenvolvimento, o setor da construção representa o "motor" da economia. A falta de competitividade do setor acarreta prejuízos milionários. 
Ao mesmo tempo, em países industrializados, a globalização e aumento da competitividade internacional pressiona as empresas a buscarem melhores competências, eficiência e produtividade.

Couto (2007) destaca que o problema do atraso também é encontrado comumente em países europeus. Sendo atualmente muito mais exigentes, os clientes europeus não se importam em contratar empresas de fora de seus países de origem, se elas forem mais eficientes. Segundo o autor, a saída para as empresas que antes tinham certa estabilidade mas hoje perderam competitividade é implantar novas estratégias de gestão. O autor destaca que o não cumprimento de prazos tem papel central na busca por esta competitividade, pois suas consequências são sempre graves e de difícil resolução.

Souto (2006) destaca que as empresas construtoras no Brasil ainda não dominam o processo de planejamento da produção e esta falta de domínio afeta o desempenho de seus empreendimentos, consequentemente a competitividade da empresa no setor. Assim, são fundamentais estudos para a estruturação e organização dos processos de planejamento da produção.

Voltando à realidade brasileira, o mercado vive atualmente uma situação diferente do que foi relatado anteriormente, quando referenciou-se o último período de aquecimento do setor. Reflexo da crise econômica mundial e em especial a crise política brasileira, outra onda de desaceleração atingiu o setor da construção.

Mas mesmo após ajustes técnicos e uma reestruturação tardia do mercado para compensar a fraca demanda atual, os atrasos ainda estão presentes.

Questiona-se então quais seriam os verdadeiros motivos pelos quais as obras continuam atrasando.

As reclamações de consumidores e os prejuízos financeiros das incorporadoras e construtoras desde este período até os dias de hoje cresceram demasiadamente.

Uma pesquisa realizada pela Tapai Advogados (2014), empresa especialista em direito imobiliário, constata que as ações contra construtoras, apenas em São Paulo, subiram quase $2.600 \%$ em cinco anos, passando de 140 processos em 2008 para 3.779 em 2013. 
Parte deste crescimento em reclamações está em parte correlacionado ao aumento dos lançamentos e disponibilidade de unidades imobiliárias. Mesmo assim, os números são desproporcionais ao simples crescimento do mercado.

Um problema que sempre existiu no setor imobiliário, em especial residencial, parece se agravar de tal forma que os prazos de carência de entrega descritos nos contratos têm se tornado parte do prazo normal previsto pelas empresas para a conclusão das obras.

Esta prática repercutiu de forma tão forte que há alguns anos projetos de lei foram idealizados para se regulamentar esta prática, com a possível adoção de menores prazos de carência de contrato (para 90 dias ao invés dos tradicionais 180 dias) e altas multas às construtoras que não o cumprirem (vinculadas ao que já tem sido definido por jurisprudências a este respeito), como será explicitado em capítulo posterior.

Independente da regulamentação ou do endurecimento das penalidades, o fato é que as empresas não atrasam suas obras porque existe algum benefício. Elas simplesmente não estão conseguindo cumprir seu planejamento. E por que razão isto ocorre?

Segundo Moraes e Serra (2009), um dos principais problemas observados é a falta de adequação dos processos de planejamento existentes às condições presentes na maioria das empresas de construção de edificações.

Tais processos estariam focando o uso de ferramentas, técnicas e sistemas computacionais, muitas vezes sofisticados e caros. Mas segundo as autoras, o setor carece de propostas que consigam lidar com questões de incertezas, comprometimento, transparência e formalização do processo de planejamento.

Russel et al. (2014) afirmam que devido à natureza inerente da indústria da construção, todos os projetos têm alguma quantidade e tipo de incerteza. Essa incerteza pode levar a variações nas durações das tarefas do projeto, a partir do que foi originalmente planejado.

Mydin et al. (2014) descrevem que o atraso em um projeto na indústria da construção é um fato observável em nível mundial e em larga escala afeta não apenas a indústria 
da construção, mas a economia de um país. Por esta razão, a necessidade de se identificar e tratar as causas de atrasos em obra.

As próprias empresas hoje buscam explicações satisfatórias, que podem estar relacionadas tanto à falta de um planejamento confiável, como a inadequação de um modelo de gestão de obra que era utilizado até o final do século.

Neste ambiente, verificou-se a importância de um estudo aprofundado sobre o tema, objetivando-se analisar todas as questões que afetam o bom desempenho físico de um projeto de construção.

Complementando esta análise, entende-se necessário também identificar as ferramentas disponíveis para a boa gestão dos prazos de empreendimento imobiliários (baseados principalmente nos conceitos atuais de gerenciamento de projetos), buscando-se estruturar um método que auxilie a aplicação efetiva das práticas à realidade do mercado brasileiro de construção civil. 


\section{DEFINIÇÃO DOS OBJETIVOS E MÉTODOS DE PESQUISA}

\subsection{Planejamento da pesquisa}

Segundo Silva e Menezes (2001), o planejamento de uma pesquisa depende basicamente de três fases:

- fase decisória: referente à escolha do tema, à definição e à delimitação do problema de pesquisa;

- fase construtiva: referente à construção de um plano de pesquisa e à execução da pesquisa propriamente dita;

- fase redacional: referente à análise dos dados e informações obtidas na fase construtiva. É a organização das ideias de forma sistematizada visando à elaboração do relatório final, sendo a apresentação deste relatório obedecendo às formalidades requeridas pela academia.

No caso desta pesquisa, o relatório corresponde à própria tese de doutorado, que foi estruturada atendendo-se às formalidades da Escola Politécnica da Universidade de São Paulo, conforme descrito em documentos específicos (USP, 2004).

Utilizando-se como base as fases citadas por Silva e Menezes (2001), incluindo-se as considerações do plano de pesquisa, metodologia, protocolos, realização das atividades de campo e contribuições do autor, pode-se descrever o planejamento da pesquisa conforme apresentado na figura 1 .

Segundo este planejamento, após a contextualização do tema da pesquisa, buscouse a definição do foco e abrangência do trabalho, estabelecendo-se empreendimentos imobiliários verticais de múltiplos pavimentos. Esta tipologia foi adotada pela disponibilidade de amostragem relacionada ao ambiente profissional do autor.

Com a definição dos objetivos, que são descritos e detalhados no item 2.2 a seguir, finalizou-se então a Fase Decisória da pesquisa. As demais fases (Construtiva e Redacional) são descritas a partir do item 2.3, onde são detalhados os métodos aplicados na pesquisa. 
Figura 1 - Estrutura do planejamento da pesquisa

\begin{tabular}{|c|c|c|}
\hline Fase Decisória & Fase Construtiva & Fase Redacional \\
\hline $\begin{array}{l}\text { - Projeto de Pesquisa } \\
\text { - Definição da } \\
\text { abrangência e foco } \\
\text { da pesquisa } \\
\text { - Definição dos } \\
\text { objetivos da } \\
\text { pesquisa }\end{array}$ & 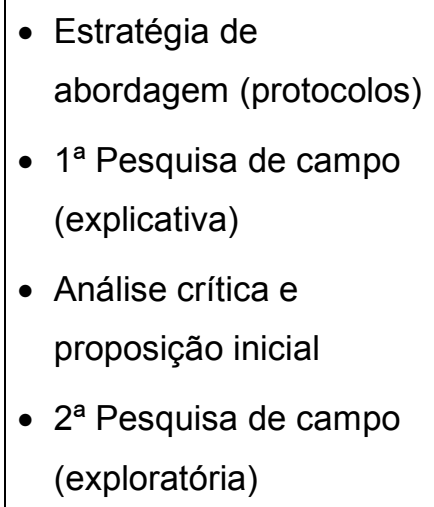 & $\begin{array}{l}\text { - Compilação de } \\
\text { dados } \\
\text { - Proposição final } \\
\text { - Validação do } \\
\text { método } \\
\text { - Redação final }\end{array}$ \\
\hline \multicolumn{3}{|c|}{ Atividades de Apoio } \\
\hline \multicolumn{3}{|c|}{$\begin{array}{l}\text { - Revisão bibliográfica e pesquisa documental } \\
\text { - Publicação de artigos científicos }\end{array}$} \\
\hline
\end{tabular}

Fonte: O Autor

\subsection{Objetivo da pesquisa}

Para a finalização da Fase Decisória, buscou-se estabelecer os objetivos que melhor pudessem atender aos questionamentos e necessidades de pesquisa contextualizados no capítulo 1.

Como objetivo principal deste trabalho pode-se descrever:

- Estabelecer um método estruturado para a melhoria da gestão de prazos em projetos de construção civil, com base em premissas para melhor utilização das técnicas de planejamento tático-operacional atualmente existentes, mas que reflitam a realidade do mercado e auxiliem à identificação antecipada de riscos de não cumprimento das programações de produção.

Como objetivos secundários deste trabalho, que foram necessários para se alcançar o objetivo principal descrito anteriormente, podem-se citar:

- Levantar e organizar a bibliografia que trata sobre atrasos de obra em todo o mundo e no Brasil, bem como influências e causas identificadas pelos autores que estudam o tema; 
- Identificar de forma direcionada e através de casos reais no Brasil, aspectos que influenciem os atrasos de obras de construção, limitados à tipologia de empreendimento abordada nesta pesquisa, estruturando um ranking com as principais ocorrências, que auxiliem na definição do método de planejamento e gestão;

- Estudar ferramentas e premissas de planejamento que sejam aderentes ao melhor controle de prazos de obra para a tipologia de empreendimento estudada.

\subsection{Métodos de pesquisa aplicados}

Este trabalho utilizou praticamente as três classificações de pesquisa com base em seus objetivos, conforme descrito por Gil (2008): pesquisa exploratória, descritiva e explicativa.

Cada tipologia de pesquisa também pode ser classificada com base nos procedimentos técnicos utilizados, o que para melhor entendimento, podem ser descritos como métodos ou técnicas.

Inicialmente foi utilizada a pesquisa descritiva para a identificação das ferramentas e modelos de planejamento atualmente existentes, através da técnica de levantamento.

Em seguida, para a identificação de causas de atraso e ferramentas de gestão de prazos (buscando-se atender aos objetivos secundários deste trabalho), utilizou-se a pesquisa explicativa, sob a forma de ex-post facto.

No entanto, além dos métodos descritos anteriormente, o principal método de pesquisa utilizado foi o Design Science Research (DSR).

Este método incorporou as técnicas anteriormente utilizadas como parte inicial do entendimento do problema e posteriormente organizou todas as iniciativas em curso de uma forma integrada, que garantiram alcançar o objetivo principal da tese.

Para se iniciar a construção do método, buscou-se avaliar a aplicabilidade das diretrizes de melhoria de planejamento e gestão de prazos com uma pesquisa exploratória. Posteriormente, os resultados desta pesquisa e outras ações de 
evolução da construção do método foram desenvolvidas, conforme orienta a método DSR.

\subsection{Design Science e Design Science Research}

O conceito de Design Science, foi primeiramente estabelecido por Simon (1996), que apresenta as diferenças entre o que o autor define como "Ciência Natural" e "Ciência do Artificial". Esta última também conhecida como Ciência do Projeto, ou ainda pelo termo mais utilizado atualmente: Design Science.

Dresch (2013), incluindo também o conceito de "Ciências Sociais" a este contexto, apresenta no quadro 1, uma síntese das principais características destas ciências.

Quadro 1 - Síntese das ciências naturais, sociais e Design Science

\begin{tabular}{cccc}
\hline Característica & Ciência Natural & Ciência Social & Design Science \\
\hline $\begin{array}{c}\text { Áreas ou } \\
\text { disciplinas }\end{array}$ & $\begin{array}{c}\text { Física, química, } \\
\text { biologia }\end{array}$ & $\begin{array}{c}\text { Antropologia, } \\
\text { economia, política, } \\
\text { sociologia, história }\end{array}$ & $\begin{array}{c}\text { Medicina, engenharia, } \\
\text { gestão }\end{array}$ \\
Propósito & $\begin{array}{c}\text { Entender fenômenos } \\
\text { complexos. Descobrir } \\
\text { como as coisas são e } \\
\text { justificar o porquê de } \\
\text { serem desta forma }\end{array}$ & $\begin{array}{c}\text { Descrever, entender } \\
\text { e refletir sobre o ser } \\
\text { humano e suas } \\
\text { ações }\end{array}$ & $\begin{array}{c}\text { Projetar. Produzir sistemas } \\
\text { que ainda não existem. } \\
\text { Modificar situações } \\
\text { existentes para alcançar } \\
\text { melhores resultados. Foco } \\
\text { nas soluções }\end{array}$ \\
$\begin{array}{c}\text { Objetivo da } \\
\text { pesquisa }\end{array}$ & $\begin{array}{c}\text { Explorar, descrever, } \\
\text { explicar e quando } \\
\text { possível predizer }\end{array}$ & $\begin{array}{c}\text { Explorar, descrever, } \\
\text { explicar e quando } \\
\text { possível predizer }\end{array}$ & $\begin{array}{c}\text { Prescrever. As pesquisas } \\
\text { são orientadas à solução de } \\
\text { problemas }\end{array}$ \\
\hline
\end{tabular}

Fonte: Dresch (2013)

Design Science para Vaishnavi e Kuechler (2015) é a ciência na forma de construções, técnicas, métodos, modelos e teorias bem desenvolvidas que auxiliam o mapeamento do conhecimento para criar artefatos que satisfaçam determinados conjuntos de exigências funcionais.

Surge então o termo "Artefato", largamente utilizado pelos pesquisadores desta área. Dresch (2013) afirma que Artefato é algo que é construído pelo homem; uma interface entre o ambiente interno e o ambiente externo de um determinado sistema. 
Assim, conforme a própria autora define, o conceito de Design Science seria a ciência que procura projetar e desenvolver soluções para melhorar sistemas existentes, resolver problemas e criar novos artefatos.

O Design Science Research (DSR), por sua vez, segundo Vaishnavi e Kuechler (2015), seria a pesquisa que tenta preencher esta lacuna do conhecimento utilizando projeto, análise, reflexão e abstração.

Em artigos e textos que tratam sobre pesquisas relacionadas ao tema, o termo Design Science Research também é encontrado sob uma forma simplificada, apenas como Design Research (DR) ou ainda quando traduzido, como Pesquisa Construtiva.

Independente de como o termo é encontrado, conforme descrito por Bayazit (2004), a DSR é o método que operacionaliza e fundamenta a condução da pesquisa quando o objetivo a ser alcançado é um artefato, ou ainda, uma prescrição.

O autor ainda destaca que a pesquisa fundamentada na Design Science pode ocorrer tanto no âmbito acadêmico quanto dentro das organizações.

Para Vaishnavi e Kuechler (2015), a DSR é um conjunto de técnicas analíticas que permitem o desenvolvimento de pesquisas nas mais diversas áreas, inclusive na engenharia.

Bayazit (2004) estabelece que a DSR se constitui como um processo rigoroso de projetar artefatos para resolver problemas, avaliar o que foi projetado ou o que está funcionando, e comunicar os resultados obtidos.

Para Machado et.al. (2013), o método de Design Research pressupõe a ação do pesquisador em uma determinada realidade, compreendendo um problema e construindo uma possível solução. O pesquisador não é mais um observador, mas um indivíduo que age no contexto pesquisado, buscando compreender uma determinada realidade em que utiliza seu potencial criativo para a geração de soluções para problemas ou necessidades reais.

Embora existam vários pontos em comum entre o DR e o método da Pesquisa-Ação (PA), eles não são equivalentes. Vaishnavi e Kuechler (2015) destacam que uma das condições para a Pesquisa-Ação é que a escolha dos problemas que serão analisados 
parta dos pesquisados e não dos pesquisadores. Na PA o pesquisador participa efetivamente para mudar uma determinada realidade, mas não define qual o problema a ser resolvido e não estabelece as prioridades. Na DR a identificação do problema e proposição do projeto em geral parte dos pesquisadores.

Desta forma, Vaishnavi e Kuechler (2015) definem a DR como um processo de utilização do conhecimento para projetar e criar artefatos úteis, e depois usar diferentes métodos rigorosos para se analisar o porquê, ou porque não, um artefato em particular é eficaz.

Outros métodos de pesquisa também podem apresentar objetivos similares ao DSR, embora sejam claramente diferentes. Dresch (2013) estabelece uma síntese comparativa dos principais objetivos e métodos, que pode ser observada no quadro 2. Nela evidencia-se a importância da definição do método DSR se alcançar os objetivos deste trabalho.

Quadro 2 - Síntese dos métodos de pesquisa e os objetivos da pesquisa

\begin{tabular}{|c|c|c|c|c|c|}
\hline \multirow{2}{*}{ Objetivos da Pesquisa } & \multicolumn{5}{|c|}{ Métodos de Pesquisa } \\
\hline & $\begin{array}{l}\text { Estudo } \\
\text { de Caso }\end{array}$ & $\begin{array}{c}\text { Pesquisa } \\
\text {-Ação }\end{array}$ & Survey & Modelagem & DSR \\
\hline Descrever um fenômeno & $x$ & & $x$ & & \\
\hline Testar uma teoria & $x$ & & $x$ & & \\
\hline Criar uma teoria & $x$ & & & & \\
\hline Resolver um problema prático & & $x$ & & $x$ & $x$ \\
\hline Explicar um processo prático & & $x$ & & $x$ & \\
\hline Avaliar comportamentos & & & $x$ & & \\
\hline Construir um artefato & & & & & $x$ \\
\hline Aplicar artefato em ambiente real & & $x$ & & & $x$ \\
\hline Formalizar um artefato & $x$ & $x$ & & $x$ & \\
\hline Prescrever soluções & & & & & $x$ \\
\hline
\end{tabular}

Fonte: Dresch (2013)

Machado et.al. (2013) afirmam que a criação de um artefato na DR é o principal meio pelo qual se pode gerar novos conhecimentos baseados em experiências práticas. 
Mas segundo os autores, o artefato em si não é necessariamente o principal resultado desta pesquisa construtiva. Os resultados da aplicação da Design Research são diversos, conforme descritos nos itens a seguir:

- Construtos ou conceitos: formam o vocabulário de conceituação utilizada para descrever os problemas dentro do domínio e para especificar respectivas soluções. Definem os termos usados;

- Modelo: é um conjunto de proposições ou declarações que expressam as relações entre os construtos. Em atividades de design, os modelos representam situações como problemas e afirmações de soluções. Um modelo pode ser visto simplesmente como uma descrição, isto é, como uma representação de como as coisas são;

- Método: é um conjunto de passos (um algoritmo ou orientação) usado para executar uma tarefa. Métodos baseiam-se em um conjunto de constructos subjacentes (linguagem) e uma representação (modelo) em um espaço de solução. Os métodos podem ser ligados aos modelos, onde as etapas do método podem utilizar partes do modelo como uma entrada que o compõe. Os métodos são muitas vezes utilizados para representar um caminho para resolução de um problema;

- Instantiation: é a utilização de um artefato em seu ambiente. A instantiation operacionaliza construtos, modelos e métodos. Porém, uma instantiation pode, na prática, preceder a articulação completa de seus construtos, modelos e métodos. Demonstram a viabilidade e a eficácia dos modelos e métodos que a contemplam;

- Melhoria nas teorias: a construção de um artefato de forma análoga à ciência natural experimental.

Estes resultados, sejam eles de qualquer tipo, podem ser impactantes ao conjunto de conhecimento sobre as diversas áreas científicas. Tanto que alguns autores, como Lacerda et.al.(2013), por exemplo, os descrevem como os próprios tipos de artefatos existentes resultantes da Design Research.

O desenvolvimento e a aplicação da metodologia DR necessitam de uma sequência de etapas para atingir os objetivos estabelecidos. Para a configuração desta aplicação 
na presente tese, buscou-se um modelo que mais se adequasse ao tema da pesquisa, uma vez que a maior parte dos trabalhos pesquisados de Design Research não contempla o ambiente da construção civil.

Inicialmente estudou-se o modelo de Takeda el.al. (1990), citado por grande parte dos autores que tratam do tema, no qual se destaca o conceito da evolução do metamodelo. Ele se inicia com especificações funcionais e à medida em que ocorrem os diversos refinamentos obtidos com os experimentos e implantações, a solução para o problema vai tornando-se mais próxima.

De acordo com os autores, um dos principais resultados obtidos nos experimentos é um modelo cognitivo dos processos de concepção quando se examina um processo de DR a partir de um ponto de vista de resolução de problemas. Este modelo é construído a partir de unidades de ciclos de projeto, como pode ser observado na figura 2.

Figura 2 - Ciclo do projeto de uma DR

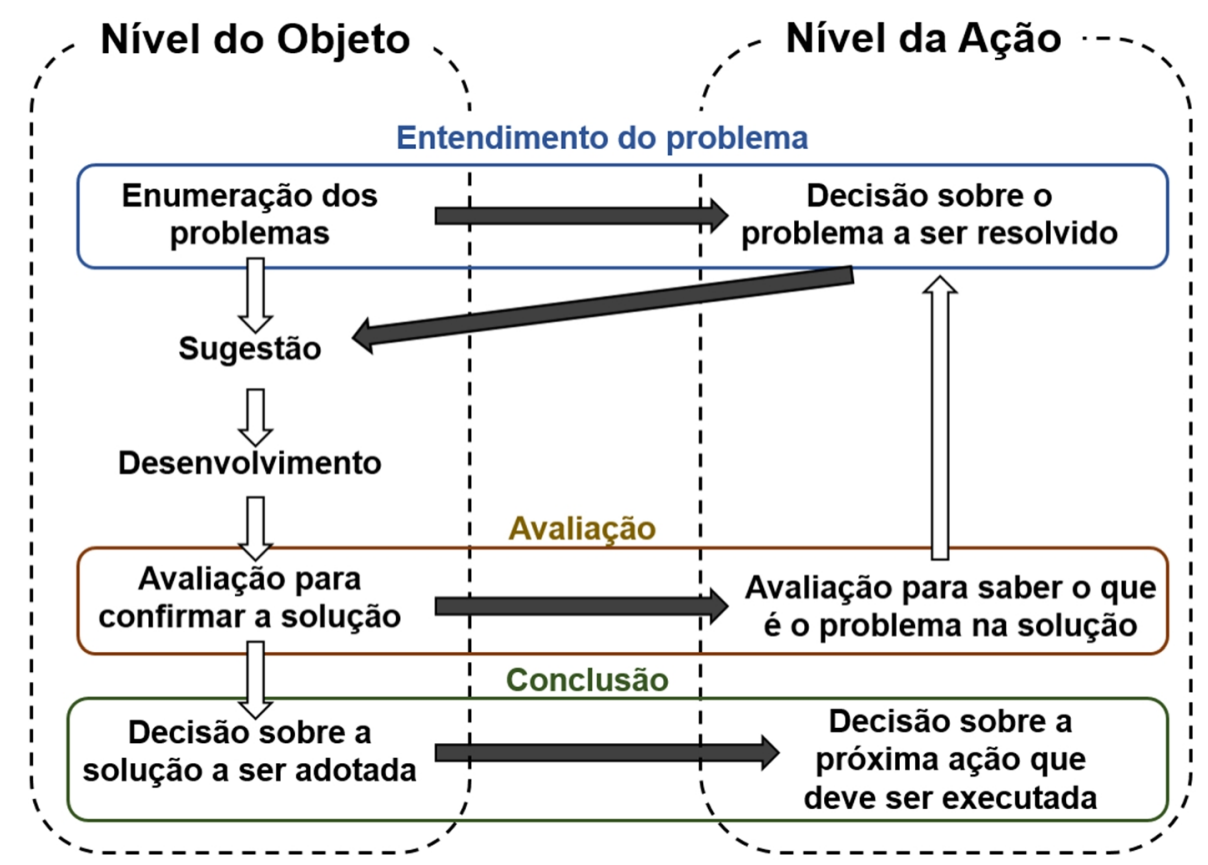

Fonte: Takeda et al. (1990)

O modelo de Takeda et.al. (1990) foi adaptado por Vaishnavi e Kuechler (2015), os quais também destacam os resultados de cada etapa do processo, ajudando uma melhor formatação do modelo a ser aplicado nesta pesquisa. 
Figura 3 - Modelo do processo de uma Design Science Research

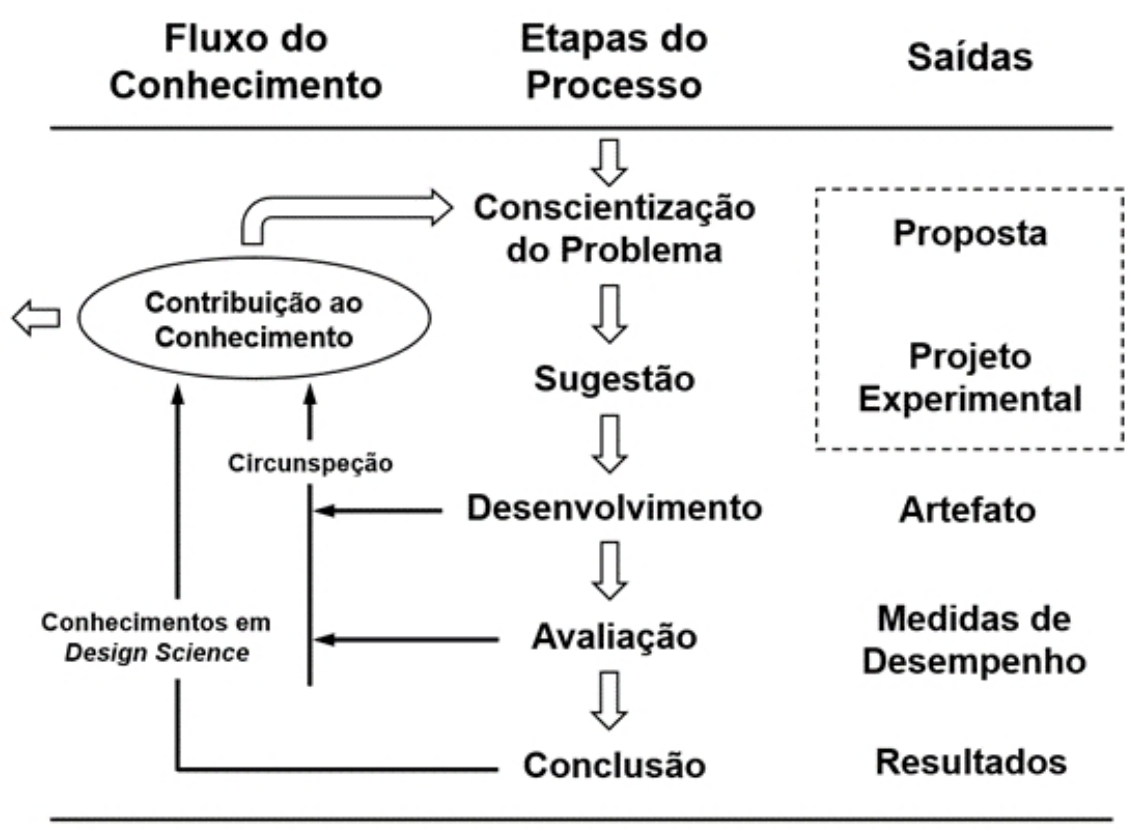

Fonte: Vaishnavi e Kuechler (2015)

Este novo modelo pode ser observado na figura 3 e compõe-se das seguintes etapas:

- Conscientização do Problema: o processo de investigação começa quando o pesquisador toma conhecimento de um problema ou oportunidade de pesquisa;

- Sugestão: durante a etapa de sugestão, elabora um ou mais modelos de tentativa para a resolução do problema. Os projetos preliminares estão ligados a uma proposta formal que inclui, normalmente, um projeto experimental. Esta etapa é totalmente criativa, e é nesta fase que diferentes pesquisadores irão chegar a diferentes modelos experimentais. Observa-se que as sugestões para o problema são delineadas a partir da existência de conhecimento ou teoria de base sobre o problema;

- Desenvolvimento: nesta etapa, o pesquisador construirá um ou mais artefatos. As técnicas utilizadas variam, dependendo do artefato a ser construído;

- Avaliação: uma vez construído, o artefato deve ser avaliado em função dos critérios que estão implícitos ou implicitamente contidos na proposta. Quaisquer desvios de expectativas devem ser relatados pelos pesquisadores. Antes e durante a construção, os pesquisadores formulam hipóteses sobre como será o comportamento do artefato. Na Design Research raramente as 
hipóteses iniciais são descartadas; porém, os desvios de comportamento esperados do artefato forçam os pesquisadores a redefinir e buscar novas sugestões;

- Conclusão: Nesta fase são consolidados e registrados os resultados da pesquisa.

Conforme descreve Hevner (2007), o DSR tem uma natureza essencialmente pragmática, devido à sua ênfase na relevância; trazendo contribuições claras para o ambiente de aplicação. No entanto, a utilidade prática por si só não define uma boa pesquisa utilizando este método. É a sinergia entre relevância e rigor, e as contribuições ao longo tanto do ciclo de relevância e do ciclo de rigor, que definem uma boa pesquisa em Design Science Research.

Para melhor entendimento, estes ciclos e a sinergia que os mesmos trazem ao DSR são ilustrados na figura 4.

Figura 4 - Ciclos da Design Science Research

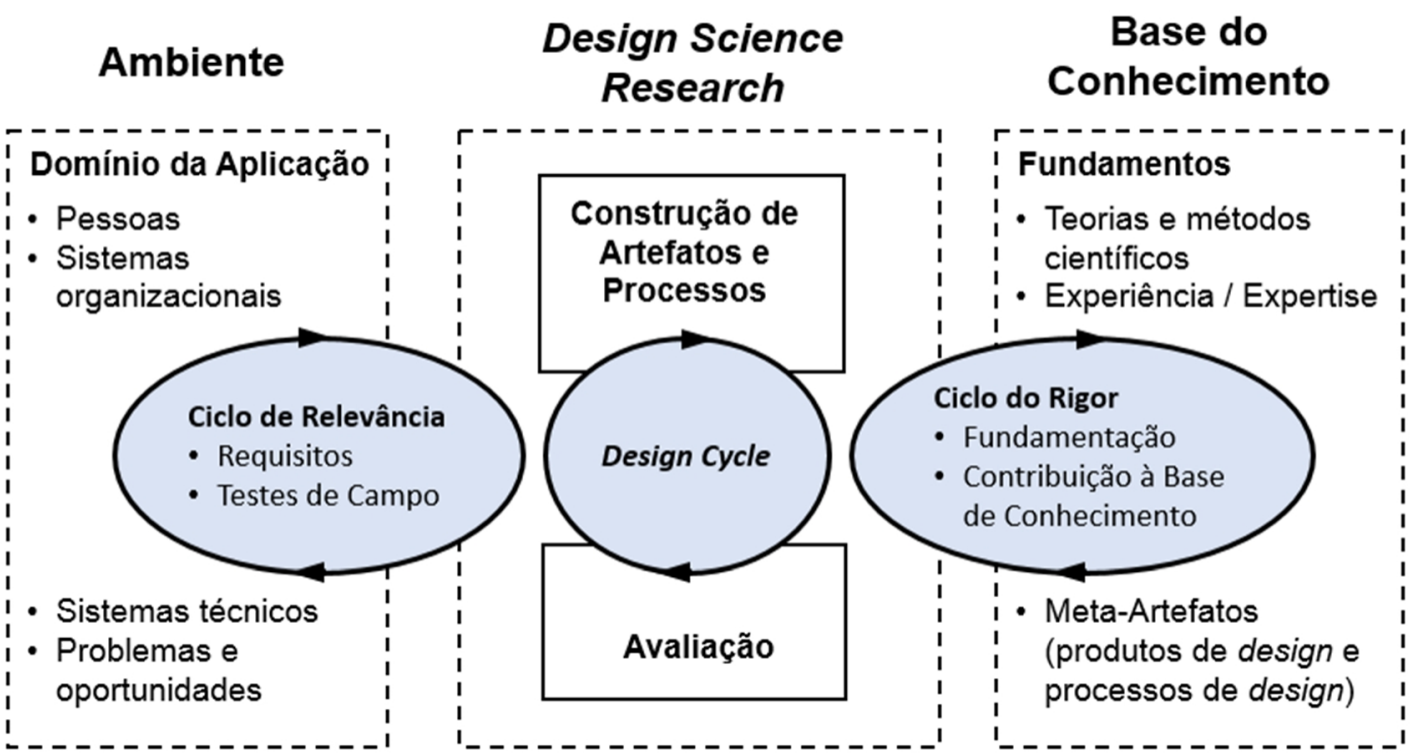

Fonte: Hevner (2007)

Desta forma, buscando-se esta sinergia, buscou-se um planejamento da pesquisa que garantisse tanto a relevância dos pontos e problemas apontados, como a fundamentação que permitisse que a pesquisa pudesse contribuir à base de conhecimento relativa ao tema. 
Quando se trata de rigor, não necessariamente está se referindo ao uso de métodos sofisticados. O rigor implica cuidados para se evitar que a pesquisa afirme ou conclua algo que ela sozinha não tenha condições de suportar.

Assim, destaca-se a importância da etapa de avaliação da DSR, para demonstrar e justificar os procedimentos adotados e aumentar a confiabilidade do artefato e seus resultados quando em uso.

De acordo com Lacerda et al. (2013), para aumentar a confiabilidade nos resultados da pesquisa, é necessário um conjunto de cuidados e procedimentos rigorosos que minimizem o viés nos resultados obtidos e/ou nas soluções geradas. Dessa forma, a partir de uma filosofia pragmática, o artefato gerado deve sofrer uma série de avaliações rigorosas que possam demonstrar sua robustez.

Hevner et al. (2004), em suas pesquisas sobre DSR, estabelecem sete diretrizes para orientar pesquisadores em como definir um plano de pesquisa eficaz utilizando este método. Apesar dos autores focarem projetos de pesquisa na área de sistema de informação, entende-se que são aplicáveis à área de projetos de construção.

Um dos pontos de destaque neste conjunto de diretrizes diz respeito a avaliação do artefato, que segundo os autores é crucial. Eles destacam diversos métodos para avaliação, que podem ser observados no quadro 3.

Outra forma de avaliação do artefato, segundo Lacerda et al. (2013), é a utilização dos chamados Grupos Focais de estudo, que realizam uma discussão mais profunda e colaborativa em relação ao que foi desenvolvido pela pesquisa. Estes grupos auxiliariam, ainda, na realização da análise crítica dos resultados obtidos durante a pesquisa, estimulando a produção de novas possibilidades com o objetivo de encontrar melhores soluções para os problemas em estudo.

Interessante notar que este método de avaliação não é explicitado no quadro de Hevner et al. (2004), ficando sua classificação entre uma avaliação analítica e descritiva.

De acordo com McDonagh-Philp e Bruseberg (2000), um grupo focal envolve a reunião de usuários-alvo do artefato, para uma discussão relativamente informal sobre um tópico ou assunto específico. Um moderador promove a discussão entre o grupo, 
assegurando que este discuta questões chave que envolvem o artefato, mas sem colocar sua opinião própria. A sinergia entre os participantes ajuda a descobrir ou a destacar questões menos tangíveis.

Segundo as autoras, os grupos focais coletam dados qualitativos. O conteúdo da discussão pode levar direções inesperadas ou abrir novos tópicos. Embora a técnica ofereça um alto grau de flexibilidade na forma como as perguntas são feitas, as respostas variam e a padronização dos dados não é o foco da pesquisa. Os dados fornecem insights detalhados sobre crenças e experiências das pessoas, ao invés de fatos estatisticamente seguros. A validade dos dados pode ser aumentada através da aplicação de amostragem intencional (que envolve a seleção de participantes pertencentes a grupos de usuários específicos).

Quadro 3 - Métodos de avaliação de artefatos em DSR

\begin{tabular}{|c|c|}
\hline Classificaçãc & Métodos de Avaliação \\
\hline Observacional & $\begin{array}{l}\text { - Estudo de Caso: estudar o artefato em profundidade no ambiente de } \\
\text { negócios; } \\
\text { - Estudo de Campo: monitorar o uso do artefato em projetos múltiplos. }\end{array}$ \\
\hline Analítico & $\begin{array}{l}\text { - Análise Estática: examinar a estrutura do artefato para qualidades } \\
\text { estáticas (por exemplo, sua complexidade); } \\
\text { - Análise da Arquitetura: estudar o encaixe do artefato na arquitetura } \\
\text { técnica do sistema (muito específico para sistema de informação); } \\
\text { - Otimização: demonstrar as propriedades ótimas inerentes ao artefato ou } \\
\text { os limites de otimização no comportamento do artefato; } \\
\text { - Análise Dinâmica: estudar o artefato durante o uso para avaliar suas } \\
\text { qualidades dinâmicas (por exemplo, seu desempenho). }\end{array}$ \\
\hline Experimental & $\begin{array}{l}\text { - Experimento Controlado: estudar o artefato em ambiente controlado } \\
\text { para verificar suas qualidades (por exemplo, se é útil naquele meio); } \\
\text { - Simulação: executar o artefato com dados artificiais. }\end{array}$ \\
\hline Teste & $\begin{array}{l}\text { - Teste Funcional: executar as interfaces do artefato para descobrir } \\
\text { possíveis falhas e identificar defeitos; } \\
\text { - Teste Estrutural: realizar testes de cobertura de algumas métricas para } \\
\text { implementação (por exemplo, caminhos para a execução). }\end{array}$ \\
\hline Descritivo & $\begin{array}{l}\text { - Argumento informado: utilizar a informação das bases de conhecimento } \\
\text { (por exemplo, de pesquisas relevantes) para construir um argumento } \\
\text { convincente a respeito da utilidade do artefato; } \\
\text { - Cenários: construir cenários detalhados em torno do artefato, para } \\
\text { demonstrar sua utilidade. }\end{array}$ \\
\hline
\end{tabular}


De acordo com Tremblay et al. (2010), um grupo focal é definido como uma discussão moderada entre seis a doze pessoas. Eles discutem um tópico sob a direção de um moderador, cujo papel é promover a interação e manter a discussão focada no tópico de interesse.

Segundo os autores, a técnica do Grupo Focal tem sido utilizada há muito tempo em pesquisas sociais para estudar ideias em um ambiente de grupo. Eles defendem que deve ser adaptada para DR considerando basicamente os dois principais objetivos do DR: refinamento do artefato (melhorias incrementais) ou sua avaliação (demonstrar a utilidade dos artefatos desenvolvidos no campo de aplicação). Esta adaptação deve seguir os passos descritos na figura 5 .

Figura 5 - Passos para a implantação do Grupo Focal em DSR

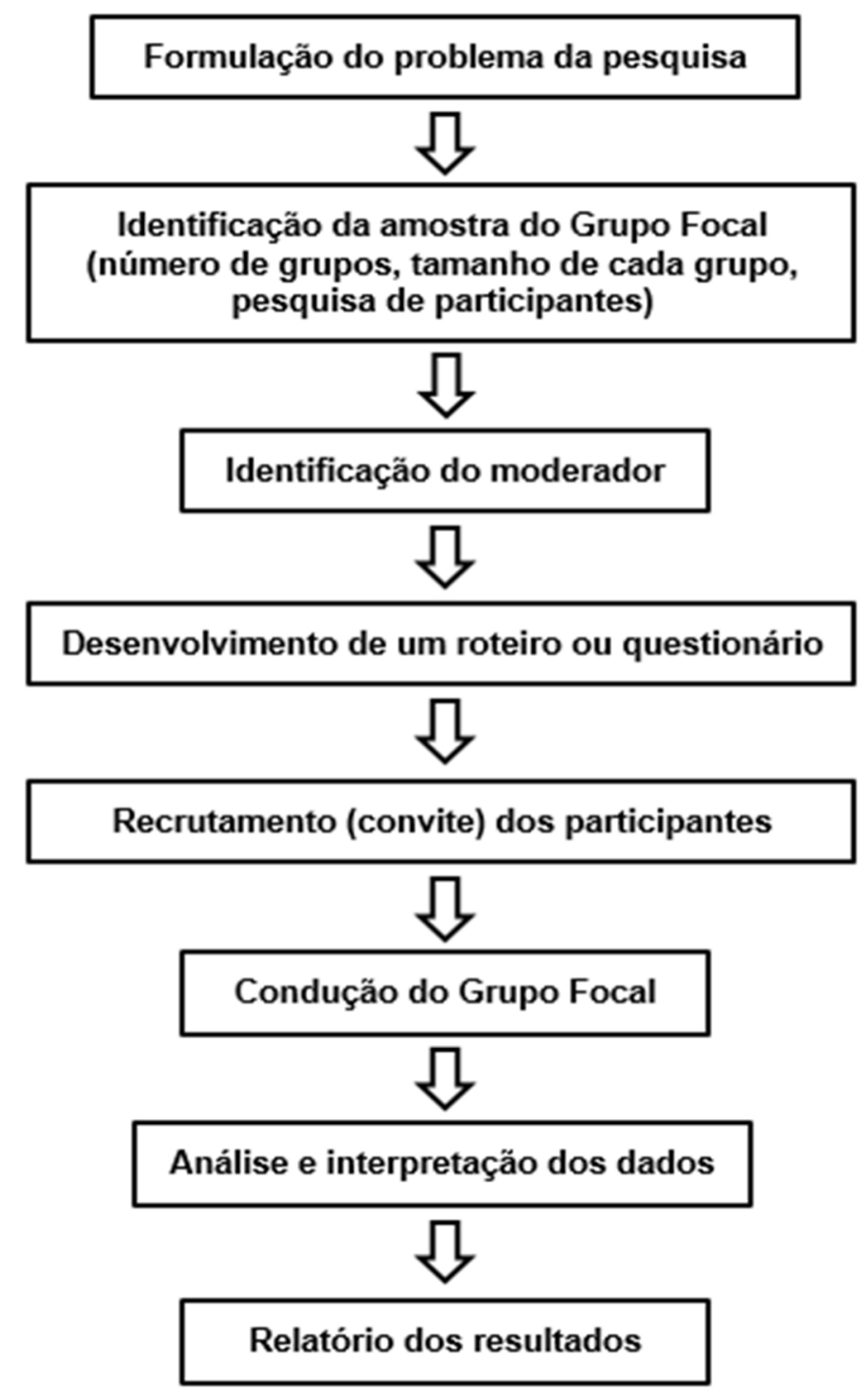

Fonte: Tremblay et al. (2010) 


\subsection{A aplicação da DSR como método de pesquisa principal da tese.}

Tomando como referência os processos usuais de uma DSR descritos por Vaishnavi e Kuechler (2015) e levando em consideração os ciclos de Hevner (2007), buscou-se um modelo de pesquisa que atendesse aos objetivos da tese e ao mesmo tempo trouxesse contribuições importantes à base do conhecimento.

Este modelo e suas etapas podem ser identificados no quadro 4, onde para cada etapa, se correlacionou os objetivos sequenciais, bem como as técnicas que foram usadas em cada momento, desde os primeiros levantamentos bibliográficos, as pesquisas de campo, a validação do artefato e conclusão da DSR.

Quadro 4 - Etapas do DSR previsto para a tese

\begin{tabular}{|c|c|c|}
\hline Etapa & Objetivos / Atividades & Técnica \\
\hline $\begin{array}{l}\text { Entendimento do } \\
\text { problema }\end{array}$ & $\begin{array}{l}\text { - Identificação clara do problema } \\
\text { (atrasos de obra); } \\
\text { - Conceituação dos principais termos } \\
\text { relacionados ao problema; } \\
\text { - Compreensão do assunto do ponto de } \\
\text { vista teorico e prático; } \\
\text { - Identificação de ferramentas e modelos } \\
\text { de planejamentro (conceitual / clássico); } \\
\text { - Identificação das causas de atraso } \\
\text { (conceitual / pesquisas de autores). }\end{array}$ & $\begin{array}{c}\text { Levantamento (pesquisa } \\
\text { bibiográfica e pesquisa } \\
\text { documental) } \\
\text { Classificação:Pesquisa } \\
\text { descritiva }\end{array}$ \\
\hline $\begin{array}{c}\text { Sugestão e } \\
\text { Desenvolvimento }\end{array}$ & $\begin{array}{l}\text { - Identificação das principais causas de } \\
\text { atraso (mercado); } \\
\text { - Identificação de ferramentas de gestão } \\
\text { (mercado); } \\
\text { - } \quad \text { Proposta de diretrizes para eliminação } \\
\text { das causas de atraso (projeto } \\
\text { experimental); } \\
\text { - Construção inicial do método (artefato). }\end{array}$ & $\begin{array}{c}\text { Pesquisa Ex-Post facto } \\
\text { Classificação:Pesquisa } \\
\text { explicativa }\end{array}$ \\
\hline Avaliação & $\begin{array}{l}\text { - Aplicação dos conceitos; } \\
\text { - Avaliação do método (artefato); } \\
\text { - Constatação de premissas e proposição } \\
\text { - de melhorias; } \\
\text { - Validação do método (artefato). }\end{array}$ & $\begin{array}{l}\text { Estudo de caso } \\
\text { (adaptado para DSR) } \\
\text { Classificação:Pesquisa } \\
\text { exploratória; e } \\
\text { Grupo focal (avaliação } \\
\text { confirmatória) }\end{array}$ \\
\hline Conclusão & $\begin{array}{l}\text { - Análise dos resultados e refinamento do } \\
\text { método / proposição da tese; } \\
\text { - Organização do conhecimento (inclusão } \\
\text { à Base de Conhecimento sobre o } \\
\text { assunto). }\end{array}$ & $\cdots$ \\
\hline
\end{tabular}


As etapas da DSR previstas para esta tese são detalhadas nos itens a seguir.

\subsubsection{Etapa de Entendimento do Problema (primeira parte)}

O processo de pesquisa teve início com diversas atividades que possibilitassem o total entendimento do problema principal que se pretendia estudar: atrasos de obra.

Antes disso, entendeu-se como importante a conceituação de termos ligados ao tema da pesquisa, desde a própria definição de atraso, até os aspectos ligados à gestão de prazos de obra.

Para se obter a compreensão profunda do assunto, uma ampla pesquisa bibliográfica foi desenvolvida, focando-se autores que tratassem dos mais variados aspectos relacionados aos atrasos de obra (modelos de planejamento, ferramentas de controle, ocorrências de atraso, causas, impactos, mitigação, resultados nas obras, dentre outros).

Para Silva e Menezes (2001), neste tipo de revisão em um trabalho de pesquisa, o autor tem como objetivo mostrar, através da literatura já publicada, o que já se sabe sobre o tema, quais as lacunas existentes e onde se encontram os principais entraves teóricos ou metodológicos.

Assim, nesta etapa buscou-se a determinação do "estado da arte" no tema proposto, apresentado no capítulo 3.

\subsubsection{Etapa de Entendimento do Problema (segunda parte)}

Para complementar o levantamento descrito no item anterior, foi também realizada uma pesquisa documental, conforme sugerem Marconi e Lakatos (2008), com a análise de arquivos, relatórios, informações recebidas de empresas do setor e outros documentos particulares utilizados no âmbito profissional do autor.

Evidenciando-se a relevância do problema na prática e de modo a finalizar a etapa de Entendimento do Problema, além do vasto levantamento citado, decidiu-se desenvolver uma pesquisa de campo com uma amostra significativa de construtoras e obras, que pudesse traduzir todos os conceitos pesquisados e conforme a realidade brasileira. Isto foi importante, uma vez que vários problemas de atrasos identificados 
no levantamento bibliográfico relacionam-se a realidades do mercado de construção dos autores pesquisados, sendo a maior parte deles fora do Brasil.

Assim, um total de 50 obras onde o problema do atraso era significativo foram analisadas, gerando-se um ranking com as principais causas de atraso. Esta ordenação direcionaria, mais tarde, os estudos sobre as ferramentas e práticas que ajudassem de forma mais efetiva na diminuição da ocorrência do problema em projetos imobiliários.

Como os resultados a serem obtidos por esta pesquisa seriam quantitativos (análise da frequência de ocorrência da causa), a pesquisa utilizou um protocolo baseado nas conclusões daqueles autores que pudessem trazer classificações específicas e resultados também quantitativos.

Os autores que realizaram pesquisas conceituais ou com resultados qualitativos foram também muito importantes para a definição do método de gestão, embora neste primeiro momento acabaram não sendo relacionados.

Para a obtenção de tais informações buscou-se a implantação da pesquisa denominada de ex-post facto com as seguintes etapas, conforme sugere Gil (2008):

- Formulação do problema e construção das hipóteses;

- Operacionalização das variáveis;

- Localização dos grupos para investigação;

- Coleta de dados;

- Análise e interpretação dos dados;

- Apresentação das conclusões.

Esta primeira pesquisa de campo e seus resultados são apresentados de forma detalhada no capítulo 4.

\subsubsection{Etapas de Sugestão e Desenvolvimento}

A partir dos dados analisados e do ranking das principais causas de atraso advindos desta tipologia de obra, iniciou-se a etapa de Sugestão, com a proposição de diretrizes 
genéricas para o planejamento e controle de prazos de obra, as quais focam a eliminação destas principais causas.

Em seguida, parte-se para a etapa de Desenvolvimento, onde as diretrizes genéricas começam a ser estudadas e transformadas em uma construção inovadora para solucionar o problema real. Esta nova construção buscou ações práticas correlacionadas às diretrizes da etapa anterior. Inicialmente, as práticas sugeridas advêm do levantamento bibliográfico (relacionado a modelos de planejamento e gestão), mas também da experiência do autor em atividades profissionais de consultoria e gerenciamento.

A organização de todas estas práticas de uma forma estruturada resulta no artefato principal da tese de doutorado, e por suas características essenciais, classificada como um método.

Implementar a solução e testar sua aplicabilidade prática foram as atividades previstas para a etapa seguinte, que foi dividida em duas partes.

\subsubsection{Etapa de Avaliação (primeira parte)}

Para a análise do método proposto, bem como a constatação das premissas sugeridas para o planejamento e a gestão dos prazos das obras, realizou-se uma nova pesquisa de campo, mas agora de caráter exploratória, analogamente ao que se costuma realizar com a técnica do estudo de caso, mas adaptado para a DSR.

Nesta primeira parte da Etapa de Avaliação, a sistemática adotada foi a análise aprofundada de mais 8 obras de empreendimentos imobiliários. Estas agora teriam características positivas de planejamento e controle, que possibilitassem evidências de práticas que garantissem a não ocorrência de atrasos, ou ainda, sem necessariamente ser objetivo das práticas, a antecipação de prazos.

Neste momento também buscou-se identificar possíveis circunscrições, ou seja, a detecção de contradições no método (que não funcionaram conforme a teoria), e que desta forma, também contribuíram para a constituição do artefato.

Conforme definição de diversos autores, como Gil (2008) e Marconi e Lakatos (2008), este tipo de pesquisa tem como objetivo desenvolver a hipótese, aumentar a 
familiaridade do pesquisador com o ambiente e fenômenos, para a realização de uma pesquisa futura mais precisa ou modificar e clarificar conceitos. Este último objetivo acabou sendo o propósito mais forte na adoção deste tipo de pesquisa, que geralmente não utiliza técnicas probabilísticas.

Normalmente, conforme descrito pelos autores, esta forma de pesquisa exploratória é utilizada para o estudo relativamente intenso de pequeno número de unidades.

Segundo Yin (2010) um estudo de caso é uma investigação empírica de um fenômeno contemporâneo dentro de seu contexto da vida real, especificamente quando os limites entre o fenômeno e o contexto não estão claramente definidos. A investigação enfrenta uma situação em que haverá muito mais variáveis de interesse do que pontos de dados e beneficia-se do desenvolvimento prévio de proposições teóricas para conduzir a coleta e a análise de dados.

A diferença entre um estudo de caso tradicional e esta adaptação, utilizada dentro do método de DSR, relaciona-se ao fato de que nesta pesquisa o problema já é conhecido desde o início, e o entendimento já foi realizado à exaustão através das etapas anteriores. Desta forma, apesar de escolhido como o processo mais adequado para esta pesquisa de campo, o estudo de caso precisou sofrer adaptações em sua aplicação.

Existem diversos tipos de estudo de caso, dentro eles os estudos de caso único ou múltiplo. Os resultados de estudos de casos múltiplos são considerados mais convincentes, mas de maior dificuldade para coleta, análise e integração dos resultados. Para garantir a confiabilidade e validação do trabalho como uma tese de doutorado, naturalmente foi adotado o estudo de casos múltiplos, mas com os devidos cuidados necessários.

Yin (2010) identifica três princípios para garantir o sucesso da coleta de dados em um estudo de caso:

- Utilizar várias fontes de evidência;

- Criar um banco de dados para o estudo de caso;

- Manter o encadeamento de evidências. 
Assim, para atender a estes princípios, foram realizadas diversas atividades para a coleta de dados, partindo-se de tipos diferentes de fonte de evidência:

- Documentos (projetos, memoriais, atas de reunião, relatórios, artigos sobre o empreendimento ou projeto, propostas e outros documentos internos);

- Registros em arquivo (normalmente assumindo a forma de arquivos e registro em computador, como mapas, gráficos, tabelas, dados de clientes e outros);

- Entrevistas formais com os envolvidos (através de roteiros estruturados);

- Observação direta (visita de campo, participação de reuniões ou atividades informais de coleta de dados);

- Observação participante (estudos onde o pesquisador é membro da equipe do projeto ou desempenha papel funcional nas atividades prestando serviço).

Todas as informações foram organizadas em um banco de dados previamente estruturado, com base nos objetivos definidos para a pesquisa, através de notas, coleta formal de documentos, tabelas ou narrativas.

\subsubsection{Etapa de Avaliação (segunda parte)}

Esta segunda parte da etapa buscou auxiliar na validação do artefato utilizando-se um Grupo Focal com amostragem intencional.

De acordo com McDonagh-Philp e Bruseberg (2000), o sucesso do grupo depende de um planejamento prévio e da definição de forma clara dos objetivos deste estudo. É altamente recomendável a construção de um guia para o moderador, que determina a estrutura da sessão, incluindo os seguintes itens:

- Objetivos da sessão;

- Os diferentes tópicos a serem abordados;

- As perguntas a serem formuladas aos participantes;

- O fluxo ou dinâmica das discussões;

- Como serão promovidas as discussões;

- Recursos visuais e estímulos externos que possam ser utilizados;

- Durações de cada atividade. 
As autoras ainda destacam que tradicionalmente os Grupos Focais envolvem cerca de 8 a 10 pessoas, mas têm-se observado grupos menores de 6 a 7 pessoas como mais adequados.

Desta forma, seguindo os passos sugeridos por Tremblay et al.(2010) e as orientações de McDonagh-Philp e Bruseberg (2000) para montagem dos roteiros, estruturou-se a aplicação da técnica do Grupo Focal através de um workshop presencial de profissionais de planejamento de obra.

Entende-se workshop como uma reunião de um grupo de pessoas interessadas em um determinado assunto, onde ocorrem atividade para discussão sobre o tema que é de interesse para todos. Como o workshop enfatiza a troca de ideias ou até mesmo a demonstração e/ou aplicação de técnicas e habilidades, julgou-se totalmente aderente ao objetivo desta pesquisa.

Os resultados do workshop foram compilados e auxiliaram tanto no refinamento do artefato proposto (método), como em sua validação (confirmação).

Além disso, as contribuições dos participantes trouxeram elementos importantes quanto às restrições da pesquisa, pontos não abordados pelo método ou sobre a necessidade de maiores esclarecimentos sobre determinadas etapas ou descrições do trabalho, garantindo melhor entendimento da metodologia e dos resultados alcançados.

\subsubsection{Etapa de Conclusão}

Por fim, entrando na etapa de Conclusão, buscou-se analisar a contribuição teórica do artefato construído. Neste caso, não caracterizou-se pela criação de novas ferramentas inovadoras, mas sim como a organização do conhecimento, a geração de dados concretos de um assunto pouco cientificado no Brasil e um método que utiliza diversas destas ferramentas, e de como elas devem ser utilizadas na prática.

Esta análise de contribuição é muito importante para garantir a aderência com o ciclo do rigor, descrito por Hevner (2007). 


\subsection{Estruturação da tese com base nos métodos de pesquisa propostos}

De acordo com todos os itens discutidos, em especial buscando-se atender aos preceitos da DSR, para melhor entendimento da proposição da tese, decidiu-se então estruturar este documento da forma como é apresentada na figura 6.

De acordo com esta organização, no capítulo 1 é realizada a contextualização do assunto da pesquisa, com a introdução dos problemas intrínsecos à gestão dos prazos de empreendimentos imobiliários, sobretudo a questão dos atrasos de obra. Neste capítulo também é apresentada a justificativa pela escolha do tema da pesquisa.

Em seguida, no capítulo 2, buscou-se estabelecer os objetivos da pesquisa proposta, bem como a abrangência do estudo. Os métodos de pesquisa para se alcançar tais objetivos também são descritos neste bloco, bem como a estrutura final da tese que entendeu-se mais adequada.

No capítulo 3 é descrita toda a revisão bibliográfica sobre o tema, atendendo ao modelo conceitual pré-estabelecido para o Design Science Research, no qual inicialmente busca-se o conhecimento profundo do assunto (gestão de prazos de obra e ferramentas de planejamento) e do problema a ser tratado na pesquisa (atrasos). Buscou-se desta forma a primeira contribuição acadêmica desta pesquisa: uma forma de organização do conhecimento sobre o tema, dentro e fora do país. Assim atendeuse a um dos objetivos secundários da tese.

No capítulo 4 é apresentada outra contribuição acadêmica, mas agora trazendo resultados concretos de uma pesquisa de campo para a identificação das principais causas de atraso em obras, atendendo a outro objetivo secundário da tese.

Em seguida, verifica-se o início do desenvolvimento do artefato concreto da pesquisa no capítulo 5. Esta estruturação, apesar de preliminar, baseia-se em vasto material, resultado da análise dos resultados da pesquisa de campo (descritos no capítulo anterior), de toda a revisão bibliográfica sobre o tema e de todo o conhecimento adquirido pelo autor em suas atividades profissionais e acadêmicas.

No capítulo 6, buscou-se a avaliação da aplicabilidade do artefato preliminar, com a realização da segunda pesquisa de campo. Descreve-se os resultados individuais 
alcançados no estudo de cada caso, bem como a aderência dos conceitos e práticas de planejamento e gestão propostas no capítulo anterior.

O capítulo 7 consolida os resultados da segunda pesquisa de campo, direcionando uma proposição mais estruturada para o método de planejamento e gestão de prazos. O capítulo também descreve a implantação do grupo focal especialmente organizado para validação dos conceitos e refinamento do artefato resultante da pesquisa.

O método revisado e validado (artefato final) é apresentado de forma detalhada no capítulo 8.

O capítulo 9 traz as considerações finais do autor sobre os resultados de todo este trabalho, a avaliação do atendimento dos objetivos propostos, bem como proposições para o avanço de pesquisas sobre o tema.

As referências bibliográficas citadas ao longo de todo o texto são apresentadas no último capítulo.

Além disso, ao final deste trabalho, apresentam-se dois apêndices, com os resultados completos da primeira pesquisa de campo, uma vez que os dados apresentados e utilizados como referência durante a tese, relacionam-se apenas aos itens mais frequentemente observados na pesquisa. Os dados da segunda pesquisa de campo, por sua vez, são referências e utilizados de forma integral na tese, dispensando-se a necessidade de se utilizar um apêndice com este objetivo. 
Figura 6 - Estrutura da tese

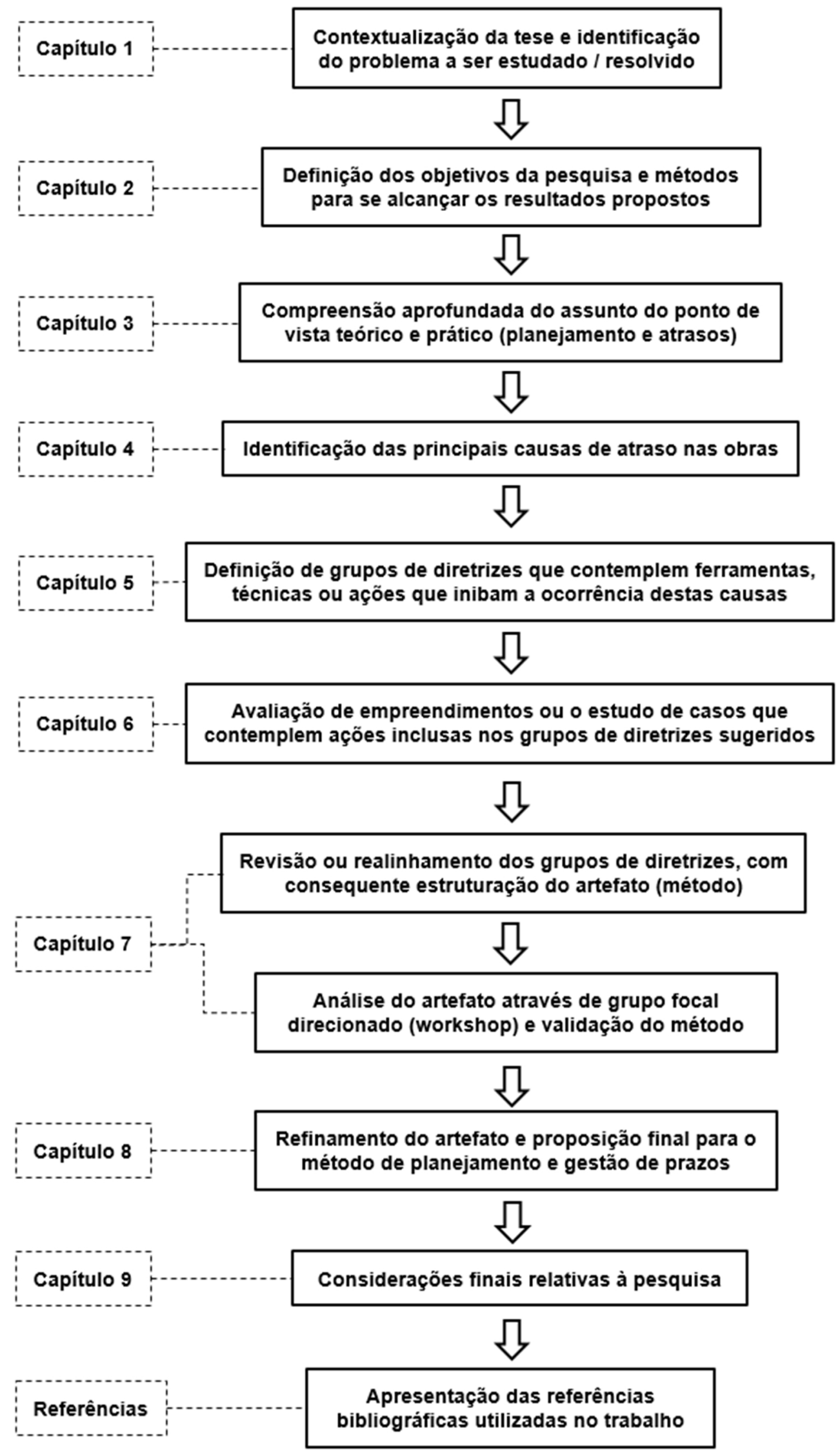

Fonte: O Autor 


\section{REVISÃO BIBLIOGRÁFICA}

\subsection{A obra como um projeto}

Como inicialmente descrito no capítulo introdutório, as atividades de uma organização geralmente podem ser divididas entre projetos e atividades operacionais. Por atividades operacionais podem-se entender funções básicas que são executadas repetidamente no dia a dia da organização.

Já um projeto, segundo o PMI (2013), é o meio pelo qual uma organização desenvolve um produto, serviço ou resultado único.

Tomando-se a indústria automotiva como exemplo, a fabricação de peças e a montagem seriam exemplos de atividades operacionais, enquanto o desenvolvimento de um novo modelo de carro seria um projeto.

Pode-se então dizer que sempre que uma empresa deseja fornecer um novo produto ou serviço, ela também recorrerá a um projeto.

Assim, os projetos estão presentes no plano estratégico de uma organização. Quando uma empresa busca modificar seus processos, buscando maior eficiência ou atender a novas demandas de mercado, recorre a um projeto que lhe traga os resultados desejados.

Desta forma, é possível afirmar que a maneira de uma empresa conduzir seus projetos de mudanças ou inovações irá determinar em parte se ela estará bem ou mal posicionada perante o mercado e seus concorrentes. E em mercado competitivo como o atual, mudanças são exigidas de forma rápida e frequente. Por estes motivos a importância dada à forma como a empresa conduz seus projetos vem crescendo ao longo dos anos.

Em algumas empresas como as de consultoria ou construção civil, no entanto, o projeto se confunde com o produto final entregue aos clientes. Neste e em outros casos pode haver sobreposição entre as duas categorias mencionadas. 
Segundo Kerzner (2006), um projeto (em qualquer área) caracteriza-se por um esforço com objetivo identificável, que consome recursos e opera sob pressões de prazo, custos e qualidade.

Além de seu caráter temporário, citado pelo PMI (2013) como imprescindível para a definição de um projeto, existem outras características intrínsecas a ele, como as citadas por Meredith e Mantel (2011):

- Propósito: o projeto normalmente é uma atividade periódica com um conjunto bem definido de resultados finais pretendidos;

- Ciclo de Vida: desde o lento começo de seu progresso, desenvolvimento, auge, início do declínio e término, o projeto sempre apresenta um ciclo de vida claramente definido;

- Interdependência: os projetos geralmente interagem com outros que estão sendo executados pelas empresas que deles participam;

- Singularidade: os elementos de cada projeto são únicos, mesmo que possuam estruturas similares, quando rotineiros dentro de uma mesma empresa;

- Conflitos: exatamente por sua interdependência dentro de uma organização, os projetos compartilham recursos, além de competirem muitas vezes com os departamentos funcionais da empresa, o que gera diversos conflitos internos; além disso, os diversos stakeholders ${ }^{1}$ do projeto têm objetivos distintos, o que também gera conflitos de interesse e outros problemas externos ao ambiente da empresa.

Dentro desta definição, na construção civil, uma obra engloba todas estas características, sendo seu ciclo de vida iniciado no desenvolvimento das plantas ou desenhos, passando pelo planejamento, execução e entrega da obra ao cliente.

(1) Stakeholder é um termo comumente utilizado em gerenciamento de projetos que representa qualquer parte interessada ou envolvida direta ou indiretamente no projeto, tais como investidores, financiadores, projetistas, construtores, autoridade pública, fornecedores e representantes de clientes. 
Meredith e Mantel (2011) descrevem que os primeiros objetivos do projeto têm origem em 3 vertentes representadas pelos eixos do gráfico da figura 7 , dando origem à meta do projeto.

Figura 7 - Objetivos e meta de um projeto

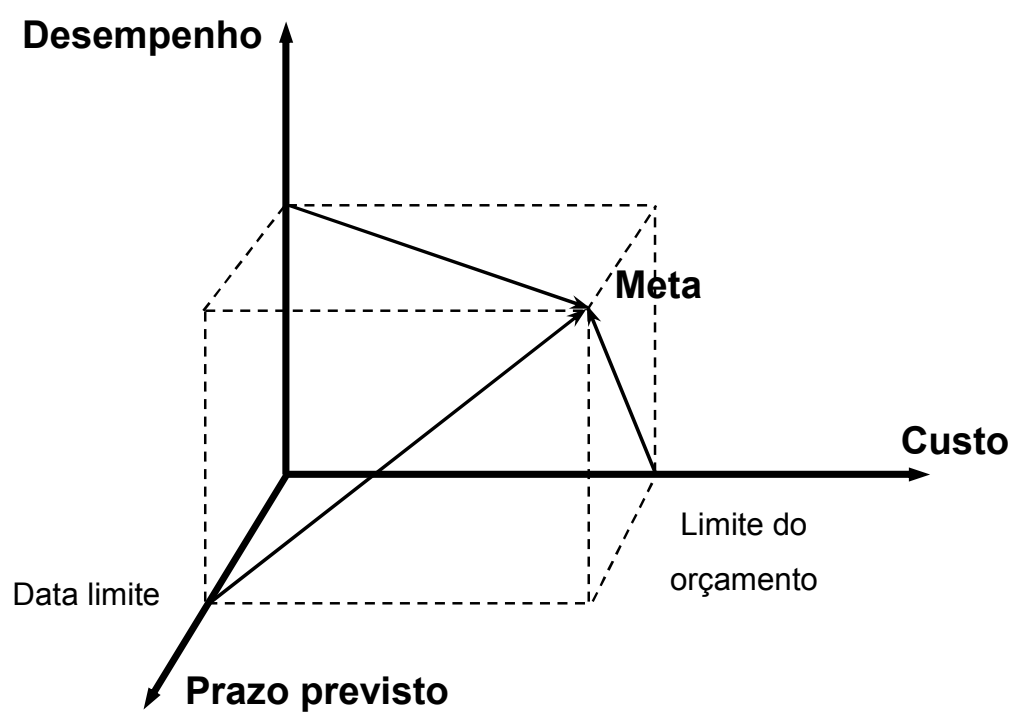

Fonte: Meredith e Mantel (2011)

Os propósitos de um projeto, apesar de variarem de empreendimento para empreendimento, constantemente referem-se ao relacionamento ou conflito de tais vertentes.

Os eixos intitulados de prazo e custo são mensuráveis, de fácil entendimento, mas o conceito de desempenho descrito pelos autores ainda traz inúmeras subjetividades.

É possível definir os objetivos de todo projeto como o desenvolvimento de um produto, serviço ou resultado, de acordo com as especificações (escopo), no prazo determinado e dentro do orçamento aprovado para tal. Para estes três elementos (escopo, prazo e custo) costuma-se dar o nome de restrição tripla.

Os componentes da restrição tripla estão intimamente interligados. Uma redução no prazo de entrega do projeto pode implicar numa redução do escopo, aumento de custos ou ambos. Uma redução no orçamento disponível para um projeto pode ocasionar uma redução de escopo, atraso da entrega ou ambos. Por outro lado, acrescentar itens ao escopo de um projeto geralmente acarretará atraso na entrega, estouro no orçamento previsto ou ambos. 
Alguns autores, por sua vez, tentam identificar fatores que caracterizariam um empreendimento bem sucedido. Kerzner (2006), por exemplo, aponta como fatores primários o atendimento do prazo, orçamento e o nível de qualidade desejado, e como fator secundário a aceitação do cliente.

O autor ainda cita algumas empresas que definem sucesso em termos de fatores críticos (ou Critical Sucess Factors - CSFs) e indicadores de desempenho (ou Key Performance Indicators - KPIs), como identificado no quadro 5.

De uma certa forma, os itens apontados por Kerzner (2006) estão relacionados com os objetivos de Meredith e Mantel (2011) e trazem elementos que podem caracterizar de forma mais específica o desempenho de um projeto. No entanto, pela complexidade na definição de "sucesso de um empreendimento", nesta pesquisa prefere-se manter o termo "propósito".

Quadro 5 - CSFs e KPIs

\begin{tabular}{ll}
\hline \multicolumn{1}{c}{ CSFs - Critical sucess factors } & KPIs - Key performance indicators \\
\hline - cumprimento da programação; & $\bullet \begin{array}{l}\text { utilização da metodologia de gestão } \\
\text { de projetos; }\end{array}$ \\
- atendimento do orçamento; & $\bullet \begin{array}{l}\text { estabelecimento dos processos de } \\
\text { - controle; }\end{array}$ \\
- e oportunidade da assinatura do contrato; & $\bullet \quad$ uso de indicadores; \\
- cumprimento do processo de controle de & $\bullet \begin{array}{l}\text { qualidade dos recursos aplicados X } \\
\text { mudança; }\end{array}$ \\
- formalização dos aditivos ao contrato & $\bullet$ envolvimento do cliente. \\
\hline
\end{tabular}

Fonte: Kerzner (2006)

Cada projeto dentro de uma organização é único e por isso necessita de abordagens diferentes para ser executado com sucesso. No entanto, os projetos geralmente apresentam as mesmas fases e utilizam os mesmos processos para serem concluídos. Em tempo, as boas práticas que levam ao sucesso podem ser semelhantes em todos os tipos de projeto.

Estas práticas, aplicadas de forma repetitiva podem se tornar processos, que comporão modelos de gestão de projetos ou obras, criados para se alcançar os objetivos dos projetos. 


\subsection{Os processos da gestão de projetos ou obras}

Uma vez que se verifica a importância de organizar estas práticas em processos, o PMI (2013) organizou os mesmos em grupos para estudo e classificação das atividades que os compõe. Esta organização buscou adequá-los com base no ciclo de vida de um projeto, conforme pode ser observado na figura 8.

Figura 8 - Grupos de processos de gerenciamento de projetos

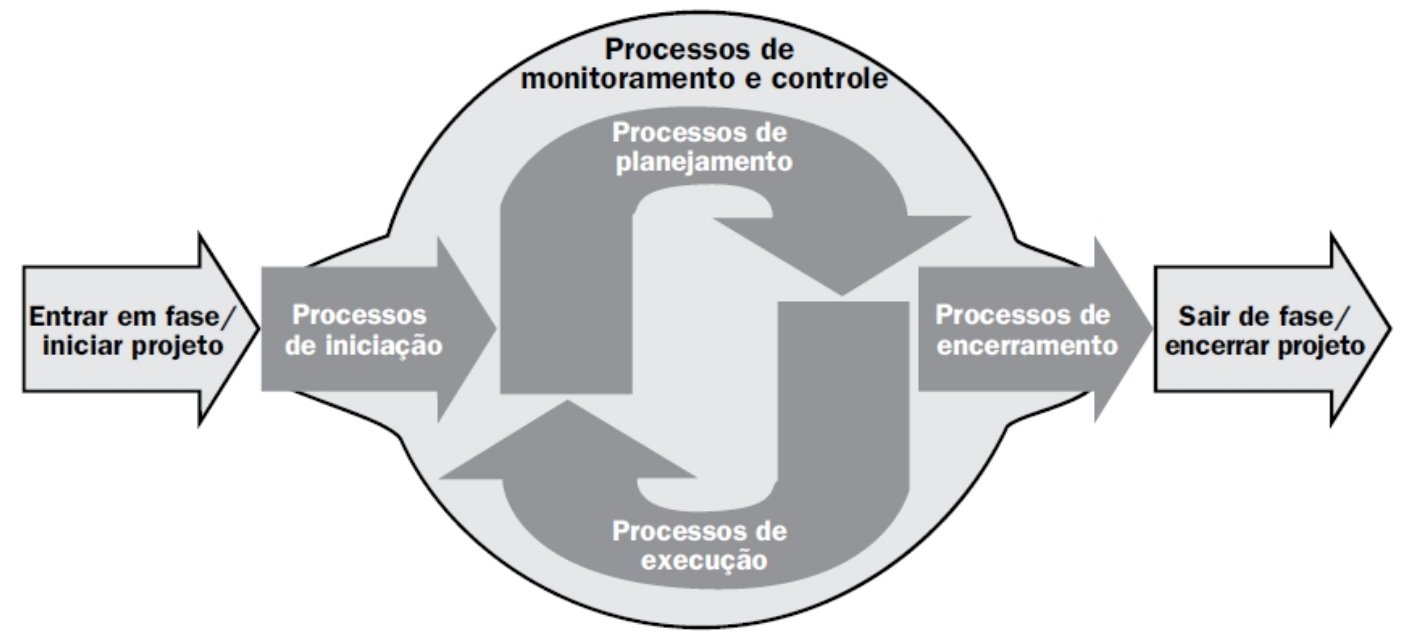

Fonte: PMI (2013)

De acordo com o PMI (2013), a natureza integrativa da gestão de projetos requer que o grupo de processos de monitoramento e controle interaja com os outros grupos de processo, ocorrendo aos mesmo tempo que os demais. Então, conforme mostra a figura, o processo de monitoramento e controle é descrito como um grupo de processo "de fundo" para os outros quatro grupos de processos.

Apesar de enumerados todos os processos geralmente empreendidos em uma gestão eficiente de projetos, cabe ao gerente de um projeto específico determinar quais processos serão necessários para atingir os objetivos em questão e com que rigor devem ser seguidos.

Pode-se entender processos como mecanismos que podem ser utilizados repetidas vezes, em pontos e tempos diferentes, dentro da grande máquina transformadora que representa o projeto.

Desta forma, apesar do estudo de processos, é importante lembrar que eles ocorrem em um ambiente de projetos, ou seja, evento único e com prazos determinados. Desta 
forma, em cada etapa do projeto, cada grupo de processos terá uma importância e impacto diferente no resultado final. Além disso, eles têm interação contínua entre si, como pode ser observado na figura 9.

Dentre todos os grupos, dois deles são intimamente ligados ao tema desta pesquisa: o grupo de processos de planejamento, e o grupo de processos de monitoramento e controle.

Os processos de planejamento são responsáveis por coletar informações, gerar estimativas mais precisas de escopo, prazo e custo e definir que atividades serão necessárias, quando e como deverão ser cumpridas, quanto deverão custar, quem será responsável, quais os riscos envolvidos e quais serão os padrões de qualidade empregados.

Figura 9 - Interação entre os processos de gerenciamento de projetos

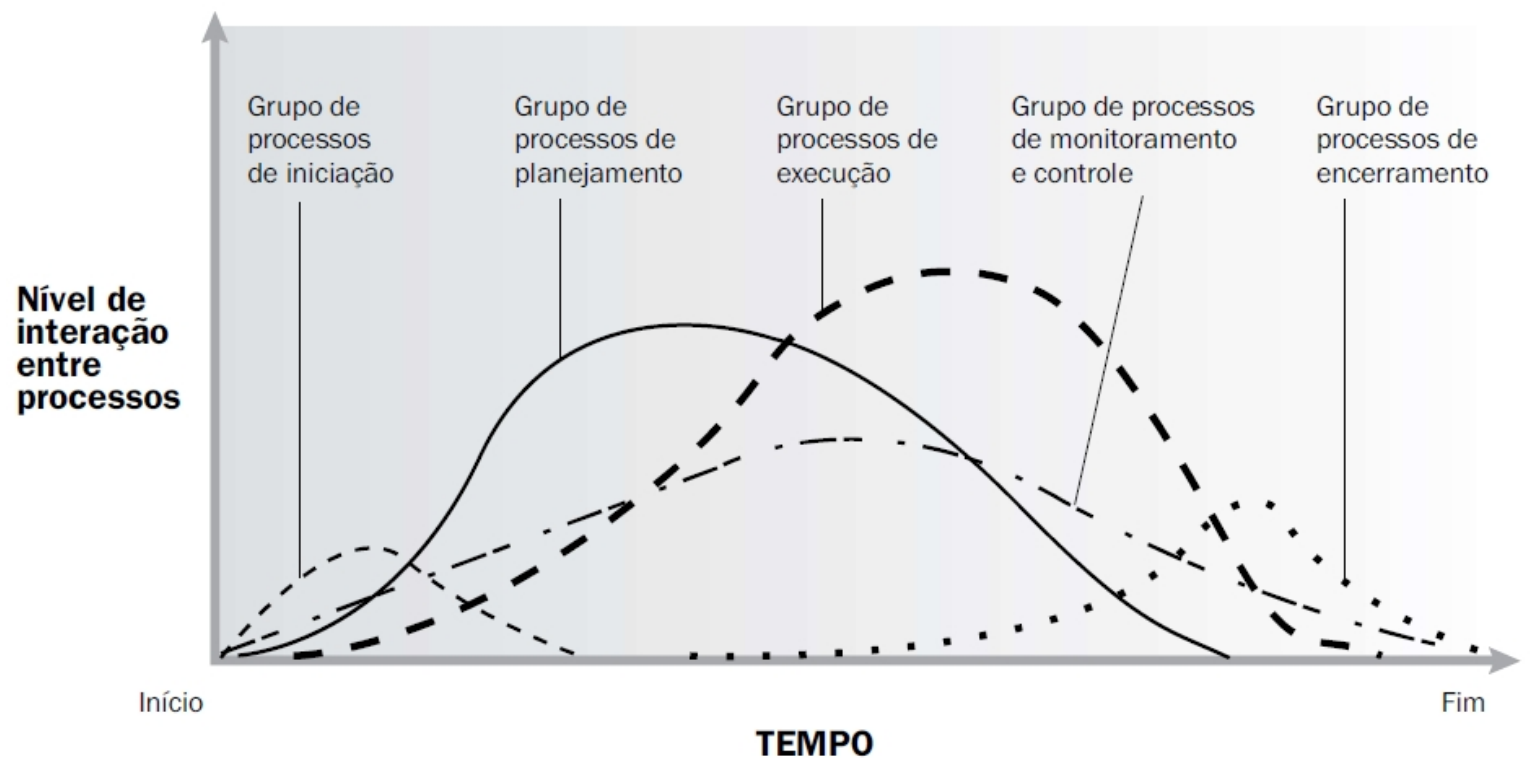

Fonte: PMI (2013)

O benefício principal do grupo de processos de planejamento, segundo o PMI (2013) é delinear a estratégia e a tática e também o curso de ação ou caminho para a conclusão do projeto com sucesso.

Ainda segundo o texto, os processos de planejamento geram como saída o plano do gerenciamento e os documentos do projeto que serão usados para executá-lo. Como a gestão de projetos é naturalmente complexa, normalmente os planos necessitam de retroalimentações periódicas. À medida que mais informações ou características do 
projeto são conhecidas, novas atualizações no plano são realizadas. Ou então, novas condições do projeto ou alterações significativas do escopo, geram também novas atualizações ou planejamentos adicionais (mais detalhados, por exemplo).

Quando este grupo de processos é bem gerenciado, fica mais fácil conquistar a adesão e a participação de todos os interessados no plano gerado, e consequentemente se atingir o propósito ou os objetivos do projeto.

Já o grupo de processo de monitoramento e controle consiste dos processos necessários para acompanhar, analisar e organizar o progresso e desempenho do projeto. Com base nos resultados obtidos, ele identifica quais alterações serão necessárias ao plano.

\subsection{Conceito de Planejamento}

Outras abordagens, além daquelas focadas em gerenciamento de projetos, tratam do tema do planejamento de forma mais detalhada. Entende-se como importante alinhar este conceito e assim buscaram-se definições na bibliografia especializada sobre o que venha a ser exatamente planejamento.

Um dos primeiros autores que iniciaram esta conceituação e que é citado em muitas pesquisas sobre o tema é Ackoff (1976), que define Planejamento como algo que é necessário ser feito antes de agir; isto é, tomada antecipada de decisão. É um processo de decidir o que fazer e como fazê-lo, antes que se requeira uma ação.

De acordo com a visão do autor, o planejamento só é necessário quando as situações exigem tomadas de decisão antes dos acontecimentos que tais decisões influenciem. Em outras palavras, caso em algum processo fosse possível a tomada de decisão no momento da ocorrência, de forma rápida e precisa, talvez não haveria a necessidade de se planejar.

A autor afirma ainda que o planejamento é necessário quando para a efetiva realização do estado futuro desejado são necessárias decisões interdependentes, isto é, um sistema de decisões. 
Desta forma, o planejamento deve não apenas estabelecer de que forma as atividades precisam acontecer, mas também preocupar-se em evitar que ações incorretas sejam decididas.

Na visão de Ackoff (1976), por exemplo, se o curso natural dos acontecimentos vai produzir o estado futuro desejado, ou seja, não há riscos deste não ocorrer, então não haveria a necessidade de se planejar.

Outro autor importante e bastante citado, Limmer (1996), descreve que o planejamento é um processo por meio do qual se estabelecem objetivos, discutem-se expectativas de ocorrências de situações previstas, veiculam-se informações e comunicam-se resultados pretendidos entre pessoas, unidades de trabalho, departamentos e entre empresas.

Segundo o autor, o planejamento permite:

- Definir a organização para executar a obra;

- Tomar decisões;

- Alocar recursos;

- Integrar e coordenar esforços de todos os envolvidos;

- Assegurar boa comunicação entre os participantes da obra;

- Suscitar a conscientização dos envolvidos para prazos, qualidade e custos;

- Caracterizar a autoridade do gerente;

- Estabelecer um referencial para controle;

- Definir uma diretriz para o empreendimento.

Mas segundo alguns autores, o planejamento não se resume a antever detalhadamente o projeto.

Formoso et al. (1999), por exemplo, definem planejamento como o processo de tomada de decisão que envolve o estabelecimento de metas e dos procedimentos necessários para atingi-las, sendo efetivo quando seguido de um controle.

Na mesma linha, Varalla (2003) descreve que planejamento é um processo de previsão de decisões, que envolve o estabelecimento de metas e a definição dos 
recursos necessários para atingi-las. Portanto, o planejamento não fornece dados que podem ser considerados definitivos e, sim, um conjunto de diretrizes para a ação.

Assim, pelo conceito vigente de planejamento, conforme estabelece Assumpção (1996), a essência do processo de planejamento consiste no estabelecimento de diretrizes para a ação, acompanhada do monitoramento dos resultados.

De uma certa forma, o planejamento seria baseado em dois sistemas, conforme apresentado na figura 10.

Figura 10 - Estrutura do planejamento

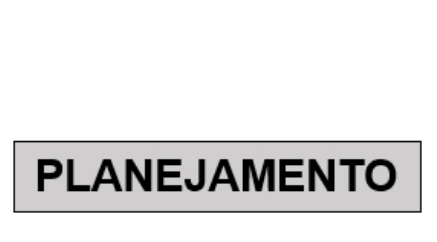

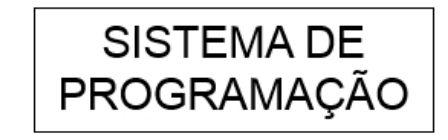

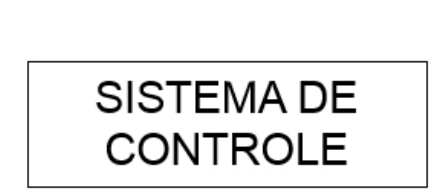

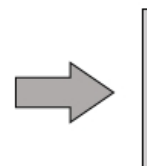

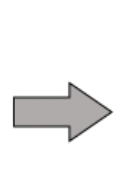

Informações na forma de expectativas

Informações na forma de resultados

Fonte: Adaptado de Assumpção (1996)

$\mathrm{Na}$ bibliografia especializada, diversos termos, teoricamente com 0 mesmo significado, são encontrados e podem trazer interpretações ligeiramente diferentes do contexto do tema em estudo.

Um caso clássico são os termos em inglês "planning" (ou "planejamento" em tradução livre) e "scheduling" (ou "agendamento" em tradução livre).

Segundo Mubarak (2010), tais termos são largamente utilizados como sinônimos, mas são na verdade, conceitos diferentes. O termo "planning" é mais abrangente, e considera tudo o que está relacionado ao Plano de um Projeto, ou seja: o que será feito, de que forma, quando, onde, por quem. Já o termo "scheduling" considera a determinação dos prazos e a sequência de operações do projeto.

Desta forma, o agendamento do projeto seria apenas uma parte do planejamento, na dimensão "quando", conforme pode ser observado na figura 11. 
Segundo Oberlender (2000), o planejamento (planning) é um pré-requisito para se elaborar o cronograma (schedule), ou seja, para efetivamente agendar as atividades (scheduling).

Figura 11 - Conceituação de Planning e Scheduling

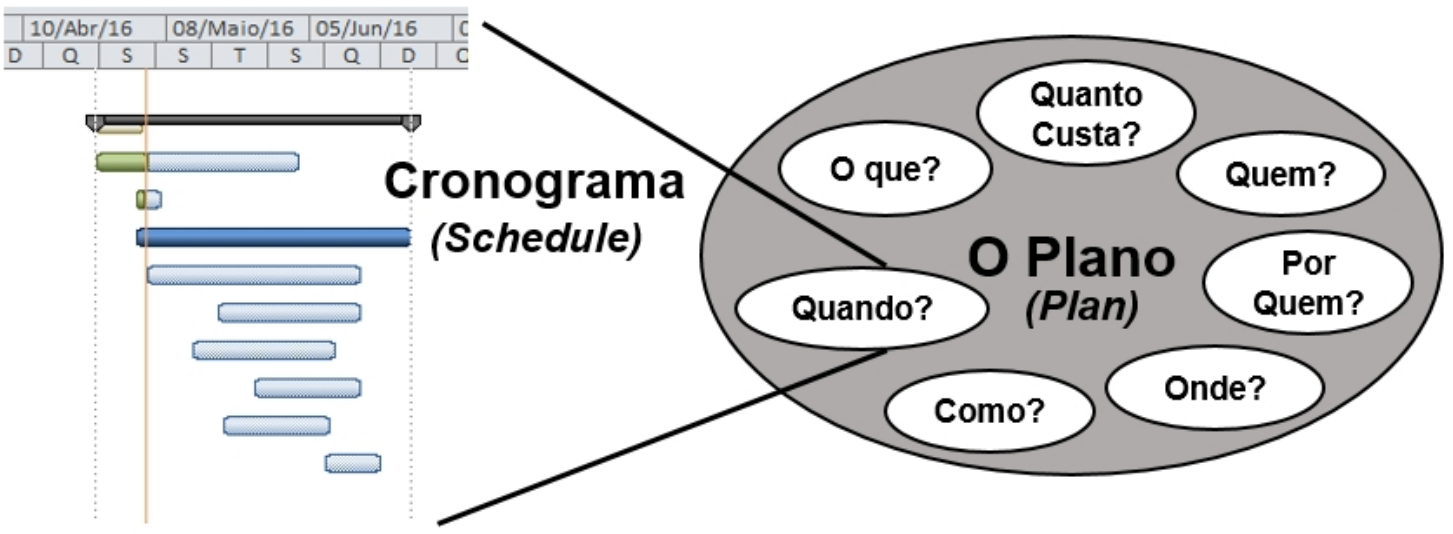

Fonte: Mubarak (2010)

Diversas são as classificações dos planejamentos e eles também possuem sua hierarquia, de forma similar às questões decisórias apontadas nos capítulos anteriores. Assim, também existem os planejamentos estratégicos, táticos e operacionais. Esta é denominada de hierarquia vertical do planejamento.

Como não é objetivo deste trabalho abordar estas classificações, adota-se genericamente a palavra planejamento nos itens a seguir, lembrando-se sempre que o foco dos processos continua sendo a interface entre empreendimento e produção e o foco do trabalho na gestão tático-operacional.

\subsection{Hierarquias do planejamento de projetos ou obras}

\subsubsection{Hierarquia vertical do planejamento e da estrutura de decisões}

Para Assumpção (1996), os sistemas de planejamento devem ser estruturados a partir do correto entendimento das relações de conflito e instabilidade que ocorrem no ambiente da empresa e mercado. Estes sistemas operam com a manipulação de dados e geração de informações que permitem avaliar alternativas para a implementação de ações no âmbito da empresa e de seus empreendimentos. 
Uma vez estabelecida a necessidade da escolha de alternativas, verifica-se que existem então aspectos de gestão que devem trazer informações para a tomada de decisões.

As decisões que ocorrem durante o desenvolvimento de um empreendimento são originárias desde a fase de concepção até a implantação (ou produção) e podem ser consolidadas de uma forma genérica através do esquema da figura 12 , idealizada por Lima Jr. (2004).

Figura 12 - Processo de decisão: da ideia ao empreendimento

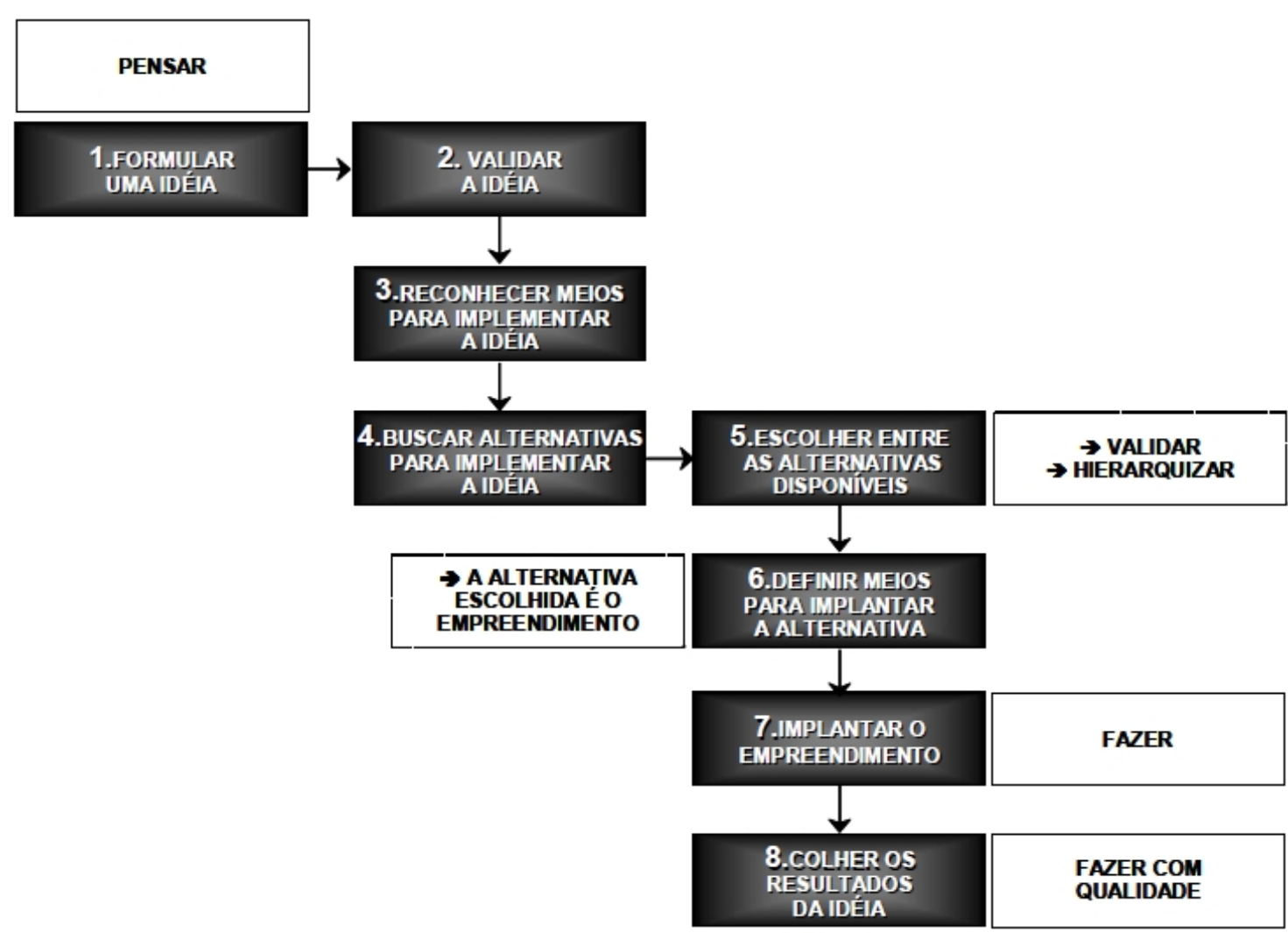

Fonte: Lima Jr (1990)

Assim, o processo de decisão necessita de ferramentas que auxiliem os responsáveis no estabelecimento das melhores alternativas existentes, o que ocorre através de planos específicos.

De acordo com Assumpção (1996) os planos seriam desenvolvidos conforme as características das decisões, que estariam estabelecidas em diversos níveis hierárquicos. O quadro 6 ilustra os tipos de decisão com base no caráter e na hierarquia do processo de empreender. 
De uma forma genérica as decisões de caráter operacional, na visão do autor, são tipicamente relacionadas às rotinas administrativas no escritório e no canteiro, aproximando-se de atividades repetitivas, ou seja, de processos relativamente padronizados.

Por exemplo, independente do porte do empreendimento, padrão de acabamento ou localização, as rotinas administrativas como pagamentos e cobranças são realizadas de uma mesma forma na empresa, bem como as rotinas de produção como solicitação de materiais, programação de serviços e medição de empreiteiros.

Quadro 6 - Hierarquia das decisões

\begin{tabular}{|c|c|c|}
\hline $\begin{array}{c}\text { Caracterítica da } \\
\text { decisão }\end{array}$ & $\begin{array}{l}\text { Hierarquia do } \\
\text { empreendimento }\end{array}$ & Hierarquia da Produção \\
\hline $\begin{array}{c}\text { Decisões de } \\
\text { caráter } \\
\text { estratégico/tático }\end{array}$ & $\begin{array}{l}\text { - Ciclo de produção; } \\
\text { - Vendas do } \\
\text { empreendimento; } \\
\text { - Recursos financeiros para } \\
\text { implantação. }\end{array}$ & $\begin{array}{l}\text { - Diretrizes de produção; } \\
\text { - Equacionamento dos meios } \\
\text { para se executar a obra; } \\
\text { - Horizonte amplo (todo o } \\
\text { prazo da obra). }\end{array}$ \\
\hline $\begin{array}{c}\text { Decisões de } \\
\text { caráter } \\
\text { operacional }\end{array}$ & $\begin{array}{l}\text { - Rotinas administrativas e } \\
\text { comerciais; } \\
\text { - Administração das vendas; } \\
\text { - Carteira de cobrança; } \\
\text { - Atendimento ao cliente. }\end{array}$ & $\begin{array}{l}\text { - } \text { Rotina do canteiro; } \\
\text { - Liberação de ações de } \\
\text { produção; } \\
\text { - } \text { Alocação de equipes e } \\
\text { equipamentos; } \\
\text { - Suprimento efetivo de } \\
\text { materiais; } \\
\text { - Horizonte trimestral. }\end{array}$ \\
\hline
\end{tabular}

Fonte: Assumpção (1996)

As decisões de caráter estratégico, por sua vez, podem estar relacionadas a soluções muitas vezes previsíveis para profissionais no meio, mas dependem de diversos fatores diretamente ligados ao projeto em si, ou seja, às características do empreendimento.

A definição das características do lançamento de um empreendimento, o prazo de entrega da obra, a metodologia de construção mais apropriada, e diversas outras decisões deste tipo somente são definidas com base nas especificidades do produto de real estate em questão. 
Ackoff (1976) já há muito tempo descrevia que a distinção entre planejamento tático e estratégico é sempre feita, mas quase nunca é clara. Decisões que para alguns parecem estratégicas, podem parecer táticas para outros. A diferença é tridimensional:

- Quanto mais demorado for o efeito de um plano e quanto mais difícil for alteralo, mais estratégico será. Longo e curto é relativo, então tático e estratégico também;

- Quanto mais as atividades de uma organização forem afetadas por um evento amplo, mais estratégico ele será. Ou seja, planejamento estratégico é amplo e o planejamento tático é restrito;

- Planejamento tático se destina a escolher os meios pelos quais se tentará atingir os objetivos especificados (meios). O estratégico destina-se à formulação dos objetivos (fins).

Desta forma, verifica-se que a interface de sistemáticas de gerenciamento para o empreendimento e para a produção estaria mais próxima neste último nível hierárquico. Uma decisão estratégica-tática relacionada à gestão do empreendimento influencia diretamente as decisões estratégicas-táticas da produção, e vice versa.

Fabricio e Melhado (2001) propõem o estabelecimento de uma cooperação mais estreita entre os agentes do projeto ou empreendimento, envolvendo três interfaces principais de colaboração e outras duas referentes à retroalimentação das fases de execução e de uso, conforme ilustra a figura 13.

Nesta mesma linha Codinhoto (2003) propõe diretrizes para o planejamento e controle integrado dos processos de projeto e produção de empreendimentos da construção.

Segundo Assumpção (1996), a etapa de contratação e coordenação dos projetos seria parte importante do processo de empreender e nem sempre é bem conduzida dentro das empresas de empreendimento imobiliários, causando conflitos internos que decorrem de visões diferentes que o empreendedor e o construtor têm quanto ao conceito de qualidade que é atribuído ao projeto. Para o empreendedor, a qualidade é associada ao projeto arquitetônico, pois é o que define o produto e sua qualidade segundo a ótica do mercado. Para o construtor, a qualidade é avaliada a partir das 
soluções construtivas e a integração entre as várias especialidades e etapas de projetos.

Figura 13 - Interfaces do processo de projeto

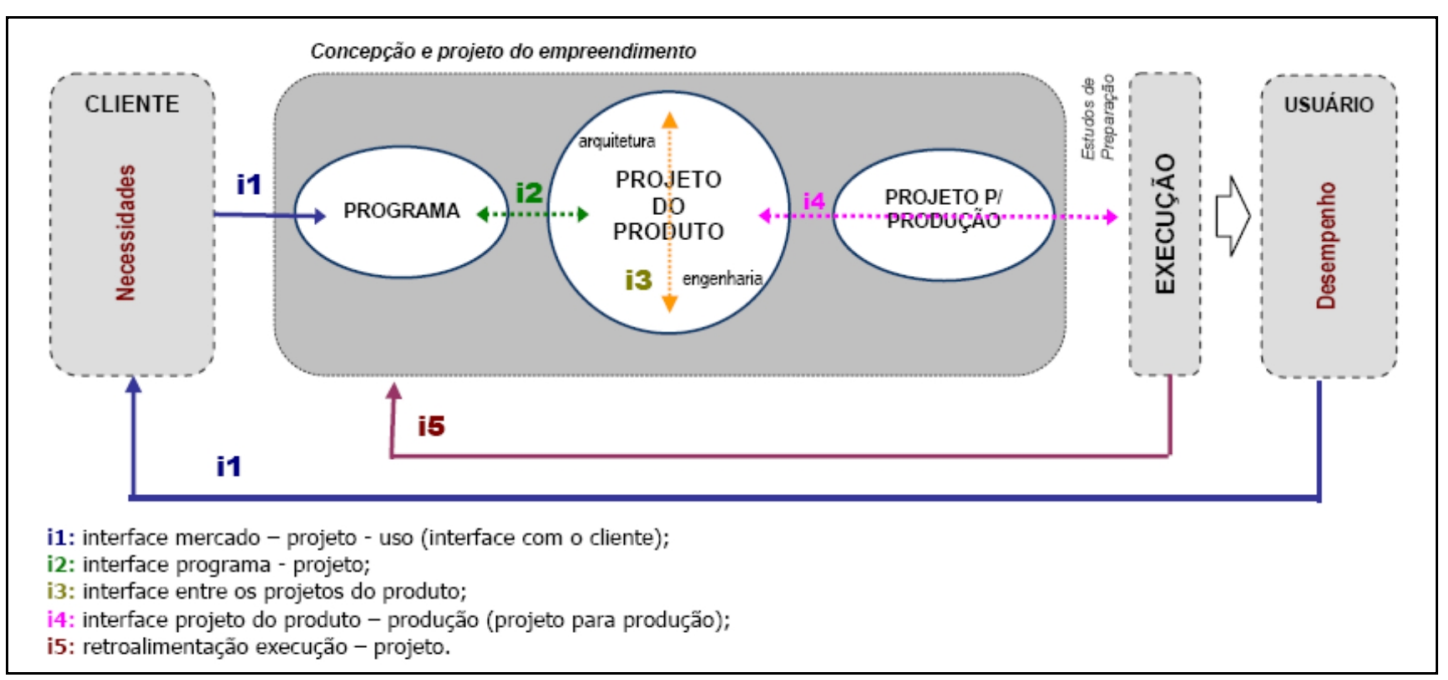

Fonte: Fabricio e Melhado (2001)

Estes dois entendimentos nem sempre convergem, sendo necessário utilizar mecanismos para administrá-los, implantando-se, por exemplo, programas de qualidade para projetos de edificações, que devem contar com o suporte de sistemas de planejamento.

Halpin e Riggs (1992) estabelecem níveis de hierarquia conforme o foco dos objetivos e das decisões no setor da construção.

Esta hierarquia e tipos de decisão podem ser observados no quadro 7 .

De acordo com os autores, embora os empreendimentos de construção são tipicamente únicos, os métodos de construir frequentemente são repetitivos ou cíclicos, proporcionando condições de se estudar as atividades como processos operacionais ou o estabelecimento de modelos de planejamento e gestão.

Analisando os dados do quadro, verifica-se primeiramente que as atividades de gestão do empreendimento estão localizadas na parte superior (atributos do projeto) e aquelas relacionadas à produção na parte inferior (ações de campo). Além disso, à medida que o nível hierárquico do empreendimento diminui, o foco das decisões tornase cada vez mais repetitivo. 
Desta forma, a estruturação dos processos de gestão na interface estaria relacionada aos níveis de atividade e operação, como controle de prazos e custos, uso de recursos, métodos construtivos e resumo dos processos de trabalho.

Quadro 7 - Níveis de hierarquia no gerenciamento da construção

\begin{tabular}{|c|c|c|}
\hline Foco Geral & $\begin{array}{c}\text { Nível } \\
\text { Hierárquico }\end{array}$ & Descrição do foco básico (específico) \\
\hline $\begin{array}{l}\text { Foco nos } \\
\text { atributos do } \\
\text { projeto e } \\
\text { componentes } \\
\text { físicos }\end{array}$ & Organizacional & $\begin{array}{l}\text { - Foco no negócio e estrutura da empresa; } \\
\text { - Alta direção e departamentos funcionais; } \\
\text { - Portfólio de projetos; } \\
\text { - Atributos importantes: custo total, duração, fluxo } \\
\text { de caixa, percentual completado. } \\
\text { - Definições de projetos, contratos, desenhos e } \\
\text { especificações; } \\
\text { - Definição do produto e subdivisões em } \\
\text { atividades de projeto; } \\
\text { - Controle de custos, prazos, e recursos. } \\
\text { - Atendimento dos aspectos físicos do projeto } \\
\text { - Usmparado com prazos e custos; } \\
\text { - Uso dos recursos, durações e custos correntes. }\end{array}$ \\
\hline $\begin{array}{c}\text { Foco nas } \\
\text { ações de } \\
\text { campo e } \\
\text { tecnologia de } \\
\text { processos }\end{array}$ & $\begin{array}{c}\text { Tarefa / } \\
\text { Trabalho }\end{array}$ & $\begin{array}{l}\text { - Foco no método construtivo; } \\
\text { - Significado da construção; } \\
\text { - Lista de recursos; } \\
\text { - Resumo dos processos de trabalho. } \\
\text { - Foco na seqüencia técnica básica; } \\
\text { - Tarefas integradas de forma lógica; } \\
\text { - Ações individuais ou mixadas para ação } \\
\text { corretiva; } \\
\text { - Reconhecimento das operações de construção; } \\
\text { - Foco na unidade de trabalho e campos } \\
\text { fundamentais das ações. } \\
\text { - Foco na unidade de trabalho e campos } \\
\text { - fundamentais; } \\
\text { - Conhecimento intrínseco e desafios tratados no } \\
\text { - Bível mais baixo; }\end{array}$ \\
\hline
\end{tabular}

Fonte: Halpin e Riggs (1992)

Verificam-se em todas as estruturas citadas anteriormente uma convergência para alguns aspectos importantes do gerenciamento, todos eles de forma parcial ou totalmente relacionados à previsão e monitoramento da restrição tripla (escopo, prazos e custos) para o nível hierárquico de nosso estudo. 
Como descrito anteriormente pelo PMI (2013), o gerenciamento do escopo, prazo e custo apresenta os seguintes processos:

- Gerenciamento do escopo: planejamento, definição, verificação e controle de alterações de escopo;

- Gerenciamento do prazo: definição de atividades, sequenciamento, estimativa de duração, desenvolvimento e controle do cronograma;

- Gerenciamento do custo: planejamento dos recursos, estimativas e controle dos custos.

Pode-se entender que todos estes processos estariam incluídos dentro do conceito mais atual de planejamento.

Para Laufer e Tucker (1987), dentro de uma organização, o objetivo de cada setor da empresa é diferente. A alta direção tem como objetivo definir onde a empresa estará no futuro, identificar oportunidades de mercado e estratégias para alcançar essas oportunidades. Quando esta empresa é voltada a projetos, em especial uma empresa de construção, sob a visão dos incorporadores ou contratantes da obra, os objetivos estratégicos são predominantemente financeiros e este nível do planejamento tem como objetivo maior antecipar as decisões relativas a estes objetivos. Sob a visão da empresa construtora, esta utiliza o planejamento como base para previsões de todas suas operações.

A representação destes níveis está ilustrada na figura 14.

Figura 14 - Evolução do planejamento e níveis da gestão

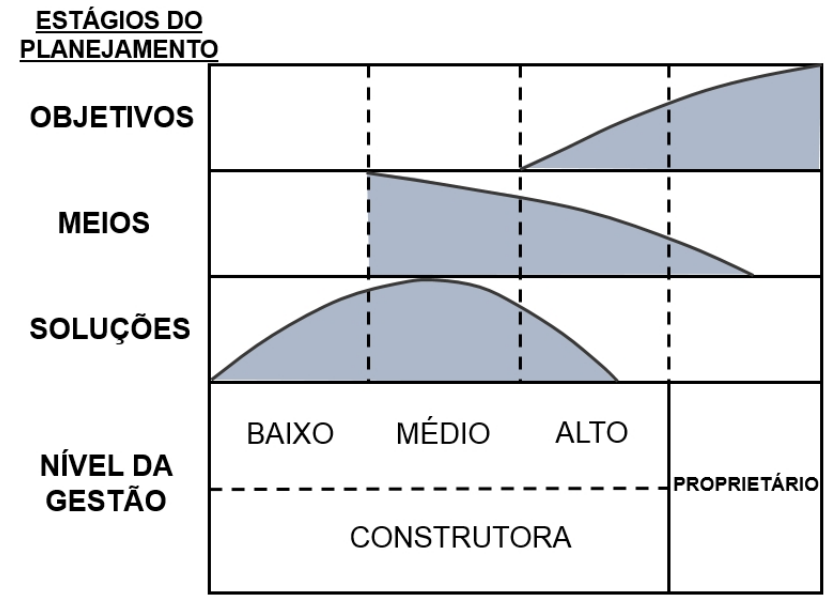

Fonte: Laufer e Tucker (1987) 
Assim, o planejamento de um empreendimento de construção engloba muitas etapas e diversos níveis gerenciais. Assim, cada etapa do planejamento deve atender às necessidades de cada nível gerencial. Neste aspecto, Laufer e Tucker (1987) propõem uma divisão representada por três grandes níveis:

- Nível dos objetivos: a alta direção utiliza do planejamento para definir objetivos e metas do empreendimento, tais como tipologia do produto, custo, prazos e qualidade, como descrito anteriormente como restrição tripla;

- Nível dos meios: a média gerência utiliza-se do planejamento para prever e garantir os meios necessários para atingir os objetivos, sendo sua responsabilidade planejar e disponibilizar os recursos;

- Nível das soluções: a baixa gerência utiliza-se no planejamento para identificar as melhores ações e caminhos para se atingir os objetivos definidos.

Os autores destacam que uma das maiores dificuldades dos planejadores é manter a consistência hierárquica dos planejamentos, uma vez que para que estes estejam correlacionados, deve haver uma sobreposição das responsabilidades de cada nível gerencial do empreendimento, sendo que cada um destes níveis deve participar de forma mais direta ou indireta, nas decisões de planejamento dos demais níveis hierárquicos.

\subsubsection{Hierarquia horizontal dos processos de planejamento}

O sistema de decisões citados anteriormente, segundo Ackoff (1976), é muito grande para ser tratado de forma única. Por esta razão, recomenda-se que seja dividido em fases sequenciais, ou seja, subconjuntos independentes mas inter-relacionados, pois a decisão que é tomada em um subconjunto irá afetar um subconjunto sucessor.

Laufer e Tucker (1987), Limmer (1996) e outros autores, destacam que o grau de detalhamento também deve variar conforme o horizonte do planejamento, o que é chamado de hierarquia horizontal.

Neste sentido, o nível mais abrangente é chamado de planejamento de longo prazo e o nível mais detalhado, chamado de curto prazo. 
A grande maioria dos autores pesquisados estabelece três níveis de planejamento relacionados à hierarquia horizontal.

Alguns, como Fachini (2005), utilizam os mesmos três níveis, mas o foco não são as abrangências de duração das atividades, mas o conceito de planejamento formado por três grandes áreas de decisões: decisões de longo prazo, decisões de médio prazo e decisões de curto prazo.

Iniciando a análise destes níveis pelo planejamento de longo prazo, Bernardes (2001), por exemplo, estabelece que o planejamento neste nível pode ser denominado como "plano mestre" e deve ser utilizado para facilitar a identificação dos objetivos principais do empreendimento. Esse plano descreve todo o trabalho que deve ser executado através de metas gerais.

De acordo com Limmer (1996), o plano mestre de um projeto deve conter, entre outros, os seguintes elementos:

- Resumo descritivo do projeto;

- Especificações das características e níveis de desempenho do produto final;

- Definição da metodologia de execução;

- Cronograma mestre, composto por redes de atividades, listagem de eventos e marcos significativos;

- Procedimentos e práticas do projeto, administrativos e operacionais;

- Alocação dos recursos de mão de obra, materiais e equipamentos com respectivos histogramas de distribuição e curva S;

- Matriz de responsabilidades;

- Organização do projeto em sua estrutura organizacional;

- Plano de gerenciamento;

- Plano de alocação qualitativa de pessoal;

- Sistema de informações do projeto;

- Sistema de controle do projeto. 
O que o autor apresenta como resumo descritivo do projeto, pode-se entender como a definição do escopo básico do empreendimento. Esta definição pode ser estabelecida através de uma estruturação dos itens do projeto.

Segundo Halpin (2006), o planejamento de um projeto envolve a definição de um objetivo e do escopo de trabalho que deve ser entregue. A estruturação resumida de uma forma hierárquica dos pacotes de trabalho, ou seja, do que deve ser entregue até o final do projeto, para atender aos objetivos estabelecidos, é o que se chama Estrutura Analítica de Projeto (EAP) ou Work Breakdown Structure (WBS).

Assim, complementando os itens listados por Limmer (1996), o plano mestre deveria também contemplar o estabelecimento da rede de atividades, o que é citado por Halpin (2006), denominado de sequenciamento.

Para se entender a importância da WBS no planejamento de um projeto, o autor estabelece de uma forma resumida que o planejamento (ou a programação do projeto, na definição utilizada neste trabalho) poderia ser entendido (ver figura 15).

Figura 15 - Importância da WBS no planejamento

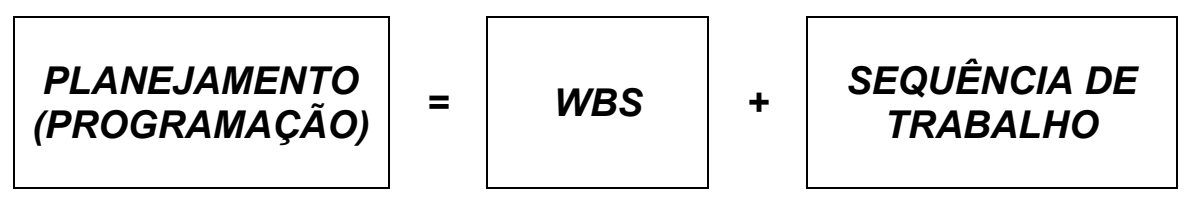

Autor: Halpin (2006)

O PMI (2013) estabelece que a WBS de um projeto é resultado de uma série de processos de identificação e planejamento do escopo, ou seja, uma das saídas deste processo.

Alguns autores têm pesquisado as ferramentas de identificação e gestão do escopo de um projeto. No entanto, este tema não é foco deste trabalho. Entende-se apenas que é importante a consideração resumida deste tema pois a definição do escopo é parte do plano mestre.

De acordo com o PMI (2013) independente da formalização ou não do escopo de uma forma integrada, de fato, os itens levantados são relevantes e podem incluir, por exemplo: objetivos do projeto, descrição do escopo do produto, condições de entrega, 
limites do projeto (o que está incluído no projeto), entregas, critérios de aceitação, restrições, premissas, riscos, marcos, entre outros.

Fachini (2005) descreve que as decisões de longo prazo são abrangentes, tratando de questões sobre a forma de se produzir o produto, a localização do sistema produtivo e de suas partes, o dimensionamento da capacidade produtiva e os momentos em que esta capacidade deve ser ampliada.

De uma certa forma, devido às incertezas do ambiente produtivo, em especial do mercado de construção civil, segundo Bernardes (2001), um plano destinado ao longo prazo de execução deve apresentar poucos detalhes para sua comunicação aos envolvidos.

De acordo com Coelho (2003), o grau de detalhamento de cada nível de planejamento deve ser inversamente proporcional a incerteza existente.

Buscando-se um maior detalhamento dos planejamentos, verificam-se estudos que são focados nos níveis de médio e curto prazo.

A programação de médio prazo busca vincular as metas fixadas no plano-mestre àquelas designadas no curto prazo. O planejamento nesse nível tende a ser móvel, e, por isso, segundo Bernardes (2001), à medida que as atividades são programadas é estabelecido um conjunto de ações visando a disponibilização dos recursos necessários à sua execução.

Uma vez que existe a necessidade de que as atividades desse nível sejam executadas para não comprometer o fluxo de trabalho existente, deve-se recorrer à realização de ações que permitam disponibilizar tais recursos.

De certa forma, a programação de médio prazo já enfatiza as tarefas dentro do canteiro, estabelecendo características fora do ambiente de interface entre a gestão do empreendimento e da produção.

Coelho (2003) estabelece que os objetivos mais relevantes do planejamento de médio prazo são: 
- Proteção do planejamento: aumentar a confiabilidade dos planos, protegendo a produção dos efeitos da incerteza. O foco está em eliminar restrições, evitando-se a necessidade constante de mudanças emergenciais;

- Integração entre os níveis de planejamento: garantir que todos os serviços descritos no planejamento de longo prazo sejam incluídos no planejamento de curto prazo e que todos os pacotes de trabalho sejam programados e executados com base nas datas marco definidas do planejamento de médio e longo prazo;

- Controle e aprendizagem: para se realizar as reuniões de planejamento de médio prazo são necessárias a disponibilização de indicadores de curto prazo e uma visão global do empreendimento, o que torna um ambiente adequado ao aprendizado.

O autor destaca ainda algumas funções complementares do planejamento de médio prazo, como a análise de fluxos físicos e a gestão de custos (item este que não será tratado neste trabalho).

Fachini (2005) destaca que as decisões de médio prazo tratam da alocação dos recursos, como a programação de materiais e mão-de-obra, e estoques necessários e possíveis na obra, sendo esta alocação de recursos a cada pacote de trabalho. Neste nível, as decisões de longo prazo condicionam ou limitam a disponibilidade dos recursos.

Por sua vez, as decisões de médio prazo são as restrições das decisões de curto prazo. As decisões de curto prazo definem a produção diária, os recursos alocados a cada tarefa e a prioridade das tarefas.

De uma certa forma, analisando os autores que tratam do assunto desta hierarquia horizontal, a convergência dos conceitos aponta três níveis de planejamento:

- Planejamento de longo prazo: os horizontes do planejamento abrangem todo o período de construção e têm como principal objetivo à definição dos ritmos das atividades, grandes etapas, processos construtivos e estratégia de execução da obra (plano de ataque do empreendimento). Também neste nível 
se estabelece a sequência das atividades e possíveis interferências entre equipes;

- Planejamento de médio prazo: tem como função ajustar os planos produzidos no planejamento de longo prazo, compatibilizando os recursos disponíveis, a capacidade de produção das equipes e o cumprimento de prazos e custos;

- Planejamento de curto prazo: é o nível no qual são tomadas as últimas ações a respeito do fluxo de trabalho, tais como pequenos ajustes na sequência das equipes em função do cumprimento de tarefas antecessoras e da disponibilidade de recursos tanto de mão-de-obra quanto de materiais e equipamentos, eliminando-se ou reduzindo-se a influência de imprevistos que gerem problemas para a execução completa das atividades operacionais.

\subsection{Foco no planejamento e controle de prazo}

Como descrito nos itens 3.1 e em parte no item 3.3, observa-se que os modelos de planejamento apresentados pelos autores tratam de forma conjunta a restrição tripla, principalmente o planejamento de prazos e custos.

No entanto, tomando como referência os objetivos deste trabalho, todo o foco do estudo será relacionado à gestão de prazos. Sendo assim, a análise dos processos está relacionada ao planejamento físico de empreendimentos ou obras.

Uma vez que o PMI (2013) organiza o conjunto de conhecimento em gestão de projetos em grandes grupos, o cruzamento dos processos de planejamento, com àqueles relacionados à gestão de tempo, naturalmente ilustrará o foco do trabalho e os limites entre os demais processos que não farão parte do estudo aprofundado.

Este cruzamento pode ser observado no quadro 8. 
Quadro 8 - Processos X Áreas de Conhecimento em gestão de projetos

\begin{tabular}{|c|c|c|c|c|c|}
\hline \multirow[b]{2}{*}{$\begin{array}{l}\text { Áreas de } \\
\text { conhecimento }\end{array}$} & \multicolumn{5}{|c|}{ Grupos de processos de gerenciamento de projetos } \\
\hline & $\begin{array}{c}\text { Grupo de } \\
\text { processos } \\
\text { de iniciação }\end{array}$ & $\begin{array}{c}\text { Grupo de } \\
\text { processos de } \\
\text { planejamento }\end{array}$ & $\begin{array}{c}\text { Grupo de } \\
\text { processos } \\
\text { de execução }\end{array}$ & $\begin{array}{c}\text { Grupo de } \\
\text { processos de } \\
\text { monitoramento } \\
\text { e controle }\end{array}$ & $\begin{array}{c}\text { Grupo de } \\
\text { processos de } \\
\text { encerramento }\end{array}$ \\
\hline $\begin{array}{l}\text { 4. Gerenciamento } \\
\text { da integração } \\
\text { do projeto }\end{array}$ & $\begin{array}{l}\text { 4.1 Desenvolver o } \\
\text { termo de abertura } \\
\text { do projeto }\end{array}$ & $\begin{array}{l}\text { 4.2 Desenvolver o } \\
\text { plano de } \\
\text { gerenciamento do } \\
\text { projeto }\end{array}$ & $\begin{array}{l}\text { 4.3 Orientare } \\
\text { gerenciar o trabalho } \\
\text { do projeto }\end{array}$ & $\begin{array}{l}\text { 4.4 Monitorar e } \\
\text { controlar o trabalho } \\
\text { do projeto } \\
4.5 \text { Realizar o } \\
\text { controle integrado } \\
\text { de mudanças }\end{array}$ & $\begin{array}{l}\text { 4.6 Encerrar o } \\
\text { projeto ou fase }\end{array}$ \\
\hline $\begin{array}{l}\text { 5. Gerenciamento } \\
\text { do escopo do } \\
\text { projeto }\end{array}$ & & $\begin{array}{l}5.1 \text { Planejar o } \\
\text { gerenciamento do } \\
\text { escopo } \\
5.2 \text { Coletar os } \\
\text { requisitos } \\
5.3 \text { Definir o escopo } \\
5.4 \text { Criar a estrutura } \\
\text { analitica do projeto } \\
\text { (EAP) }\end{array}$ & ----- & $\begin{array}{l}5.5 \text { Validar o escopo } \\
5.6 \text { Controlar o } \\
\text { escopo }\end{array}$ & \\
\hline $\begin{array}{l}\text { 6. Gerenciamento } \\
\text { do tempo do } \\
\text { projeto }\end{array}$ & $\begin{array}{l}1 \\
1 \\
1 \\
1 \\
1\end{array}$ & $\begin{array}{l}\text { 6.I Planejar o } \\
\text { gerenciamento do } \\
\text { cronograma } \\
6.2 \text { Definir as } \\
\text { atividades } \\
6.3 \text { Sequenciar as } \\
\text { atividades } \\
6.4 \text { Estimar os } \\
\text { recursos das } \\
\text { atividades } \\
6.5 \text { Estimar as } \\
\text { duracóes das } \\
\text { atividades } \\
6.6 \text { Desenvolver o } \\
\text { cronograma }\end{array}$ & & $\begin{array}{l}6.7 \text { Controlar o - } \\
\text { cronograma }\end{array}$ & $\begin{array}{l}1 \\
1 \\
1 \\
\prime\end{array}$ \\
\hline $\begin{array}{l}\text { 7. Gerenciamento } \\
\text { dos custos do } \\
\text { projeto }\end{array}$ & & $\begin{array}{l}7.1 \text { Plànejar } 0 \\
\text { gerenciamento đos- } \\
\text { custos } \\
7.2 \text { Estimar os } \\
\text { custos } \\
7.3 \text { Determinar o } \\
\text { orçamento }\end{array}$ & ----- & eustos & \\
\hline $\begin{array}{l}\text { 8. Gerenciamento } \\
\text { da qualidade do } \\
\text { projeto }\end{array}$ & & $\begin{array}{l}8.1 \text { Planejar o } \\
\text { gerenciamento da } \\
\text { qualidade }\end{array}$ & $\begin{array}{l}\text { 8.2 Realizar a } \\
\text { garantia da } \\
\text { qualidade }\end{array}$ & $\begin{array}{l}8.3 \text { Controlar a } \\
\text { qualidade }\end{array}$ & \\
\hline $\begin{array}{l}\text { 9. Gerenciamento } \\
\text { dos recursos } \\
\text { humanos do } \\
\text { projeto }\end{array}$ & & $\begin{array}{l}\text { 9.1 Planejar o } \\
\text { gerenciamento dos } \\
\text { recursos humanos }\end{array}$ & $\begin{array}{l}\text { 9.2 Mobilizar a } \\
\text { equipe do projeto } \\
9.3 \text { Desenvolver a } \\
\text { equipe do projeto } \\
9.4 \text { Gerenciar a } \\
\text { equipe do projeto }\end{array}$ & & \\
\hline $\begin{array}{l}\text { 10. Gerenciamento } \\
\text { das } \\
\text { comunicaçōes } \\
\text { do projeto }\end{array}$ & & $\begin{array}{l}10.1 \text { Planejar o } \\
\text { gerenciamento das } \\
\text { comunicaçôs }\end{array}$ & $\begin{array}{l}10.2 \text { Gerenciar as } \\
\text { comunicações }\end{array}$ & $\begin{array}{l}10.3 \text { Controlar as } \\
\text { comunicaçōes }\end{array}$ & \\
\hline $\begin{array}{l}\text { 11. Gerenciamento } \\
\text { dos riscos do } \\
\text { projeto }\end{array}$ & & $\begin{array}{l}11.1 \text { Planejar o } \\
\text { gerenciamento dos } \\
\text { riscos } \\
11.2 \text { Identificar os } \\
\text { riscos } \\
11.3 \text { Realizar a } \\
\text { análise qualitativa } \\
\text { dos riscos } \\
11.4 \text { Realizar a } \\
\text { análise quantitativa } \\
\text { dos riscos } \\
11.5 \text { Planejar as } \\
\text { respostas aos riscos }\end{array}$ & & $\begin{array}{l}\text { 11. } 6 \text { Controlar os } \\
\text { riscos }\end{array}$ & \\
\hline $\begin{array}{l}\text { 12. Gerenciamento } \\
\text { das aquisições } \\
\text { do projeto }\end{array}$ & & $\begin{array}{l}12.1 \text { Planejar o } \\
\text { gerenciamento das } \\
\text { aquisiçōes }\end{array}$ & $\begin{array}{l}12.2 \text { Conduzir as } \\
\text { aquisiçōes }\end{array}$ & $\begin{array}{l}12.3 \text { Controlar as } \\
\text { aquisições }\end{array}$ & $\begin{array}{l}12.4 \text { Encerrar as } \\
\text { aquisiçōes }\end{array}$ \\
\hline $\begin{array}{l}\text { 13. Gerenciamento } \\
\text { das partes } \\
\text { interessadas } \\
\text { no projeto }\end{array}$ & $\begin{array}{l}13.1 \text { Identificar as } \\
\text { partes interessadas }\end{array}$ & $\begin{array}{l}\text { 13.2 Planejar o } \\
\text { gerenciamento das } \\
\text { partes interessadas }\end{array}$ & $\begin{array}{l}\text { 13.3 Gerenciar o } \\
\text { engajamento das } \\
\text { partes interessadas }\end{array}$ & $\begin{array}{l}13.4 \text { Controlar o } \\
\text { engajamento das } \\
\text { partes interessadas }\end{array}$ & \\
\hline
\end{tabular}

Fonte: PMI (2013) 


\subsection{Ferramentas de planejamento físico de obras}

A seguir são apresentados os conceitos relacionados às principais ferramentas de planejamento de prazos, que terão suas aplicações posteriormente analisadas.

\subsubsection{Diagrama de Barras}

Talvez a ferramenta mais conhecida em planejamento físico seja o chamado Diagrama de Barras, que associa a duração da atividade a uma barra, sendo esta alocada em determinado intervalo de tempo.

Segundo Mubarak (2010), o Diagrama de Barras é uma forma gráfica de representação das atividades do projeto, que mostra barras lineares em uma escala de tempo, sem nenhum link entre as atividades.

De acordo com o autor, o diagrama de barras foi originalmente desenvolvido por Henry Gantt em $1917^{2}$ e por esta razão, é alternativamente chamado de "Diagrama de Gantt".

No entanto, segundo Marsh (1999), em 1896, um engenheiro chamado Karol Adamiecki já apresentava um modelo representativo desta natureza, denominado Harmonograma.

O gráfico de Adamiecki consistia de um quadro com tiras de papel destacável, uma para cada operação, e rotulada de acordo com a operação que representa (figura 16). Uma vez que as tiras e guias estejam preparadas, pode-se otimizar o fluxo de trabalho de uma forma manual e simples, organizando as tiras no quadro, na ordem adequada e deslizando as guias.

Há também registros de gráficos de barras e outras ferramentas de planejamento antes das publicações de Gantt, como por exemplo, as apresentadas por Schürch (1915) para a programação de uma construção de uma ponte ferroviária em 1912 (figura 17).

(2) Existem autores que descrevem que Gantt desenvolveu seu diagrama de barras em 1915 
Figura 16 - Exemplo de Harmonograna de Adamiecki

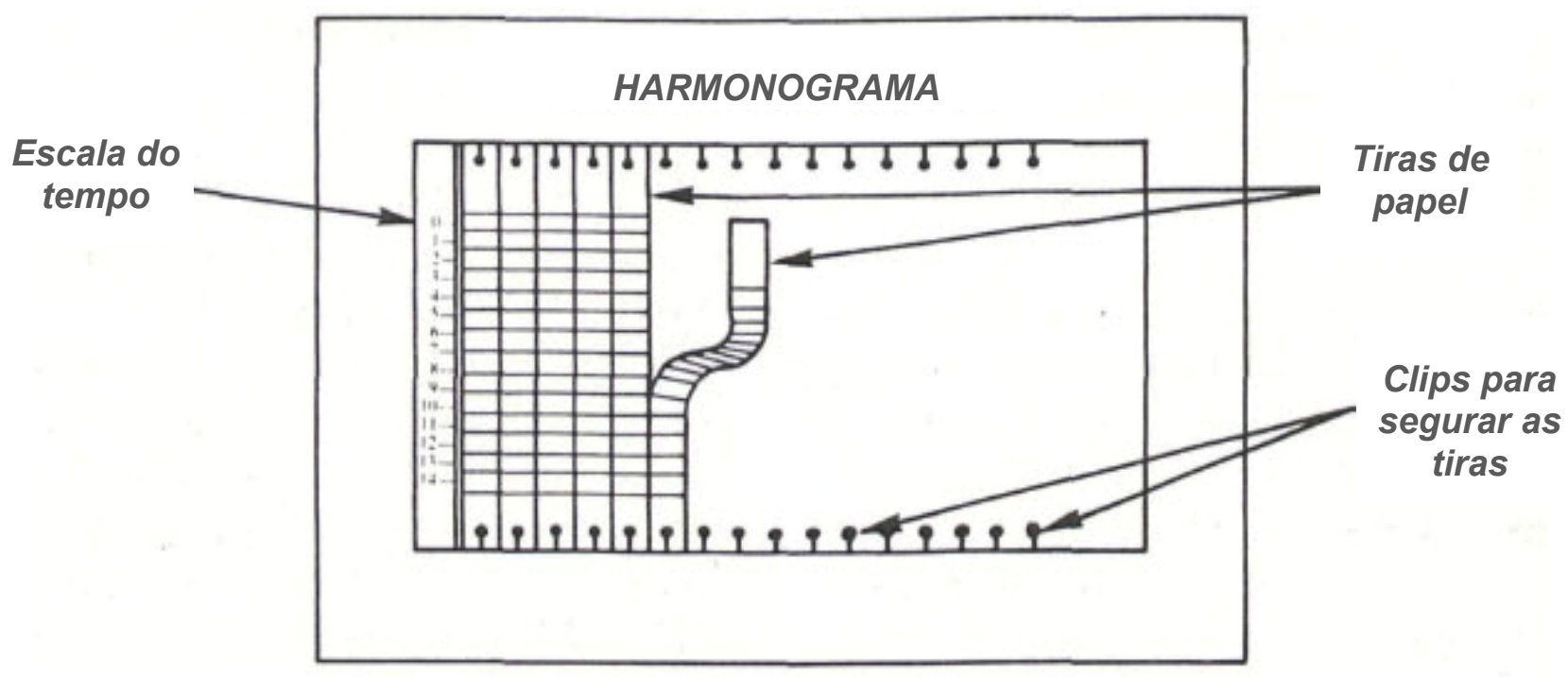

Fonte: Marsh (1999)

Figura 17 - Programação de construção de uma ponte em 1912

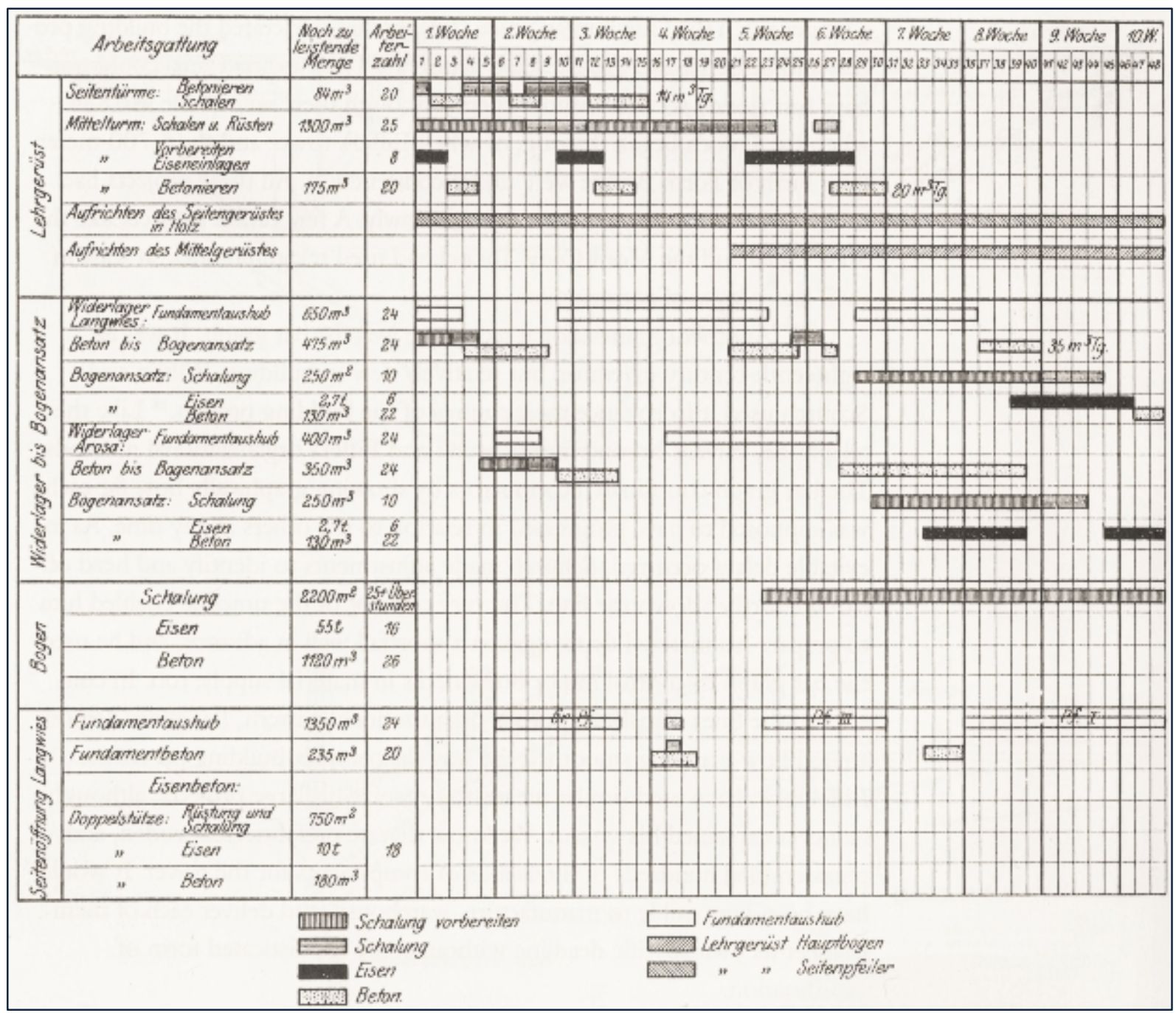

Fonte: Schürch (1915) 
Assim, existe uma controvérsia se Gantt realmente inventou os gráficos de barras simples que mostram o tempo de trabalho previsto para ocorrer. Mas como seu trabalho era focado no aumento da produção, ele se utilizou de diversos gráficos diferentes, que focavam medições e a busca por um planejamento eficaz. Ele trouxe inovações aos gráficos já disponíveis na época, tornando-se assim muito conhecido e posteriormente seu nome foi correlacionado a esta ferramenta.

O Gráfico de Gantt se tornou extremamente popular, especialmente na indústria da construção civil, por sua habilidade em representar graficamente as atividades de um projeto na escala de tempo.

Originalmente, este gráfico possibilita, de forma simples e funcional, a visualização das datas de início e de término de cada atividade, gerando as barras que demonstram graficamente a duração das mesmas, como observado no exemplo da figura 18.

Figura 18 - Exemplo de Gráfico de Gantt

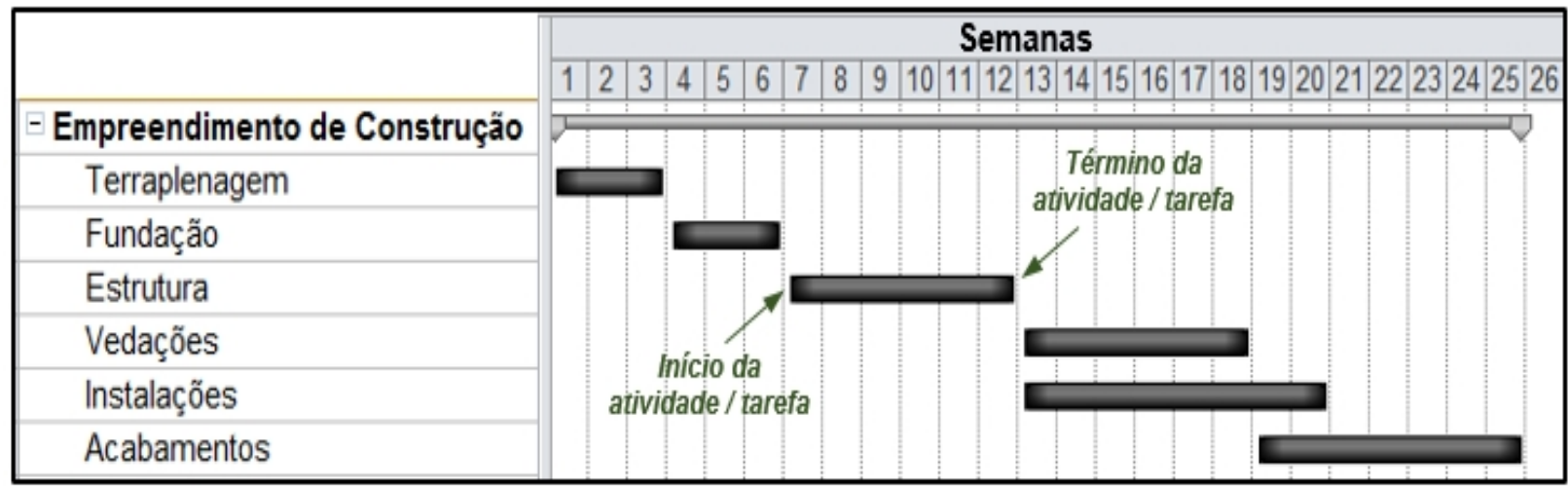

Fonte: O Autor

A grande vantagem desta ferramenta é sua simplicidade e atrelada a ela, a facilidade de comunicação entre os envolvidos no projeto, pois os dados são de fácil compreensão.

Como desvantagem, a ferramenta não considera as ligações entre as atividades; consequentemente, não se pode avaliar a repercussão do atraso de uma atividade sobre o prazo das demais.

O gráfico então não traz o fluxo do trabalho e nele, em sua forma original, não é possível se identificar o caminho crítico do projeto. 
Posteriormente, com a criação dos diagramas de rede e a introdução das conexões entre as atividades, buscou-se representar estes links no Diagrama de Gantt (em alguns textos são denominados de "diagrama de barras conectados").

Quando um projeto é simples, estas representações são interessantes, como pode ser observado na figura 19 , referente ao mesmo exemplo.

Figura 19 - Exemplo do mesmo Gráfico de Gantt com conexões

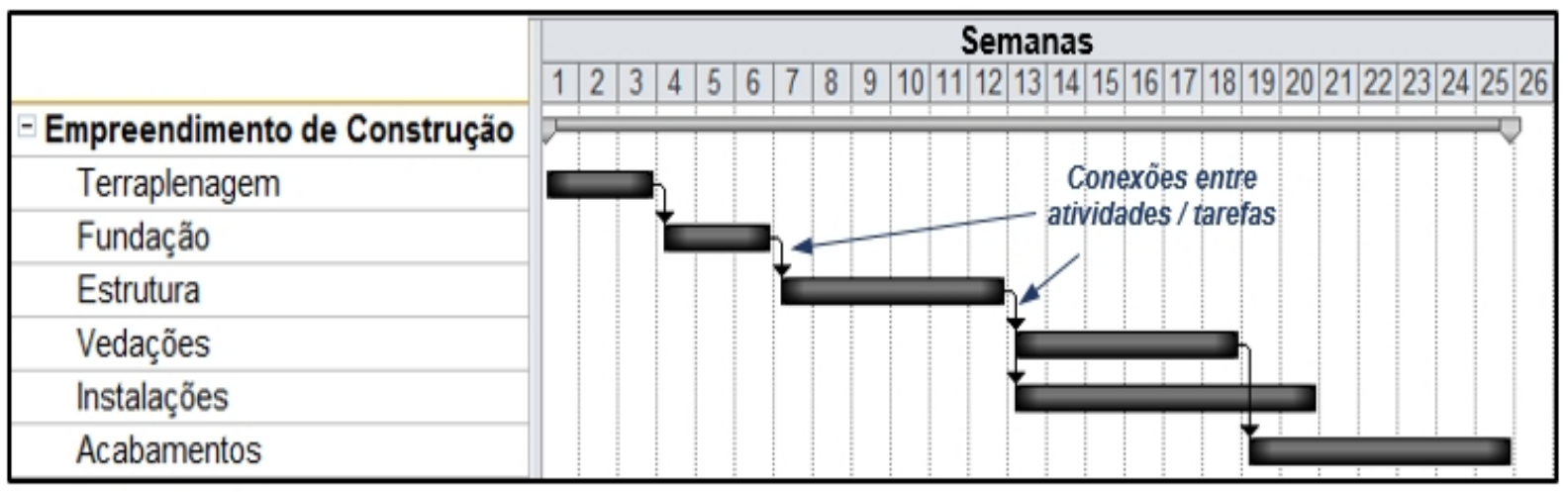

Fonte: O Autor

Além disso, originalmente, o diagrama de barras também não estabelece atributos para as atividades, como por exemplo o ritmo ou o progresso.

Mas com o advento na informática e uso intensivo dos computadores, os programas de planejamento utilizam o Gráfico de Gantt como representação do cronograma, ou seja, como a saída dos diagramas de rede mais complexos e ainda podem incluir outras informações interessantes ao planejador.

Assim, o diagrama de barras também pode ser utilizado de forma eficiente para representar o andamento das atividades do projeto. Desta forma, com a introdução de uma linha que representa a data de "status" (ou de análise) e as atualizações do progresso das atividades até àquela data, gera-se com a mesma simplicidade de antes, a visualização do status do projeto como um todo, o que facilita a comunicação entre todos os envolvidos (figura 20). 
Figura 20 - Exemplo do mesmo Gráfico de Gantt com progresso de atividades

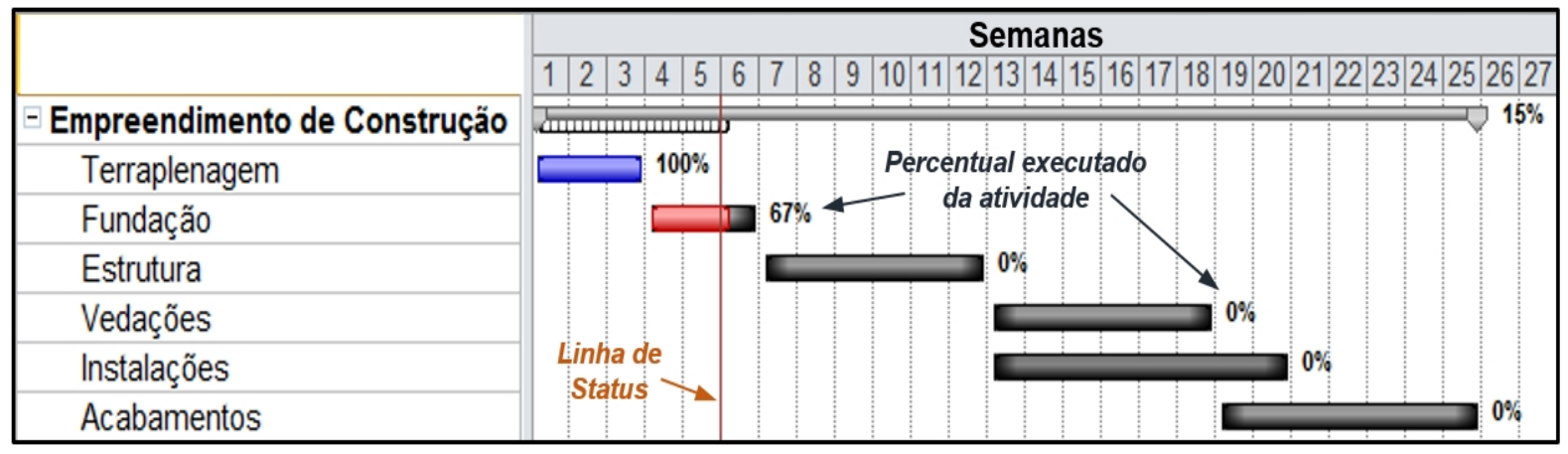

Fonte: O Autor

\subsubsection{Diagramas de Rede}

\subsubsection{Conceitos e representação gráfica}

O Diagrama de Redes é uma sequência lógica entre atividades ou tarefas. De acordo com Vanoucke (2012), esta relação lógica é chama ade relações de precedência.

Embora tais diagramas tragam informação para os cálculos do projeto, tais ferramentas não são baseadas em restrições de recursos ou tempo.

As representações destas redes normalmente são feitas através de 2 formas: aquelas que representam as atividades ou tarefas por "flechas" ou aquelas que representam as atividades através de "nós" (quadro 9).

Quadro 9 - Comparação entre formas de representação de Diagrama de Redes

\begin{tabular}{|c|c|c|}
\hline $\begin{array}{c}\text { Tipo de } \\
\text { representação }\end{array}$ & $\begin{array}{c}\text { ADM (Arrow Diagramming } \\
\text { Method) } \\
\text { Também denominado de método } \\
\text { AOA - Activity on Arrow }\end{array}$ & $\begin{array}{c}\text { PDM (Precedence Diagramming } \\
\text { Method) }\end{array}$ \\
\hline $\begin{array}{c}\text { Características } \\
\text { do método }\end{array}$ & $\begin{array}{c}\text { Método do Diagrama de Flechas, } \\
\text { usa "flechas" para representar as } \\
\text { atividades e usa "nós" para mostrar } \\
\text { as relações de dependência }\end{array}$ & $\begin{array}{c}\text { Método do Diagrama de Precedência, } \\
\text { usa "blocos" para representar as } \\
\text { atividades e "flechas" para representar } \\
\text { relações de dependência }\end{array}$ \\
\hline $\begin{array}{c}\text { Representação } \\
\text { gráfica }\end{array}$ & $\bigcirc \stackrel{\text { Tarefa A }}{\longrightarrow} \bigcirc \stackrel{\text { Tarefa B }}{\longrightarrow} \bigcirc$ & Tarefa A \\
\hline Vantagens & $\begin{array}{c}\text { Pode-se introduzir atividades } \\
\text { dummy (sem durações), para criar } \\
\text { restrições (e assim resolver } \\
\text { problemas de programação) }\end{array}$ & $\begin{array}{c}\text { Liberdade para se alterar as ligações } \\
\text { entre as atividades, sem alterar a } \\
\text { configuração da rede }\end{array}$ \\
\hline
\end{tabular}

Fonte: O Autor 
Como exemplo de elaboração de um diagrama de rede, estabeleceu-se uma lista de atividades de um projeto genérico (tabela 1). Estas atividades serão utilizadas para a elaboração de um diagrama das atividades através do método do Diagrama de Flechas, conforme apresentado na figura 21.

Tabela 1 - Exemplo de lista de atividades para Diagrama de Redes

\begin{tabular}{ccc}
\hline Nome da Tarefa & Predecessoras & Duração \\
\hline Tarefa A & -- & 3 dias \\
Tarefa B & A & 5 dias \\
Tarefa C & A & 3 dias \\
Tarefa D & B;E & 5 dias \\
Tarefa E & C & 5 dias \\
Tarefa F & E & 3 dias \\
Tarefa G & D;F & 2 dias \\
\hline
\end{tabular}

Fonte: O Autor

Para a análise da duração total do projeto, é necessário avaliar os caminhos possíveis para se chegar do início do projeto $(S)$ ao término do projeto $(E)$.

Percebe-se pelo exemplo, que existem praticamente 3 caminhos possíveis: (a) S-1-26-E; (b) S-1-4-5-6-E; e (c) S-1-4-5-2-6-E, sendo este último o mais longo, com duração de 18 dias, portanto chamado de "caminho crítico".

Figura 21 - Exemplo de Diagrama de Redes pelo método ADM

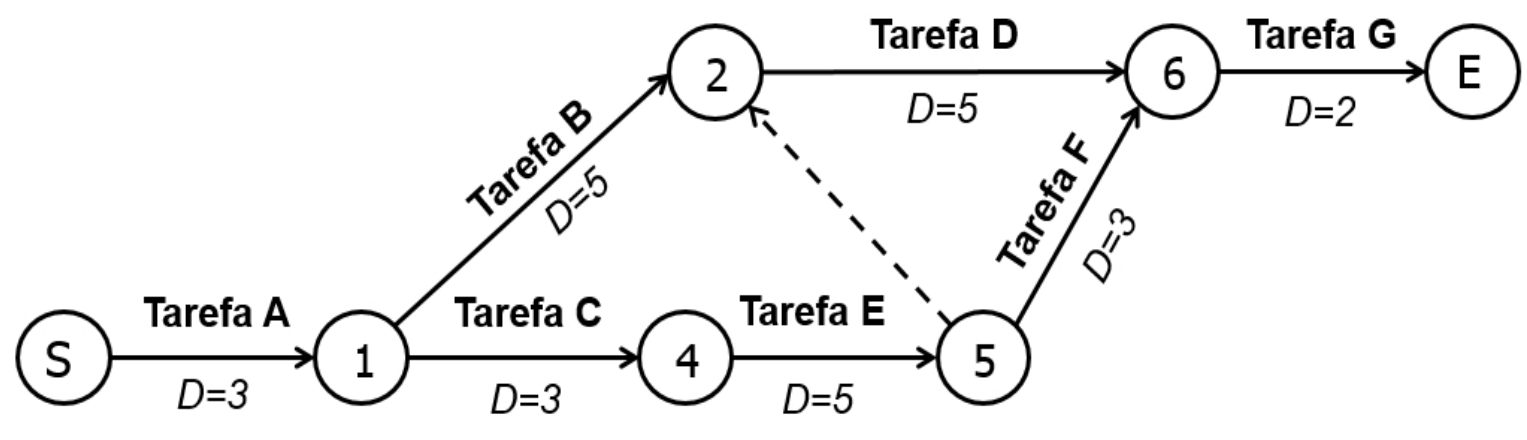

Fonte: O Autor 


\subsubsection{Métodos CPM e PERT}

Segundo Mattos (2009), o surgimento do Critical Path Method (CPM) remonta ao ano de 1957, quando a empresa Du Pont, proprietária do computador mais potente da época, o UNIVAC I, buscava mais aplicações para esta máquina e decidiu investigar de forma mais aprofundada a correlação tempo-custo dos projetos de engenharia das fábricas da empresa. Os responsáveis por estes estudos, os matemáticos Morgan Walker e James Kelley sabiam que para obter um prazo reduzido de um projeto, a forma mais eficiente não era simplesmente acelerar todas as atividades, uma vez que isto incorreria em aumento significativo do custo. Eles entendiam que o ideal seria encontrar as atividades "certas", o que os autores denominaram de "cadeia principal". Mais tarde esta cadeia seria chamada de "caminho crítico".

A técnica básica do CPM é listar: (i) as atividades necessárias para completar o projeto; (ii) o tempo de cada tarefa vai demorar; e (iii) a relação entre as atividades (precedências). Esta lista é então utilizada para a elaboração de um diagrama que identifica cada uma das atividades, sua sequência de execução e o momento previsto para que cada uma delas seja realizada. O diagrama é então usado para determinar o "caminho crítico", ou seja, o caminho mais longo a ser percorrido e que resultará no prazo total do projeto.

Uma vez obtido o caminho crítico, é possível se verificar todas as folgas das atividades da rede e com isso gerenciar melhor as atividades do projeto.

Neste sentido, o método CPM buscou ainda uma forma de representação onde se pudesse trabalhar as datas de realização das atividades. Se uma delas tem folga prevista, existe um intervalo de datas onde ela pode efetivamente ser iniciada sem comprometer o prazo final do projeto. Estas datas estão compreendidas entre as chamadas "data de início mais cedo" e "data de início mais tarde". Uma vez que o CPM é um método determinístico, baseado nas durações previstas para cada atividade, consequentemente obtêm-se as datas de término "mais cedo" e "mais tarde".

A representação de todas estas informações pode ser observada na figura 22. 
Figura 22 - Representação da atividade no CPM

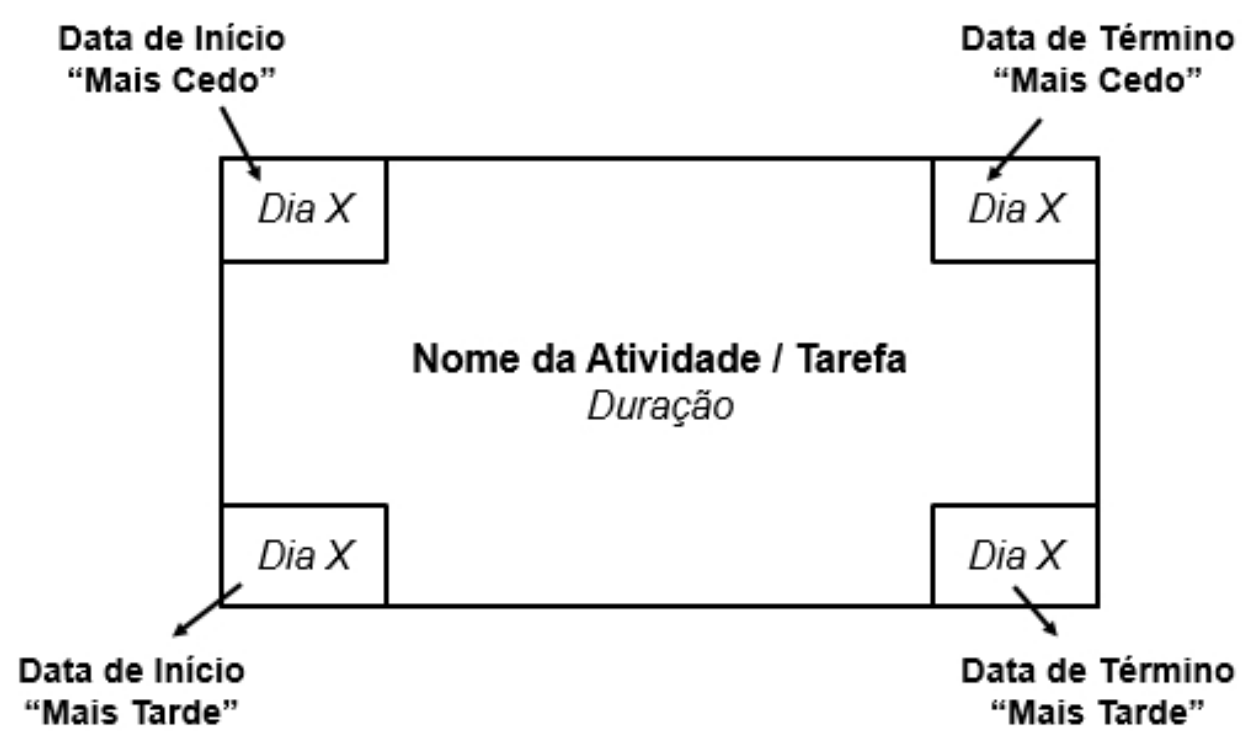

Fonte: O Autor

Utilizando estes conceitos, pode-se calcular a rede e todas as informações das atividades, conforme pode ser observado na figura 23 , que retrata a rede CPM relativo ao projeto hipotético apresentado anteriormente na tabela 1.

Figura 23 - Exemplo de cálculo de rede pelo CPM (método PDM)

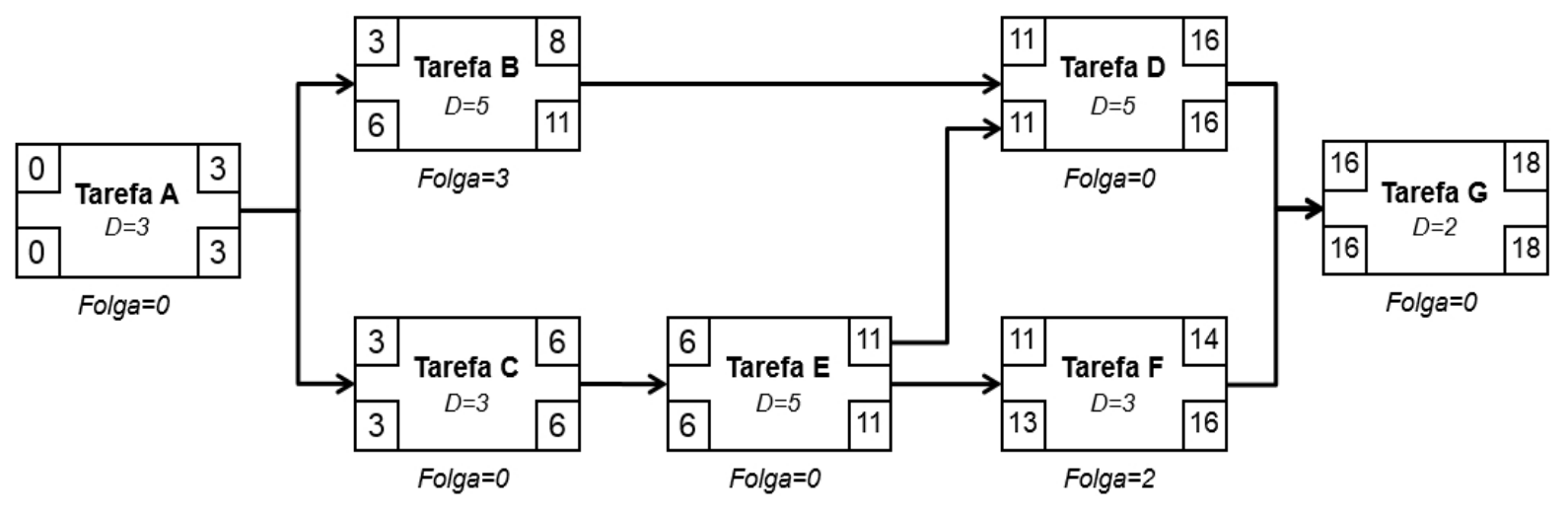

Fonte: O Autor

O Program Evaluation and Review Technique (PERT) por sua vez, surgiu na mesma época do CPM.

Segundo Meredith e Mantel (2011), a técnica foi desenvolvida pela Marinha Americana, com a cooperação da Booz-Allen Hamilton e da Lockheed Corporation para o projeto do míssil/submarino Polaris, em 1958. 
Tanto o PERT como o CPM utilizam flechas e nós para a construção gráfica do projeto. Originalmente, o PERT utilizava flechas para representar as atividades, enquanto o CPM utilizava nós para essa representação. Outra diferença estava associada à estimativa de tempo para a realização das atividades, onde PERT fazia uso das três estimativas de tempo: otimista, pessimista e a mais provável, para a realização de uma atividade, enquanto o CPM utilizava uma única estimativa de tempo, a mais provável. Essa distinção está associada à origem do PERT para a programação de projetos científicos avançados (como missões para a lua), que eram caracterizados pela incerteza, enquanto o uso inicial do CPM estava associado a atividades de rotina de manutenção de fábricas. Assim, o PERT era frequentemente utilizado quando a variável básica de interesse era o tempo, enquanto o CPM era utilizado quando a variável principal era o custo.

Conforme descreve Vanhoucke (2012), a utilização original da metodologia PERT, como método probabilístico, adota que a forma de distribuição de probabilidade da variável randômica entre as 3 estimativas de duração de uma atividade (otimista, mais provável e pessimista) não é uma distribuição normal. Isto porque normalmente a variação entre a duração mais provável (mais frequente) e a otimista é maior do que a diferença entre a mais provável e a pessimista. Assim, o método adota uma distribuição Beta.

Considerando as durações o=otimista, $m=$ mais provável e $p=$ pessimista, e que a distribuição esteja efetivamente contida no intervalo " $\mu+3 \sigma$ " e " $\mu-3 \sigma$ " (sendo " $\mu$ " a média e " $\sigma$ " o desvio padrão), ou seja, em um intervalo de três desvios-padrão, o que garantiria cerca de $99,73 \%$ de chances do resultado estar neste intervalo, uma ótima aproximação para a média seria:

$$
\mu=\frac{o+4 m+p}{6}
$$

e o valor para o desvio-padrão seria:

$$
\sigma^{2}=\frac{p-o}{6}^{2}
$$


Desta forma, o método PERT trabalha estas variáveis, construindo cenários que vislumbrem a simulação destas variações e o cálculo da probabilidade do projeto ser realizado no prazo previsto, conforme ilustra a figura 24.

Figura 24 - Estimativas de tempo (durações) pelo CPM e pelo PERT

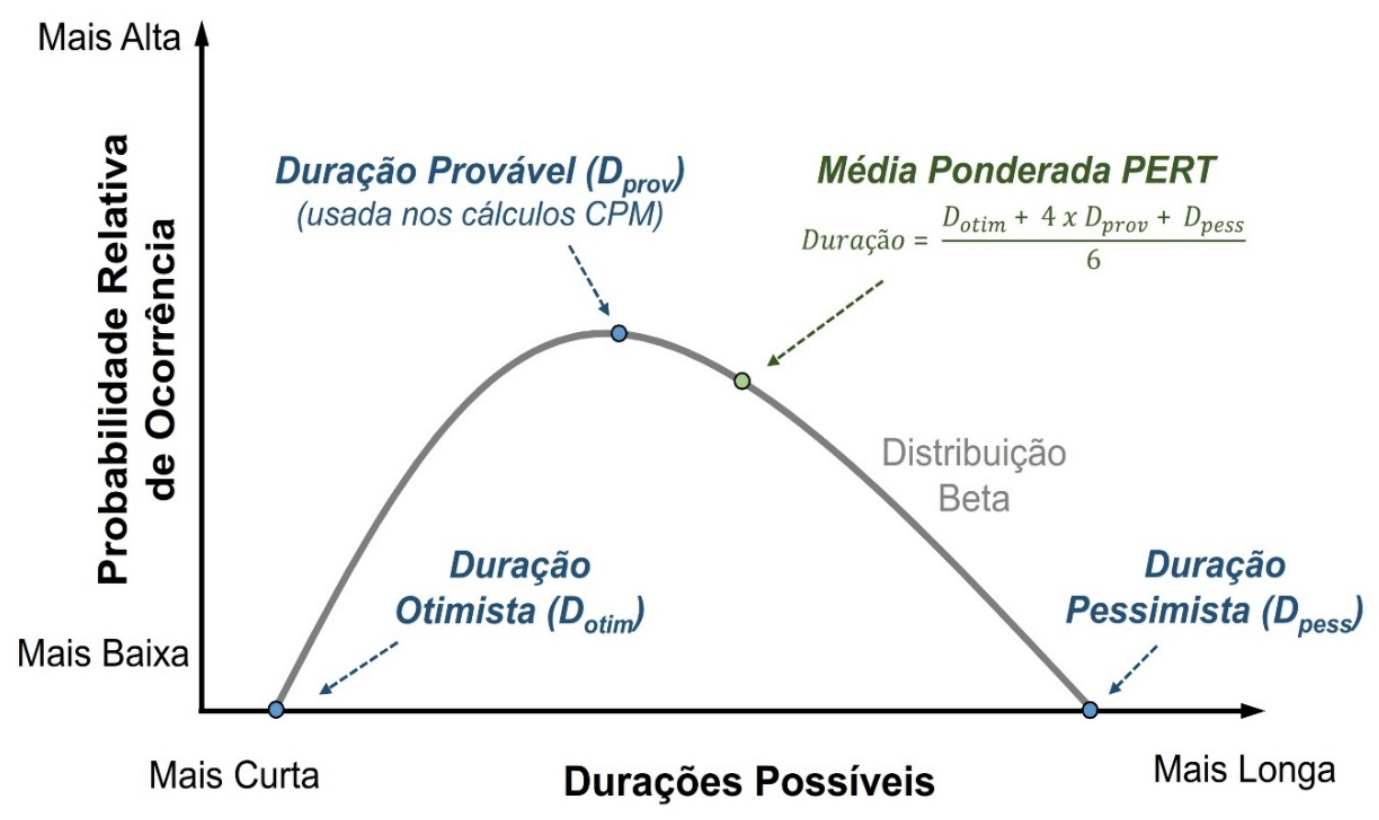

Fonte: Adaptado de Meredith e Mantel (2011)

De acordo com Meredith e Mantel (2011), exemplos práticos mostram que o PERT tem sido basicamente utilizado em projetos de pesquisa e desenvolvimento, enquanto que o CPM é largamente utilizado pela indústria da construção.

\subsubsection{Utilização atual do PERT / CPM}

Com o passar do tempo, as diferenças entre as técnicas não distinguem mais o PERT do CPM. Isso ocorreu porque os usuários do CPM começaram a fazer uso das três estimativas de tempo e os usuários de PERT passaram a tratar os nós da representação gráfica como atividades.

Por esta razão, atualmente estas técnicas são apresentadas em conjunto.

Como os computadores se tornaram amplamente disponíveis, estas técnicas se adaptaram ao universo dos gestores de projeto e ganharam notória popularidade, pois os cálculos e os desenhos das redes já não precisam ser feitos à mão. 
Muitos softwares foram desenvolvidos para esta finalidade e atualmente projetos de grande escala podem ser gerenciados globalmente em tempo real através de redes de comunicações por computador.

Conforme destaca Akkari (2003), pela complexidade das obras atuais, demandas por precisão maiores e a possibilidade efetiva de acesso a estes recursos por grande parte das empresas, o uso de softwares é natural. Mas quando se propõe o uso efetivo das redes de precedência como o CPM, por exemplo, torna-se praticamente obrigatório.

O MS Project, um dos softwares mais simples e conhecidos no mercado, já traz em sua configuração padrão, todas as informações do CPM.

A figura 25 apresenta o cálculo da mesma rede do exemplo da figura 21, as informações referentes às datas "mais cedo" e "mais tarde", folgas, o respectivo gráfico de Gantt, com a identificação das conexões entre as atividades. Ou seja, atualmente, o uso do CPM através dos modelos computacionais tornou-se bastante acessível.

Figura 25 - Exemplo de cálculo de rede pelo CPM com MS Project

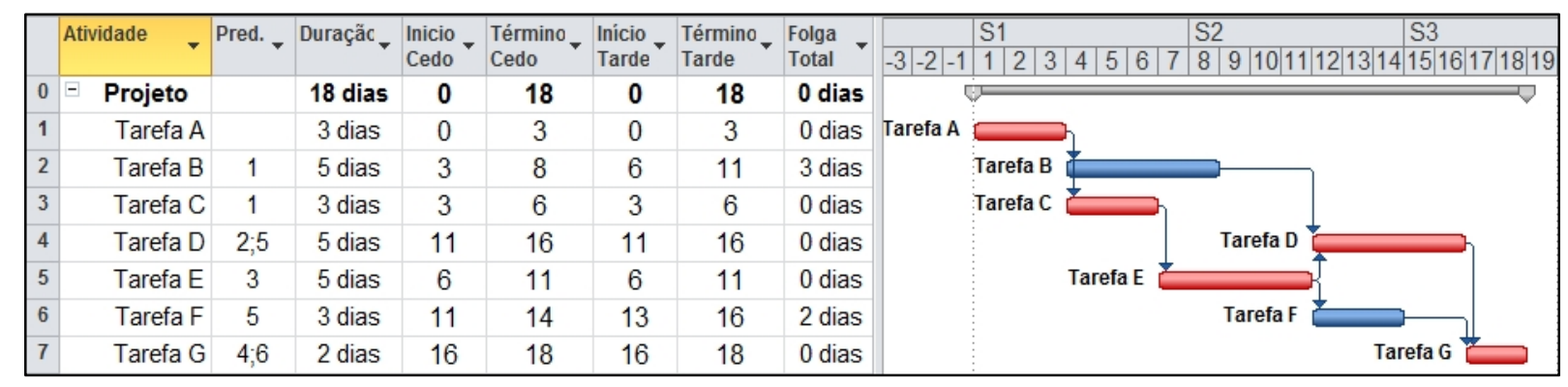

Fonte: O Autor

Comprovando o fato desta utilização conjunto dos dois métodos (PERT e CPM), o próprio MS Project ${ }^{3}$, há tempos atrás disponibilizava recursos para o uso simplificado de alguns conceitos do PERT. Existia, por exemplo, a possibilidade do usuário incluir as durações "otimista", "pessimista" e "mais provável" para cada tarefa, calculando a média ponderada e possibilitando ao planejador o uso das durações resultantes na rede.

(3) Estes recursos existiam nas versões até 2007. A partir da versão 2010 este recurso foi retirado do pacote básico disponível no programa. 
Em projetos de construção, talvez esta seja a utilização mais próxima do conceito do PERT, embora claramente verifica-se sua limitação. Se for utilizado o critério da média ponderada para a definição de uma única duração prevista para o projeto, na verdade não se está utilizando o conceito probabilístico do PERT, mas sim, um critério mais sofisticado de se calcular a rede de maneira determinística.

Entende-se que o uso adequado do método, e hoje já há programas que trazem esta funcionalidade, seja para o cálculo efetivo da probabilidade de se conseguir finalizar o projeto em um prazo determinado.

Além disso, alguns autores questionam a efetiva aplicação do PERT para este propósito.

Dodin (2006) destaca que para efeito de cálculos probabilísticos, o PERT possui a premissa de que as atividades do projeto são independentes umas das outras. Neste aspecto, os projetos de construção teriam certa limitação, pois verificam-se determinadas dependências que não são apenas àquelas relativas às redes de precedência.

Segundo este autor, seria interessante propor modelos de análise de diagramas estocásticos, como o PERT, que trouxessem maior precisão em seus resultados.

\subsubsection{Diagramas Condicionados}

Outro método de elaboração de diagrama de rede, menos utilizado, é o chamado Método do Diagrama Condicionado ou Conditional Diagramming Method (CDM).

Segundo Barcaui et al. (2013), o conceito foi apresentado em meados de 1960 como um procedimento para análise de redes com atividades que necessitavam de diferentes distribuições probabilísticas. Sua representação mais comum é feira por meio da técnica conhecida como Graphical Evaluation and Review Technique (GERT) no qual é possível a inclusão de derivações probabilísticas, múltiplas saídas, desvios condicionais, efeitos recursivos e nós com repetição de eventos (loops).

O modelo é citado primeiramente por Pritsker (1966) em relatório desenvolvido pela NASA e RAND Corporation, no qual o autor agradece a contribuição de outros pesquisadores, tais como Happ, Drezner e Whitehouse, que os ajudou na formulação 
da GERT e nos estudos de aplicação na resolução de problemas probabilísticos ou de engenharia, seja nas áreas de manufatura, pesquisa e desenvolvimento, ou mesmo em jogos de guerra.

Este tipo de representação é flexível e é aplicado a projetos mais complexos, onde é possível se prever a variação da rede com a introdução de ciclos. Da mesma forma como o método PERT (original), o modelo é mais indicado a projetos de pesquisa e desenvolvimento, sendo dificilmente aplicado a projetos de construção

Segundo Meredith e Mantel (2011), a GERT proporciona a combinação da teoria de fluxo de sinais gráficos, redes probabilísticas, o uso do próprio método PERT/CPM e árvores de decisão, tudo isto em uma mesma estrutura. O modelo é composto por nós lógicos e arcos diretos com dois parâmetros, sendo que para cada parâmetro estabelece-se a probabilidade de realização e sua duração estimada.

Para melhor entendimento do modelo, Mubarak (2010) apresenta um exemplo simples de como deve ser a representação da GERT. Utilizando o conceito dos nós lógicos em uma rede tipo ADM, conforme figura 26, o autor apresenta duas possibilidades de ramificação do nó, uma determinística (a) e outra probabilística (b). As probabilidades de ocorrência daquelas atividades (descritas nas ramificações) estão abaixo da representação da atividade na flecha.

Figura 26 - Ramificações (a) determinísticas e (b) probabilísticas na GERT

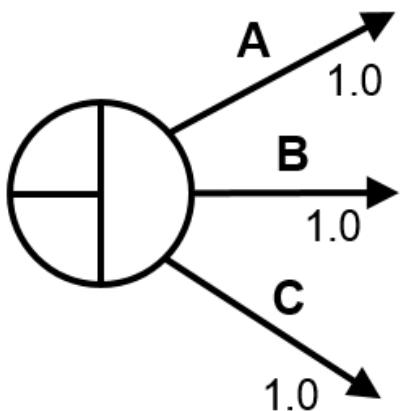

(a)

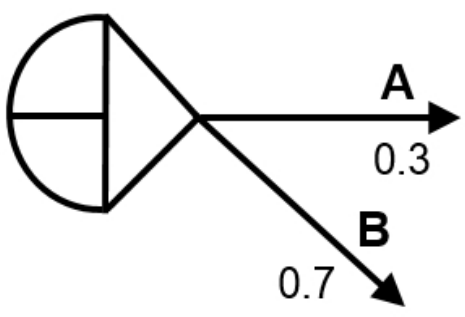

(b)

Fonte: Mubarak (2010)

Com base no exemplo "a", as atividades A, B e C tem 100\% de chances de ocorrência e assim, devem ser consideradas como efetivamente realizadas e em paralelo, nos 
cálculos da rede, que desta forma serão determinísticos. No caso "b", apenas uma das atividades A ou B será realizada, uma vez que a somatória das duas probabilidades será $100 \%$. Neste caso será necessário aplicar cálculos probabilísticos para a solução da rede.

Na figura 27, Mubarak (2010) apresenta também a aplicação dos loops, talvez a característica mais marcante da GERT, que não pode ser representada pelos métodos PERT/CPM. Na figura, observam-se três possibilidades de ocorrência após o término da atividade $A$ : a realização da atividade $B$ (com $30 \%$ de probabilidade), a realização da atividade $\mathrm{C}$ (com outros $50 \%$ de probabilidade) e a realização da atividade $\mathrm{D}$ (com os outros $20 \%$ de probabilidade), que remonta à repetição da atividade A. Este último caso poderia representar, por exemplo, a rejeição de uma peça de manufatura, o que levaria à necessidade de um novo processamento, caracterizado como atividade $\mathrm{A}$.

Figura 27 - Exemplos de três ramificações possíveis procedentes da Atividade A

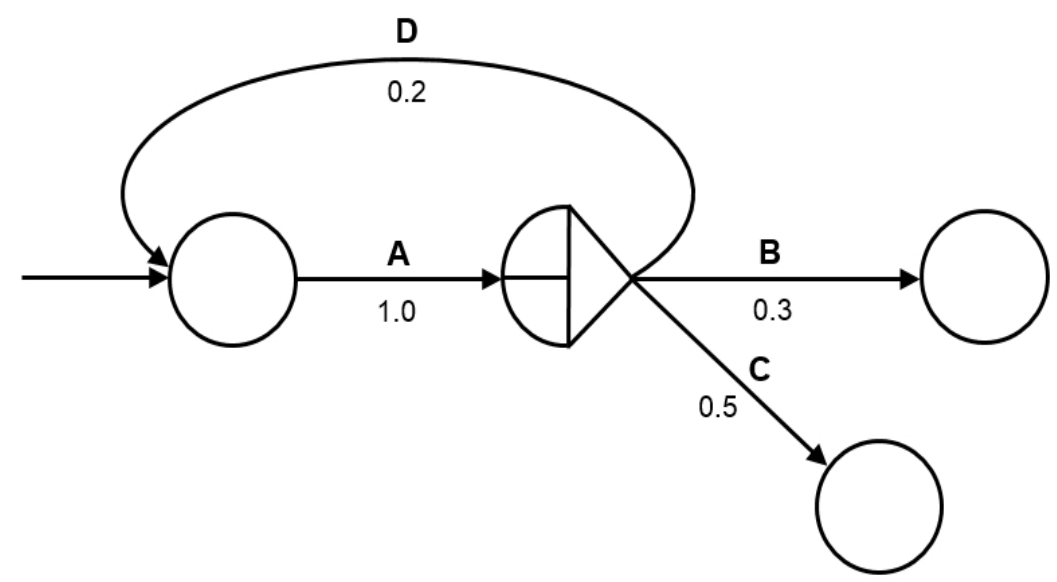

Fonte: Mubarak (2010)

Apesar de interessante, conforme destaca o autor, a GERT não ganhou popularidade na indústria da construção.

\subsubsection{Buffer e Corrente Crítica (CCPM)}

O método da Corrente Crítica (Critical Chain Project Management - CCPM), segundo o PMI (2013) é um método que permite que a equipe de projeto crie buffers (reservas) ao longo de qualquer caminho do cronograma para levar em consideração recursos limitados ou incertezas do projeto. O caminho crítico restrito por recursos é conhecido como "corrente crítica". 
Quelhas e Barcaui (2004), descrevem o conceito de CCPM como a aplicação da Teoria das Restrições (Teory of Constraints - TOC) ao ambiente de projetos. Os autores afirmam que se trata de uma abordagem gerencial e de diagramação de rede, que eleva a performance de projetos buscando resolver seus conflitos principais, através de algumas práticas, dentre as quais destacam-se:

- Diminuição agressiva na inserção de margens de segurança na estimativa de tempo individualmente por tarefa;

- Redução significativa da multitarefa (não definição de tarefas prioritárias);

- Uso de buffers ao final da corrente crítica (project buffer), formando a data final de entrega do projeto;

- Uso de buffers em caminhos que se unem a corrente crítica, chamados pulmões de convergência (feeding buffers), para garantir que não se tornem críticos também.

Segundo Mendes et al. (2014), a teoria da CCPM foi criada por Eliyahu Goldratt a partir da teoria das restrições e hoje é tida como uma das mais modernas ferramentas de gerenciamento de cronogramas.

De acordo com o autor, observa-se que os técnicos têm a tendência de fazer estimativas conservadoras, mas apesar disto, os projetos frequentemente atrasam. Desta forma, de algum modo sistematicamente desperdiça-se a margem de segurança que é colocada em cada atividade.

O tamanho de cada buffer deve levar em conta a incerteza na duração da corrente de atividades dependentes deste buffer, mas, de acordo com Goldratt (1998), sugere-se que sejam inseridos buffers com cerca de $50 \%$ do total da segurança removida no caminho em questão (proteção da corrente), como pode ser observado no exemplo simplificado da figura 28.

No exemplo, as durações conservadoras das tarefas A, B e C são de 12 dias, sendo 9 dias como duração provável (ou realista) e 3 dias sugeridos pelo planejador como margem de segurança. Implantando a CCPM em todo o projeto, representado pelo resumo $A B C$, todas as margens de segurança de cada tarefa individual foram retiradas 
e acrescentado um buffer de 4 ou 5 dias (metade dos 9 dias de margens de segurança somadas).

Figura 28 - Exemplo de uso de buffer de controle na CCPM

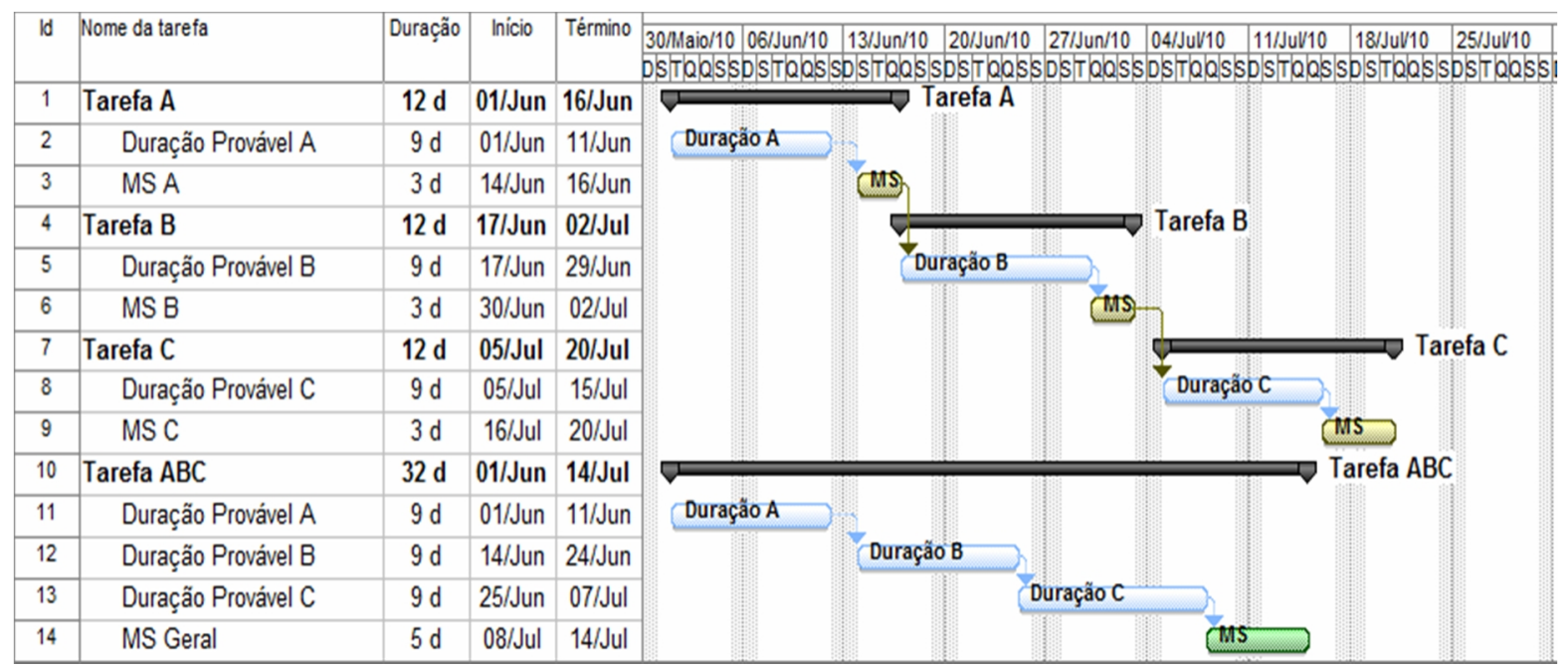

Fonte: O Autor

De acordo com o PMI (2013), um buffer colocado no final da corrente crítica é conhecido como "Buffer do Projeto" e protege a data alvo de término contra o seu desvio ao longo da corrente crítica. Buffers adicionais, conhecidos como "Buffers de Alimentação", são colocados estrategicamente sempre que uma cadeia de atividades dependentes, apesar de não estar no caminho crítico, alimenta ou converge para a corrente crítica. Desta forma, protegem a corrente crítica contra os desvios ao longo da cadeia de alimentação, como pode ser observado na figura 29.

Figura 29 - Exemplo de rede com buffers de projeto e alimentação (CCPM)

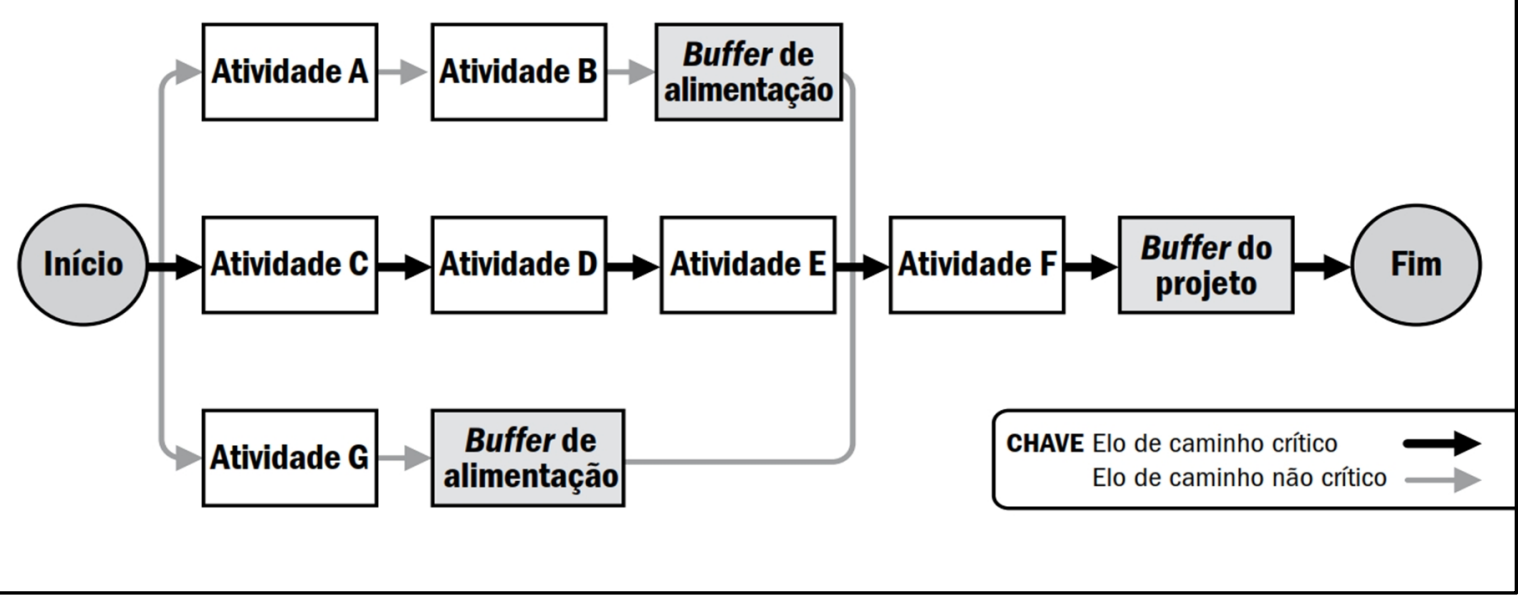

Fonte: PMI (2013) 
Consequentemente, ao invés de gerenciar a folga total dos caminhos da rede, o método foca o gerenciamento das durações restantes dos buffers. A corrente crítica pode ser estabelecida como o maior caminho do projeto (principal restrição do projeto), considerando as dependências de atividades e recursos, diferindo do caminho crítico proposto pelo tradicional CPM.

Caso, durante o monitoramento de um buffer de alimentação, por exemplo, verificarse que este está diminuindo a ponto de acabar, há o indício que aquele caminho, que antes não estava na corrente crítica, deverá tornar-se uma nova restrição principal do projeto. Por sua vez, deverá afetar então as durações restantes do buffer de projeto.

Apesar destes dois tipos de buffer serem os mais citados, Akkari (2009) destaca o uso de um terceiro tipo, denominado "Buffer de Recurso". Esta outra tipologia de pulmão pode ser entendida como uma tarefa virtual introduzida previamente nas cadeias críticas que requerem recursos escassos.

Segundo Akkari (2009), os buffers de recursos não consomem nenhum recurso, não geram acréscimos de prazo e nem de custo. São colocados em forma de aviso, indicando que um determinado recurso crítico possa ser antecipado para uma tarefa do caminho crítico, em detrimento de seu uso em uma tarefa que possa ser postergada, ou seja, que esteja fora do caminho crítico.

Outro aspecto interessante do uso desta ferramenta é a associação de probabilidade na definição das durações dos buffers. Por exemplo, lembrando dos conceitos descritos no PERT no item 3.6.2.2, caso o planejador deseje um projeto com $99 \%$ de chance de alcançar o prazo de entrega previsto, ele deverá adotar um buffer com

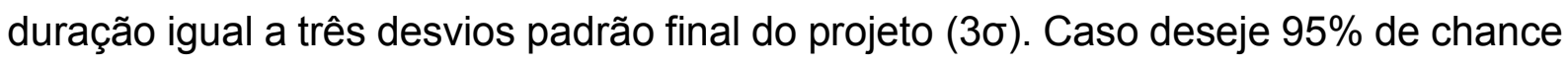
de sucesso, adotará dois desvios padrão $(2 \sigma)$ e se for $67 \%$ de probabilidade, irá utilizar uma buffer com duração de um único desvio padrão $(\sigma)$.

Este exemplo descrito por Mendes et al. (2014) é representado na figura 30, onde no primeiro grupo de atividades são previstas as durações conservadoras (Projeto pessimista) e suas respectivas margens de segurança, bem ao conceito do CPM. No segundo grupo, o gráfico (Projeto PERT) ilustra as mesmas atividades, mas agora sem a margem de segurança e as possibilidades de inclusão dos buffers com 1, 2 ou três desvios padrão de duração. 
Figura 30 - Uso de buffers de controle com probabilidades (PERT)

\begin{tabular}{|c|c|c|c|c|c|c|c|c|c|c|}
\hline ID & (1) & Task name & Duration & M1 & M2 & M3 & M4 & M5 & M6 & M7 \\
\hline 1 & & Projeto CPM pessimista & 120 days & & & & & & & \\
\hline 2 & & $a$ & 12,5 days & & & & & & & \\
\hline 3 & & $b$ & 12,5 days & & & & & & & \\
\hline 4 & & c & 15 days & & & & & & & \\
\hline 5 & & d & 25 days & & & & & & & \\
\hline 6 & & e & 15 days & & & & & & & \\
\hline 7 & & $f$ & 25 days & & & & & & & \\
\hline 8 & & $g$ & 15 days & & & & & & $\square$ & $9 \%$ \\
\hline 9 & & & & & & & & & & \\
\hline 10 & & Projeto PERT & 91 days & & & & & & & \\
\hline 11 & & a & 7,5 days & & & & & & & \\
\hline 12 & & b & 7,5 days & & & & & & & \\
\hline 13 & & c & 9,5 days & & L & & & & & \\
\hline 14 & & d & 15,5 days & & & & & & & \\
\hline 15 & & $\mathrm{e}$ & 9 days & & & & & & & \\
\hline 16 & & $f$ & 15 days & & & & & & & \\
\hline 17 & & $\mathrm{~g}$ & 9 days & & & & & & & \\
\hline 18 & & Buffer & 18 days & & & & & & & \\
\hline 19 & & 1 desvio & 6 days & & & & & & & \\
\hline 20 & & 2 desvios & 6 days & & & & & & & \\
\hline 21 & & 3 desvios & 6 days & & & & & & & \\
\hline
\end{tabular}

Fonte: Mendes et.al. (2014)

Por fim, pode-se destacar outra aplicação da CCPM. Akkari (2009) destaca que os princípios da CCPM podem ser aplicados para se estabelecer um método nivelamento de recursos relacionado ao planejamento operacional. Este aspecto é bem interessante, pois o CCPM direciona a gestão dos buffers, mas usualmente apenas como forma de se garantir os prazos de um projeto.

\subsubsection{Diagramas Tempo-Caminho}

O diagrama tempo-caminho (ou espaço-tempo) é um dos métodos mais utilizados por planejadores envolvidos em projetos com diversas unidades de repetição, os chamados projetos lineares.

Em projetos de construção, esta forma de representação indica o sequenciamento da atividade pelas diversas unidades de repetição de uma obra (pavimentos, apartamentos, casas unifamiliares, quilômetros de estrada, metros de canalização, dentre outras).

Segundo Limmer (1997), este diagrama consiste basicamente no traçado de linhas, em um plano cartesiano, que representam, cada uma delas, uma atividade e seu 
respectivo andamento, sendo que a inclinação de cada reta indica o ritmo no qual a atividade deverá ser executada.

O ritmo da atividade também pode ser encontrado em alguns trabalhos como takt time (originário da palavra alemã "takt”, que significa o compasso de uma música, o ritmo).

No entanto, são necessários alguns cuidados no uso deste termo, que às vezes é também confundido com "tempo de ciclo". Alvarez e Antunes Jr. (2001) descrevem que a aplicação do takt time é restrita a sistemas de produção que trabalhem com fluxos unitários, com elevadas quantidades de produção de unidades e assim, sistemas de Planejamento e Controle da Produção (PCP) que possibilitem a absorção e diluição de variações de demanda.

Por esta razão, neste trabalho será utilizado mais frequentemente o termo ritmo ou cadência.

Quando se utiliza esta técnica para alinhar o ritmo das atividades nas diversas unidades de repetição de um projeto, pode-se dizer que as atividades estão balanceadas. Assim, o método é comumente conhecido como Linhas de Balanço, como pode ser observada na figura 31.

Figura 31 - Diagrama tempo-caminho (a) não balanceado e (b) balanceado

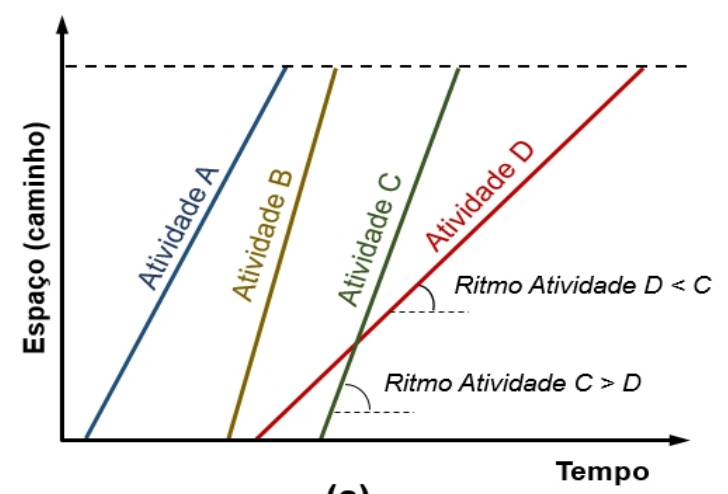

(a)

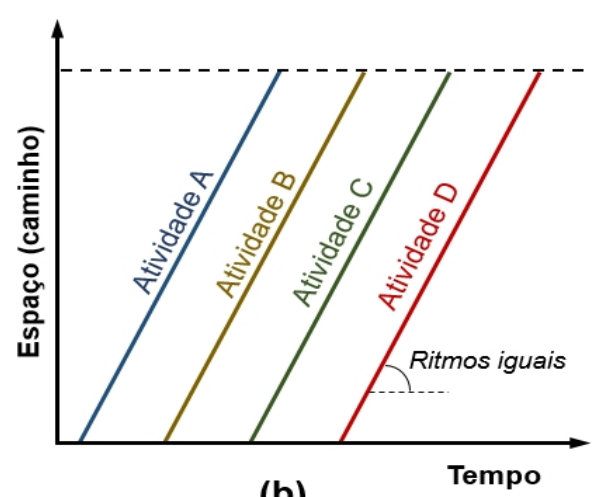

(b)

Fonte: O Autor

Segundo Junqueira (2006), a técnica da Linha de Balanço (Line of Balance - LOB) para programação de tarefas foi criada pela Goodyear nos anos 40 e suas primeiras aplicações foram na indústria de manufaturados para programar o fluxo de produção. Seu uso na construção civil se difundiu mais na Europa em obras com serviços repetitivos (estradas e pontes) e recentemente vários pesquisadores vêm procurando 
diversas formas de difundir seu uso nos EUA e outros países, em conjuntos habitacionais e edifícios altos, estudando seus conceitos juntamente com outras técnicas matemáticas ou computacionais, como simulações.

Segundo o autor, o balanceamento das linhas pode ser obtido através de:

- Eliminação de conflitos entre equipes pela mudança da precedência de uma atividade ou pela mudança de ritmo (alterando-se por exemplo o número de operários em cada equipe);

- Eliminação dos gargalos na obra (tarefas que são executadas com ritmo lento atrapalhando as demais);

- Definição de estratégias de execução que permitam o espalhamento das atividades pela obra diminuindo o tempo de ocupação ou de entrega de uma unidade.

Kemmer (2006) traz um comparativo entre as vantagens e desvantagens do uso da técnica da LOB, que pode ser observado no quadro 10.

Quadro 10 - Vantagens e desvantagens do uso da LOB

Vantagens da $L O B$

- Fácil viasualização de índices de produção e duração das atividades;

- Detecção dos gargalos de produção;

- Simplificação de decisões acerca da direção e velocidade do trabalho, além do número de atividades por ciclo;

- Possibilidade do balanceamento nos ritmos ou velocidades de execução;

- Evitam-se conflitos ou espera na execução dos serviços;

- e obtendo situações favoráveis de nivelamento das equipes;

- Organização do ataque à obra;

- Representação do intervalo de tempo entre atividades e folgas existentes;

- Fixação de metas, proporcionando motivação da mão-de-obra;

- Indução do efeito aprendizagem;

- Visualização imediata das atividades que se desviaram do programa inicial.

\section{Desvantagens da $\angle O B$}

- Assume ritmos constantes para atividades, o que pode ser questionado pela natureza estocástica dos processos de construção;

- Especialização da mão-de-obra, tornando o operário conhecedor apenas da tarefa que executa;

- Necessidade de um projeto integrado à forma de execução;

- Dificuldade de se considerar o grande número de variáveis influentes no processo construtivo (algumas exigem escalas diferentes para a mesma linha de balanço);

- Necessidade de elaborar programação à parte para itens não repetitivos;

- Entrega do domínio do processo à gerência e não ao operário;

- Limitação quanto à simulação, pelo fato de não operar com atividades inter-relacionadas;

- Dificuldade de disseminação e operacionalização (poucos aplicativos comerciais para operar com a técnica). 
Kemmer (2006) descreve ainda que a técnica é adequada também para a simulação de alternativas na condução dos trabalhos em canteiro.

Alguns trabalhos que surgiram posteriormente demonstram que algumas das desvantagens citadas por Kemmer (2006) não se confirmam, como a rigidez dos ritmos constantes, por exemplo, como será descrito mais à frente.

Alguns autores recomendam a utilização da LOB nos estudos de estratégias de produção, onde os serviços são tratados em um nível macro, sem levar em conta um detalhamento maior da produção.

Acredita-se que esta técnica favoreça a explicitação de variáveis de produção advindos da associação com os princípios do Lean Construction (tema que será abordado no item 3.8.3), como por exemplo, o tempo de ciclo e de atravessamento (figura 32).

Figura 32 - Exemplos de variáveis de produção identificadas na linha de balanço.

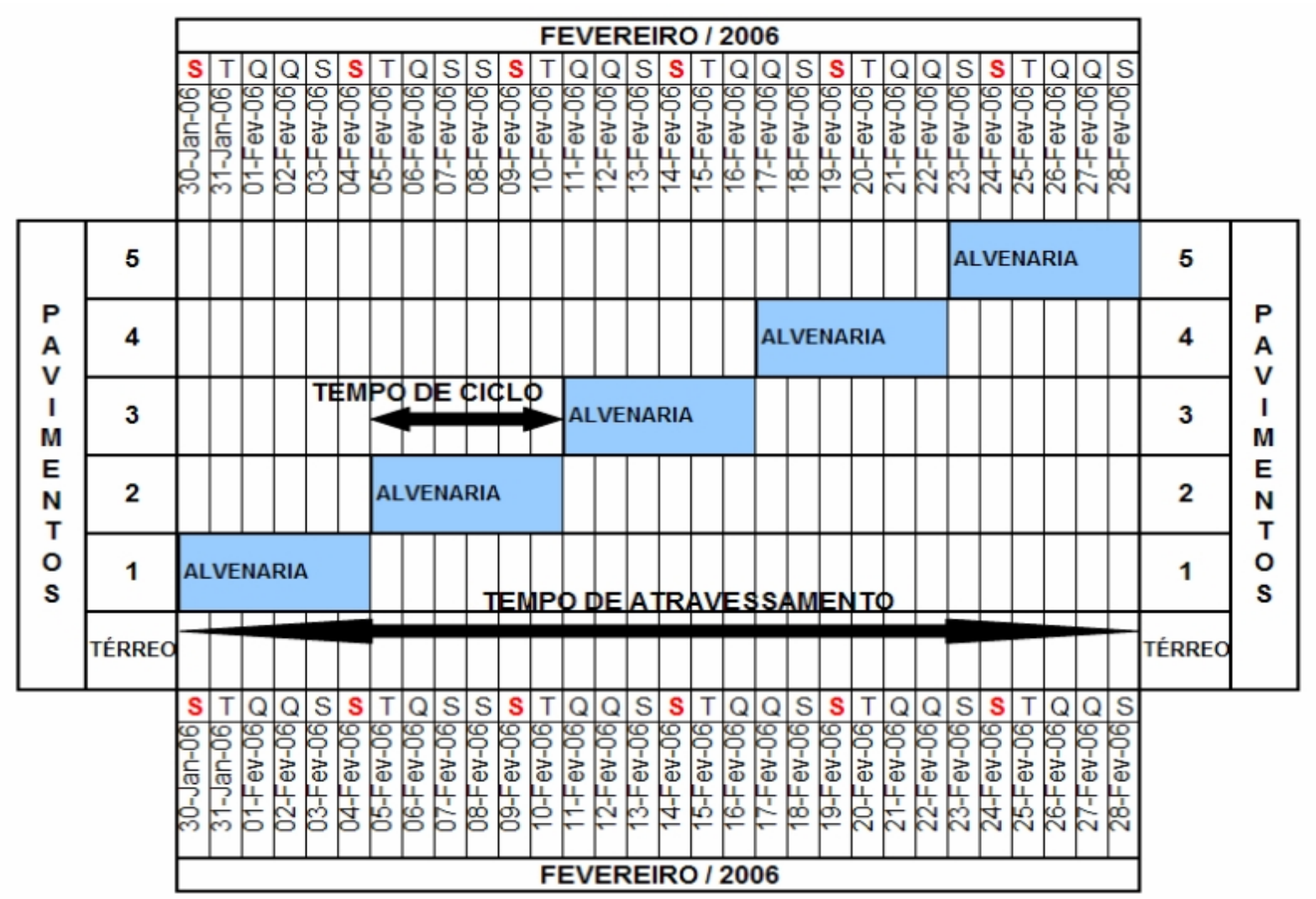

Fonte: Kemmer (2006) 
Segundo Cardim e Picchi (2015), a linha de balanço (LOB) é um diagrama de quantidade-tempo e representa graficamente as atividades de um processo sequenciado através do tempo, considerando a natureza repetitiva das atividades.

De acordo com os autores, através da LOB, pode-se inferir importantes informações de um planejamento, tais como:

- Qual atividade será executada;

- Onde essa atividade ocorre;

- Quando será executada; e

- Quem é o responsável pela execução (ou a equipe responsável), neste último caso, dependendo da forma como o gráfico é elaborado.

Como citado, não é comum se identificar as equipes que irão executar as atividades, mas a análise dos recursos disponíveis é essencial para o balanceamento das linhas. Assim, a identificação dos responsáveis pode ser uma interessante prática, como pode ser observado no gráfico apresentado por Kenley e Seppänen (2009), representado na figura 33.

Figura 33 - Exemplo de LOB com indicação de equipes para balanceamento

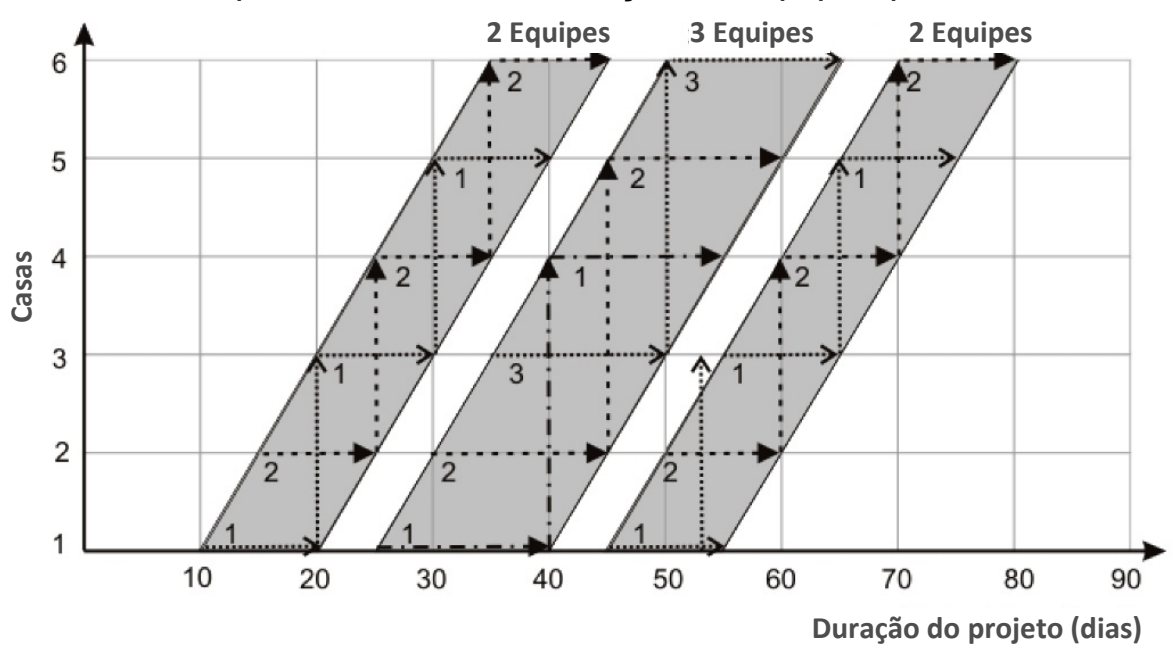

Fonte: Kenley e Seppänen (2009)

Cardim e Picchi (2015) defendem que esta técnica pode ser utilizada com eficiência para a redução do prazo de duração de uma obra, antecipando-se datas de início e adequando taxas de produção das atividades. 
No entanto, eles verificarem em sua pesquisa que quando se busca a redução das durações verifica-se ociosidade de mão de obra em determinadas atividades, reforçando a importância e potencialidade na prática que existissem no canteiro equipes multidisciplinares.

Outros autores, como Moura e Heineck (2014) destacam que a técnica, entre diversas vantagens (tais como a visão dos ciclos, simplificação das operações, redução da variabilidade e a visão do fluxo de execução, já citados anteriormente) pode reduzir o chamado Lead Time.

De acordo com Ballard (2000), em um processo sequencial, o lead time corresponde ao somatório de todos os tempos necessários à produção de uma unidade. Consideram-se não apenas o processamento, mas as etapas de inspeção, transporte, esperas e todos os tempos relativos a um fluxo completo de uma unidade deste produto.

Trazendo este conceito para um projeto de construção que apresenta serviços com algum tipo de repetição, Moura e Heineck (2014) descrevem que o lead time seria o tempo necessário para que todas as atividades ocorram em uma unidade de repetição (como por exemplo, uma prumada, um trecho de periferia ou um pavimento tipo).

Segundo os autores, a diminuição do lead time pode ocorrer pelo balanceamento das atividades ou pelo "efeito aprendizado" da equipe, como pode ser observado nas figuras 34 e 35 .

Figura 33 - Redução do lead time pelo balanceamento das atividades

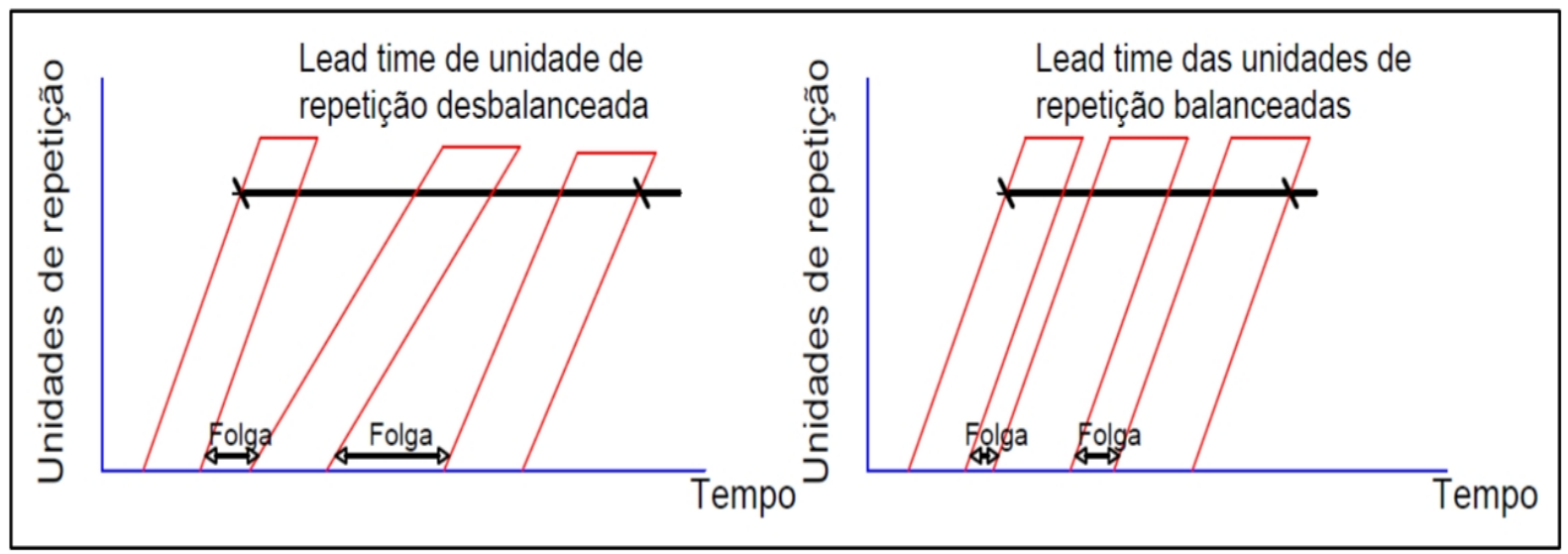

Fonte: Moura e Heineck (2014) 
Figura 35 - Redução do lead time pelo efeito aprendizado

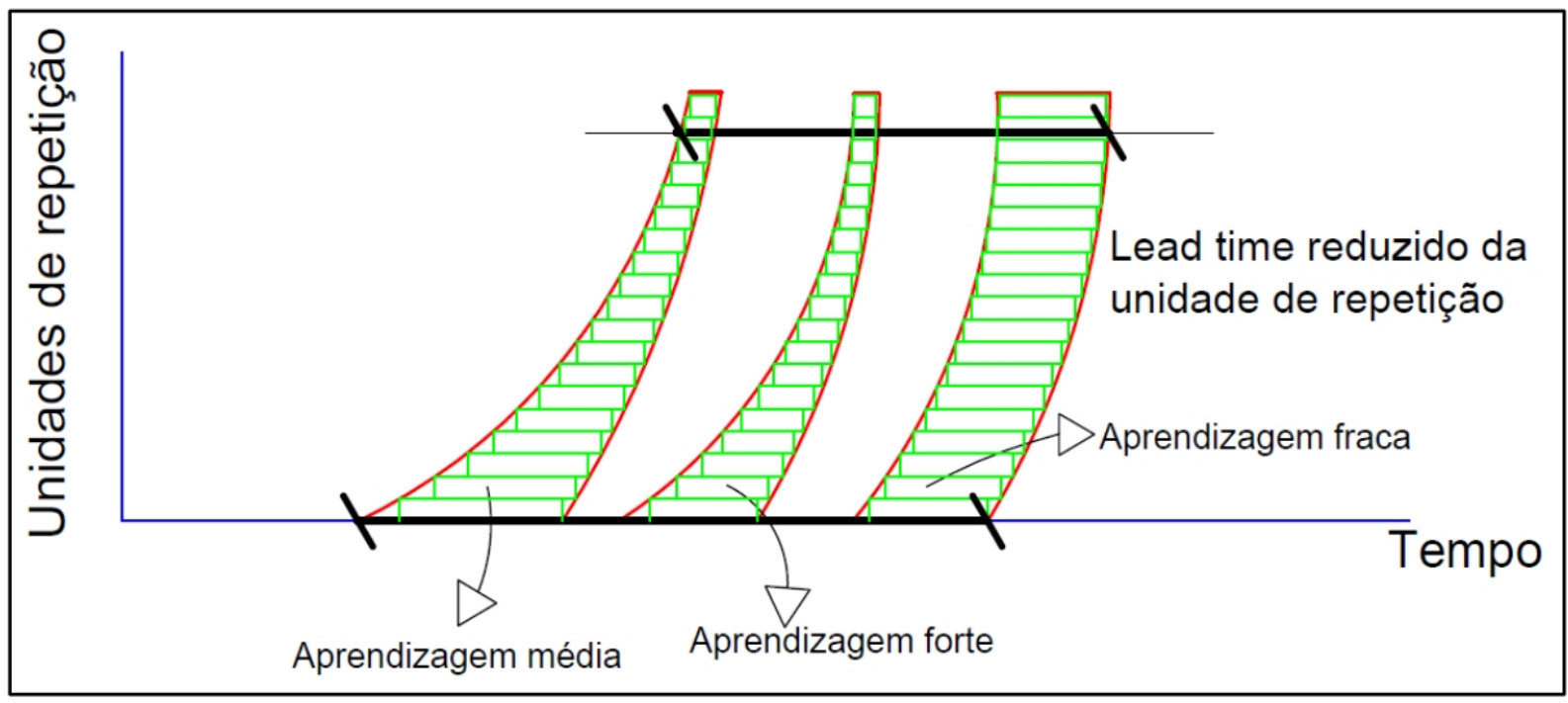

Fonte: Moura e Heineck (2014)

Cardim e Picchi (2015) observam que reduzir o lead time das atividades pode fazer com que se aumente o número de equipes trabalhando nas frentes de serviço. Quando isso ocorre, pode-se experimentar um efeito negativo que é a diminuição do número de vezes que a mesma equipe realiza o mesmo serviço. Com isso, perdemse as vantagens decorrentes do "efeito aprendizado".

Kemmer (2006) demonstra também o uso da LOB como alternativa prática e operacional para se trabalhar as diversas possibilidades de se planejar um empreendimento de construção civil.

O autor estabelece diversas premissas que são utilizadas para a definição do plano de ataque de uma obra vertical de múltiplos pavimentos, focando variações das hipóteses de planejamento para o que ele define como serviços do núcleo da rede (revestimentos cerâmicos ou de pedra natural de piso, paredes, revestimentos de gesso e forro), em especial: (i) se as atividades devem ser executadas dos andares inferiores aos superiores ou vice-versa; (ii) se serão adotados ciclos longos ou curtos para estas atividades; e (iii) se serão estabelecidos vínculos entre as equipes que garantam continuidade das mesmas quando os profissionais têm mesma habilidade e competência, garantindo menos variabilidade nos serviços pela continuidade dos recursos alocados e motivação dos colaboradores.

Alguns dos planos de ataque desenvolvidos para o empreendimento em questão são apresentados na figura 36 . 
Figura 36 - Comparação entre planos de ataque com uso de linhas de balanço

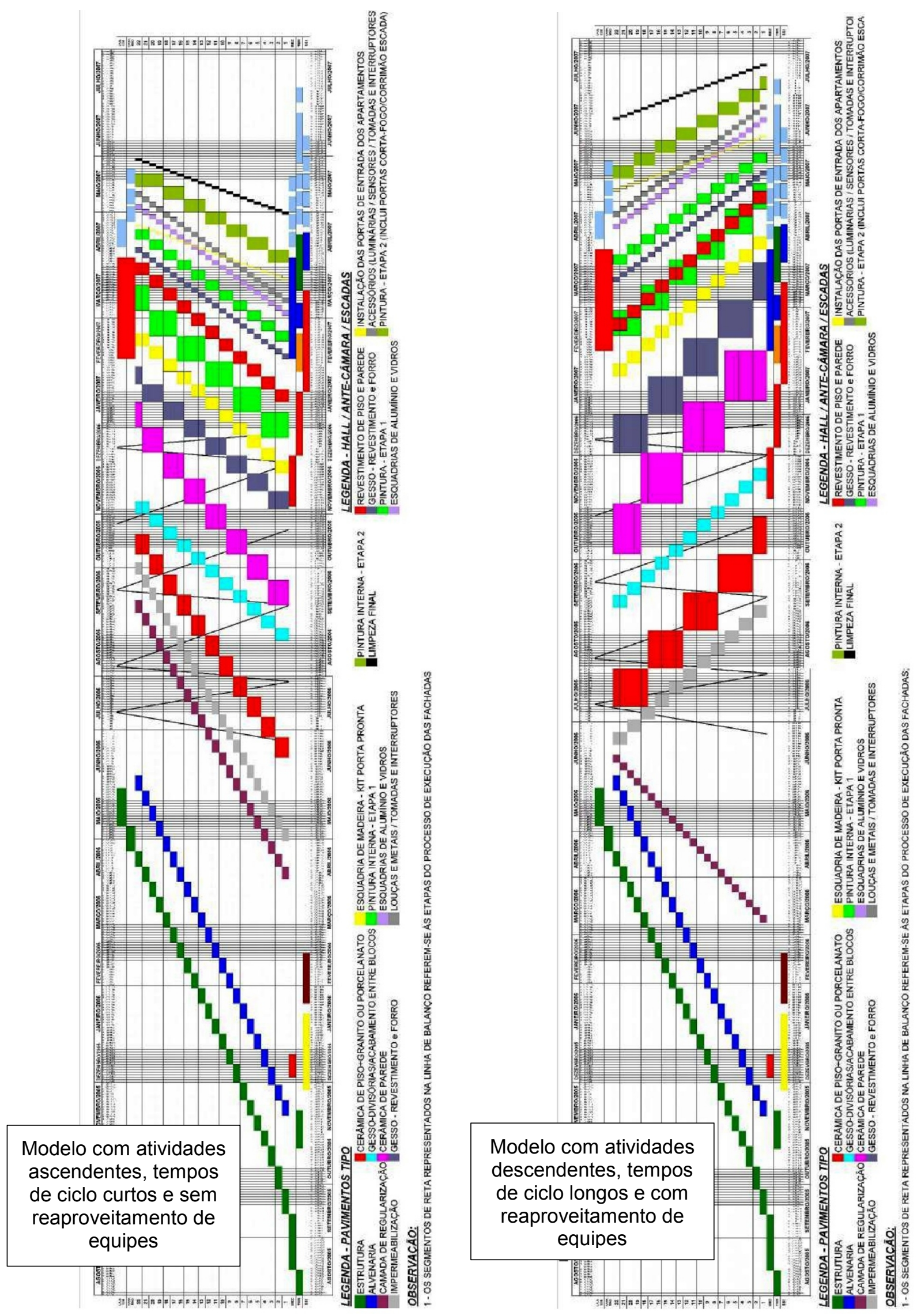

Fonte: Kemmer (2006) 


\subsection{Utilização adequada das ferramentas de planejamento físico}

Vários autores discutem aspectos, dificuldades e até limitações contidas dentro das filosofias mencionadas no item anterior. Muitas das questões levantadas buscam então estabelecer diretrizes ou ferramentas para melhorar os métodos até então utilizados pelos gestores em seus empreendimentos.

Muitas vezes a crítica não está na ferramenta em si, mas no contexto em que ela é aplicada.

O PMI (2013), por exemplo, sugere a utilização da ferramenta de "cronograma de barras" de diversas formas dentro de um mesmo projeto. Entende-se que a gestão da interface entre o plano estratégico e operacional necessita de informações mais sumarizadas, que podem ser representadas pelo cronograma sumarizado. $O$ cronograma de marcos ${ }^{4}$ seria ideal para o gerenciamento do empreendimento e o cronograma detalhado para o acompanhamento da produção.

Outro ponto debatido por muitos autores relaciona-se às possibilidades de se organizar processos de planejamento quando se têm projetos com atividades repetitivas, ou projetos que possam ser repetidos em determinados momentos, com pequenas alterações.

Questiona-se que, para se programar projetos desta natureza, utilizar diagramas de rede pode não ser eficiente. Neste tipo de projeto, ferramentas mais tradicionais como o CPM, por exemplo, são complexas ou não agregam o valor esperado.

Autores como Amor (2002), Elbeltagi e Dawood (2011) e outros apresentam pesquisas sugerindo formas alternativas de planejamento de projetos repetitivos, enquanto alguns como Assumpção e Fugazza (1998) e Ferreira (2001), por sua vez, identificam diversos benefícios no uso da ferramenta CPM.

(4) Entende-se "marco" como um evento importante do projeto, um instante no tempo, sem duração ou recursos. Assim, um cronograma de marcos, em projetos de construção, normalmente é representado por datas que marcam início ou fim de etapas importantes a serem controladas. 
O Método do Caminho Critico (ou Critical Path Method - CPM) é um dos vários métodos de análise de planejamento, cujas atividades ou tarefas críticas definem o caminho crítico, ou seja, revelam a sequência de tarefas que condicionam a duração total do projeto.

Hegazy e Menesi (2010) concordam que o CPM tem sido útil para o planejamento de projetos de construção, mas apresentam graves inconvenientes que dificultam seu uso como ferramenta de apoio à decisão. Isto porque uma rede CPM bem elaborada é muito detalhada, sendo difícil uma análise adequada das flutuações do caminho crítico e da alocação de recursos limitados. Os autores propõem uma rede onde as durações das atividades seriam consideradas como "blocos contínuos de tempo". Assim, um novo caminho crítico segmentado poderia evitar relações de rede muito complexas facilitando a análise mais precisa dos atrasos no projeto.

Vanhoucke (2006) estabelece que alguns projetos envolvem a repetição de atividades ao longo de suas etapas. Os recursos necessários para realizar essas atividades são deslocados de um estágio para o outro. Desta forma, um dos principais objetivos da programação desses projetos é manter a continuidade do trabalho de forma a minimizar o tempo ocioso dos recursos.

Em projetos com esta característica, vários autores estudam a utilização de ferramentas de programação linear.

Huang e Sun (2006) relatam que métodos de programação repetitiva são mais eficazes do que os tradicionais métodos de caminho crítico no planejamento e programação de projetos de construção repetitivos. No entanto, quase todos os métodos de programações repetitivas desenvolvidas recentemente são baseados na premissa de que um projeto repetitivo é composto de muitas unidades de produção idênticas, o que traria certa limitação aos modelos. Os autores estabelecem um modelo que minimiza tais problemas.

Kallantzis et al. (2007) também entendem que métodos de programação linear oferecem uma forma alternativa de agendamento de projetos repetitivos, em relação aos métodos de rede comumente usados. A identificação do caminho crítico é um atributo importante para ambos os métodos. 
Segundo Mattila e Park (2003), várias técnicas de programação linear têm sido propostas ao longo dos anos, sendo que as limitações destas técnicas tem sido sempre as mesmas, ou seja, a incapacidade para se determinar as atividades críticas. Recentemente, dois métodos diferentes com esta diretriz têm se destacado, o modelo de programação linear e o método de agendamento repetitivo.

Lucko (2008) concorda que estes dois métodos são os mais desenvolvidos além do CPM (o modelo de programação linear e o método de agendamento repetitivo). Segundo o autor, no método de agendamento, a produtividade deve ser baseada em funções de singularidades que forneçam um modelo flexível e poderoso matematicamente para atividades de construção.

Fan e Tserng (2006) relatam que a aplicação de técnicas de rede para a programação de projetos repetitivos tem sido criticada pois não oferece recursos adequados para ajudar a manter a continuidade do trabalho. Além disso, as técnicas de rede atuais requerem um grande número de atividades para representar um projeto repetitivo e que haja uma premissa de que existe apenas uma sequência lógica mais adequada. Isso faz com que se consuma muito esforço para desenvolver e controlar o projeto. Segundo os autores, a lógica escolhida pelo planejador pode estar longe de ser o menor prazo possível (resultado da rede tradicional).

Kim e La Garza (2003) apontam também que um cronograma baseado no CPM tradicional não é realista, porque esta ferramenta não estabelece limitações de recursos para cada atividade. Conceitualmente, pode-se trabalhar com recursos ilimitados, alguns dos quais são altamente escassos na prática. No entanto, continua sendo uma ferramenta muito importante porque nenhuma outra traz de forma tão clara as folgas corretas e o caminho crítico.

Segundo Yi et al. (2002) o CPM constitui uma lógica que é estabelecida através da intuição e da experiência humana. Devido a isso, uma variedade de redes alternativas CPM pode ser criada na programação do mesmo projeto. O uso da rede mais desejável pode levar a uma considerável redução na duração dos projetos. Isto pode ser obtido através da identificação precisa das atividades mais importantes e ligandoas da forma mais adequada possível. 
Mas um bom planejamento não é feito apenas com o CPM ou programações lineares. Ele engloba um conjunto de diversas ferramentas ou práticas, que precisam ser organizadas de maneira a se obter o melhor resultado para o projeto.

Para o acompanhamento dos prazos, o PMI (2013) estabelece as seguintes ferramentas:

- Relatório de progresso: situação atual do cronograma, datas de início e de término reais e percentual completo das atividades do cronograma;

- Sistema de controle de mudanças no cronograma: procedimentos para efetuar mudanças no cronograma do projeto e níveis de aprovação necessários;

- Medição de desempenho: técnicas de medição que produzam a variação de prazos e índices de desempenho, para avaliar o impacto das variações no cronograma;

- Software de gerenciamento de projetos: possibilita acompanhar as datas planejadas em relação às datas reais e prever os efeitos das mudanças no cronograma do projeto, sejam elas reais ou potenciais;

- Análise da variação: análise da variação de prazos do cronograma durante o processo, comparação entre datas do cronograma alvo e as datas de início e término, e variação da folga total;

- Gráficos de barras de comparação do cronograma: exibição de duas barras para cada atividade do cronograma (atual real e a da linha de base do cronograma do projeto aprovado).

Como citado, o uso adequado das diversas ferramentas dentro do contexto de projeto ou de uma filosofia de abordagem pode significar um melhor resultado. Por esta razão, pretende-se também abordar alguns sistemas ou modelos de planejamento, como apresentado no item a seguir.

\subsection{Sistemas, modelos e métodos de planejamento}

De acordo com Assumpção (1996), a essência do processo de planejamento consiste na construção de modelos que representem as relações entre as atividades que se desenvolvem no ambiente da empresa e de seus empreendimentos, aliado a 
sistemas, que permitem operar com estes modelos e gerar informações. Estas informações são produzidas, ora na forma de expectativas de comportamento do modelo (diretrizes para ação), ora avaliando o comportamento das ações já empreendidas (monitoramento dos resultados).

O autor destaca que isto ocorre em todos os níveis de hierarquia do projeto.

A figura 37 apresentada por Souto (2006) ilustra um sistema genérico de planejamento, conforme esta essência citada por Assumpção (1996).

Figura 37 - Sistema de Planejamento

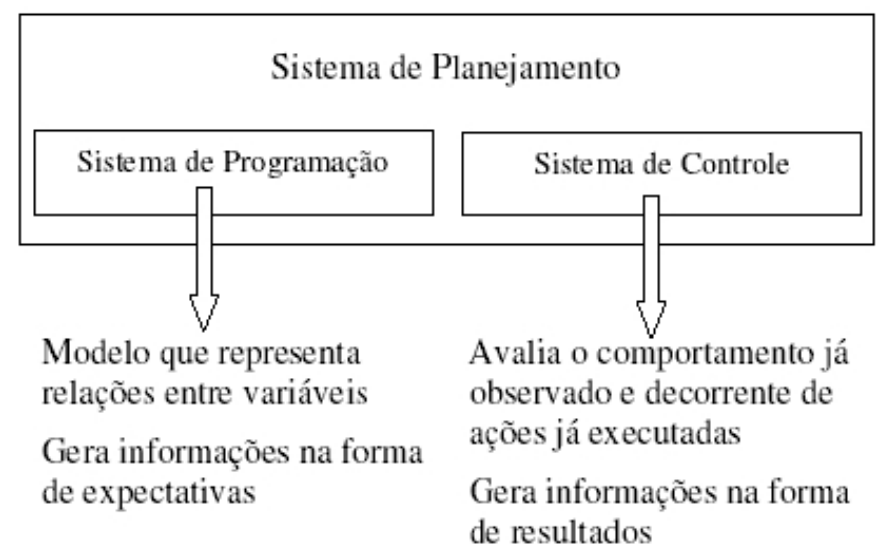

Fonte: Souto, 2006

Assim, analisando-se o processo de planejamento na dimensão horizontal, um sistema ou um modelo de planejamento estabelece as etapas pelas quais este planejamento (com seus subsistemas de programação e controle) é realizado.

Há muito tempo, Laufer e Tucker (1987) estabeleceram uma configuração para o ciclo de planejamento, que é até hoje referenciada por muitos autores que estudam modelos de planejamento. Este sistema seria estruturado das seguintes etapas:

- Preparação do processo de Planejamento;

- Coleta de informações;

- Preparação de Planos;

- Difusão da informação; e

- Avaliação do processo de planejamento. 
Conforme pode ser observado na figura 38, após a definição do método que será implementado no projeto ou empreendimento, este ciclo inicia-se com a coleta de informações sobre o sistema que está sendo controlado. As informações (incluindo metas de execução) são processadas na etapa de preparação de planos e comunicadas às áreas que necessitam destas programações. A partir destas informações, são geradas ações que possibilitam o cumprimento das metas definidas nesta programação. São então coletadas novamente informações sobre o sistema controlado, com objetivo de se identificar os desvios das metas e suas causas. Mais uma vez as informações são processadas, os planos revisados e novamente comunicados às áreas.

Com o objetivo de organizar diversas ferramentas e processos que auxiliam a melhor gestão de prazos, alguns autores organizaram métodos estruturados para que o processo de planejamento de obras seja implantado em cada empreendimento.

Tais modelos são baseadas em filosofias gerenciais ou experiências que os autores apresentam sobre o tema.

Figura 38 - Etapas do ciclo de planejamento

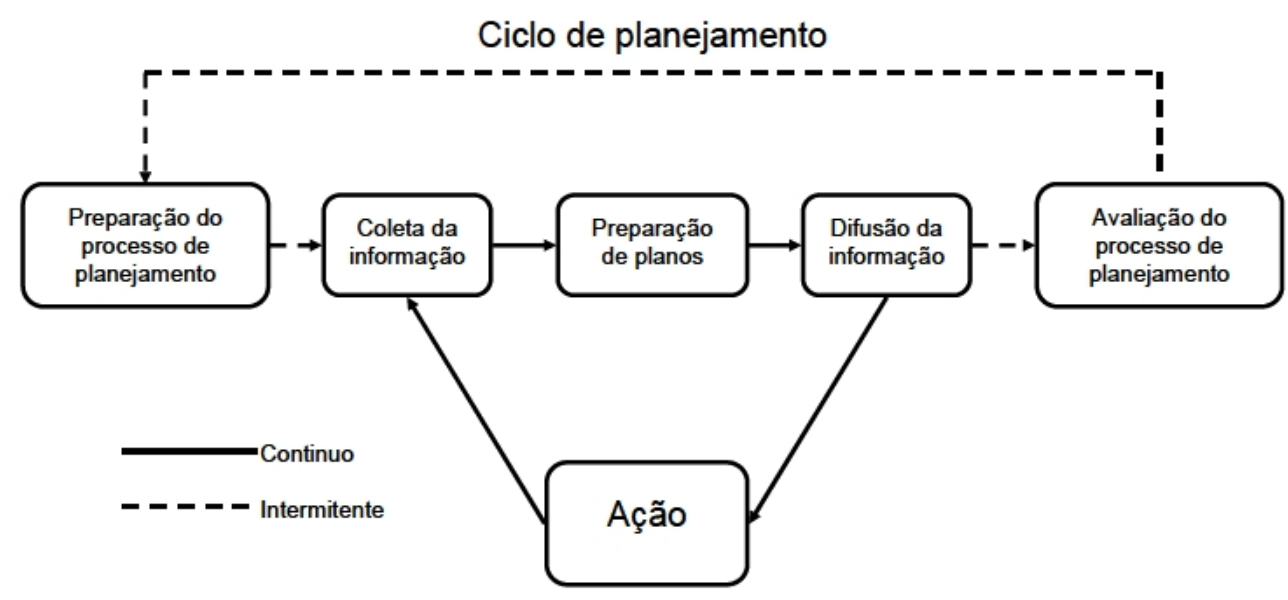

Fonte: Laufer e Tucker (1987)

\subsubsection{Sistemas de planejamento tradicional}

Antes de se conceituar sistemas diferenciados de planejamento, destacam-se alguns julgados como tradicionais por inúmeros autores. 
No chamado planejamento tradicional, a base do processo é a interligação entre atividades relativamente estanques. Nestes modelos, o planejamento é desenvolvido de uma forma onde as programações serão executadas exatamente da forma como foram previstas. As variações são tratadas pela gerência da obra como inconsistências na execução da programação, em geral utilizando-se de mais recursos para garantir que sejam recuperadas.

Assumpção (1996), por exemplo organizou academicamente processos e ferramentas de planejamento tradicionais até aquele momento utilizados em construtoras do mercado imobiliário. Este modelo, segundo o autor, seria inovador por apresentar como resultado, procedimentos de planejamento aliado a estrutura diferenciada para uso de técnicas de programação e de sistemas de aplicativos abertos.

Figura 39 - Modelo básico de Planejamento

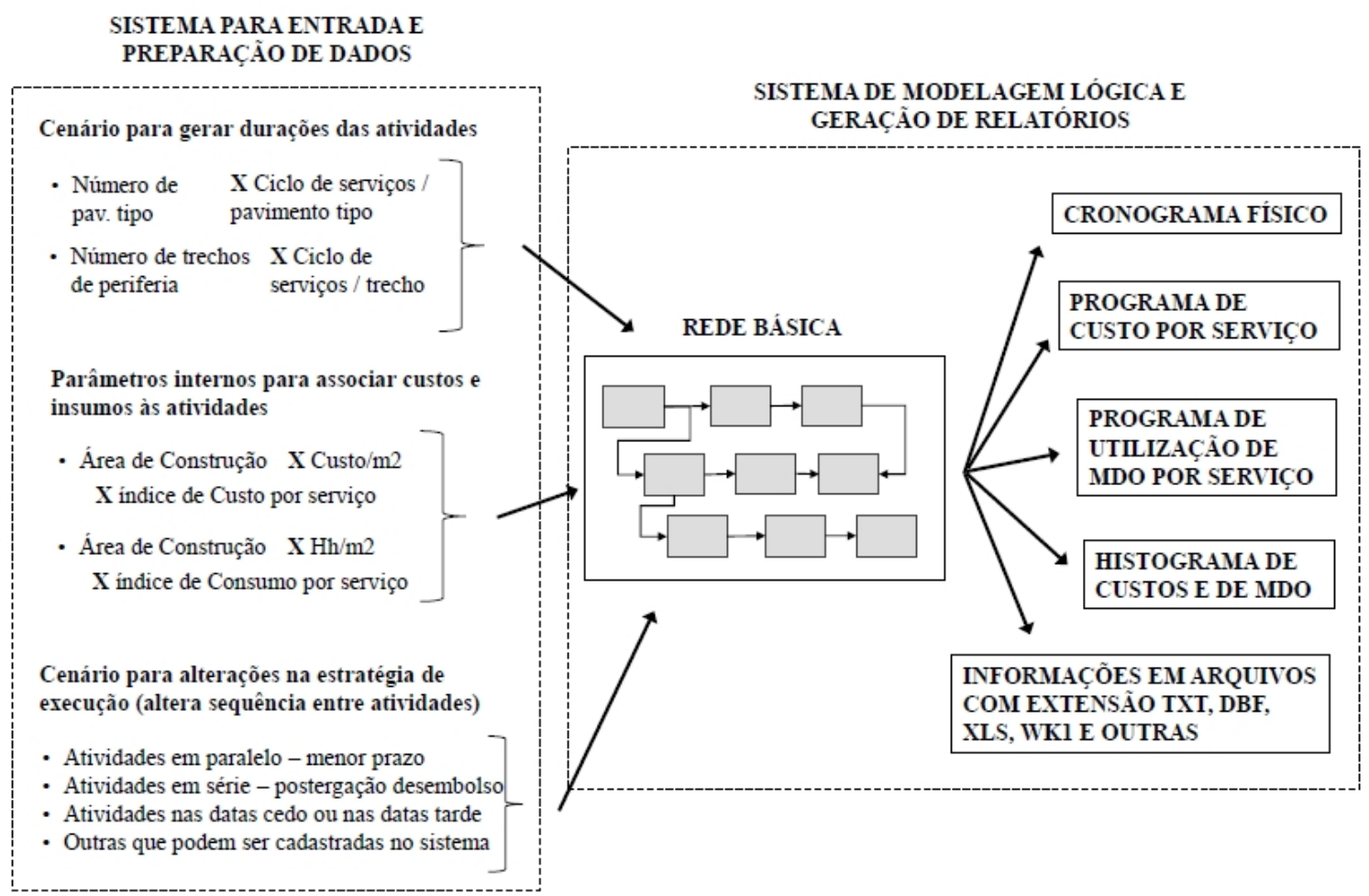

Fonte: Assumpção (1996)

O modelo seria formado por dois sistemas complementares (conforme pode ser observado na figura 39):

- Sistema para entrada e preparação de dados: este sistema seria composto primeiramente de: (i) um cenário para gerar durações das atividades 
(estimando-se ciclos de serviços por pavimento tipo, mais ciclos de serviço por trecho de periferia); (ii) de parâmetros internos para a definição de custos (baseados em índices paramétricos por área de construção; e de (iii) um cenário para alterações na estratégia de execução (possibilidades diferentes de alocação de equipes e desembolsos);

- Sistema de modelagem lógica e geração de relatórios: composto de uma rede básica estruturada com as atividades para a execução da obra e as saídas deste sistema, que seriam as ferramentas de gestão de prazos (cronogramas, histogramas, curvas de agregação de recursos, informações dos monitoramentos, dentre outras).

Para Assumpção (1996), as principais dificuldades encontradas na implantação deste modelo seriam a falta de padronização e de critérios para a obtenção dos indicadores, sendo mais impactante o controle dos indicadores de custos. Uma vez que a presente pesquisa foca a gestão dos prazos, este modelo é totalmente aderente como referência para a estruturação de uma metodologia complementar, objetivo do trabalho.

Na mesma época, Limmer (1996) estabelecia uma metodologia para planejamento de empreendimentos de construção baseada em nos seguintes passos:

- Identificar as atividades a serem executadas através da análise dos elementos e informação disponíveis, como projetos e especificações;

- Ordenar as atividades identificadas em uma sequência lógica em função de metodologia e processo de execução definidos para o projeto;

- Estabelecer macros e objetivo;

- Determinar a duração de cada atividade;

- Determinar o prazo de execução do projeto;

- Alocar e nivelar recursos de mão-de-obra, materiais e equipamentos e reavaliar o prazo de execução do projeto;

- Determinar a estimativa básica de custo do projeto;

- Determinar o sistema de controle do projeto. 


\subsubsection{Location-Based Management System}

O LBMS é uma técnica de planejamento e controle da produção que utiliza em sua essência o método de LOB, mas como foco mais amplo e direcionado ao processo de controle.

O sistema procura incluir aspectos importantes como o fluxo de trabalho contínuo e as restrições de locais, e detalhando premissas de planejamento como taxas de produção, quantidades e consumo de recursos em locais específicos para estimar as durações das atividades.

Segundo Kenley e Seppänen (2009), cada tarefa é definida e pertence a um nível hierárquico relacionado à subdivisão do local de trabalho (location breakdown structure), tais como apartamento, pavimento, casa, trecho, dentre outros. E para cada tarefa devem ser estabelecidas as seguintes informações:

- Dados de produção padronizada: taxas de consumo padrão para equipes de ideais e recursos (fornecem um padrão para o processo de planejamento de recursos);

- Requisitos de recursos previstos e reais: demandas de recursos planejado e consumo de recurso real para a tarefa);

- Equipes de trabalho: composição e o número de equipes de trabalho para o desempenho planejado e real do trabalho (equipes de trabalho agregam os recursos para uma determinada tarefa e estes podem estar inclusive restritos à determinada equipe);

- Restrições lógicas: relação lógica e sequencial no projeto (pode ser uma rede CPM, por exemplo);

- Pré-requisitos para a produção: quaisquer pré-requisitos para que se inicie a tarefa (materiais, equipamentos, atividades predecessoras) e que serão então parte do método de controle da tarefa;

- Desempenho e previsões: desempenho real da atividade é registrado e pode ser usado para estimar o desempenho futuro da mesma atividade.

Conforme descreve Olivieri et al. (2016), o LBMS é um sistema que adiciona linhas de fluxo aos cronogramas de Gantt, melhorando a visualização dos cronogramas. A 
figura 40 mostra um exemplo de cronograma LBMS para as atividades de vedações, comparando as datas previstas, realizadas e projetadas para cada atividade e local, e apontando alarmes para os principais desvios detectados.

Figura 40 - Modelo de Cronograma LBMS

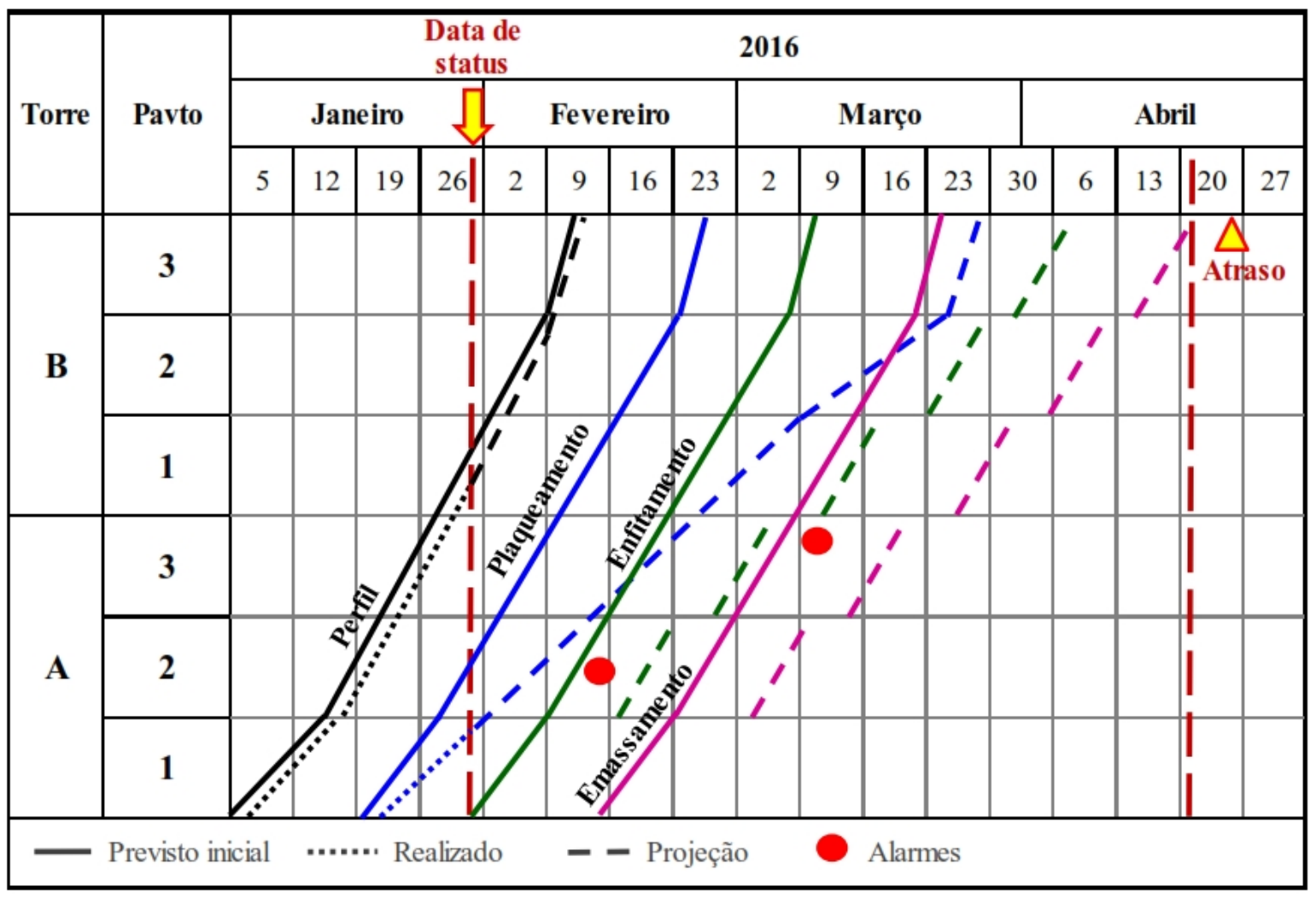

Fonte: Olivieri et al. (2016)

Verifica-se que nesta representação, as restrições lógicas não são explícitas no gráfico, nem informações relativas aos recursos e equipes. Mas todas estas relações são utilizadas na programação e o no gerenciamento das atividades. Elas impactam diretamente nas projeções dos serviços posteriores, bem como na identificação dos pontos de atenção (alarmes).

As restrições são estabelecidas através de conexões entre as principais atividades, sejam estas relacionadas a questões físicas dos locais, disponibilidade de recursos ou ao próprio sequenciamento natural, o que define os caminhos críticos.

A figura 41, apresentada por Kenley e Seppänen (2009), ilustra o impacto da diminuição do ritmo de produção de uma atividade instável (atividade 3) e como isto impactou na reprogramação da atividade sucessora (atividade 4). 
Figura 41 - Linhas de fluxo balanceadas, impactadas por instabilidades de atividade

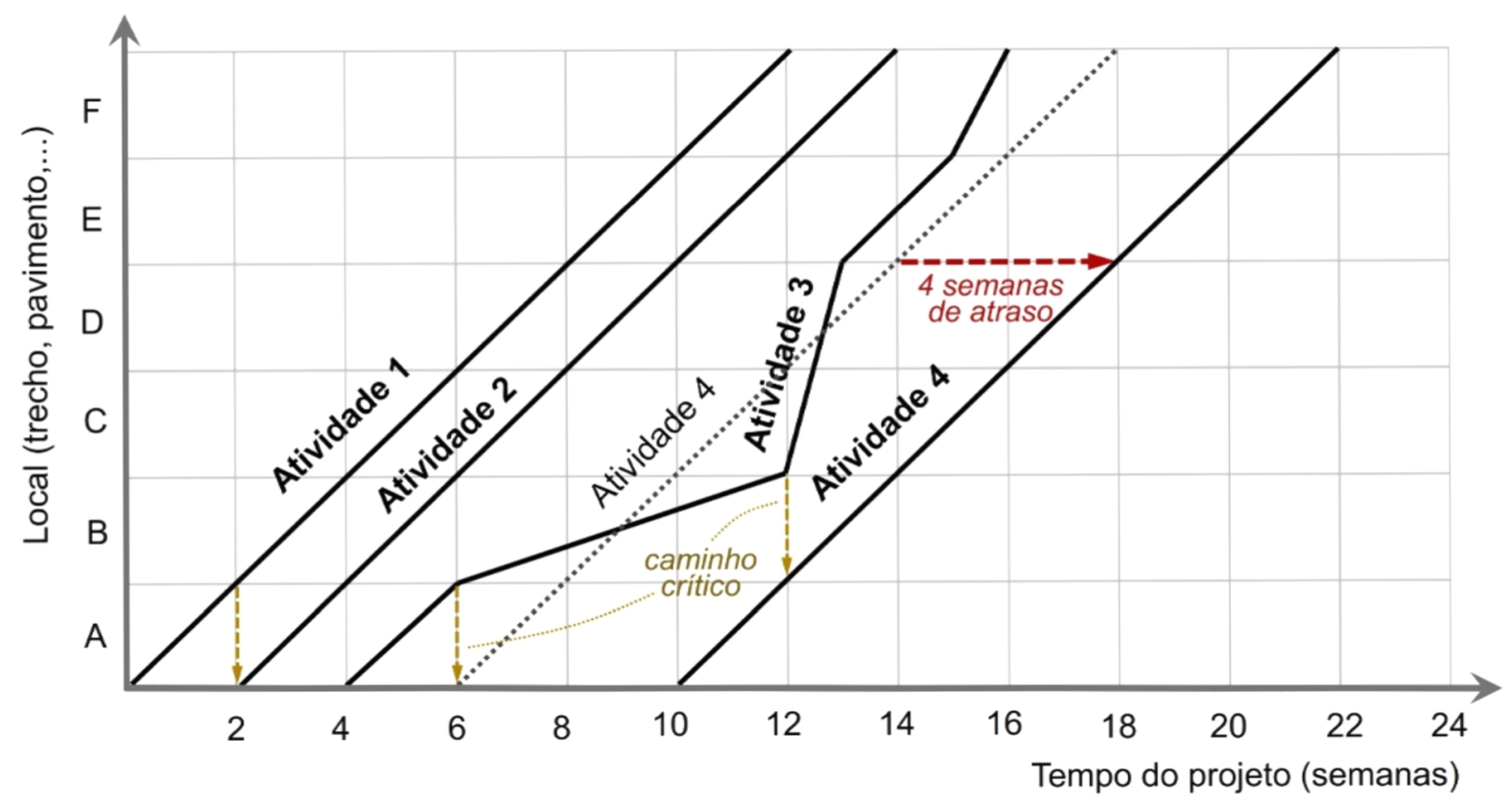

Fonte: Adaptada de Kenley e Seppänen (2009)

Como descrito anteriormente, existem restrições não identificadas em um gráfico de LBMS, e quando estas conexões representam o caminho crítico do projeto, acabam direcionando novas condições de reprogramação, como destacado de forma complementar na própria figura.

A principal contribuição do LBMS é a utilização do conceito de LB, que é a principal ferramenta para programação baseada em local (location-based scheduling), comum para atividades com ciclos repetitivos, combinando os algoritmos de redes (em especial o CPM), além dos controles de quantidades por unidade em cada local estabelecido na programação.

\subsubsection{Lean Construction}

Alguns autores com filosofias baseadas no Sistema Toyota de produção, por exemplo, defendem a chamada Lean Construction. Esta filosofia de abordagem do processo produtivo envolve o chamado pensamento "enxuto", ou seja, produtivo, sem desperdícios ou Lean Thinking. Adaptado para o mercado da construção civil, é chamado então de Lean Construction. 
O pensamento enxuto é baseado nas ideias utilizadas por Ohno (1997), onde as estratégias de produção eram definidas em função das demandas a jusante na cadeia produtiva, dentro de um plano de trabalho que garantia o ritmo planejado ao longo de todo o processo produtivo, evitando desperdícios.

De acordo com o autor, os desperdícios que precisam ser combatidos no processo produtivo são:

- Desperdício de superprodução;

- Desperdício de tempo disponível (espera);

- Desperdício em transporte;

- Desperdício do processamento em si;

- Desperdício de estoque disponível (estoque);

- Desperdício de movimentos;

- Desperdício de produzir produtos defeituosos (retrabalho).

Ohno (1997) descreve que a eliminação destes desperdícios aumenta a eficiência de operação por uma ampla margem, o que foi vital para o sucesso do Sistema Toyota de Produção.

Conte (2002) por sua vez, lembra que o foco do Lean Construction é a busca de um fluxo contínuo de produção com a adoção de políticas de monitoramento de cada etapa desses processos visando a redução de estoques de insumos.

Segundo Formoso (2002), a diferença básica entre a filosofia gerencial tradicional e a filosofia envolvida no Lean Construction é principalmente conceitual.

O modelo conceitual dominante na construção civil define a produção como um conjunto de atividades de conversão, que transformam os insumos (materiais, informação) em produtos intermediários (por exemplo, alvenaria, estrutura, revestimentos) ou final (edificação).

Utilizando-se a filosofia do "pensamento enxuto", por sua vez, buscam-se os chamados ciclos controlados, baseados na estabilidade e previsibilidade. Existe a premissa de que independente do grau de detalhamento e estudos envolvidos no 
planejamento, variações irão ocorrer. Desta forma, é importante criar sistemas para identificar e possibilitar ações corretivas rapidamente. Cada variação precisa ter sua causa identificada para possibilitar a ação.

O Lean Construction é baseado, segundo Formoso (2002), resumidamente, nos seguintes princípios:

- Reduzir a parcela de atividades que não agregam valor;

- Aumentar o valor do produto ou do serviço a partir das considerações dos clientes externos e internos;

- Reduzir a variabilidade do processo;

- Reduzir o tempo de ciclo;

- Minimizar o número de passos e partes;

- Aumentar a flexibilidade de saída;

- Aumentar a transparência do processo;

- Focar o controle no processo global;

- Introduzir melhorias contínuas no processo;

- Equilibrar melhorias de fluxo e conversão;

- Utilização de benchmarking para a melhoria dos processos.

O primeiro autor a trazer a filosofia do pensamento enxuto para o setor foi Koskela (1992), que descreve a aplicação destes conceitos em processos de produção na construção civil. O autor descreve que esta nova filosofia origina-se de experiências do sistema de produção Just In Time (JIT) e controle de qualidade no Japão na década de 1950. Independente dos termos que foram sendo utilizados nos diversos setores e épocas (produção enxuta, novo sistema de produção, JIT, TQC, dentre outros), esta filosofia apresentou um impacto profundo em indústrias como na fabricação de automóveis e produtos eletrônicos.

Koskela (1992) traz três conceitos importantes para o entendimento do Lean Construction: (i) atividades de "conversão"; (ii) atividades de "fluxo"; e o conceito de "agregar valor" às atividades. Se o modelo da conversão está vinculado à transformação de matérias primas em produtos (saídas), o modelo de fluxo agrega a 
este conceito as atividades de espera, inspeção e movimentação entre as diferentes conversões. Enquanto todas as atividades consomem tempo e geram custos, apenas as atividades de conversão agregam valor ao insumo que está sendo transformado em um produto.

Assim, a melhoria das atividades de fluxo deve focar em reduzir ou eliminar atividades que não agregam valor, e as atividades de conversão devem ser feitas da forma mais eficiente possível.

Esta filosofia acaba então trazendo ideias, que de certa forma podem parecer divergentes dos métodos gerenciais convencionais, como o método sequencial de realização do projeto ou o método de rede CPM. Segundo os autores que defendem esta filosofia, modelos que utilizam o CPM deterioram os fluxos por violar os princípios do desenho de processos de fluxo e melhoria. Como consequência, não há desperdício considerável na indústria da construção.

Segundo Formoso (2002), no controle do projeto, o foco acaba sendo o combate diário dos problemas (apagar incêndio), consumindo recursos e há pouco espaço para o adequado planejamento e controle global do processo.

O trabalho de Koskela (1992) ressaltava a importância dos fluxos nos processos produtivos, além dos aspectos ligados à conversão de insumos em produtos acabados, como importante etapa para a redução do desperdício de valor em canteiros de obra.

Ballard (2000) é um dos autores que se destacam na interpretação dos conceitos do Lean Construction e como eles se aplicavam nos processos de planejamento de obras. Segundo o autor, esta filosofia foi baseada em conceitos da indústria seriada e para que tenha êxito em projetos de construção, precisa ser adaptada à realidade deste mercado.

No processo industrial tradicional, por exemplo, a fábrica é estruturada com arranjos físicos fixos, buscando-se alguma forma de controle central, com a existência de um único tomador de decisão e vários executores. Na indústria da construção, os empreendimentos são considerados como sistemas de produção temporários e com ambiente de produção dinâmico, no qual a distância física existente entre um possível 
centro de controle e o local onde se executam os serviços, usualmente inviabiliza um controle central da produção.

Além disso, o autor destaca a dificuldade de implantação de ciclos de avaliação intermediários, uma vez que o produto de um projeto de construção é único, com considerável variabilidade em sua produção.

A premissa de que não existem ciclos rotineiros em projetos resulta em sistemas de planejamento que se restringem a estabelecer um plano de produção e gerar informações que possibilitem a detecção e correção de problemas. Ele auxilia a identificação de qual setor ou etapa do processo produtivo necessita ser tratado para que o plano volte a ser executado adequadamente. Assim, no processo de controle de empreendimentos, a comparação com o planejado é o único passo do sistema de controle.

Já no processo de controle industrial, segundo Ballard (2000), a comparação do executado com o planejado é somente o passo inicial do processo. Depois de coletados, os dados obtidos a partir desta comparação são retroalimentados, possibilitando a correção imediata de eventuais desvios. Geralmente os processos de planejamento nestes ambientes empregam sistemas de produção puxados, na qual o propósito do controle é causar os eventos conforme o planejado.

Todos estes conceitos já eram discutidos anteriormente pelo autor e outros pesquisadores ligados ao estudo do Lean Construction.

Figura 42 - Implementação da estratégia de estabilização de fluxo de produção

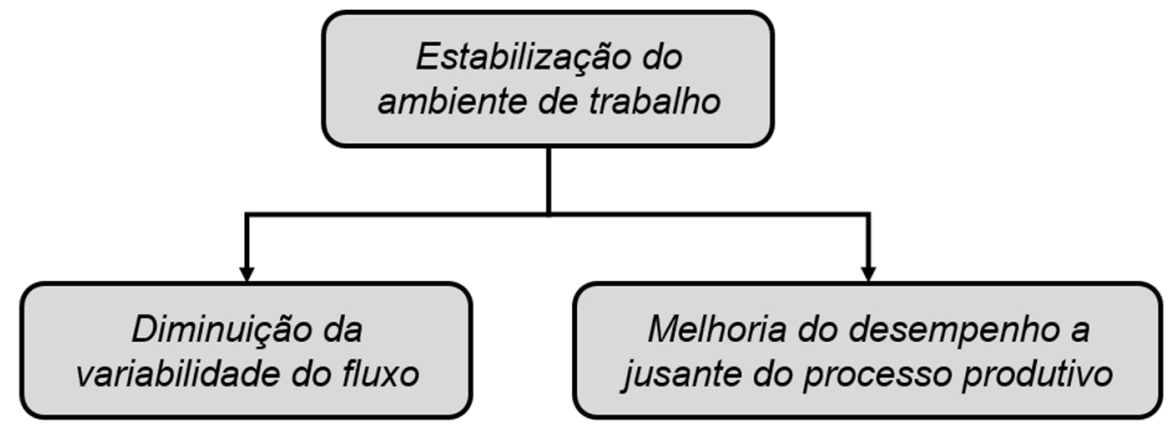

Fonte: Howell e Ballard (1994a)

Alguns trabalhos publicados por Howell e Ballard (1994a, 1994b e 1994c), apresentavam a necessidade de estabilização dos serviços no determinado ambiente 
de trabalho e em seguida ações de diminuição da variabilidade do fluxo e melhoria do desempenho a jusante do processo produtivo, conforme ilustra a figura 42 , o que mais tarde ajudaria na estruturação e definição do sistema Last Planner.

Os autores demonstraram que a utilização de procedimentos formais e flexíveis de planejamento da produção devem ser o passo inicial para a estabilização do ambiente produtivo, destacando-se três conceitos como ferramentas de uso imediato em qualquer canteiro de obras: (a) programações de curto prazo (diárias, semanais);(b) sistemas que possibilitem análises de restrições para se cumprir estas programações; e (c) o uso de índices de desempenho destas programações, com destaque para o indicador de Percent Plan Complete (PPC), que nada mais é do que número de atividades planejadas que foram concluídas dividido pelo número total de atividades planejadas.

Alguns autores apresentam alguns modelos de ferramentas com estas características. Formoso el al. (2001), por exemplo, ilustram uma planilha para análise de restrições de tarefas (figura 43) e outra, bem simples, que ilustra o detalhamento da produção de custo prazo (figura 44).

Figura 43 - Exemplo de planilha de análise de restrições

\begin{tabular}{|c|c|c|c|c|c|c|c|c|}
\hline \multicolumn{9}{|c|}{ PLANILHA PARA ANÁLISE DE RESTRIÇõES DAS TAREFAS } \\
\hline Obra: & \multicolumn{2}{|c|}{$\begin{array}{l}\text { Período: } 11 / 08 \text { - } \\
\text { 07/09/2000 }\end{array}$} & \multicolumn{6}{|c|}{ Responsável: } \\
\hline \multirow[t]{2}{*}{ Tarefa } & \multirow[t]{2}{*}{ Equipe } & \multirow{2}{*}{$\begin{array}{l}\text { Data de } \\
\text { início da } \\
\text { execução }\end{array}$} & \multirow{2}{*}{$\begin{array}{l}\text { Data limite } \\
\text { p/ remoção } \\
\text { da restrição }\end{array}$} & \multicolumn{5}{|c|}{ Restrições } \\
\hline & & & & Projeto & Material & Espaço & $\begin{array}{c}\text { Mão de } \\
\text { obra }\end{array}$ & Equipam. \\
\hline $\begin{array}{l}\text { 1. Marcação da } \\
\text { alvenaria - casas } 1 \text { a } \\
10\end{array}$ & A & $11 / 08$ & $04 / 08$ & $\begin{array}{l}\text { Paginação } \\
\text { da } \\
\text { alvenaria }\end{array}$ & & & & \\
\hline $\begin{array}{l}\text { 2. Elevação da } \\
\text { alvenaria - casas } 1 \text { a } \\
10\end{array}$ & B & $18 / 08$ & $08 / 08$ & & $\begin{array}{l}10.000 \\
\text { Tijolos de } 8 \\
\text { furos }\end{array}$ & \begin{tabular}{|l} 
Preparar \\
local de \\
descarga
\end{tabular} & & \\
\hline $\begin{array}{l}\text { 3. Colocação de contra } \\
\text { marcos - casas } 1 \text { a } 10\end{array}$ & $\mathrm{C}$ & $25 / 08$ & $12 / 08$ & & $\begin{array}{l}\text { Preparar os } \\
\text { contra } \\
\text { marcos pré } \\
\text { moldados }\end{array}$ & & & \\
\hline $\begin{array}{l}\text { 4. Execução de contra- } \\
\text { piso - casas } 1 \text { - } 10\end{array}$ & $\bar{D}$ & $01 / 09$ & $20 / 08$ & & & & $\begin{array}{l}\text { Contratar } \\
\text { mão de } \\
\text { obra }\end{array}$ & \\
\hline
\end{tabular}

Fonte: Formoso et al. (2001) 
Figura 44 - Exemplo de planilha de planejamento semanal

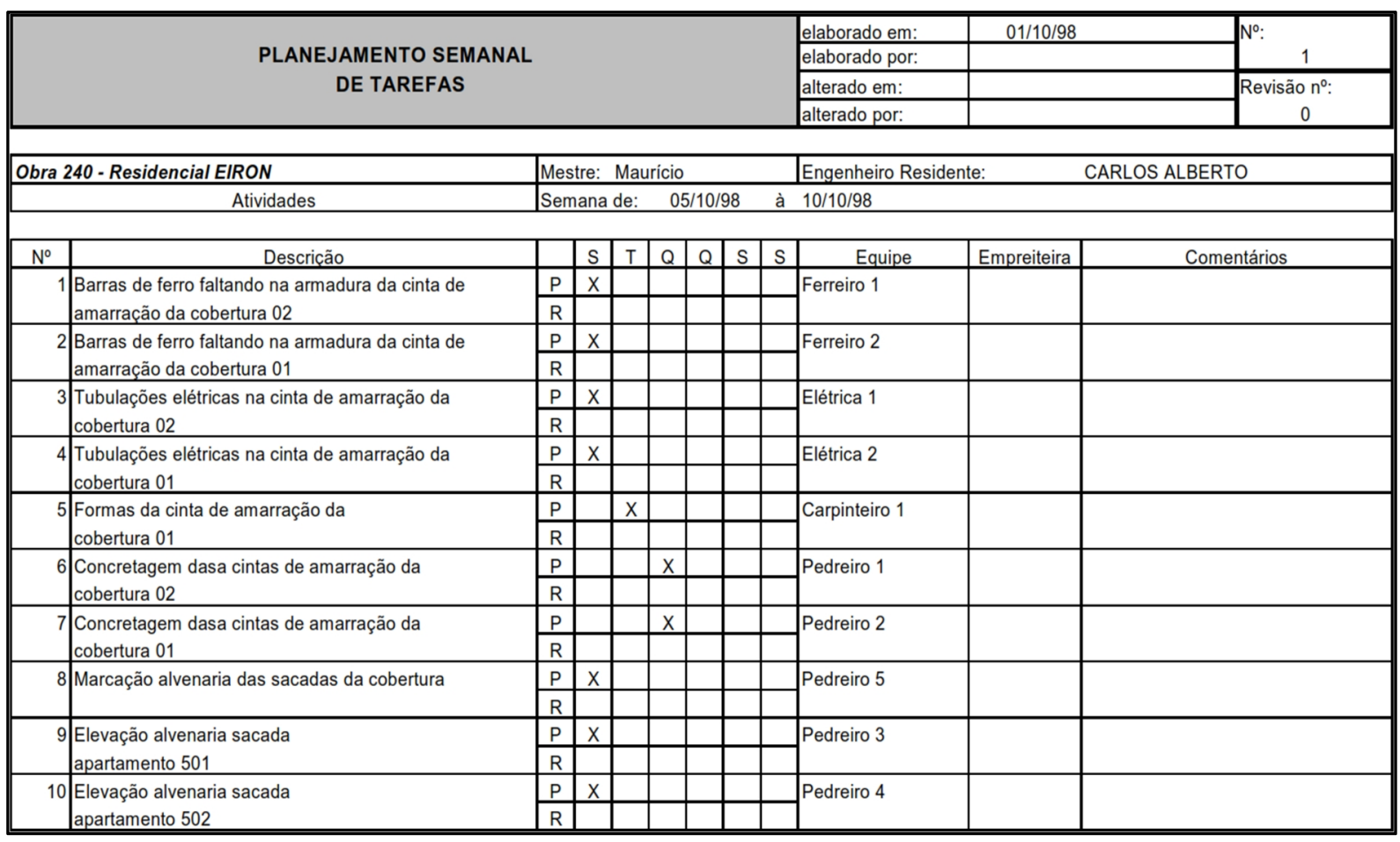

Fonte: Formoso et al. (2001)

Soares (2003), por sua vez, apresenta um modelo de planilha de planejamento semanal, já com o cálculo do PPC integrado (figura 45), o que é uma prática comum em formulários para este tipo de programação.

Figura 45 - Exemplo de planilha de planejamento semanal com cálculo de PPC

\begin{tabular}{|c|c|c|c|c|c|c|c|c|c|c|c|c|}
\hline & $\begin{array}{c}\text { PLANEJAMENTO SEMANAL } \\
\text { PLANEJAMENTO } \\
\text { X EXECUÇÃO }\end{array}$ & & $\begin{array}{l}\text { Obr } \\
\text { Eng } \\
\text { Mes }\end{array}$ & $\begin{array}{l}\text { a: M } \\
\text { enhe } \\
\text { tre: }\end{array}$ & $\begin{array}{l}\text { tove } \\
\text { ro: } \\
\text { osé }\end{array}$ & lo & & & $\mathrm{PC}=$ & $2 / 3=6$ & $67 \%$ & $\begin{array}{l}\text { Semana: } 8 \\
\text { Data: } 10 / 05\end{array}$ \\
\hline \multirow[t]{2}{*}{ Equipe } & \multirow{2}{*}{\multicolumn{2}{|c|}{ Pacote de trabalho }} & $\mathrm{S}$ & $\mathrm{T}$ & Q & $\mathrm{Q}$ & $\mathrm{S}$ & $\mathrm{S}$ & $\mathrm{S}$ & $\mathrm{D}$ & \multirow[t]{2}{*}{$\%$} & \multirow[t]{2}{*}{ Problemas } \\
\hline & & & 22 & 23 & 24 & 25 & 26 & 27 & 29 & 30 & & \\
\hline \multirow[t]{2}{*}{ José } & \multirow[t]{2}{*}{ Montagem fôrmas vigas refeitório } & $\mathrm{P}$ & 5 & 5 & 5 & & & & & & \multirow{2}{*}{100} & \multirow[t]{2}{*}{-} \\
\hline & & $\bar{E}$ & 4 & 4 & 4 & 4 & & & & & & \\
\hline \multirow[t]{3}{*}{ Mário } & \multirow[t]{3}{*}{ Colocação de azulejo sala de lavagem } & $\mathrm{P}$ & & 3 & 3 & 3 & & & & & \multirow{3}{*}{100} & \multirow[t]{3}{*}{-} \\
\hline & & $\mathrm{E}$ & & 2 & 3 & 3 & 3 & & & & & \\
\hline & & $\mathrm{E}$ & & & & & & & & & & \\
\hline \multirow[t]{2}{*}{ João } & \multirow{2}{*}{$\begin{array}{l}\text { Execução de alvenaria de blocos do } \\
\text { sanitário sala } 1\end{array}$} & $\mathrm{P}$ & & & & 3 & 3 & 3 & & & \multirow{2}{*}{0} & \multirow{5}{*}{$\begin{array}{l}\text { Faltou } \\
\text { material }\end{array}$} \\
\hline & & $\mathrm{E}$ & & & & & & & & & & \\
\hline \multicolumn{12}{|c|}{ Tarefas reservas } & \\
\hline \multirow[t]{2}{*}{ João } & \multirow{2}{*}{$\begin{array}{llll}\text { Reboco } & \text { paredes } & \text { divisórias } & \text { do } \\
\text { escritório } & & & \end{array}$} & $P$ & & & & 2 & & & & & \multirow[t]{2}{*}{-} & \\
\hline & & $\mathrm{E}$ & & & & - & & & & & & \\
\hline
\end{tabular}

Fonte: Soares (2003)

O cálculo do PPC é muito utilizado em empreendimentos que são gerenciados com base na filosofia do Lean Construction. Usualmente, este índice é calculado 
semanalmente para se verificar onde encontram-se os problemas da obra. Além disso, proporciona uma avaliação da qualidade dos planejamentos de curto prazo que são desenvolvidos no respectivo empreendimento.

A figura 46 ilustra uma avaliação do PPC ao longo de um período de execução de uma obra hipotética.

Figura 46 - Exemplo de uma análise de PPC de produção de uma obra

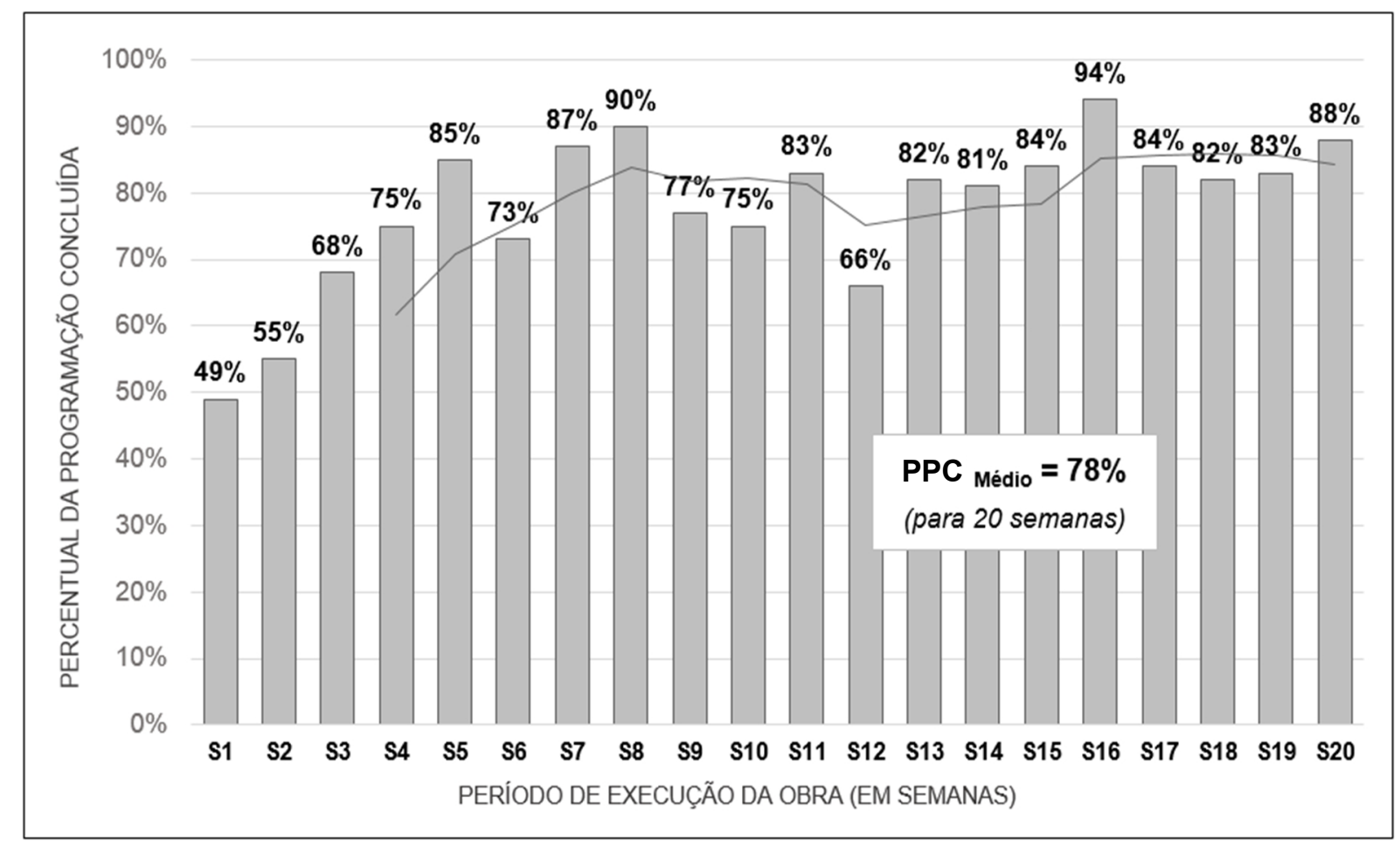

Fonte: O Autor

A coleta de dados ao longo da evolução do empreendimento proporciona o cálculo de outros índices, como o PPC médio da obra, muito usado pelos gestores de produção para comparação de desempenho de empreendimentos similares, ou como indicativo de melhoria de desempenho da obra após a implantação de algum novo processo ou ação gerencial importante. O PPC médio de uma obra hipotética também é representado na figura 46.

Conte (2002) destaca ainda que estes princípios de estabilização de fluxo, que baseados no Lean Construction, podem ser aplicados a qualquer tipo de produção na Construção Civil, independentemente da tecnologia de execução empregada. 
O autor descreve experiências particulares, que demonstram reduções médias de prazo entre $20 \%$ e $30 \%$ do prazo inicialmente previsto, e reduções do custo de produção entre $5 \%$ e $12 \%$ do valor total em obras totalmente diversas, tais como a construção de lojas do McDonald's ou templos de igreja, condomínios residenciais horizontais, prédios comerciais e residenciais e shopping centers.

\subsubsection{O sistema Last Planner}

Conforme já apresentado no Capitulo 3.3, dentro da estrutura de um planejamento, a programação estabelece metas e um sequenciamento de atividades para atingi-las. O controle, por sua vez, orienta com que as atividades sejam realizadas da forma como foram pensadas, pois desencadeia a necessidade de uma reprogramação quando se verifica que a sequência prevista não é mais viável, gerando um processo natural de aprendizagem.

Mas segundo Ballard (2000), devido a indústria da construção civil ter um ambiente dinâmico e um sistema de produção incerto e variável, um planejamento confiável e detalhado fica difícil de ser elaborado com muita antecedência e assim, é importante se verificar como melhorar os controles relacionados às programações de curto prazo, para que esta consigam atender ao que foi estabelecido no Plano Mestre.

Segundo o autor, após o planejamento do trabalho físico para o curto prazo (por exemplo, na semana seguinte) deve haver a comunicação das exigências do último planejador (last planner) para com a equipe de produção. Fazendo com que os produtos do planejamento ao nível da unidade de produção seja um compromisso de toda a organização.

O último planejador determina o que será executado. Assim, considera-se que as atividades produzidas como o resultado do planejamento devem procurar adaptar o que "será executado" com o que "deveria ser executado", verificando as restrições do que "pode ser executado", conforme apresentado na figura 47.

Desta forma, buscando desenvolver um novo sistema de controle que se adaptasse melhor as características da construção civil e ao conceito do último planejador, Glenn Ballard e Gregory Howell desenvolveram o chamado Last Planner System (LPS). 
Figura 47 - Estrutura do processo Last Planner

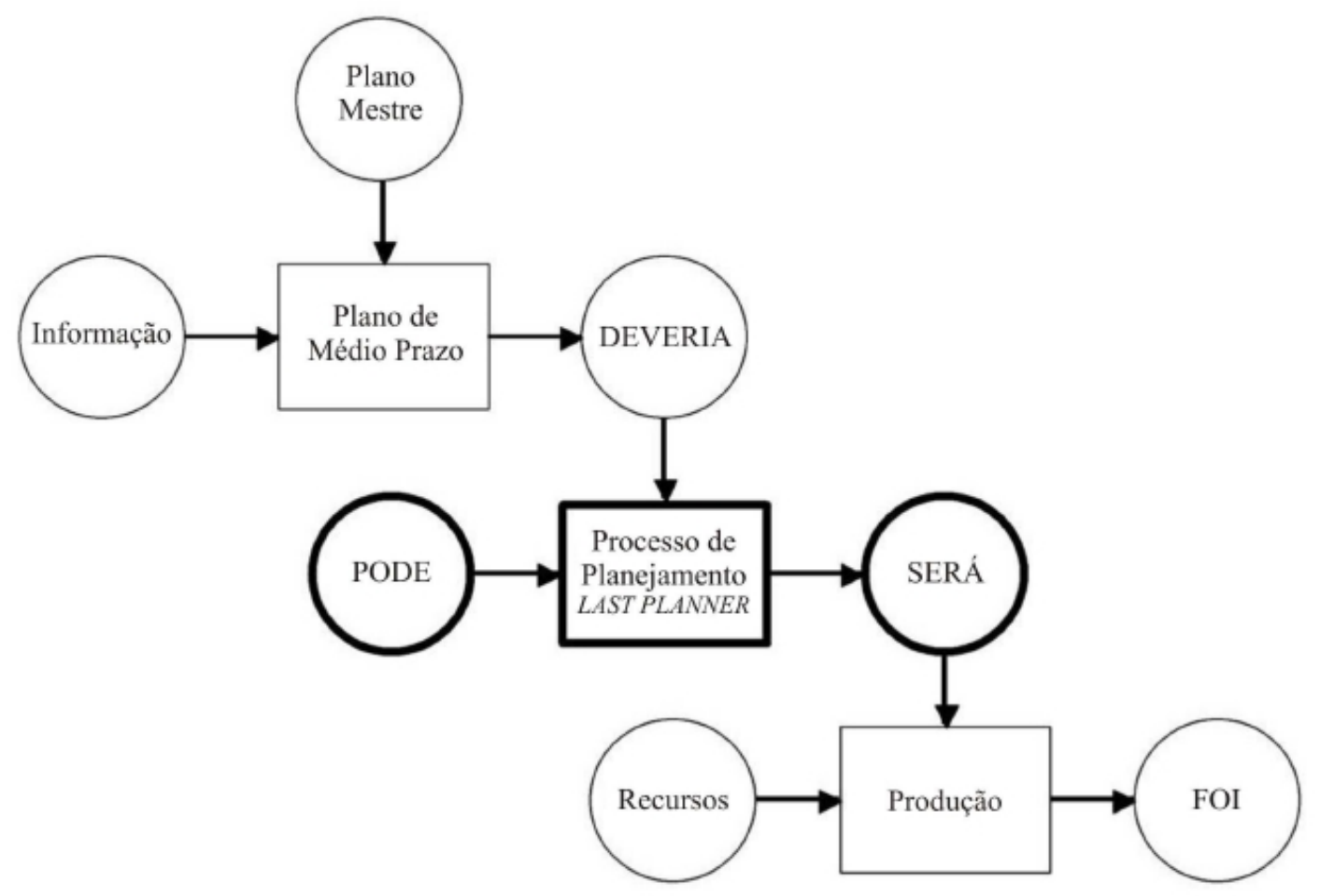

Fonte: Ballard (2000)

De acordo com Ballard (1997), o LPS engloba em seu escopo de execução não só ferramentas e técnicas de controle, mas também formas de planejamento que objetivam melhores condições de controle sobre o empreendimento. Este sistema integra novas funções aos níveis hierárquicos da equipe de Planejamento e Controle da Produção (PCP) objetivando a proteção da produção a partir do aumento da confiabilidade dos planos gerados.

Esta confiabilidade foi ilustrada com a apresentação do conceito de produção blindada (shielding production) ou produção protegida, descrita no artigo de Ballard e Howell (1997).

Segundo os autores, o processo de blindagem começa com identificação dos serviços a serem executados no médio prazo e a elaboração do respectivo cronograma (Lookahead Schedule). Esta programação conduz ao processo de eliminação das restrições, onde se definem a atividades que precisam ser executadas para garantir que tudo esteja pronto para o início de cada serviço, bem como a alocação dos recursos necessários para garantir a melhor produtividade.

Um modelo de Lookahead Schedule é apresentado na figura 48. 
Figura 48 - Modelo 5 Week Lookahead Schedule conforme LPS

\begin{tabular}{|c|c|c|c|c|c|c|c|c|c|c|c|c|c|c|c|c|c|c|c|c|c|c|}
\hline \multirow[t]{3}{*}{ Projeto: Piloto } & \multicolumn{22}{|c|}{ Programação de 5 Semanas (Lookahead) } \\
\hline & \multicolumn{5}{|c|}{ Semana 2} & \multicolumn{5}{|c|}{ Semana 3} & \multicolumn{6}{|c|}{\begin{tabular}{l|l} 
Semana 4 & \\
\end{tabular}} & \multicolumn{5}{|c|}{ Semana 5} & \multirow{2}{*}{ Necessidades } \\
\hline & \begin{tabular}{l|l|}
$\mathbf{S}$ & $\mathbf{T}$ \\
\end{tabular} & $\mathbf{Q}$ & $\mathbf{Q}: \mathbf{S}$ & $\mathbf{s} \mathbf{s}$ & 5 & s. & $\mathrm{T}$ & $\mathbf{Q} \mathbf{Q}$ & s & $\mathbf{s}$ & $\mathbf{s}$ & $\mathbf{T}$ & $\mathbf{Q} \mathbf{C}$ & $\mathbf{Q} \mathbf{S}$ & s & $s$ & $T$ & c & 20 & $\begin{array}{ll}\mathrm{Q} & \mathrm{S} \\
\end{array}$ & $s$ & \\
\hline \multicolumn{23}{|c|}{ Equipe 1 (Líder: João) } \\
\hline Atividade A & & & & & & & & & & & & & & & & & & & & & & Entrega do Material em 10/08/13 \\
\hline Atividade $B$ & & & & & & & & & & & & & & & & & & & & & & Material no canteiro \\
\hline \multicolumn{23}{|c|}{ Equipe 2 (Líder: Carlos) } \\
\hline Atividade C & & & & & & & & & & & & & & & & & & & & & & Material no canteiro \\
\hline Atividade $D$ & & & & & & & & & & & & & & & & & & & & & & \begin{tabular}{|l|} 
Instalar o equipamento de apoio $3 e$ \\
receber material previsto para $08 / 08 / 13$
\end{tabular} \\
\hline Atividade $E$ & & & & & & & & & & & & & & & & & & & & & & Liberar material para aplicação \\
\hline \multicolumn{23}{|c|}{ Equipe 3 (Lider: Ricardo) } \\
\hline Atividade $F$ & & & & & & & & & & & & & & & & & & & & & & Liberar serviços de pintura \\
\hline Atividade $\mathrm{G}$ & & & & & & & & & & & & & & & & & & & & & & $\begin{array}{l}\text { Checar material disponivel; Finalizar } \\
\text { serviço B2 }\end{array}$ \\
\hline Atividade $H$ & & & & & & & & & & & & & & & & & & & & & & Fazer a solicitação do material \\
\hline
\end{tabular}

Fonte: Adaptado de Ballard (1997); Ballard (2000)

OBS: O planejamento de 5 semanas exclui a semana que está detalhada no planejamento semanal WWP.

A saída deste processo permite a organização das tarefas em períodos específicos, normalmente gerando um plano semanal de compromissos (Weekly Work Plan WWP). Os planos semanais são inspecionados em relação a sua para a solidez, dimensionamento e sequência antes de ser aprovados para produção.

Um modelo de Lookahead Schedule é apresentado na figura 49.

Figura 49 - Modelo de Weekly Work Plan conforme LPS

\begin{tabular}{|c|c|c|c|c|c|c|c|c|c|}
\hline \multicolumn{8}{|c|}{ Programação Semanal (Weekly Work Plan) } & \multicolumn{2}{|c|}{$\begin{array}{l}\text { Local: Setor } 5 \\
\text { Lider: Carlos } \\
\text { Data: _____ }\end{array}$} \\
\hline Atividade & Pré-Requisitos (restrições) & Seg & Ter & Qua & Qui & Sex & Sab & PPC & \begin{tabular}{|c|} 
Problema \\
(causa do desvio)
\end{tabular} \\
\hline Atividade $B$ & Material no canteiro & $\mid \begin{array}{l}X X X \\
\text { José }\end{array}$ & Eduarc & do, Alb & & & & $100 \%$ & \\
\hline Atividade $F$ & $\begin{array}{c}\text { Necessidade de novo } \\
\text { equipamento para o serviço }\end{array}$ & José & $\begin{array}{l}X X X \\
\text { Eduarc }\end{array}$ & $\begin{array}{l}X X X \\
\text { do, } R a\end{array}$ & & & & $100 \%$ & \\
\hline Atividade $\mathrm{J}$ & Liberação da frente 2 & $\begin{array}{l}X X X \\
\text { Carlos }\end{array}$ & $\begin{array}{l}X X X \\
\text { S, Anto }\end{array}$ & $\begin{array}{l}X X X \\
\text { onio, } A\end{array}$ & berto & & & $100 \%$ & \\
\hline Atividade Reserva & & & & & & & & & \\
\hline Atividade $X X$ & & & & & & & & & \\
\hline & & & & & & & & & \\
\hline
\end{tabular}

Fonte: Adaptado de Ballard (1997) 
Após a execução do plano e consumo dos recursos, verifica-se a quantidade de tarefas concluídas, calcula-se o PPC da semana e identificam-se os motivos pelos quais as demais tarefas não foram concluídas.

O conceito de produção protegida é ilustrado na figura 50.

Neste sistema, a principal função do planejador é ajustar a necessidade de cumprimento de cronogramas à capacidade de execução das equipes, baseado na situação atual do processo de produção.

Figura 50 - Representação do Shielding Production

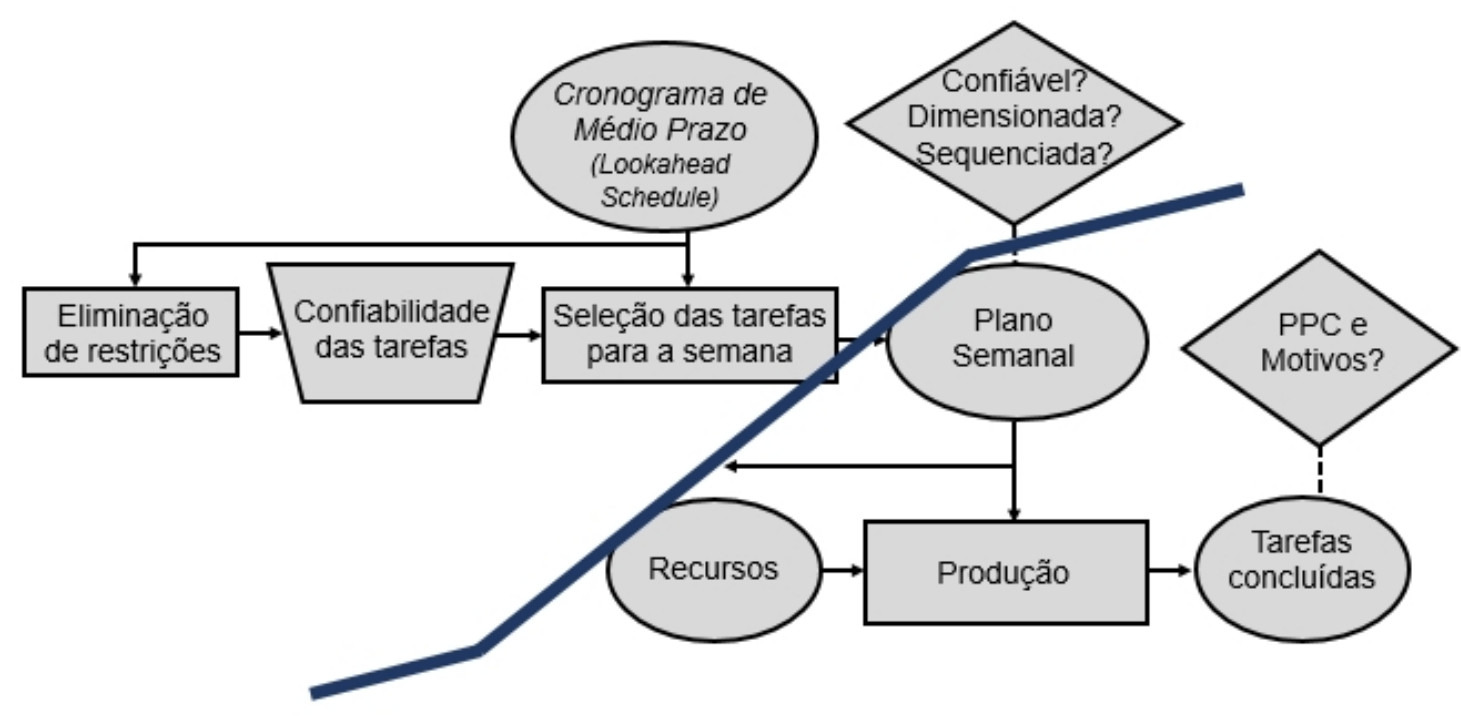

Fonte: Ballard e Howell (1997)

Conforme define Ballard (2000), o LPS é dividido em dois componentes principais: o controle da unidade de produção e o controle do fluxo de trabalho. O objetivo do primeiro é gerar, progressivamente, melhores planos, através da aprendizagem contínua e de ações corretivas. Normalmente, as funções deste componente são cumpridas pelo planejamento de curto prazo. O objetivo do segundo componente é gerar pró-ativamente o fluxo trabalho através das unidades de produção, na melhor sequência e custo possível, o que usualmente ocorre no planejamento de médio prazo. 


\subsubsection{Evolução do Last Planner}

Anos depois de estabelecerem o conceito do LPS, Ballard e Howell (2003) iniciaram uma avaliação mais detalhada dos resultados que este sistema alcançava em diversos países onde fora implantado.

Apesar de resultados notáveis, os autores identificaram que em muitos casos, o LPS foi interpretado como uma ferramenta de gerenciamento de projetos tradicional, e que desta forma talvez não obtivessem seus melhores resultados.

Um dos pontos relatados, por exemplo, refere-se à subdivisão do escopo do projeto, que utilizando-se as premissas do gerenciamento de projetos tradicional, como aquelas defendidas pelo PMI (2013), por exemplo, é realizado em pacotes de trabalho cada vez menores, até se chegar no nível da atividade. Esta subdivisão incentiva naturalmente a contratação, programação e controle dos serviços de forma segregada, limitando a visão de possíveis benefícios caso a analise fosse realizada através do melhor processo de produção.

Como estes conceitos são defendidos e adotados por grande parte dos gestores de projeto, os autores sugerem adaptações que consigam unir parte destas diretrizes e ganhos com a adoção do LPS.

Uma das diretrizes propostas estabelece que os cronogramas sejam expressos focando-se em processos ou fases e não pelo escopo de trabalho, sendo que o LPS seria uma ferramenta para orientar a produção em direção às metas de cronograma.

Esta visão é compartilhada por vários autores, como Hamzeh et al. (2012). Os autores, que neste trabalho discutem a dificuldade de algumas empresas na implantação do LPS e propõem procedimentos para a geração de planos de produção mais confiáveis, ilustram o LPS como um sistema onde a EAP ou WBS de um projeto são quebradas como se fossem rochas, tornando-se fragmentos cada vez maiores até que se chegue na tarefa ou operação (figura 51).

Segundo os autores, o LPS é dividido em quatro processos de planejamento com diferentes extensões cronológicas: o Plano Mestre, o Planejamento de Fases, a Programação Lookahead e a Programação Semanal. 
Figura 51 - Representação dos processos do LPS

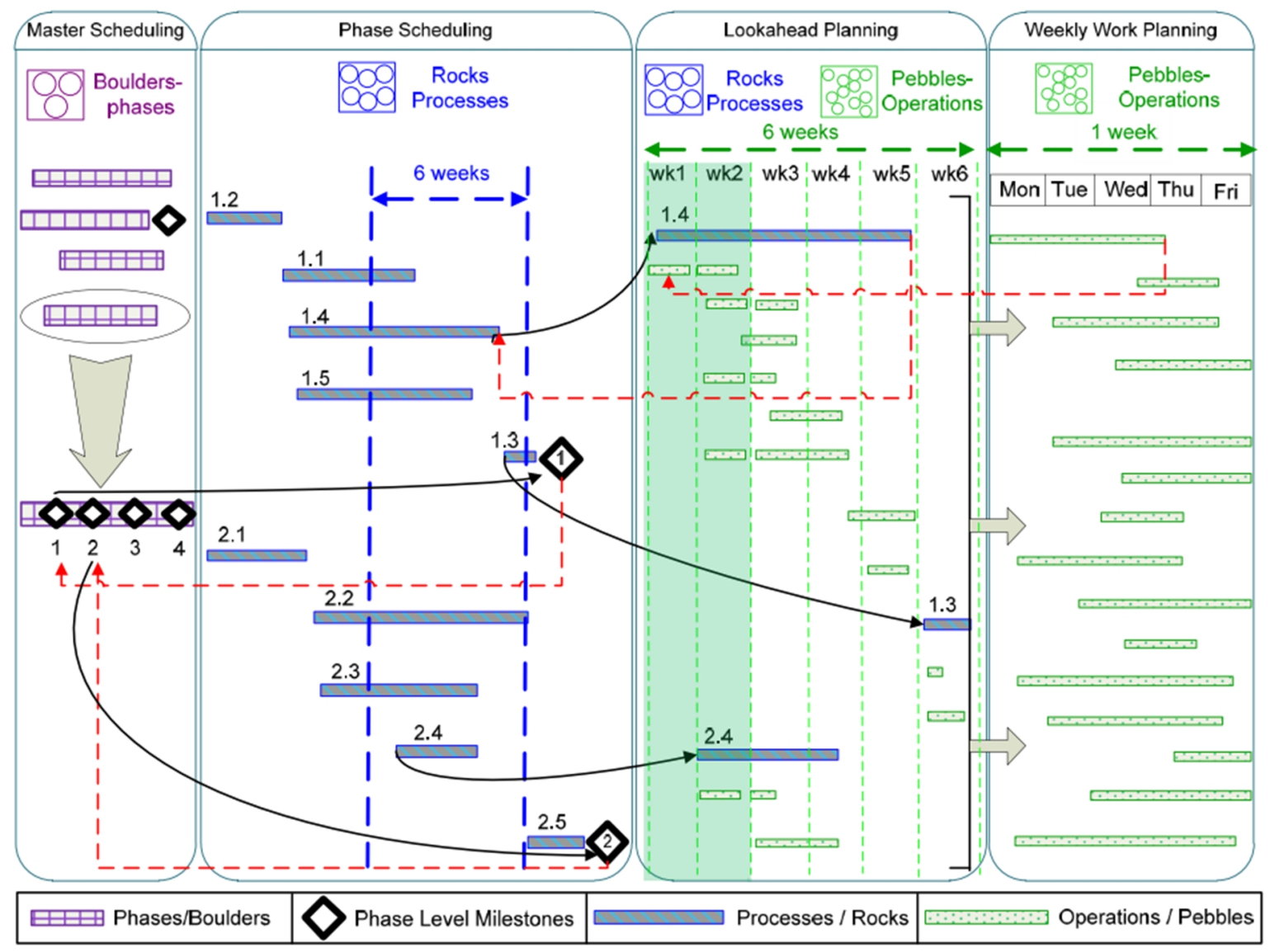

Fonte: Hamzeh et al. (2012)

Cada processo é detalhado nos tópicos a seguir:

- O Plano Mestre é um processo de planejamento macro que estabelece as fases mais abrangentes do projeto, que devem ser realizadas ao longo de toda a duração da obra. Como resultado obtêm-se neste processo as datas-marco mais importantes do projeto, que são utilizados em propostas comerciais ou documentos de contratação;

- O Planejamento de Fases gera cronogramas de cada fase identificada no Plano Mestre, tais como fundações, estrutura, vedação, acabamentos. Este planejamento precisa ser colaborativo e desta forma, recomenda-se a participação de especialistas ou das equipes que irão realizar as operações;

- A Programação Lookahead já é o primeiro passo no controle da produção e abrange, normalmente, um período de tempo seis semanas. Nesta fase, as atividades já são divididas nos níveis de operação, com suas restrições identificadas e atribuições de responsabilidades; 
- A Programação Semanal representa o plano mais detalhado no sistema e mostra a interdependência entre os diversos serviços e atividades. Deve ser estabelecido neste nível o comprometimento da realização de cada tarefa, e para proteger-se das incertezas, as atribuições são descritas de forma detalhada. No final de cada período do plano (semana), a confiabilidade do planejamento é checada, verifica-se o cumprimento das tarefas e as razões das falhas, buscando-se melhoria contínua.

Outro destaque no artigo de Ballard e Howell (2003) refere-se aos conceitos de planejamento puxado e estabilização do fluxo de produção.

No planejamento tradicional, busca-se sempre a data de término dos pacotes de trabalho. No sistema de fluxo estabilizado, estabelecendo-se as datas de início dos serviços e monitorando-se adequadamente o fluxo, as datas de término são consequências (não mais os objetivos principais das programações de produção).

Conte (2002) acrescenta ao conceito de estabilização dos fluxos o aspecto que tão importante quanto se planejar adequadamente a obra é ter-se flexibilidade para readequar este planejamento tendo em vista eventuais desvios observados durante a sequência diária de operações no canteiro de obras.

Nesta linha, Ballard e Howell (2003) complementam as novas diretrizes para o LPS, as quais englobam ações que garantam o envolvimento dos trabalhadores nas correções dos desvios na própria frente de trabalho, reuniões diárias para alinhar atribuições, reconhecimento de compromissos, a inclusão do componente "aprendizagem" e o uso do PPC de forma mais adequada.

Dentro deste último ponto, por exemplo, segundo a teoria original do LPS, os resultados práticos da utilização do LPS podem ser observados pela elevação do PPC para patamares próximos de $100 \%$, o que representaria uma maior confiabilidade nos processos de planejamento de curto prazo.

Conte (2002) acredita porém, que um PPC próximo de 100\% não garante que a obra esteja sendo executada dentro do prazo, custo e qualidade previstos. $\mathrm{O}$ autor descreve que é comum observar empreendimentos que apresentam PPC elevados, mas que acabam desviando-se de seus objetivos principais. Isto ocorre pelo fato de 
não existem informações que monitorem com precisão o quanto o empreendimento desviou de seus objetivos iniciais a cada período de controle, impedindo assim as equipes de produção de replanejarem suas atividades, buscando resgatar o que foi inicialmente planejado.

Essa situação favorece posturas gerenciais que focam somente a manutenção do prazo final de execução dos trabalhos, sacrificando muitas vezes o custo e a qualidade final do empreendimento.

Conte (2002), em trabalhos de Lean Construction realizados em mais de 20 construtoras brasileiras, no que diz respeito ao planejamento de prazos (há princípios para o controle de custos e insumos também em seu trabalho) procurou definir sua atuação dentro dos seguintes princípios básicos:

1. Planejamento da Produção visando a manutenção do ritmo dos trabalhos (picos de alta produtividade melhoram o desempenho de um serviço, mas nem sempre do empreendimento como um todo);

2. Utilização da técnica das Linhas de Balanço (LOB) para otimizar o estudo sobre o ritmo dos serviços a serem executados (identificação imediata de gargalos e buffers);

3. Desenvolvimento de um Desenho de Processo para cada pacote de serviços descrito nas LOB (com escopo, sequência diária, equipe, materiais, equipamentos, instantes de disponibilização, padrões de qualidade, desempenho esperado e cuidados de segurança do trabalho);

4. Utilização de um novo indicador de desempenho, baseado na LOB e nos Desenhos de Processo, representado pela projeção da data de término da obra, calculada a cada semana;

5. Utilização da técnica do LPS para o acompanhamento semanal dos trabalhos, focando-se a análise de restrições (essencialmente restrições de compra e contratação, e restrições de alocação e disponibilização de materiais, equipamentos, ferramentas e mão de obra);

6. Análise semanal do PPC, permitindo identificar as causas de quebra no ritmo observadas nos trabalhos e contribuindo para o aprendizado sistemático na obra; 
7. Reavaliação semanal das estratégias de ataque, após a análise das Datas de Término Projetadas e do nível de estabilização dos processos produtivos (PPC global da obra e de cada subcontratado) alterando, se necessário, a lógica de execução dos serviços a jusante da seguinte forma: (a) inserindo ou removendo recursos no Pacote de Serviços, (b) modificando as relações de precedência entre os serviços, viabilizando a superposição de atividades e reduzindo o prazo global de execução; e (c) reorganizando as atividades de diferentes Pacotes de Serviço para viabilizar um número menor de ciclos de produção simultâneos.

\subsubsection{Modelos integrados}

Alguns autores mais recentes, estudando os principais modelos e sistemas, sobretudo aqueles citados nos capítulos anteriores, buscaram estabelecer modelos integrados, que se utilizavam das principais premissas e ferramentas de cada um dos modelos.

Desta forma, independente das premissas definidas por cada modelo conceitual, muitas vezes mais filosófico do que prático, estes autores buscaram atender ao conjunto de necessidades de melhoria dos processos que afetam o dia-a-dia das obras, sobretudo à questão dos atrasos.

Um dos exemplos é o modelo de Bernardes (2001), que estabelece o foco na hierarquização do planejamento, citada no item 3.4.2. Seu modelo básico é formado por (conforme verificam-se na figura 52):

- Plano de Longo Prazo: através da elaboração de um cronograma físicofinanceiro;

- Plano de Médio Prazo Bimestral: formado por (i) uma programação bimestral para contratação ou demissão de mão-de-obra, (ii) uma programação de alocação de recursos, (iii) uma programação de compra de insumos de alto valor, e (iv) uma programação bimestral de atividades;

- Plano de Curto Prazo Semanal: formado por diretrizes para a produção e geração de informações que retroalimentes os planos em cada nível, sendo a retroalimentação de curto prazo com (i) metas semanais alcançadas, (ii) identificação e registros dos problemas, (iii) medição da produção; e a 
retroalimentação de médio e longo prazo com dados sobre os (i) serviços executados, (ii) as causas pelas quais o serviço não cumpre o plano e (iii) o plano das equipes.

Este modelo, segundo o próprio autor, seria fortemente vinculado aos conceitos e princípios do Lean Construction. No entanto, pode-se verificar neste modelo básico, ainda traços fortes dos sistemas tradicionais, citados no início do capítulo.

Figura 52 - Modelo básico de Bernardes

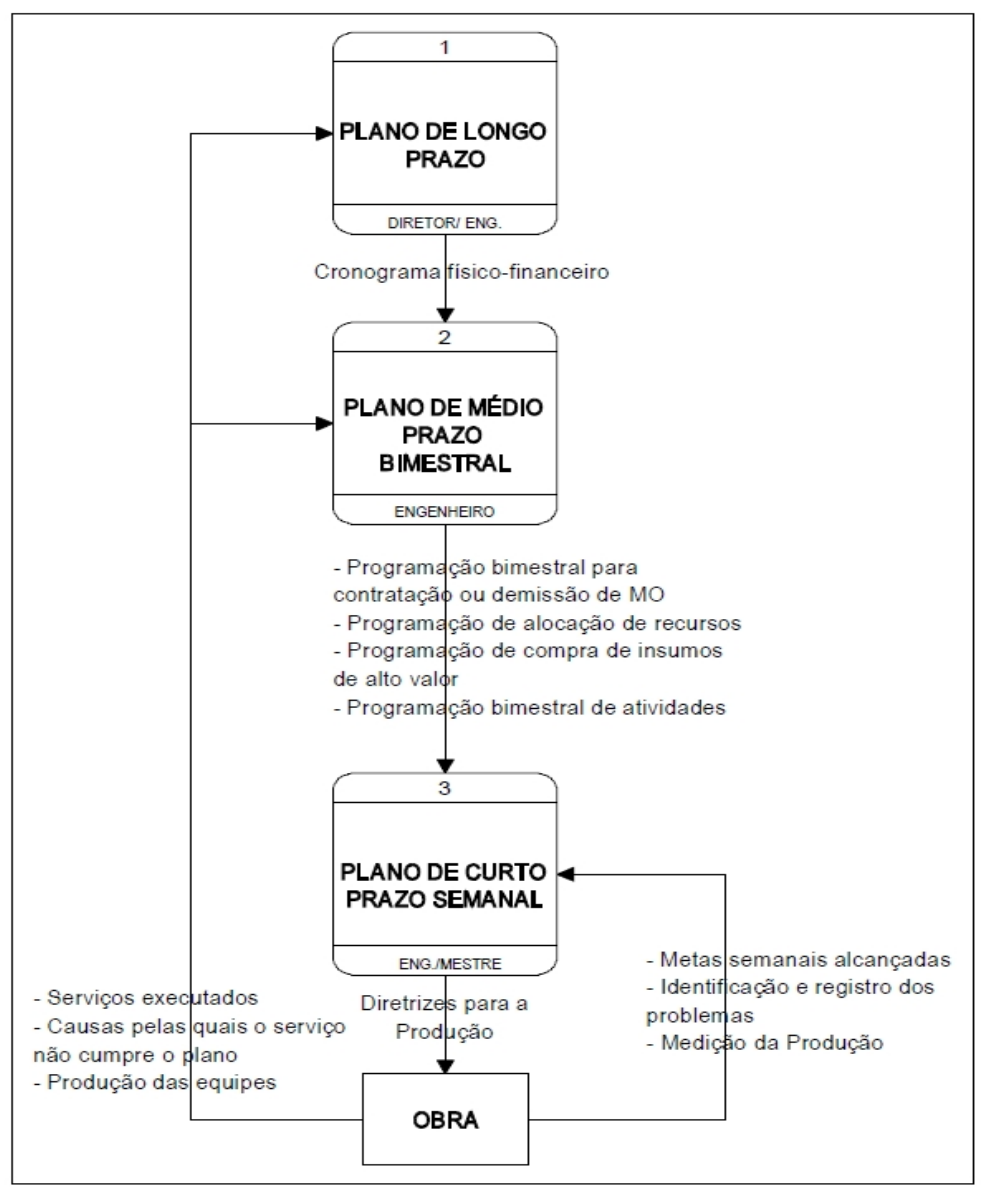

Fonte: Bernardes (2001)

Durante a implantação de seu modelo básico, Bernardes (2001) identificou dificuldades e possibilidades de melhoria, as quais podem ser listadas a seguir:

- Maior transparência ao modelo através de maior detalhamento de suas etapas constituintes (maior facilidade de replicação);

- Integração com outros processos da empresa (orçamento, projetos, planejamento estratégico); 
- Necessidade de utilização de hierarquização de metas através da divisão do trabalho (por exemplo, usando conceitos relacionados à estrutura analítica de projeto - EAP);

- Inclusão de uma etapa de avaliação do processo de planejamento (PCP);

- Análise de fluxos físicos (melhor sequenciamento do fluxo de trabalho no nível de médio prazo).

Assim, após as melhorias propostas pelo autor, verifica-se que o resultado é bastante didático e trouxe aquilo que foi destacado no início deste tópico: conceitos integrados de diversos sistemas (tendência dos modelos e métodos propostos pelos autores mais recentes). O modelo completo é apresentado na figura 53.

Figura 53 - Modelo completo de Bernardes

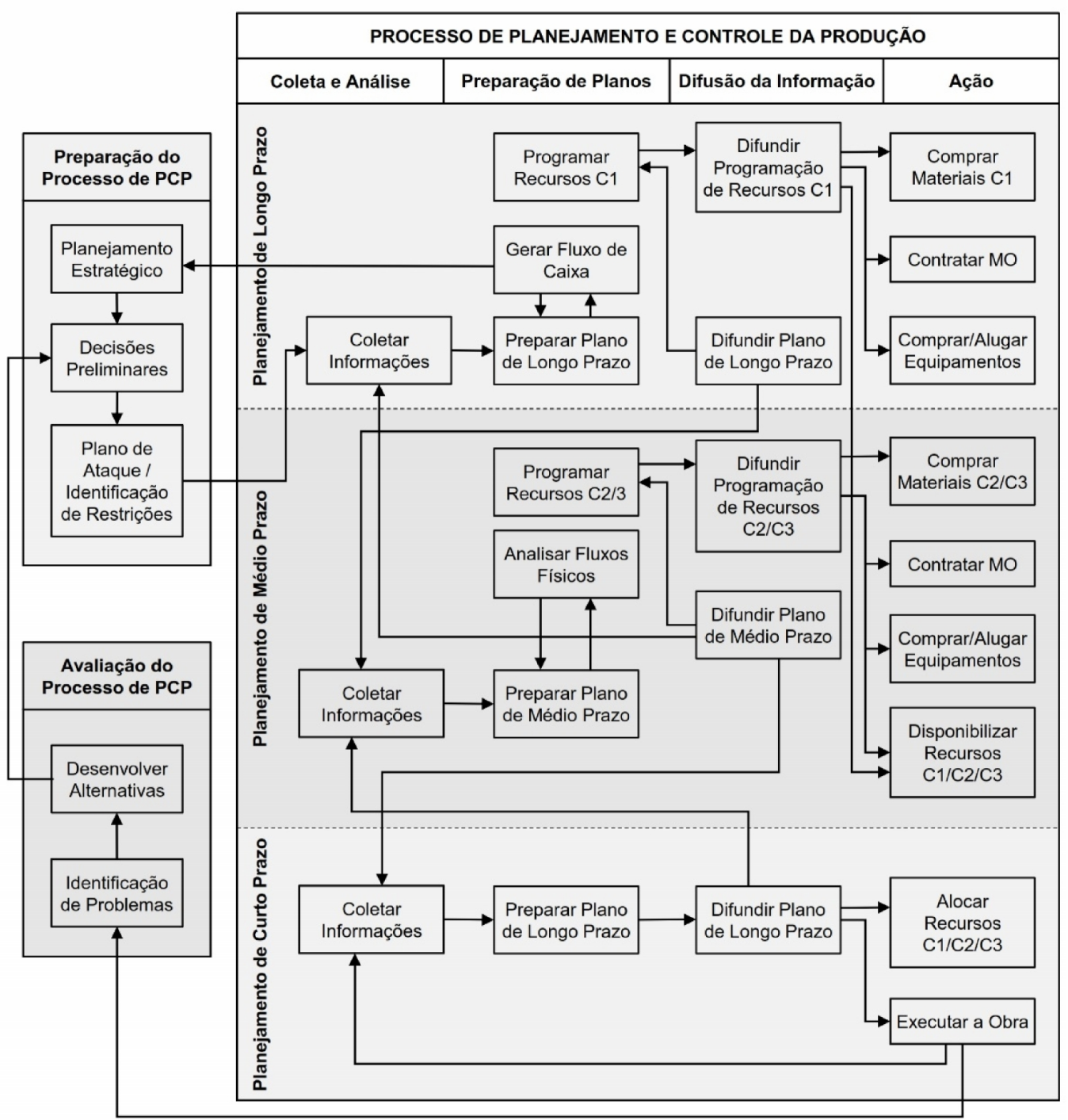

Fonte: Adaptado de Bernardes (2001) 
Conforme pode ser observado, o modelo é composto por três etapas básicas: (i) preparação; (ii) planejamento e controle da produção; e (iii) avaliação do processo. Destacou-se nesta pesquisa o detalhamento da segunda etapa, ou seja, o planejamento e controle da produção, que analogamente ao modelo básico anterior, está dividido hierarquicamente nos níveis de planejamento de longo, médio e curto prazo.

Olivieri et al. (2016) estabelecem um modelo integrado que propõe a inclusão de ferramentas do sistema LBMS aos sistemas LPS e tradicional. A ideia central por trás da criação deste modelo está em alcançar melhores resultados quando se pretende incrementar novas ferramentas aos sistemas tradicionais (uma vez que estes já estão aculturados nas rotinas da grande maioria das empresas de construção), do que quando se buscam rupturas muito fortes dos modelos tradicionais existentes.

O modelo traz inúmeros conceitos, inclusive um exemplo de programação de curto prazo com elementos dos três sistemas, como observado na figura 54.

Figura 54 - Exemplo de planejamento de curto prazo

\begin{tabular}{|c|c|c|c|c|c|c|c|c|c|c|c|c|c|c|c|c|c|c|}
\hline \multirow{3}{*}{ Item } & \multirow{3}{*}{ Pacote de trabalho } & \multicolumn{3}{|c|}{ Local } & & & \multicolumn{2}{|c|}{ Responsável } & \multirow{3}{*}{ Status } & \multicolumn{7}{|c|}{ Dias da semana } & \multirow{3}{*}{$\begin{array}{c}\% \\
\text { Realizado }\end{array}$} & \multirow{3}{*}{$\begin{array}{c}\text { Causas } \\
\text { atraso / } \\
\text { sucesso }\end{array}$} \\
\hline & & \multirow{2}{*}{ Torre } & \multirow{2}{*}{ Pavto } & \multirow{2}{*}{ Unidade } & \multirow{2}{*}{\multicolumn{2}{|c|}{ Equipe }} & \multirow{2}{*}{ Empresa } & \multirow{2}{*}{ Mestre } & & 9 & 10 & 11 & 12 & 13 & 14 & 15 & & \\
\hline & & & & & & & & & & $\mathbf{S}$ & $\mathbf{T}$ & $\mathbf{Q}$ & $\mathbf{Q}$ & $\mathbf{s}$ & $\mathbf{S}$ & D & & \\
\hline \multirow{2}{*}{1} & \multirow{2}{*}{ Grauteamento das alvenarias } & \multirow{2}{*}{ A } & \multirow{2}{*}{3} & \multirow{2}{*}{31 e 32} & Oficial & 1 & \multirow{2}{*}{ A } & \multirow{2}{*}{ Arthur } & Prev. & & & & & & & & \multirow{2}{*}{$100,00 \%$} & \multirow{2}{*}{ Sucesso } \\
\hline & & & & & Ajud & 1 & & & Real & & & & & & & & & \\
\hline \multirow{2}{*}{2} & \multirow{2}{*}{$\begin{array}{l}\text { Colocação da escada pré- } \\
\text { moldada }\end{array}$} & \multirow{2}{*}{ A } & \multirow{2}{*}{3} & & Oficial & & \multirow{2}{*}{ A } & \multirow{2}{*}{ Arthur } & Prev. & & & & & & & & $10000 \%$ & Sucesso \\
\hline & & & & & Ajud & 1 & & & Real & & & & & & & & & sucesso \\
\hline 3 & Montagem do escoramento da & $A$ & Locaçã & das & Oficial & & $\mathrm{P}$ & João & Prev. & & & & & & ntific: & & $10000 \%$ & Sucesso \\
\hline 3 & laje & A & & & Ajud & 2 & B & Paulo & Real & & & & & & isual & & $100,00 \%$ & sucesso \\
\hline 4 & Montagem de laje pré- & & & & Oficial & 1 & $\Gamma$ & Iمã & Prev. & & & & & & nal d & & & \\
\hline 4 & moldata & A & 3 & - & Ajud & 1 & Dimens & ionar & Real & & & & & & & & $100,00 \mathrm{Q}$ & Sucesso \\
\hline 5 & & $\mathrm{~A}$ & 3 & 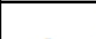 & Oficial & 1 & recur & 30 sos & Prev. & & & & & & & & Ap & Iração \\
\hline$J$ & IY Descrição clara do & A & $J$ & - & Ajud & 1 & as tar & & Real & & & & & & & & 100 & dos \\
\hline 6 & II trabalho a realizar - & A & 3 & 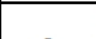 & Oficial & 1 & as rat & Márcio & Prev. & & & & & & & & res & $\sqrt{\mathrm{de}}$ \\
\hline 0 & h apropriada à área & A & 3 & - & Ajud & 1 & D & Marcio & Real & & & & & & & & $90,00 \%$ & material \\
\hline 7 & técnica e ser & $A$ & 3 & 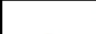 & Oficial & 2 & $C$ & Poulo & Prev. & & & & & & & & $7000 \%$ & Predecescor \\
\hline 1 & I compreendida pela & A & 3 & - & Ajud & 2 & $\mathrm{c}$ & Pauo & Real & & & & & & & & $70,00 \%$ & Predecessora \\
\hline 8 & T] equipe de campo que & 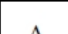 & 4 & 418 & Oficial & 2 & 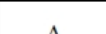 & Arthur & Prev. & & & & & & & & $5000 \%$ & Dredecessom \\
\hline 8 & IV reallzara o trabano & A & 4 & $41 \mathrm{e} 42$ & Ajud & 2 & A & Arthur & Real & & & & & & & & $50,00 \%$ & Predecessora \\
\hline 9 & Montagem da proteção & A & 8 & fachadas & Oficial & & A & Arthur & Prev. & & & & & & & & $5000 \%$ & Chuvg \\
\hline 9 & periférica & A & 0 & 1 e 2 & Ajud & 2 & A & Artunur & Real & & & & & & & & $50,00 \%$ & Cnuva \\
\hline
\end{tabular}

Fonte: Olivieri et al. (2016)

Destaca-se no exemplo, características importantes de um planejamento de curto prazo, tais como: (i) a descrição clara do trabalho a ser realizado; (ii) o local de realização das atividades; (iii) a equipe que deve ser alocada para cada trabalho; (iv) a data prevista para a tarefa; e (v) campos relativos ao controle do que foi efetivamente 
executado, possibilitando a geração de índices e descrição das causas do não cumprimento, caso isto ocorra.

O modelo integrado proposto pelos autores não sugere práticas inovadoras ou ferramentas diferentes das já apresentadas até então. Mas organiza o uso destas de forma a se obter a maior sinergia entre os três sistemas, a fim de atender às necessidades das equipes de produção das obras.

O modelo completo de Olivieri et al. (2016) é apresentado na figura 55.

Figura 55 - Integração do planejamento tradicional, LBMS e LPS

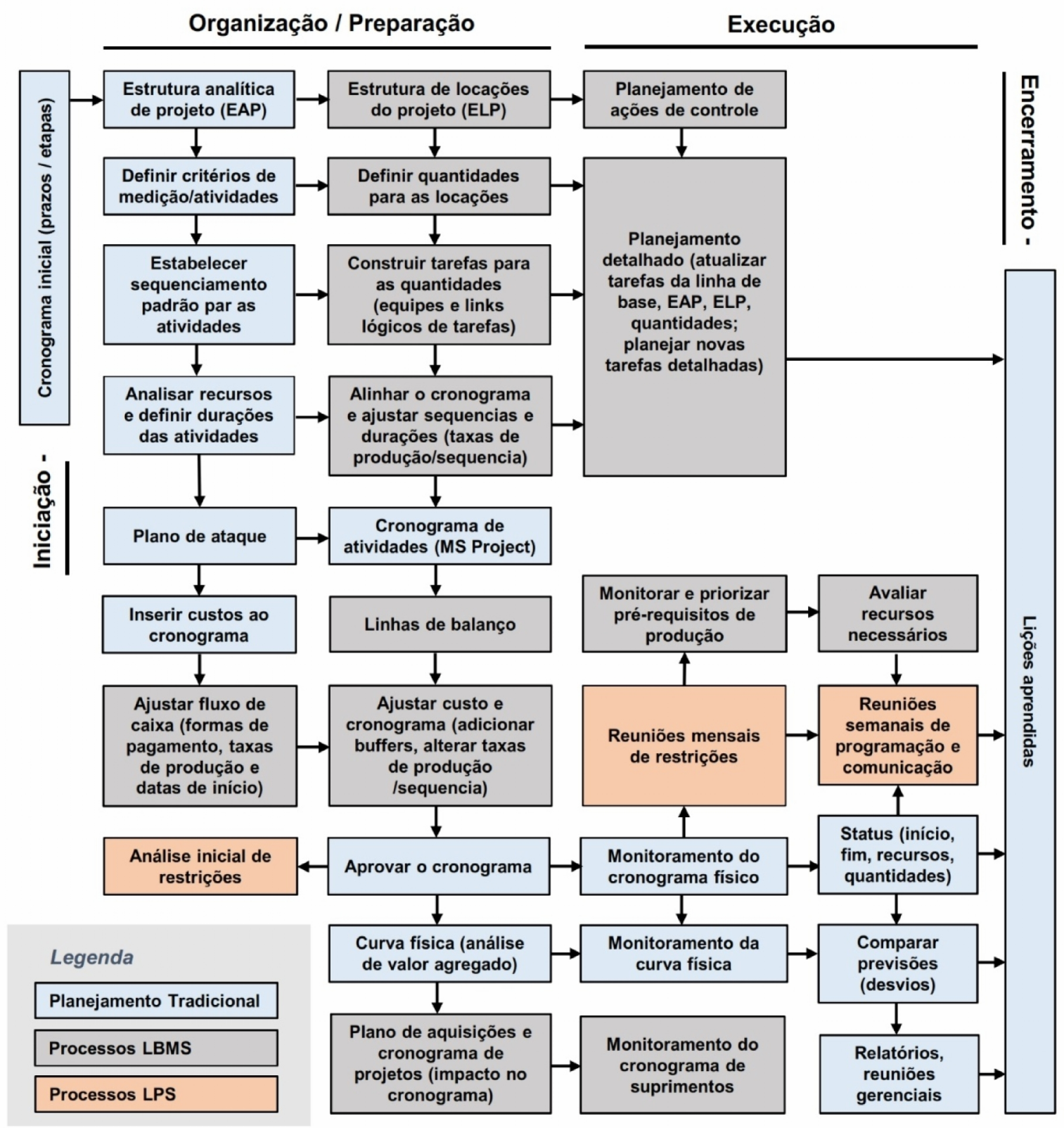

Fonte: Adaptado de Olivieri et. al (2016) 


\subsection{Aspectos que interferem no prazo das obras}

\subsubsection{Atrasos de obra}

Quando se planeja um projeto de construção, diversas premissas precisam ser definidas, de maneira que se estabeleçam elementos objetivos para estimativas e redes de precedência razoavelmente confiáveis. O domínio destas premissas e a definição daquelas que sejam mais apropriadas para um determinado projeto contribuem para que a diferença entre o planejamento e a execução da obra sejam proporcionalmente menores.

Assim, para se estabelecer um controle efetivo dos prazos de um projeto, é importante antecipar os processos e as condições que cercam a execução de uma obra. Isto garante a implantação de ações que minimizem os impactos no prazo final, caso estas condições verificadas sejam diferentes das premissas inicialmente propostas para o planejamento do projeto.

No entanto, conforme estabelece Halpin (2006), frequentemente existem circunstâncias que cercam o gerente do projeto, que não são razoavelmente antecipadas, gerando os chamados "atrasos". O autor afirma que a possibilidade de sempre ocorrer estes atrasos torna muito difícil ou até impossível o conhecimento da data precisa de término de um projeto.

Segundo Couto (2007), atraso de um projeto de construção é a execução tardia de um trabalho, excedendo os prazos previstos na programação ou distribuição das atividades ou o prazo contratual global do projeto.

Esta definição é contestada por alguns autores, uma vez que para parte dos pesquisadores, o atraso de uma obra seria caracterizado apenas pelo impacto no prazo final ou contratual. Segundo esta vertente, distorções nas programações intermediárias fazem parte de um processo amplo e natural de planejamento e controle das obras.

Dentro deste último conceito, esta pesquisa irá primeiramente analisar atrasos relacionadas a empreendimentos que tiveram impactados seus prazos contratuais. Entende-se como "prazo contratual" aquele estabelecido nos contratos de construção, 
ou seja, na relação comercial entre o Empreendedor (ou Cliente) e a Construtora Principal (ou Empreiteiro), e não os prazos contratuais dos clientes finais dos imóveis, que muitas vezes apresentam folgas para a entrega (exatamente para combater os riscos de atrasos comuns verificados no mercado brasileiro) ou que representam prazos desde a compra do imóvel e não desde o início efetivo da obra.

Assim, a pesquisa trata do termo "projeto", como a execução da "obra" e não do empreendimento como um todo. Neste último caso, outros fatores impactantes no prazo do empreendimento deveriam ser listados e analisados, tais como aqueles que se relacionariam ao desenvolvimento do produto, processos comerciais, velocidade de vendas, aspectos jurídicos, repasse de financiamento, e outros processos não contemplados na análise tanto da bibliografia, como nas obras estudadas.

Após a identificação das principais causas de atrasos contratuais e elaboração dos protocolos de pesquisa, será analisado então nos estudos de caso o impacto das então distorções nas programações e possivelmente como tais eventos geraram então os atrasos contratuais.

\subsubsection{Consequências dos atrasos}

Conforme entrevista de Reis (2010) com empresários conceituados do mercado imobiliário, foi evidente nesta época o número de clientes insatisfeitos e a perda quase que total dos resultados das empresas. A autora identifica, através dos resultados das entrevistas um efeito "dominó", que pode ser resumido nos seguintes pontos:

- Aumento de custos (custos fixos do canteiro, juros do empréstimo à produção e postergação do recebimento dos juros dos mutuários);

- Problemas de fluxo de caixa;

- Indisponibilidade das equipes (dificuldade de novas originações se agrava pela indisponibilidade de MDO alocadas mais tempo que o necessário);

- Perda de credibilidade (risco de vendas futuras e confiança do consumidor);

- Perda de clientes e devolução de parcelas (pela insatisfação do atraso);

- Indenizações (mesmo com a entrega atrasada, ações de danos morais e materiais). 
Esta insatisfação geral, como também descrito no capítulo 1 deste trabalho, provocou até mesmo a comoção da classe política, que por pressões da população estabeleceu projetos de lei que visavam penalizar incorporadores que não conseguissem entregas suas obras no prazo. Como exemplo podem-se citar:

- Projeto de Lei 3019/2008: estabelece o pagamento por mês de atraso ao equivalente ao aluguel de uma unidade semelhante à adquirida (situação atual: aguardando apreciação pelo Senado Federal, uma vez que em dezembro de 2015 teve sua redação final aprovada pela Comissão de Constituição e Justiça e de Cidadania (CCJC) e em seguida remetida ao Senado Federal pela Mesa Diretora da Câmara dos Deputados - Of. nº 711/15/PS-GSE;

- Projeto de Lei 7059/2010: limita a carência a 90 dias, sendo que após este prazo, a construtora deve arcar com encargos mensais relativos ao imóvel em construção ou pagamento mensal de $1 \%$ do valor de aquisição (situação atual: arquivada em janeiro de 2011, mesmo após aprovação pela Comissão de Desenvolvimento Urbano (CDU) em dezembro de 2010);

- Projeto de Lei 178/2011: estabelece multa de 1\% do valor até então pago pelo comprador após o prazo de 180 dias de atraso, mais 0,5\% a cada mês de atraso (situação atual: aguardando apreciação pelo Senado Federal, uma vez que em março de 2015 teve sua redação final aprovada pela Comissão de Constituição e Justiça e de Cidadania (CCJC) e em seguida remetida ao Senado Federal pela Mesa Diretora da Câmara dos Deputados - Of. $\mathrm{n}^{\circ}$ 57/15/PS-GSE).

Mesmo sem a aprovação destas leis, atualmente, é praxe a previsão de multa no contrato em caso de atraso de mais de 180 dias. No Rio de Janeiro, uma lei estadual $(6.454 / 13)$ prevê multa de $2 \%$, como estabelecia o projeto inicial da Lei 178/11.

\subsubsection{Causas dos atrasos das obras}

Segundo Mattos (2007), as razões para a frustração dos cronogramas são diversas, algumas de natureza técnica, outras de natureza gerencial. Em todas elas, verifica-se que frequentemente elaboram-se cronogramas inexequíveis ou não há por parte dos gerentes, capacidade de interpretá-los e comunicar adequadamente as equipes, gerando um planejamento desvirtuado e desacreditado logo no início do projeto. 
O autor levanta diversas causas, citando pesquisas do PMI, em especial: falta de consideração de recursos, ausência de contingência de tempo, atualização do cronograma sem geração de relatórios, estrutura de planejamento mal definida, falta de utilização do cronograma para gerenciar o projeto, falta de interpretação das modificações do cronograma após atualizações. Outras, menos relevantes, mas também citadas nos estudos: utilização de calendários inadequados, vínculos excessivos entre as tarefas, pouca cobrança de clientes e uso de programadores competentes em TI mas que não conhecem adequadamente conceitos de planejamento.

Como forma de se estruturar os estudos de caso, buscou-se identificar trabalhos que identificassem os motivos dos atrasos de obra.

Abd El-Razek et al. (2008) analisaram as principais causas de atraso em projetos de construção no Egito a partir do ponto de vista de empreiteiros, consultores e proprietários. Os resultados globais indicam que as causas mais importantes são:

- Financiamento pelo contratante durante a construção;

- Atrasos no pagamento do contratado pelo proprietário;

- Alterações do projeto pelo proprietário ou seu representante durante a construção;

- Pagamentos parciais durante a construção;

- Não utilização de uma gestão de contrato profissional.

Já na Nigéria, Aibinu e Odeyinka (2006) afirmam que os atrasos na construção são perturbadores e geram elevação dos custos de construção. A pesquisa dos autores destaca as causas dos atrasos, focando-se nas ações e omissões dos participantes do projeto e fatores externos. Uma análise de Pareto revelou que $88 \%$ dos fatores foram responsáveis por $90 \%$ dos atrasos em geral. Isto sugere que não há diferença perceptível entre os fatores de atraso diferentes e nenhum realmente se destaca como contribuindo para uma grande porcentagem do problema.

Esta pesquisa demonstra a vasta gama de problemas que são encontrados em obra e a necessidade de se estudar o tema de forma focada em tipologias que possam ser comparadas ou cujos resultados possam ser complementares entre si. 
Em Hong Kong, Lo et al. (2006) verificaram que os atrasos na construção são comuns, inevitáveis e que resultam em reclamações contratuais e aumento de custos do projeto.

Na Malásia, Abdul-Rahman et al. (2006) descrevem a importância da aplicação de uma gestão adequada para lidar com atrasos na construção em países com economia em crescimento. A pesquisa identificou ferramentas de gestão que são praticadas na indústria de construção local e os principais fatores que levam aos atrasos do projeto. Os autores também estabelecem recomendações sobre como superar ou mitigar os efeitos dos problemas identificados.

Uma pesquisa desenvolvida por Assaf e Al-Hejji (2006) sobre o desempenho dos projetos de construção na Arábia Saudita, identificou as causas de atraso e seus impactos, de acordo com cada um dos participantes do projeto (proprietário, consultor e contratante). A pesquisa revela que a causa mais comum de atraso identificado pelas três partes está correlacionada às ordens de alteração durante a obra. A pesquisa identificou que 45 dos 76 projetos analisados atrasaram sua entrega.

Yang e Wei (2010) identificam que os problemas de atraso ocorrem em todas as fases de empreendimento de construção. Enquanto a maioria dos estudos anteriores se concentram em descobrir causas ou superar atrasos na fase de construção, poucos estudos têm analisado os problemas de atraso nas fases de planeamento e projeto (design).

Os resultados analíticos destes autores revelam que nos empreendimentos analisados, as chamadas "mudanças na exigência do cliente" foram as principais causas dos atrasos nestas fases (planejamento e design). Os resultados estão relacionados ao fato de que muitos dos empreendimentos analisados pelos autores são obras públicas e que em muitos clientes governamentais, muitas mudanças ocorrem durante o planejamento e as fases de design, conforme os impactos das políticas setoriais e interessem dos entes mandatários.

No Brasil, trabalhos similares a estes foram realizados. De acordo com Pereira (2012), em sua pesquisa sobre atrasos de obras de edifícios verticais, os principais fatores levantados para os desvios de prazo foram: 
- Escassez de mão de obra;

- Mudanças solicitadas pelo cliente final;

- Mão de obra não qualificada;

- Atrasos nos trabalhos dos subempreiteiros; e

- Retrabalho em virtude de erros.

Segundo Santos et al. (2015), após seu diagnóstico sobre as causas que geram atrasos de obras de edificações públicas, os autores identificaram as principais causas sob dois aspectos diferentes: maior impacto (ou potencial de atrasar o contrato) e mais frequentes.

As cinco causas com maior potencial para afetar o prazo dos empreendimentos, de acordo com esta pesquisa foram: (i) "duração do contrato irrealista"; (ii) "falta de compatibilização dos projetos"; (iii) "atraso em revisões e aprovações de documentos de projeto pelo contratante"; (iv) "erros nos levantamentos de quantitativos/planilha"; e (v) "erros nas investigações de solo".

Descrevendo em seguida as causas mais frequentes levantadas pelos autores, podem-se citar: (i) "erros nos levantamentos de quantitativos/planilha"; (ii) "falta de compatibilização dos projetos"; (iii) "atraso na finalização de preços para itens extras"; (iv) "atraso por parte do contratante nos pagamentos dos trabalhos executados pelo empreiteiro"; e (v) "duração do contrato irrealista".

Existem outros trabalhos de grande relevância, fora do ambiente da construção, mas que são totalmente aplicáveis à discussão deste tema. Em um deles, Elder (2006) estabelece cinco razões pelas quais os projetos não alcançam seus resultados pretendidos, sobretudo os prazos planejados:

- Multitarefa Nociva: as equipes de um projeto enfrentam constantemente prioridades que mudam, fazendo com que se interrompa uma tarefa e se trabalhe em outra. Trabalhando-se em inúmeras atividades ao mesmo tempo, com todos os clientes exercendo uma pressão similar para que sua tarefa seja finalizada, naturalmente as prioridades de realização das atividades mudam frequentemente. Qualquer quantidade de tempo não trabalhado numa tarefa por simples indefinição de prioridades, significa que ela está atrasando mais 
do que se houvesse maior dedicação ao seu término. Assim, a multitarefa sempre faz com que uma tarefa demore mais do que deveria;

- Lei de Parkinson ${ }^{5}$ : os membros da equipe de projeto embutem maior segurança nas estimativas de tarefas e uma vez definido o prazo, mesmo que confortável, o trabalho se expande para preencher o tempo disponível;

- Síndrome do Estudante ou procrastinação: é um mecanismo de defesa natural do ser humano. Significa adiar o trabalho até o último momento possível, não porque as pessoas são preguiçosas, mas pelo contrário, trabalha-se duro em outras tarefas que julga-se mais importante;

- Dependência entre tarefas: um dos efeitos negativos causado pela dependência entre tarefas é chamado de "probabilidade de eventos dependentes". Essa teoria afirma que o tempo total requerido para eventos dependentes, em termos de probabilidade, é o produto da probabilidade de todos os eventos dependentes. Além disso, os atrasos são passados adiante, mas os adiantamentos não;

- Efeito das transições de tarefas: o término de uma atividade não significa que a outra irá ser iniciada imediatamente. O efeito é similar à corrida de revezamento, onde se deve ter certeza que a próxima pessoa na fila está sempre pronta para iniciar a próxima tarefa logo quando o trabalho for entregue. Muitos gerentes de projetos demoram a contatar o próximo recurso na fila e notificá-lo sobre quando sua tarefa deverá iniciar.

Desta forma, Elder (2006) descreve que para se remover os obstáculos que implicam nos atrasos de projeto, é necessário desenvolver um sistema que garanta que todas as tarefas comecem, não quando elas estão agendadas para começar, mas quando as entradas necessárias estiverem disponíveis. Isso é especialmente importante para as tarefas no caminho crítico.

(5) Os conceitos de Lei de Parkinson e Síndrome de Estudante tiveram sua aplicação em gerenciamento de projetos descrita por Goldratt (1998) quando da definição do conceito de CCPM, conforme descrito no item 3.6.3. 


\subsection{Aspectos que interferem na gestão dos prazos e possíveis melhorias}

\subsubsection{Problemas na gestão dos atrasos}

Nepal et al. (2006) estudaram que acelerar um projeto pode ser gratificante mas as consequências podem ser problemáticas quando a produtividade e a qualidade são sacrificadas (para se manter à frente do cronograma). Assim, os benefícios reais para o cronograma, muitas vezes não valem a pena. As compensações e os caminhos de pressão de se antecipar, bem com suas consequências são muitas vezes esquecidos. Quando as decisões sobre o cronograma são feitas, tornam-se premissas verdadeiras e esquecem-se no momento que os problemas acontecem.

Ibbs e Nguyen (2007) descrevem que a indústria da construção utiliza diversas técnicas de análise cronograma para apoiar reivindicações de atraso. Paradoxalmente, as questões relacionadas com recursos são frequentemente ignoradas, embora possam também afetar o tempo de conclusão do projeto. A pesquisa apresentada pelos autores mostra que a análise de atraso sem a prática de alocação de recursos afeta substancialmente os resultados da análise de programação. Algum atraso pode causar a alocação de recursos irrealista no serviço posterior, o que pode atrasar ainda mais o projeto. $O$ efeito da alocação de recursos pode aumentar ou reduzir a gravidade de algum evento atrasar.

Hanna et al. (2005) estudaram os impactos das horas extras com duração estendida na produtividade do trabalho de construção. Os resultados mostram uma diminuição na produtividade com o aumento do número de horas trabalhadas por semana e/ou com o aumento da duração do projeto (horas extras definidas como as horas trabalhadas além das 40 horas típicas programadas por semana).

\subsubsection{Ações para se evitar atrasos e melhorar o controle de prazos}

Kim e La Garza (2005) defendem a utilização do método do caminho crítico com vários calendários para efetivamente representar as condições do projeto diversos, tais como propriedades de trabalho, disponibilidades de recursos, condições meteorológicas, dentre outras. 
Nassar e Hegab (2006) analisaram que vários fatores contribuem para a complexidade dos cronogramas de projetos, incluindo o número de atividades, o nível de detalhe, e a forma da rede do projeto. A pesquisa apresenta uma proposta de avaliação da complexidade de cronogramas de projetos em termos de conectividade das atividades. Diferente de avaliações semelhantes, a proposta não considera as relações redundantes no cronograma do projeto, mas o grau de inter-relações entre as atividades no cronograma como um todo.

Barraza (2011) escreve que os gerentes de projeto implementam o conceito de contingência de tempo para considerar a incerteza nas estimativas de duração e evitar atrasos na conclusão do projeto. Alguns gerentes também estabelecem prazos de contingência para as atividades do projeto para criar uma programação mais fácil de ser atendida e gerenciada. Geralmente, tanto a estimativa, quanto a distribuição do tempo de contingência são realizados por meio de abordagens subjetivas. $O$ autor sugere que a estimativa de tempo de contingência do projeto e sua alocação no nível de atividade deve ser obtido considerando-se a variabilidade de desempenho de cada atividade ao invés de se basear no julgamento humano.

Arditi et al. (2002) tentam estabelecer melhorias na utilização e representação das linhas de balanço incluindo o desenvolvimento de um algoritmo que lida com a aceleração do projeto de forma eficiente e precisa. O modelo reconhece o tempo e as dependências do espaço, lidando com limitações de recursos e datas-marco, e incorporando atividades ocasionais não-lineares, a definição de um novo conceito de criticidade, e ainda incluindo o efeito da curva de aprendizagem.

Winch e North (2006) relatam que nos projetos de construção, o problema de programação do canteiro de obras e seu arranjo físico não tem recebido a devida atenção de pesquisadores e profissionais.

De acordo com os autores, existem hoje métodos sofisticados de planejamento e análise da sequência das tarefas, mas o local onde as tarefas devem ser executadas não é bem correlacionado, principalmente porque esses espaços são dinâmicos no decorrer do projeto. Sabe-se que o congestionamento no local reduz a produção e gera riscos, mas atualmente, os profissionais de planejamento na construção civil têm que confiar em sua experiência e intuição. 
La Garza et al. (2007) identificam que dentro das práticas de programação atual, a folga total é considerada "livre" e não pertence exclusivamente a nenhuma parte específica no processo de construção, mas sim, ao projeto como um todo. Ela pode ser usada tanto por proprietários, como para contratados para mitigar o impacto potencialmente negativo de atrasos.

Assim, de acordo com os autores, as atividades iniciais do cronograma utilizarão as folgas primeiramente dentro destas perspectivas. Os envolvidos com as atividades posteriores que sofrerão atraso terão maior probabilidade de serem responsabilizados pelo atraso global do projeto de construção. Sendo assim, os autores sugerem que seja introduzido o conceito de pré-alocação de float (folgas) e de um método de gestão do caminho crítico analisando os consumos destes floats. Por fim, recomendam incluir cláusulas de contrato para regular o seu uso e para explicar a maneira pela qual a responsabilidade por qualquer atraso resultante pode ser atribuída.

A utilização de buffers como ferramenta de melhoria da programação e controle dos prazos em projetos é discutida atualmente por diversos autores, entre eles Rogalska e Hejducki (2007).

O uso adequado dos buffers foi já citado anteriormente por alguns destes autores, em especial aqueles que estudam o conceito da Corrente Crítica (CCPM), como Quelhas e Barcaui (2004), Akkari (2009) e Mendes et al. (2014).

Alguns autores conseguiram em seus trabalhos, consolidar várias práticas de melhoria dos processos de planejamento. Souto (2006), por exemplo, realizou um estudo dos processos de planejamento em três construtoras que realizam obras na região metropolitana de São Paulo.

Como resultado a autora identifica práticas bem sucedidas nestes processos e sugere também ações de melhoria para processos que julgados como inadequados nas empresas pesquisadas por ela (quadro 11).

Destaca-se que várias ações propostas pela autora já são atualmente praticadas por muitas empresas de construção. São apenas diretrizes sugeridas especificamente para as empresas estudadas por ela. Apesar de não ser tão recente, a pesquisa 
mostra a diferença de realidade entre construtoras, mesmo em uma região bem desenvolvida como a capital do Estado de São Paulo.

Quadro 11 - Boas práticas de planejamento

\begin{tabular}{|c|c|}
\hline $\begin{array}{l}\text { Práticas bem sucedidas já } \\
\text { implementadas nas empresas }\end{array}$ & $\begin{array}{c}\text { Ações propostas para a melhoria do } \\
\text { processo de planejamento }\end{array}$ \\
\hline $\begin{array}{l}\text { - Reunião de passagem de informações } \\
\text { do processo comercial para o PCP } \\
\text { (definição das diretrizes de produção, } \\
\text { logística e tecnologia); } \\
\text { - Check list após aprovação do } \\
\text { planejamento de longo prazo para } \\
\text { verificação do atendimento aos } \\
\text { requisitos de viabilidade da obra; } \\
\text { - Simulações no modelo com os dados } \\
\text { de controle e com a previsão } \\
\text { atualizada, para auxiliar na visão do } \\
\text { andamento da obra em termos de } \\
\text { detalhamento das atividades e } \\
\text { sequenciamento adotado; } \\
\text { Definição dos critérios de medição } \\
\text { física no momento da elaboração da } \\
\text { programação; } \\
\text { Estabelecimento de indicadores para o } \\
\text { monitoramento dos desvios de } \\
\text { planejamento; } \\
\text { - Realização de reuniões com diretoria, } \\
\text { gerência e equipes de produção para } \\
\text { validação da programação, para que } \\
\text { todos se comprometam com as metas } \\
\text { estabelecidas; } \\
\text { flaboração de relatório de avaliação } \\
\text { final da obra, com as justificativas dos } \\
\text { desvios de programação, índices de } \\
\text { progresso físico, custos e } \\
\text { programal e entrega de obra na } \\
\text { - }\end{array}$ & 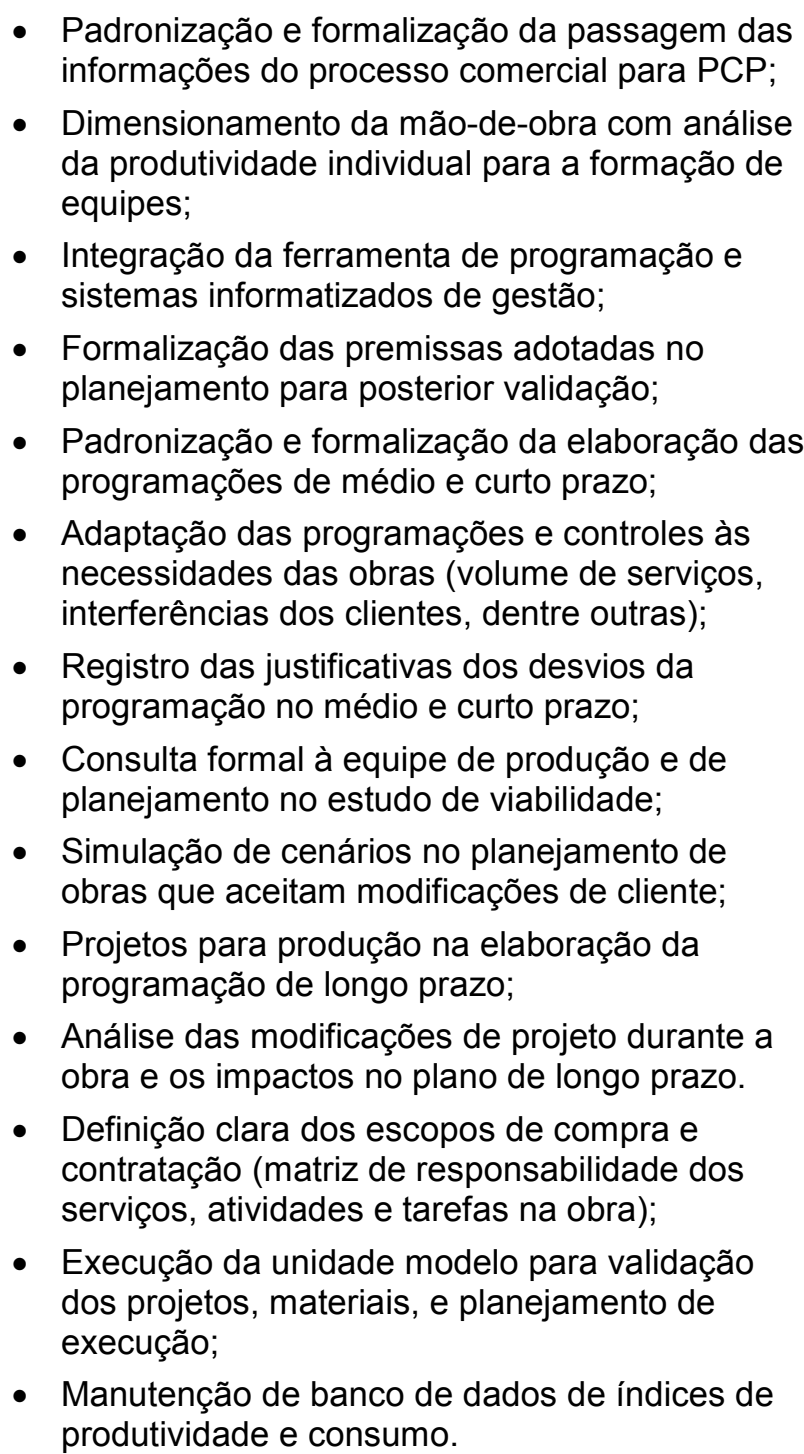 \\
\hline
\end{tabular}

Fonte: Adaptado de Souto (2006)

Como se vê, o foco das ações de melhoria está concentrado em comprometimento e formalizações dos processos de planejamento, seja nas etapas de viabilidade ou no planejamento operacional, fato que é evidenciado em muitos empreendimentos de construção, como um dos fatores de causa de atraso. 


\section{PESQUISA DE CAMPO EXPLICATIVA}

\subsection{Objetivos desta pesquisa de campo}

Esta pesquisa explicativa teve como objetivo inicial levantar quais as principais causas do não atendimento dos prazos previstos em empreendimentos de construção, de maneira a orientar quais seriam os itens de estudo para a definição de práticas de minimização de atrasos.

Paralelamente, durante a avaliação de cada empreendimento, pôde-se também analisar diversas práticas de gestão de prazos de empreendimentos, comparando-as com métodos e técnicas apresentados na pesquisa bibliográfica. Caso se identificasse alguma prática importante até então não estudada e que pudesse subsidiar possíveis definições de diretrizes para a redução dos problemas de atraso (que serão abordadas no capítulo 5), tal fato deveria ser adequadamente registrado.

Para que os resultados obtidos fossem confiáveis foi definida uma amostra representativa de 50 obras. Primeiramente foi realizado um estudo de caso piloto com 3 obras, de maneira a avaliar a estruturação da pesquisa de campo e pertinência em relação ao foco do trabalho. Em seguida, foi aprimorada a técnica de coleta de dados, para que fosse possível replicá-la de forma segura aos demais itens da amostra (outras 47 obras), bem como revisão das três primeiras baseado nos novos conceitos de análise.

\subsection{Preparação da lista de referência de causas de atraso}

Conforme verificou-se no capítulo 3 , a forma como os autores que estudam o tema classificam e analisam as causas de atraso é variável e dependem da realidade de cada região ou país que retratam em suas pesquisas.

Assim, para que fosse possível a realização desta primeira pesquisa de campo, se entendeu necessário estabelecer uma compilação das classificações e descrições destas causas, complementando o protocolo de estudo.

Estudando-se as estruturas das pesquisas de diversos autores, tais como Chan e Kumaraswamy (1997), Assaf e Al-Hejji (2006), Couto (2007), Faridi e El-Sayegh (2006), Marzouk e El-Rasas (2014) e alguns outros, identifica-se que uma das 
primeiras providências para melhor entender as causas dos atrasos é mapear todas as partes integrantes do processo de construção, identificando-se de que maneira cada uma delas poderia gerar um atraso de obra.

De uma forma mais processual, seria o mesmo que realizar uma análise de causa e efeito de um problema que ainda não ocorreu. Conforme descreve Gündüz et al. (2013), quando se identifica esta questão, uma ferramenta muito utilizada é o diagrama conhecido como Ishikawa ou "espinha de peixe", como pode ser ilustrado na figura 56.

Figura 56 - Diagrama de Ishikawa para identificação de causas de atraso

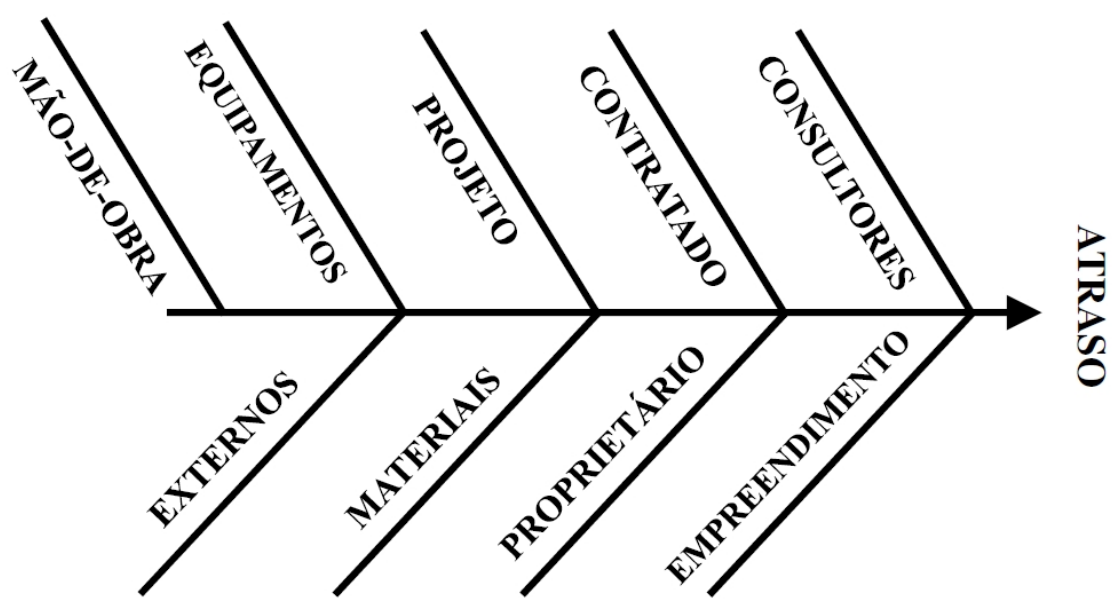

Fonte: Gündüz et al.(2013)

Os autores realizam esta análise buscando-se a classificação ou categorização mais adequada para então fazer as reflexões das causas mais prováveis pelos atrasos de obra. Neste caso, estabeleceram nove categorias: Projeto (Empreendimento), Proprietário, Materiais, Consultores, Contratados, Projeto (design), Equipamentos, Mão-de-obra e Fatores Externos.

O mesmo foi feito pelos outros autores pesquisados. Assaf e Al-Hejji (2006), por exemplo, estabeleceram esta classificação também em nove grupos: Contrato, Proprietário, Contratado, Consultor, Projeto (design), Materiais, Equipamentos, Mãode-obra e Fatores Externos.

Outros como Couto (2007), relacionaram as causas a três grandes classes (Cliente, Empreiteiro e Terceira Parte) e em seguida subdivide o Grupo Empreiteiro, gerando ao final oito classificações: Cliente (Dono da Obra), Materiais, Mão-de-obra, 
Equipamentos, Subempreiteiro, Financiamentos, Gestão dos Empreiteiros e Terceira Parte.

Marzouk e El-Rasas (2014), mais recentemente, classificam as causas de atrasos em grupos como: Proprietário (Empreendedor), Consultores, Contratado, Materiais, Mãode-obra e Equipamentos, Projeto e Questões Externas.

Por fim, Muianga et al. (2015), em uma revisão sistemática de literatura, identificaram 92 estudos primários entre 1985 e 2014 , sobre os fatores que influenciam os desvios de custos e prazos na construção. Com base na avaliação do que foi publicado neste período, sugerem que as causas dos desvios sejam classificadas em 95 fatores, sendo estes agrupados em 9 categorias, como descrito nos itens a seguir:

- Relações governamentais: fatores relacionados com licenças, leis, procedimentos burocráticos governamentais;

- Contratos: fatores relacionados com obrigações dos contratos, imposições contratuais, contratos inadequados;

- Organização: fatores relacionados com a supervisão, comunicação, coordenação do trabalho;

- Gerenciamento: fatores relacionados com o gerenciamento, planejamento, cronograma e recursos de materiais no empreendimento;

- Financiamento: fatores relacionados ao financiamento do empreendimento;

- Projeto e documentação: fatores relacionados à qualidade do projeto;

- Alterações de escopo: fatores relacionados ao retrabalho, ordens de variação e alteração do escopo inicial;

- Aspectos ambientais e econômicos: fatores relacionados aos efeitos sociais, ambientais e econômicos;

- Atividades e equipamentos: fatores relacionados ao desempenho, habilidades da mão de obra, instruções do trabalho, métodos de construção, ferramentas e equipamentos. 
Interessante observar nesta pesquisa que os fatores relacionados à categoria "Gerenciamento", de uma forma geral, foram os mais recorrentes (37\% dos fatores levantados).

No entanto, é importante destacar que a categorização de Muianga et al. (2015) refere-se a fatores que influenciam desvios focando-se aspectos de prazos e de custos. Embora grande parte impacte de forma conjunta ambos os aspectos, alguns dos fatores impactam apenas um. Desta forma, é necessária uma avaliação criteriosa para utilizar estes resultados como referência no desenvolvimento desta tese, que foca apenas o aspecto prazo.

As classificações demonstram uma certa convergência e muitos dos itens destacados por algum autor podem estar contidos em grupos de outro autor. Talvez apenas as classificações de Muianga et al. (2015) sejam um pouco desalinhadas, mas em geral trazem muitos dos fatores em comum aos demais.

Assim, por conveniência e tentando seguir a maioria das referências, buscou-se identificar dez classificações ou grupos de causas mais relevantes e mais comumente listadas pelos autores. Com base neste referencial organizou-se a seleção das principais causas de atrasos que são citadas nestas pesquisas.

Diversas causas podem ser classificadas em grupos diferentes, e isso ocorre quando se faz comparações mais aprofundadas entre as pesquisas. Este fato não é importante, desde que a causa seja detectada e não seja ocultada na base de dados.

Essa tarefa apresentou certa dificuldade, uma vez que, conceitualmente, algumas das causas levantadas poderiam ser incluídas em mais de um grupo. A questão foi solucionada de três formas diferentes:

- Alterando-se o nome ou referência de cada causa (incluindo-se "OU" na descrição);

- Ampliando o item, a partir de uma maior descrição;

- Juntando-se dois grupos anteriormente diferentes com a mesma classificação, e revisando-se as classificações feitas desde a primeira pesquisa analisada. 
Assim, após uma avaliação detalhada, buscou-se compilar essas causas, gerando um amplo quadro com 100 delas, e ainda uma classificação que se adequasse à maior parte dos trabalhos referenciados. Essa lista está apresentada no quadro 12.

Embora existam outros trabalhos interessantes relacionadas a atrasos de obra e seus impactos, como os já citados Al-Moumani (2000) e Mezher e Tawil (1998), ou até mesmo os mais recentes Doloi et al. (2012) e Russel et al. (2014), buscaram-se pesquisas que efetivamente trouxessem as descrições qualitativas das causas e a frequência com que elas aparecem nos empreendimentos de construção em cada um dos países onde as pesquisas foram realizadas. Elencaram-se quinze autores que mais se aproximaram desse ideal (os autores estão destacados no próprio quadro 12).

Como pode ser observado, metade das causas identificadas estão relacionadas diretamente ao contratado principal para a execução da obra, ou seja, a construtora ou o empreiteiro. Destaca-se que em quase três quartos das pesquisas estudadas a questão do planejamento mal elaborado ou de uma programação de serviços que não representa a realidade da obra é, se não a mais impactante, uma em posição de destaque entre as mais frequentes causas em cada artigo.

Em seguida, identificam-se causas ligadas a questões financeiras, que, em se tratando de países em desenvolvimento, se justificam como uma parte importante dos riscos de execução de um empreendimento de construção.

Por fim, é também importante observar que aspectos relacionados à gestão da obra e à interferência do empreendedor no projeto ou na própria construção são também alguns dos impactos mais influentes dos atrasos dos empreendimentos. 
Quadro 12 - Classificação e identificação das causas de atrasos (continua)

\begin{tabular}{|c|c|c|c|c|c|c|c|c|c|c|c|}
\hline 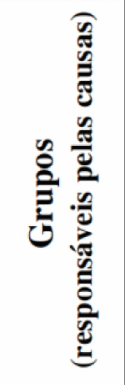 & $\begin{array}{l}\text { Descrição das Causas } \\
\text { mais Comuns }\end{array}$ & 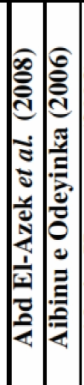 & 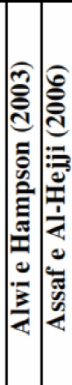 & 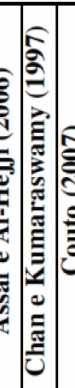 & 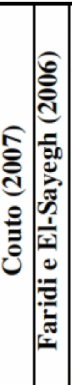 & 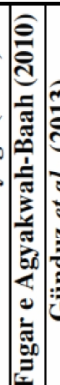 & 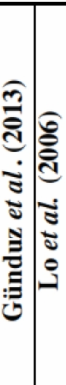 & 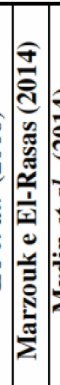 & 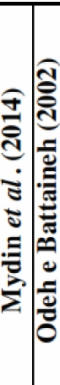 & 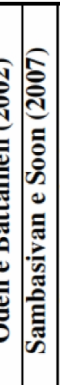 & \\
\hline \multirow{10}{*}{ 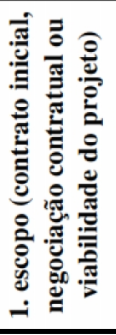 } & - Conflitos entre os envolvidos na propriedade (terreno) & & & & & & & & & & \\
\hline & - Indefinições de contrato ou escopo/negociações inconclusivas & & & & & & & & & & \\
\hline & - Disputas jurídicas entre as partes & & & & & & & & & & \\
\hline & - Tipo de licitação ou negociação apenas pelo menor preço & & & & & & & & & & \\
\hline & - Tipo de contrato inadequado para o projeto (turn key, adm, PMG, etc.) & & & & & & & & & & \\
\hline & - Duração do contrato irrealista (muito curta) & & & & & & & & & & \\
\hline & - Indisponibilidade de incentivos para contratado terminar antes o projeto & & & & & & & & & & \\
\hline & - Penalidades de atraso ineficazes & & & & & & & & & & \\
\hline & - Erros e discrepâncias dos documentos de contrato & & & & & & & & & & \\
\hline & - Estudo técnico, viabilidade/proposta malfeita ou sem se analisar riscos & & & & & & & & & & \\
\hline \multirow{10}{*}{ 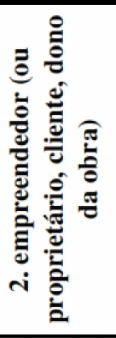 } & - Inexperiência do empreendedor como contratante & & & & & & & & & & \\
\hline & - Demora na tomada de decisão pelo empreendedor & & & & & & & & & & \\
\hline & - Interferências do empreendedor ou proprietário nas operações & & & & & & & & & & \\
\hline & - Falha na divulgação de informações vitais do projeto (comunicação) & & & & & & & & & & \\
\hline & - Atraso na revisão e aprovação de documentos pelo empreendedor & & & & & & & & & & \\
\hline & - Atraso no fornecimento e entrega do canteiro para o empreiteiro & & & & & & & & & & \\
\hline & - Atraso nos pagamentos dos empreiteiros pelo proprietário & & & & & & & & & & \\
\hline & - Alterações de escopo (ou contrato) pelo empreendedor durante construção & & & & & & & & & & \\
\hline & - Atraso/defeito da entrega do material pelo empreendedor ou cliente & & & & & & & & & & \\
\hline & - Suspensão do trabalho pelo empreendedor & & & & & & & & & & \\
\hline \multirow{10}{*}{ 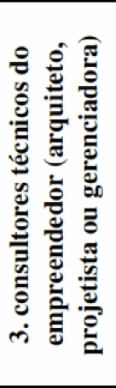 } & - Experiência inadequada do consultor (qualificação insuficiente) & & & & & & & & & & \\
\hline & - Não utilização de gestor profissional & & & & & & & & & & \\
\hline & - Atraso do orçamento ou de definição dos valores dos trabalhos & & & & & & & & & & \\
\hline & $\begin{array}{l}\text { - Atraso na preparação ou aprovação de desenhos ou especificações pelo } \\
\text { consultor }\end{array}$ & & & & & & & & & & \\
\hline & $\begin{array}{l}\text { - Atraso na aprovação das mudanças de escopo (solicitadas pelo cliente) pelo } \\
\text { consultor }\end{array}$ & & & & & & & & & & \\
\hline & - Inflexibilidade (rigidez) do consultor ou projetista & & & & & & & & & & \\
\hline & - Conflitos consultor $\mathrm{x}$ projestista $\mathrm{x}$ eng obra (ou coordenação) & & & & & & & & & & \\
\hline & - Falta de controle de qualidade & & & & & & & & & & \\
\hline & - Inexperiência do inspetor / atraso nas inspeções ou liberações & & & & & & & & & & \\
\hline & - Gerenciamento do contrato em geral & & & & & & & & & & \\
\hline \multirow{10}{*}{ 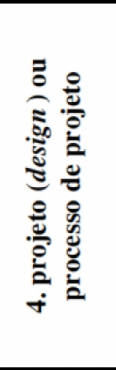 } & $\begin{array}{l}\text { - Incompreensão do proprietário em relação às requisições do projetista ou } \\
\text { consultor }\end{array}$ & & & & & & & & & & \\
\hline & - Dados insuficientes ou pesquisa malfeita para elaboração do projeto & & & & & & & & & & \\
\hline & - Complexidade do projeto ou sua elaboração (ou subestimou-se o projeto) & & & & & & & & & & \\
\hline & - Atraso na produção dos projetos e desenhos & & & & & & & & & & \\
\hline & - Detalhes pouco claros e inadequadas em desenhos & & & & & & & & & & \\
\hline & - Erros e discrepâncias nos documentos de projeto & & & & & & & & & & \\
\hline & - Poucos Projetos (projetos pobres ou insuficientes) & & & & & & & & & & \\
\hline & - Muitas revisões de projeto & & & & & & & & & & \\
\hline & - Não utilização de ferramentas/softwares avançados de design & & & & & & & & & & \\
\hline & - Inexperiência da equipe de projeto (design ) & & & & & & & & & & \\
\hline \multirow{9}{*}{ 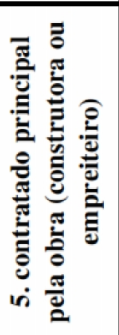 } & - Inexperiência do contratado (ou trabalho inadequado do empreiteiro) & & & & & & & & & & \\
\hline & - Dificuldades financeiras do empreiteiro (limitações de fluxo de caixa) & & & & & & & & & & \\
\hline & - Deficiência na previsão do fluxo de caixa (planejamento financeiro) & & & & & & & & & & \\
\hline & - Conflitos entre empreiteiro e outras partes & & & & & & & & & & \\
\hline & $\begin{array}{l}\text { - Má gestão ou supervisão (ou organização da equipe) no local de trabalho } \\
\text { (canteiro de obras) }\end{array}$ & & & & & & & & & & \\
\hline & - Falta, pouca ou tardia supervisão (controle do empreiteiro) & & & & & & & & & & \\
\hline & - Demora na tomada de decisões internas (na produção) & & & & & & & & & & \\
\hline & - Planejamento do projeto malfeito ou programações ineficazes & & & & & & & & & & \\
\hline & - Revisão do progresso físico inadequado & & & & & & & & & & \\
\hline
\end{tabular}

Fonte: O Autor 
Quadro 12 - Classificação e identificação das causas de atrasos, por autor (conclusão)

\begin{tabular}{|c|c|c|c|c|c|c|c|c|c|c|}
\hline 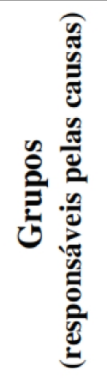 & $\begin{array}{l}\text { Descrição das Causas } \\
\text { mais Comuns }\end{array}$ & 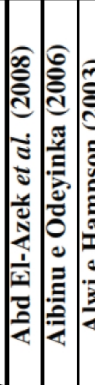 & 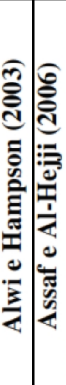 & 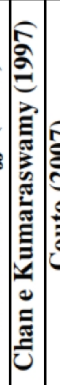 & 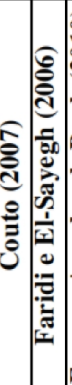 & 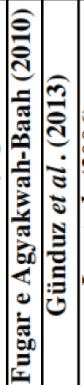 & 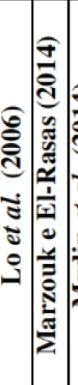 & 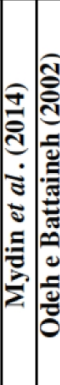 & 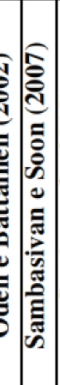 & 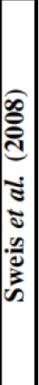 \\
\hline \multirow{11}{*}{ 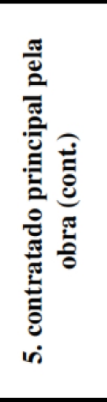 } & - Atraso na elaboração de desenhos, especificações e/ou amostras de material & & & & & & & & & \\
\hline & - Atraso ou baixa mobilização de MDO no canteiro (local de trabalho) & & & & & & & & & \\
\hline & - Layout ruim do canteiro (logística) & & & & & & & & & \\
\hline & - Retrabalho devido a erros durante a construção & & & & & & & & & \\
\hline & - Metodo de construção improprio (ou artesanal) para o projeto & & & & & & & & & \\
\hline & - Conflitos nas programações dos subempreiteiros & & & & & & & & & \\
\hline & - Atraso no pagamento de subempreiteiros & & & & & & & & & \\
\hline & - Atrasos nos trabalhos de subempreiteiros (ou terceiros) & & & & & & & & & \\
\hline & $\begin{array}{l}\text { - Interferência dos subempreiteiros em outras atividades (ou trabalho } \\
\text { inadequado dos mesmos) }\end{array}$ & & & & & & & & & \\
\hline & - Mudança frequente de subempreiteiros pelo trabalho ineficiente & & & & & & & & & \\
\hline & - Sobrecarga de trabalho & & & & & & & & & \\
\hline \multirow{8}{*}{ 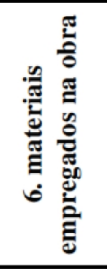 } & - Escassez de materiais de construção no mercado & & & & & & & & & \\
\hline & - Atraso na entrega de material & & & & & & & & & \\
\hline & - Programação de entrega no canteiro muito ruim, malfeita ou tardia & & & & & & & & & \\
\hline & - Atraso na seleção/definição de materias de acabamento (opções) & & & & & & & & & \\
\hline & - Atraso na fabricação de materiais ou componentes especiais & & & & & & & & & \\
\hline & - Alterações nos tipos de materiais e especificações durante a obra & & & & & & & & & \\
\hline & - Qualidade dos materiais (ou uso de material impróprio para a obra) & & & & & & & & & \\
\hline & - Materiais danificados ou problemas de manuseio de materiais & & & & & & & & & \\
\hline \multirow{7}{*}{ 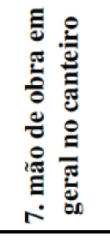 } & - Escassez de MDO (fornecimento de MDO) & & & & & & & & & \\
\hline & - Mão de obra não qualificada & & & & & & & & & \\
\hline & - Escassez de pessoal técnico especializado (inclui do empreiteiro) & & & & & & & & & \\
\hline & - Baixo nível de produtividade do trabalho (MDO, fraca execução) & & & & & & & & & \\
\hline & - Falta de mecanismos de incentivo da MDO (motivação de operários) & & & & & & & & & \\
\hline & - Nacionalidade dos trabalhadores/fatores sociais e culturais & & & & & & & & & \\
\hline & - Conflitos pessoais entre os trabalhadores & & & & & & & & & \\
\hline \multirow{5}{*}{ 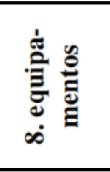 } & - Disponibilidade de equipamentos (escassez) & & & & & & & & & \\
\hline & - Falha de equipamento/avaria do equipamento & & & & & & & & & \\
\hline & - Atraso na entrega do equipamento & & & & & & & & & \\
\hline & - Baixo nível de habilidade do operador do equipamento & & & & & & & & & \\
\hline & - Equipamento/ferramenta inadequado ou com baixa eficiência & & & & & & & & & \\
\hline \multirow{11}{*}{ 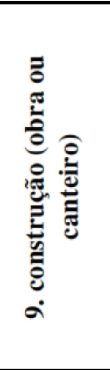 } & - Efeitos das condições do subsolo (solo, lençol freático alto, etc.) & & & & & & & & & \\
\hline & - Problemas de controle de tráfego, transporte ou restrições do canteiro & & & & & & & & & \\
\hline & - Indisponibilidade de serviços públicos (água,luz, telefone, etc.) & & & & & & & & & \\
\hline & - Atraso dos serviços de utilidades (água, eletricidade, etc.) & & & & & & & & & \\
\hline & - Acidente durante a construção & & & & & & & & & \\
\hline & - Pobre qualidade da documentação do canteiro & & & & & & & & & \\
\hline & - Condições do canteiro (desfavoráveis) & & & & & & & & & \\
\hline & - Diferentes condições do canteiro anteriormente previstas & & & & & & & & & \\
\hline & - Variações comuns do projeto durante a obra & & & & & & & & & \\
\hline & - Problema com vizinhos & & & & & & & & & \\
\hline & - Trabalhos em conflito com utilidades existentes no canteiro & & & & & & & & & \\
\hline \multirow{9}{*}{ 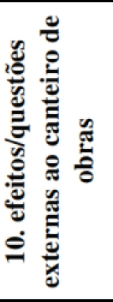 } & - Tempo/condições meteorológicas (calor, chuva, etc) & & & & & & & & & \\
\hline & - Restrições ambientais & & & & & & & & & \\
\hline & - Mudanças de leis e regulamentações & & & & & & & & & \\
\hline & - Lentidão de autorizações (licenças, alvará) pelo governo/município & & & & & & & & & \\
\hline & - Atraso na inspeção final ou certificação por terceira parte & & & & & & & & & \\
\hline & - Falta de comunicação entre as partes (geral) & & & & & & & & & \\
\hline & - Estrutura organizacional inadequada entre todas as partes do projeto & & & & & & & & & \\
\hline & - Flutuações no custo/moeda (ou em preços de material e equipamentos) & & & & & & & & & \\
\hline & - Força maior (guerra, greve, terremotos, etc.) ou fatores externos & & & & & & & & & \\
\hline
\end{tabular}

Fonte: O Autor 


\subsection{Caracterização e planejamento desta pesquisa}

\subsubsection{Escolha das obras para estudo}

Para que os dados obtidos com as pesquisas de campo fossem aproveitáveis e contribuam adequadamente com os resultados do trabalho a escolha dos empreendimentos foi extremamente importante.

Desta forma, foram identificados projetos que estejam dentro das restrições estabelecidas no plano de pesquisa, que neste caso deveriam possuir as seguintes características:

- Empreendimentos de construção similares (edificações residenciais de médio ou grande porte, com ao menos 10 pavimentos, garantindo certa repetitividade de serviços em cada torre);

- Realizadas totalmente pelo setor privado (descarta-se obras públicas ou Parcerias Público-Privadas - PPPs);

- Com prazos relativamente longos, onde há a possibilidade de se avaliar efeitos de ações gerenciais (ao menos 12 meses de obra);

- Obras com atrasos relativamente expressivos em relação à linha de base ou contratos, ou seja, cujas penalidades ou consequências sejam importantes às empresas construtoras;

- Onde o pesquisador tenha acesso a informações fornecidas pela alta direção das empresas envolvidas, mas principalmente pelos responsáveis técnicos pelos empreendimentos (gerentes, coordenadores de obra, dentre outros).

Tais características foram escolhidas por conveniência deste autor, relacionada ao ambiente profissional de atuação, buscando-se assim a disponibilidade de número suficiente de obras para se compor uma amostra representativa.

Apenas como esclarecimento, as caracterizações do porte das construtoras foram realizadas de forma subjetiva, apenas para auxiliar no entendimento da amostra escolhida. Isto porque a definição exata depende de dados contábeis não disponíveis, além da interpretação da quantidade de empregados por empresa, que no caso da construção, podem estar alocados de formas diferentes dentro da empresa em si ou 
nas diversas Sociedades de Propósito Específico (SPE) que são abertas para comercialização e execução de cada empreendimento imobiliário.

Como parâmetro mais direto, sem considerar receitas anuais, por exemplo, utilizouse como referência as definições do SEBRAE (2013), que estabelece o setor da construção como uma indústria e o porte das empresas relacionado ao número de funcionários ou pessoas ocupadas. Desta forma, as empresas de pequeno porte teriam menos de 100 pessoas ocupadas a as de grande porte mais de 500 pessoas ocupadas, restando às empresas de médio porte a faixa intermediária entre as duas classificações.

Além disso, a escolha dos empreendimentos analisados priorizou alguns fatores que possibilitassem as avaliações mais realistas e que possam ao final do trabalho ser conclusivas, evitando-se (mas não garantindo) que as conclusões sejam demasiadamente influenciadas por características específicas de local, empresa, profissionais e/ou época. Assim, buscou-se que as obras estudadas:

- Sejam de localidades diversas (pelo menos 10 cidades diferentes);

- Sejam de empresas diferentes (pelo menos 20 construtoras diferentes);

- Tenham períodos de execução dentro de um prazo distribuído relativamente igual ao longo dos 5 anos de pesquisa;

- Grande parte dos empreendimentos seja acompanhado do início ao fim.

Analogamente ao que foi esclarecido em relação à escolha da tipologia de obras, para a definição do número mínimo de localidades e de construtoras que seriam contempladas na pesquisa, não se utilizou um critério probabilístico. Foi definido um número "redondo" considerado grande o suficiente para uma análise crítica posterior.

Desta forma o primeiro contato com os envolvidos no projeto foi extremamente crítico e direto, buscando-se identificar toda a estrutura de gestão e empresas envolvidas, garantindo-se que os parâmetros inicialmente previstos fossem atendidos. 


\subsubsection{Elaboração do protocolo de estudo}

Atendendo recomendações descritas por Yin (2010) e as diretrizes estabelecidas no capítulo 2 para se organizar o banco de dados dos estudos de campo, buscou-se a elaboração de um protocolo de referência. Este protocolo orientou a maneira como os dados seriam coletados, uma vez que em um estudo como este provavelmente as informações seriam disponibilizadas com estruturas e detalhamentos diferentes em cada empreendimento estudado.

Assim, primeiramente buscou-se organizar uma lista de causas de atrasos comumente encontradas nas referências bibliográficas, de maneira a orientar a investigação, garantindo no mínimo que ao final de cada análise se obtivesse informações preliminares de evidência ou não nas obras pesquisadas, dos fatos relatados pelos autores estudados.

Como as descrições em cada trabalho publicado eram diferentes, buscou-se a consolidação destas informações em uma classificação única. Em seguida, esta classificação foi conferida, identificando-se a citação de cada um dos itens de atraso nas pesquisas publicadas, adequando-se a descrição utilizada pelo autor em outra classificação similar.

O resultado desta compilação será apresentado no item 4.4.3.

Verificou-se na maior parte dos trabalhos, que os motivos descritos eram abrangentes, destacando-se problemas ocorridos na obra como um todo, e não relacionando-se com determinados atividades, serviços ou etapas da obra. Além disso, as causas não foram correlacionadas a possíveis tipologias diferentes dos projetos abordados pelos autores.

Assim, esta pesquisa poderia propiciar uma coleta mais detalhadas do que os trabalhos de referência, se o protocolo também garantisse que estas informações seriam investigadas nos estudos de campo.

O protocolo para a primeira pesquisa de campo foi estruturado na forma de um fluxograma simplificado com 4 etapas orientativas de investigação e é representado na figura 57 . 
Figura 57 - Protocolo para realização da primeira pesquisa de campo

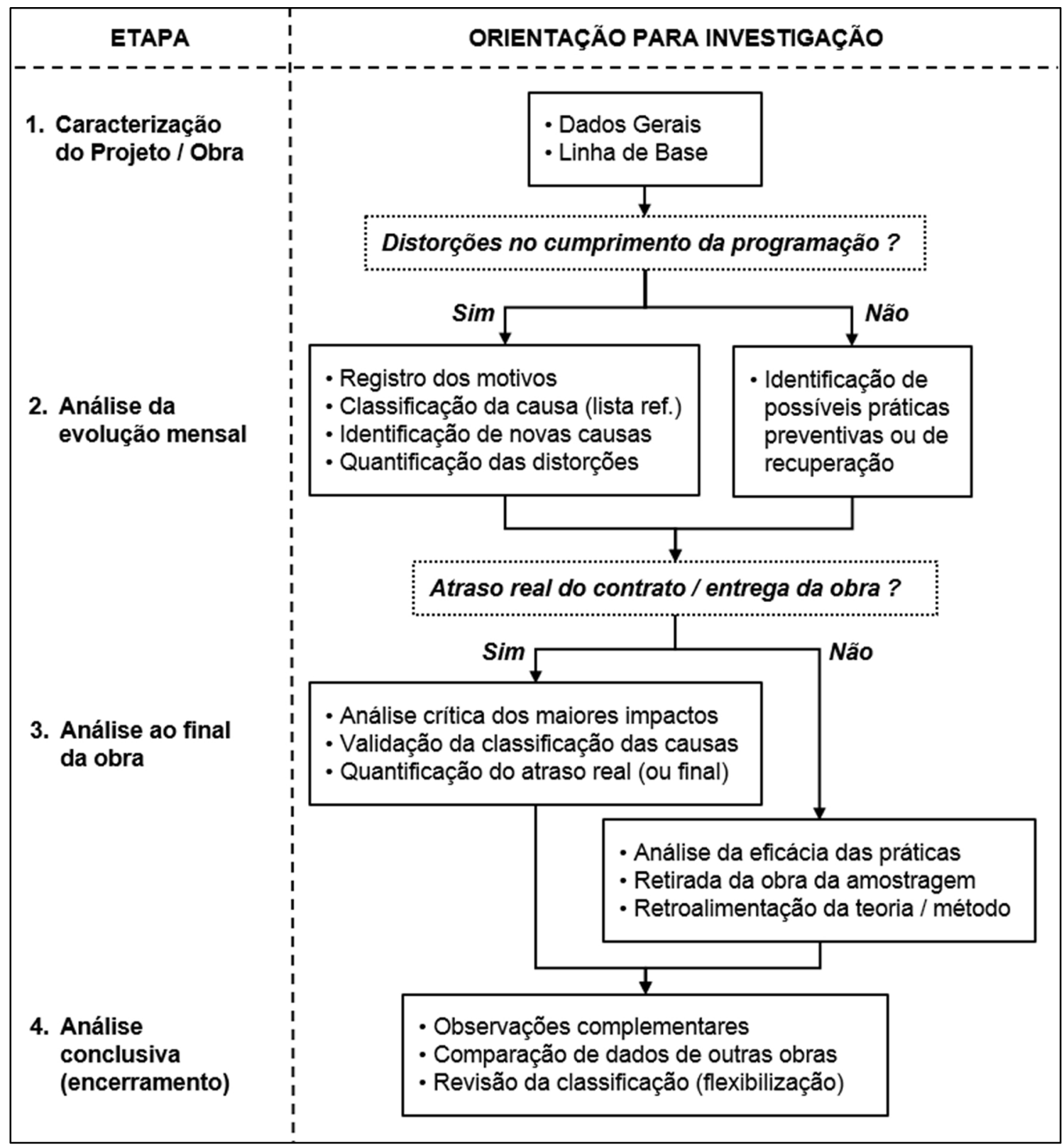

Fonte: O Autor

\subsubsection{Fontes de evidência}

As fontes de evidência estão relacionadas com as características da coleta de dados. Uma vez que o método proposto é o ex-post facto, serão utilizadas fontes de evidência compatíveis, tais como descritas a seguir:

- Unidade de análise: processos de planejamento e gestão de prazos em empreendimentos de construção civil residenciais ou comerciais;

- Unidade de coleta de dados: pessoas, mas principalmente documentos disponíveis no processo de planejamento e gestão do empreendimento; 
- Fontes de coleta: documentos relativos à evolução da obra, em especial os relatórios gerenciais de acompanhamento do desempenho físico de cada obra.

Com base no histórico mensal de cada empreendimento, descrito nos relatórios gerenciais de desempenho físico, foi possível analisar em que momento da obra ocorreram os problemas e qual o impacto deles no prazo final.

Os dados descritos nos relatórios gerenciais analisados seriam insuficientes para a avaliação adequada das causas. Por essa razão, de forma a complementar a análise dos fatos, previu-se a realização de entrevistas com a equipe operacional da obra, com a equipe técnica de planejamento e controle da empresa, ou ainda com terceirizados contratados especificamente para as atividades de planejamento.

As entrevistas focaram resgatar os problemas normalmente ocultos em relatórios, atas ou diários de obra, e ainda buscar o enquadramento do(s) fato(s) resultante(s) do atraso nas classificações propostas pelo protocolo.

\subsection{Pesquisa aplicada}

\subsubsection{Análise das obras piloto e validação do protocolo de estudo}

O protocolo descrito no item 4.3.2 foi implantado de forma preliminar em 3 empreendimentos. Os resultados nestas obras revelaram a necessidade de uma abertura maior para algumas causas de atraso não previstas, ou que na verdade estariam abrangidas por outra classificação de atraso.

Após uma pequena alteração no conteúdo e a inclusão de parte do banco de dados para a coleta de informações não específicas (mas que poderiam auxiliar no desenvolvimento das premissas desta tese), o protocolo foi validado e implantado para as demais obras, repetindo-se a avaliação das três primeiras obras com base no protocolo revisado.

\subsubsection{Amostra obtida na pesquisa de campo}

Os 50 empreendimentos analisados têm suas caraterísticas descritas na tabela 2. 
Tabela 2 - Características das obras pesquisadas

\begin{tabular}{|c|c|c|c|c|c|c|c|c|c|c|}
\hline Obra & Construtora & Cidade & Torres & $\begin{array}{c}\text { Área } \\
\text { Constr. }\end{array}$ & Início & $\begin{array}{l}\text { Término } \\
\text { Previsto }\end{array}$ & $\begin{array}{l}\text { Prazo } \\
\text { (mês) }\end{array}$ & $\begin{array}{c}\text { Término } \\
\text { Real }\end{array}$ & $\begin{array}{l}\text { Atraso } \\
\text { (mês) }\end{array}$ & $\%$ \\
\hline 1 & A & São Paulo & 2 & 8.140 & 01/01/2006 & $01 / 11 / 2007$ & 22 & $20 / 06 / 2008$ & 8 & $35 \%$ \\
\hline 2 & B & São Paulo & 2 & 24.080 & $10 / 02 / 2007$ & $05 / 11 / 2008$ & 21 & $14 / 01 / 2009$ & 2 & $11 \%$ \\
\hline 3 & $S$ & Goiânia & 1 & 30.000 & $01 / 05 / 2007$ & $12 / 06 / 2009$ & 26 & $30 / 01 / 2010$ & 8 & $30 \%$ \\
\hline 4 & C & São Paulo & 1 & 9.477 & $04 / 05 / 2007$ & $11 / 09 / 2008$ & 17 & $23 / 10 / 2008$ & 1 & $8 \%$ \\
\hline 5 & $C$ & São Paulo & 1 & 21.273 & $17 / 07 / 2007$ & $27 / 11 / 2009$ & 29 & $21 / 05 / 2010$ & 6 & $20 \%$ \\
\hline 6 & $\mathrm{D}$ & São Paulo & 1 & $7.078^{* *}$ & $01 / 08 / 2007$ & $30 / 03 / 2009$ & 20 & $01 / 10 / 2009$ & 6 & $30 \%$ \\
\hline 7 & $\mathrm{D}$ & Santo André & 2 & 20.088 & $01 / 08 / 2007$ & $01 / 02 / 2009$ & 18 & $01 / 10 / 2009$ & 8 & $44 \%$ \\
\hline 8 & $C$ & São Paulo & 1 & 13.195 & $08 / 08 / 2007$ & $08 / 01 / 2010$ & 29 & $29 / 05 / 2010$ & 5 & $16 \%$ \\
\hline 9 & $C$ & São Paulo & 1 & 11.414 & $01 / 10 / 2007$ & $01 / 02 / 2010$ & 28 & $27 / 08 / 2010$ & 7 & $24 \%$ \\
\hline 10 & $E$ & São Paulo & 4 & 25.984 & $01 / 11 / 2007$ & $01 / 07 / 2009$ & 20 & $15 / 01 / 2010$ & 7 & $33 \%$ \\
\hline 11 & $\mathrm{~F}$ & São Paulo & 1 & $4.367^{* \star}$ & $01 / 12 / 2007$ & $01 / 07 / 2009$ & 19 & $10 / 09 / 2009$ & 2 & $12 \%$ \\
\hline 12 & $S$ & Goiânia & 1 & 25.000 & $01 / 12 / 2007$ & $03 / 12 / 2009$ & 24 & $28 / 06 / 2010$ & 7 & $28 \%$ \\
\hline 13 & G & São Paulo & 1 & 23.313 & $31 / 01 / 2008$ & $01 / 11 / 2008$ & $9^{*}$ & $19 / 02 / 2009$ & 4 & $40 \%$ \\
\hline 14 & $\mathrm{H}$ & S.B.Campo & 4 & 28.000 & $02 / 05 / 2008$ & $30 / 11 / 2010$ & 31 & 10/03/2011 & 3 & $11 \%$ \\
\hline 15 & $\mathrm{H}$ & São Paulo & 2 & 15.000 & $02 / 05 / 2008$ & $02 / 02 / 2011$ & 34 & $15 / 04 / 2011$ & 2 & $7 \%$ \\
\hline 16 & $P$ & Praia Grande & 2 & 69.900 & $02 / 06 / 2008$ & $27 / 10 / 2010$ & 29 & $30 / 07 / 2011$ & 9 & $31 \%$ \\
\hline 17 & 1 & São Paulo & 1 & 9.221 & $15 / 09 / 2008$ & $31 / 08 / 2010$ & 24 & $28 / 02 / 2011$ & 6 & $25 \%$ \\
\hline 18 & $\mathrm{~J}$ & São Paulo & 3 & 27.000 & $15 / 09 / 2008$ & $24 / 05 / 2010$ & 21 & $30 / 09 / 2010$ & 4 & $21 \%$ \\
\hline 19 & 1 & São Paulo & 1 & 9.223 & $22 / 09 / 2008$ & $31 / 12 / 2010$ & 28 & $15 / 05 / 2011$ & 5 & $16 \%$ \\
\hline 20 & $\mathrm{~K}$ & São Paulo & 1 & 21.358 & $01 / 10 / 2008$ & $01 / 12 / 2010$ & 26 & $20 / 01 / 2011$ & 2 & $6 \%$ \\
\hline 21 & $C$ & São Paulo & 1 & 13.432 & $21 / 10 / 2008$ & $26 / 04 / 2011$ & 31 & $24 / 06 / 2011$ & 2 & $6 \%$ \\
\hline 22 & B & São Paulo & 1 & 18.711 & $01 / 12 / 2008$ & $31 / 07 / 2010$ & 20 & $28 / 12 / 2010$ & 5 & $25 \%$ \\
\hline 23 & B & São Paulo & 1 & 16.395 & $01 / 12 / 2008$ & $30 / 07 / 2010$ & 20 & $07 / 01 / 2011$ & 5 & $27 \%$ \\
\hline 24 & $x$ & RibeirãoPreto & 2 & 28.000 & $01 / 07 / 2009$ & $29 / 02 / 2012$ & 32 & $30 / 09 / 2012$ & 7 & $22 \%$ \\
\hline 25 & $Q$ & Natal & 1 & 13.302 & $01 / 08 / 2009$ & $31 / 10 / 2011$ & 27 & $31 / 05 / 2012$ & 7 & $26 \%$ \\
\hline 26 & $U$ & São Paulo & 1 & 28.601 & $01 / 10 / 2009$ & $02 / 08 / 2012$ & 35 & 16/11/2012 & 4 & $10 \%$ \\
\hline 27 & $\mathrm{~L}$ & São Paulo & 2 & 23.119 & $11 / 11 / 2009$ & $30 / 08 / 2011$ & 22 & $30 / 06 / 2012$ & 10 & $46 \%$ \\
\hline 28 & $Q$ & Natal & 3 & 40.588 & $01 / 01 / 2010$ & $31 / 12 / 2011$ & 24 & $30 / 06 / 2012$ & 6 & $25 \%$ \\
\hline 29 & Z & São Paulo & 4 & 29.000 & $01 / 09 / 2010$ & 13/01/2012 & 17 & $31 / 08 / 2012$ & 8 & $46 \%$ \\
\hline 30 & C & Santos & 1 & 21.491 & $18 / 09 / 2010$ & $30 / 04 / 2013$ & 32 & $31 / 07 / 2013$ & 3 & $10 \%$ \\
\hline 31 & $\mathrm{~L}$ & São Paulo & 3 & 52.893 & $01 / 11 / 2010$ & $30 / 11 / 2012$ & 25 & $30 / 01 / 2013$ & 2 & $8 \%$ \\
\hline 32 & M & Guarulhos & 3 & 35.886 & $01 / 11 / 2010$ & $26 / 06 / 2012$ & 20 & $31 / 10 / 2012$ & 4 & $21 \%$ \\
\hline 33 & $\mathrm{R}$ & Barueri & 1 & 34.658 & 01/12/2010 & $31 / 05 / 2013$ & 30 & $30 / 11 / 2013$ & 6 & $20 \%$ \\
\hline 34 & C & S.CaetanoSul & 4 & 80.750 & $01 / 03 / 2011$ & $30 / 07 / 2013$ & 29 & $30 / 09 / 2013$ & 2 & $7 \%$ \\
\hline 35 & $C$ & Campinas & 2 & 14.621 & $15 / 03 / 2011$ & $14 / 01 / 2013$ & 22 & $29 / 08 / 2013$ & 8 & $34 \%$ \\
\hline 36 & $M$ & Taboão Serra & 4 & 64.300 & 01/04/2011 & $29 / 03 / 2013$ & 24 & $31 / 01 / 2014$ & 10 & $42 \%$ \\
\hline 37 & $\mathrm{M}$ & São Paulo & 6 & 15.500 & $02 / 05 / 2011$ & $31 / 10 / 2012$ & 18 & $30 / 04 / 2013$ & 6 & $33 \%$ \\
\hline 38 & C & São Paulo & 1 & 15.200 & $01 / 06 / 2011$ & $10 / 05 / 2013$ & 24 & $30 / 08 / 2013$ & 4 & $16 \%$ \\
\hline 39 & $T$ & Florianópolis & 3 & 26.318 & $02 / 06 / 2011$ & $02 / 02 / 2013$ & 20 & $20 / 03 / 2014$ & 14 & $67 \%$ \\
\hline 40 & 0 & São Paulo & 2 & 18.561 & $24 / 06 / 2011$ & $24 / 05 / 2013$ & 23 & $29 / 09 / 2013$ & 4 & $18 \%$ \\
\hline 41 & $\mathrm{~N}$ & São Paulo & 2 & 12.855 & 01/07/2011 & $30 / 06 / 2013$ & 24 & $30 / 11 / 2013$ & 5 & $21 \%$ \\
\hline 42 & 0 & São Paulo & 1 & 4.400 & $13 / 02 / 2012$ & $28 / 02 / 2013$ & 13 & $30 / 03 / 2013$ & 1 & $8 \%$ \\
\hline 43 & 0 & São Paulo & 1 & 11.485 & $14 / 04 / 2012$ & $28 / 02 / 2014$ & 23 & $30 / 05 / 2014$ & 3 & $13 \%$ \\
\hline 44 & M & São Paulo & 3 & 12.293 & 02/05/2012 & $30 / 08 / 2013$ & 16 & $20 / 12 / 2013$ & 4 & $23 \%$ \\
\hline 45 & $\mathrm{~L}$ & Santos & 1 & 11.332 & 01/08/2012 & 18/11/2014 & 28 & $21 / 08 / 2015$ & 9 & $33 \%$ \\
\hline 46 & C & Piracicaba & 3 & 55.219 & $01 / 09 / 2012$ & $27 / 02 / 2015$ & 30 & $30 / 09 / 2015$ & 7 & $24 \%$ \\
\hline 47 & $\mathrm{M}$ & São Paulo & 6 & 37.000 & $17 / 09 / 2012$ & $31 / 01 / 2014$ & 17 & $30 / 08 / 2014$ & 7 & $42 \%$ \\
\hline 48 & 0 & São Paulo & 1 & 4.827 & 04/01/2013 & $04 / 03 / 2014$ & 14 & $22 / 09 / 2014$ & 7 & $48 \%$ \\
\hline 49 & V & São Paulo & 1 & 16.610 & $15 / 04 / 2013$ & $01 / 04 / 2015$ & 24 & $15 / 08 / 2015$ & 5 & $19 \%$ \\
\hline 50 & $\mathrm{~J}$ & São Paulo & 2 & 19.398 & $02 / 09 / 2013$ & $30 / 06 / 2015$ & 22 & $31 / 08 / 2015$ & 2 & $9 \%$ \\
\hline
\end{tabular}

$\left({ }^{\star}\right)$ Obra reiniciada, por isto o prazo previsto é pequeno, $\left.{ }^{* *}\right)$ Área útil e não construída 
Como pode ser observado, os empreendimentos selecionados localizam-se principalmente na região metropolitana de São Paulo. No entanto, conseguiu-se ao menos 11 projetos (mais de 20\%) fora desta região geográfica. No total, conseguiuse uma amostra em 15 cidades diferentes.

As datas de execução foram distribuídas de maneira uniforme, como previsto nas diretrizes iniciais, variando com inícios entre 2006 e 2013, sendo que o último empreendimento analisado foi entregue em 2015. Os prazos em geral variaram de 13 a 35 meses. Há um único caso de prazo onde se identifica 9 meses, mas neste caso específico, trata-se de um projeto onde a construtora assumiu uma obra anteriormente embargada e por esta razão o prazo da linha de base referencial era para a finalização da obra, que já apresentava estrutura completa e boa parte da alvenaria executada.

Como forma de se iniciar as avaliações dos empreendimentos com obras que evidentemente apresentaram problemas, verifica-se que estes empreendimentos apresentaram no mínimo $5 \%$ de atraso. Assim, todos eles contribuíram de forma importante para as avaliações de atrasos e seus motivos.

Além da diversidade das obras, buscou-se encontrar empreendimentos que fossem executados por diferentes construtoras.

Ao todo foram analisadas 24 construtoras, responsáveis pelos 50 empreendimentos escolhidos para a amostra, com características diferentes:

- As construtoras "A", "F”, "G”, "H”, “J”, "N", “R”, “U”, "V” e "Z" são de pequeno porte e realizam poucas obras simultâneas, normalmente na região metropolitana de São Paulo e normalmente regionalizadas (em bairros próximos ou áreas específicas da cidade);

- As construtoras "C", "E", “K", "L”, "M" e "P" são de médio porte, com maior estrutura e atuam no mercado paulistano em geral, incluindo interior e baixada santista;

- As construtoras "S", "T" e "X", são empresas de pequeno porte com atuação regional em cidades grandes, mas fora do eixo Rio-São Paulo;

- A construtora " $Q$ " é uma grande empresa que tem forte atuação em toda a região Nordeste do país; 
- Já as construtoras "B", “D”, "I" e "O” compõe a lista das quinze maiores construtoras do mercado imobiliário brasileiro em área construída, e embora concentrem suas atividades no Rio de Janeiro e São Paulo, atuam nacionalmente, sendo 2 delas de capital aberto.

Os prazos e atrasos foram expressos em meses "cheios" (valores arredondados), para se gerar uma ordem de grandeza que facilitasse o entendimento imediato dos impactos em cada empreendimento, embora o cálculo final (\%) tenha considerado os dias exatos entre os as datas de início e término.

Através do histórico de cada uma das obras, durante toda sua fase de execução, realizou-se uma avaliação qualitativa dos fatos que causaram em algum momento, atrasos parciais nas atividades programadas e que se somados caracterizaram o atraso global indicado neste quadro.

Nesta pesquisa não houve preocupação com a identificação de quais desses fatos impactaram de forma mais contundente o atraso final (ou seja, aqueles que possivelmente afetaram o caminho crítico da obra), e sim a frequência com que eles ocorrem nas obras. Posteriormente, em uma pesquisa mais abrangente, a classificação desses impactos poderá ser também estudada.

\subsubsection{Resultados da pesquisa de campo}

Após a avaliação detalhada do histórico de cada empreendimento, os resultados foram compilados de forma que se pudesse identificar em quantas obras a causa foi evidenciada, tanto nos relatórios como nas entrevistas. Assim, de um total de 50 empreendimentos, a quantidade de obras onde se verificou a ocorrência gerou uma porcentagem caracterizada simplificadamente como a "frequência" de ocorrência.

Os resultados completos de cada empreendimento (vinculação da causa com o histórico da obra) foram anexados ao final desta tese (Apêndice A).

Uma vez que o protocolo de pesquisa foi baseado em fatores levantados em outros países, que podem ter realidades diferentes, alguns ajustes precisaram ser feitos, ainda mais em se tratando de uma pesquisa qualitativa analítica. 
Um exemplo interessante desse fato foi a identificação de uma causa de atraso relacionada ao roubo de materiais dentro do canteiro, item não contemplado na lista, mas que foi adaptado para o item do Grupo 6 "materiais danificados ou problemas de manuseio de materiais", uma vez que os impactos desse tipo de problema são similares (considerando, por exemplo, quando parte dos materiais é danificada e precisa ser descartada).

Outras adaptações importantes estão relacionadas à organização do trabalho e à forma de estruturação de equipes características de algumas regiões do país, em especial a região metropolitana de São Paulo, que contempla a grande maioria dos empreendimentos da amostra. Nestas regiões é muito comum a utilização de subempreiteiros para a grande maioria dos serviços dentro do canteiro, o que difere de cidades no interior do estado e de outras regiões do Brasil, como o Nordeste.

Assim, algumas causas listadas no protocolo, como "atraso na mobilização da mão de obra", podem estar relacionadas a problemas ou atraso na contratação de tais subempreiteiros, muito mais do que à estruturação de uma equipe de produção da própria construtora.

Por fim, outra realidade encontrada nas obras refere-se a problemas de terminalidade (quando atividades predecessores não são integralmente finalizados por algum motivo de tal forma que mesmo com pequenos detalhes ou ajustes, não possibilitam a entrada do próximo serviço) e ou faltas de frente de serviço para esses subempreiteiros, e como tais fatores não estão claramente expressos no protocolo foram classificados como "problemas de programações de subempreiteiros" ou mesmo como "interferência de subempreiteiros em outras atividades".

Para facilitar a análise desses resultados, ordenou-se a frequência encontrada, criando-se um ranking e buscou-se focar a avaliação nas 20 causas mais frequentes, referenciando-se o Princípio de Pareto $^{6}$, como indicado na tabela 3.

(6) Pelo Princípio ou Lei de Pareto, dentre várias interpretações, $80 \%$ das consequências decorrem de $20 \%$ das causas (ou ainda, $20 \%$ do esforço relaciona-se com $80 \%$ dos resultados). Esta lei foi proposta por Joseph Juran, famoso consultor de negócios. E sugeriu esse nome em homenagem ao economista italiano Vilfredo Pareto, que em suas pesquisas no final do século XIX, observou que $80 \%$ da renda na Itália provinha de apenas $20 \%$ da população. 
Tabela 3 - As causas mais frequentes, compiladas na pesquisa

\begin{tabular}{|c|c|c|c|c|c|c|}
\hline & Ranking & & $\begin{array}{l}\text { scrição resumida da causa do atraso identificada nas } \\
\text { obras pesquisadas }\end{array}$ & & $\begin{array}{c}\mathbf{N}^{\circ} \\
\text { Obras }\end{array}$ & Frequência \\
\hline | & $1^{\circ}$ & A) & Má gestão ou organização das equipes no canteiro de obras & 5 & 34 & $68,0 \%$ \\
\hline & $2^{\circ}$ & B) & Interferência de equipes / subempreiteiros em outras atividades & 5 & 33 & $66,0 \%$ \\
\hline 1 & $3^{\circ}$ & C) & Planejamento mal feito ou programação de serviço ineficaz & 5 & 30 & $60,0 \%$ \\
\hline 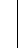 & $3^{\circ}$ & & Baixo nível de produtividade do trabalho (MDO ruim) & 7 & 30 & $60,0 \%$ \\
\hline 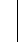 & $5^{\circ}$ & E) & Atraso ou pouca mobilização de MDO no canteiro & 5 & 27 & $54,0 \%$ \\
\hline 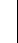 & $5^{\circ}$ & F) & Retrabalho devido a erros durante a construção & 5 & 27 & $54,0 \%$ \\
\hline ( & $7^{\circ}$ & & Atraso na entrega de material & 6 & 24 & $48,0 \%$ \\
\hline 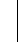 & $8^{\circ}$ & & Escassez de MDO (não fornecimento) & 7 & 23 & $46,0 \%$ \\
\hline & $9^{\circ}$ & I) & Demora na tomada de decisões internas (na produção) & 5 & 22 & $44,0 \%$ \\
\hline tan & $10^{\circ}$ & J) & Reprogramação inadequada (não reflete a realidade da obra) & 5 & 21 & $42,0 \%$ \\
\hline 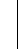 & $10^{\circ}$ & & Conflitos nas programações das equipes ou subempreiteiros & 5 & 21 & $42,0 \%$ \\
\hline & $10^{\circ}$ & L) & Programação de entregas no canteiro mal feita ou tardia & 6 & 21 & $42,0 \%$ \\
\hline | & $10^{\circ}$ & & Duração do contrato irrealista (muito curta) & 1 & 21 & $42,0 \%$ \\
\hline & $14^{\circ}$ & N) & Atrasos no trabalho de terceiros que seguram frentes de serviço & 5 & 19 & $38,0 \%$ \\
\hline | & $15^{\circ}$ & & Demora na tomada de decisão pelo empreendedor & 2 & 18 & $36,0 \%$ \\
\hline 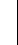 & $15^{\circ}$ & & Atraso na entrega de equipamentos & 8 & 18 & $36,0 \%$ \\
\hline 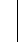 & $17^{\circ}$ & & Indefinições de contrato ou escopo / negociações inconclusivas & 1 & 15 & $30,0 \%$ \\
\hline | & $17^{\circ}$ & R) & Falta ou pouca supervisão de equipes / empreiteiros (ou tardia) & 5 & 15 & $30,0 \%$ \\
\hline & $17^{\circ}$ & & Mudança frequente de subempreiteiros(ineficiência/recuperação) & 5 & 15 & $30,0 \%$ \\
\hline | & $17^{\circ}$ & & Tempo / Condições Meteorológicas (calor, chuva, outros) & 10 & 15 & $30,0 \%$ \\
\hline | & $-21^{0}-$ & -- & 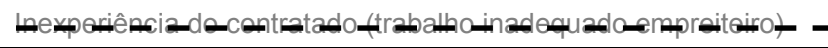 & $-5-$ & $-14-$ & $--220 \%--$ \\
\hline & $22^{\circ}$ & & Tipo de contrato inadequado (turn key, administração, PMG,.. & 1 & 13 & $26,0 \%$ \\
\hline & $22^{\circ}$ & & Estudo técnico, viabilidade mal feito / ignoraram-se os riscos & 1 & 13 & $26,0 \%$ \\
\hline & $22^{\circ}$ & & Inexperiência do empreendedor como contratante & 2 & 13 & $26,0 \%$ \\
\hline & $22^{\circ}$ & & Interferências do empreendedor ou proprietário nas operações & 2 & 13 & $26,0 \%$ \\
\hline & $22^{\circ}$ & & Atraso na elaboração de desenhos, especificações & 5 & 13 & $26,0 \%$ \\
\hline & $\ldots$ & & $\ldots$ & & & $\ldots$ \\
\hline & $96^{\circ}$ & & Restrições ambientais & 10 & 1 & $2,0 \%$ \\
\hline & $96^{\circ}$ & & Mudanças de leis e regulamentações & 10 & 1 & $2,0 \%$ \\
\hline & $98^{\circ}$ & & Inflexibilidade (rigidez) do consultor ou projetista & 3 & 0 & $0,0 \%$ \\
\hline & $98^{\circ}$ & & Flutuações dos preços de material e equipamentos (ou câmbio) & 10 & 0 & $0,0 \%$ \\
\hline & $98^{\circ}$ & & Força Maior (guerra, greve, terremotos, outros) & 10 & 0 & $0,0 \%$ \\
\hline
\end{tabular}

Fonte: O Autor

Observa-se que os 20 primeiros itens do ranking (portanto $20 \%$ das causas) obtiveram frequência igual ou maior do que $30 \%$, considerando-se dentro de uma zona confiável como objeto de análise crítica, ou mesmo entendido como impactante.

A compilação das frequências totais (e consequente ordenação dos resultados) foi anexada ao final desta tese (Apêndice B). 
Verifica-se que o Grupo 5 (Construtora ou Empreiteiro) detém a maior concentração de causas de atraso das obras (cinco itens entre os seis primeiros), sendo que em mais de dois terços dos empreendimentos estudados (68\%) verificam-se problemas de gestão das equipes no canteiro e de como elas são organizadas.

Esse fato é reforçado quando analisam-se outros fatores apontados como mais frequentes, como interferências entre as atividades (66\%) e atraso na mobilização (54\%), que estão intimamente ligados à boa gestão das equipes no canteiro.

Percebem-se também muitos problemas relacionados ao fornecimento de materiais (48\%) e sua programação de entrega (42\%), ou seja, um impacto importante da cadeia de suprimentos nos atrasos dessas obras. Convém lembrar que não se trata exclusivamente de falhas de fornecedores, uma vez que também se identificaram muitos problemas de programação e de contratação feitas pela construtora. Dessa forma, diversos motivos dos atrasos de entrega dos materiais estão relacionados também a compras emergenciais ou fora dos trâmites adequados e prazos de entrega requeridos pelos fornecedores.

Fatores relacionados à realidade do mercado brasileiro também podem ser observados como impactantes, tais como a baixa produtividade (60\%) e a escassez da mão de obra (46\%), fatores estes que impactam de forma indireta em outro item muito citado, embora menos frequente $(38 \%)$ como o que se denominou "atraso de terceiros", claramente relacionados aos altos índices de improdutividade e escassez de trabalhadores.

Diferentemente do que foi constatado pelos autores pesquisados na revisão da literatura, as questões financeiras não são vistas como impactantes nas obras aqui estudadas, e as interferências do proprietário ou empreendedor também. Essa diferença pode estar relacionada tanto pela estrutura do setor imobiliário brasileiro atual como pela tipologia de obras que foram utilizadas nas amostragens.

Alguns dos trabalhos de autores pesquisados incluíam, além de obras imobiliárias particulares, similares às da amostra desta tese, alguns empreendimentos de construção para órgãos públicos, o que difere da amostra desta pesquisa. 


\subsubsection{Desdobramentos da pesquisa}

Como alguns dos resultados encontrados na revisão bibliográfica, notadamente em pesquisas de outros países, apresentam pontos relativamente diferentes em comparação aos que foram identificados nesta primeira pesquisa, entende-se importante uma reflexão sobre a realidade de algumas destas regiões que foram estudadas por estes autores.

Em alguns países que apresentam situações políticas ou econômicas mais instáveis, como em Gana e Paquistão, as ações elencadas, além de tratar de processos produtivos, focam em questões estruturais das empresas envolvidas nos projetos.

Haseeb et al. (2011) destacam a necessidade de modelos financeiros menos suscetíveis a mudanças de governo e investimentos em equipamentos mais modernos de produção.

Fugar e Agyakwah-Baah (2010) evidenciam a prioridade na alocação de profissionais mais qualificados nas obras e a diminuição da burocracia dos processos financeiros das empresas, uma realidade local.

Alguns autores estabelecem diretrizes mais globais. Tanto Marzouk e El-Rasas (2014) como Olawale e Sun (2010) estabelecem recomendações para os problemas identificados em todos os grupos de classificação das causas, tendo esse último trabalho descrito em detalhes as ações mitigatórias, com cerca de 90 fatores inibidores de atraso.

Russell et al. (2014), por exemplo, identificam em sua pesquisa variações muito grandes entre as causas dos atrasos e os motivos pelos quais são incluídos buffers nos planejamentos dessas obras, mostrando a necessidade de pesquisas mais aprofundadas em todos os níveis de gestão dos empreendimentos.

Talvez Günduz et al. (2013) identifiquem resultados mais próximos daqueles verificados nesta pesquisa, quando estabelecem como diretrizes de mitigação dos atrasos: alocação de pessoas ou empresas mais capacitadas para a execução dos projetos; melhoria nas ferramentas de planejamento; e agilidade na tomada de decisões, comunicação e coordenação dos vários agentes dos processos de execução de uma obra. 


\subsection{Conclusões da primeira pesquisa de campo}

Como já observado, as causas mais significativas dos atrasos identificados nas obras pesquisadas são relativamente diferentes daquelas apresentadas pelos autores pesquisados. Mas, independentemente da região e das características dos empreendimentos, os principais problemas observados nas 50 obras parecem estar relacionados muito mais às questões internas, de organização do canteiro e dos gestores das construtoras contratadas, do que a questões externas que possam impactar a obra.

Dessa forma, verifica-se a importância do investimento em qualificação, sistemas e metodologias, mesmo que simplificados, de planejamento e controle de obras. Evidencia-se que, embora muitas das questões relacionadas a atrasos sejam afetadas por fatores externos (chuvas, solo, mercado, cliente, dentre outros), e que frequentemente os discursos dos envolvidos foquem nesses aspectos, estes são identificados como motivadores de atrasos de menor relevância.

Esse fato motiva ainda mais os estudos do tema, mostrando que é preciso retomar os esforços para se entenderem processos, ferramentas, recursos humanos, e como todos esses fatores se interligam para a obtenção do sucesso do projeto.

Da mesma forma, os resultados desta pesquisa podem ser úteis para promover estudos mais detalhados. Um dos focos seria a identificação e comparação de causas de atraso em projetos de natureza diferente dos aqui pesquisados (tais como obras horizontais ou em outras regiões do Brasil). Outro também importante seria identificar, ou até mesmo estruturar, ações ou métodos que ajudem no combate dessas causas e consequentemente diminuam os problemas de atrasos de empreendimentos.

Convém citar também que durante a realização da pesquisa completa, parte dos dados coletados foram analisados e divulgados em um artigo acadêmico: De Filippi e Melhado (2015). 


\section{INÍCIO DA ESTRUTURAÇÃO DO MÉTODO}

\subsection{Tratamento dos resultados e estruturação inicial do método}

Com base nos dados coletados na pesquisa de campo, iniciou-se uma análise qualitativa de cada causa de atraso e quais caminhos são possíveis para se evitar sua ocorrência.

As causas similares foram agrupadas, convergindo-se a grupos cujos objetivos estivessem claros e abrangentes, o que se denominou "Diretrizes".

Em seguida, agora referenciando-se à vasta literatura levantada, bem como experiência profissional do autor, idealizaram-se diversos exemplos de ações concretas (práticas) que são usualmente identificadas em obras desta natureza.

O método que foi desenvolvido teria inicialmente uma estruturação similar à que é apresentada na figura 58 .

Figura 58 - Estruturação do artefato (método)

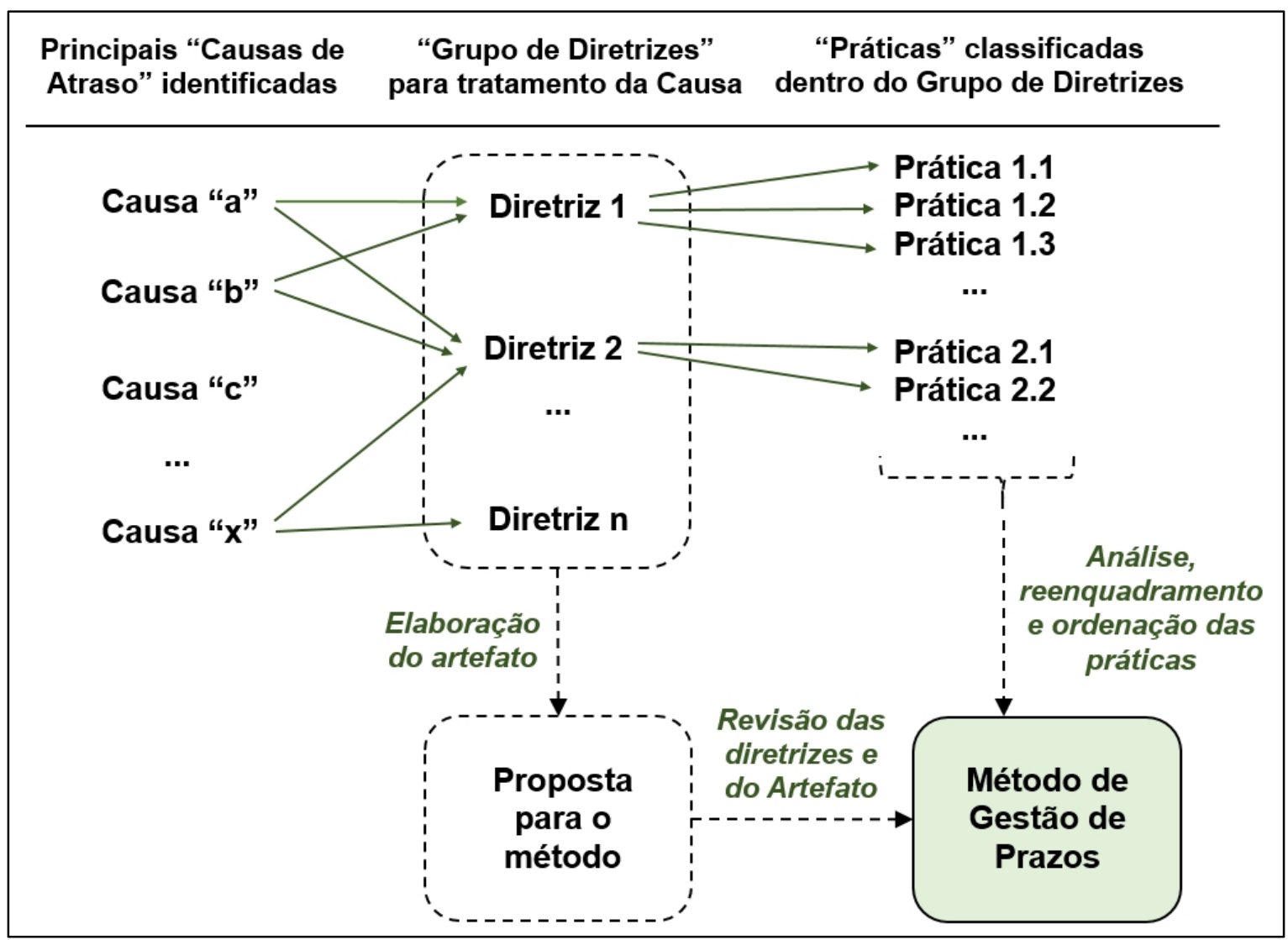

Fonte: O Autor 
Estas práticas formaram então a base do método que se pretende apresentar.

A correta aplicação das diretrizes e efetivação das ações sugeridas foram ainda analisadas em uma segunda pesquisa desta tese, que auxiliaria então na validação do Artefato proposto.

Assim, a quantidade de diretrizes poderia ser alterada conforme resultado final da pesquisa de campo explicativa.

\subsection{Descrição das diretrizes de planejamento e gestão}

A definição das diretrizes que irão compor o método é baseada em fatos claramente verificados na pesquisa e por esta razão, embasados e justificados, sendo necessária sua análise na prática.

A estrutura proposta (quantidade, tipos, caracterização) foi resultado da interpretação dos fatores motivadores por este autor. Todas as diretrizes acabaram sendo interrelacionadas entre si e desta forma, independente de como foram propostas, seu conjunto abrange todas as causas levantadas, sendo mais importante este resultado do que a discussão individualizada de cada uma delas. Talvez algumas delas poderiam ser unificadas, ou ainda, possuírem enfoques amplos que poderiam ser tratados de maneira individualizada.

Sendo assim, estas são apresentadas nos subitens a seguir, bem como suas possíveis inter-relações.

\subsubsection{Planejamento com definições de equipe e sua mobilização}

Para se buscar melhor organização nas frentes de trabalho, deve-se desenvolver o planejamento tático-operacional da obra, com a definição clara das equipes para cada atividade, em especial aquelas do caminho crítico. Não basta apenas a elaboração de um histograma consolidado, que é útil para dimensionamento do canteiro e áreas administrativas e de vivência, mas também é importante que sejam detalhados os números de oficiais e ajudantes em cada equipe, as datas precisas em que estas equipes precisam ser mobilizadas (às vezes, para o mesmos serviços são mobilizadas equipes diferentes e em diferentes momentos), a localização das mesmas em cada 
fase (evitando-se interferência em determinados setores da obra), logística de abastecimento (com a clara definição de quem irá levar e trazer o material, apoiar nos transportes, guardar ferramentas, dentre outras responsabilidades).

\subsubsection{Planejamento com premissas monitoráveis}

Além das definições das equipes, como citado no item anterior, todo planejamento é baseado em outras inúmeras premissas, tais como durações, produtividade das equipes, equipamentos, condições externas, distâncias, incluindo probabilidades de que estas não sejam efetivamente alcançadas ao longo da obra. Assim, é muito importante destacar todas as premissas que foram utilizadas como referência na determinação dos ciclos, prazos e redes de precedência entre as atividades, incluindo a logística de abastecimento e composições adicionais.

Um aspecto que muitas vezes não é levado em consideração é que as premissas precisam ser monitoráveis, ou seja, que apresentem características de composição mensuráveis. Assim, com o início dos serviços, as premissas podem ser controladas e em caso de apresentarem condições diferentes das previstas, as ações corretivas terão maior assertividade.

Este enfoque de conhecimento detalhado das premissas pelos envolvidos, diretamente no planejamento operacional e na produção, é importante também no momento nas etapas iniciais do planejamento, ou mesmo quando este planejamento ainda é estratégico.

Durante a construção do modelo de execução da obra (plano de ataque, logística e demais itens), muitas incertezas existem que podem ser traduzidas em composições com premissas mais frágeis ou menos embasadas tecnicamente. Com a evolução do planejamento, as premissas começam a ser mais detalhadas e a discussão em torno de sua validade com as condições reais de obra ganha argumentos que antes não existiam, diminuindo os riscos em sua adoção, já que serão validadas ou revisadas. 


\subsubsection{Sistemas que assegurem a terminalidade dos serviços}

Uma das principais contribuições para a diminuição da produtividade de uma equipe é a necessidade de retornar a um local para terminar um serviço inacabado. Além disso, o serviço inacabado impede que o sucessor seja iniciado, gerando mais atrasos.

O serviço inacabado ocorre normalmente por duas razões: caso as condições de execução e finalização não sejam adequadas (falta material, equipe, indefinição de projeto, ordem externa, quebra de equipamentos, dentre outras) ou, quando o serviço é executado fora dos parâmetros adequados de aceitação, tolerâncias, especificações, e necessita ser refeito. O retrabalho, além de gerar atrasos, geram custos adicionais não previstos.

Assim, independente das razões e da forma como aconteça, é importante que o sistema de planejamento adotado na obra condicione a terminalidade dos serviços.

\subsubsection{Sistemas de produção puxado, que evitem desperdícios}

Diferentemente do item anterior, mesmo sem haver retrabalho, muitas atividades são executadas com muitas perdas intrínsecas ao serviço. Estas perdas, segundo Ohno (1997) seriam evitadas caso o planejamento ou programação levasse em conta a diminuição das atividades que não agregam valor, ou seja, aquelas que trazem diversos tipos de desperdício, tais quais o transporte, produção excessiva, tempo disponível (espera), processamento em si, estoque, movimentos e produtos defeituosos. Dois tipos de desperdício foram tratados no item anterior (espera e produto defeituoso). Assim, outras fontes de desperdício devem ser analisadas.

O estoque necessário para se executar uma atividade ou a produção excessiva são elementos que surgem em uma obra quando não há uma uniformização dos ciclos ou quando as equipes executam atividades focadas em suas necessidades e não as da obra como um todo.

Esta uniformização dos ciclos é proposta por Conte (2002). Com ciclos uniformes, há maior previsibilidade de quando as tarefas serão executadas, e assim, as programações de serviços podem ser elaboradas considerando-se estoques mínimos para o período do ciclo ou de parte controlada deste. 
Além disso, para se evitar produção excessiva, o ideal seria que as atividades sejam executadas com base no que as tarefas sucessoras estão necessitando. Isto garantiria que em cada serviço seja executada apenas a produção necessária. Este tipo de abordagem é chamado pelos autores que estudam o Lean Construction de produção "puxada".

\subsubsection{Gestão à vista (comunicação nos locais de produção)}

O processo de elaboração do planejamento de uma obra envolve muitas pessoas e tempo. Desta forma, mesmo que se tenha a participação dos líderes neste processo (como descrito no item 5.2.8), a comunicação a todos os níveis da obra e a forma como as equipes conseguem entender a programação precisa ser também trabalhada de forma criteriosa. Buscando-se a participação de todos e seu comprometimento com as metas de produção, não há segredo algum em tais premissas.

Assim, além da linguagem adequada a cada nível, é importante que estes critérios, premissas, metas e métodos estejam disponíveis para acesso de todos os colaboradores. Defende-se assim a total transparência das informações e que sejam amplamente divulgadas.

Isto pode ser feito através de sinalizações frequentes em cada frente de produção, com informações sobre a programação das equipes, atendendo, por exemplo, a diretriz descrita no item 5.2.1 (locais liberados, equipes que deveriam estar no local), ou mesmo as condições dos serviços no local (serviços aprovados, reprovados, em andamento, dentre outras condições).

Além disso, informações sobre o andamento dos serviços, programação de uso de equipamentos, metas do dia ou da semana, disponibilizadas em locais estratégicos, ajudam a motivar os trabalhadores, além de organizar as frentes, de modo e se evitar interferências também citadas no item 5.2.1.

\subsubsection{Foco em continuidade de serviços e cadência de obra}

Conforme é verificado em Ballard (2000), Conte (2002) e Vanhoucke (2006), é desejável que o projeto apresente um ritmo constante ou uma cadência definida. Este ritmo de obra garante que o repasse das metas de produção às equipes seja natural, 
simplificado. Talvez exista uma complexidade maior nos ajustes de equipe e processo produtivo no início dos serviços, para que todas as premissas anteriormente definidas sejam realinhadas de forma a que o resultado seja a cadência global das atividades.

No entanto, após este ajuste inicial, a manutenção do ritmo e das premissas acaba sendo a nova rotina da equipe de planejamento e dos líderes de cada frente. $O$ engajamento dos grupos acaba sendo potencializado, pois o objetivo agora é comum.

Talvez esta diretriz seja aquela que mais interfira nas causas levantadas na pesquisa, como pode ser observado no quadro 13, uma vez que ela auxilia na melhor organização das equipes no canteiro e em um aspecto dos mais relevantes para motivar as equipes no canteiro: frentes de serviço garantidas e previsíveis.

Um dos itens que desmotivam um subempreiteiro na obra são os picos de produtividade e desaceleração. Estas alternâncias implicam na necessidade de uma gestão muito mais flexível e que extrapolam o ambiente interno da obra. Conforme o momento, será necessário mobilizar ou desmobilizar mais trabalhadores, processo que exige muito esforço e praticamente nenhum retorno. Uma vez que não há garantia de faturamento contínuo no período, os melhores profissionais podem ser deslocados para obras onde há esta garantia, "sobrando" na obra apenas aqueles que se sujeitam a este risco, normalmente menos capacitados.

\subsubsection{Planejamento formalizado}

Esta deveria ser a primeira premissa de um planejamento adequado às necessidades da obra. Um bom planejamento é traduzido e estruturado através de um bom plano.

Entende-se o plano como uma das saídas do processo de planejamento e pode ter diversos componentes ou documentos, tais como termos, cronogramas, descrições e matrizes.

Em projetos mais simples, um planejamento informal pode ser até mais ágil, pois gera flexibilidade e menos burocracias, mas quando se trata de empreendimentos de construção, ou seja, um projeto complexo, um plano formal é fundamental. 
O grau de formalização de um planejamento também é variável, mas independente do detalhamento do plano, uma preocupação grande é que ele seja uma ferramenta de comunicação, informação e referência dos profissionais no empreendimento.

Muitos planos são elaborados com informações detalhadas, mas que não traduzem as necessidades de quem precisa ser orientado. Este é o ponto fundamental desta diretriz, pela qual sugere-se que sejam formalizadas tanto as metas de produção (acordadas entre os participantes do processo produtivo), como também informações relevantes do que poderia gerar dúvidas do caminho a seguir (o que efetivamente evitaria desvios).

\subsubsection{Participação das equipes de produção na definição de metas}

Esta diretriz garante maior comprometimento das equipes no que foi traçado como necessário para a obra. Não é difícil verificar que em muitos projetos, as metas de produção são simplesmente comunicadas aos responsáveis, que mesmo as aceitando, já estabelece as justificativas pelo não atendimento, quando ocorrer.

Envolver os líderes das equipes na definição dos pacotes de trabalho que serão entregues, consultá-los antes de formalizar as metas e analisar em conjunto as condições de suas equipes para o cumprimento do que foi definido é primordial e gera confiança de que o que foi estabelecido é possível de ser alcançado. Melhor do que isto, no caso do surgimento de pequenos empecilhos, há maior disposição para se honrar o que foi acordado.

\subsubsection{Utilização de metas realistas, sem folgas arbitrárias}

Como já exposto por Goldratt (1998), Elder (2006), La Garza et.al.(2007), Barraza (2011) e outros, é muito comum que na definição dos prazos a serem executados, os profissionais tendam a incluir folgas arbitrárias que lhe propiciam menores riscos de execução. O problema é que em um ambiente complexo como uma obra, com inúmeras equipes multidisciplinares interligadas pelas redes de precedência, estas folgas acabam sendo somadas ao prazo do projeto.

Pela Lei de Parkinson, como citado anteriormente, o trabalho tende a se expandir para preencher todo o tempo disponível para realizá-lo. 
Assim, mesmo conseguindo-se obter maior produtividade do que a prevista, as durações reais acabam sendo efetivamente àquelas previstas. O inverso não é verdadeiro, quando há restrições de execução, premissas divergentes ou mesmo produtividade inferior às previstas, o atraso é inevitável, as durações reais acabam englobando não apenas os prazos das restrições, mas também as folgas inseridas nas atividades.

O contrário também é igualmente prejudicial. Não é raro o desenvolvimento do planejamento utilizando-se sempre um cenário otimista ou, como estabelece Mattos (2007), o estabelecimento de cronograma inexequíveis. Nestes casos, quando uma equipe percebe que a meta é inviável, naturalmente o esforço em alcançá-la acaba abandonado. Se não há a intervenção dos gerentes e responsáveis pelo planejamento, o descrédito também pode contaminar outras frentes de serviço.

Outro ponto em que a diretriz tem impacto está relacionado à reprogramação. A observância dos ciclos passados e o entendimento em detalhes de como ele foi obtido traz elementos para que possíveis erros nas premissas sejam corrigidos. Por esta razão, complementando o monitoramento das premissas descrito no item 5.2.2, a revisão das próximas durações e inter-relação com demais atividades precisa buscar também o que efetivamente é viável. O descrédito é completo quando se verifica que os ciclos são mantidos, mesmo que nenhuma ação seja tomada, ou seja, são mantidas as premissas iniciais imaginando-se que por alguma razão no mês seguinte será possível obter-se o cenário otimista o qual foi usado como referência para o planejamento inicial.

A reprogramação ganha importância novamente quando se verifica que o planejamento está equivocado. É comum encontrar obras onde a reprogramação nada mais é do que acumular atividades não realizadas à jusante, mas mantendo-se as datas de finalização. O que se promove com esta prática é a criação de uma "bomba relógio", onde em determinado momento que fica claro que as atividades não serão realizadas no prazo previsto, o planejador assume que os prazos de conclusão serão outros e normalmente o novo prazo não é um mero ajuste da rede, mas sim um adiamento considerável e repentino do prazo final do projeto. 


\subsubsection{Métodos que busquem menor variabilidade}

Esta diretriz está intimamente ligada ao que estabelece no item 5.2.4, complementando a busca de diminuição dos desperdícios relacionados ao processo produtivo, em especial: espera, movimentação e transporte.

É importante destacar que, embora as ações que estejam relacionadas a esta diretriz também devam gerar aumento de produtividade, este não é o foco. É claro que quando já se identifica problemas de prazo em um projeto, uma das ações é buscar aumento de produtividade para a recuperação do atraso. Mas neste caso, o atraso já está configurado e o objetivo agora seria o tratamento do problema.

$\mathrm{Na}$ verdade, o que se busca é garantir que a produtividade prevista não seja impactada ao longo do processo e assim gerar os atrasos na obra. $O$ foco principal deste trabalho é a minimização dos atrasos, sejam eles relativos a processos simples ou complexos.

É fato que a quantidade de premissas que se precisa controlar para garantir o atendimento do prazo em um processo simples é bem menor do que nos sistemas mais complexos, e talvez, indiretamente, os processos mais simples apresentam menos riscos de não atendimento das expectativas de produção.

Mas também, processos simples não necessariamente devem ser artesanais. Existem processos simples com tecnologia aplicada e que podem também gerar menos riscos de não atendimento das premissas de planejamento, consequentemente não atendimento do prazo da obra.

Talvez o ponto focal da diretriz seja evitar a combinação de muitos processos complexos e que não tenham correlação adequada, gerando constantes adaptações dos processos de planejamento e gestão. $O$ tempo entre a finalização de um processo produtivo e início de outro (usando uma comparação com a indústria, o chamado "changeover time" ou o tempo de transição), depende da maturidade e integração entre as equipes e complexidades dos próprios processos. Com suas simplificações, este efeito também pode ser minimizado. 


\subsubsection{Ambiente de trabalho organizado}

Inicialmente fora da abrangência do trabalho (uma vez que relaciona-se à gestão de pessoas ou infraestrutura de obra), identificou como necessária para se combater fatores que causam os atrasos.

Existem muitos exemplos onde a falta de organização dos canteiros gera várias restrições de execução que não são previstas no início do planejamento. Assim, mesmo com o estudo da melhor logística de transporte e estoque, os fluxos de materiais e pessoas serão totalmente diferentes nestas condições.

Junta-se a isso fatores que promovem qualidade inferior na execução dos serviços, e que irão gerar novos atrasos pela necessidade de retrabalho de serviços.

Por fim, um ambiente mais adequado de trabalho promove ações pró ativas dos funcionários e motivam aqueles com maior produtividade a permaneceram naquela obra.

\subsubsection{Contratações conjuntas}

Esta diretriz sugere que a relação com os fornecedores da obra sejam as melhores possíveis e que as negociações sejam feitas com transparência e utilizando-se o conceito do ganha-ganha.

Um dos itens que desmotivam fornecedores é o fato de, conhecendo o projeto como um todo, ser solicitado para atender apenas parte dele. Numa relação de parceria, é importante que esteja claro quais as limitações que estão sendo verificadas no fornecedor e por que razão o mesmo está sendo demandado daquela forma.

É interessante também agrupar nos pacotes de contratação, serviço considerados mais fáceis e serviços onde haverá esforço maior, de maneira que o fornecedor obtenha equilíbrio na alocação de profissionais.

Este equilíbrio está estritamente alinhado com questões motivacionais descritas na diretriz anterior, bem como cria um ambiente favorável para a busca das continuidades do serviço (item 5.2.6), como potencializa a questão da terminalidade (5.2.3). 


\subsubsection{Planejamento específico para suprimentos}

Verifica-se que somente com uma visão integrada de todo o processo produtivo consegue-se definir adequadamente as premissas de planejamento (item 5.2.2) e as restrições que possam existir das mesmas serem efetivamente comprovadas ao longo da obra.

Neste aspecto, todos os intervenientes e componentes para o abastecimento da obra, sejam eles, de material, equipamentos ou mão-de-obra geram riscos similares caso não consigam entregar no momento oportuno o insumo adquirido.

As atividades de seleção, compra, contratação, fabricação, transporte, entrega, mobilização, entre outras relacionadas ao processo de suprimentos são atividades consideradas de apoio, e que normalmente estão fora dos cronogramas clássicos de obra, que muitas vezes consideram apenas as atividades de produção no canteiro.

Assim, por sua importância e impacto direto nos atrasos das obras, uma vez que os atrasos de entrega ou de mobilização de equipes são apontados como uma das principais causas de atraso da obra como um todo, sugere-se que exista um tratamento especial a estas etapas, com planos específicos.

O controle mais rígido das partes do processo de suprimentos pode evitar os desvios do processo como um todo, mas além disso, estas etapas devem estar correlacionadas aos demais processos ou atividades que ocorrem no canteiro. As entregas ou mobilizações precisam acontecer no momento oportuno. Tão importante quanto se evitar os atrasos é não proporcionar antecipações indevidas, evitando desperdícios, como estoques desnecessários ou esperas.

Assim, a retroalimentação e revisão do plano de suprimentos conforme atualizações do cronograma de atividades do canteiro também deve ser tratada com atenção pelos gestores de obra.

\subsubsection{Previsão de curvas de aprendizado}

Os projetos de construção não correspondem a uma linha de produção rígida, são únicos (apesar de muitas vezes serem similares) e constituídos por atividades realizadas por diferentes equipes em um mesmo local de trabalho. Assim, todo início 
e término de cada uma delas irão apresentar fatalmente condições diferentes do ritmo considerado adequado (ótimo) e que foi previsto no estudo do ciclo da atividade.

Assim, uma das diretrizes propostas para se evitar atrasos é simples: prever durações ou premissas diferentes de execução no início de cada atividade. Esta diretriz não representa ganhos de tempo, mas quando busca trazer ao planejamento uma antevisão realista do que efetivamente irá ocorrer na obra.

Alinhado com o que foi estabelecido na diretriz do item 5.2.9, esta condição permite que as metas sejam realistas e da mesma forma como colocado neste item, não se deve utilizar o pretexto de início dos serviços e incluir uma folga arbitrária. O que se espera é que seja feito um estudo de efetiva duração da etapa inicial dos serviços, dentro das condições de trabalho e produtividade ainda não possíveis neste período.

Por fim, a finalização de uma atividade também pode acarretar condições diferentes das previstas para o ritmo padrão do serviço. Este fato deve ser levado em consideração. Embora não seja entendido como "aprendizado", afeta a produtividade da equipe e suas consequências devem ser previstas nas premissas de planejamento, conforme cada tipo de serviço ou equipe, pois elas podem ser redirecionadas, desmobilizadas, transferidas ou simplesmente terem motivação alterada.

\subsubsection{Controle da qualidade dos serviços}

Nas mesmas condições do que foi estabelecido na diretriz descrita no item 5.2.4, de maneira a se evitar o desperdício de retrabalho, é importante se adotar políticas de controle da qualidade da produção.

Apesar de em alguns serviços preverem-se perdas intrínsecas ao processo produtivo, não se definem premissas de planejamento para retrabalho. Desta forma, qualquer execução errada ou com defeito, não estará considerada no fluxo ou na rede do projeto, gerando atrasos. E assim, devem ser estabelecidas sistemáticas que evitem estas ocorrências.

No entanto, processos de controle que garantam que as atividades sejam executadas com base nas melhores práticas ou normas também necessitam estar previstas no planejamento da obra. 
A inserção de atividades de controle, inspeção, liberação, muitas vezes não são estabelecidas como parte do processo produtivo. Desta forma, é importante que isto seja pré-definido no momento do plano estratégico-tático, especialmente para as atividades do caminho crítico, para que ao serem implantadas, estas não sejam exatamente a justificativa de aumento de prazos das atividades ou de postergação de início de outras, gerando os tão combatidos atrasos.

\subsubsection{Logística de canteiro com condições especiais}

Todo bom planejamento deveria sempre prever uma avaliação completa do canteiro de obras, como será a implantação das diversas etapas no local, onde serão as áreas de estoque, escritórios de apoio, posicionamento dos equipamentos de transporte, acessos, dentre outros aspectos.

Normalmente esta análise é realizada durante a definição do plano de ataque da obra e deve contemplar todo o prazo do empreendimento. Com a evolução da obra e as prováveis alterações das condições iniciais, mudanças de estratégias, adaptações a novas situações, este planejamento sofre diversas revisões, demandando muita flexibilidade da ferramenta.

Quando um canteiro apresenta alto grau de restrições (como por exemplo, terrenos muito pequenos, com grandes desníveis, com solo ruim ou contaminado, ou com nível d'água aflorando), este plano torna-se crítico para o sucesso do empreendimento.

\subsubsection{Análise das condições locais de abastecimento}

Esta diretriz, complementar a anterior, foca a necessidade de avaliação dos itens que estejam fora do terreno onde será implantada a construção. Trata-se de avaliar as reais capacidades dos fornecedores locais em suprir as necessidades de abastecimento, dentro das condições de canteiro que são disponíveis.

Muitas vezes, as condições locais inviabilizam a escolha de determinado método construtivo que a construtora esteja acostumada a utilizar. Em outros, as condições locais se alteram em função de períodos específicos, o que será tratado também no item 5.2.24. 


\subsubsection{Sistemas de alerta antecipado}

Talvez um dos itens que menos se observa nas obras atuais, a diretriz estabelece que se implante um sistema de comunicação que identifique de forma rápida as restrições para a execução das atividades previstas.

A resposta rápida a uma interferência pode ser observada em atitudes das equipes de produção. Mas para que um bom planejamento não dependa apenas da competência das equipes envolvidas, a criação destes sistemas ajuda que sejam tomadas ações de recuperação ou eliminação de restrições o quanto antes.

Há diversos modelos de sistemas de alerta, desde gerenciais mecanismos de inspeção e supervisão de programação, como descrito por Machado (2003), até mesmo sistemas eletrônicos como os andons citados por Kemmer et al. (2006).

A eficácia destes modelos está intimamente ligada à forma como os problemas são tratados no ambiente da obra. Não adianta nada que os problemas sejam identificados de forma rápida, mas as decisões demorem a ser tomadas ou planos de ação demorem a serem implantados. Por esta razão a importância da integração desta diretriz com as definidas no 5.2.19 a seguir.

\subsubsection{Métodos de hierarquização das decisões}

Como descrito por Assumpção (1996), os processos de planejamento estão intimamente ligados ao processo de decisão. Da mesma forma como as decisões de caráter estratégico são tomadas por níveis mais altos da organização ou do projeto e decisões operacionais são tomadas por pessoas que exerçam a responsabilidade pelos processos produtivos no canteiro, é importante que se estabeleça uma hierarquia de decisões baseadas na importância dos serviços para o sucesso do empreendimento.

Uma obra apresenta, ao longo de seu desenvolvimento, momentos-chave onde estas restrições podem resultar em atrasos pontuais ou em um atraso irrecuperável.

Por isso, é importante a definição de quem irá efetivamente resolver pela paralisação de um serviço, alteração de sequência, mudança de método de execução ou de abastecimento. 
Analogamente ao que se estabeleceu em relação aos planejamentos estratégico e operacional, as decisões que geram mudanças de escopo, acréscimo de custos, e outros impactos importantes, naturalmente devem ser tomadas por pessoas com autoridade para tal.

O simples fato de se perder tempo decidindo quem será o responsável pela decisão já afeta sua resolução. Por isso, algumas empresas costumam estabelecer reuniões frequentes com as equipes de proteção, onde as soluções para os impasses sejam encontradas em prazos aceitáveis para o tratamento (normalmente estabelece-se que os envolvidos somente sairão da reunião com o problema solucionado, tornando os ambientes de decisões verdadeiras "war rooms").

Caso não se estabeleçam modelos de decisões compartilhadas, ao menos a definição de quem será o responsável pela tomada de decisão precisa ficar claro, tanto para as equipes de produção, como para os agentes externos ao canteiro.

\subsubsection{Plano Mestre detalhado}

Complementando a diretriz 5.2.16 e 5.2.17, o plano mestre necessita estar detalhado ao menos nos serviços do caminho crítico.

No estabelecimento do plano mestre do empreendimento, normalmente utiliza-se uma estimativa menos precisa, uma vez que neste momento do planejamento normalmente não se dispõe de informações completas sobre o escopo do projeto, sendo necessário criar um cenário para esta estimativa.

No entanto, o cenário imaginado precisa contemplar os principais serviços que irão resultar no prazo total estimado do projeto.

O que sugere-se nesta diretriz é que, mesmo que este cenário seja provavelmente alterado no futuro breve, se estabeleçam premissas específicas para a realização do estudo das durações de ciclos e atividades do caminho crítico. Estas premissas podem ser suposições técnicas coerentes com o cenário estabelecido.

O detalhamento exigirá um exercício de abstração e que talvez não seja tão simples no início, mas que trará maior solidez ao plano mestre e consequente aceitação para seu uso como ferramenta de planejamentos estratégico. 
Desta forma, após sua elaboração e com o passar do tempo, quando as informações do projeto começam a ser detalhadas e o escopo tornar-se mais claro, é possível validar as premissas preestabelecidas e rapidamente analisar o impacto das alterações nos prazos do plano mestre.

Se o impacto for muito grande, os focos de atuação da equipe de planejamento estarão também identificados, seja, para a revalidação de novos prazos referenciais realistas, seja na busca de alternativas de mudança de escopo, caso o prazo final do projeto não possa ser alterado.

\subsubsection{Envolvimento do cliente}

Esta diretriz é intuitiva. Pois na verdade, quanto mais stakeholders participarem do processo de planejamento, melhor será o resultado final.

Entende-se cliente como aquele responsável pela contratação do projeto (obra), normalmente o empreendedor, que pode ser um investidor, uma incorporadora. No caso de empreendimentos imobiliários, não se trata do futuro usuário ou proprietário das unidades individualizadas, mas do empreendimento como um todo.

Muitos problemas nas estimativas de durações estão relacionados a indefinições de escopo de projeto, seja por dúvidas ou alterações constantes na definição do produto imobiliário, seja no estudo de métodos e processos mais adequados, eficientes e de menor custo possível. As indefinições geram postergação de decisões importantes e estratégicas para o projeto e a demora impacta diretamente nos prazos finais do projeto.

Isto fez com que o envolvimento do cliente (proprietário do negócio) acabasse se caracterizando como um dos pontos mais relevantes no resultado da primeira pesquisa, e destacando este participante em relação às demais partes interessadas e envolvidas no projeto, como o construtor, projetista, fornecedores, dentre outros.

Assim, a participação mais próxima do cliente ou proprietário nas decisões de planejamento aparece como uma diretriz importante na minimização das principais causas de atraso identificadas. 


\subsubsection{Métodos de gestão de escopo do projeto}

Bastante vinculada à diretriz anterior (5.2.21), uma indefinição de escopo prejudica muito o andamento do projeto.

Desta forma, é importante que se estabeleça uma metodologia simples e rápida de se gerenciar o escopo do projeto.

O uso de ferramentas como a WBS, termos de declaração de escopo e respectivos projetos e memoriais são importantes para esta definição, mas além disso, recomenda-se um processo ágil para que o escopo seja sempre verificado, questionado e revisado, quando necessário.

Termos de alteração de escopo, aditivos e outras ferramentas são comuns em obras mais complexas, mas deveriam fazer parte de todo tipo de empreendimento.

\subsubsection{Sistemas de fiscalização independentes}

Uma das formas de se garantir isenção no monitoramento dos prazos de um empreendimento é buscar uma avaliação de um ente externo ao processo.

Esta visão externa muitas vezes ajuda a eliminar certos "vícios" do planejamento, uma vez que as equipes de produção podem estar focando apenas o plano de curto prazo e este não representar de forma adequada ao cumprimento do Plano Mestre ou uma efetiva ação de recuperação.

Este fato que pode acontecer, como já citado neste trabalho por Conte (2002), quando o PPC de um projeto está beirando a $100 \%$, mas a previsão de atraso global é grande. Isto mostra hipoteticamente que a equipe da obra está cumprindo de forma competente, programações que são na verdade ineficazes.

Isto não significa que a avaliação externa não possa estar ligada indiretamente ao processo produtivo. Pode ser realizada tanto por departamentos de apoio à produção, como por terceiros contratados para tal. 


\subsubsection{Premissas por tipo de serviço}

Como destacado por alguns autores, entre eles Kim e La Garza (2005), as diversas condições que envolve a execução de um projeto podem afetar de forma diferente determinados tipos de atividades.

Condições ambientais adversas (chuva intensa, por exemplo), afetam diretamente serviços como terraplenagem, execução de fachadas, impermeabilização externa e pintura. Como outros serviços, principalmente internos, não são afetados por estas condições (revestimentos, enfiação, forros, instalação de bancas, dentre outros), é necessário se estabelecer diferenciação entre os dias úteis disponíveis em um determinado período (semana ou mês) para o primeiro grupo e para o segundo.

Este fato não precisa ser apenas vinculado a condições meteorológicas, mas pode estar relacionado a questões regionais (feriados ou datas festivas), condições de restrição de recursos em determinada época do ano (por exemplo no verão em cidades litorâneas), acessos restritos (festas de rua, manifestações) ou simples condição mercadológica de determinados grupos de serviços.

\subsubsection{Resumo dos grupos de diretrizes e inter-relações}

De maneira a melhor se entender a abrangência das diretrizes propostas e como elas impactam positivamente o tratamento das causas de atrasos apontadas na primeira pesquisa, referenciaram-se todas elas de forma ilustrada no quadro 13. 
Quadro 13 - Grupos de diretrizes e referência às causas pesquisadas

\begin{tabular}{|c|c|c|c|c|c|c|c|c|c|c|c|c|c|c|c|c|c|c|c|c|c|}
\hline \multirow[b]{2}{*}{$\mathbf{N}^{\circ}$} & \multirow[b]{2}{*}{ Descrição Genérica da Diretriz } & \multicolumn{20}{|c|}{ Tratamento das principais causas (pesquisa) } \\
\hline & & A & B & C & D & $\mathbf{E}$ & $\mathbf{F}$ & $\mathbf{G}$ & $\mathbf{H}$ & I & $\mathbf{J}$ & $\mathbf{K}$ & $\mathbf{L}$ & $\mathbf{M} \mathbf{I}$ & $\mathbf{v}$ & b & & $\mathbf{Q}$ & $\mathbf{R}$ & & $\mathbf{T}$ \\
\hline 1 & $\begin{array}{l}\text { Definição clara de equipes, } \\
\text { local e mobilização }\end{array}$ & & & & & & & & & & & & & & & & & & & & \\
\hline 2 & $\begin{array}{l}\text { Uso de premissas } \\
\text { mensuráveis e monitoráveis }\end{array}$ & & & & & & & & & & & & & & & & & & & & \\
\hline 3 & $\begin{array}{l}\text { Métodos que assegurem a } \\
\text { terminalidade dos serviços }\end{array}$ & & & & & & & & & & & & & & & & & & & & \\
\hline 4 & $\begin{array}{l}\text { Sistemas de produção puxada } \\
\text { e que evitem desperdícios }\end{array}$ & & & & & & & & & & & & & & & & & & & & \\
\hline 5 & $\begin{array}{l}\text { Gestão à vista (comunicação, } \\
\text { transparência e sinalização) }\end{array}$ & & & & & & & & & & & & & & & & & & & & \\
\hline 6 & $\begin{array}{l}\text { Foco em continuidade de } \\
\text { serviços, cadência da obra }\end{array}$ & & & & & & & & & & & & & & & & & & & & \\
\hline 7 & Planejamento formalizado & & & & & & & & & & & & & & & & & & & & \\
\hline 8 & $\begin{array}{l}\text { Participação das equipes de } \\
\text { producão na definicão de metas }\end{array}$ & & & & & & & & & & & & & & & & & & & & \\
\hline 9 & $\begin{array}{l}\text { Definição de metas realistas } \\
\text { (sem folgas arbitrárias) }\end{array}$ & & & & & & & & & & & & & & & & & & & & \\
\hline 10 & $\begin{array}{l}\text { Métodos que melhorem a } \\
\text { produtividade das equipes }\end{array}$ & & & & & & & & & & & & & & & & & & & & \\
\hline 11 & $\begin{array}{l}\text { Ambiente de trabalho } \\
\text { organizado, incentivos }\end{array}$ & & & & & & & & & & & & & & & & & & & & \\
\hline 12 & $\begin{array}{l}\text { Contratações conjuntas, } \\
\text { transparência c/ fornecedores }\end{array}$ & & & & & & & & & & & & & & & & & & & & \\
\hline 13 & $\begin{array}{l}\text { Planejamento de suprimentos } \\
\text { (antecedência) }\end{array}$ & & & & & & & & & & & & & & & & & & & & \\
\hline 14 & $\begin{array}{l}\text { Previsão de curvas de } \\
\text { aprendizado }\end{array}$ & & & & & & & & & & & & & & & & & & & & \\
\hline 15 & $\begin{array}{l}\text { Controle da qualidade dos } \\
\text { serviços }\end{array}$ & & & & & & & & & & & & & & & & & & & & \\
\hline 16 & $\begin{array}{l}\text { Logística de canteiro com } \\
\text { condições especiais }\end{array}$ & & & & & & & & & & & & & & & & & & & & \\
\hline 17 & $\begin{array}{l}\text { Analise de condições locais de } \\
\text { abastecimento }\end{array}$ & & & & & & & & & & & & & & & & & & & & \\
\hline 18 & $\begin{array}{l}\text { Sistemas de alertas } \\
\text { antecipados }\end{array}$ & & & & & & & & & & & & & & & & & & & & \\
\hline 19 & $\begin{array}{l}\text { Métodos de hierarquização de } \\
\text { decisões (prioridades) }\end{array}$ & & & & & & & & & & & & & & & & & & & & \\
\hline 20 & $\begin{array}{l}\text { Plano mestre mais detalhado } \\
\text { (caminho crítico) }\end{array}$ & & & & & & & & & & & & & & & & & & & & \\
\hline 21 & $\begin{array}{l}\text { Envolvimento do cliente no } \\
\text { planejamento e riscos }\end{array}$ & & & & & & & & & & & & & & & & & & & & \\
\hline 22 & $\begin{array}{l}\text { Métodos de gestão de escopo } \\
\text { do projeto }\end{array}$ & & & & & & & & & & & & & & & & & & & & \\
\hline 23 & $\begin{array}{l}\text { Sistemas de fiscalização } \\
\text { independente }\end{array}$ & & & & & & & & & & & & & & & & & & & & \\
\hline 24 & Premissas por tipo de serviços & & & & & & & & & & & & & & & & & & & & \\
\hline
\end{tabular}

Fonte: O Autor 


\section{PESQUISA DE CAMPO EXPLORATÓRIA}

\subsection{Objetivos desta pesquisa de campo}

Este estudo tem como objetivo analisar se as premissas sugeridas na estruturação inicial do método descritas no capítulo 5 apresentam pertinência, verificando-se de forma aprofundada quais das práticas descritas foram aplicadas na gestão dos prazos em cada empreendimento, bem como possíveis impactos das mesmas na prevenção dos atrasos ou recuperação caso ocorram.

Conforme descrito no item 2.5.4, para que os resultados obtidos sejam confiáveis será realizado um estudo em diversas obras.

\subsection{Caracterização e planejamento desta pesquisa}

\subsubsection{Elaboração do protocolo de estudo}

Analogamente ao que foi estabelecido na primeira pesquisa de campo, e conforme recomendações de Yin (2010), para se organizar o banco de dados dos estudos de caso, buscou-se a elaboração de um protocolo de referência. Este protocolo orienta a forma como os dados serão coletados, uma vez que em um estudo exploratório como este, as informações certamente serão disponibilizadas de formas diferentes, e eventualmente, dispersas ou incompletas.

Primeiramente foram buscados projetos que, por uma avaliação prévia do pesquisador, com base em sua experiência profissional, tivessem chance de trazer dados concretos e descrever casos de sucesso (obras que não atrasem). No entanto, isto não é uma garantia de que os resultados serão favoráveis, fato que deve ser incluso no protocolo.

Não necessariamente foi possível escolher empreendimentos que, além de potencial de não atrasarem, estivessem com as obras se iniciando no mesmo momento de início da pesquisa. Assim, o protocolo também deveria orientar esta questão.

Em seguida, o planejamento dos trabalhos sugere o estabelecimento de rotinas de acompanhamento da evolução física da obra, registros e conclusões. 
A figura 59 ilustra o protocolo utilizado na avaliação das obras da amostra desta segunda pesquisa de campo.

Figura 59 - Protocolo de estudo para a segunda pesquisa de campo

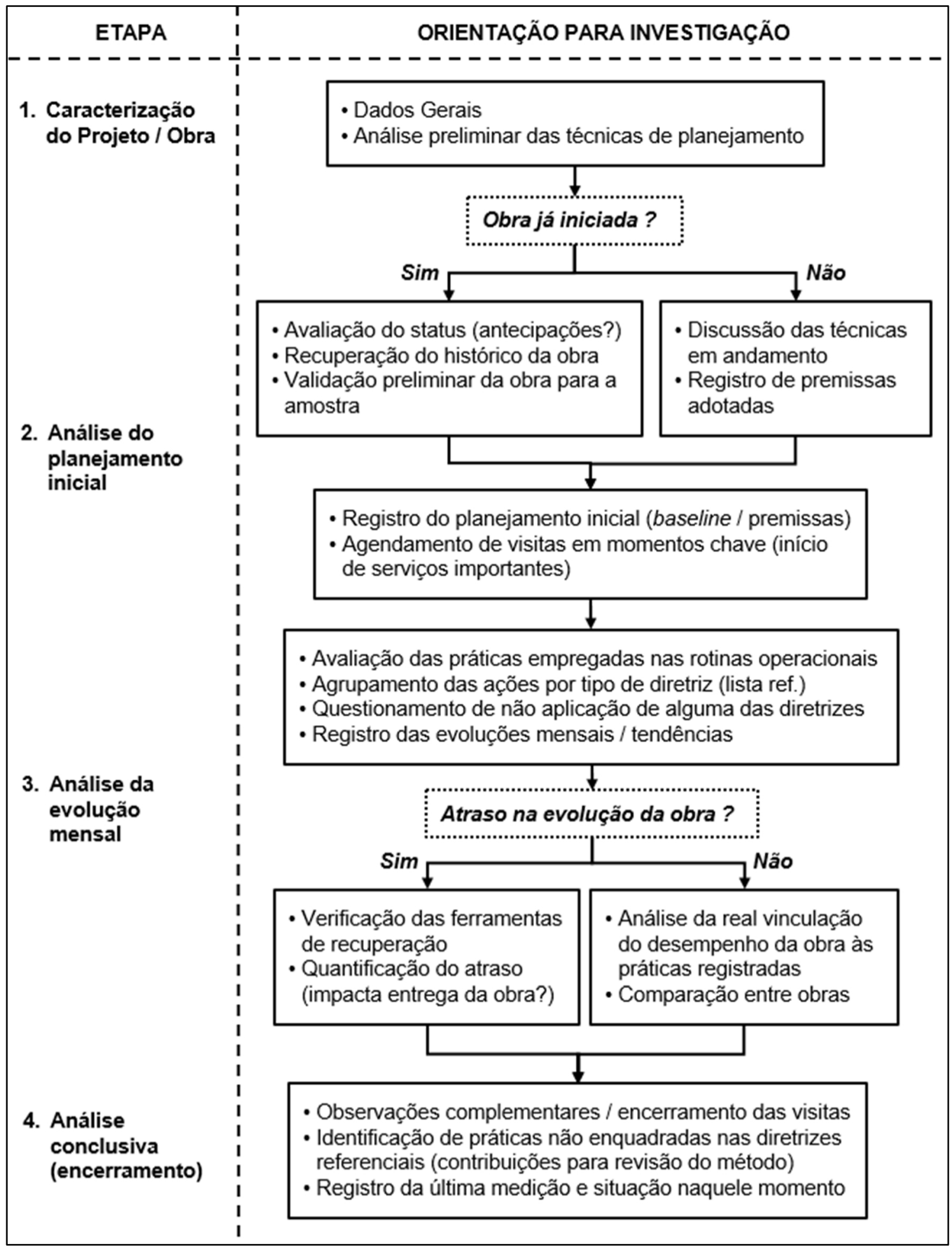

Fonte: O Autor 


\subsubsection{Escolha das obras para estudo}

Da mesma forma que descrito no capítulo 4, foi necessário que os projetos escolhidos como parte desta segunda pesquisa estivessem dentro das restrições estabelecidas no plano de pesquisa e compatíveis com àquelas definidas na primeira pesquisa de campo.

Assim, a maior parte delas foi mantida (edifícios residenciais e comerciais multipavimentos), com exceção dos atrasos expressivos, uma vez que nesta nova amostra, buscaram-se projetos que não apresentaram atrasos significativos.

Como esta pesquisa busca a identificação de ferramentas, práticas ou rotinas nos empreendimentos, entende-se que, mesmo que cada obra seja um projeto independente e possua sua singularidade, muito provavelmente os métodos e processos de planejamento sejam similares quando se trata de obras de uma mesma construtora. Assim, deu-se preferência para a escolha de um empreendimento representativo por construtora.

Como o estudo foi embasado em um protocolo que continha as diretrizes a serem verificadas, estes empreendimentos foram acompanhados em um período específico após janeiro de 2015 , quando esta parte do desenvolvimento e proposição inicial do Artefato já estava a finalizada.

Assim, algumas obras já estavam iniciadas e além das observações "in loco", foram discutidos seus históricos, principalmente aspectos relacionados ao planejamento inicial.

Outros empreendimentos, ao contrário, foram acompanhados desde o início, mas seu término acabou não contemplado pelas análises desta pesquisa. Estabeleceram-se os meses de abril e maio de 2016 como limites para esta avaliação e consideraramse os índices de referência de progresso e ações de gestão positivas até aquele momento. Caso posteriormente, fatos inesperados ou novas condições de trabalho ou mercado impactassem negativamente o progresso destes empreendimentos, infelizmente estes fatos não poderiam ser utilizados para avaliação.

No total, obras de oito empreendimentos foram estudadas em detalhes, sendo que as estruturas de seus processos de planejamento podem ser verificadas no quadro 14. 
Quadro 14 - Características do processo de planejamento nas obras

\begin{tabular}{|c|c|c|}
\hline $\begin{array}{l}\text { Obra / } \\
\text { Construtora }\end{array}$ & $\begin{array}{l}N^{\circ} \text { Obras*/ } \\
\text { Locais }\end{array}$ & $\begin{array}{c}\text { Estrutura e características do processo de planejamento } \\
\text { na construtora, em especial na obra estudada }\end{array}$ \\
\hline $\begin{array}{l}\text { Construtora C } \\
\text { (médio porte) }\end{array}$ & $\begin{array}{l}7 \text { obras } \\
\text { (Estado SP) }\end{array}$ & $\begin{array}{l}\text { - Equipe de planejamento enxuta, responsável pelos estudos } \\
\text { estratégicos, orçamentos e negociações contratuais (venda); } \\
\text { - Plano mestre e planos operacionais realizados por empresa } \\
\text { especializada terceirizada junto com o Diretor Técnico; } \\
\text { - Programações de curto prazo realizadas pela equipe da obra. }\end{array}$ \\
\hline $\begin{array}{l}\text { Empreendimento II } \\
\text { Construtora J } \\
\text { (pequeno porte) }\end{array}$ & $\begin{array}{l}3 \text { obras } \\
\text { (S.Paulo/SP) }\end{array}$ & $\begin{array}{l}\text { - Diretor técnico centraliza as definições estratégicas (sócio } \\
\text { diretor focado em produtos e questões financeiras); } \\
\text { - Plano mestre, planejamento e programação realizados por } \\
\text { empresa parceira terceirizada. }\end{array}$ \\
\hline $\begin{array}{l}\text { Empreendimento } \\
\qquad \text { III } \\
\text { Construtora W } \\
\text { (pequeno porte) }\end{array}$ & $\begin{array}{l}6 \text { obras } \\
\text { (S.Paulo/SP) }\end{array}$ & $\begin{array}{l}\text { - Sócios atuando diretamente nos processos de pré-engenharia } \\
\text { (experiência de anos em outras construtoras); } \\
\text { - Equipe de planejamento interno, responsável pelos } \\
\text { orçamentos, plano mestre e planejamento operacional; } \\
\text { - Especificamente nesta obra foi alocado engenheiro de } \\
\text { planejamento (especialista), embora não seja prática usual. }\end{array}$ \\
\hline $\begin{array}{l}\text { Empreendimento } \\
\qquad \text { IV } \\
\text { Construtora O } \\
\text { (grande porte) }\end{array}$ & $\begin{array}{l}21 \text { obras } \\
(\text { SP e RJ) }\end{array}$ & $\begin{array}{l}\text { - Equipe de planejamento corporativa especializada, que atende } \\
\text { todas as obras, desde a pré-engenharia até as programações } \\
\text { de curto prazo, controles e indicadores; } \\
\text { - Pouco envolvimento da alta direção no plano operacional; } \\
\text { - A obra segue modelos corporativos e diretrizes do gerente; } \\
\text { - Técnico de planejamento (especialista) alocado na obra. }\end{array}$ \\
\hline $\begin{array}{c}\text { Empreendimento V } \\
\text { Construtora Y } \\
\text { (grande porte) }\end{array}$ & $\begin{array}{l}98 \text { obras } \\
\text { (Brasil) }\end{array}$ & $\begin{array}{l}\text { Equipe de planejamento corporativa especializada, atende } \\
\text { todas as obras, com foco na pré-engenharia e plano mestre; } \\
\text { - Envolvimento do diretor técnico regional em todos os } \\
\text { processos operacionais; } \\
\text { - Gerente da obra com bastante autonomia (responsável pelo } \\
\text { desempenho do empreendiento em todos os aspectos). }\end{array}$ \\
\hline $\begin{array}{l}\text { Empreendimento } \\
\qquad \mathrm{VI} \\
\text { Construtora AA } \\
\text { (pequeno porte) }\end{array}$ & $\begin{array}{c}3 \text { obras } \\
\text { (S.Paulo e } \\
\text { interior SP) }\end{array}$ & $\begin{array}{l}\text { - Sócio participa diretamente das discussões de planejamento } \\
\text { inicial, mas não é técnico (incorporador / financeiro); } \\
\text { - Equipe de planejamento terceirizada, responsável pelos } \\
\text { estudos estratégicos e planejamentos operacionais, que são } \\
\text { validados diretamente pelo diretor; } \\
\text { - Programações de curto prazo realizadas pela equipe da obra. }\end{array}$ \\
\hline $\begin{array}{l}\text { Empreendimento } \\
\qquad \text { VII } \\
\text { Construtora } A B \\
\text { (grande porte) }\end{array}$ & $\begin{array}{l}11 \text { obras } \\
(\mathrm{GO}, \mathrm{DF} \text { e } \\
\text { SP) }\end{array}$ & $\begin{array}{l}\text { Equipe de planejamento na sede (GO) atende todas as obras } \\
\text { (alocação de profissional especilizado em obras de DF e SP); } \\
\text { - Gerente da obra com bastante autonomia, responsável pelo } \\
\text { planejamento e pelo desempenho do empreendimento. }\end{array}$ \\
\hline $\begin{array}{l}\text { Empreendimento } \\
\qquad \text { VIII } \\
\text { Construtora M } \\
\text { (médio porte) }\end{array}$ & $\begin{array}{l}5 \text { obras } \\
\text { (Estado SP) }\end{array}$ & $\begin{array}{l}\text { - Diretor técnico centraliza as definições estratégicas e deve } \\
\text { prestar contas aos sócios da empresa; } \\
\text { - Plano mestre, planejamento e programação realizados por } \\
\text { empresa parceira terceirizada. }\end{array}$ \\
\hline
\end{tabular}

(*) média de obras em andamento simultâneas no momento em que as obras estudadas estavam no período de obra bruta (estrutura, alvenaria e fachada) 


\subsubsection{Fontes de evidência}

As fontes de evidência utilizadas são praticamente as mesmas da primeira pesquisa de campo, relacionadas com as características da coleta de dados, como descrito a seguir:

- Unidade de análise: processos de planejamento e gestão das obras de empreendimentos de construção civil residenciais ou comerciais;

- Unidade de coleta de dados: pessoas e documentos disponíveis no processo de planejamento e gestão do empreendimento;

- Fontes de coleta: de forma mais abrangente que a primeira pesquisa, são entrevistas com os envolvidos no processo de gestão do empreendimento específico (através de roteiros estruturados); documentos (cartas, memorandos, minutas de reunião, relatórios ou artigos sobre o empreendimento); registros em arquivo (mapas, gráficos, tabelas, dados de clientes e outros), observação direta (visita de campo, participação de reuniões ou atividades informais de coleta de dados) e observação participante (estudos onde o pesquisador é membro da equipe do projeto ou desempenha papel funcional em atividades de prestação de serviço).

\subsection{Resultados individuais da pesquisa aplicada}

Com o início dos trabalhos de campo, foi possível verificar diversas práticas correlacionadas às diretrizes descritas no capítulo 5. No entanto, claramente várias destas práticas acabam por atender ou correlacionar-se com mais de uma diretriz sugerida na proposição inicial.

Este fato influenciou a estruturação da proposição final descrita nos capítulos 7 e 8 . Buscou-se uma nova forma de apresentação, uma organização mais focada na evolução do processo de planejamento no empreendimento, do que em grupos de diretrizes genéricos para todas as etapas, como havia sido sugerido inicialmente.

Como este capítulo tem como objetivo apresentar os resultados da pesquisa, definiuse que isto seria feito com foco no relacionamento das práticas (ou um grupo de práticas analisadas de forma conjunta) e em cada uma das descrições. As diretrizes 
propostas são elencadas e destacadas livremente, sendo novamente tratadas de forma ordenada na consolidação dos resultados apresentada no item 6.4.

Pretende-se nos itens a seguir, descrever em detalhes, de forma sequencial por empreendimento, como cada diretriz foi comprovada, as ações, evidências ou simples iniciativas.

Caso alguma diretriz não seja citada nas descrições das obras, significa que não se identificou nenhuma ação naquela direção. Isto será posteriormente destacado no quadro do item 6.4 .

A exceção se dá para a diretriz \#7 (formalização do planejamento), a qual foi claramente identificada em todas as oito obras, e desta forma, entendeu-se que não acrescentaria maiores ganhos à individualidade do empreendimento, se fosse destaca uma a uma em cada descrição.

De forma geral, todas as obras analisadas formalizaram suas ações de planejamento, seja através de planos diretores detalhados, seja em programações de curto prazo simples e práticas. Na própria descrição de aderência às outras diretrizes pode-se perceber o grau de formalização do planejamento das obras, deixando claro que esta diretriz é compartilhada por todos os gestores pesquisados.

No que se refere às demais diretriz, estas são destacadas nos itens dos empreendimentos a seguir.

\subsubsection{Empreendimento I}

O Empreendimento I, executado pela Construtora C (que já teve obras avaliadas na primeira pesquisa) caracteriza-se pela execução de 1 torre residencial de 27 pavimentos (sendo 3 deles sobressolos) e 1 subsolo, com 198 unidades, totalizando $22.744 \mathrm{~m}^{2}$ de área construída, localizado em um térreo de $1.712 \mathrm{~m}^{2}$ na cidade de Santos/SP.

O empreendimento teve início em 20/08/2014, com previsão de término em 30/11/2016, mesma data da linha de base e 90 dias antes do prazo contratual. Até a última data de acompanhamento dentro das atividades desta pesquisa (medição em $30 / 04 / 2016$ ), a obra apresentava adiantamento de $4,62 \%$ do progresso físico previsto 
na linha de base e, desta forma, a obra foi escolhida para análise de boas práticas de planejamento físico e gestão de prazos.

A figura 60 ilustra a construção do edifício em duas datas diferentes, sendo algumas das vezes em que o pesquisador acompanhou as atividades desta obra.

Figura 60 - Fotos do Empreendimento I (Set/15 e Jan/16)

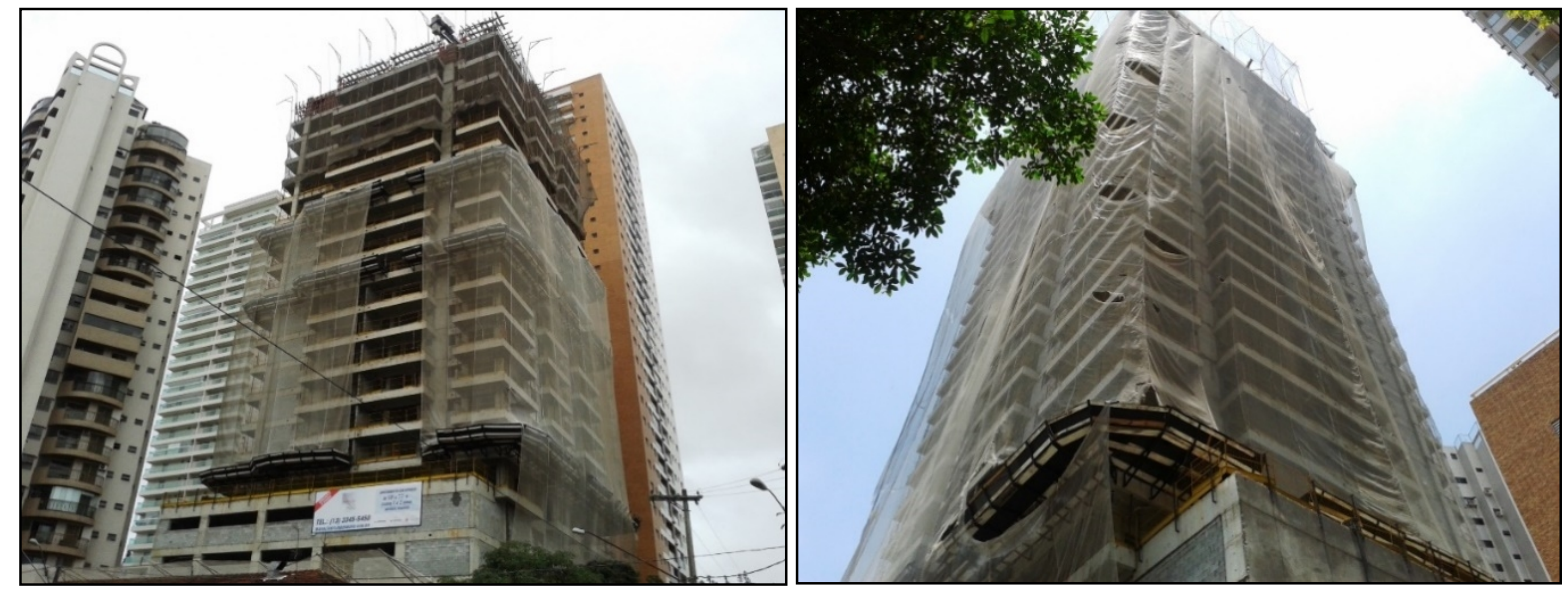

Fonte: O Autor

As práticas identificadas nesta obra são descritas nos tópicos a seguir.

\section{Cronograma preliminar detalhado no caminho crítico}

O prazo que estava sendo negociado com o cliente, durante o processo de seleção da construtora era de 28 meses. No entanto, o projeto possuía característica singular e não usual para a construtora: a área de lazer localizava-se na cobertura do prédio.

Desta forma, verificou-se que muitos dos serviços deste setor, que normalmente são executados em paralelo com parte das atividades da torre (pavimentos tipo), seriam concentrados nos meses finais da obra, caracterizando-os como parte do caminho crítico do empreendimento e gerando um risco para se alcançar o prazo em negociação.

Elaborando-se um cronograma preliminar detalhado, que envolveu a participação de empresas parceiras ainda não contratadas, em especial o subempreiteiro de fachada, chegou-se a um prazo ideal de 31 meses, mesmo com a antecipação de parte dos serviços que antes estavam concentrados no final da obra. 
Desta forma, evidencia-se um exemplo de prática baseada na diretriz \#20 (plano mestre detalhado). Esta prática foi muito importante para se levantar os riscos do não cumprimento do contrato e auxiliar as negociações em curso.

Como resultado, buscando-se manter a competitividade junto ao cliente, entendeu-se que comercialmente seria mantido o prazo de 28 meses, mas seria permitido à construtora a antecipação da mobilização da equipe de obra e execução dos serviços preliminares, de terraplenagem e contenção, fato que ocorreu. Desta forma, apesar de contratualmente a obra ter início em abril de 2014, diversos serviços já foram iniciados em janeiro daquele mesmo ano, sendo estes custos arcados pela construtora até a primeira medição contratual em abril. Apesar de certo impacto no fluxo de caixa, este investimento inicial somente foi aceito pela diretoria da construtora pela justificativa técnica que o estudo preliminar detalhado mostrou.

\section{$>$ Elaboração de cronograma sem folgas}

O fato da linha de base ser definida praticamente como o próprio cronograma desafio gerou ao menos um fato positivo, de que todas as atividades foram definidas sem folgas, evidenciando práticas alinhadas à diretriz \#9 (metas realistas), descrita na proposição inicial.

No entanto, foram relatados diversos impasses entre equipe de planejamento e equipe da obra com relação às metas de programação, sempre com a pressão de se estabelecer uma certa folga por parte do engenheiro da obra, o que não foi atendida.

Outro aspecto importante foi estabelecer o sábado como dia não útil no cronograma, embora efetivamente trabalhado em canteiro. De uma certa forma, este dia foi utilizado muitas vezes como um "pulmão" para a obra, mas sua utilização mais importante relacionava-se a serviços auxiliares (não menos importantes) que não constavam no cronograma. Estas atividades, tais como limpezas contínuas, organização, ascensão da bandeja, dentre outras, geravam restrições no pleno atendimento das programações semanais se não adequadamente executados.

\section{> Utilização de calendários diferenciados por serviço}

A prática de utilização de múltiplos calendários, aderente à diretriz \#24 (premissas por tipo de serviço), pôde ser claramente observada na obra. 
A equipe de planejamento utilizou praticamente dois calendários diferentes de dias úteis para a elaboração dos cronogramas, como pode ser observado na figura 61.

Figura 61 - Cronograma com 2 calendários de dias úteis (padrão e chuva)

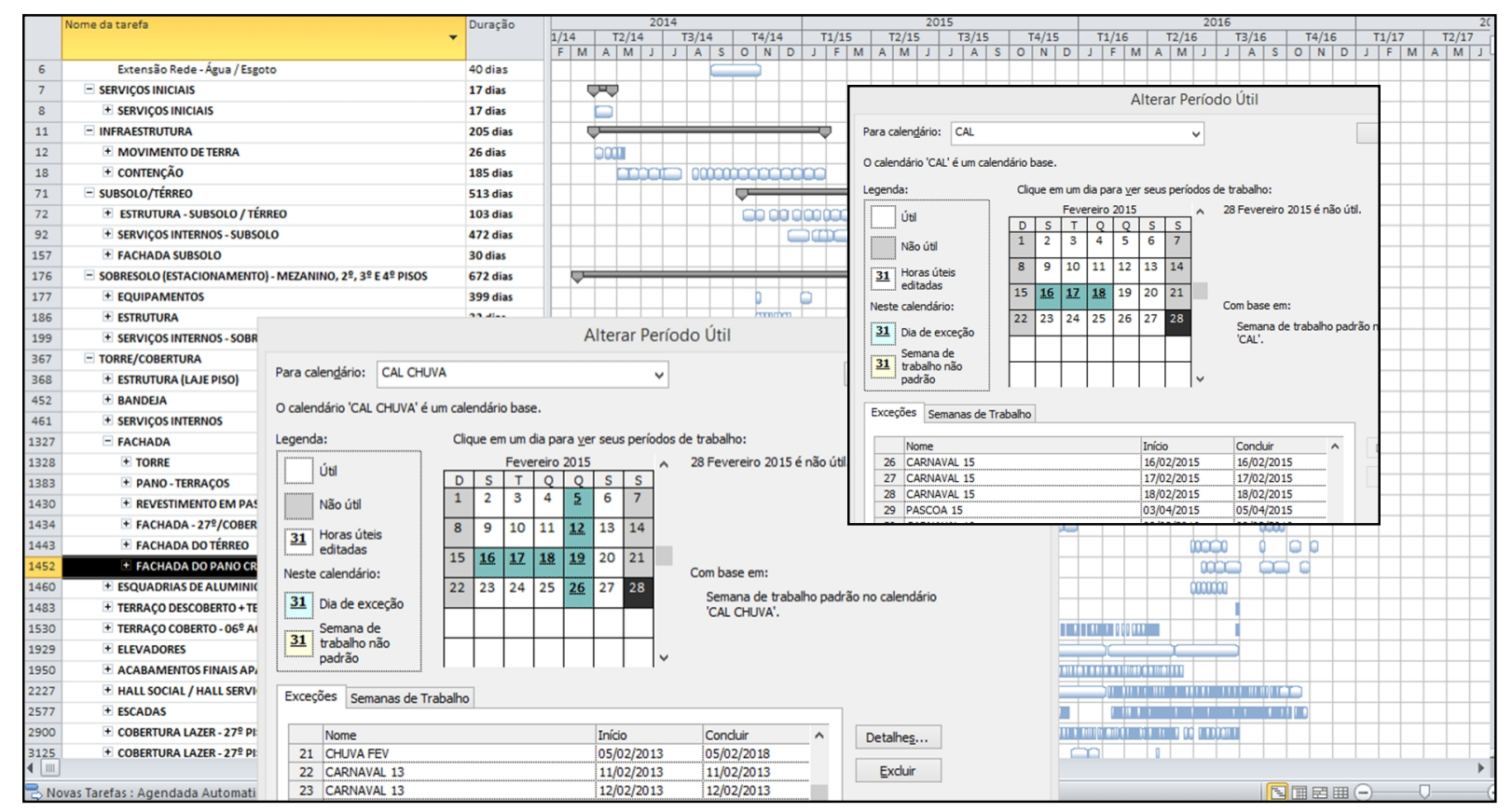

Fonte: O Autor (retirado do planejamento da Construtora C)

De acordo com o modelo adotado pela obra, os calendários são:

- Calendário padrão: com 5 dias úteis (sábado não contemplado, conforme descrito no item anterior) e feriados nacionais, além de emendas e recessos de final de ano compatíveis às rotinas padrão da empresa; e

- Calendário de chuvas: que incluía dias não trabalhados adicionais aleatórios conforme período: para os meses de outubro e março (3 dias trabalhados a menos), em novembro e fevereiro (4 dias), dezembro e janeiro (5 dias) e nos demais meses, 1 dia útil a menos.

O calendário de chuvas foi correlacionado aos serviços de fundação, estrutura, fachada, terraços (piso, impermeabilização, revestimento) e térreo externo (pisos, impermeabilização, revestimentos externos, piscina, dentre outros).

Desta forma, estes serviços não tiveram alteração em suas durações, mas as datas de início e término previstas variaram de forma diferente das demais atividades relacionadas ao calendário padrão. 
Um ponto interessante observado com esta prática está no fato de que, se o serviço correlacionado ao calendário de chuvas tiver previsão de início exatamente no dia posterior a algum dia não trabalhado incluso aleatoriamente, a programação irá perder um dia efetivamente útil. Esta questão era corrigida pelos líderes das equipes nas ordens de serviço diárias, muitas vezes não contempladas no planejamento formal.

\section{Inserção de curvas de aprendizado das durações de serviços repetitivos}

Verificou-se a prática de estabelecer durações diferentes para a execução dos ciclos iniciais do serviço de estrutura dos pavimentos tipo, conforme sugere a diretriz \#14 (curvas de aprendizado) do da proposição inicial.

Conforme projeto de estrutura, o andar tipo inicia-se efetivamente no $7 .^{\circ}$ andar, após a execução dos sobressolos (até $033^{\circ}$ andar) e dos pavimentos com áreas diferenciadas ou mezaninos (até 0 6. ${ }^{\circ}$ andar). Desta forma, verificou-se 0 planejamento da linha de base com ciclos distintos a partir desta laje: $7 .^{\circ}$ pavimento (ciclo de 8 dias), $8^{\circ}$ e $9^{\circ}$ pavimentos (ciclo de 6 dias) e a partir do $10 .^{\circ}$ pavimento, o ciclo de 5 dias que garantia a concretagem de em média 1 laje por semana até o 26 . $^{\circ}$ andar.

Esperava-se que esta prática fosse estendida a outros serviços importantes, inclusive àqueles de relação direta com a estrutura, como alvenaria, por exemplo. No entanto isto não foi verificado, restringindo-se o uso apenas às atividades de estrutura.

\section{Contratações de serviços similares com o mesmo subempreiteiro}

Identificou-se nesta obra a contratação de forma global para inúmeros serviços similares, minimizando a complexidade na gestão das equipes no canteiro e buscando incentivar os profissionais que foram alocados no empreendimento. Assim, a prática está alinhada às diretrizes \#10 (sistemas para aumento de produtividade) e \#12 (contratações conjuntas).

Ao menos dois exemplos foram vivenciados pelo autor. O primeiro refere-se à contratação de uma empresa para a execução da estrutura (tipos e periferia) e de parte da fundação (blocos, baldrames, sapatas). O segundo refere-se a outra empresa que foi contratada para a realização de todas as atividades de alvenaria, contrapiso e revestimentos argamassados. 
Apesar dos benefícios da diminuição de interações com líderes de empresas diferentes, esta prática traz um risco que deve ser avaliado: a concentração de serviços em poucas empresas gera maior dependência das mesmas, o que só é possível com um bom conhecimento da estrutura e quantidade de obras atendidas pela empresa contratada, bem como avaliação anterior de serviços já prestados.

Assim, a transparência é vital para o sucesso da parceria, que inclui também supervisão mais próxima das equipes, em especial da quantidade de funcionários por tipo de serviço, uma vez que alguns deles poderão executar mais de uma frente diferente.

\section{> Cronograma de contratações}

Seguindo premissas definidas com base na diretriz \#13 (planejamento de suprimentos), a obra estabeleceu uma programação específica para as atividades de suprimentos, desde a etapa de pré-obra, buscando-se antecipação das contratações.

O cronograma consolidado estabelecia as principais atividades referentes ao processo de aquisição de materiais, serviços e equipamentos, desde a elaboração das cartas convite aos possíveis participantes das concorrências, até a datas previstas para mobilização ou entrega, como apresentado na figura 62.

Figura 62 - Cronograma de contratações do empreendimento

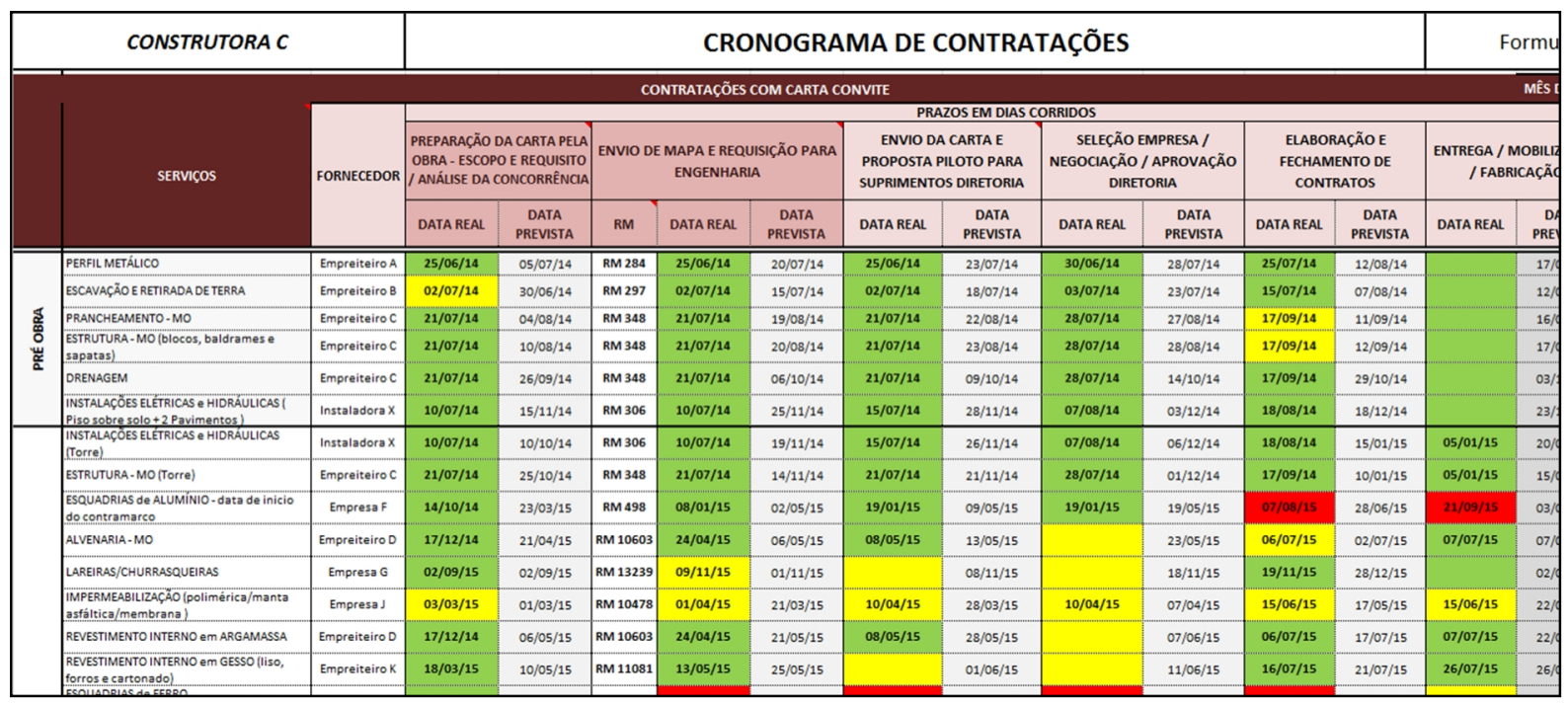

Fonte: O Autor (retirado do planejamento da Construtora C) 
Este planejamento é dinâmico, atualizado mensalmente com a inserção das datas de status (controle), que alimenta as datas previstas para cada atividade, identificando se as mesmas estão em dia ou não.

Desta forma, pode-se focar quais itens necessitam de ação gerencial para que não se transformem em restrições de início das atividades do cronograma global (que também deve estar constantemente alinhado com as datas do cronograma de contratações, evitando-se antecipação de entrega ou mobilização indesejada).

\section{Avaliação de restrições da programação mensal}

Identificou-se nesta obra uma sistemática de hierarquização da importância da atividade em relação ao seu comprometimento com o avanço físico da obra. Esta prática é conceituada internamente pela construtora como avaliação das restrições da programação, item aderente à diretriz \#19 (hierarquização de decisões).

$\mathrm{Na}$ visão consagrada de análise de restrições defendida por autores ligados ao Lean Construction, a restrição é analisada sob a ótica de várias vertentes que inviabilizam o início dos serviços (falta de material, falta de definições de projetos, abastecimento, ou outras restrições classificadas previamente com base em um banco de dados da empresa). Neste conceito, cada restrição tem a mesma importância (a somatória de todos gera o cálculo do de índices de restrições ou IRR). Nesta obra, a análise de restrições utiliza os pesos das atividades para o cálculo de um índice de risco.

A análise se resume a três tipos de restrição: (a) frente de serviço liberada, (b) material já entregue na obra (disponível) e, (c) equipe dimensionada (ou já mobilizada). Uma tarefa que possui 1 destas três restrições é classificada com o "farol" amarelo e com 2 ou 3 das restrições anteriores com o "farol" vermelho.

A ideia do farol gera o senso de urgência na eliminação das restrições. O peso das atividades em relação à meta de progresso físico gera o senso de priorização de quais delas devem ser primeiramente tratadas para se aumentar as chances de se atingir a meta de produção. Desta forma, esta prática complementa outras citadas anteriormente, que estão alinhadas às diretrizes \#10 (sistemas para aumento de produtividade) e \#18 (sistemas de alerta antecipado). 
A tabela de pesos com os índices de restrição é apresentada na figura 63. No exemplo, a meta de progresso do mês de maio é de $5,91 \%$, sendo $0,91 \%$ (ou seja, cerca de 1/6 do peso da programação deste mês) com ao menos 1 tipo de restrição a ser eliminada em campo.

Figura 63 - Tabela de pesos com índices de restrição

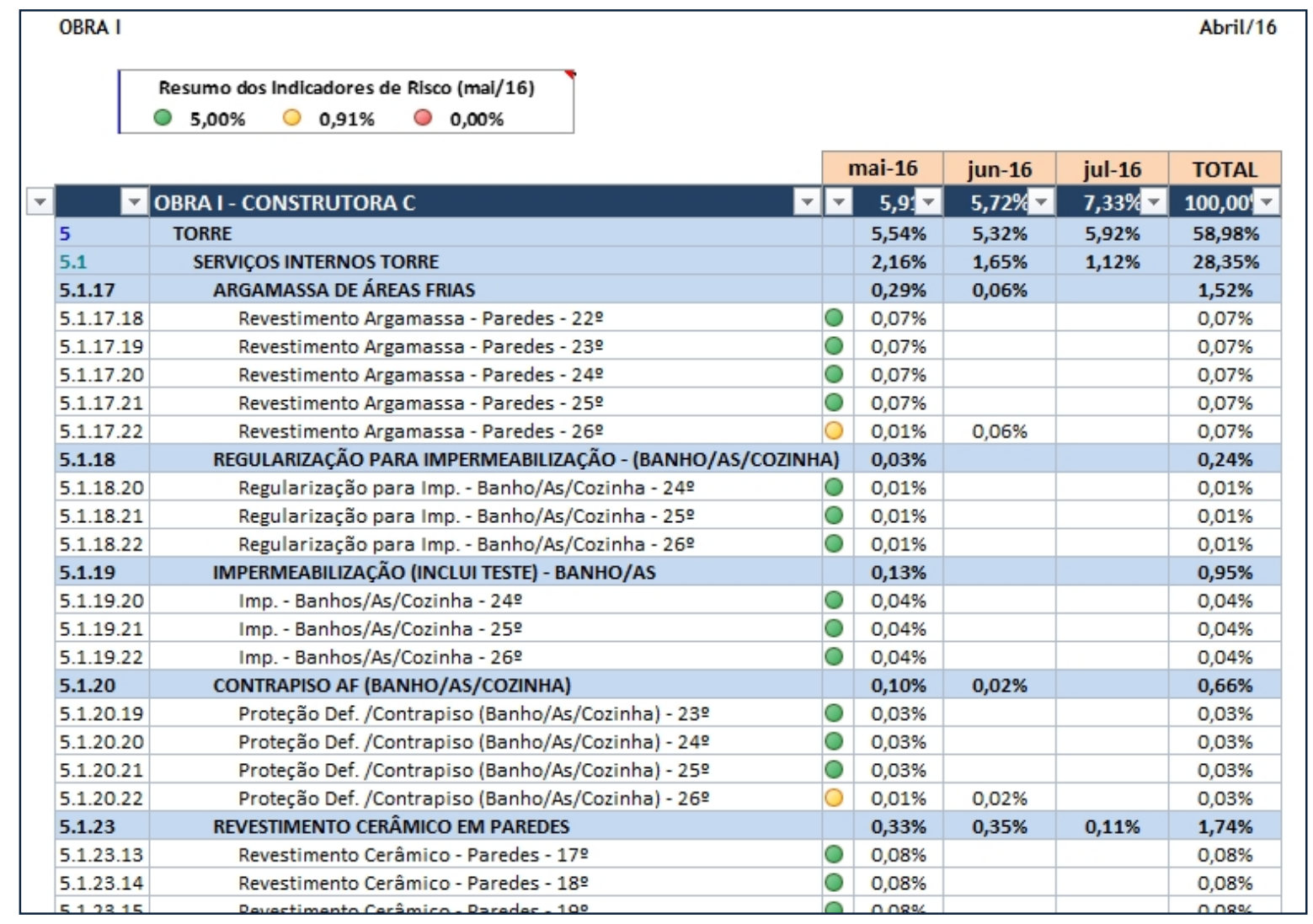

Fonte: O Autor (retirado do planejamento da Construtora C)

A tabela também apresenta pesos relacionados às metas de mais 2 meses, apenas para se avaliar possíveis atividades que matematicamente não são impactantes no primeiro mês, mas que em breve podem ser importantes. Estes dados podem visualmente indicar a necessidade de atuação prioritária em itens que não estão sinalizados com o farol.

Outra forma de se avaliar estes indicadores é o risco de não cumprimento da meta de produção. Mas o índice gera uma variável quantitativa para expressar apenas o risco de não atendimento por restrição (não contempla risco de não atendimento por improdutividade ou falhas durante a execução). 
Reuniões específicas de programação e comprometimento com as metas

Uma prática interessante identificada no empreendimento relaciona-se ao modo como as programações e metas de produção eram acordadas com as equipes.

Nesta obra não eram realizadas reuniões gerais de planejamento, com a participação de todas as equipes. Embora seja também uma boa prática e traga seus benefícios, nesta obra foi adotada a realização de reuniões individuais, com discussões aprofundadas e participação não apenas dos líderes ou encarregados de cada subempreiteiro, mas muitas vezes com os sócios das empresas.

Nestas reuniões, não apenas eram discutidas as metas, logística de abastecimento e restrições (o que demonstra um alinhamento inicial à diretriz \#17 - avaliação das condições de abastecimento), mas também registrava-se o comprometimento das equipes no atendimento daquelas metas, com a formalização de atas que eram assinadas pelos encarregados e arquivadas pela equipe de planejamento e de produção da obra, como pode ser observado na figura 64 .

Figura 64 - Ata de reunião de planejamento com metas de produção

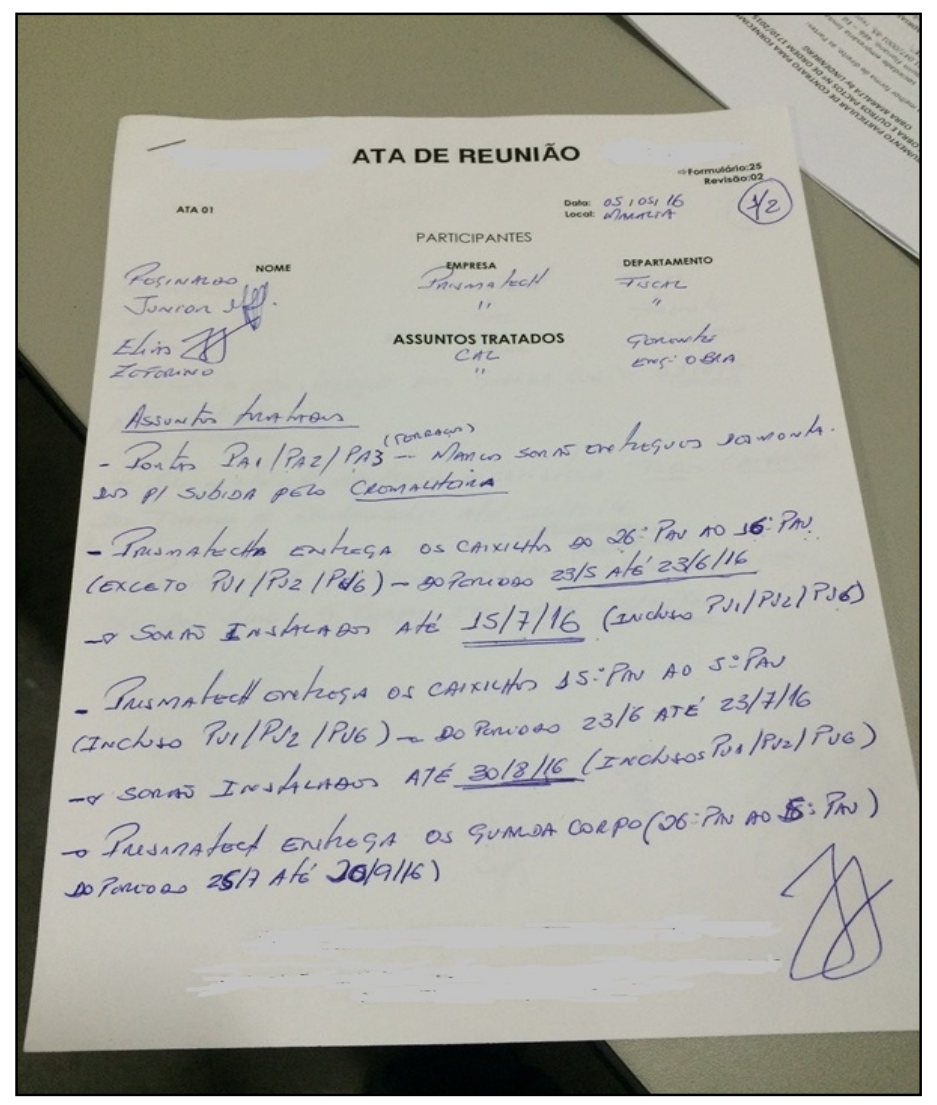

Fonte: O Autor (exemplo de documento de planejamento da Construtora C) 
Desta forma, evidenciam-se ações relacionadas às diretrizes \#7 (formalização do planejamento) e \#8 (participação das equipes de produção).

\section{Detalhamento da logística de abastecimento da obra}

O projeto do canteiro é dinâmico e seu planejamento está reproduzido em grandes painéis instalados nas imediações dos escritórios de engenharia e sala de reuniões. O painel é metálico e possui peças imantadas representativas das salas, estoques, equipamentos, locais de produção e diversos outros desenhos importantes, que são constantemente atualizados, com base nas programações de abastecimento ou plano de ataque dos serviços (figura 65).

Figura 65 - Projeto de canteiro dinâmico

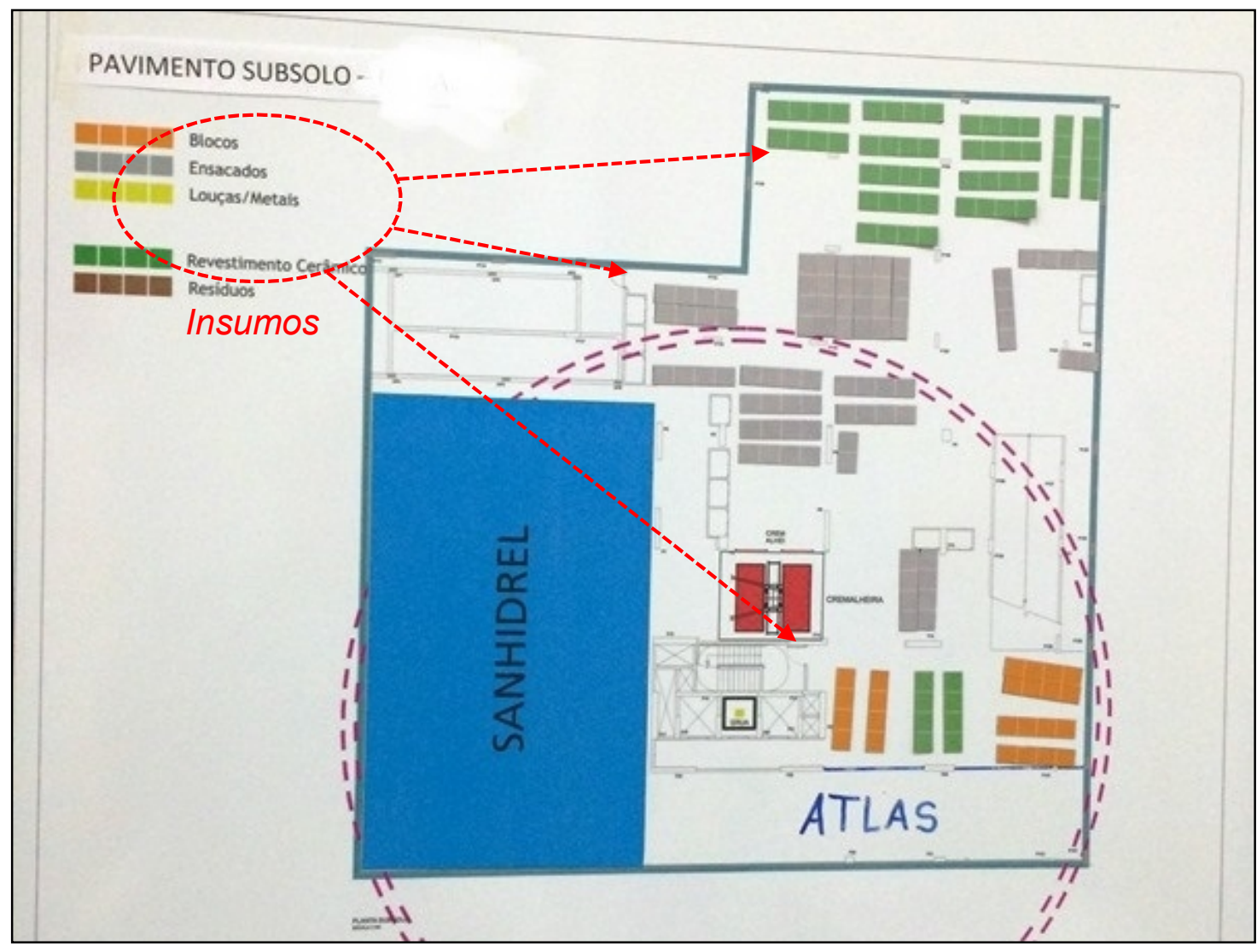

Fonte: O Autor (retirado do planejamento da Construtora C)

Como o canteiro tem acessos restritos, esta prática foi determinante para minimizar os gargalos de abastecimento e fluxo, alinhada com a diretriz \#16 (logística de canteiro). 
Esta ferramenta se mostrou muito interessante, não apenas pela facilidade de visualização dos locais de estoque e organização da obra após a definição dos espaços, mas como ferramenta de discussão nas reuniões de planejamento. Como o quadro pode ser alterado rapidamente e seus elementos representam aproximadamente as escalas corretas dos espaços por tipo de insumo, é possível a construção de diversos cenários visuais para que todos possam decidir qual a melhor estratégia para o momento da obra, bem como analisar possíveis restrições pontuais.

Normalmente, quando se estabelecem projetos de canteiro "estáticos", busca-se uma representação gráfica que ilustre a maior parte dos momentos (datas / horários) naquela etapa, otimizando-se tempo de elaboração, impressões e troca de quadros. Mas, muitas vezes as restrições ocorrem nos momentos onde as condições apresentadas no projeto são ligeiramente diferentes do que foi planejado ou de momentos pontuais não contemplados, o que com a utilização da ferramenta, foi evitado.

\section{$>$ Estabelecimento de datas-marco de controle}

Para este empreendimento, foram estabelecidas desde o início do processo 10 datasmarco importantes para a gestão adequada do caminho crítico da obra. A maior parte delas relaciona-se com datas de concretagem de setores que liberam outros serviços, além de itens de fachada e habite-se.

Além de trazerem de forma clara as metas parciais a serem atendidas pelas equipes de obra (o que gera certa motivação e sentimento de trabalho em equipe), estas datas geram alertas antecipados de problemas que às vezes não são claros em programações muito detalhadas e/ou com problemas de compatibilidade.

Desta forma, esta prática demonstra alinhamento da obra com a diretriz \#18 (sistemas de alerta antecipado).

A importância dada a estas datas pode ser observada posteriormente na figura 66, que retrata a visibilidade destas informações nos ambientes da obra. 
$>$ Comunicação visual do planejamento, metas e performance dos serviços

Finalizando os pontos evidenciados no empreendimento que estão alinhados às diretrizes da proposição inicial do método, observou-se que há uma preocupação dos gestores em divulgar de forma visualmente clara e sempre atualizada, as informações referentes ao planejamento operacional da obra (o que demonstra convergência à diretriz \#5 - gestão à vista).

A figura 66 apresenta alguns dos exemplos de comunicação relacionadas ao planejamento que são implementadas pela empresa, tais como os quadros referentes à logística da obra, suprimentos, programações e acompanhamento da evolução dos serviços.

Figura 66 - Exemplos de comunicação visual sobre itens do planejamento
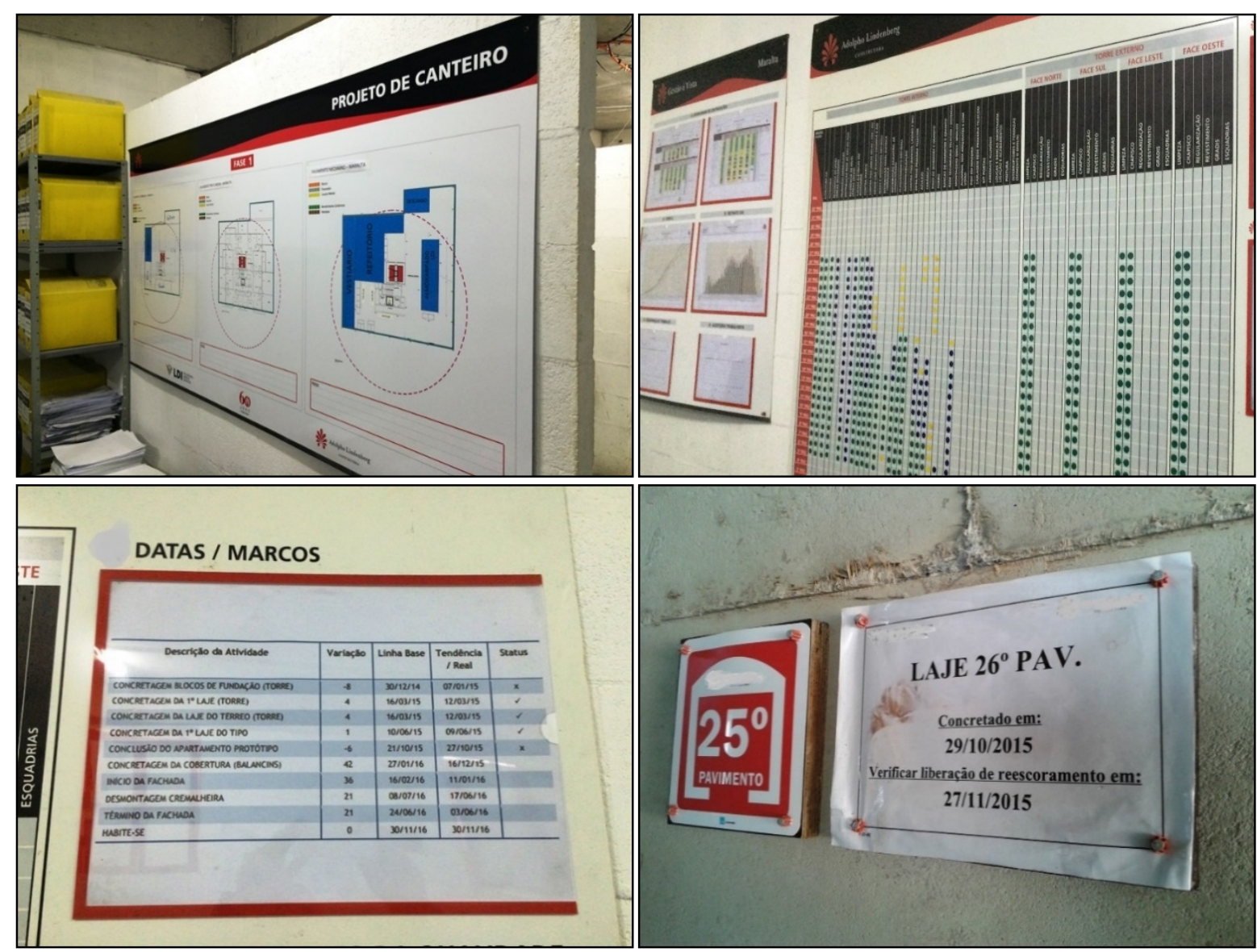

Fonte: O Autor (fotografado na obra, parte do processo de planejamento da Construtora C)

As metas de produção (incluindo datas-marco) e status de cada serviço são visualizados por todos, incluindo serviços que apresentam restrição de execução. 
Por fim, verificou-se a comunicação de serviços relativos à estrutura e ao reescoramento sinalizados em cada andar tipo do edifício, como destaca também a figura 66.

Assim, de forma ainda inicial, percebe-se que a diretrizes \#1 (planejamento de equipes) e \#4 (produção puxada) estão presentes em parte das ações de planejamento do empreendimento. Como não se verificou ações similares para outros serviços que são realizados no andar (que com certeza trazem interferências nas programações, principalmente obra fina e acabamentos), entende-se que estas diretrizes ainda não são evidentes no empreendimento.

\section{Comentários gerais}

Nas entrevistas com os responsáveis pela obra, algumas práticas eram apresentadas como implantadas, embora em sua essência não trouxessem elementos que pudessem caracterizá-las como válidas. Alguns exemplos são citados:

- Apesar de descritos alguns elementos que melhoram as condições de execução dos serviços e podem até gerar motivação das equipes (datas marco, contratações conjuntas, dentre outros), todos eles trazem esta questão de forma indireta, o que não demonstra a efetiva aderência à diretriz \#11 (ambiente de trabalho organizado) com práticas específicas com este objetivo;

- Segundo a equipe de planejamento, a obra utilizava dois cronogramas de referência: um contratual e um com metas de produção arrojada (desafio). Esta prática demonstraria, na visão dos gestores, a constituição de cenários que pudessem auxiliar a antecipação de riscos, ou ainda representam a diferenciação de durações realistas e otimistas. No entanto, o que se verificou foi a existência de uma curva de referência contratual, que nada tinha a ver com um planejamento detalhado em cenário adverso e um cronograma "desafio", que era exatamente a linha de base. Assim, a única referência técnica era a linha de base com cenário mais provável;

- De acordo com a equipe da obra, há uma cadência definida para o projeto, correlacionada ao ciclo da estrutura; mas observando-se os cronogramas em uso, diversos serviços apresentavam ciclos diferentes; 
- Foi comentado pelos gestores que há práticas para se garantir a terminalidade e evitar retrabalho, tais como a existência de um macro fluxo, e o monitoramento constante da equipe da qualidade. Mesmo sendo verificada a implantação, julga-se que estes processos não garantem eficientemente a terminalidade na obra, pois vários pontos de descontinuidade foram encontrados (talvez o macro fluxo seja apenas uma orientação e não um mecanismo de controle);

- Apesar de não se verificar sistemas de garantia de terminalidade, existe um sistema de gestão da qualidade implantado na obra, com suas padronizações e limitações próprias deste tipo de ferramenta (diretriz \#5 - gestão à vista, evidenciada de forma inicial);

- Pretendeu-se identificar o monitoramento das premissas de planejamento, tal qual foi relatado pela equipe da obra. No entanto, a grande maioria das informações eram acompanhadas sem registros de evolução formal, como quantitativos e restrições.

\subsubsection{Empreendimento II}

O Empreendimento II, executado pela Construtora J (que já teve obras avaliadas na primeira pesquisa) caracteriza-se pela execução de 2 torres residenciais de 16 pavimentos cada uma, edifício garagem e estacionamento descoberto, com 263 unidades, totalizando $15.250,67 \mathrm{~m}^{2}$ de área construída, localizado em um terreno de $5.381,72 \mathrm{~m}^{2}$ na cidade de São Paulo/SP.

O empreendimento teve início em 01/09/2015, com previsão de término em 30/06/2017, mesma data da linha de base e 32 dias antes do prazo contratual. Até a última data de acompanhamento desta pesquisa (medição em abril de 2016), a obra apresentava adiantamento de $2,76 \%$ do progresso físico previsto. Desta forma, também foi escolhida para análise de boas práticas de planejamento e gestão.

A figura 67 ilustra a construção do edifício em dois momentos quando se deu a interface do pesquisador com a equipe da obra. 
Figura 67 - Fotos do Empreendimento II (Fev/16 e Mai/16)
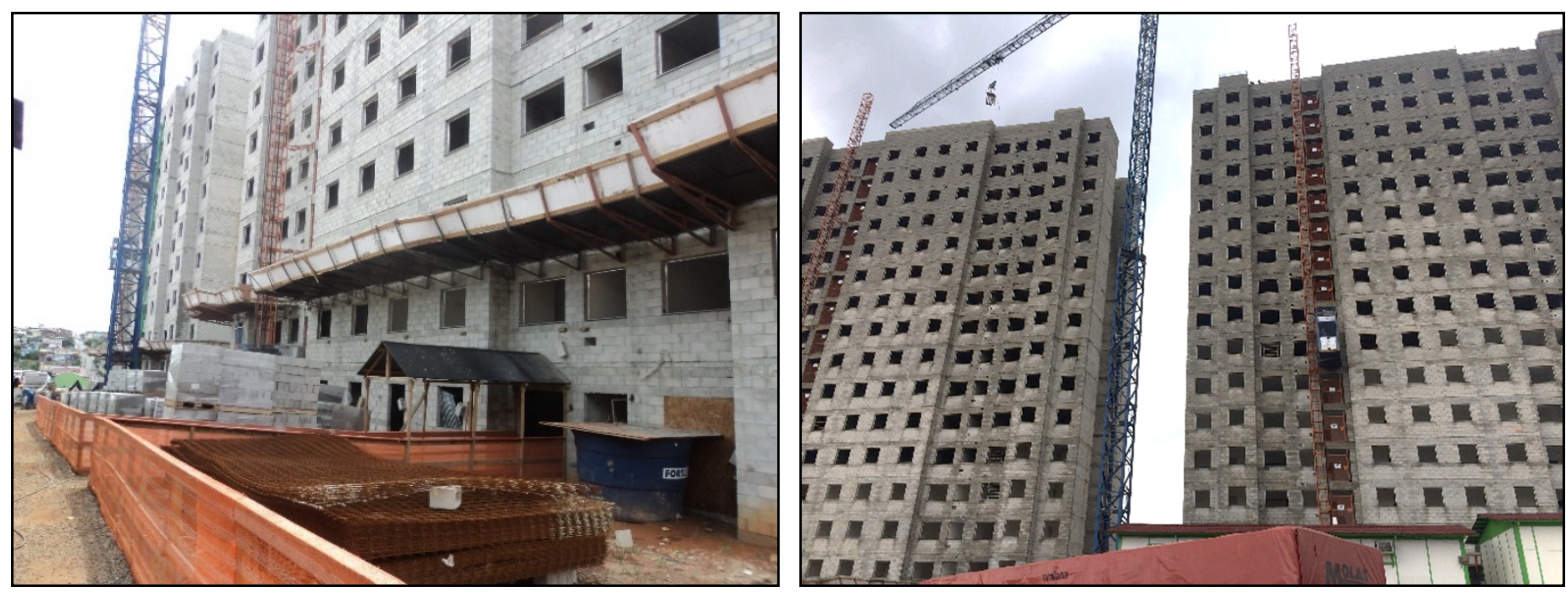

Fonte: O Autor

As práticas identificadas no empreendimento são descritas nos tópicos a seguir.

\section{Estabelecimento de cenários com metas realistas}

Observou-se no planejamento da obra, uma preocupação em se estabelecer metas de produção aderentes à realidade das condições do canteiro, equipes e subcontratados, não permitindo a procrastinação de atividades ou o consumo de margens de segurança aleatórias que pudessem trazer riscos ao projeto. Esta orientação alinha-se totalmente com a diretriz \#9 (metas realistas).

Ao mesmo tempo, como o cliente contratante exige uma referência contratual também realista, optou-se em estabelecer 2 cenários de referência.

Um deles retrata um referencial realista e que será estabelecido como base para a definição de datas-marco de controle e obrigações contratuais. Estas premissas e a rede de precedência resultante, bem como seu cronograma e Curva $S$ foram utilizados como linha de base da obra.

Em seguida, buscou-se a antecipação de todas as atividades com a revisão das premissas para um cenário otimista. Estas datas e o cronograma resultante seriam utilizados como referência para as metas de curto prazo (chamado em algumas empresas de cronograma desafio). Na verdade esta nova referência acaba sendo o real parâmetro de acompanhamento das equipes no canteiro. Dela é possível se verificar o ritmo das atividades. 
A figura 68 ilustra a curva com os dois cenários, sendo uma curva a linha de base (contratual, com premissas mais prováveis) e a outra, a curva de reprogramação resultante do andamento real da obra.

É possível verificar que esta sistemática garantiu que a obra permanecesse adiantada em relação à linha de base inicial e pelos dados mensais plotados no gráfico, claramente comprova-se que é a referência usual de programação da obra.

Esta prática poderia ser classificada também como uma ação de produção "puxada", lembrando a diretriz \#4 (produção puxada), embora não no contexto original de quando foi criado este conceito. Desta forma, classificou-se como uma diretriz ainda inicial no empreendimento.

Figura 68 - Curva S dos 2 cenários de planejamento (realista e otimista)

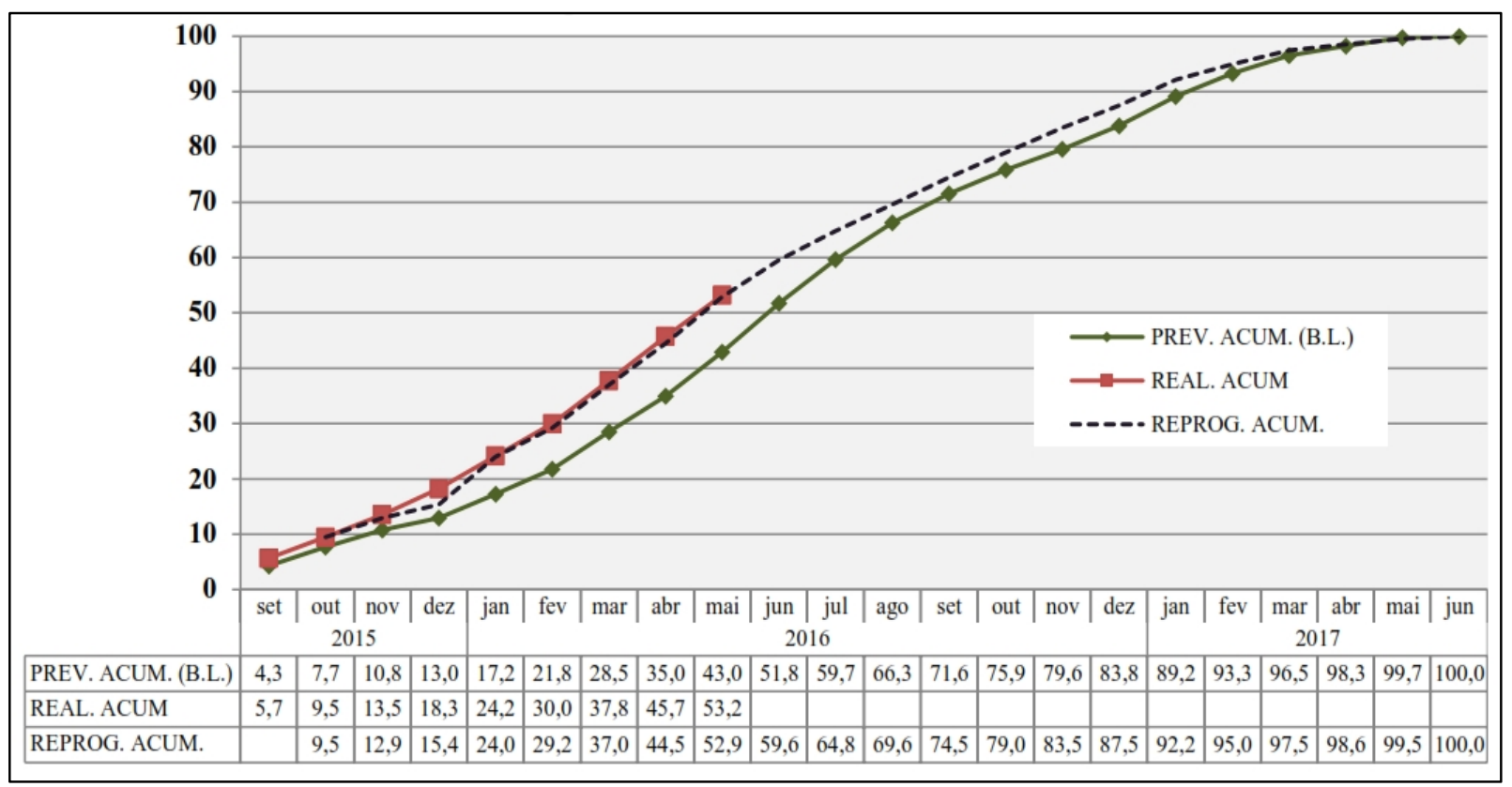

Fonte: O Autor (retirado do planejamento da Construtora J)

\section{Definição de premissas mensuráveis}

Para o desenvolvimento das durações de cada atividade, a equipe de planejamento da obra estabeleceu alguns memoriais de cálculo com premissas de produtividade, equipe e o cálculo de quantidades dos projetos executivos. Um exemplo deste memorial e desenho de apoio pode ser observado na figura 69. 
Figura 69 - Exemplo de memorial de cálculo dos serviços

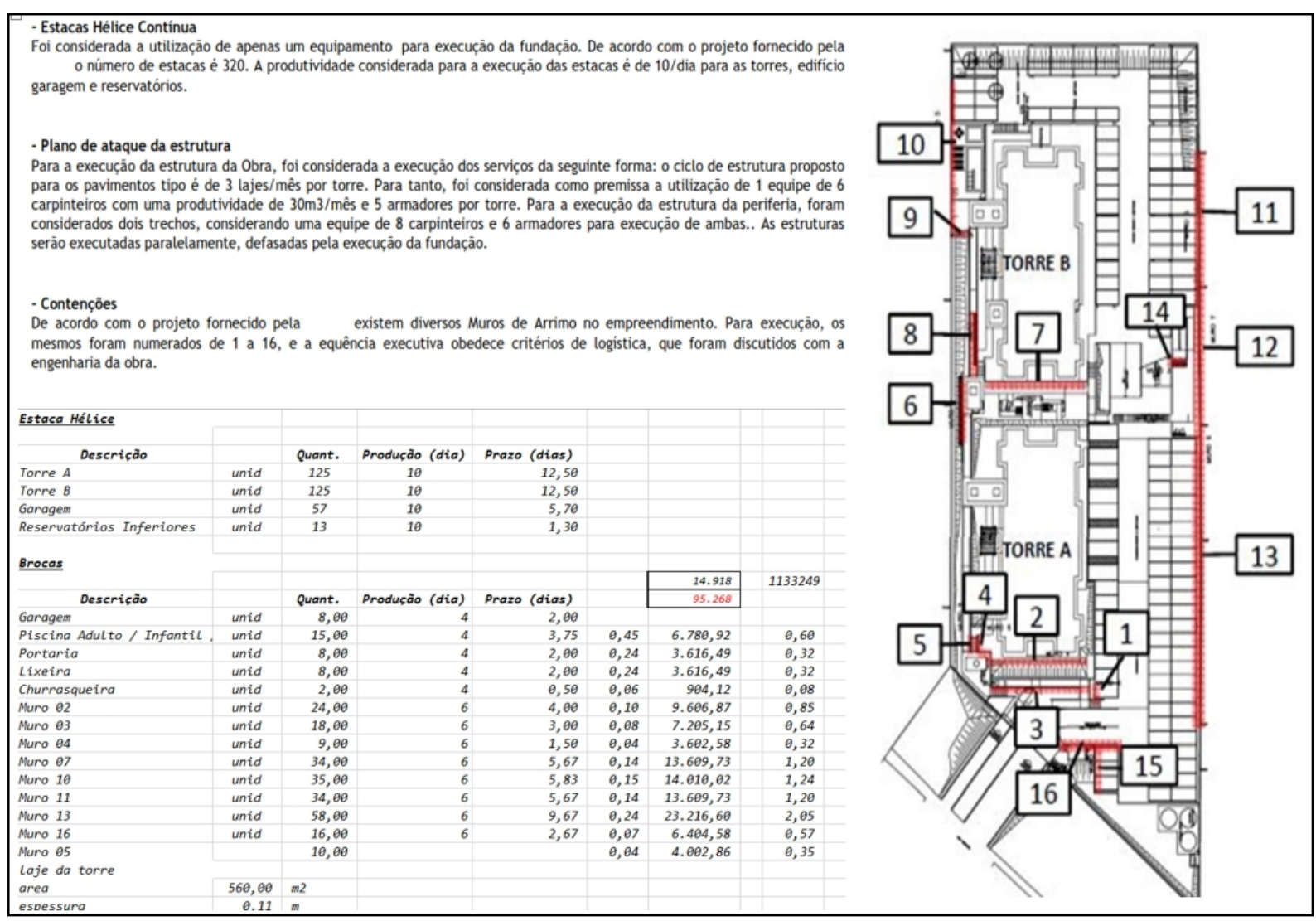

Fonte: O Autor (recorte do processo de planejamento da Construtora J)

Com o andamento da obra, a cada início de serviço atrasado ou medição de progresso inferior ao previsto na linha de base ou na reprogramação, estas premissas eram revistas. Identificavam-se quais delas não estavam sendo prioritariamente cumpridas, afetando a programação mensal ou trimestral.

Tal procedimento comprova a aplicação da diretriz \#2 (premissas mensuráveis), embora o monitoramento não seja realizado de forma padrão, sistemático.

Observa-se também que a prática foi implementada apenas em atividades do caminho crítico. Apesar de suficiente para os gestores do projeto, entende-se que poderia ser também estendido para outras atividades importantes para o empreendimento.

\section{Utilização de calendário de chuvas}

A utilização de calendários diferentes, em especial relativo a chuvas (aderente à diretriz \#24 - premissas por tipo de serviço) foi verificado na obra. 
A sistemática é muito semelhante à descrita no Empreendimento I, sendo aplicados 2 bases de referência de dias úteis, uma delas apenas com dias não trabalhados em feriados ou recessos, e outro com menor previsão de dias úteis em alguns meses (calendário de chuvas).

O calendário de chuvas para esta obra foi correlacionado às atividades de fundação, estrutura, revestimento de fachada, impermeabilização da cobertura e atividades externas do térreo.

\section{Datas de referência do caminho crítico}

Conforme descrito no item anterior, a obra estabeleceu algumas datas-marco para controle do caminho crítico. Esta prática, alinhada com a diretriz \#18 (sistemas de alerta antecipado), fornece subsídios para a tomada de ações preventivas, pois a ferramenta está ligada diretamente às datas de reprogramação, ou seja, não são informações estáticas.

Conforme pode ser observado na figura 70, as datas da linha de base são fixas e mensalmente, após a reprogramação do período as novas datas de previsão de início e término são alimentadas, evidenciando os possíveis atrasos de forma antecipada.

Figura 70 - Recorte da planilha de datas marco da obra

\begin{tabular}{|c|c|c|c|c|c|}
\hline \multicolumn{6}{|c|}{ TORRE 2} \\
\hline DESCRIÇÃO ATIVIDADE & $\begin{array}{l}\text { VARIAÇÃo } \\
\text { (LB } \times \text { Real) }\end{array}$ & LINHA BASE & PREVISÃo & DATA REAL & $\begin{array}{c}\text { STATUS } \\
\text { (RE } \times \text { REAL) }\end{array}$ \\
\hline TÉRMINO BLOCOS DE FUNDAÇÃO & -3 & $29 / 10 / 15$ & $26 / 10 / 15$ & $26 / 10 / 15$ & $O K$ \\
\hline CONCRETAGEM DA LAJE - $1^{\circ}$ PAVIMENTO & -54 & $11 / 01 / 16$ & $18 / 11 / 15$ & $18 / 11 / 15$ & $O K$ \\
\hline CONCRETAGEM DA LAJE - $2^{\circ}$ PAVIMENTO & -59 & $25 / 01 / 16$ & $27 / 11 / 15$ & $27 / 11 / 15$ & $O K$ \\
\hline CONCRETAGEM DA LAJE - COBERTURA & -82 & $13 / 07 / 16$ & $22 / 04 / 16$ & $22 / 04 / 16$ & $O K$ \\
\hline TÉRMINO DA FACHADA & -64 & $13 / 12 / 16$ & $10 / 10 / 16$ & & - \\
\hline CONCLUSÃO DE MONTAGEM DOS ELEVADORES & -60 & $04 / 03 / 17$ & $03 / 01 / 17$ & & - \\
\hline \multicolumn{6}{|c|}{ LIGAÇÕES DEFINITIVAS / ALVARÁS } \\
\hline DESCRIÇÃO ATIVIDADE & $\begin{array}{l}\text { VARIAÇÃO } \\
\text { (LB x Real) }\end{array}$ & LINHA BASE & PREVISÃo & DATA REAL & $\begin{array}{c}\text { STATUS } \\
\text { (RE } \times \text { REAL) }\end{array}$ \\
\hline APARTAMENTO MODELO & 69 & $08 / 04 / 16$ & $21 / 01 / 16$ & $30 / 03 / 16$ & ATRASO \\
\hline INICIO DE VISTORLAS & 30 & $17 / 03 / 17$ & $16 / 04 / 17$ & & - \\
\hline EMISSÃO $A V C B$ & 0 & $30 / 03 / 17$ & $30 / 03 / 17$ & & - \\
\hline LIGAÇÃO DEFINITIVA DE ENERGLA & -18 & $03 / 05 / 17$ & $15 / 04 / 17$ & & - \\
\hline TESTE DE GASS & -68 & $10 / 05 / 17$ & $03 / 03 / 17$ & & - \\
\hline INSTALAÇÃO DE MEDIDOR DE GÁSS & -61 & $30 / 05 / 17$ & $30 / 03 / 17$ & & - \\
\hline LIGAÇÃO DE ESGOTO OU ETE & -78 & $10 / 05 / 17$ & $21 / 02 / 17$ & & - \\
\hline INSTALAÇ ÃO DO HIDROAMETRO DE AGUA & -76 & $30 / 05 / 17$ & $15 / 03 / 17$ & & - \\
\hline
\end{tabular}

Fonte: O Autor (retirado do planejamento da Construtora J) 
No quadro em questão, verificam-se serviços que teoricamente não estão atrasados, mas sim, pela reprogramação, tem previsão de serem realizados em datas posteriores ao definido na linha de base. Este alerta faz com que, naturalmente, sejam discutidas e registradas as consequências em se manter as premissas de reprogramação válidas.

\section{Aspectos positivos de comunicação visual}

Focando-se na análise de práticas que evidenciam a diretriz \#5 (gestão à vista), verifica-se que no empreendimento há uma divulgação dos aspectos mais importantes do planejamento, porém realizados de forma muito simples e pouco sistematizada. Algumas destas informações podem ser visualizadas na figura 71.

Figura 71 - Exemplos de comunicação visual sobre itens do planejamento

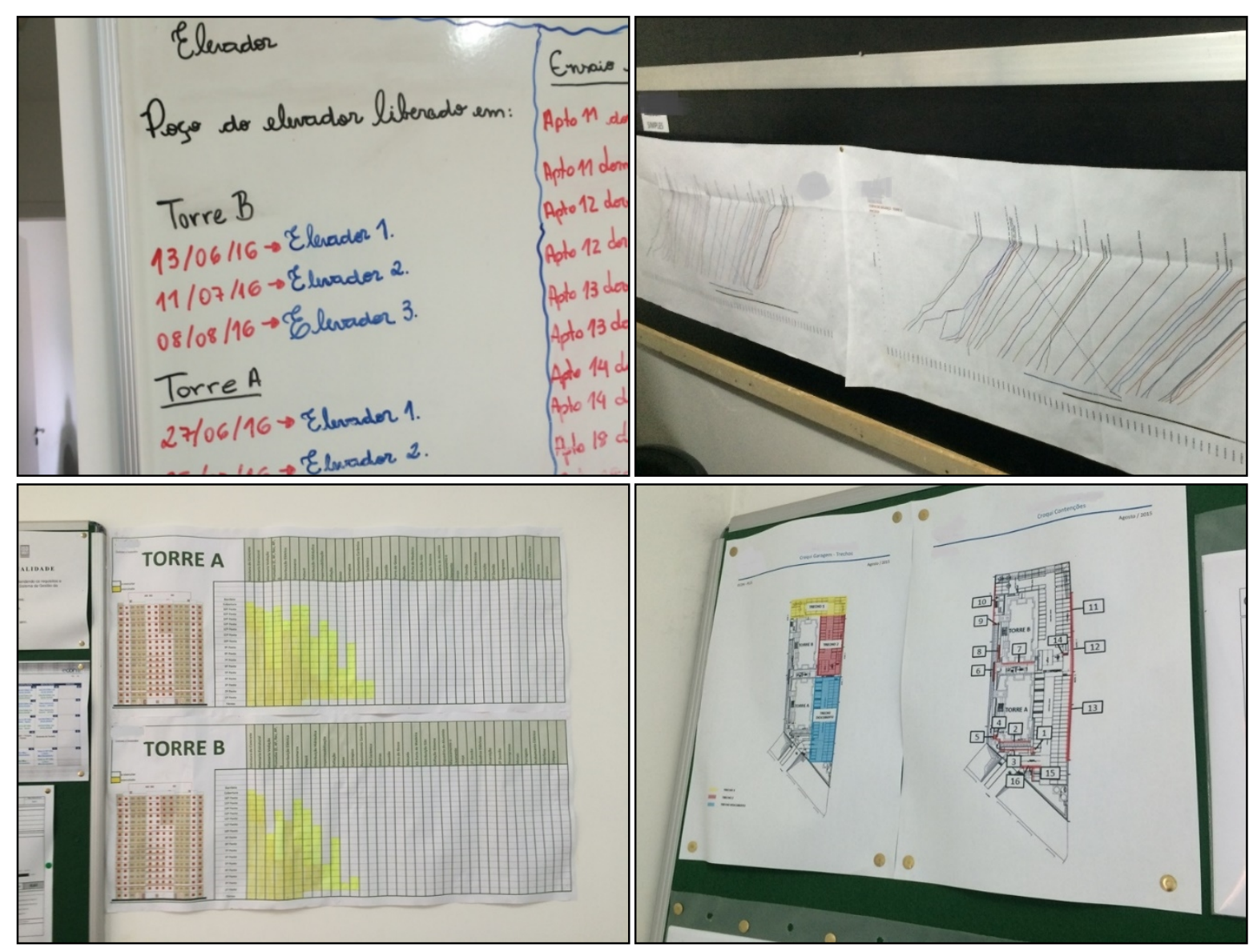

Fonte: O Autor (fotografado na obra, parte do processo de planejamento da Construtora J) 


\section{Programação por equipe}

Analogamente o item anterior, verifica-se uma iniciativa de implantação de modelos de programação por equipe, com o objetivo de organizar o fluxo de subcontratados, o que se corretamente implantados, poderiam evidenciar a diretriz \#1 (planejamento detalhado de mobilização de equipes).

Porém, houve o entendimento que a ferramenta disponível não é a mais adequada, uma vez que traz somente as metas quinzenais de cada equipe e não o detalhe de como devem ser mobilizadas, efetivos ou quando devem entrar em cada local (pois dependem do término de serviços de outras equipes).

A figura 72 ilustra a planilha muito simples utilizada ela obra para cada empreiteiro, que é impressa e entregue nas reuniões de planejamento da obra.

Figura 72 - Programação (metas) por empreiteiro

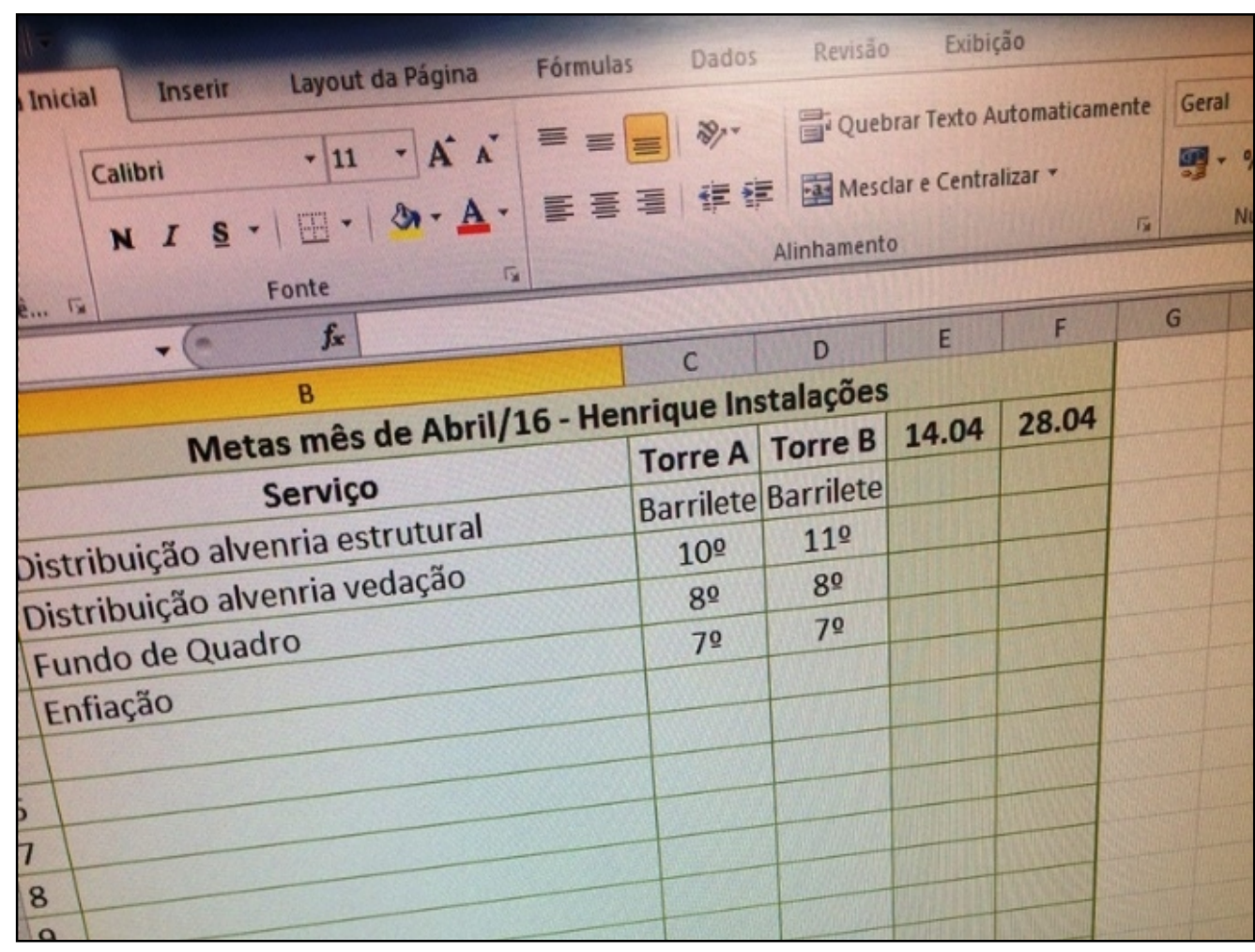

Fonte: O Autor (planilha de planejamento e controle da obra, Construtora J)

Mesmo não proporcionando grandes organizações de fluxo, uma qualidade desta ferramenta é o total entendimento das equipes de suas metas, sejam elas que todos os níveis (encarregados, líderes e oficiais). Por ser simples, a planilha incentiva a discussão das possibilidades ou não do cumprimento e o fato das metas serem 
quinzenais geram foco do alcance dos objetivos, indiretamente trazendo informalmente ações relacionadas à diretriz \#8 (participação das equipes de produção).

\section{Processo simples de análise de restrições}

Outro aspecto importante identificado na obra refere-se à implementação de uma prática muito simples de análise de restrições. Apesar de não formalizada adequadamente, é realizada uma análise semanal com o objetivo de se avaliar quais seriam as necessidades de ações internas que garantam a execução das atividades. Funciona como uma lista de pendências para se evitar a parada das frentes.

Uma das listas de pendências é ilustrada na figura 73.

Figura 73 - Exemplo simples de análise de restrições para início de serviços

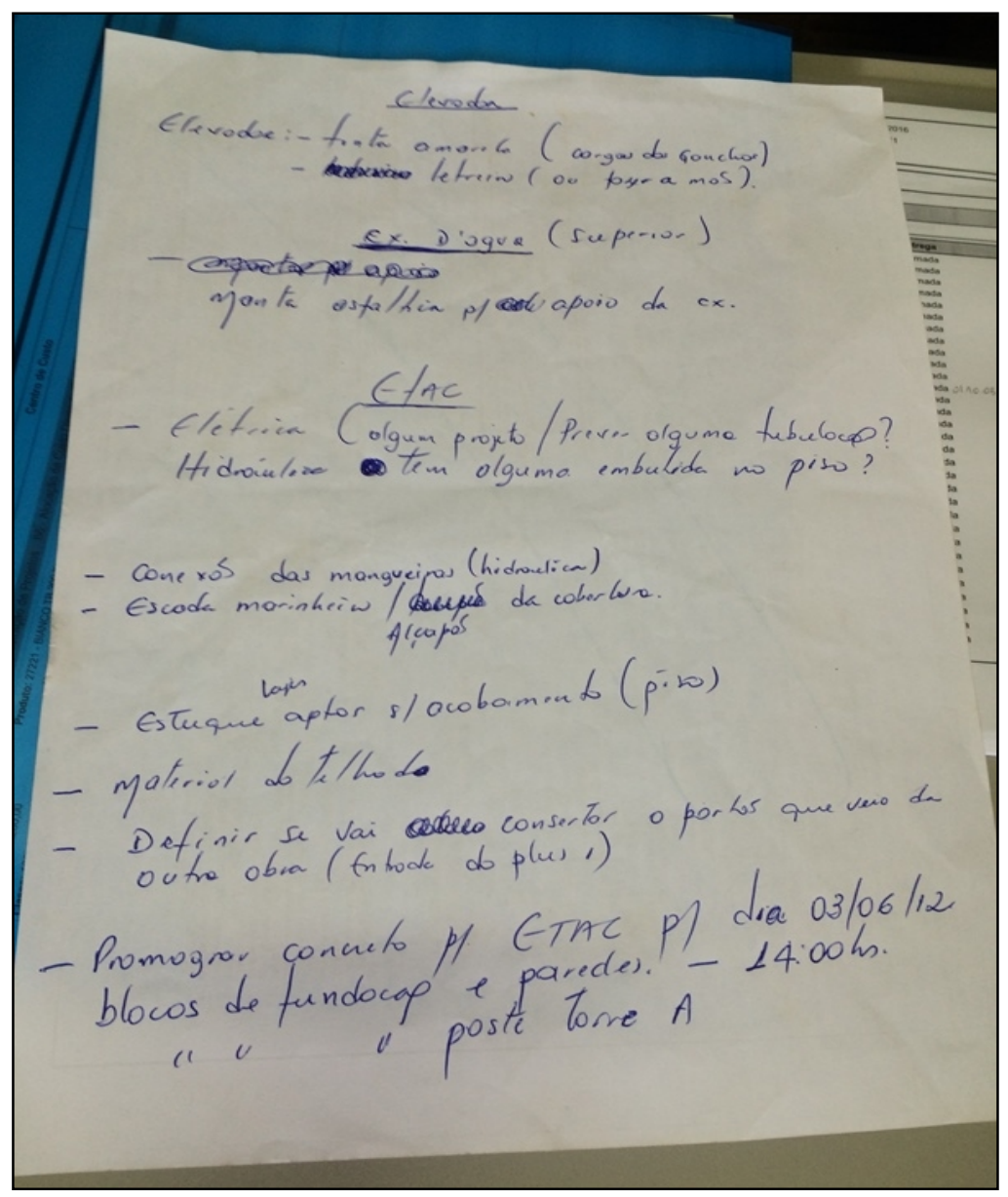

Fonte: O Autor (documento relativo ao processo de planejamento da Construtora J)

Esta prática simples, talvez usual em diversos empreendimentos, não é evidenciada de forma clara e sistematizada, continua informal e dependendo de atitudes gerenciais 
da equipe da obra, o que não a caracteriza como diretriz \#19 (hierarquização de decisões) efetivamente implantada.

Desta forma, pode ser tomada como um ponto inicial para a discussão de melhorias e inclusão de ações ou registros complementares, que estruturem uma prática efetiva e direcionadas a outras obras da empresa.

Uso de linhas de balanço para organização da produção

Verificou-se neste empreendimento o uso da LOB, como forma de se exemplificar práticas aderentes à diretriz \#6 (cadência dos serviços).

A ferramenta foi aplicada de forma independente nas duas torres do empreendimento e como ilustrado na figura 74. Seu uso mais característico no empreendimento está relacionado à identificação de incompatibilidades do plano de médio prazo.

Os dados de entrada para a linhas vêm diretamente do cronograma (datas de início de término de cada serviço que são plotadas no gráfico) e pela figura, podem ser observados vários pontos onde estas linhas se cruzam (círculos vermelhos), indicando pontos de ajuste no planejamento.

Figura 74 - Linhas de balanço com incompatibilidades (destacadas em vermelho)

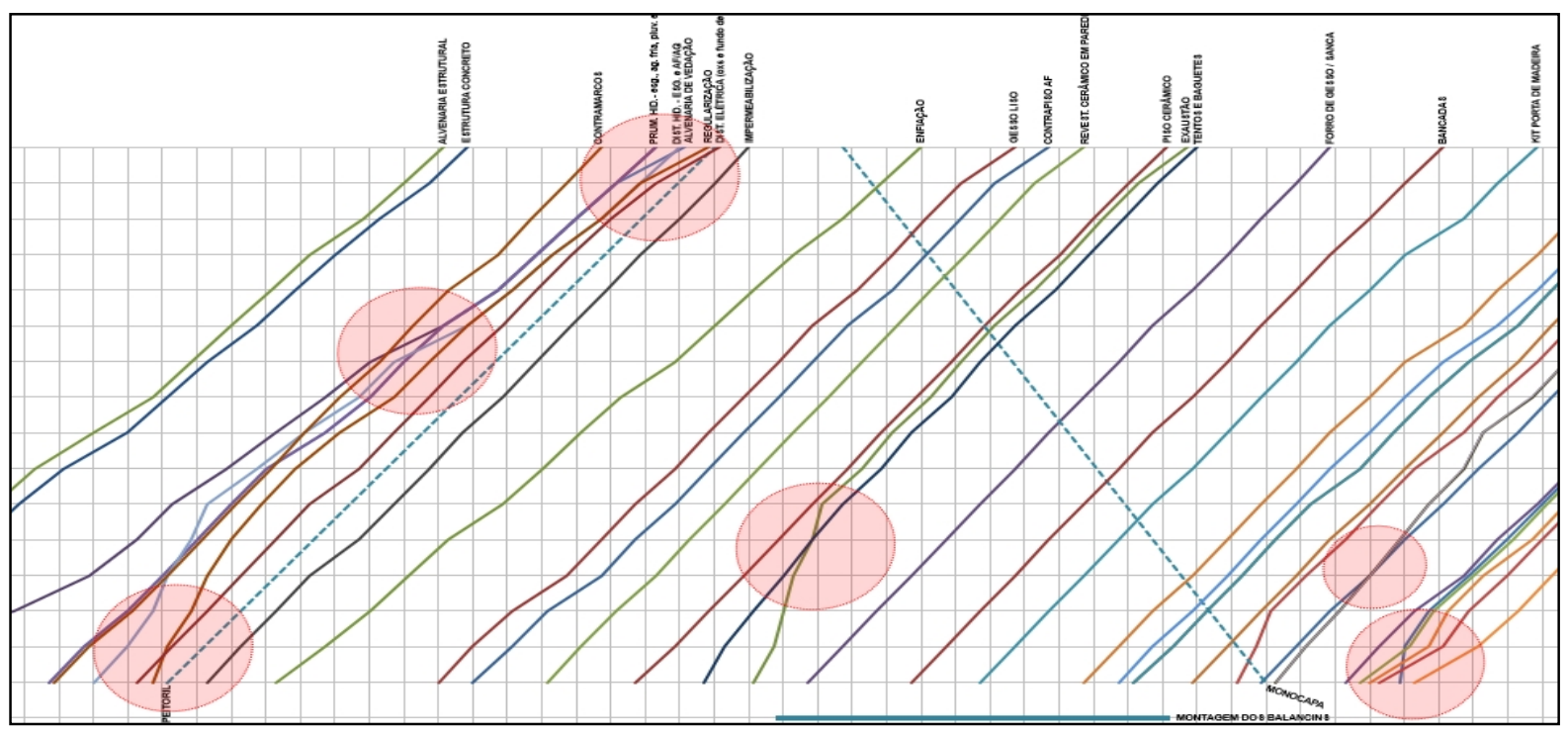

Fonte: O Autor (arquivo fornecido pela Construtora J)

Assim, entende-se que o empreendimento não se beneficia de todas as qualidades do método. Percebem-se por exemplo, linhas que nem precisariam ser representadas, 
pois são características de praticamente o mesmo ciclo produtivo, caso das linhas de "alvenaria estrutural" e "estrutura de concreto" (laje), por exemplo. Naturalmente estes dois serviços poderiam ser representados em um único ciclo de estrutura, este sim, com a necessidade de ser balanceado.

Percebem-se também muitos "vazios" entre as linhas, o que indica possíveis folgas entre as equipes, indicando possibilidades de antecipação de serviços ou a diminuição do lead time.

Mesmo com todas estas possíveis melhorias, o fato de maior importância verificado na obra é a manutenção do ritmo das atividades, comprovado pelas inclinações uniformes das atividades. Isto mostra de apesar do uso restrito da ferramenta, há uma preocupação da equipe da obra no balanceamento das atividades no canteiro (manter o ritmo da obra), o que muito ajudou a garantir a previsibilidade das programações e administração dos fluxos do canteiro.

\section{Comentários gerais}

Outras práticas interessantes menos impactantes na redução de atraso foram identificadas ou descritas pelos responsáveis da obra. Porém, estas caracterizavamse mais como iniciativas promissoras do que como evidências de diretrizes da proposição inicial.

Pode-se citar, por exemplo, a elaboração de um cronograma preliminar e desenhos de apoio para discussão antecipada do plano de execução da obra. Ação esta que por não ter elaboração sistematizada (era apenas uma referência prévia do cronograma final que estava em elaboração e dependia de informações voluntárias dos envolvidos) não foi considerada como evidencia da diretriz \#20 (plano mestre detalhado).

Outro ponto interessante está relacionado às contratações de pacotes conjuntos, o que poderia evidenciar a diretriz \#12 (contratações conjuntas). No entanto, o que se verificou não era uma diretriz que buscasse ganhos de produtividade e minimização de riscos, mas sim apenas uma tradição da empresa de se contratar os mesmos fornecedores. Não havia controles ou direcionamentos dos pacotes por condição de atendimento, apenas de uma condição favorável para a obra. 


\subsubsection{Empreendimento III}

O Empreendimento III, executado pela Construtora W (não tem obras avaliadas na primeira pesquisa) caracteriza-se pela execução de 1 torre residencial de 24 pavimentos, 4 sobressolos, com 302 unidades, totalizando 23.615,00 $\mathrm{m}^{2}$ de área construída, localizado em um terreno de $2.792,00 \mathrm{~m}^{2}$ na cidade de São Paulo/SP.

O empreendimento teve início em 13/03/2015, com previsão de término em 22/05/2017, mesma data da linha de base e 31 dias antes do prazo contratual. Na última data de acompanhamento do pesquisador (medição em abril de 2016), a obra apresentava adiantamento de $28,1 \%$ do progresso físico previsto na linha de base, embora como se descreverá mais adiante, a referência adotada posteriormente seria a curva desafio da produção. Por esta característica, a obra também foi escolhida para compor a amostragem da pesquisa.

Este empreendimento apresenta uma característica interessante: um dos sócios do incorporador, ou seja, o cliente do projeto, é um fundo de investimento imobiliário estrangeiro. Desta forma, todos os relatórios gerenciais da obra eram desenvolvidos e duas línguas (português e inglês)

A figura 75 ilustra a construção do edifício em duas datas diferentes quando da realização de algumas das visitas do pesquisador.

Figura 75 - Fotos do Empreendimento III (Set/15 e Abr/16)

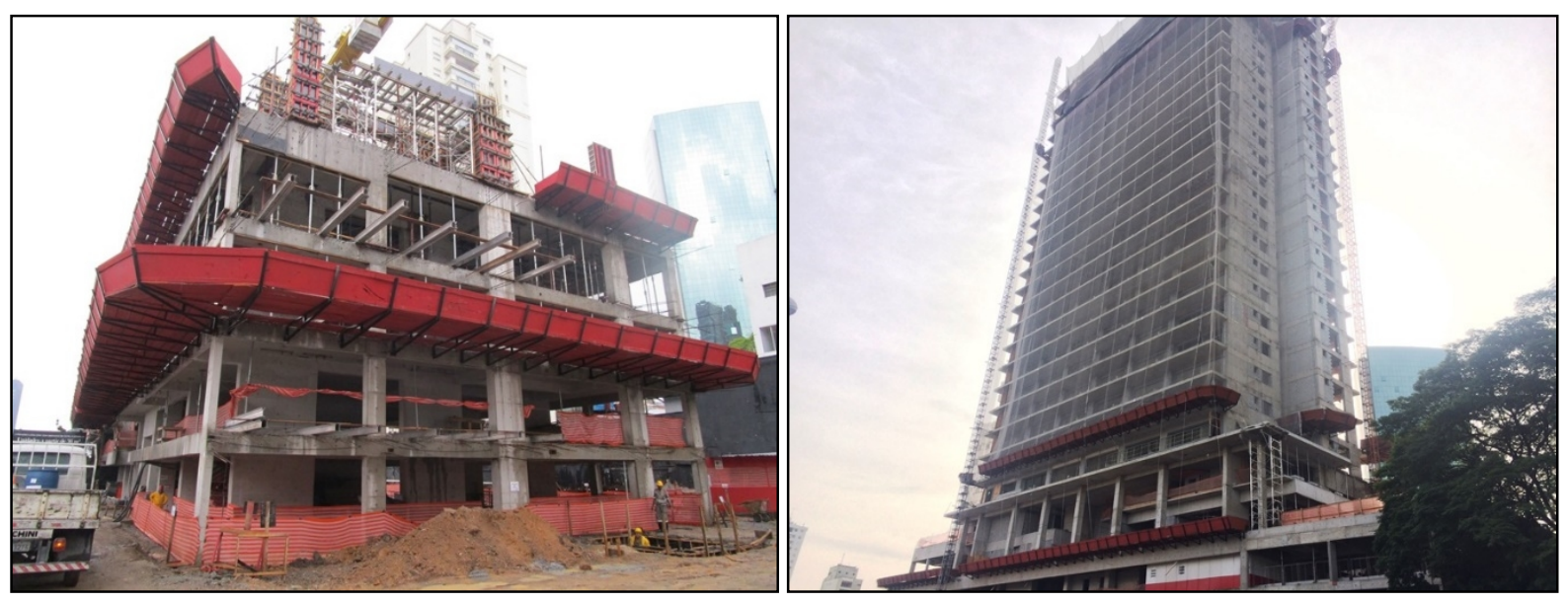

Fonte: O Autor 


\section{Premissas de planejamento mensuráveis e gerenciáveis}

Nesta obra foi verificado um cuidado especial no dimensionamento adequado das atividades, com base em levantamentos quantitativos e na construção de parâmetros de produção que originaram o estabelecimento das durações das atividades.

Esta prática está intrinsecamente ligada à diretriz \#2 (premissas mensuráveis), mas pode-se afirmar que também há uma complementariedade na diretriz \#24 (premissas por tipo de serviço), pois há fortes indícios de preocupação de diferenciação dos parâmetros conforme tipo de serviço a ser executado no canteiro, e também da diretriz \#10 (sistemas para aumento de produtividade), uma vez que os melhores caminhos para melhorar a produtividade são estudados com frequência, baseada nos diversos cenários que os estudos trazem para a mesa de discussão de planejamento.

Foram evidenciados neste empreendimento durante a etapa de definição das premissas, estudos de quantitativos, equipes e índices de produção para os serviços de estrutura, alvenaria, contrapiso, revestimentos argamassados internos, gesso e fachada. A figura 76 ilustra um destes levantamentos, no caso, relativo ao serviço de contrapiso.

Figura 76 - Premissas para planejamento do serviço de contrapiso

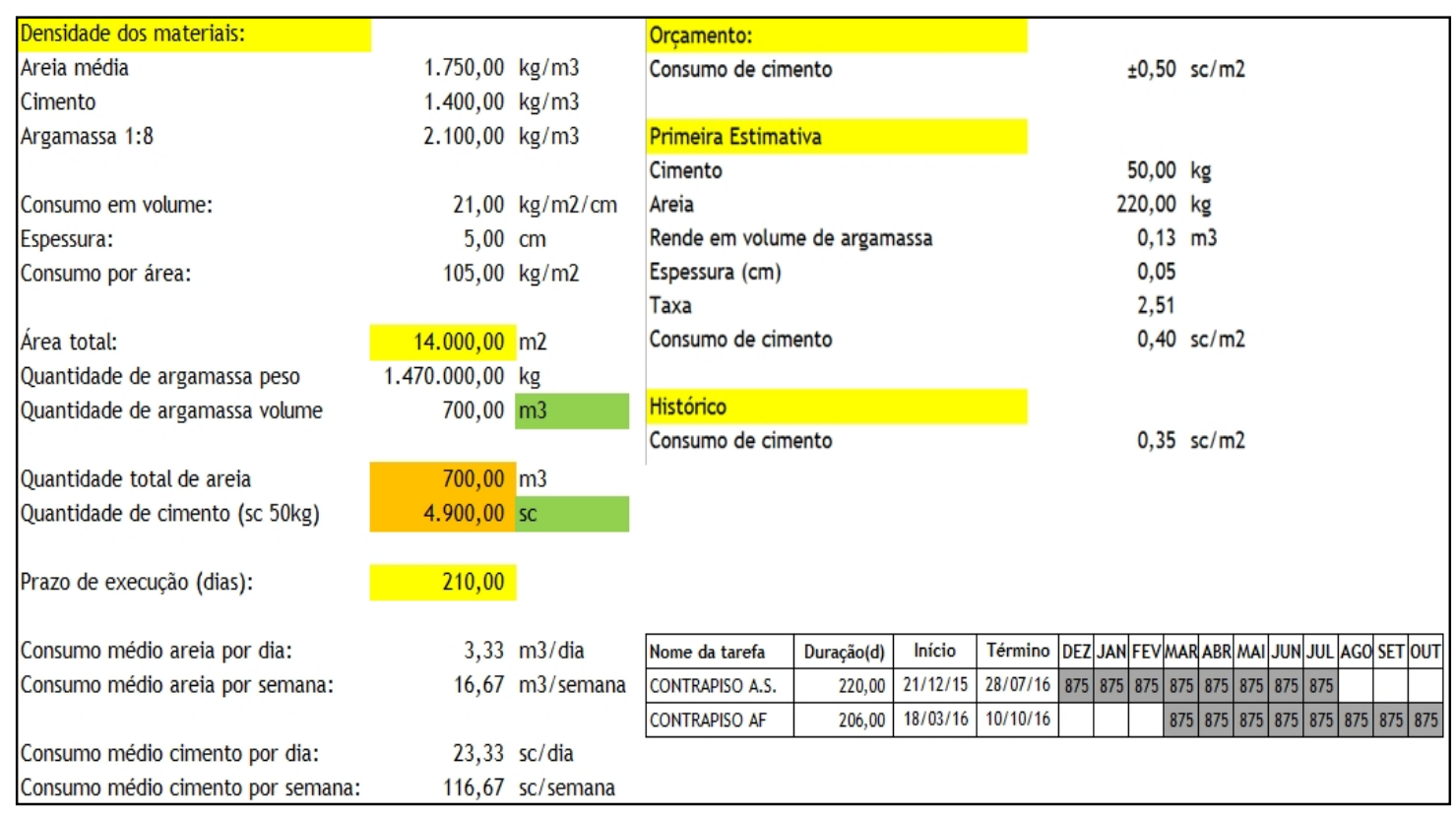

Fonte: O Autor (dados fornecidos pela Construtora W) 
Plano de ataque com detalhes de logística e abastecimento

Figura 77 - Evolução do canteiro por fases

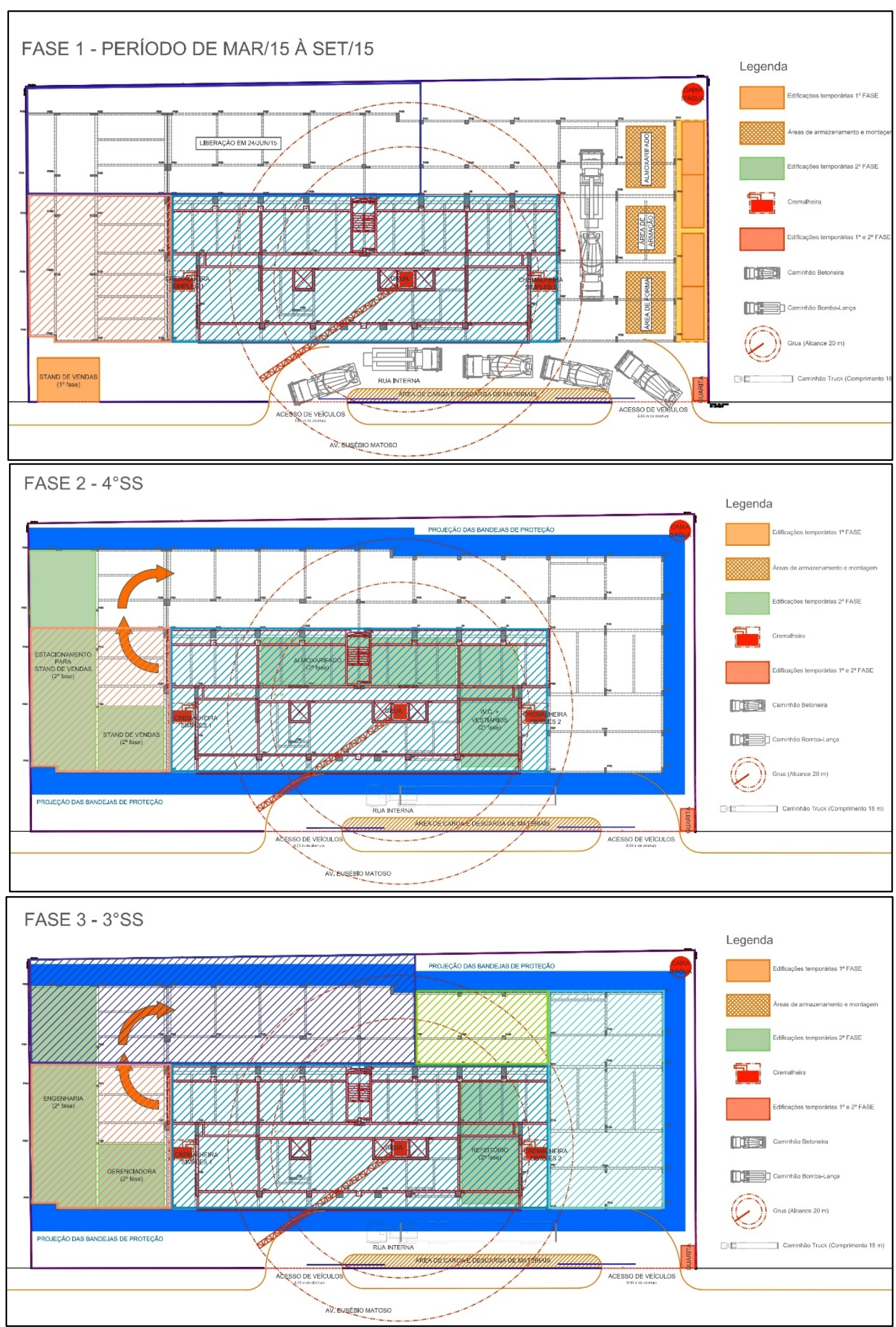

Fonte: O Autor (parte do plano mestre da Construtora W) 
Nesta obra observa-se a preocupação muito grande de estudos detalhados de como sevem ser realizadas as diversas atividades no canteiro, desde o estudo de posicionamentos de equipamentos, os locais de estoque, até a evolução do canteiro.

A figura 77 ilustra o planejamento da logística por etapas, que é acompanhado dos desenhos e programação do uso dos equipamentos de transporte vertical (grua e cremalheiras), atendendo as diretrizes \#16 (logística de canteiro) e \#20 (plano mestre detalhado).

Os líderes de obra participaram ativamente na definição das premissas, como descrito no item posterior, o que garantiu comprometimento das equipes com as metas estabelecidas e com a forma de execução das atividades, item também alinhado com a diretriz \#8 (participação das equipes de produção).

For fim, verifica-se ainda uma referência parcial à diretriz \#17 (avaliação das condições de abastecimento), pois as discussões de logística também envolveram aspectos da localização do empreendimento, que se situa em uma zona de restrição importante na cidade de São Paulo. O que fez com que as práticas não fossem totalmente aderentes a esta diretriz foi a falta de uma sistemática de consulta efetiva aos subcontratados e fornecedores, pois a previsão foi realizada através da experiência do corpo gerencial da construtora.

\section{Análise de cenários}

De forma similar ao que foi observado no empreendimento anterior, a obra busca de forma contínua a antecipação dos serviços descritos na linha de base contratual.

Neste caso, a diferença ocorre na definição da linha de base inicial (e contratual), que foi estabelecida com algumas margens de segurança propositais, visto a multa contratual pesada em que a construtora estava submetida.

Assim, claramente esta curva e seus planos resultantes não poderiam ser utilizados como ferramentas de programação de produção, pois fatalmente trariam riscos ao empreendimento. Naturalmente, foi estabelecido um planejamento denominado "desafio", o qual considera prazos "otimistas" para os serviços de ocorrência mais próximos da data de status da obra, ou prazos "mais prováveis", em alguns casos, 
para serviços que serão realizados mais tarde ou com alguma indefinição de premissa ou contratação naquele momento.

O que se percebeu nesta prática, é que, com o passar dos meses, pelo fato das datas de execução reais estarem muito antecipadas à linha de base, o próprio cliente (no caso, um fundo internacional) não utilizava mais esta curva como referência, pois todas as datas de controle não eram coerentes com a realidade da obra.

Como o cliente preferiu acompanhar a evolução da obra pela curva "desafio", esta foi colocada no relatório e à medida que alguma antecipação substancial da obra era vislumbrada, a curva "desafio" (goal) de referência era atualizada, como pode ser verificado na figura 78 , que apresenta uma segunda e uma terceira revisão da curva desafio, num intervalo de 4 meses entre as duas versões.

Figura 78 - Referenciais contratual, desafio e real, em 2 momentos da obra

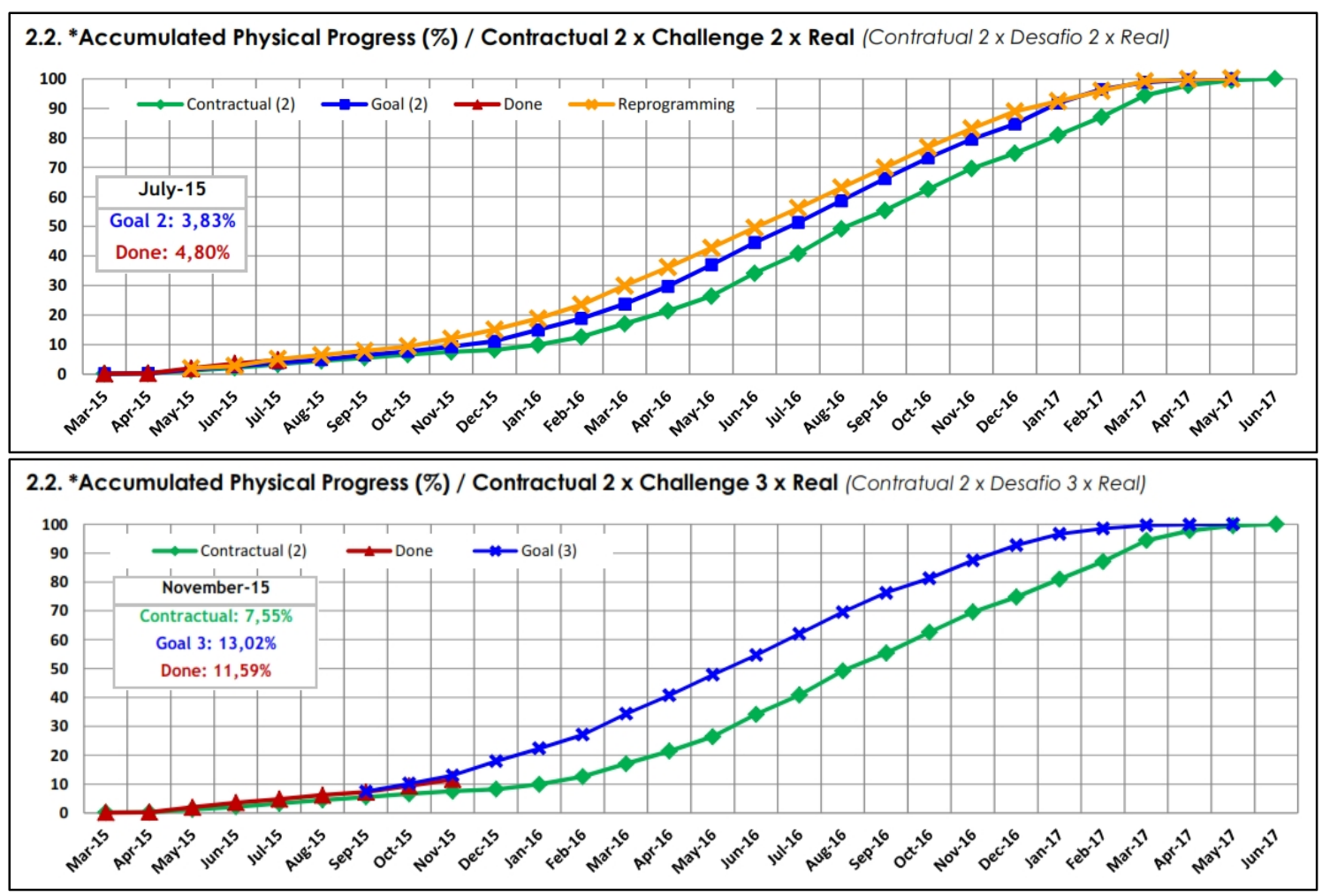

Fonte: O Autor (retirado de relatórios gerenciais da Construtora W)

Assim, entende-se que na obra há uma sistemática de busca contínua de antecipação de tarefas e eliminação de folgas arbitrárias (mesmo que elas existam como referencial contratual, como observado), itens alinhados às diretrizes \#4 (produção puxada) e \#9 (metas realistas). 
Indicadores de performance vinculados com alertas formais de problemas futuros

Complementando as práticas que demonstram a preocupação da equipe de planejamento da obra com a antecipação dos fatos e formalização dos problemas (diretrizes características de \#2 - premissas mensuráveis, \#18 - sistemas de alerta antecipado e \#19 - hierarquização de decisões), verifica-se o registro das restrições em relatórios detalhados por serviços e as ações para recuperação, quando necessário.

A figura 79 traz um recorte de parte do relatório que é enviado ao cliente, destacando os indicadores de progresso e as ações que estão sendo tomadas pelas equipes da obra.

Figura 79 - Indicadores e ações de recuperação

\begin{tabular}{|c|c|c|c|c|}
\hline \multicolumn{5}{|c|}{ 2.5. Main Activities (Principais Atividades) } \\
\hline \multirow{2}{*}{$\begin{array}{l}\text { Activities } \\
\text { (Atividades) }\end{array}$} & \multicolumn{2}{|c|}{$\begin{array}{c}\text { Global Performance } \\
\text { (Desempenho global) }\end{array}$} & \multirow{2}{*}{$\begin{array}{c}\text { SPI } \\
\text { (EVA) }\end{array}$} & \multirow{2}{*}{$\begin{array}{l}\text { Comments } \\
\text { (Comentários) }\end{array}$} \\
\hline & $\begin{array}{l}\text { * Foreseen } \\
\text { (Previsto) }\end{array}$ & $\begin{array}{c}\text { Done } \\
\text { (Realizado) }\end{array}$ & & \\
\hline $\begin{array}{l}\text { 2.3.2. PILE CAPS - } \\
\text { PERIPHERY (BLOCOSE } \\
\text { BALDRAMES - PERIFERIA) }\end{array}$ & $100,0 \%$ & $87,5 \%$ & 0,88 & \multirow{2}{*}{$\begin{array}{l}\text { The structure of the periphery of the sectors "IPHAN" and "A" is delayed } \\
\text { compared to baseline. To recover the structure delay, these two sectors and } \\
\text { sector B will be executed in parallel, and will be finished by May/16. } \\
\text { A estrutura da periferia nos setores "IPHAN" e "A" apresentam um atraso em } \\
\text { relação a linha de base. Para recuperação do atraso, os dois trechos mais parte } \\
\text { do setor B serão executado em paralelo, com término previsto no início de } \\
\text { maio/ } 16 .\end{array}$} \\
\hline $\begin{array}{l}\text { 2.7.2. STRUCTURE - } \\
\text { PERIPHERY (ESTRUTURA } \\
\text { DO SOBRESSOLO/TÉRREO - } \\
\text { PERIFERIA) }\end{array}$ & $88,9 \%$ & $43,0 \%$ & 0,48 & \\
\hline $\begin{array}{c}\text { 2.9.2. STRUCTURE - } \\
\text { TOWER (ESTRUTURA DA } \\
\text { TORRE) }\end{array}$ & $\mathbf{5 7 , 9 \%}$ & $64,9 \%$ & 1,12 & $\begin{array}{l}\text { On the Tower, which is the critical path, the structure is one floor ahead } \\
\text { schedule comparing with Goal } 3 \text { baseline. The 22th floor was poured on } \\
\text { February } 24,2016 \text {, and according to the baseline, the 22th floor was } \\
\text { scheduled for March } 14 \text { th. } \\
\text { A estrutura da Torre, que é caminho crítico da obra, está adiantada um } \\
\text { pavimento em relação ao cronograma linha de base 3. Dia } 24 / 02 / 16 \text { foi } \\
\text { concretada a laje do } 22^{\circ} \text { pavimento. Em linha de base estava previsto a } \\
\text { concretagem deste pavimento em } 14 / 03 / 16 \text {. }\end{array}$ \\
\hline
\end{tabular}

Fonte: O Autor (retirado de relatórios gerenciais da Construtora W)

\section{Micro planejamento dos fluxos por serviço}

Nesta obra foi estudado em detalhes os ciclos de diversos serviços que impactam o fluxo dentro do canteiro, tais como estrutura, alvenaria, contrapiso e até a última visita de acompanhamento na obra, o estudo detalhado de como seria realizada a fachada.

Como exemplo destas práticas utilizadas no empreendimento, a figura 80 ilustra o micro planejamento (com detalhes em horas) para o ciclo da estrutura. 
Figura 80 - Micro planejamento do ciclo da estrutura (5 dias)

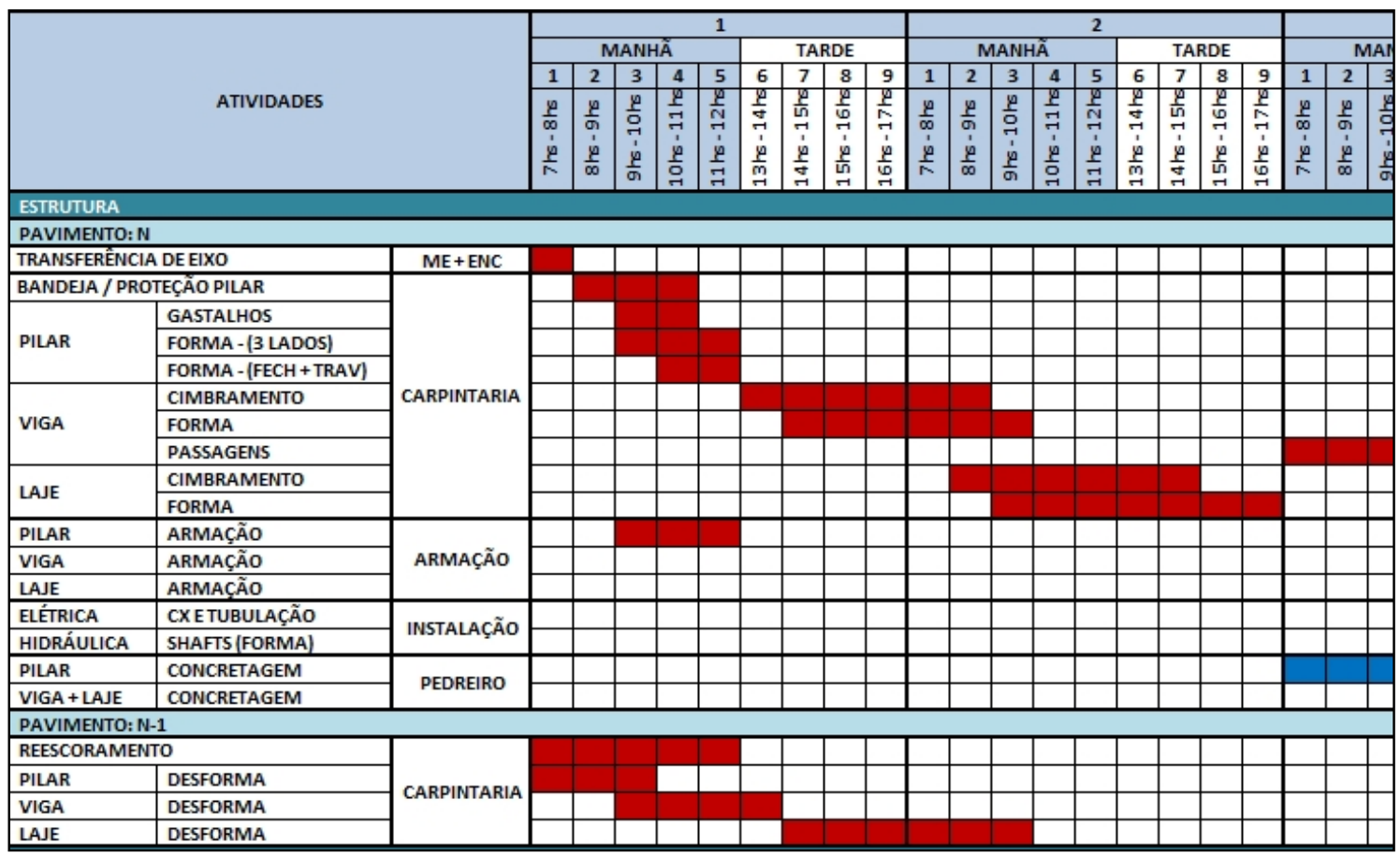

Fonte: O Autor (recorte de arquivo fornecido pela Construtora W)

Para melhor visualização e organização das equipes no local de trabalho (complementando a diretriz \#1 - planejamento específico de equipes) e possibilitando o acompanhamento das premissas de planejamento que originaram o ciclo descrito no micro planejamento (diretriz \#2 - premissas mensuráveis), a empresa também estabelece uma série de representações gráficas.

Na figura 81 pode-se observar a distribuição das equipes na laje do pavimento tipo, bem como a sequência de movimentação de cada uma delas em cada parede ou forma de pilar a ser executada, representada na numeração em azul, demonstrando ao menos para o serviço de estrutura, práticas alinhada à diretriz \#1 (planejamento de equipes).

No exemplo, o micro planejamento tem característica de desenho de processo, e indica 3 equipes, seu dimensionamento, delimitação de ambiente por equipe, sequência de movimentação na laje (fluxo interno) e até detalhes de transporte de material (indicativos de abastecimento interno).

Por fim, cada uma das etapas do micro planejamento é representada em corte dos pavimentos em execução $(\mathrm{N})$, com numeração sequencial e outros itens que estão sendo executados nos pavimentos abaixo (N-1 e N-2). 
Figura 81 - Definição de distribuição das equipes por setor (pavimento tipo)

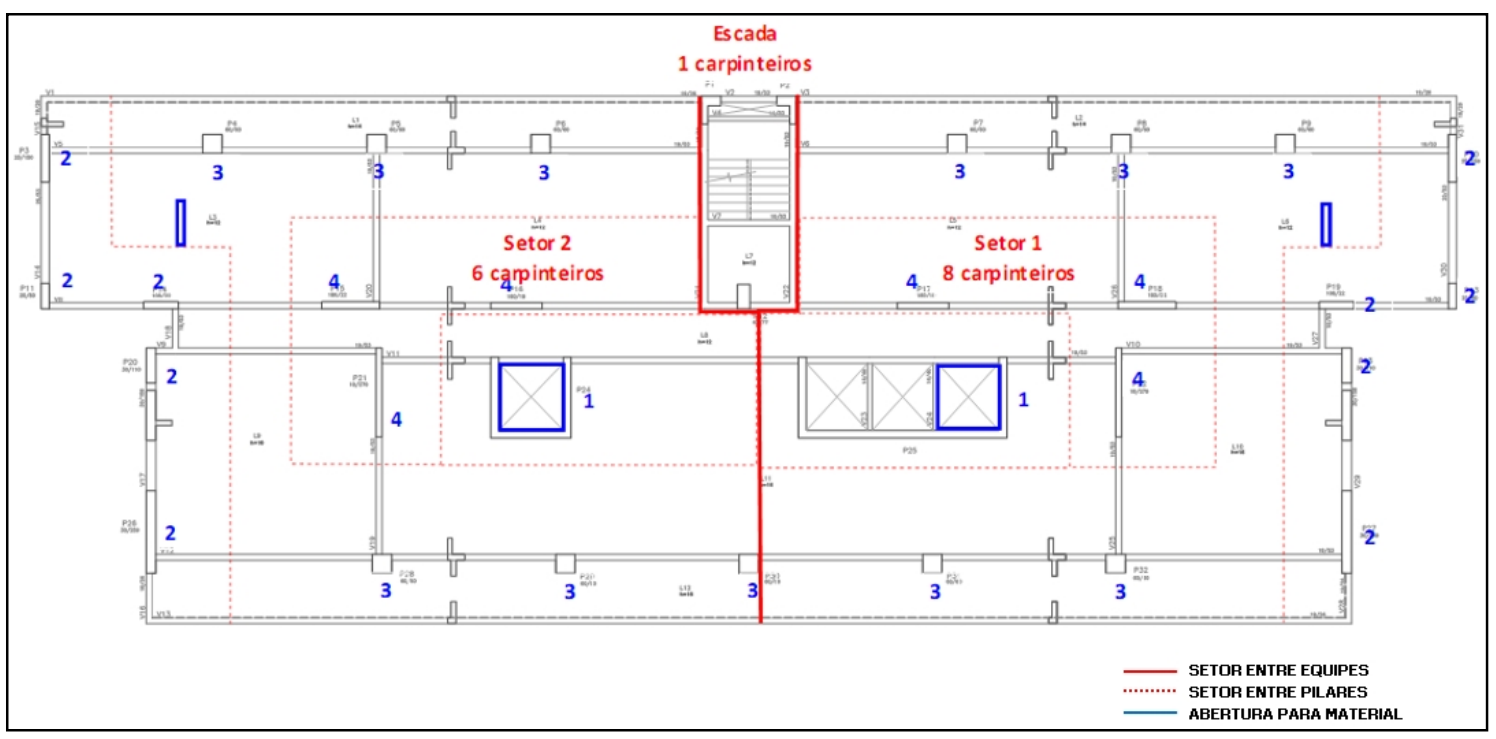

Fonte: O Autor (arquivo fornecido pela Construtora W)

Os desenhos de duas destas etapas podem ser observados na figura 82 .

Figura 82 - Exemplos de representação gráfica do micro planejamento

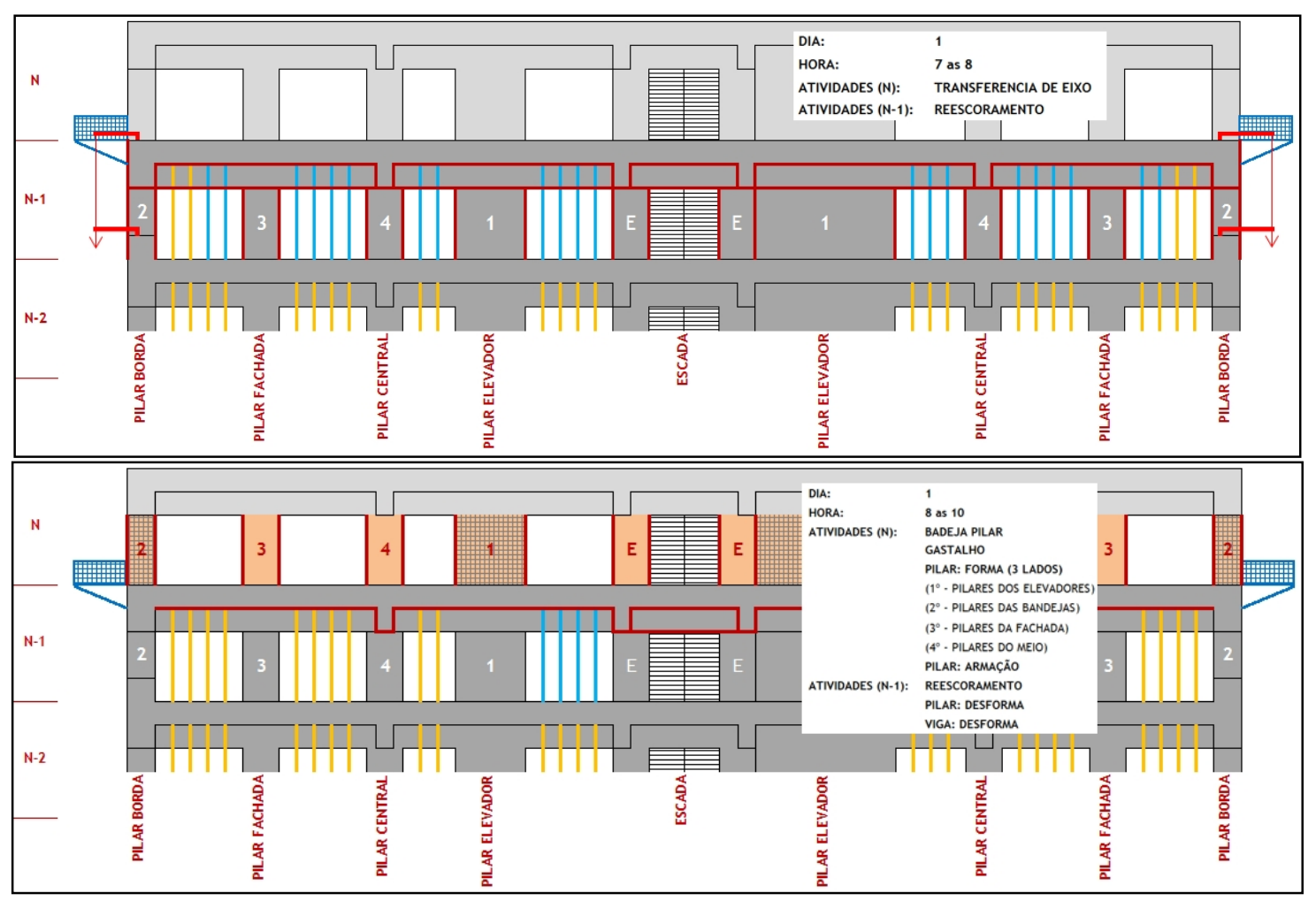

Fonte: O Autor (arquivo fornecido pela Construtora W)

Já nas figuras 83 e 84 observa-se todo o estudo de programação estabelecido apenas para o serviço de alvenaria. 
Figura 83 - Planejamento por serviço (abastecimento e execução) - alvenaria

\begin{tabular}{|c|c|c|c|c|c|c|c|c|c|c|c|c|c|c|c|c|c|c|c|}
\hline & \multicolumn{6}{|c|}{ PLANEJAMENTO DA ALVENARIA - OUT15 } & & \multicolumn{6}{|c|}{$\begin{array}{l}\text { Distribuido em todo o andar } \\
\text { Subida da plataforma }\end{array}$} & \multicolumn{6}{|c|}{$\begin{array}{l}78 \text { Palets de blocos / pavimento } \\
185 \text { Sacos de argamassa / pavimento }\end{array}$} \\
\hline & \multirow{2}{*}{ DESCRIÇÃO } & \multicolumn{6}{|c|}{1} & \multicolumn{6}{|c|}{2} & \multicolumn{6}{|c|}{3} \\
\hline & & Seg & Ter & Qua & Qui & Sex & Sáb & Seg & Ter & Qua & Qui & Sex & Sáb & Seg & Ter & Qua & Qui & Sex & Sáb \\
\hline \multirow{3}{*}{ Ciclo 1} & Limpeza & & & & & & & & & & & & & & & & & & \\
\hline & Marcação & & & & & & & & & & & & & & & & & & \\
\hline & Parede & & & & & & & & & & & & & & & & & & \\
\hline \multirow{3}{*}{ Ciclo 2} & Limpeza & & & & & & & & & & & & & & & & & & \\
\hline & Marcaçã̃o & & & & & & & & & & & & & & & & & & \\
\hline & Parede & & & & & & & & & & & & & & & & & & \\
\hline \multirow{3}{*}{ Ciclo 3} & Limpeza & & & & & & & & & & & & & & & & & & \\
\hline & Marcação & & & & & & & & & & & & & & & & & & \\
\hline & Parede & & & & & & & & & & & & & & & & & & \\
\hline \multirow{3}{*}{ Cíclo 1} & Subida de palets / Grua & & & 12 & 12 & 12 & 12 & 12 & & & & & & & & & & & \\
\hline & Subida da argamassa / Cremalheira & & & 37 & 37 & 37 & 37 & 37 & & & & & & & & & & & \\
\hline & Subida de palets / Cremalheira & & & & & & 6 & 6 & 6 & & & & & & & & & & \\
\hline \multirow{3}{*}{ Ciclo 2} & Subida de palets / Grua & & & & & & & & & 12 & 12 & 12 & 12 & 12 & & & & & \\
\hline & Subida da argamassa / Cremalheira & & & & & & & & & 37 & 37 & 37 & 37 & 37 & & & & & \\
\hline & Subida de palets / Cremalheira & & & & & & & & & & & & 6 & 6 & 6 & & & & \\
\hline \multirow{3}{*}{ Ciclo 3} & Subida de palets / Grua & & & & & & & & & & & & & & & 12 & 12 & 12 & 12 \\
\hline & Subida da argamassa / Cremalheira & & & & & & & & & & & & & & & 37 & 37 & 37 & 37 \\
\hline & Subida de palets / Cremalheira & & & & & & & & & & & & & & & & & & 6 \\
\hline & Total de blocos (palets) & - & - & 12 & 12 & 12 & 18 & 18 & 6 & 12 & 12 & 12 & 18 & 18 & 6 & 12 & 12 & 12 & 18 \\
\hline & Total de argamassa (sc) & - & - & 37 & 37 & 37 & 37 & 37 & - & 37 & 37 & 37 & 37 & 37 & - & 37 & 37 & 37 & 37 \\
\hline \multicolumn{20}{|c|}{ ENTREGAS E ESTOQUES } \\
\hline & Entregas de blocos na obra (palets) & & & 24 & 24 & 12 & 12 & 12 & 12 & 12 & 12 & 12 & 24 & 12 & & 24 & 12 & 12 & 12 \\
\hline & Estoque de bloco na obra (palets) & - & - & 12 & 24 & 24 & 18 & 12 & 18 & 18 & 18 & 18 & 24 & 18 & 12 & 24 & 24 & 24 & 18 \\
\hline & \begin{tabular}{|l|} 
Entregas de argamassa na obra (sc) \\
\end{tabular} & & & 200 & & & 80 & & & 80 & & 80 & & & 80 & & & 80 & \\
\hline & Estoque de argamassa na obra (sc) & - & - & 163 & 126 & 89 & 132 & 95 & 95 & 138 & 101 & 144 & 107 & 70 & 150 & 113 & 76 & 119 & 82 \\
\hline \multicolumn{20}{|c|}{ GRUA E CREMALHEIRA (BLOCOS) } \\
\hline & Tempo de subida + descida ( $\mathrm{min}$ ) & 10 & 10 & 10 & 10 & 10 & 10 & 10 & 10 & 10 & 10 & 10 & 10 & 10 & 10 & 10 & 10 & 10 & 10 \\
\hline & \begin{tabular}{|l|} 
Grua (horas) \\
\end{tabular} & - & - & 2,0 & 2,0 & 2,0 & 2,0 & 2,0 & -1 & 2,0 & 2,0 & 2,0 & 2,0 & 2,0 & -1 & 2,0 & 2,0 & 2,0 & 2,0 \\
\hline & \begin{tabular}{|c|} 
Cremalheira (horas) \\
\end{tabular} & - & - & 0,2 & 0,2 & 0,2 & 1,2 & 1,2 & 1,0 & 0,2 & 0,2 & 0,2 & 1,2 & 1,2 & 1,0 & 0,2 & 0,2 & 0,2 & 1,2 \\
\hline \multicolumn{20}{|c|}{ CREMALHEIRA (ARGAMASSA) } \\
\hline & Tempo de subida + descida ( $\mathrm{min}$ ) & 10 & 10 & 10 & 10 & 10 & 10 & 10 & 10 & 10 & 10 & 10 & 10 & 10 & 10 & 10 & 10 & 10 & 10 \\
\hline & Grua (horas) & - & - & 0,2 & 0,2 & 0,2 & 0,2 & 0,2 & - & 0,2 & 0,2 & 0,2 & 0,2 & 0,2 & - & 0,2 & 0,2 & 0,2 & 0,2 \\
\hline
\end{tabular}

Fonte: O Autor (arquivo fornecido pela Construtora W)

Figura 84 - Croqui de abastecimentos do andar - pallets de blocos

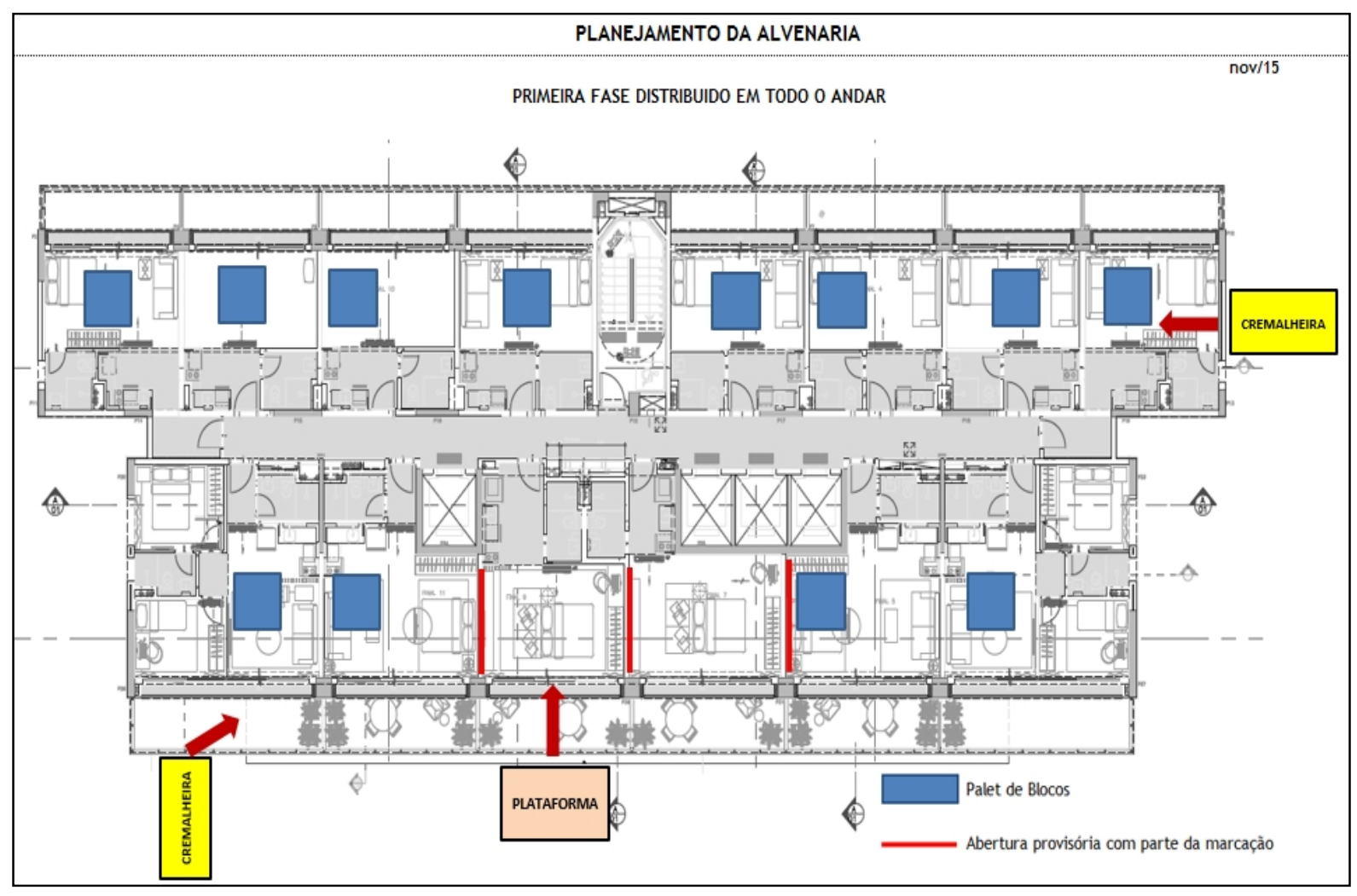

Fonte: O Autor (arquivo fornecido pela Construtora W) 
Todas estas práticas demonstram a preocupação com a previsibilidade dos processos de abastecimento, eliminando indiretamente as restrições mais complexas de acessos e fluxo, a assim complementando as diretrizes \#16 (logística de canteiro), \#20 (plano mestre detalhado) e \#24 (premissas por tipo de serviço) citadas anteriormente, mas também abrangendo as diretrizes \#2 (premissas mensuráveis), pelo detalhamento das informações de e condições de planejamento, só que de forma visual; \#5 (gestão à vista), pelos mecanismos de comunicação detalhados; e \#13 (planejamento de suprimentos), considerando a extensão do planejamento de suprimentos para as condições de abastecimento.

\section{Planejamento por pavimento}

Além das programações específicas por serviço, outro tipo de programação foi verificado como destaque neste empreendimento, a programação por pavimento. $\mathrm{Na}$ verdade, o principal objetivo desta ferramenta, segundo a equipe de planejamento da obra, é tornar visualmente claro quando cada equipe deve ser mobilizada em cada pavimento (diretriz \#1 - planejamento de equipes).

Após o término dos serviços de estrutura, estas programações são afixadas mensalmente na entrada de cada pavimento tipo (hall), de maneira que visualmente as equipes da obra verifiquem seu local de trabalho, que deverá estar compatível com as programações individuais dos serviços. Tal prática é a essência da diretriz \#1 (planejamento de equipes) e \#5 (gestão à vista).

A figura 85 ilustra uma destas programações (exemplo no $10^{\circ}$ pavimento), que são geradas a partir de filtros por pavimento na programação mensal geral da obra.

Além de focar a diretriz \#1 (planejamento de equipes), esta prática certamente ajudou a organização dos fluxos no canteiro e a se evitar problemas de interferência entre subempreiteiros nos locais de produção (diretriz \#3 - terminalidade). 
Figura 85 - Exemplo de programação por pavimento

\begin{tabular}{|c|c|c|c|c|c|c|c|c|c|c|c|c|c|c|c|c|c|c|c|c|c|c|c|c|c|c|c|c|c|c|}
\hline \multicolumn{31}{|c|}{ 10 PAVIMENTO } \\
\hline \multirow{3}{*}{ SERVIÇO } & \multirow{3}{*}{ INí́cio } & \multirow{3}{*}{ TÉRMINO } & \multicolumn{28}{|c|}{ MARÇO } \\
\hline & & & 01 & \begin{tabular}{l|l}
02 & 0 \\
\end{tabular} & & & \begin{tabular}{l|l}
5 & 06 \\
\end{tabular} & & 08 & & & & & & & & & & 18 & & & & & & & & & & & \begin{tabular}{|l|l|l|l}
30 & 31 \\
\end{tabular} \\
\hline & & & $T$ & \begin{tabular}{l|l}
$a$ & $C$ \\
\end{tabular} & \begin{tabular}{l|l}
$\mathrm{Q}$ & $\mathrm{s}$ \\
$\mathrm{s}$
\end{tabular} & 5 & $\mathrm{D}$ & $\mathrm{s}$ & $T$ & $\mathrm{Q}$ & $\mathrm{Q}$ & s & s & D & & & & & \begin{tabular}{c|c} 
\\
\end{tabular} & \begin{tabular}{c|c} 
& 1 \\
\end{tabular} & D: & s. & $\mathrm{T}$ & $\begin{array}{ll}a & c \\
c\end{array}$ & 25 & $\begin{array}{l}5 \\
\end{array}$ & D & $\mathrm{s}$ & \begin{tabular}{|l|l}
$\mathrm{T}$ \\
\end{tabular} & \begin{tabular}{l|l|}
$Q$ & $Q$ \\
\end{tabular} \\
\hline $\begin{array}{l}\text { PRUMADA HIDRÁULICA - } \\
\text { ÁGUA }\end{array}$ & $01 / \mathrm{mar}$ & $05 / \mathrm{mar}$ & & & & & & & & & & & & & & & & & & & & & & & & & & & & \\
\hline $\begin{array}{l}\text { CONTRAPISO A.S. - } \\
\text { (acústico c/ manta) }\end{array}$ & $01 / \mathrm{mar}$ & $07 / \mathrm{mar}$ & & & & & & & & & & & & & & & & & & & & & & & & & & & & \\
\hline $\begin{array}{l}\text { ENCUNHAMENTO DE } \\
\text { ALVENARIA }\end{array}$ & $08 / \mathrm{mar}$ & $14 / \mathrm{mar}$ & & & & & & & & & & & & & & & & & & & & & & & & & & & & \\
\hline $\begin{array}{l}\text { DISTRIBUIÇÃOO } \\
\text { HIDRÁULICA - (ÁGUA) }\end{array}$ & $15 / \mathrm{mar}$ & $19 / \mathrm{mar}$ & & & & & & & & & & & & & & & & & & & & & & & & & & & & \\
\hline $\begin{array}{l}\text { DISTRIBUIÇÃO } \\
\text { HIDRÁULICA - (ESGOTO) }\end{array}$ & $17 / \mathrm{mar}$ & $22 / \mathrm{mar}$ & & & & & & & & & & & & & & & & & & & & & & & & & & & & \\
\hline $\begin{array}{l}\text { DISTRIBUIÇÃO } \\
\text { HIDRÁULICA - (AP) }\end{array}$ & $17 / \mathrm{mar}$ & $22 / \mathrm{mar}$ & & & & & & & & & & & & & & & & & & & & & & & & & & & & \\
\hline ENFIAÇ̃̃o ELÉTICA & $15 / \mathrm{mar}$ & $19 /$ mar & & & & & & & & & & & & & & & & & & & & & & & & & & & & \\
\hline $\begin{array}{l}\text { ENCHIMENTO } \\
\text { TUBULAÇÃO - TERRAÇO }\end{array}$ & $24 / \mathrm{mar}$ & $01 / a b r$ & & & & & & & & & & & & & & & & & & & & & & & & & & & & \\
\hline $\begin{array}{l}\text { CONTRAPISO - HALL + } \\
\text { CIRCULAÇÃ̃O }\end{array}$ & $03 / \mathrm{mar}$ & $09 / \mathrm{mar}$ & & & & & & & & & & & & & & & & & & & & & & & & & & & & \\
\hline $\begin{array}{l}\text { PRUMADA - AR } \\
\text { CONDICIONADO }\end{array}$ & $22 / \mathrm{mar}$ & $29 / \mathrm{mar}$ & & & & & & & & & & & & & & & & & & & & & & & & & & & & \\
\hline $\begin{array}{l}\text { DUTO DE PRESSURIZAÇÃO } \\
\text { - ESCADA }\end{array}$ & $29 / \mathrm{mar}$ & $04 / a b r$ & & & & & & & & & & & & & & & & & & & & & & & & & & & & \\
\hline
\end{tabular}

Fonte: O Autor (arquivo fornecido pela Construtora W)

\section{Uso de critérios de aprendizado nos ciclos}

$\mathrm{Na}$ elaboração dos cronogramas foi possível verificar a utilização do conceito de aprendizado das equipes, como sugere a diretriz \#14 (curvas de aprendizado). Isto ocorre nos serviços relacionados e previamente identificados no caminho crítico do projeto, como pode ser exemplificado na figura 86, destacando-se as atividades de estrutura e marcação de alvenaria.

Figura 86 - Aplicação do conceito de aprendizado no cronograma da obra

\begin{tabular}{|c|c|c|c|}
\hline $\begin{array}{l}\text { - ESTRUTURA - (Laje Piso / Estrutura + } \\
\text { Instação Elétrica) }\end{array}$ & STRUCTURE & 180 dias & $15 / 10 / 15$ \\
\hline Estrutura -19 & 1st LEVEL & 12 dias & $15 / 10 / 15$ \\
\hline Estrutura - 29 & 2nd LEVEL & 15 dias & $03 / 11 / 15$ \\
\hline Estrutura - 39 & 3rd LEVEL & 10 dias & $25 / 11 / 15$ \\
\hline Estrutura - 49 & 4th LEVEL & 8 dias & $09 / 12 / 15$ \\
\hline Estrutura -59 & 5th LEVEL & 6 dias & 04/01/16 \\
\hline Estrutura - 69 & 6th LEVEL & 6 dias & $14 / 01 / 16$ \\
\hline Estrutura - 79 & 7th LEVEL & 5 dias & $26 / 01 / 16$ \\
\hline Estrutura - 89 & 8th LEVEL & 5 dias & $04 / 02 / 16$ \\
\hline Estrutura - 99 & 9th LEVEL & 5 dias & $16 / 02 / 16$ \\
\hline Estrutura - 109 & 10th LEVEL & 5 dias & $25 / 02 / 16$ \\
\hline Estrutura - 119 & 11th LEVEL & 5 dias & $03 / 03 / 16$ \\
\hline Estrutura - $12 \%$ & 12th LEVEL & 5 dias & $10 / 03 / 16$ \\
\hline Estrutura - 139 & 13th LEVEL & 5 dias & $17 / 03 / 16$ \\
\hline Estrutura - 149 & 14th LEVEL & 5 dias & $24 / 03 / 16$ \\
\hline
\end{tabular}

\begin{tabular}{|c|c|c|c|}
\hline - MARCAÇÃO ALVENARIA & MASONRY MARK & 165 dias & $04 / 01 / 16$ \\
\hline Marcação Alvenaria - 19 & 1st LEVEL & 4 dias & $04 / 01 / 16$ \\
\hline Marcação Alvenaria - 20 & 2nd LEVEL & 4 dias & $08 / 01 / 16$ \\
\hline Marcação Alvenaria - 3 ? & 3rd LEVEL & 4 dias & $18 / 01 / 16$ \\
\hline Marcação Alvenaria - $4^{\circ}$ & 4th LEVEL & 4 dias & $12 / 02 / 16$ \\
\hline Marcação Alvenaria - 59 & 5th LEVEL & 3 dias & $22 / 02 / 16$ \\
\hline Marcação Alvenaria - 60 & 6th LEVEL & 3 dias & $04 / 03 / 16$ \\
\hline Marcação Alvenaria - 70 & 7th LEVEL & 3 dias & $17 / 03 / 16$ \\
\hline Marcação Alvenaria - 89 & 8th LEVEL & 3 dias & $28 / 03 / 16$ \\
\hline Marcação Alvenaria - 9o & 9th LEVEL & 3 dias & $04 / 04 / 16$ \\
\hline Marcação Alvenaria - 10 ? & 10th LEVEL & 3 dias & $11 / 04 / 16$ \\
\hline Marcação Alvenaria - 119 & 11th LEVEL & 3 dias & $18 / 04 / 16$ \\
\hline Marcação Alvenaria - $12^{\circ}$ & 12th LEVEL & 3 dias & $25 / 04 / 16$ \\
\hline Marcação Alvenaria - 13 ? & 13th LEVEL & 3 dias & $02 / 05 / 16$ \\
\hline Marcação Alvenaria - $14^{\circ}$ & 14th LEVEL & 3 dias & $09 / 05 / 16$ \\
\hline Marcarã Alvenaria - 15 ? & 15th DFVEL & 3 dias & $16 / 05 / 16$ \\
\hline
\end{tabular}

Fonte: O Autor (retirado do planejamento da Construtora W)

\section{Gestão de escopo}

O empreendimento implementa processo de controle do escopo do projeto, em especial do contrato, fato relacionado à diretriz \#22 (métodos de gestão de escopo). 
Verificou-se que nesta obra o cliente participa intensamente das discussões de projeto (diretriz \#21 - participação do cliente), envolvendo-se não apenas nas aprovações de especificações (quando não estavam claramente definidas em projeto), mas também nas contratações, formas de execução, plano de ataque da obra e até nas decisões de recuperação de problemas (quando ocorrem).

Este fato seria talvez um agravante caso as decisões do cliente não ocorressem nos prazos pertinentes. No entanto, pelo que foi observado na pesquisa, este fato teve impactos positivos, contrariando esta premissa.

Claramente identifica-se que esta intervenção gera realmente várias alterações no escopo inicial do contrato, algumas delas significativas em termos de custo.

Para garantir que isto não afetasse as ações rotineiras e/ou desavenças futuras há um sistema de controle de alterações interessante e atuante. As indefinições ou alterações são estudadas com antecedência (fruto de planos de ataque ou desenhos de processo realizados no planejamento inicial), registradas em formulários específicos de solicitação de alteração, acordadas com a equipe da obra e implementadas em seguida.

Uma planilha apresentada na figura 87 exemplifica um dos controles de escopo adotados na obra.

Figura 87 - Controle de solicitação de alterações de escopos e aditivos

\begin{tabular}{|c|c|c|c|c|}
\hline \multirow{2}{*}{$\begin{array}{c}\text { Description } \\
\text { Toilet fixtures specification (Alteração dos metais) }\end{array}$} & \multirow{2}{*}{$\begin{array}{l}\text { № } \\
01\end{array}$} & \multicolumn{2}{|c|}{$\begin{array}{l}\text { Estimated Cost } \\
\text { (Custo estimado) }\end{array}$} & \multirow{2}{*}{$\begin{array}{l}\text { Status } \\
\text { Pending }\end{array}$} \\
\hline & & $-R \$$ & $126.255,88$ & \\
\hline Glazing Tickness Change from $12 \mathrm{~mm}$ to $10 \mathrm{~mm}$ (Alteração da espessura do vidro) & 02 & $-R \$$ & $98.366,50$ & Pending \\
\hline Acoustical aluminum frames at units (Linha acústica dos caixilhos de aluminio) & 03 & $\mathrm{R} \$$ & $47.024,87$ & Approved \\
\hline Change masonry vs concrete structure at parking levels (Mureta armada garagem) & 04 & $\mathrm{RS}$ & $21.115,41$ & Pending \\
\hline Elevator car finish specification (Decoração do elevador) & 06 & $\mathrm{R} \$$ & $107.922,78$ & Pending \\
\hline Acustical change at generator (Revestimento acústico do gerador) & 07 & $\mathrm{R} \$$ & $33.866,77$ & Pending \\
\hline Reception desk (Balcão do lobby) & 08 & $\mathrm{R} \$$ & $16.516,69$ & Pending \\
\hline Steel frames miscelaneus (Aço inox no PNE) & 09 & $\mathrm{R} \$$ & $35.495,00$ & Pending \\
\hline Garden at ground level (Sky garden) & 10 & $\mathrm{R} \$$ & $30.762,43$ & Pending \\
\hline Wood footer specification at corridor (Alteração do rodapé no corredor - Memo 05) & 12 & $\mathrm{R} \$$ & $13.832,23$ & Pending \\
\hline Lighting fixtures (Luminárias) & 13 & $\mathrm{R} \$$ & $414.971,14$ & Pending \\
\hline Electrical cabin main entrance (Câmara transformadora) & 14 & $\mathrm{R} \$$ & $140.000,00$ & Pending \\
\hline New piles at water tank (Estacas do reservatório) & 15 & $\mathrm{R} \$$ & $5.093,75$ & Approved \\
\hline Water well (Poço artesiano) & 16 & $\mathrm{R} \$$ & $88.444,87$ & Pending \\
\hline & GERAL: & $\mathrm{R} \$$ & $730.423,56$ & \\
\hline
\end{tabular}

Fonte: O Autor (parte de documento fornecido pela Construtora W) 
É interessante discutir que, segundo o PMI (2013), este processo faz parte de um grupo diferente do que se está estudando (gerenciamento de prazo).

Sendo assim, verifica-se que é muito difícil separar totalmente práticas que estejam vinculadas a outros eixos da restrição tripla, como descrito no item 3.1, pois algumas delas tem efeitos diretos nos outros eixos, em espacial no de prazos.

\section{$>$ Comunicação visual}

Por fim, outro aspecto que também é verificado nas visitas ao canteiro relaciona-se às comunicações visuais relativas ao planejamento e acompanhamento dos serviços na obra, como pode ser observado nos exemplos ilustrados na figura 88.

Figura 88 - Comunicação visual do planejamento da obra

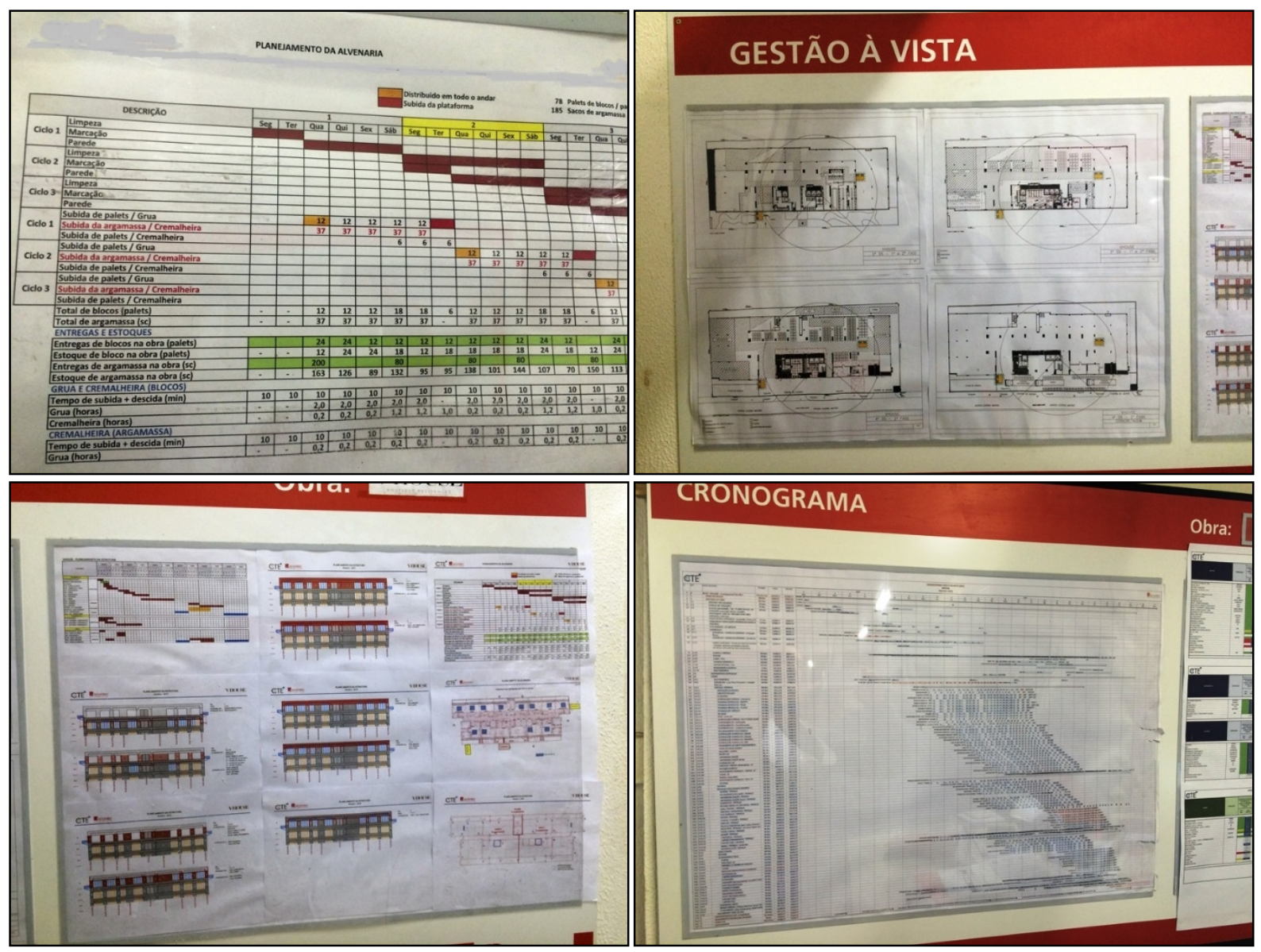

Fonte: O Autor (fotografado na obra, Construtora W)

Verifica-se que a principal comunicação está ainda nas salas de engenharia, sala de reunião e de encarregados dos subempreiteiros, lembrando ainda que em cada 
pavimento há a programação especifica do andar, como descrito no item anterior, práticas aderentes à diretriz \#5 (gestão à vista).

Controle de qualidade e fiscalização externa

Verifica-se no canteiro, uma estrutura completa para controle dos serviços.

Primeiramente existe um sistema de gestão da qualidade implantado e atuante, que utiliza formulários específicos para verificação interna e registro de nãoconformidades.

Além disso, existe uma consultoria externa, contratada pela construtora, que realiza inspeções de qualidade por amostragem, gerando relatórios com maior isenção comparados com os controles externos. Estes relatórios apontam problemas de serviço acabado e também uma avaliação do sistema de qualidade da construtora, promovendo melhorias contínuas dos processos adotados.

Por fim, o cliente contratou ainda uma gerenciadora externa para fiscalização da construtora, independente do trabalho da consultoria. Esta última empresa registra todo o andamento da obra, os problemas de execução da programação e qualidade dos serviços.

Com todo este esforço e investimento em controle, entende-se que há práticas alinhadas ao que se estabeleceu na proposição inicial como diretrizes \#15 (controle da qualidade) e \#23 (fiscalização independente).

\section{Comentários gerais}

Um fato controverso foi identificado neste empreendimento. Apesar de todas as ferramentas de controle de serviços descritas no item anterior, identificou-se descontinuidade de alguns serviços em alguns momentos da evolução da obra.

Analisando as razões desta situação, verificou-se que estas descontinuidades foram causadas por problemas de qualidade na execução dos serviços. O ponto mais crítico foi a execução sem cuidados ou proteção adequada de alguns serviços, que acabaram danificando serviços já acabados. Neste caso, apesar se não representar efetivamente uma falta de terminalidade (pois os serviços anteriores foram 
corretamente executados), não se considerou a classificação das ações de controle citadas anteriormente como compatíveis com a diretriz \#3 (terminalidade).

Outro fato destacado relaciona-se à forma de divulgação das programações semanais. Existem reuniões específicas de repasse do planejamento e isto é muito positivo. No entanto, acompanhando-se a condução destas reuniões, verifica-se que os subcontratados se posicionam de forma passiva. Estas empresas simplesmente aceitam as condições propostas pela equipe gerencial da construtora, não sendo possível evidenciar a diretriz \#8 - participação das equipes de produção (que segundo as previsões do autor, teria grandes oportunidades de ser evidenciada no empreendimento, mas não o foi).

\subsubsection{Empreendimento IV}

O Empreendimento IV, executado pela Construtora O (que já teve obras avaliadas na primeira pesquisa) caracteriza-se pela execução de 1 torre comercial de 18 lajes corporativas, com 5 subsolos, totalizando 46.119,00 $\mathrm{m}^{2}$ de área construída, e localizado em um terreno de $6.221,00 \mathrm{~m}^{2}$ na cidade de São Paulo/SP.

A contratação desta obra ocorreu em duas fases, a primeira relacionada ao escopo de escavação, contenção e terraplenagem (5 subsolos) foi realizada em 8 meses, a partir de novembro de 2014 e entregue sem atrasos.

A segunda fase contemplou todo o escopo complementar do empreendimento, a partir dos serviços de fundação. Para adequação às premissas de escolha da amostra desta pesquisa, considerou-se como referencial de análise apenas a segunda fase da obra.

A segunda fase teve início em 01/07/2015 e a entrega da obra está prevista para 31/03/2017, mesma data da linha de base e do prazo contratual. Até a penúltima data de acompanhamento dentro das atividades desta pesquisa (medição em março de 2016), a obra apresentava adiantamento de $6,07 \%$ do progresso físico previsto na linha de base e desta forma a obra também foi escolhida para análise de boas práticas de planejamento físico e gestão de prazos.

Estabeleceu-se esta data como último referencial para a análise desta obra, pois no último mês de acompanhamento, verificou-se que por uma decisão comercial e 
vinculada com a situação atual do mercado imobiliário, o ritmo da obra deveria ser diminuído, o que trouxe resultados inferiores aos demais meses de acompanhamento e isto fatalmente afetaria uma análise mais adequada dos dados do empreendimento.

A figura 89 ilustra a construção do edifício em duas datas diferentes, sendo algumas das vezes em que o pesquisador acompanhou as atividades desta obra.

Figura 89 - Fotos do Empreendimento IV (Jun/15 e Jan/16)
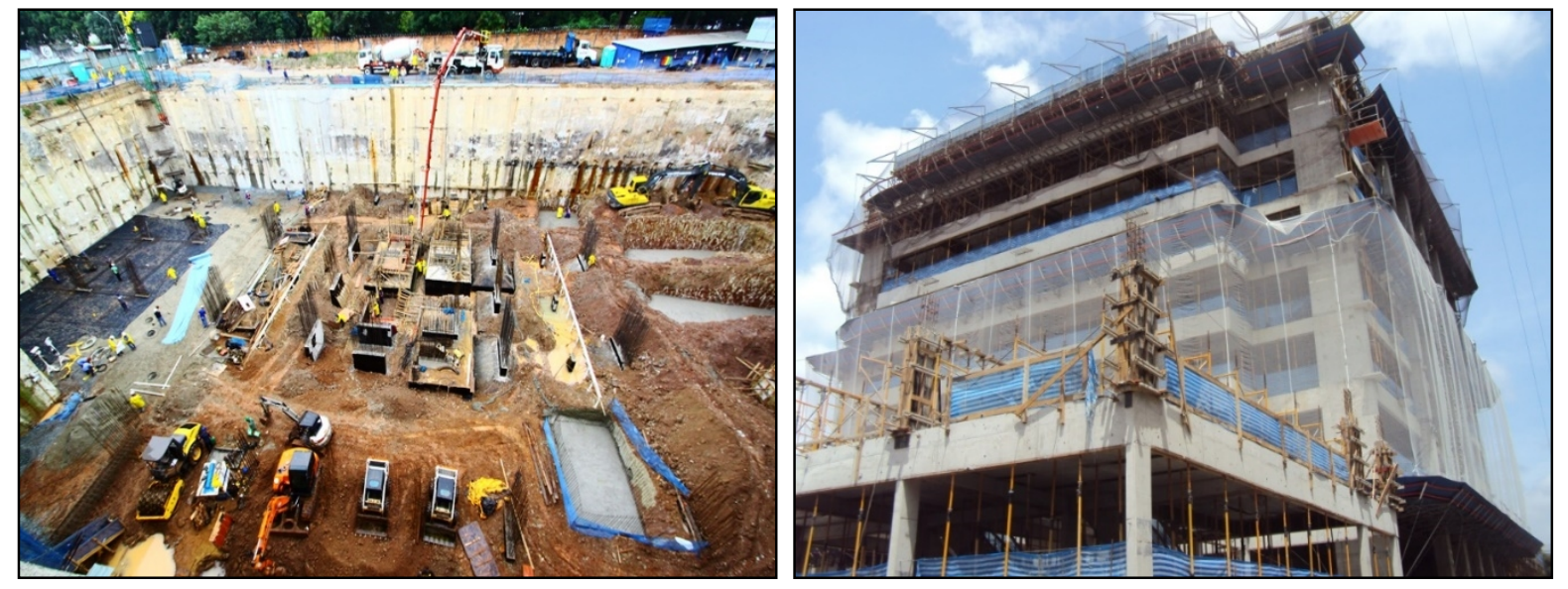

Fonte: O Autor

\section{$>$ Programações detalhadas e análise de restrições}

Um dos primeiros pontos interessantes observados nesta obra relaciona-se às ferramentas de planejamento ricas em indicadores e detalhes de cumprimento das programações.

A planilha que é utilizada como programação de curto prazo é bem completa, relacionando-se as atividades vinculadas ao cronograma do MS Project, aos locais e responsáveis (líderes de equipe e fornecedores).

A figura 90 apresenta a planilha utilizada, onde pode-se verificar, além dos itens descritos anteriormente, a criticidade das atividades (orientando priorizações, se necessário, de forma aderente à diretriz \#19 - hierarquização de decisões) e a identificação de possíveis problemas de não cumprimento das metas de produção, as quais são classificadas de forma padronizada (códigos referenciados ao banco de dados de restrições ou causas de não cumprimento verificados no histórico de obras de empresa). 
Figura 90 - Programação mensal do Empreendimento IV

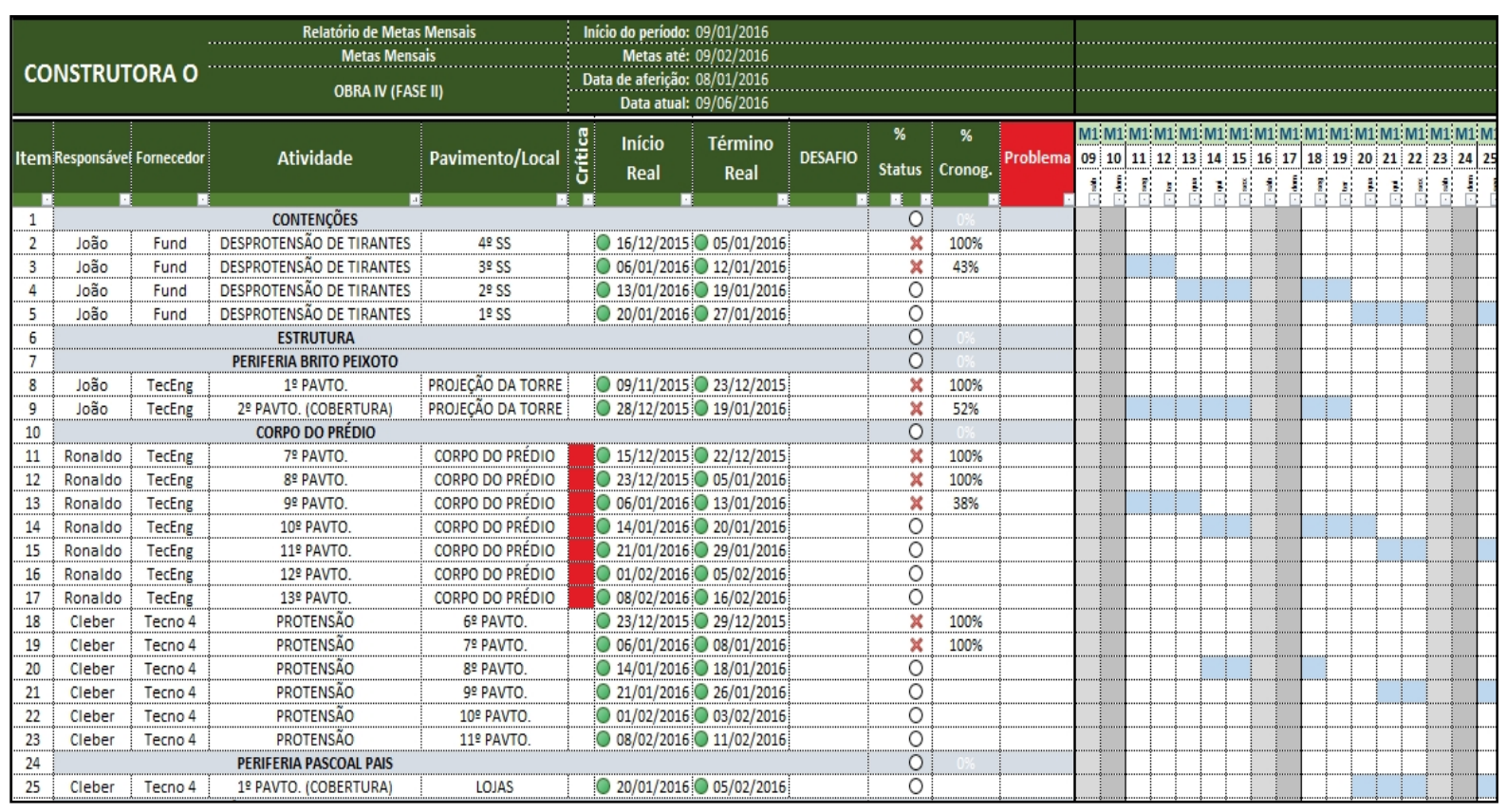

Fonte: O Autor (parte de arquivo fornecido pela Construtora O)

A planilha estabelece os locais das frentes de serviço por equipe ou subcontratado (incluindo o líder, que participou das definições das metas em momento pré-definidos, de forma aderente à diretriz \#8 - participação das equipes de produção). Como esta definição de local é realizada apenas de forma genérica para a atividade programada mensal, entendeu-se que a diretriz \#1 (planejamento de equipes) foi parcialmente implementada. Segundo o autor, a obra merece ações de maior detalhe de mobilização e dimensionamento para ser efetivamente atendida.

Para um controle mais efetivo destes problemas e desempenho das programações, a obra utiliza-se de alguns conceitos clássicos de análise de restrições, como a definição de listas de restrições padronizadas, como apresentada na figura 91 (incluindo nesta o acompanhamento dos índices por subempreiteiro) e os cálculos das metas concluídas e o tradicional PPC, como ilustrado na figura 92.

Destacam-se assim também ligações destas práticas às diretrizes \#4 (produção puxada) e \#18 (sistemas de alerta antecipado). 
Figura 91 - Planilha de análise de restrições

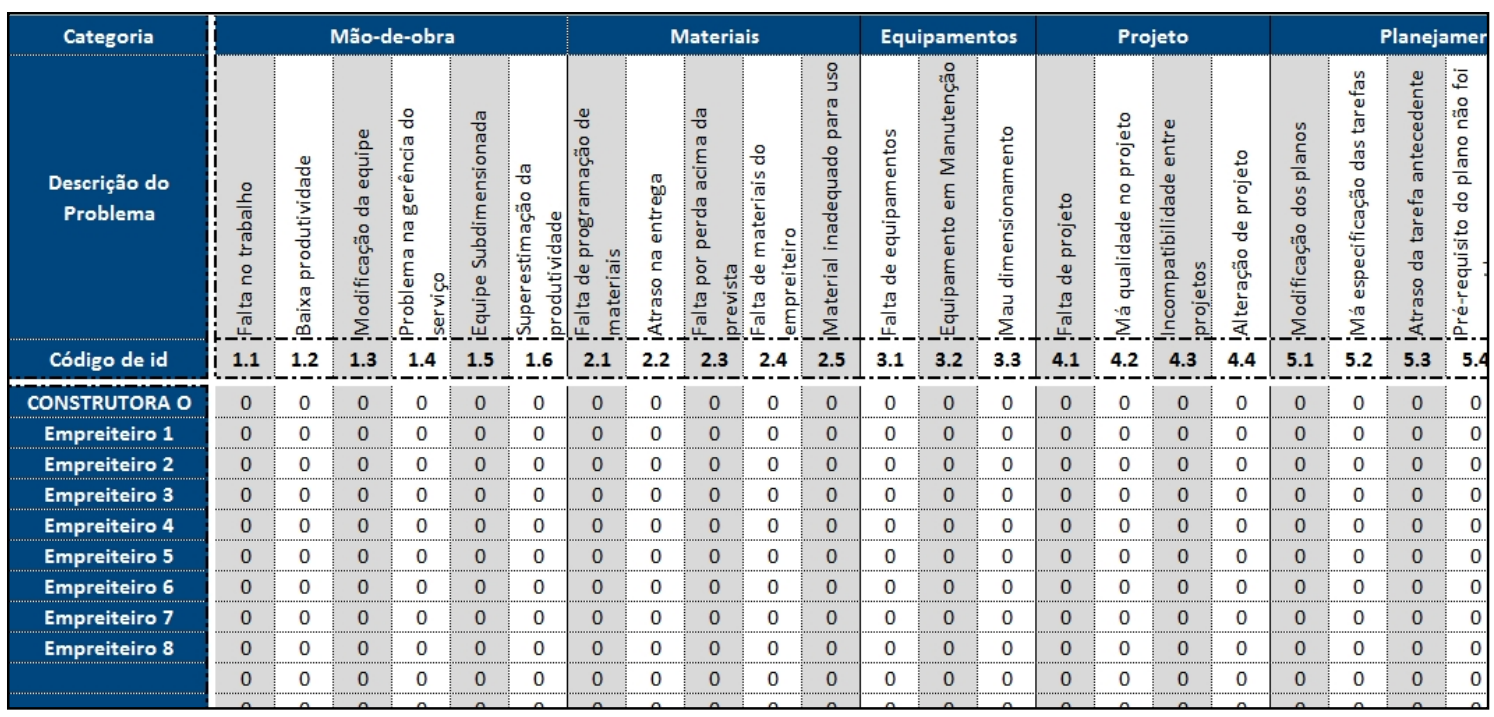

Fonte: O Autor (retirado do planejamento da Construtora O)

Figura 92 - Planilha de análise de cumprimento e cálculo do PPC

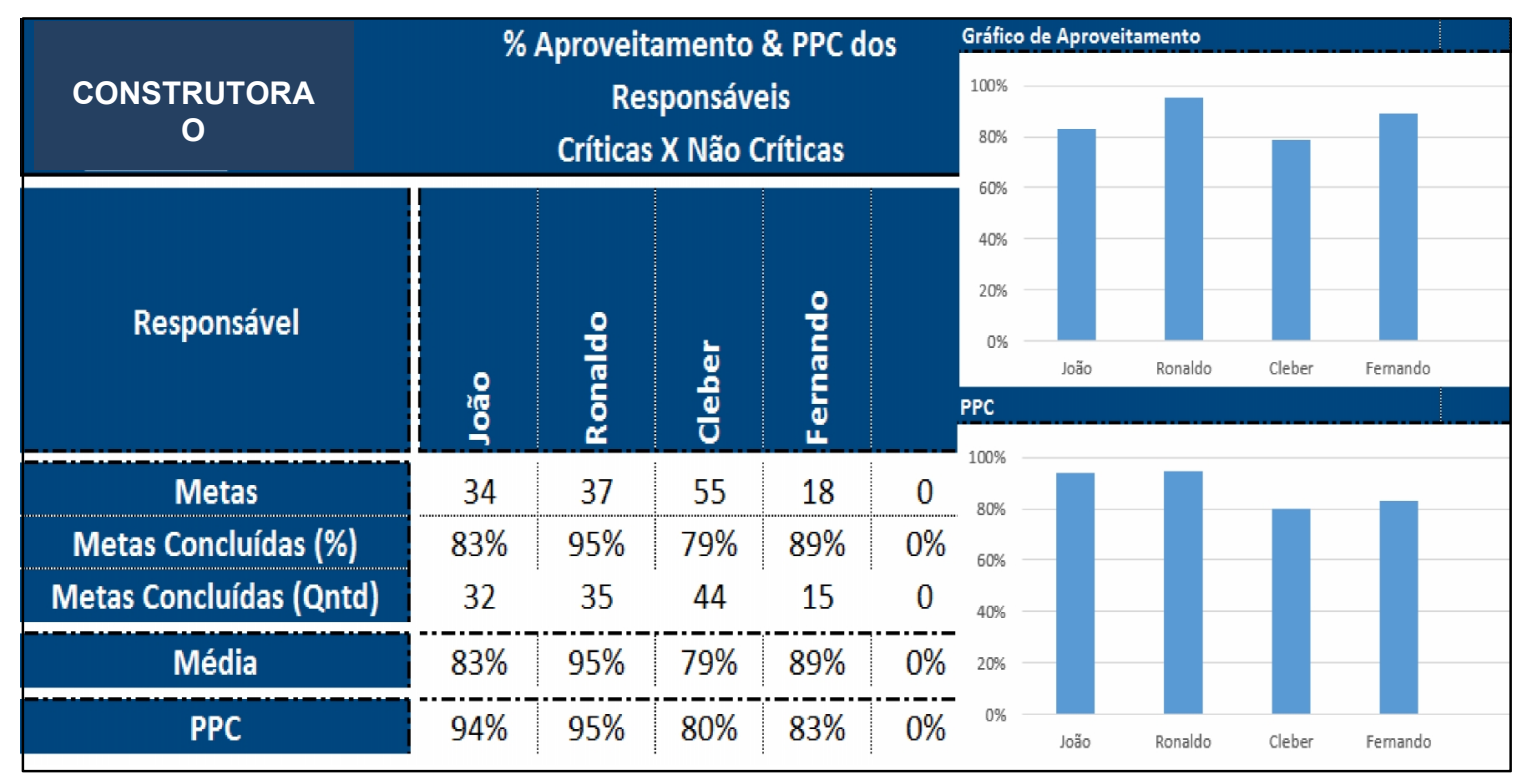

Fonte: O Autor (retirado do planejamento da Construtora O)

\section{Uso de pulmão controlado no cronograma}

O cronograma desafio utilizado pela equipe de produção apresentava uma peculiaridade, já citada anteriormente na revisão bibliográfica. Relaciona-se à inclusão de buffers de controle em partes estratégicas do cronograma, prática aderente à diretriz \#9 (metas realistas).

Este fato foi verificado nesta obra, como pode ser observado na figura 93, que destaca um pulmão inserido artificialmente na rede, na parte final da obra (entrega). 
Figura 93 - Inserção de pulmão no cronograma desafio

\begin{tabular}{|c|c|c|c|c|c|c|c|c|c|c|c|c|}
\hline \multirow{2}{*}{ Id $\rightarrow$} & \multirow[t]{2}{*}{ Nome da tarefa } & \multirow{2}{*}{ Duraçãc } & \multirow{2}{*}{ Início } & \multirow[t]{2}{*}{ Término } & \multirow{2}{*}{$\frac{P}{F}$} & \multicolumn{3}{|c|}{ Dezembro } & \multicolumn{3}{|c|}{ Janeiro } & \multirow{2}{*}{\begin{tabular}{l|l}
\multicolumn{2}{c}{ Fev } \\
\end{tabular}} \\
\hline & & & & & & 1 & M & $\mathrm{F}$ & 1 & M & $\mathrm{F}$ & \\
\hline 0 & $\begin{array}{l}\text { - Obra IV - Cronograma } \\
\text { Desafio Validado - MP } 2007\end{array}$ & $419 \mathrm{~d} ?$ & $01 / 06 / 15$ & $31 / 01 / 17$ & & & & & & & & \\
\hline 1 & + FUNDAÇÃO & $26 d$ & $01 / 06 / 15$ & $07 / 07 / 15$ & & & & & & & & \\
\hline 52 & + PISO 5 SS & $38 \mathrm{~d}$ & $10 / 06 / 15$ & $03 / 08 / 15$ & & & & & & & & \\
\hline 83 & + ESTRUTURA & $236 d$ & $06 / 07 / 15$ & $15 / 06 / 16$ & & & & & & & & \\
\hline 171 & + SUBSOLOS & $253 \mathrm{~d}$ & $04 / 11 / 15$ & $07 / 11 / 16$ & & & & & & & & \\
\hline 823 & † TÉRREO & $249 d$ & $10 / 12 / 15$ & $07 / 12 / 16$ & & & & & & & & \\
\hline 1201 & + TRANSPORTE VERTICAL & $344 \mathrm{~d}$ & $01 / 06 / 15$ & $13 / 10 / 16$ & & & & & & & & \\
\hline 1210 & + ELEVADORES & $273 d$ & $30 / 10 / 15$ & $02 / 12 / 16$ & & $\nabla$ & & & & & & \\
\hline 1254 & + ESCADAS DE EMERGÊNCIA & $228 \mathrm{~d}$ & $20 / 10 / 15$ & $15 / 09 / 16$ & & & & & & & & \\
\hline 2423 & † SERVICCOS INTERNOS & $256 d$ & $17 / 12 / 15$ & $23 / 12 / 16$ & & & & & & & & \\
\hline 3931 & + FACHADA & $120 \mathrm{~d}$ & $10 / 02 / 16$ & $29 / 07 / 16$ & & & & & & & & \\
\hline 4021 & + TRECHO CREMALHEIRA & $54 \mathrm{~d}$ & $13 / 10 / 16$ & $30 / 12 / 16$ & & & & & & & & \\
\hline 4028 & + JARDIM ANEXO & $50 \mathrm{~d}$ & $15 / 06 / 16$ & $24 / 08 / 16$ & & & & & & & & \\
\hline 4035 & † LEGALIZAÇõ̃ES & $391 \mathrm{~d}$ & $01 / 06 / 15$ & $21 / 12 / 16$ & & & & & & & & \\
\hline 4070 & ENTREGA DEFINITIVA & $0 \mathrm{~d}$ & $30 / 12 / 16$ & $30 / 12 / 16$ & & ENTR & ADEF & IVA $Q$ & $30 / 12$ & & & \\
\hline 4071 & PULMÃo & $22 \mathrm{~d} ?$ & $30 / 12 / 16$ & 31/01/17 & & & & HÃO & & & I & \\
\hline 4072 & ENTREGA DESAFIO & Od & $31 / 01 / 17$ & $31 / 01 / 17$ & & & & & ENTR & EGA & $10 \Omega$ & $31 / 01$ \\
\hline
\end{tabular}

Fonte: O Autor (retirado do planejamento da Construtora O)

Apesar da tentativa inicial de utilização desta prática, sentiu-se falta da implantação de buffers de alimentação que complementassem o buffer do projeto, como orientado por alguns autores e como será discutido no item 6.4. O fato pode então não trazer todos os benefícios sugeridos pelos autores com a técnica.

\section{Planejamento de suprimentos sistematizado}

O planejamento de suprimentos é outro ponto de destaque no empreendimento. Ele é detalhado e utiliza ferramentas ágeis, mesmo que simples, aderentes à diretriz \#13 (planejamento de suprimentos) e indiretamente \#17 (avaliação das condições de abastecimento).

As figuras 94 e 95 ilustram o processo de planejamento de contratações, bastante completo, correlacionado aos prazos do departamento de compras da construtora e procedimentos internos do departamento técnico e da obra, através de 2 categorias: (a) o planejamento das contratações, vinculada ao cronograma de médio prazo da obra e, (b) o acompanhamento das contratações (chamado de solicitações de orçamento), que dá diretrizes para o monitoramento das restrições dos serviços que serão executados, uma vez que para cada um dos itens constantes já entrou no processo de concorrência e/ou fechamento de contrato. 
Figura 94 - Planilha de itens a contratar

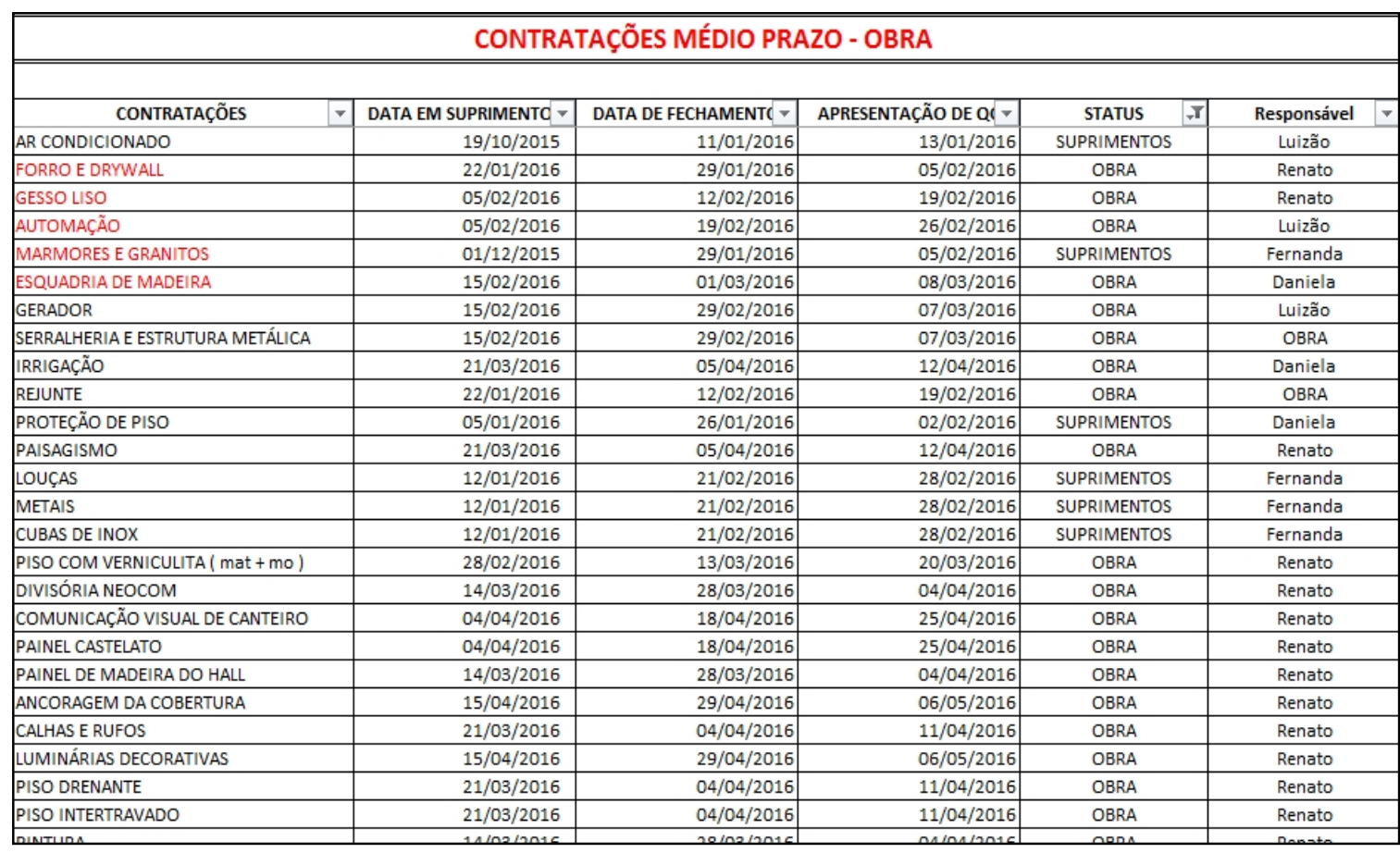

Fonte: O Autor (retirado do planejamento da Construtora O)

Figura 95 - Planilha de acompanhamento das contratações

\begin{tabular}{|c|c|c|c|c|c|c|}
\hline \multicolumn{7}{|c|}{ SOLICITAÇÕES DE ORÇAMENTO - CONSTRUTORA O 2015} \\
\hline CONTRATAÇÕES EM ATRASOS & $\begin{array}{c}\text { Data enviada para } \\
\text { suprimentos }\end{array}$ & $\begin{array}{l}\text { DATA PROGRAM. } \\
\text { FECHAMENTO }\end{array}$ & $\begin{array}{c}\text { DATA } \\
\text { FECHAMENT }\end{array}$ & STATUS & Responsáve - & AÇ̃̃̃ES \\
\hline Instalações & $22 / 05 / 2015$ & $03 / 06 / 2015$ & $11 / 06 / 2015$ & enviado para orçamento & Daniela & Eiko ( em revisão) / Eletrorio (OK) em revisão / Temon - decl \\
\hline Ar condicionado & $22 / 05 / 2015$ & $03 / 06 / 2015$ & $16 / 06 / 2015$ & enviado para orçamento & Daniela & Isolev / Diagrama (OK) / Climapress / Ambient Air (OK) / Ser \\
\hline Automação & $22 / 05 / 2015$ & 03/06/2015 & & & Dario & Servitec (OKrevisão)/E vertical ( em revisão) / Smart/MML/ \\
\hline CFTV & $22 / 05 / 2015$ & $03 / 06 / 2015$ & & & Dario & Servitec/E vertical / Smart/MML/Controller \\
\hline SCA & $22 / 05 / 2015$ & $03 / 06 / 2015$ & & & Dario & Servitec/E vertical / Smart/MML/Controller \\
\hline Sonorização & $22 / 05 / 2015$ & $03 / 06 / 2015$ & & & Dario & Servitec/E vertical / Smart/MML/Controller \\
\hline Detecção de incedio & $22 / 05 / 2015$ & $03 / 06 / 2015$ & & & Dario & Servitec/E vertical / Smart/MML/Controller \\
\hline cabeamento estruturado & $22 / 05 / 2015$ & 03/06/2015 & $03 / 06 / 2015$ & enviado para orçamento & Dario & fundamentos(ok) / engew(Declinou) \\
\hline Esquadria de Aluminio & $22 / 05 / 2015$ & $03 / 06 / 2015$ & $17 / 06 / 2015$ & enviado para orçamento & Daniela & Bimetal (OK) + Eurocentro (OK) / Luxalum/ Itefal (ok) \\
\hline Serviços civis & $22 / 05 / 2015$ & $03 / 06 / 2015$ & $01 / 06 / 2015$ & enviado para orçamento & Dario & solida (OK)/ Kawano (OK) / Unidas Cardoso \\
\hline impermeabilização & $22 / 05 / 2015$ & $03 / 06 / 2015$ & $09 / 06 / 2015$ & enviado para orçamento & Dario & Impersistem/ Unimper(ok) / Norobras(ok) \\
\hline Louças e metais & $22 / 05 / 2015$ & $03 / 06 / 2015$ & $28 / 05 / 2015$ & enviado para orçamento & Tamanduá & Deca (OK) / Roca / Fabrinox (OK) / Bobrick (OK) / Kimberly \\
\hline Acustica & $22 / 05 / 2015$ & $03 / 06 / 2015$ & $02 / 06 / 2015$ & enviado para orçamento & Paula & ISAR Ok / ISONAROK \\
\hline Fachada em pedra & $22 / 05 / 2015$ & $03 / 06 / 2015$ & $08 / 06 / 2015$ & enviado para orçamento & Dario & DPC (OK) / GMM \\
\hline Elevador & $25 / 05 / 2015$ & $03 / 06 / 2015$ & $08 / 06 / 2015$ & enviado para orçamento & Daniela & Atlas (OK)/ Thyssen OK) / Hyundai (OK) \\
\hline Grua & $25 / 05 / 2015$ & $03 / 06 / 2015$ & $08 / 06 / 2015$ & enviado para orçamento & Daniela & Grumont (OK) em revisão / Locabens (em revisão) \\
\hline Piso 50 SS & $25 / 05 / 2015$ & $03 / 06 / 2015$ & $09 / 06 / 2015$ & enviado para orçamento & Dario & Aliança / Depisos(OK) / EP (OK) \\
\hline Forma e cimbramento & $25 / 05 / 2015$ & $03 / 06 / 2015$ & $10 / 06 / 2015$ & enviado para orçamento & Dario & Ulma (Ok) / Peri (OK)/ Mills(OK) \\
\hline Concreto & $25 / 05 / 2015$ & $03 / 06 / 2015$ & $02 / 06 / 2015$ & enviado para orçamento & Daniela & Concreserv (OK) / Supermix (OK) / Engemix (OK) \\
\hline MO Fase 1 & $25 / 05 / 2015$ & $03 / 06 / 2015$ & & & Dario & Constata (OK)/ Engecap (ok)/ Rialtec (ok)/GBN ( revisando) \\
\hline PCF & $25 / 05 / 2015$ & $03 / 06 / 2015$ & $02 / 06 / 2015$ & enviado para orçamento & Dario & Metalika Ok \\
\hline Estrutura Metalica & $25 / 05 / 2015$ & $03 / 06 / 2015$ & $02 / 06 / 2015$ & enviado para orçamento & Dario & Sunto (OK) em revisão / Metalon (OK) / Python ( OK) / Engen \\
\hline
\end{tabular}

Fonte: O Autor (retirado do planejamento da Construtora O)

\section{Cronogramas de suprimentos específicos}

Além de todo o processo de planejamento e controle das contratações, a equipe da obra ainda estabelece para os principais insumos, um planejamento macro, mas com o detalhe das etapas de abastecimento, que termina na entrega do material ou 
mobilização do serviço no canteiro, eliminando este tipo de restrição, o que complementa a diretriz \#24 (premissas por tipo de serviço).

O processo também auxilia o monitoramento de premissas para atendimento das programações, alinhado indiretamente com práticas relacionadas à diretriz \#2 (premissas mensuráveis).

Um exemplo deste cronograma é apresentado na figura 96, relacionado ao insumo "caixilhos".

Figura 96 - Exemplo de planejamento específico de insumo de suprimentos

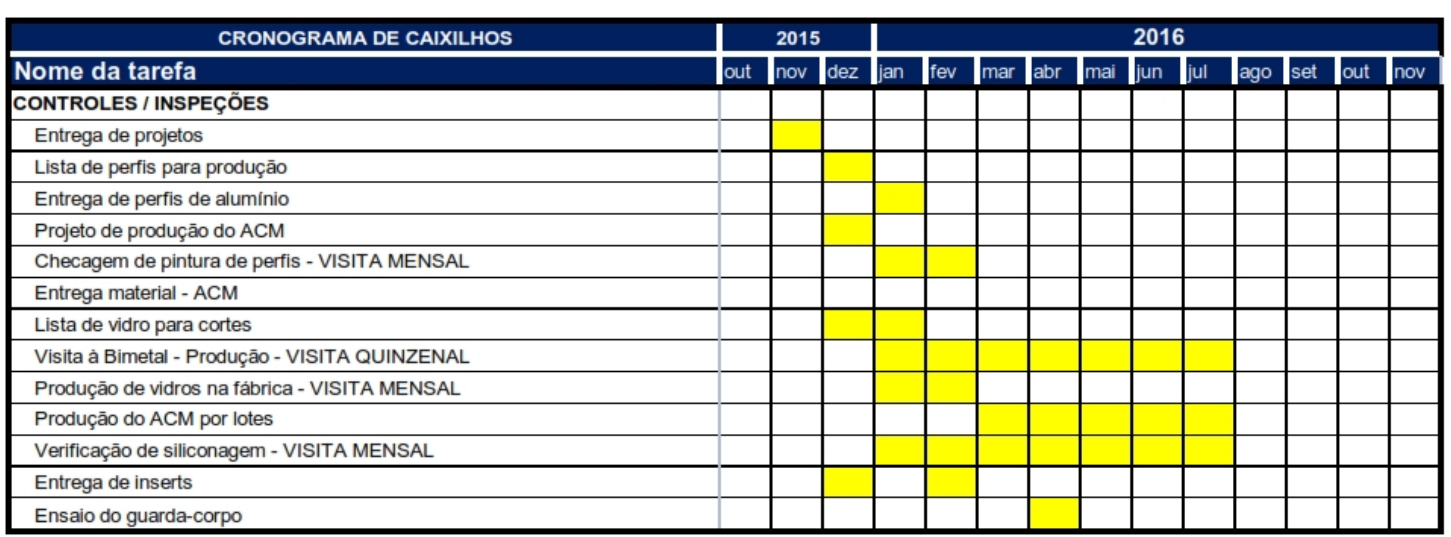

Fonte: O Autor (parte de arquivo fornecido pela Construtora O)

\section{Controle de qualidade}

Como uma empresa estruturada, a construtora possui sistemas de gestão integrado, com procedimentos e formulários de controle de qualidade, o que claramente ilustra prática aderente à diretriz \#15 (controle da qualidade).

No entanto, um fato interessante foi verificado nesta obra, que corrobora ainda mais para a ligação das práticas de garantia da qualidade com a performance em prazos.

Trata-se de uma separação dos indicadores de desempenho com os de qualidade, sendo um deles focado na qualidade efetiva da execução dos serviços (atendimento das tolerâncias de aceitação e não geração de retrabalhos), cujo resultado não é afetado por outros itens comuns de avaliação de qualidade em geral, como a organização do canteiro, limpeza, a gestão dos processos, treinamentos, documentação e registros. 
A figura 97 destaca estes indicadores, com um recorte do painel gerencial da obra, que também contém indicadores relativos à segurança do trabalho. Este item, apesar de não relacionado nas diretrizes iniciais, pode ser considerado muito importante como um tipo de restrição de execução de atividades, às vezes subestimado pelos planejadores.

Esta medição individual garante uma análise mais fidedigna do resultado e de quais ações devem ser mais importantes na obra, na produção, na gestão e no produto final, o que em parte complementa ações relativas à diretriz \#19 (hierarquização de decisões).

Figura 97 - Destaque para indicadores de qualidade

\begin{tabular}{|c|c|c|}
\hline Qualidade & Mês Ant. & Mês Atual \\
\hline Nota qualidade & 9,51 & 9,40 \\
\hline Sistema de qualidade & 9,71 & 9,44 \\
\hline Qualidade produção & 9,43 & 9,38 \\
\hline № Sistemas avaliados & 1,00 & 1,00 \\
\hline № Não conformidades & 7,00 & 9,00 \\
\hline Segurança do Trabalho & Mês Ant. & Mês Atual \\
\hline Nota seg. do trabalho & 9,63 & 9,89 \\
\hline Nota taxa de risco & 1,50 & 1,33 \\
\hline Total de não conformidades & 7,00 & 4,00 \\
\hline Total de não conformidades graves & 0,00 & 0,00 \\
\hline
\end{tabular}

Fonte: O Autor (coletado de painel gerencial da Construtora O)

\section{Gerenciamento externo}

Principais deste empreendimento e futuros proprietários, os investidores contrataram uma empresa gerenciadora para acompanhar e fiscalizar este projeto (diretriz \#23 fiscalização independente).

Um dos pontos mais importantes desta contratação é a exigência de serviços com qualidade, o que fez a diretriz \#15 (controle da qualidade) citada anteriormente se destacar na obra.

Além disso, a empresa gerenciadora, dentre outras atividades, cobra o cumprimento da programação e o vínculo deste progresso com a entrega adequada dos serviços liberados pelo sistema da qualidade. Consequentemente, a terminalidade dos 
serviços acabou sendo indiretamente alcançada e de forma sistematizada, o que demonstra aderência à diretriz \#3 (terminalidade).

Por fim, até para que se obtivesse independência para avaliação das questões técnicas que envolvem o projeto e suas adequações na obra, bem como do impacto de possíveis solicitações dos clientes no empreendimento, a gerenciadora realizava um controle detalhado do escopo do contrato, evidenciando a diretriz \#22 (métodos de gestão de escopo). Este trabalho era realizado através de procedimentos formalizados, incluindo formulários de registro de todas as alterações, como o chamado "ordem de mudança", que contemplava, data das solicitações, descrição das justificativas, avaliação do impacto em prazo e custo e aceitação ou não das partes envolvidas.

\section{Comentários gerais}

Algumas diretrizes não foram evidenciadas em sua forma completa, no entendimento do autor, mas consideradas como boas iniciativas, que, mesmo sem impactos importantes na garantia dos prazos, foram destacadas na pesquisa e podem gerar considerações relevantes na definição do método. Seguem alguns destes comentários:

- A obra apresentou um Plano Inicial relativamente detalhado para os serviços de maior relevância, mas que não destacou o caminho crítico, pelo fato destas atividades não estarem vinculadas entre si. Os macro serviços foram definidos como uma previsão próxima de um cronograma físico-financeiro contratual e assim, a diretriz \#20 (plano mestre detalhado) não foi relacionada como direcionamento desta ação;

- Foram identificadas várias ações de comunicação sobre o planejamento da obra, embora os objetivos reais destas ações não foram comentados pelos entrevistados quais os objetivos destas ações. Os documentos mais importantes foram expostos apenas na sala da engenharia, o que não se configurou como uma ação direcionada relativa à diretriz \#5 (gestão à vista);

- Verificou-se no cronograma global, a definição de durações diferentes para os ciclos iniciais apenas no item estrutura, o que não demonstrava uma preocupação focada na diretriz \#14 (curvas de aprendizado). Nas descrições 
do processo de planejamento inicial pelos responsáveis, esta questão foi descrita como uma mera estimativa, sem que o fenômeno da aprendizagem fosse discutido;

- Entendeu-se que a obra caracterizou-se por um local de ótimo ambiente de trabalho, limpo, relativamente organizado, mas esta situação não foi estabelecida de maneira estruturada e objetivando-se auxiliar o planejamento e o adequado abastecimento dos fluxos de serviço. Configurou-se em uma condição favorável, mas não essencial ou restritiva dos processos observados durante o acompanhamento da obra. Assim, classificou-se a diretriz \#11 (ambiente de trabalho organizado) como inicial ou complementar ao conjunto das outras diretrizes fundamentais para o sucesso do empreendimento;

- Na obra são realizadas reuniões periódicas com os investidores do empreendimento para discussão do avanço da obra e riscos para o não cumprimento do prazo final. Esta interação até contribui para que a equipe da obra tenha maior comprometimento com as previsões e metas acordadas, bem como com coerência das ações em andamento, mas ao final é uma ação meramente informativa, pois o cliente não interfere das decisões de planejamento (diretriz \#21 - participação do cliente) não identificada de forma completa).

\subsubsection{Empreendimento $\mathrm{V}$}

O Empreendimento $V$, executado pela Construtora $Y$ (não tem obras avaliadas na primeira pesquisa) caracteriza-se pela execução de 1 torre comercial de 24 pavimentos, 4 sobressolos, com 302 conjuntos, totalizando 23.615,00 $\mathrm{m}^{2}$ de área construída, localizado em um terreno de $2.792,00 \mathrm{~m}^{2}$ na cidade de São Paulo/SP.

O empreendimento teve início em 11/11/2013, mas após 4 meses foi paralisado por divergências dos valores previstos para o orçamento total da obra, uma vez que o contrato firmado junto à construtora foi por administração, já que os projetos não estavam totalmente finalizados. Este fato fez com que toda a previsão inicial de prazos para a entrega do empreendimento fosse revisada, sendo que os serviços seriam retomados após a conclusão de todos os projetos executivos e a definição de um 
orçamento referencial mais próximo das previsões financeiras dos empreendedores e seus investidores parceiros.

Após a retomada das obras em 01/09/2014 e a definição de uma nova linha de base de referência, a previsão de término está planejada para 31/01/2017, 58 dias antes da nova data acordada como término da linha de base (30/03/2017). Até a última data de acompanhamento dentro das atividades desta pesquisa (medição em abril de 2016), a obra apresentava adiantamento de $8,51 \%$ do progresso físico previsto na nova linha de base. Desta forma julgou-se a obra como aderente às condições de fazer parte da amostra de projetos desta pesquisa.

A figura 98 ilustra a construção do edifício em dois momentos, sendo algumas das datas em que o pesquisador acompanhou as atividades desta obra.

Figura 98 - Fotos do Empreendimento V (Out/15 e Mai/16)
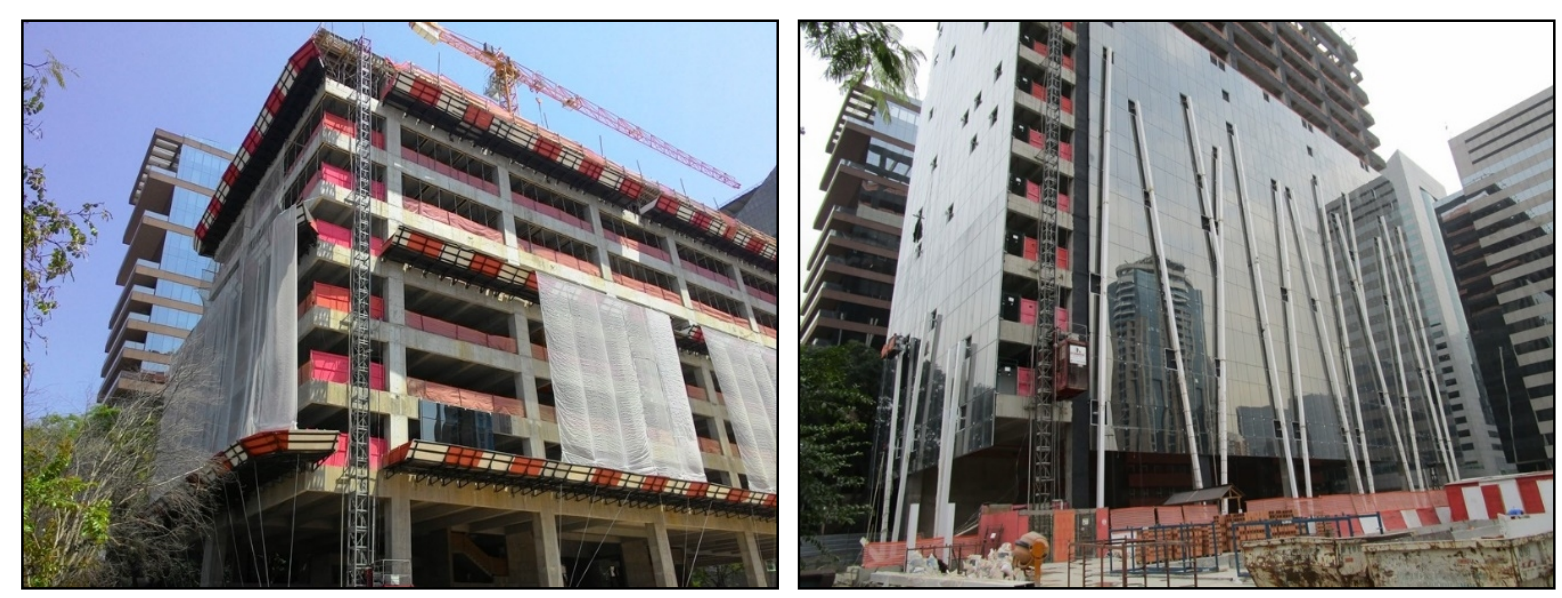

Fonte: O Autor

\section{> Plano de Ataque formalizado}

O empreendimento possui um plano mestre bem simples, mas que contém informações básicas importantes referenciais para a elaboração das programações de médio e curto prazo.

Existem muitas melhorias a serem inclusas no modelo de plano, principalmente com relação ao vínculo das definições de previsão de durações dos ciclos com premissas efetivamente mensuráveis, embasadas em técnicas para estruturação (diretriz \#20 plano mestre detalhado, parcialmente verificada). 
Outro ponto importante de melhoria seria o estudo do caminho crítico, o que provavelmente foi desenvolvido, mas não formalizado na estrutura deste plano. Fato este inclusive questionado pela gerenciadora contratada pelo cliente, assunto tratado no próximo item.

\section{Canteiro organizado}

O empreendimento mostrou-se organizado e limpo, bem como os processos internos aplicados pela construtora bem coerentes e claros (apesar de rígidos), o que o torna um ambiente favorável para se desenvolver o processo de planejamento e controle.

No entanto, não se verificou políticas de incentivo das equipes ou ações específicas vinculadas ao cumprimento dos planos de obra.

Sendo assim, analogamente ao Empreendimento IV, julgou-se que a diretriz \#11 (ambiente de trabalho organizado) não era formalmente estruturada para apoiar o planejamento, mas uma condição favorável e que não poderia ser desconsiderada como forma de contribuir para os ganhos verificados ao longo da execução da obra.

\section{Uso de curvas de aprendizado no cronograma}

Verifica-se nesta obra em diversos serviços, a utilização de curvas de aprendizado para que as equipes busquem gradativamente a melhoria dos prazos dos ciclos até chegarem naqueles definidos nas premissas de planejamento, fato aderente à diretriz \#14 (curvas de aprendizado).

Na figura 99, destacam-se dois destes serviços, através de um recorte no cronograma de execução.

Figura 99 - Aplicação de curvas de aprendizado na (a) estrutura e (b) caixilhos

\begin{tabular}{|c|r|r|}
\hline - Concreto & 283 dias & $14 / 01 / 15$ \\
\hline Concreto - Ssolo e térreo (CORPO TORRE - Teto $1^{\circ}$. SS) & 30 dias & $06 / 04 / 15$ \\
\hline Concreto - Ssolo e térreo (CORPO TORRE - Teto $2^{\circ}$. SS) & 12 dias & $18 / 03 / 15$ \\
\hline Concreto - Ssolo e térreo (CORPO TORRE - Teto $3^{\circ}$. SS) & 20 dias & $18 / 02 / 15$ \\
\hline Concreto - Ssolo e térreo (CORPO TORRE - Teto 4‥SS) & 24 dias & $14 / 01 / 15$ \\
\hline Concreto - Ssolo e térreo (Teto - TÉRREO MIOLO) & 30 dias & $20 / 05 / 15$ \\
\hline Concreto - Pvto tipo - Teto $1^{\circ}$ Pavto & 20 dias & $02 / 07 / 15$ \\
\hline Concreto - Pvto tipo - Teto 20. Pavto & 10 dias & $31 / 07 / 15$ \\
\hline Concreto - Pvto tipo - Teto 30. Pavto & 9 dias & $14 / 08 / 15$ \\
\hline Concreto - Pvto tipo - Teto 40. Pavto & 8 dias & $27 / 08 / 15$ \\
\hline Concreto - Pvto tipo - Teto 50. Pavto & 8 dias & $09 / 09 / 15$ \\
\hline Concreto - Pvto tipo - Teto 60. Pavto & 9 dias & $21 / 09 / 15$ \\
\hline Concreto - Pvto tipo - Teto 70. Pavto & 8 dias & $02 / 10 / 15$ \\
\hline Concreto - Pvto tipo - Teto 80. Pavto & 8 dias & $15 / 10 / 15$ \\
\hline C. & & \\
\hline
\end{tabular}

\begin{tabular}{|c|c|c|}
\hline - Caixilhos de alumínio & 152 dias & $15 / 01 / 16$ \\
\hline Pele de vidro ( $\left(1^{\circ}\right.$ PAVIMENTO) & 15 dias & $15 / 01 / 16$ \\
\hline Pele de vidro 20. Pavto. ( $\left(2^{\circ} \mathrm{AO} 12^{\circ} \mathrm{PAV}\right.$.) & 10 dias & $08 / 02 / 16$ \\
\hline Pele de vidro 30 . Pavto. ( $\left(2^{\circ} \mathrm{AO} 12^{\circ} \mathrm{PAV}\right.$.) & 9 dias & $23 / 02 / 16$ \\
\hline Pele de vidro 40. Pavto. ( $2^{\circ} \mathrm{AO} 12^{\circ} \mathrm{PAV}$.) & 8 dias & 07/03/16 \\
\hline Pele de vidro 50. Pavto. $\left(2^{\circ} \mathrm{AO} 12^{\circ} \mathrm{PAV}.\right)$ & 7 dias & $17 / 03 / 16$ \\
\hline Pele de vidro 60 . Pavto. $\left(2^{\circ} \mathrm{AO} 12^{\circ} \mathrm{PAV}\right.$.) & 6 dias & 29/03/16 \\
\hline Pele de vidro 70 . Pavto. ( ( $2^{\circ} \mathrm{AO} 12^{\circ} \mathrm{PAV}$.) & 6 dias & $06 / 04 / 16$ \\
\hline Pele de vidro 80 . Pavto. ( (2॰ $\mathrm{AO} 12^{\circ} \mathrm{PAV}$.) & 6 dias & 14/04/16 \\
\hline Pele de vidro 90 . Pavto. ( $2^{\circ} \mathrm{AO} 12^{\circ} \mathrm{PAV}$.) & 6 dias & $25 / 04 / 16$ \\
\hline Pele de vidro 100. Pavto. ( $2^{\circ} \mathrm{AO} 12^{\circ} \mathrm{PAV}$.) & 6 dias & $03 / 05 / 16$ \\
\hline Pele de vidro 110. Pavto. (2० AO $12^{\circ}$ PAV.) & 6 dias & $11 / 05 / 16$ \\
\hline Pele de vidro 120. Pavto. (2 $2^{\circ} \mathrm{AO} 12^{\circ} \mathrm{PAV}$.) & 6 dias & 19/05/16 \\
\hline
\end{tabular}

Fonte: O Autor (retirado do planejamento da Construtora Y) 


\section{Cronogramas de suprimentos específicos}

Como em diversos outros empreendimentos, esta obra apresenta implantada a prática de planejamento específico dos processos de suprimentos, aderente à diretriz \#13 (planejamento de suprimentos), como pode ser observado na figura 100.

Figura 100 - Cópia de parte do cronograma inicial de suprimentos da obra

\begin{tabular}{|c|c|c|c|c|c|c|c|}
\hline \multicolumn{8}{|c|}{ Planejamento de Contrataçốes - $01 / 03$ a 31/08/14 } \\
\hline Pacotes de escopo para orgamento & $\begin{array}{l}\text { Previsio Enctuega de } \\
\text { Projectos }\end{array}$ & observą̄ōes & $\begin{array}{l}\text { Entroga ae Projetos } \\
\text { Reelizado }\end{array}$ & $\begin{array}{l}\text { Prazo para Levantamento } \\
\text { I Dlas }\end{array}$ & $\begin{array}{c}\text { Levantamento atdes } \\
\text { Projeto / Datai }\end{array}$ & Envio da carla Convite & Equalizaçào de propostt: \\
\hline Projetos, Tributos, Consultorias, Despesas Técnicas & 20032014 & & & 30 & 199042014 & 24042014 & 30: \\
\hline Trabalho em solos & 20032014 & & & 30 & 19042014 & 24042014 & 30 . \\
\hline Fundação e Contençōes & 20032014 & & & so & 19042014 & $2404: 2014$ & 30 \\
\hline Estrutura & 2003:2014. & $\begin{array}{l}\text { Deverá ser orçado sem projetos, olevartamento sera } \\
\text { por locice. }\end{array}$ & & 30 & $1904 / 2014$ & 2404252014 & 60 \\
\hline Alvenaria, paredes $e$ paineis & 2003:2014 & & & 60 & $1905 / 2014$ & 240512014 & 30 \\
\hline Esquadrias Metálicas & $2003: 2014$ & & & 30. & 19642014 & 24042014 & $\infty$ \\
\hline Vidros & & 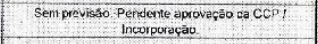 & & 30 & $30001 / 1500$ & 040215000 & $\infty$ \\
\hline Revestimentos externos & 200320014 & 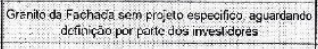 & & so & 1905052014 & $2405: 2014$ & 60 \\
\hline Instalaç̧ōes Eletricas & 2003320014 & & & $\because$ & 30032014 & $04 / 042014$ & 89 \\
\hline Instalaş̧ês Hidraulicas & 200320014 & 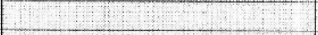 & & 0 & 300332014 & 04,0422014 & 89 \\
\hline Elevadores & 2003520014 & Concomencia ja em sndamen do & & $0^{\circ}$ & 300320014 & oarvatrolit & 89 \\
\hline Ar condicionado, Exaustäo & 200320014 & 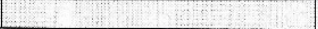 & & 10 & $3003 / 2014$ & $04,04,2014$ & 89 \\
\hline
\end{tabular}

Fonte: O Autor (documento fornecido pela Construtora Y)

\section{Fiscalização por terceira parte}

Para este empreendimento em especial, foi contratada uma empresa de fiscalização da obra (diretriz \#23 - fiscalização independente), fato que, segundo os envolvidos no projeto, trouxe alguns benefícios ao processo de planejamento, tais como:

- Definição de metas mais realistas, uma vez que as críticas ao que era apresentado como linha de base pela construtora foi intensamente discutido e revisado (prática que indiretamente resultou na complementariedade ou mesmo na evidencia de ações relacionadas à diretriz \#9 - metas realistas);

- Melhoria da terminalidade e garantia da qualidade dos serviços monitorados, uma vez que o principal escopo desta fiscalização foi exatamente o controle dos serviços (prática que indiretamente resultou na complementariedade ou mesmo na evidência de ações relacionadas às diretrizes \#3 - terminalidade e \#15 - controle da qualidade); 
- Formalização de boa parte do planejamento para apresentação à equipe de fiscalização e indiretamente ao cliente (prática complementar à diretriz \#7 formalização do planejamento);

- Agilidade nas discussões sobre os problemas da obra, seja de não eliminação de restrições, seja de não cumprimento das metas de programação, uma vez que com uma equipe dedicada e sem envolvimento direto na produção, os problemas eram identificados e relatados de forma antecipada (foco também da diretriz \#19 - hierarquização de decisões, e parcialmente a \#18 - sistemas de alerta antecipado);

- Envolvimento maior do cliente nas decisões de planejamento (relacionado também à diretriz \#21 - participação do cliente), uma vez que o ente externo contratado também trouxe questões que poderiam atrapalhar o desenvolvimento dos serviços no canteiro por responsabilidade do cliente e não apenas da equipe de obra e subcontratados (por exemplo, indefinições de projeto, customizações e alterações de escopo).

\section{Comentários gerais}

Para este empreendimento em especial, apesar de comentado por entrevistados como um procedimento padrão da empresa, não se verificou uma sistemática formalizada para a gestão do escopo (diretriz \#22 - gestão de escopo). Este trabalho de revisão do contrato é realizado caso a caso.

Outro ponto de registro refere-se às parcerias de fornecedores que acompanham a construtora em suas obras. Talvez pelo fato dos empreendimentos serem de alto valor, financeiramente interessante para muitas empresas, existe uma constante consulta sobre premissas de execução junto à subcontratados e fornecedores em potencial. Mas uma preparação específica para o empreendimento, com estudos de abastecimento vinculados às condições de canteiro e realidade de cada parceiro não foi evidenciada (diretriz \#17 - avaliação das condições de abastecimento, de forma parcial). 


\subsubsection{Empreendimento VI}

O Empreendimento VI, executado pela Construtora AA (não tem obras avaliadas na primeira pesquisa) caracteriza-se pela execução de 2 torres residenciais de 17 pavimentos e 1 subsolo, com 255 unidades, totalizando 22.947,48 $\mathrm{m}^{2}$ de área construída, localizado em um terreno de $3.240,00 \mathrm{~m}^{2}$ na cidade de Osasco/SP.

O empreendimento teve início em 05/01/2015, com previsão de término em 11/11/2016, o que representa 49 dias antes do prazo da linha de base e contratual (30/12/2016). Até a última data de acompanhamento dentro das atividades desta pesquisa (medição em maio de 2016), a obra apresentava adiantamento de 2,39\% do progresso físico previsto na linha de base e, desta forma, a obra também foi escolhida para análise de boas práticas de planejamento físico e gestão de prazos.

A figura 101 ilustra a construção do edifício em duas datas diferentes, sendo algumas das vezes em que o pesquisador acompanhou as atividades desta obra.

Figura 101 - Fotos do Empreendimento VI (Out/15 e Jan/16)
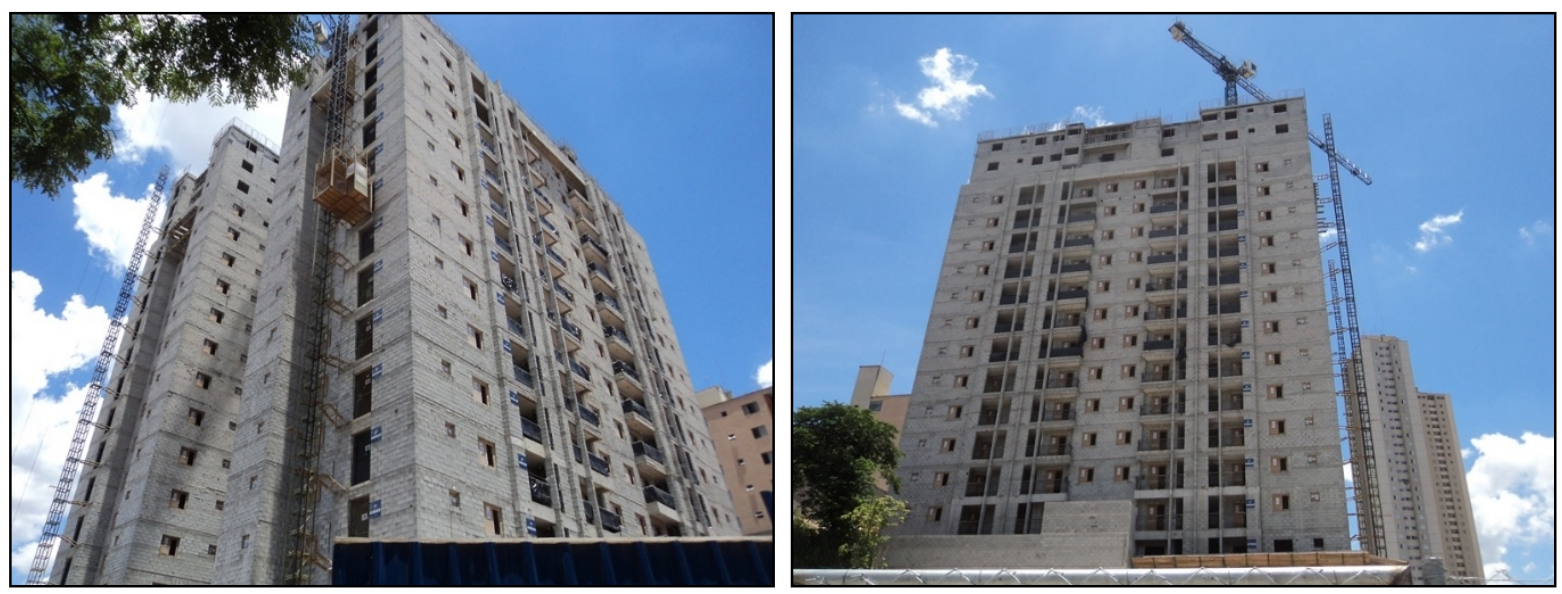

Fonte: O Autor

\section{> Planejamento de longo prazo com detalhamento de tarefas críticas}

Verificou-se no empreendimento um cuidado grande com relação ao Plano de Ataque da obra e validação das metas de produção que seriam acordadas na linha de base.

Nesta obra, um dos itens mais críticos segundo os entrevistados seria a fachada, que teve um tratamento diferenciado, a exemplo do que normalmente é realizado para os serviços de alvenaria estrutural. Estes estudos, além de diversas vezes discutidos 
pelas equipes de produção, foram formalizados para que as premissas sejam claramente entendidas e as metas de produção comprometidas por todos, como sugerido nas pela diretriz \#8 (participação das equipes de produção).

Como exemplo, a figura 102 apresenta o estudo da fachada, com destaques para o caminho crítico da obra, também então aderente à diretriz \#20 (plano mestre detalhado).

Figura 102 - Estudo de fachada com destaque para o caminho crítico

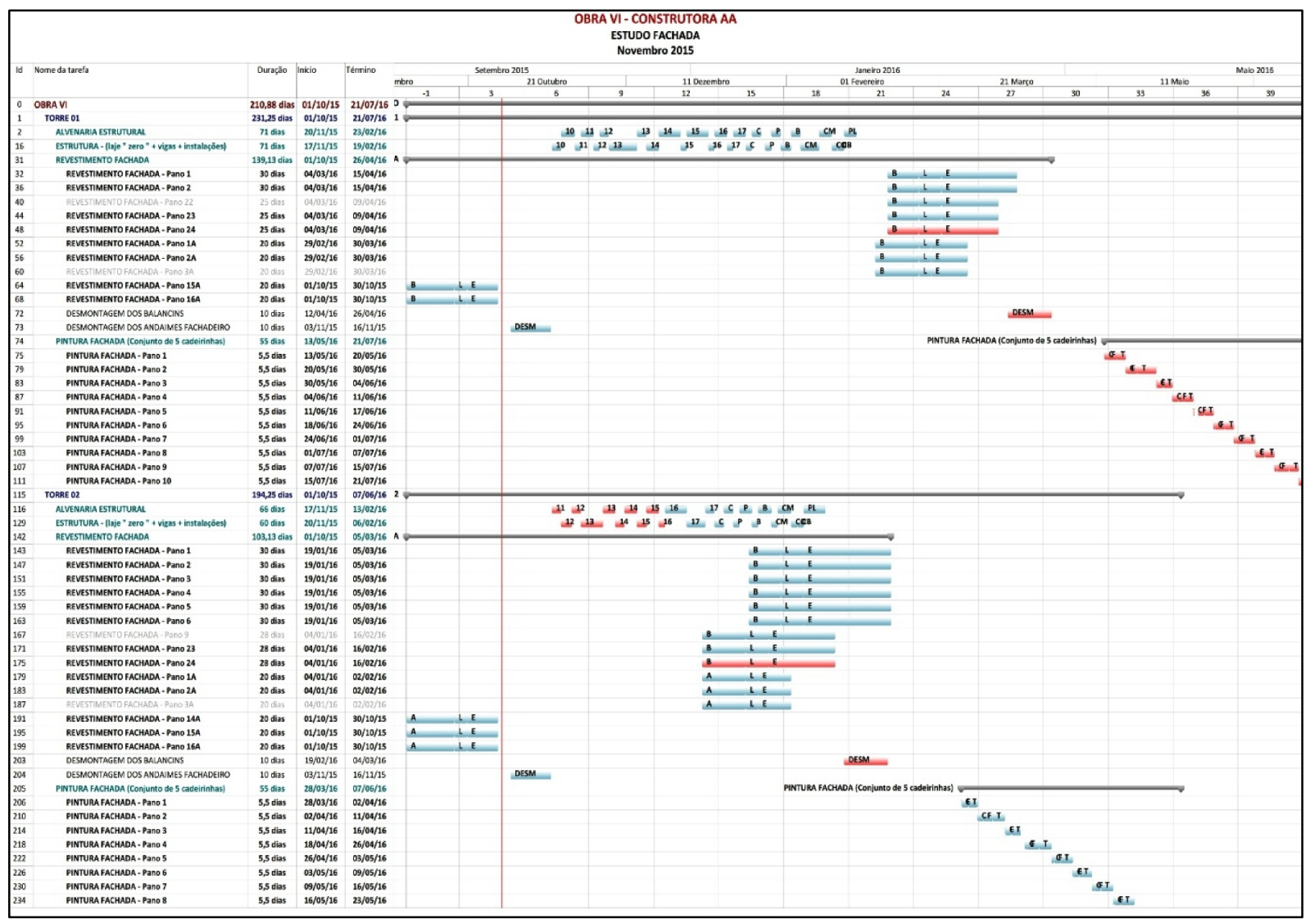

Fonte: O Autor (parte de arquivo fornecido pela Construtora AA)

Planos de médio e curto prazo detalhados e formalizados por equipe

Diversas outras ferramentas de planejamento são utilizadas para a formalização das programações e estudos detalhados das atividades e suas premissas.

A programação de médio prazo é realizada através de um cronograma detalhado em MS Project, que já possui todas as atividades do macro fluxo e divididas por local (em especial pavimentos, mas no caso do térreo e periferia, há trechos previamente 
definidos). Para cada atividade é identificada a equipe responsável, normalmente um subempreiteiro, conforme pode ser observado na figura 103.

O cronograma global detalhado auxilia de forma rápida a criação de vários modelos de relatório e programação, com o uso de filtros e ferramentas visuais que são disponibilizadas pelo software. No entanto, quanto mais detalhado é a rede para elaboração da programação de curto prazo, a reprogramação acaba sendo trabalhosa, gerando uma dúvida se a técnica é a mais indicada nestes termos.

Figura 103 - Exemplo de planejamento de médio prazo (trimestral)

\begin{tabular}{|c|c|c|c|c|c|c|c|c|c|c|c|c|c|c|c|c|c|}
\hline \multicolumn{18}{|c|}{$\begin{array}{l}\text { PROGRAMAÇÃO TRIMESTRAL } \\
\text { Obra VI - Construtora AA } \\
\text { Abril } 2016 \text { - Maio } 2016 \text { - Junho } 2016\end{array}$} \\
\hline \multirow[t]{2}{*}{ Id } & \multirow[t]{2}{*}{ Nome da tarefa } & \multirow[t]{2}{*}{ Empreiteiro } & \multirow{2}{*}{$\begin{array}{c}\text { Duraçăo } \\
\text { Reprogram. }\end{array}$} & \multirow{2}{*}{$\begin{array}{c}\text { Inicio } \\
\text { Reprogram. }\end{array}$} & \multirow{2}{*}{$\begin{array}{l}\text { Término } \\
\text { Reprogram. }\end{array}$} & \multicolumn{5}{|c|}{16} & \multirow{2}{*}{\multicolumn{4}{|c|}{17}} & \multirow{2}{*}{\multicolumn{3}{|c|}{18}} \\
\hline & & & & & & 2703 & 0320 & Abr/1 & & I & 01/05 & & & 2305 & 20105 & & Jun/16 \\
\hline 0 & OBRA VI & & 520 dias & $05 / 01 / 15$ & $30 / 12 / 16$ & & & & & & & & & & & & \\
\hline 1 & omissos & & 484 dias & 05/01/15 & $30 / 12 / 16$ & 161 & 19.18.16 & 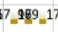 & 7.101 & $=18 \_18$ & 18 I1 = 19 & 19.188990 & 90_18_20 & 1920 & 291831 & 131.20.222 & $22=20.222 .213 .21=21$ \\
\hline $\begin{array}{l}918 \\
927\end{array}$ & $\begin{array}{l}\text { OBRA } \\
\text { VENTILACÃO PERMANENTE }\end{array}$ & & $\begin{array}{r}485 \text { dias } \\
10 \text { dias }\end{array}$ & $\begin{array}{l}05 / 01 / 15 \\
16 / 05 / 16\end{array}$ & $\begin{array}{l}11 / 11 / 16 \\
31 / 05 / 16\end{array}$ & & & & & & & & Vent & & & & \\
\hline 953 & ESTRUTURA PERIFERIA - (pilar + viga + laje + escada) & & 266,7 dias & $19 / 06 / 15$ & $24 / 08 / 16$ & & & & & & & & & & & & \\
\hline 989 & SERVIÇOS INTERNOS E FACHADA - Garagem & & 313,7 dias & $04 / 08 / 15$ & $10 / 11 / 16$ & & & & & & & & & & & & \\
\hline 990 & PRUMADAS HIDRÁULICAS - (água, esgoto, pluvial, inc & & 121,2 dias & 09/10/15 & $12 / 04 / 16$ & & & 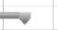 & & & & & & & & & \\
\hline 991 & Prumadas Hidráulicas - 1 10ss & DRYELETRIC & 5 dias & $15 / 10 / 15$ & $06 / 04 / 16$ & $3 .$. & 1 & & & & & & & & & & \\
\hline 992 & Prumadas Hidráulicas - Ter & DRYELETRIC & 5 dias & $09 / 10 / 15$ & $06 / 04 / 16$ & ..... & 1 & & & & & & & & & & \\
\hline 993 & Prumadas Hidráulicas - \$S & DRYELETRIC & 5 dias & $30 / 12 / 15$ & $12 / 04 / 16$ & $\ldots . . .$. & (n... & & & & & & & & & & \\
\hline 994 & ALVENARIA - (marcaçăo + assentamento + encunham & & 168,7 dias & 04/08/15 & $12 / 04 / 16$ & & $\longrightarrow$ & 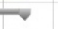 & & & & & & & & & \\
\hline 995 & ALVENARIA - $1^{0.55}$ & & 168,7 dias & $04 / 08 / 15$ & $12 / 04 / 16$ & & & & & & & & & & & & \\
\hline 1000 & Alvenaria - 1955 - Prumadas e Shafts & LINERCON & 4 dias & $07 / 04 / 16$ & $12 / 04 / 16$ & & Pru & um & & & & & & & & & \\
\hline 1001 & ALVENARIA-Ter & & 159,7 dias & $17 / 08 / 15$ & $12 / 04 / 16$ & & & & & & & & & & & & \\
\hline 1005 & Alvenaria - Ter - Prumadas e Shafts & LINERCON & 4 dias & $07 / 04 / 16$ & $12 / 04 / 16$ & & Pru & um & & & & & & & & & \\
\hline 1018 & VENTLLAÇ̄̃o PERMANENTE & & 8 dias & $01 / 06 / 16$ & $10 / 06 / 16$ & & & & & & & VENTILAC. & AÇĀO PERM & RMANENTE & TE $\sqrt{2}$ & $\longrightarrow$ & \\
\hline 1019 & Elemento vazado - $10_{5 s}$ & & 8 dias & $01 / 06 / 16$ & $10 / 06 / 16$ & & & & & & & & & & 1958 & ss & \\
\hline 1020 & INSTALAÇĀO HIDRÁULICA / INCÊNDIO - (Desvios e car & & 188 dias & 04/09/15 & $15 / 06 / 16$ & & & & & & & & & & & & \\
\hline 1021 & 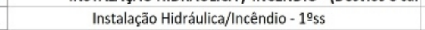 & DRYELETRIC & 60 dias & $04 / 09 / 15$ & $08 / 06 / 16$ & $\beta \ldots$ & & & & & & & & & & & \\
\hline 1022 & Instalaç̧ão Hidráulica//Incêndio - Ter & DRYELETRIC & 60 dias & $04 / 09 / 15$ & $08 / 06 / 16$ & $\ldots . .$. & & & & & & & & & & & \\
\hline 1023 & Instalą̧ão Hidráulica/Incêndio - sS & DRYELETRIC & 60 dias & $04 / 09 / 15$ & $15 / 06 / 16$ & & & & & & & & & & & & \\
\hline 1024 & RESERVATÓRIO INFERIOR & LINERCON & 20 dias & $24 / 05 / 16$ & $23 / 06 / 16$ & & & & & & & & & Resen & & & \\
\hline 1025 & DUTO DE PRESSURIZAÇ̄AOO - 19sS & & 20 dias & 09/06/16 & $07 / 07 / 16$ & & & & & & & & & & & Dut & lut \\
\hline 1034 & CABEAMENTO SISTEMAS & & 7 dias & $23 / 03 / 16$ & $04 / 04 / 16$ & & $\rightarrow$ & & & & & & & & & & \\
\hline 1035 & Cabeamento Sistemas - $10_{55}$ & & 7 dias & $23 / 03 / 16$ & $04 / 04 / 16$ & s & & & & & & & & & & & \\
\hline 1036 & Cabeamento Sistemas - Ter & & 7 dias & $23 / 03 / 16$ & $04 / 04 / 16$ & & & & & & & & & & & & \\
\hline 1037 & Cabeamento Sistemas - 55 & & 7 dias & $23 / 03 / 16$ & $04 / 04 / 16$ & & & & & & & & & & & & \\
\hline 1038 & 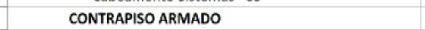 & & 9 dias & $04 / 04 / 16$ & $15 / 04 / 16$ & RMADO & $\mathrm{O}$ & $\longrightarrow$ & & & & & & & & & \\
\hline 1039 & Contrapiso armado - $10_{5 s}$ & LINERCON & 9 dias & $04 / 04 / 16$ & $15 / 04 / 16$ & & $1^{195}$ & & & & & & & & & & \\
\hline 1040 & Contrapiso armado - Ter & LINERCON & 9 dias & $04 / 04 / 16$ & $15 / 04 / 16$ & & Ter & & & & & & & & & & \\
\hline 1041 & Contrapiso armado - SS & LINERCON & 9 dias & $04 / 04 / 16$ & $15 / 04 / 16$ & & ss & & & & & & & & & & \\
\hline 1042 & PORTAS & & 15 dias & $15 / 04 / 16$ & $09 / 05 / 16$ & & & RTAS $\bar{\nabla}$ & & & & & & & & & \\
\hline 1043 & Portas - $19_{\text {ss }}$ & & 5 dias & $15 / 04 / 16$ & $25 / 04 / 16$ & & & & 19ss & & & & & & & & \\
\hline 1044 & Portas - Ter & & 5 dias & $25 / 04 / 16$ & $02 / 05 / 16$ & & & & & Ter & & & & & & & \\
\hline 1045 & Portas - SS & & 5 dias & $02 / 05 / 16$ & $09 / 05 / 16$ & & & & & & ss & & & & & & \\
\hline 1046 & PISO CERÂMICO & & 15 dias & $25 / 04 / 16$ & $16 / 05 / 16$ & & & PISO CE: & ERÁMICO & & & & & & & & \\
\hline 1047 & Piso cerâmico - $1^{\circ}$ ss & LINERCON & 5 dias & $25 / 04 / 16$ & $02 / 05 / 16$ & & & & & $195 s$ & & & & & & & \\
\hline 1048 & Piso cerâmico - Ter & LINERCON & 5 dias & $02 / 05 / 16$ & $09 / 05 / 16$ & & & & & & Ter & & & & & & \\
\hline 1049 & Piso cerâmico - SS & LINERCON & 5 dias & $09 / 05 / 16$ & $16 / 05 / 16$ & & & & & & & ss & & & & & \\
\hline 1050 & PINTURA 1ः DEMÄO & & 30 dias & $09 / 05 / 16$ & $23 / 06 / 16$ & & & & & NTURA 1: & DEMÃO & & & & & & \\
\hline 1051 & Pintura 1" Demăo - 1 QSS & & 10 dias & $09 / 05 / 16$ & $23 / 05 / 16$ & & & & & & & 1955 & 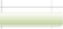 & & & & \\
\hline 1052 & Pintura 1? Demão - Ter & & 10 dias & $23 / 05 / 16$ & $08 / 06 / 16$ & & & & & & & & & Ter & & 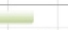 & \\
\hline 1053 & Pintura 1? Demão-SS & & 10 dias & $08 / 06 / 16$ & $23 / 06 / 16$ & & & & & & & & & & & 55 & \\
\hline
\end{tabular}

Fonte: O Autor (parte de arquivo fornecido pela Construtora AA)

No momento da programação semanal, este planejamento amplo e detalhado é filtrado por equipe e com abrangência mensal (e detalhe das metas semanais), o que remete a um exemplo de prática ligada à diretriz \#1 (planejamento de equipes), mas que é ainda muito simples para a configuração de plena aderência (figura 104). 
Figura 104 - Exemplo de planejamento de curto prazo por equipe

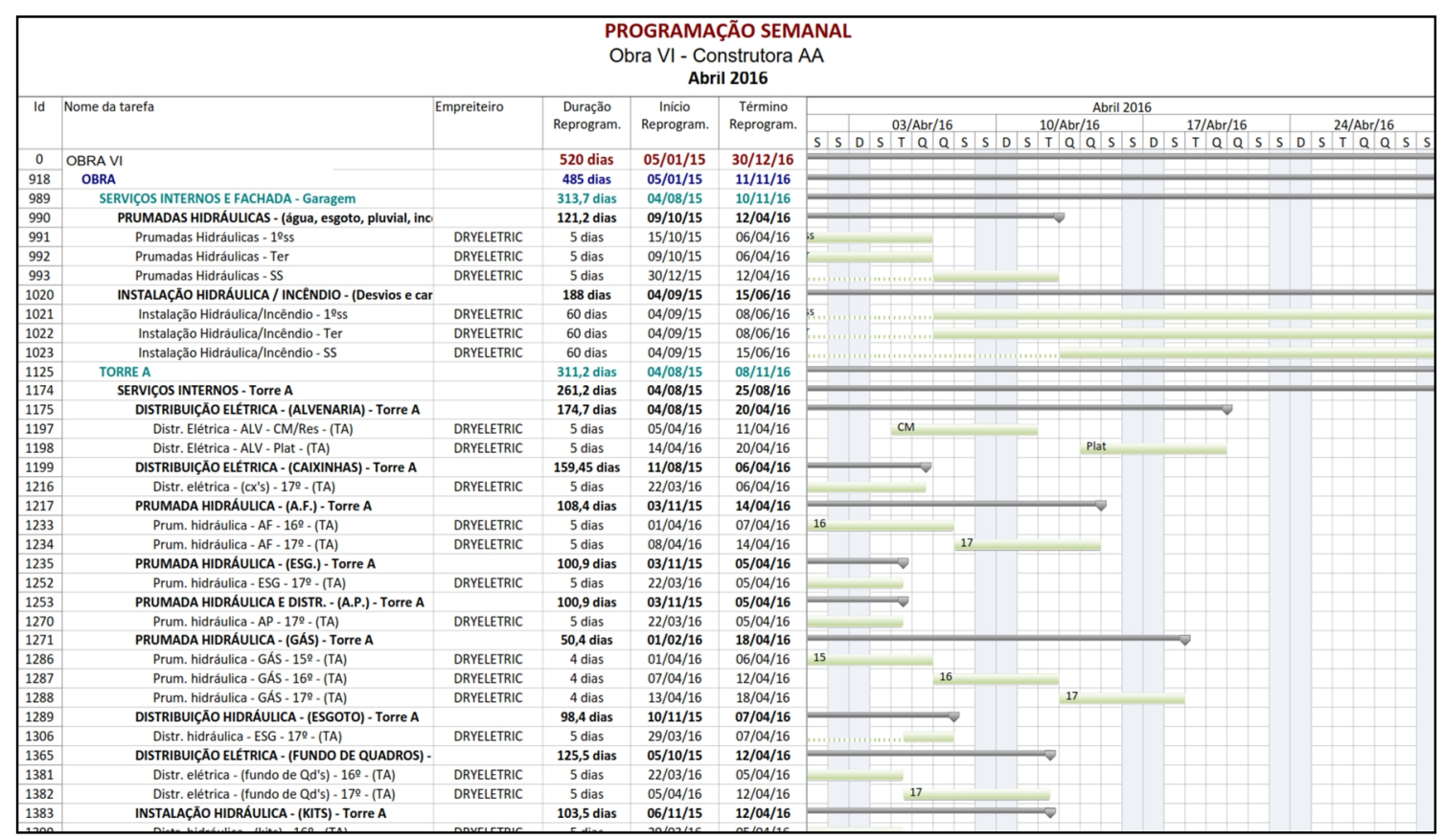

Fonte: O Autor (arquivo fornecido pela Construtora AA)

\section{Planejamento de suprimentos com contratações por pacotes}

A empresa procura manter uma base sólida de fornecedores e subcontratados para a realização de suas obras. Como a tipologia de empreendimentos é similar, utilizamse das experiências com obras passadas, bem como a análise das condições momentâneas dos fornecedores para a contratação de um grande número de serviços.

A prática envolve concentrar atividades de mesma natureza (todas as instalações, todos os serviços de argamassa, todos de cerâmica, todos de gesso, dentre outros) para as mesmas empresas, mas com um acompanhamento mais próximo de sua gestão, equipes e condições financeiras, pois a quantidade de empresas a se controlar é bem menor se adotada esta premissa.

Estas contratações são realizadas de forma controlada, através de um planejamento específico de suprimentos com datas, cronogramas e alertas de atraso dinâmicos similares a outras obras já citadas, mas coerente com os processos desta construtora. 
Estas ferramentas e estratégia, alinham-se com diretrizes como \#13 (planejamento de suprimentos) e \#18 (sistemas de alerta antecipado), mas especialmente à diretriz \#12 (contratações conjuntas).

\section{Monitoramento de problemas e ações de recuperação}

Mantendo-se as práticas de formalização para diversos itens do planejamento desta obra, conforme diretriz \#7 (formalização do planejamento, item já destacado no início do capítulo que é característica de boa parte das obras), identificou-se uma prática importante para a gestão dos prazos do empreendimento: a sistematização do registro dos motivos pelos quais as atividades programadas não foram executadas e a definição das ações que devem ser realizadas para eliminar nova ocorrência e também evitar que estas restrições se propaguem para outros serviços.

A formalização destas ocorrências é feita em reuniões quinzenais através de relatórios periódicos, embora as ações já estejam em andamento. Na realidade, muitas vezes a reunião acaba sendo importante para validar as ações que a equipe de produção já esteja implementando.

A figura 105 ilustra uma parte deste relatório gerencial, com exemplos das ações acordadas, não apenas aderentes à diretriz \#7 (formalização do planejamento) em geral (como comentada em grande parte das práticas descritas neste capítulo) mas parcialmente a diretriz \#19 (hierarquização de decisões), uma vez que de certa forma, a definição de prazos formais para a realização das ações gera indiretamente uma hierarquização das decisões.

Neste relatório, outras informações são descritas e formalizadas. Divergências nas premissas podem ser justificativas como parte do não cumprimento da programação (fato alinhado à diretriz \#2 - premissas mensuráveis, mesmo que parcial).

Outro ponto interessante deste relatório relaciona-se ao estudo de abastecimento, muitas vezes uma das restrições de execução. Mesmo que isto não seja realizado de maneira formal e sistematizada (o que garantiria a aderência da diretriz \#17 - avaliação das condições de abastecimento), a necessidade de se investigar as causas e registrar no relatório mostrou aos responsáveis pela gestão da produção na obra, que 
a prática de estudo de condições locais, incluindo fornecedores, era essencial para o sucesso deste tipo de obra.

Figura 105 - Formalização de problemas e ações de recuperação

\begin{tabular}{|c|c|c|c|c|}
\hline Item / Atividade & Descrição do Atraso & Ação Necessária & Prazo & Status \\
\hline TERRAÇOS - TORRES A / B & $\begin{array}{l}\text { Atraso na execução dos gradis do } \\
\text { terraço, em virtude de problemas na } \\
\text { entrega do material pelo fornecedor } \\
\text { e consequente instalação do mesmo. }\end{array}$ & $\begin{array}{c}\text { Foram realizadas reuniões com } \\
\text { fornecedor, que iniciou a entrega e } \\
\text { instalação dos gradis, porém de forma } \\
\text { ineficiente. Foi reprogramado início da } \\
\text { colocação para dezembro/15, o que } \\
\text { ocorreu somente em uma parte da } \\
\text { Torre B.A partir de janeiro/16 a } \\
\text { instalação dos gradis foi retomada, } \\
\text { porém ainda defasado em relação ao } \\
\text { programado. }\end{array}$ & $\begin{array}{l}\text { Término } \\
\text { previsto: } \\
\text { abril/16 }\end{array}$ & Em andamento \\
\hline FACHADA - TORRE A & $\begin{array}{l}\text { Atraso em virtude da não conclusão } \\
\text { da estrutura. }\end{array}$ & $\begin{array}{l}\text { Devido o atraso na conclusão da } \\
\text { estrutura, devido a problemas } \\
\text { recorrentes com chuva e equipe, o } \\
\text { início da fachada foi reprogramado para } \\
\text { abril/16. Como é uma atividade que } \\
\text { impacta no prazo final da obra, forma } \\
\text { feitos estudos e otimização de material, } \\
\text { afim de diminuir esse impacto. }\end{array}$ & $\begin{array}{l}\text { Data de inicio } \\
\text { dos serviços: } \\
\text { abril/16 }\end{array}$ & - \\
\hline
\end{tabular}

Fonte: O Autor (retirado de relatório gerencial da Construtora AA)

\section{Datas-marco de controle}

Verificou-se desde o início do processo de planejamento, a definição de pontos críticos de controle, que auxiliam no gerenciamento adequado do prazo global do empreendimento. Tratam-se de datas determinantes no sucesso do projeto por sua importância na liberação de processos estratégicos da obra e porque fazem parte do caminho crítico da linha base. Desta forma, caso não sejam cumpridos, fatalmente afetarão o prazo final do empreendimento.

Nesta obra em especial, estas datas-marco não foram apenas acompanhadas como datas fixas que possam identificar impactos no prazo final, mas como indicadores dinâmicos inclusive de ações de reprogramação adequadas.

Toda a rede é recalculada a cada medição e reprogramação, sendo que as datasmarco podem se alterar com as novas condições, mostrando uma nova tendência. Assim, os planejadores têm indicações antecipadas de pontos críticos que devem trabalhar, prática alinhada com a diretriz \#18 (sistemas de alerta antecipado). 
A figura 106 apresenta as principais datas-marco monitoradas.

Figura 106 - Planilha de datas marco do empreendimento

\begin{tabular}{|l|c|c|c|c|}
\hline \multicolumn{1}{|c|}{ Descrição da Atividade } & Variação & Linha Base & $\begin{array}{c}\text { Tendência } \\
/ \text { Real }\end{array}$ & Status \\
\hline \multicolumn{4}{|c|}{ TORRE B } \\
\hline CONCRETAGEM BLOCOS DE FUNDAÇÃO & 0 & $08 / 06 / 15$ & $08 / 06 / 15$ & \\
CONCRETAGEM DA 1ํ LAJE & 0 & $22 / 06 / 15$ & $22 / 06 / 15$ & \\
CONCRETAGEM DA LAJE DO ÁTRIO & 0 & $21 / 07 / 15$ & $21 / 07 / 15$ & \\
CONCRETAGEM DA 1ํ LAJE DO TIPO & 0 & $31 / 07 / 15$ & $31 / 07 / 15$ & \\
CONCRETAGEM DA COBERTURA (BALANCINS) & 0 & $15 / 06 / 16$ & $15 / 06 / 16$ & \\
INÍCIO DA FACHADA & 0 & $20 / 12 / 16$ & $20 / 12 / 16$ & \\
DESMONTAGEM DO CREMALHEIRA & 0 & $17 / 10 / 16$ & $17 / 10 / 16$ & \\
TÉRMINO DO REVESTIMENTO DA FACHADA (CORPO & 0 & $29 / 09 / 16$ & $29 / 09 / 16$ & \\
DO PRÉDIO) & 0 & $20 / 12 / 16$ & $20 / 12 / 16$ & \\
HABITE-SE & 0
\end{tabular}

Fonte: O Autor (retirado do planejamento da Construtora AA)

A prática destes alertas antecipados, por sua vez, vai além das principais datas-marco do empreendimento.

Muitas outras datas-marco (secundárias) são monitoradas de forma específica e normalmente em momentos adequados, o que até direciona parte dos esforços da equipe em ações relativas à diretriz \#24 (premissas por tipo de serviço).

Em um destes exemplos, 6 meses antes do término da obra, há o monitoramento de datas importantes relacionadas a alvarás, aprovações de concessionárias e órgãos públicos. Muitas vezes, monitoram-se datas de finalização de serviços pouco representativos em termos de progresso físico, mas condicionantes para atividades de entrega da obra (execução do barrilete, da entrada de energia, do poço de elevador, instalação de hidrantes, dentre outros). O monitoramento destas datas acaba garantindo o cumprimento de uma data-marco global, a data de Habite-se (como identificada na própria figura 105).

Outros exemplos podem ser citados, como as datas-marco secundárias de fundações, estrutura, fachadas. Entre elas, a figura 107 exemplifica o conjunto de datas marco do 
processo de elevadores, item considerado crítico em um empreendimento imobiliário como todos os selecionados dentro da amostra da pesquisa.

Figura 107 - Conjunto de datas marco do processo de elevadores

\begin{tabular}{|c|c|c|c|c|c|}
\hline Descrição da Atividade & $\begin{array}{c}\text { Variação } \\
\text { (1) - (3) }\end{array}$ & $\begin{array}{c}\text { Data } \\
\text { Contratual } \\
\text { (1) }\end{array}$ & $\begin{array}{c}\text { Data } \\
\text { da Ata } \\
\text { (2) }\end{array}$ & $\begin{array}{c}\text { Tendência } \\
\text { / Real } \\
\text { (3) }\end{array}$ & Status \\
\hline \multicolumn{6}{|c|}{ Elevador 1 - Torre A } \\
\hline DATA DE ENTREGA DOS ELEVADORES & - & - & - & $24 / 07 / 16$ & - \\
\hline LIBERAÇÃO CASA DE MAQUINAS E POÇOS & - & - & - & $03 / 08 / 16$ & - \\
\hline INÍCIO DA MONTAGEM & - & - & - & $03 / 08 / 16$ & - \\
\hline TÉRMINO DA MONTAGEM & - & - & - & $22 / 09 / 16$ & - \\
\hline LIBERAÇÃO PARA USO & - & - & - & $22 / 09 / 16$ & - \\
\hline \multicolumn{6}{|c|}{ Elevador 2 - Torre A } \\
\hline DATA DE ENTREGA DOS ELEVADORES & - & - & - & $24 / 07 / 16$ & - \\
\hline LIBERAÇÃO CASA DE MAQUINAS E POÇOS & - & - & - & $03 / 08 / 16$ & - \\
\hline INÍCIO DA MONTAGEM & - & - & - & $03 / 08 / 16$ & - \\
\hline TÉRMINO DA MONTAGEM & - & - & - & $22 / 09 / 16$ & - \\
\hline LIBERAÇÃO PARA USO & - & - & - & $22 / 09 / 16$ & - \\
\hline
\end{tabular}

Fonte: O Autor (retirado do planejamento da Construtora AA)

\section{Premissas específicas por serviço e seu monitoramento}

Analogamente ao que ocorre em alguns dos empreendimentos analisados, esta obra também estabelece em seu planejamento o detalhamento de premissas específicas para determinados serviços e em alguns casos a identificação de calendários específicos para atender suas condições.

É o caso da definição de serviços que são afetados por condições climáticas, como terraplenagem, impermeabilização de térreo, fachadas, dentre outro. Estas atividades possuem uma previsão de menos dias úteis para sua realização, em virtude de meses mais chuvosos que inviabilizem sua adequada execução ou liberação para início. Além da definição destas premissas com base no histórico de chuvas da região, a equipe da obra também monitorava as reais condições, de maneira a justificar restrições ocorridas (eliminando-se possíveis outras restrições que poderiam ter sido levantada pelos gestores como motivos dos atrasos) ou mesmo orientar ações de recuperação no caso das condições fugirem ao controle. 
Este monitoramento pode ser ilustrado na figura 108.

Figura 108 - Monitoramento de precipitações reais no local da obra

\begin{tabular}{|c|c|c|c|c|c|c|c|c|c|c|c|c|c|c|c|}
\hline Dia & fev-15 & mar-15 & abr-15 & mai-15 & jun-15 & jul-15 & ago-15 & set-15 & out-15 & nov-15 & dez-15 & jan-16 & fev-16 & mar-16 & abr-16 \\
\hline 1 & 1,7 & 17,2 & 0,3 & 1,2 & 0,0 & 2,0 & 0,0 & 2,0 & 9,0 & 54,0 & 2,0 & 5,0 & 0,0 & 12,0 & 8,0 \\
\hline 2 & 12,5 & 0,4 & 0,0 & 0,0 & 0,0 & 8,0 & 0,0 & 3,0 & 8,0 & 50,0 & 10,0 & 24,0 & 8,0 & 21,0 & 0,0 \\
\hline 3 & 6,4 & 0,0 & 0,0 & 0,0 & 0,0 & 20,0 & 0,0 & 6,0 & 8,0 & 13,0 & 0,0 & 7,0 & 6,0 & 23,0 & 5,0 \\
\hline 4 & 1,2 & 0,0 & 0,0 & 2,8 & 0,0 & 20,0 & 0,0 & 4,0 & 11,0 & 22,0 & 10,0 & 0,0 & 6,0 & 5,0 & 0,0 \\
\hline 5 & 17,9 & 0,0 & 0,0 & 10,4 & 0,0 & 12,0 & 0,0 & 2,0 & 1,0 & 22,0 & 15,0 & 0,0 & 15,0 & 5,0 & 0,0 \\
\hline 6 & 29,3 & 1,5 & 0,4 & 0,7 & 0,0 & 0,0 & 0,0 & 3,0 & 0,0 & 9,0 & 19,0 & 0,0 & 12,0 & 5,0 & 0,0 \\
\hline 7 & 19,3 & 26,5 & 6,7 & 0,0 & 0,0 & 8,0 & 0,0 & 4,0 & 0,0 & 13,0 & 8,0 & 4,0 & 23,0 & 15,0 & 0,0 \\
\hline 8 & 2,7 & 37,1 & 3,0 & 2,0 & 0,0 & 24,0 & 0,0 & 64,0 & 0,0 & 40,0 & 2,0 & 10,0 & 13,0 & 18,0 & 0,0 \\
\hline 9 & 1,4 & 27,7 & 0,0 & 0,0 & 0,0 & 0,0 & 0,0 & 2,0 & 2,0 & 24,0 & 8,0 & 12,0 & 3,0 & 0,0 & 0,0 \\
\hline 10 & 17,7 & 9,4 & 0,0 & 20,0 & 0,0 & 0,0 & 0,0 & 18,0 & 10,0 & 10,0 & 15,0 & 30,0 & 10,0 & 25,0 & 0,0 \\
\hline 11 & 8,1 & 11,1 & 0,0 & 10,0 & 0,0 & 2,0 & 0,0 & 40,0 & 15,0 & 15,0 & 15,0 & 20,0 & 19,0 & 20,0 & 5,0 \\
\hline 12 & 0,2 & 6,4 & 0,0 & 0,0 & 3,0 & 2,0 & 0,0 & 21,0 & 13,0 & 2,0 & 27,0 & 21,0 & 0,0 & 3,0 & 5,0 \\
\hline 13 & 0,0 & 2,1 & 0,0 & 2,0 & 0,0 & 0,0 & 0,0 & 9,0 & 9,0 & 11,0 & 9,0 & 9,0 & 0,0 & 2,0 & 0,0 \\
\hline 14 & 3,6 & 8,6 & 0,0 & 0,0 & 0,0 & 0,0 & 0,0 & 0,0 & 4,0 & 12,0 & 8,0 & 30,0 & 0,0 & 2,0 & 5,0 \\
\hline 15 & 7,0 & 4,5 & 0,0 & 0,0 & 28,0 & 0,0 & 0,0 & 6,0 & 0,0 & 9,0 & 8,0 & 18,0 & 25,0 & 5,0 & 0,0 \\
\hline 16 & 16,1 & 10,0 & 15,3 & 0,0 & 0,0 & 0,0 & 0,0 & 0,0 & 0,0 & 2,0 & 30,0 & 25,0 & 21,0 & 11,0 & 0,0 \\
\hline 17 & 36,3 & 27,8 & 10,4 & 0,0 & 0,0 & 0,0 & 0,0 & 0,0 & 2,0 & 10,0 & 9,0 & 25,0 & 35,0 & 0,0 & 0,0 \\
\hline 18 & 26,1 & 5,7 & 0,0 & 5,0 & 10,0 & 0,0 & 0,0 & 0,0 & 0,0 & 7,0 & 16,0 & 2,0 & 20,0 & 7,0 & 0,0 \\
\hline 19 & 11,4 & 4,5 & 0,2 & 8,0 & 8,0 & 0,0 & 0,0 & 0,0 & 0,0 & 17,0 & 18,0 & 3,0 & 11,0 & 0,0 & 0,0 \\
\hline 20 & 2,0 & 10,9 & 8,1 & 2,0 & 0,0 & 0,0 & 0,0 & 0,0 & 0,0 & 25,0 & 38,0 & 2,0 & 19,0 & 0,0 & 0,0 \\
\hline 21 & 0,0 & 11,2 & 0,2 & 0,0 & 0,0 & 6,0 & 0,0 & 0,0 & 8,0 & 30,0 & 17,0 & 0,0 & 31,0 & 5,0 & 0,0 \\
\hline 22 & 0,6 & 5,9 & 10,1 & 0,0 & 0,0 & 2,0 & 7,0 & 0,0 & 22,0 & 8,0 & 7,0 & 0,0 & 27,0 & 0,0 & 0,0 \\
\hline 23 & 0,0 & 8,1 & 10,3 & 0,0 & 2,0 & 8,0 & 12,0 & 0,0 & 5,0 & 46,0 & 16,0 & 0,0 & 15,0 & 25,0 & 0,0 \\
\hline 24 & 2,1 & 1,2 & 0,6 & 0,0 & 0,0 & 19,0 & 10,0 & 0,0 & 2,0 & 10,0 & 10,0 & 0,0 & 5,0 & 29,0 & 0,0 \\
\hline 25 & 8,1 & 0,8 & 0,2 & 0,0 & 2,0 & 9,0 & 10,0 & 2,0 & 2,0 & 0,0 & 17,0 & 0,0 & 15,0 & 30,0 & 0,0 \\
\hline 26 & 13,6 & 0,0 & 1,4 & 0,0 & 0,0 & 1,0 & 0,0 & 5,0 & 14,0 & 0,0 & 16,0 & 0,0 & 5,0 & 2,0 & 10,0 \\
\hline 27 & 0,2 & 0,0 & 0,5 & 0,0 & 0,0 & 0,0 & 26,4 & 12,0 & 30,0 & 0,0 & 6,0 & 10,0 & 9,0 & 16,0 & 10,0 \\
\hline 28 & 5,0 & 0,0 & 0,0 & 10,0 & 0,0 & 0,0 & 0,0 & 9,0 & 8,0 & 10,0 & 40,0 & 0,0 & 30,0 & 0,0 & 1,0 \\
\hline 29 & -. & 0,3 & 0,3 & 8,0 & 0,0 & 0,0 & 0,0 & 5,0 & 6,0 & 10,0 & 25,0 & 10,0 & 20,0 & 0,0 & 2,0 \\
\hline 30 & -- & 8,6 & 3,6 & 0,0 & 0,0 & 0,0 & 0,0 & 25,0 & 12,0 & 6,0 & 13,0 & 5,0 & -. & 24,0 & 0,0 \\
\hline 31 & -. & 2,2 & - & 0,0 & -. & 0,0 & 0,0 & -. & 50,0 & - & 8,0 & 0,0 & -. & 0,0 & - \\
\hline $2014 / 2015$ & fev-15 & mar-15 & abr-15 & mai-15 & jun-15 & jul-15 & ago-15 & set-15 & out-15 & nov-15 & dez-15 & jan-16 & fev-16 & mar-16 & abr-16 \\
\hline Total & 250,5 & 249,7 & 71,6 & 82,1 & 53,0 & 143,0 & 65,4 & 242,0 & 251,0 & 487,0 & 442,0 & 272,0 & 403,0 & 310,0 & 51,0 \\
\hline
\end{tabular}

Fonte: O Autor (arquivo fornecido pela Construtora AA)

\subsubsection{Empreendimento VII}

O Empreendimento VII, executado pela Construtora AB (não tem obras avaliadas na primeira pesquisa) caracteriza-se pela execução de 2 torres, uma residencial e outra comercial, com respectivamente 28 e 37 pavimentos e 1 subsolo, com 294 apartamentos, 416 salas e 25 lojas, totalizando 88.515,00 $\mathrm{m}^{2}$ de área construída, localizado em um terreno de 9.042,25 $\mathrm{m}^{2}$ na cidade de Goiânia/GO.

O empreendimento teve início em 01/07/2012 e deveria ter sido entregue totalmente em 31/08/2015. Escolheu-se este empreendimento para estudo pois apesar de atrasar sua entrega em quase 3 meses, durante praticamente 3 anos (por 35 meses) após seu início, conservou avanço físico sempre cerca de 3\% em média acima do previsto na linha de base. Para um empreendimento complexo, este fato foi extremamente interessante e incomum, e por esta razão, foi incluso para análise de boas práticas de planejamento físico e gestão de prazos. Os problemas que ocorreram nos meses 
finais de obra são descritos na avaliação, justificados e não corroboram para a caracterização das boas práticas até aquele momento.

A figura 109 ilustra a construção do edifício em duas datas diferentes.

Figura 109 - Fotos do Empreendimento VII (Set/14 e Ago/15)
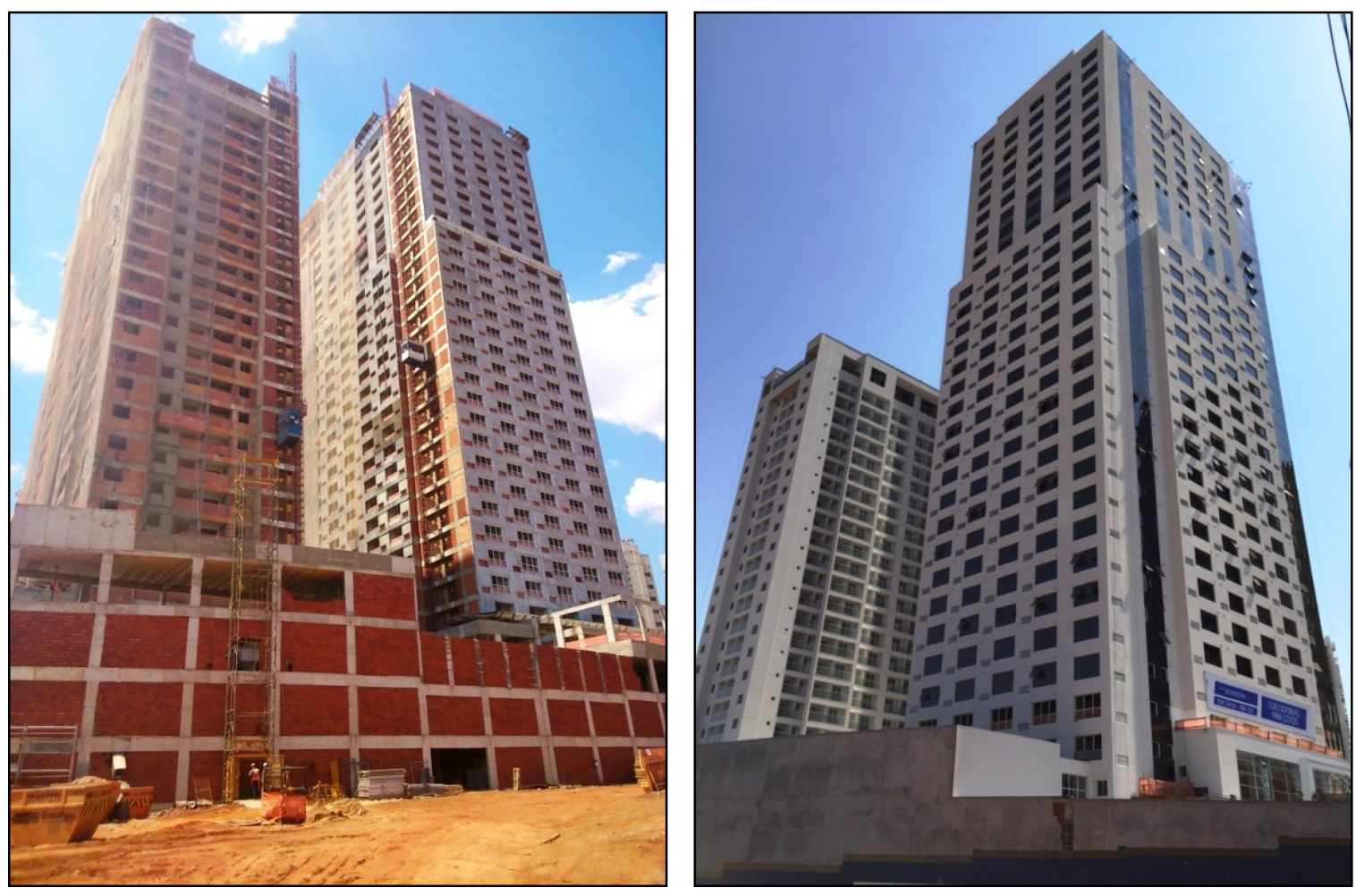

Fonte: O Autor

\section{Análise de gargalos para execução dos serviços}

Verificou-se na obra a sistemática de análise de restrições, com a formalização dos problemas que cercam o início dos serviços e posterior inclusão das ações que estão sendo implementadas em um relatório gerencial, o que demonstra ações ligadas à diretriz \#19 (hierarquização de decisões).

\section{Controle detalhado por serviço}

Verificou-se na obra uma grande quantidade de cronogramas específicos por serviço (ver figura 110), o que promove o detalhamento dos processos produtivos e maior probabilidade de execução dos mesmos, pois assim, é mais fácil encontrar as restrições ou verificar as causas do não atendimento das premissas de planejamento, conforme diretrizes \#2 (premissas mensuráveis) e \#24 (premissas por tipo de serviço). 
Figura 110 - Cronograma individualizados por serviço (exemplo da fachada)

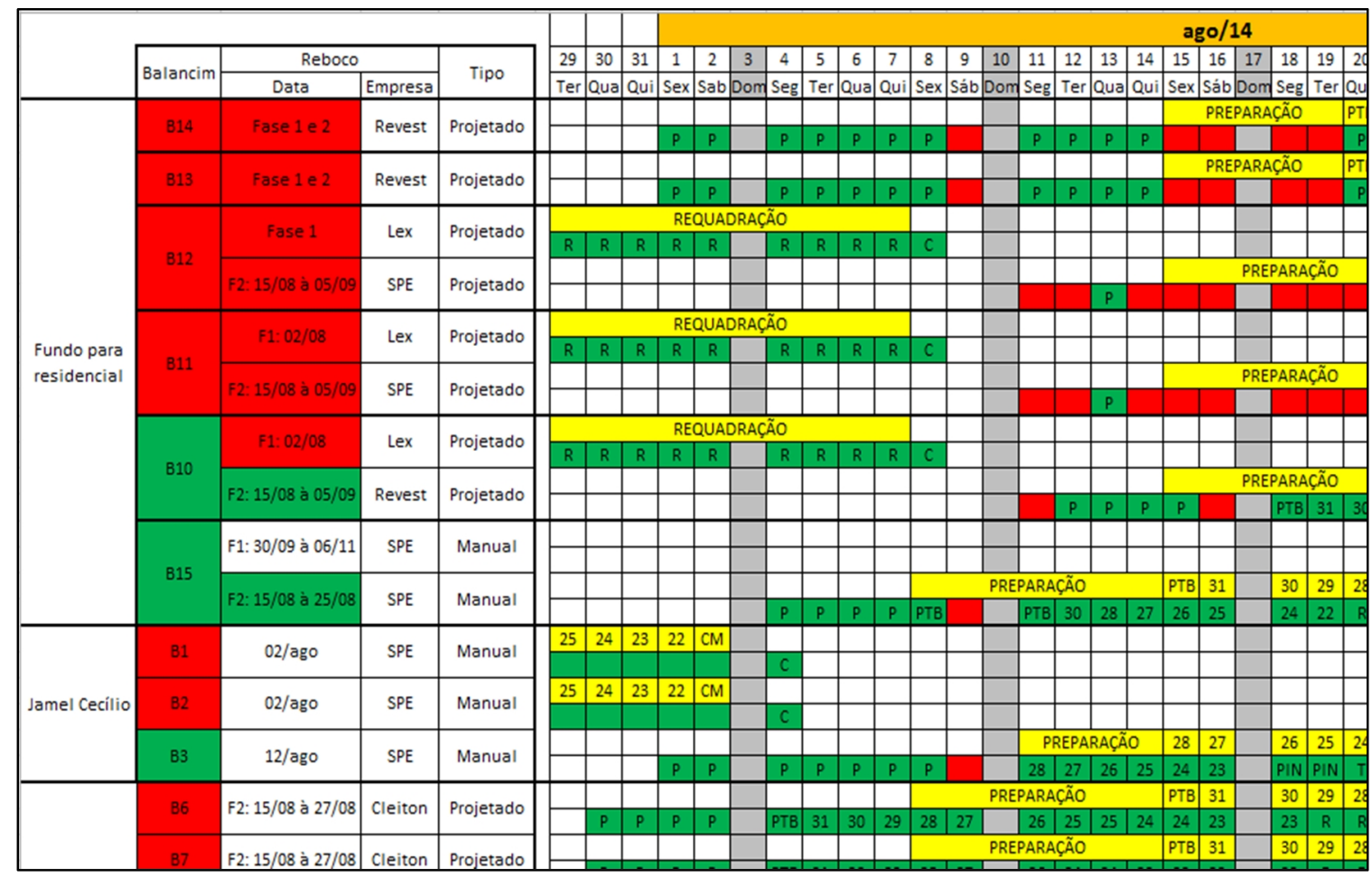

Fonte: O Autor (retirado do planejamento da construtora)

Talvez como crítica construtiva ao processo, que valeria sua classificação à aderência completa da diretriz \#2 (premissas mensuráveis) está no fato dos planejamentos de produção estarem mais focados em durações e cronogramas, do que em definições primárias de premissas ou composições de serviço que resultassem nos ciclos previstos. Só assim seria possível um monitoramento de premissas convincente.

\section{> Controle de qualidade detalhado para verificação da terminalidade}

Além de uma sistemática abrangente para a inspeção e acompanhamento dos serviços no canteiro, identificaram-se várias ferramentas para se registrar a terminalidade dos serviços e, assim, compatibilizar o planejamento físico com a realidade da obra, conforme sugere as diretrizes \#3 (terminalidade) e \#15 (controle da qualidade), este último ainda inicial.

Como exemplo de um destes controles, a figura 111 ilustra uma ferramenta muito simples para a fachada: a utilização do próprio projeto, com inclusão de faixas representativas dos detalhes executivos, de forma a se garantir que cada pequeno trecho foi liberado de forma não haver retrabalhos, mesmo que em pequeno porte. 
Figura 111 - Controle de execução de fachada (com projeto adaptado)
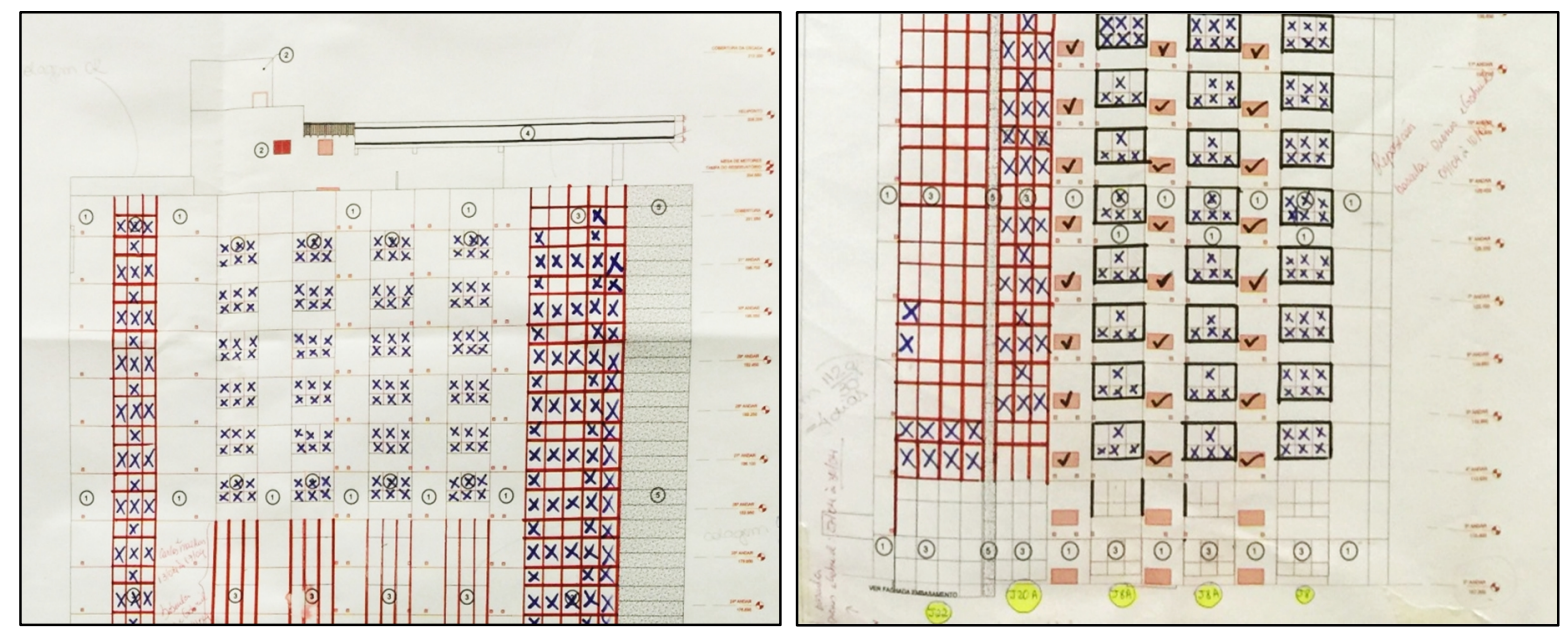

Fonte: O Autor (recorte dos registros da Construtora $A B$ )

\section{Foco em melhoria do ambiente de trabalho}

A obra é extremamente bem organizada e há exemplos de ações simples que ajudam a tornar o local mais produtivo, como sugere a diretriz \#11 (ambiente de trabalho organizado).

Como alguns exemplos, pode-se ilustrar a sistemática de garantia de limpeza do canteiro e a organização do fluxo de funcionários com faixas típicas de ambiente fabril ou de prédios de prestação de serviço com muita circulação (figura 112).

Figura 112 - Práticas de organização: (a) circulação e (b) limpeza
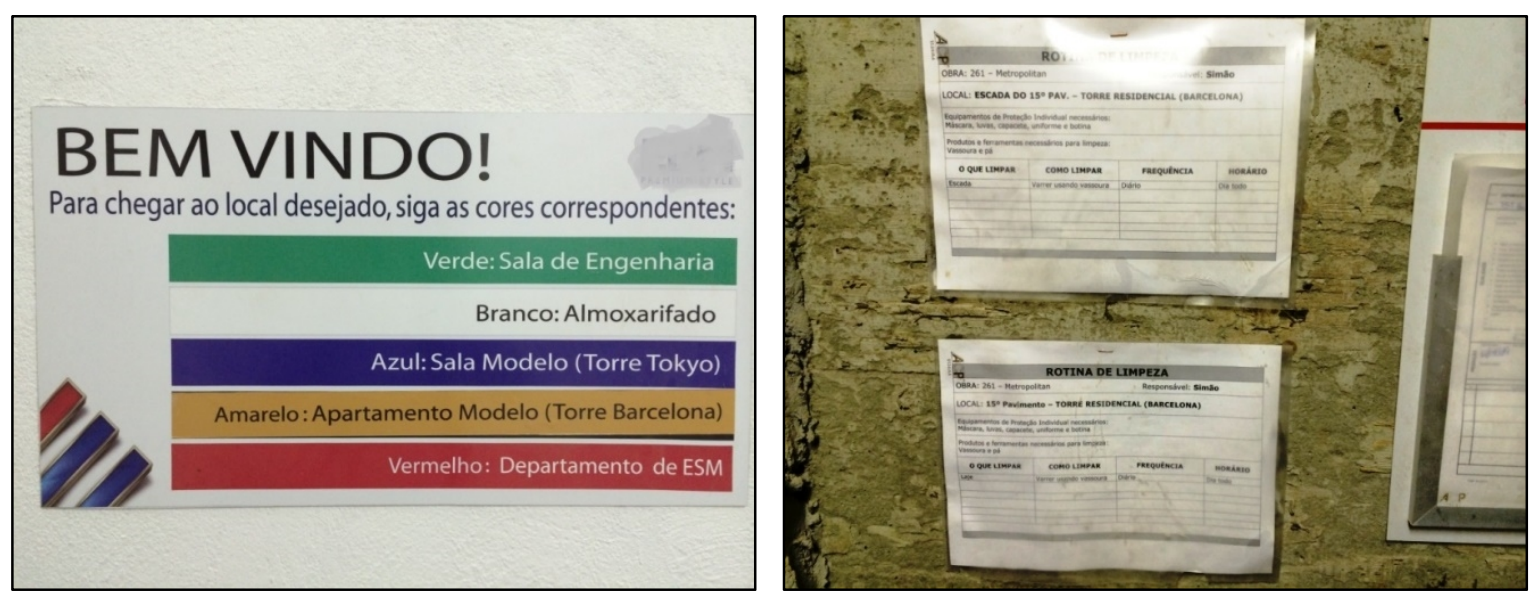

Fonte: O Autor (fotos tiradas da obra, Construtora $A B$ ) 
Foi possível verificar na obra, algumas ferramentas de registro, reprogramação e alertas (o que relaciona-se à diretriz \#18 - sistemas de alerta antecipado), como por exemplo o quadro gerencial apresentado na figura 113.

Este painel registra as datas de término, comparadas com a data de status do acompanhamento, sinalizando quais itens estão atrasados.

Neste caso, busca-se que os serviços estejam cerca de 15 dias ou mais antecipados em relação à linha de base (sem prioridade). Se ocorre antecipação em menos de 15 dias, o sinal amarelo é registrado (média prioridade) e no caso de atraso, qualquer que seja, o quadro sinaliza o vermelho (alta prioridade de ação da equipe da obra).

Figura 113 - Painel gerencial com datas de término previstas

\begin{tabular}{|c|c|c|c|c|c|c|c|c|}
\hline & \multicolumn{7}{|c|}{$\begin{array}{l}\text { Eng. Manoel } \\
\text { Estag. Fabiana e Mauricio }\end{array}$} & \multirow{2}{*}{$\begin{array}{c}\text { STATUS } \\
19 / 11 / 14 \\
\begin{array}{c}\text { CORRIMÃO } \\
\text { ESCADA }\end{array} \\
\end{array}$} \\
\hline & $\begin{array}{c}\text { DRY-WALL } \\
\text { FECHAMENTO DE } \\
\text { SHAFT E VARANDA }\end{array}$ & $\begin{array}{l}\text { PISO DE HALL } \\
\text { (CERÂMICA / } \\
\text { MÁRMORE) }\end{array}$ & $\begin{array}{l}\text { PINTURA GERAL } \\
\text { EM HALL }\end{array}$ & $\begin{array}{l}\text { PRUMADAS } \\
\text { ELÉTRICAS/ } \\
\text { CABEAMENTOS }\end{array}$ & TESTE ELÉTRICO & $\begin{array}{l}\text { RECUPERAÇÃO DE } \\
\text { ESCADA (1E2) }\end{array}$ & $\begin{array}{l}\text { PINTURA DE } \\
\text { ESCADA }\end{array}$ & \\
\hline LAZER & $10 / 12 / 14 \bigcirc 21$ & $21 / 01 / 15 \bigcirc 63$ & 04/06/15 O197 & $19 / 06 / 15 O_{212}$ & $26 / 06 / 15 O_{219}$ & $06 / 01 / 15 \bigcirc 48$ & $17 / 02 / 15 \bigcirc 90$ & 17/03/15 O118 \\
\hline 22 & $03 / 12 / 14 \bigcirc 14$ & $21 / 01 / 15 \bigcirc 63$ & $28 / 05 / 15$ O190 & $19 / 06 / 15$ O212 & $26 / 06 / 15$ O219 & $06 / 01 / 15048$ & $17 / 02 / 15 \bigcirc 90$ & $17 / 03 / 15$ O118 \\
\hline 21 & $27 / 11 / 14 \bigcirc 8$ & $21 / 01 / 15$ O63 & $21 / 05 / 15$ O183 & $18 / 06 / 15$ O211 & $26 / 06 / 15$ O219 & $06 / 01 / 15048$ & $17 / 02 / 15090$ & $17 / 03 / 15$ O118 \\
\hline 20 & $20 / 11 / 14 \bigcirc 1$ & $08 / 01 / 15$ 50 & $14 / 05 / 15$ O176 & $18 / 06 / 15 O_{211}$ & $26 / 06 / 15$ O219 & $06 / 01 / 15 \mathrm{O}_{48}$ & $17 / 02 / 15$ O90 & $17 / 03 / 15$ O118 \\
\hline 19 & $13 / 11 / 14 \bigcirc-6$ & $08 / 01 / 15$ S0 & $07 / 05 / 150169$ & $17 / 06 / 15 \quad O_{210}$ & $26 / 06 / 15 O_{219}$ & $06 / 01 / 15 \bigcirc 48$ & $17 / 02 / 15090$ & $17 / 03 / 15$ O118 \\
\hline 18 & $07 / 11 / 14 \bigcirc-12$ & $17 / 12 / 14 \bigcirc 28$ & $30 / 04 / 15$ O 162 & $17 / 06 / 15 O_{210}$ & $26 / 06 / 15 O_{219}$ & $06 / 01 / 15 O_{48}$ & $17 / 02 / 15 \bigcirc 90$ & $17 / 03 / 15$ O118 \\
\hline 17 & $07 / 11 / 14$ O-12 & $17 / 12 / 14 \bigcirc 28$ & $23 / 04 / 15$ O155 & $16 / 06 / 15 O_{209}$ & $26 / 06 / 15 \quad O_{219}$ & $06 / 01 / 15 \mathrm{O}_{48}$ & $17 / 02 / 15090$ & $17 / 03 / 15$ O118 \\
\hline 16 & OK & $11 / 12 / 14$ O22 & $16 / 04 / 15$ O148 & $16 / 06 / 15$ O209 & $26 / 06 / 15$ O219 & $06 / 01 / 15048$ & $17 / 02 / 15 \bigcirc 90$ & $17 / 03 / 15$ O118 \\
\hline 15 & OK & $08 / 12 / 14019$ & $09 / 04 / 15$ O141 & $15 / 06 / 15$ O208 & $26 / 06 / 15$ O219 & $06 / 01 / 15 \bigcirc 48$ & $17 / 02 / 15090$ & $17 / 03 / 15$ O118 \\
\hline 14 & $\mathrm{OK}$ & $03 / 12 / 14 \bigcirc 14$ & $02 / 04 / 15$ O134 & $15 / 06 / 15 O_{208}$ & $26 / 06 / 15$ O219 & $06 / 01 / 15 \bigcirc 48$ & $17 / 02 / 15 \bigcirc 90$ & $17 / 03 / 15$ O118 \\
\hline 13 & $\mathrm{OK}$ & $03 / 12 / 14 \bigcirc 14$ & $26 / 03 / 15$ O127 & $12 / 06 / 15 O_{205}$ & $26 / 06 / 15$ O219 & $06 / 01 / 15 O_{48}$ & $17 / 02 / 15090$ & $17 / 03 / 15$ O118 \\
\hline 12 & OK & $26 / 11 / 14 \bigcirc 7$ & $19 / 03 / 15$ O120 & $12 / 06 / 15$ O205 & $26 / 06 / 15 O_{219}$ & $06 / 01 / 15 \bigcirc 48$ & $17 / 02 / 15$ O90 & $17 / 03 / 15$ O118 \\
\hline 11 & $\mathrm{OK}$ & $24 / 11 / 14 \bigcirc 5$ & $12 / 03 / 15$ O113 & $11 / 06 / 15$ O204 & $26 / 06 / 15$ O219 & $06 / 01 / 15 \mathrm{O}_{48}$ & $17 / 02 / 15 \bigcirc 90$ & $17 / 03 / 15$ O118 \\
\hline 10 & $\mathrm{OK}$ & $17 / 11 / 140-2$ & $05 / 03 / 15$ O106 & $11 / 06 / 15$ O204 & $26 / 06 / 15$ O219 & $06 / 01 / 15 \bigcirc 48$ & $17 / 02 / 15090$ & $17 / 03 / 15$ O118 \\
\hline 9 & $\mathrm{OK}$ & $14 / 11 / 140.5$ & $26 / 02 / 15$ O9 & $10 / 06 / 15 O_{203}$ & $26 / 06 / 15 \quad O_{219}$ & $06 / 01 / 15$ O 48 & $17 / 02 / 15090$ & $17 / 03 / 15$ O118 \\
\hline 8 & $\mathrm{OK}$ & $07 / 11 / 14 \quad 0.12$ & $19 / 02 / 15$ O2 & $10 / 06 / 15 O_{203}$ & $26 / 06 / 15 O_{219}$ & $06 / 01 / 15 \bigcirc 48$ & $17 / 02 / 15$ O90 & $17 / 03 / 15$ O118 \\
\hline 7 & $\mathrm{OK}$ & OK & $12 / 02 / 15 \bigcirc 85$ & $09 / 06 / 15 O_{202}$ & $26 / 06 / 15 O_{219}$ & $06 / 01 / 15$ O 48 & $17 / 02 / 15 \bigcirc 90$ & $17 / 03 / 15$ O118 \\
\hline 6 & OK & OK & $05 / 02 / 15078$ & $09 / 06 / 15$ O202 & $26 / 06 / 15$ O219 & $06 / 01 / 15 \bigcirc 48$ & $17 / 02 / 15090$ & $17 / 03 / 15$ O118 \\
\hline 5 & OK & OK & $29 / 01 / 15 \bigcirc 71$ & $08 / 06 / 15$ O201 & $26 / 06 / 15$ O219 & $06 / 01 / 15 \bigcirc 48$ & $17 / 02 / 15 \bigcirc 90$ & $17 / 03 / 15$ O118 \\
\hline 4 & OK & $\mathrm{OK}$ & $22 / 01 / 15$ O64 & $08 / 06 / 15 O_{201}$ & $26 / 06 / 15$ O219 & $06 / 01 / 150_{48}$ & $17 / 02 / 15 \bigcirc 90$ & $17 / 03 / 15$ O118 \\
\hline 3 & $\mathrm{OK}$ & OK & $15 / 01 / 15$ O57 & $05 / 06 / 15$ O198 & $26 / 06 / 15 O_{219}$ & $06 / 01 / 15 O_{48}$ & $17 / 02 / 15 \bigcirc 90$ & $17 / 03 / 15$ O118 \\
\hline \multirow[t]{5}{*}{2} & $\mathrm{OK}$ & $\mathrm{OK}$ & $08 / 01 / 15 \bigcirc 50$ & $05 / 06 / 15$ O198 & $26 / 06 / 15 O_{219}$ & $06 / 01 / 15 \bigcirc 48$ & $17 / 02 / 15 \bigcirc 90$ & 17/03/15 O118 \\
\hline & LEGENDA & & & & & & & \\
\hline & 215 DIAS 0 & & & & & & & \\
\hline & $\leq 14$ DIAS $O$ & & & & & & & \\
\hline & $<0$ DIAS 0 & & & & & & & \\
\hline
\end{tabular}

Fonte: O Autor (retirado do planejamento da Construtora AB)

Um critério de priorização das atividades também pode ser verificado neste painel, correlacionando ações da diretriz \#19 (hierarquização de decisões).

\section{Comunicação visual do planejamento}

Segundo a diretriz \#5 (gestão à vista), verificam-se no canteiro diversas ações de divulgação e comunicação visual das programações de produção. 
Alguns exemplos podem ser apresentados. A figura 114 ilustra, em uma das fotos, uma das salas de escritório, com as ferramentas de planejamento destacadas e atualizadas.

Figura 114 - Práticas de comunicação: (a) visual e (b) programações semanais
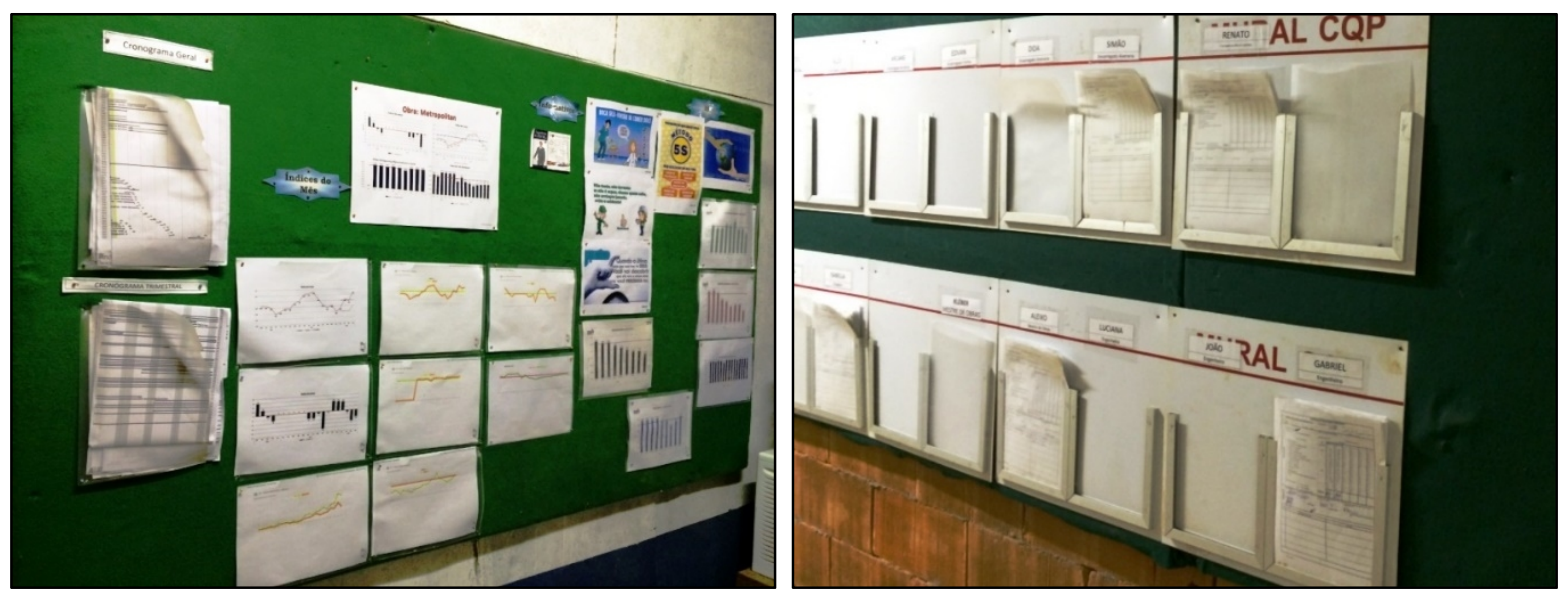

Fonte: O Autor (fotos tiradas da obra, Construtora AB)

A outra foto mostra a forma de distribuição das programações por equipe, prática aderente à diretriz \#1 (planejamento específico de equipes). Neste caso, há uma rotina de programação onde as equipes são semiautônomas e podem executar as tarefas descritas nestas programações semanais sem a necessidade de reuniões formais de liberação. Os líderes monitoram as frentes, intervindo quando identificam a ocorrência de fatores que irão afetar o cumprimento do planejamento ou fatos emergenciais.

As reuniões de planejamento de médio prazo acontecem em prazos mensais, onde são discutidas as sequências dos períodos subsequentes.

\section{Comentários gerais}

Algumas observações relativas à avaliação desta obra podem complementar o entendimento dos processos produtivos neste canteiro e como estão relacionados às diretrizes previstas na proposição inicial:

- Evidenciou-se uma descrição indireta de aprendizado no serviço de tubulação elétrica, mas sem justificativa convincente dos responsáveis pelo planejamento das razões daquela especificação (estava alinhada à diretriz \#14 - curvas de aprendizado), mas por tais esclarecimentos, foi revisada sua classificação. Talvez seja já uma praxe mais antiga da construtora (sem 
análise crítica da equipe da obra da aderência às condições da obra) ou reaproveitamento da base de cronograma de um empreendimento anterior;

- Apesar de não ter sido acompanhada pelo autor nenhuma reunião de empreiteiros (nesta obra em especial), podendo-se assim evidenciar a diretriz \#8 (participação das equipes de produção), segundo os gestores, existe esta sistemática e há contribuição e comprometimento dos subempreiteiros e equipe nas metas de programação de curto prazo;

- Os responsáveis pela obra mostraram alguns documentos que deveriam ser entendidos como o plano mestre do empreendimento, mas pela avaliação do autor, tratava-se de um registro muito simples e cuja interpretação dos detalhes do plano de ataque e logística de abastecimento não estavam formalizados (eram de conhecimento informal pelos envolvidos, em desavença ao que se propõe na diretriz \#20 - plano mestre detalhado);

- Existia uma empresa que realizava visitas periódicas na obra (a cada 15 dias) para avaliar o desenvolvimento do projeto para o proprietário (cliente). Como o trabalho desta empresa era passivo (sem interferência direta nas ações da obra) e com frequência reduzida, considerou-se que não era uma prática de fiscalização independente coerente à diretriz \#23 (fiscalização independente).

\subsubsection{Empreendimento VIII}

O Empreendimento VIII, executado pela Construtora M (empresa teve obras avaliadas na primeira pesquisa) caracteriza-se pela execução de 1 torre residencial com 26 pavimentos e estacionamento descoberto, com 208 unidades, totalizando 17.264,00 $\mathrm{m}^{2}$ de área construída, localizado em um terreno de 4.165,00 $\mathrm{m}^{2}$ na cidade de São Paulo/SP.

O empreendimento teve início em 01/11/2013 e foi entregue totalmente em 22/12/2015, 6 dias antes de seu prazo contratual e da data prevista na linha de base inicial (28/12/2015). Apesar de não tão notável esta antecipação de entrega, um ponto importante que o destacou para a avaliação nesta pesquisa foi o fato de, além de não ter atrasado, identificou-se que em a partir de setembro de 2014 e por um prazo de 13 meses, o desempenho físico da obra ficou acima de 5\% comparado com o previsto na linha de base (com picos de $8 \%$ ). Este avanço somente foi freado perto nos meses 
finais meramente por questões regulamentares e comerciais, uma vez o repasse ao público alvo da construtora não poder ser feito antecipadamente.

Verdadeiramente, todas os serviços de obra e seu acabamento acabaram cerca de 3 meses antes do prazo contratual, restando apenas atividades de vistoria e limpeza final, que se mantiveram por este período, não impactando as operações e os custos indiretos da construtora, uma vez que praticamente toda a equipe da obra foi desmobilizada.

Desta forma, entendeu-se um empreendimento interessante para estudo de práticas de planejamento e controle de prazos.

A figura 115 ilustra a construção do edifício em duas datas diferentes, sendo algumas das vezes em que o pesquisador acompanhou as atividades desta obra.

Figura 115 - Fotos do Empreendimento VIII (Jan/15 e Jan/16)
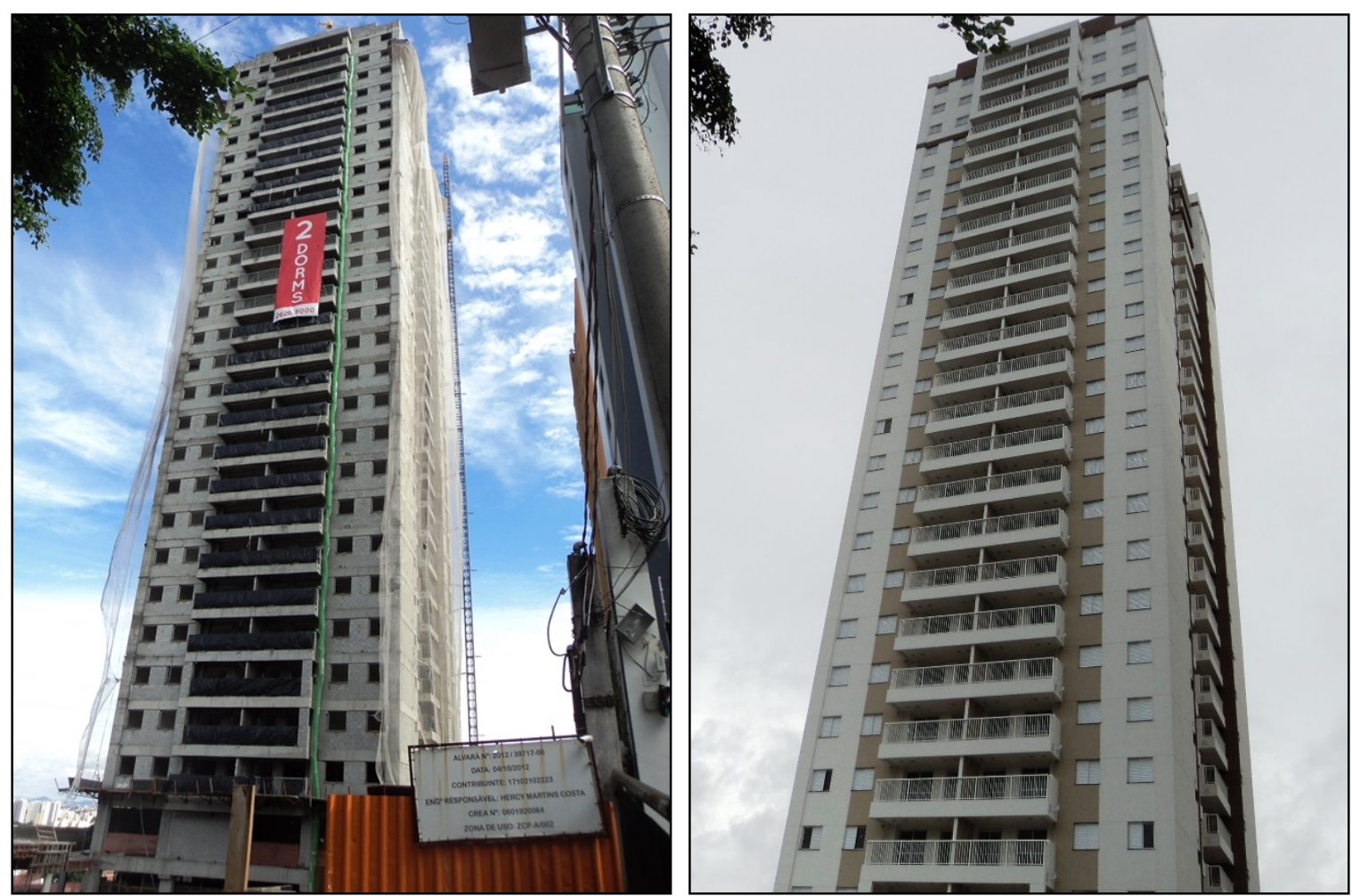

Fonte: O Autor

\section{Estabelecimento de premissas de planejamento monitoradas}

Verificou-se no empreendimento o detalhamento de premissas de planejamento e sua formalização para futuro acompanhamento, prática aderente à diretriz \#2 (premissas 
mensuráveis). As premissas envolvem taxas de produtividade, número de equipes, equipamentos, dentre outros, mas destaca-se o levantamento quantitativo elaborado pela equipe de produção.

Normalmente uma obra se utiliza dos dados advindos do orçamento da obra, que às vezes é desenvolvido por terceiros ou pelo departamento comercial da empresa.

Neste caso, no início do planejamento do empreendimento, optou-se pela revisão completa dos quantitativos dos principais serviços (áreas, paredes por tipo, quantidade de aço, dentre outros), o que garantiu que as compras, contratações e estudo dos ciclos das atividades fossem mais assertivos.

A figura 116 ilustra uma parte deste levantamento, com um recorte do documento base de levantamentos.

Figura 116 - Recorte de estudo de levantamentos quantitativos

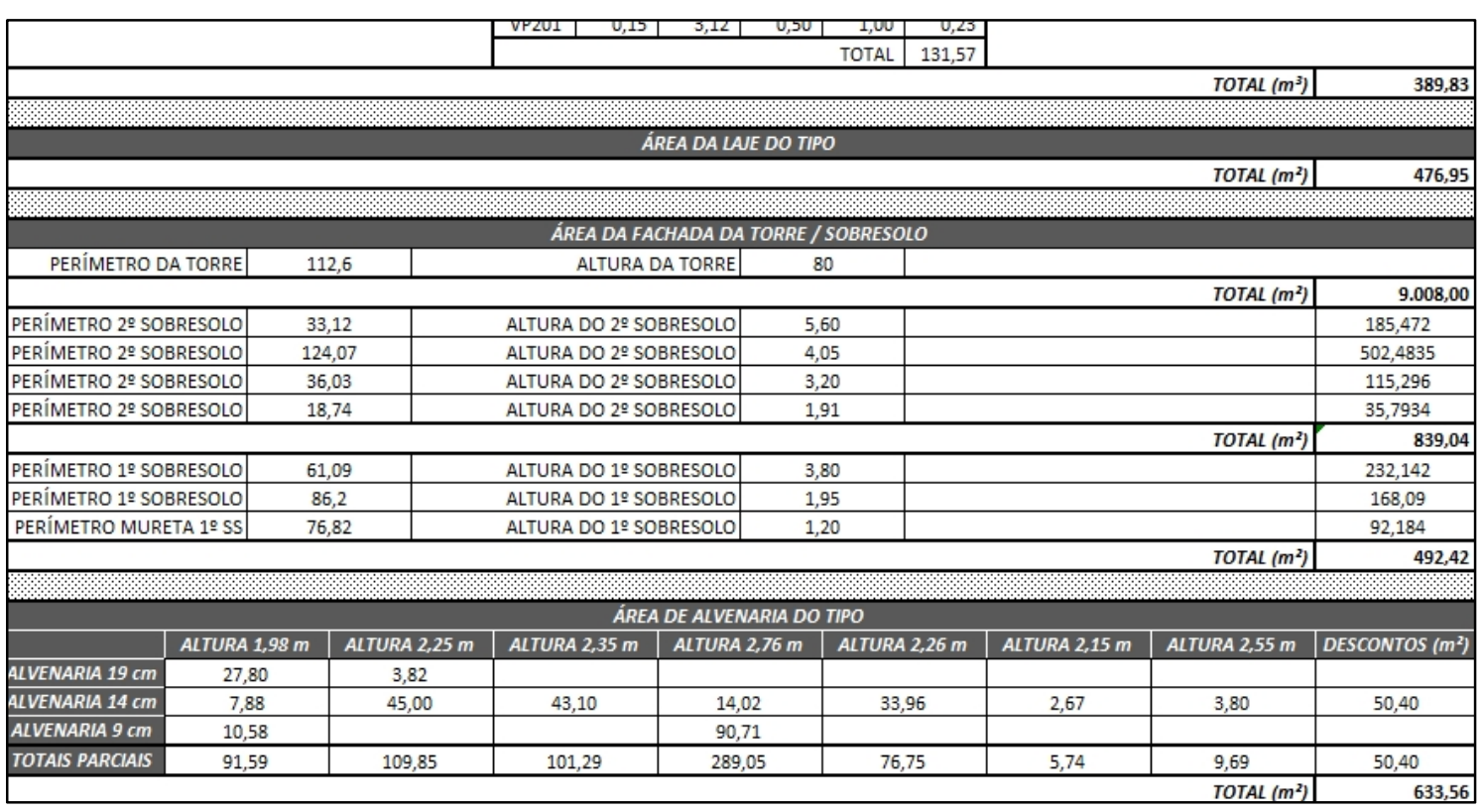

Fonte: O Autor (retirado de registros de planejamento da Construtora M)

\section{Planejamento de suprimentos e contratações de serviços de forma conjunta}

Identificou-se nesta obra, analogamente ao que se verificou nos empreendimentos I e VI, que a empresa procura trabalhar com poucos subcontratados e unificando-se pacotes de contratação de serviços similares, prática alinhada à diretriz \#12 (contratações conjuntas). 
Os serviços de instalações, tanto elétricas, como hidráulicas, bem como intervenções preliminares na obra (como as atividades de drenagem, por exemplo) são executados por uma mesma empresa. O mesmo ocorre com a fachada (entrega de balancins, revestimento argamassado, cerâmico e até pintura externa no mesmo pacote).

Esta prática possibilita, de certa forma, transparência e maior incentivo dos contratados, fatores que inicialmente estariam aderentes às diretrizes \#10 (sistemas para aumento de produtividade) e \#11 (ambiente de trabalho organizado), pois estas contratações conjuntas são negociadas de forma antecipada para todos os serviços. Assim, o fornecedor já sabe quando deverá mobilizar a equipe pré-definida.

Esta condição garante também ao engenheiro da obra, a possibilidade de maior controle das atividades preliminares e de exigir que o líder do subcontratado participe das reuniões de planejamento da obra com antecedência, mesmo se ainda não estiver prevista sua mobilização em data próxima (alinhado também de forma parcial à diretriz \#8 - participação das equipes de produção).

Por fim, toda a sistemática de contratação é definida em um planejamento específico, que detalha as etapas desde o levantamento quantitativo prévio para a concorrência até a elaboração do contrato final e mobilização, atendendo à diretriz \#13 (planejamento de suprimentos). O modelo deste planejamento é muito similar ao já apresentado em obras anteriores, tais como os Empreendimentos I, II e VI.

\section{$>$ Formalização das programações de médio e custo prazo}

Analogamente ao que foi descrito para o empreendimento VI (embora em grande parte das obras isto também ocorre de forma ligeiramente diferente), esta obra também utiliza um cronograma detalhado em MS Project como ferramenta básica para as programações de médio e curto prazo, contendo as atividades por pavimento e filtrando-se apenas as atividades do trimestre com destaque para metas mensais (para a programação de médio prazo) ou apenas as atividades do mês com destaque para as metas semanais (para a programação de curto prazo)

A diferença está no fato de que não há um direcionamento das programações por equipe ou subempreiteiro, o que é realizado através de outras ferramentas de repasse, como listas de tarefas semanais e reuniões específicas com cada empresa. 
Estas listas estão trazem, de forma ainda inicial, aderência à diretriz \#1 (planejamento específico de equipes).

\section{Cronogramas para finalização do empreendimento}

Como descrito anteriormente, a obra apresentou relativo adiantamento dos serviços.

Para que fosse possível a desmobilização antecipada e se evitar uma concentração de serviços de ajustes permanentes no canteiro, os últimos meses antes da entrega final foram monitorados com a ajuda de cronogramas de entrega que permitissem esta possibilidade, como podem ser observados nas figuras 117 e 118.

Figura 117 - Cronograma de entrega da obra (parte ref. AVCB)

\begin{tabular}{|c|c|c|c|c|c|}
\hline \multirow{27}{*}{ 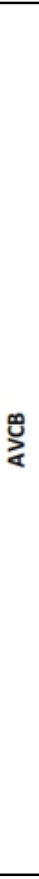 } & Atividade & Data limite & Data Real & Status & Responsável \\
\hline & Aprovação dos projetos junto ao CBESP & & $O K$ & & Obra \\
\hline & Corrimão da Caixa de Escadas & & $O K$ & $O K$ & Obra \\
\hline & Detectores de Fumaça & NA & & & \\
\hline & Sistema de Pressurização da Escadaria & NA & & & \\
\hline & lluminação de Emergência & nov-15 & nov-15 & & Obra \\
\hline & Hidrantes com Mangueiras & nov-15 & nov-15 & $O K$ & Obra \\
\hline & Stop Fire & nov-15 & nov-15 & & Obra \\
\hline & Extintores & nov-15 & nov-15 & & Obra \\
\hline & Sinalização de Emergência & out-15 & out-15 & $O K$ & Obra \\
\hline & Portas Corta-fogo & & $O K$ & $O K$ & Obra \\
\hline & Central de Interfone & out-15 & out-15 & $O K$ & Obra \\
\hline & \begin{tabular}{|l|} 
Gerador (start-up) \\
\end{tabular} & NA & & & \\
\hline & ART - Pressurização e Detecção de Fumaça & NA & & & \\
\hline & ART - Gerador & NA & & & \\
\hline & ART - Isolamento dos Pisos Prumada e Shafts & & $O K$ & $O K$ & Obra \\
\hline & ART - Instalação Hidráulica & & $O K$ & $O K$ & Obra \\
\hline & ART - Instalação Elétrica & & $O K$ & $O K$ & Obra \\
\hline & ART - Instalação de Sistemas & & $O K$ & $O K$ & Obra \\
\hline & ART - Sistema de Gás & & $O K$ & $O K$ & Obra \\
\hline & Laudo - Gerador (Abrangência) & NA & & & \\
\hline & Laudo - Pressurização da Escada & NA & & & \\
\hline & Laudo - Isolamento dos Pisos Prumada e Shafts & out-15 & out-15 & OK & Obra \\
\hline & Laudo - Isolamento da Sala do Gerador & NA & & & \\
\hline & Solicitação de Vistoria do CB & out-15 & out-15 & $O K$ & Escritório \\
\hline & Vistoria do CB & nov-15 & nov-15 & & Obra \\
\hline & Expedição do AVCB & dez-15 & dez-15 & & Obra \\
\hline
\end{tabular}

Fonte: O Autor (parte de arquivo disponibilizado pela Construtora M)

O cronograma de entrega da obra é amplo e traz para cada item que se monitora (alvarás, licenças e outros documentos de concessionárias) uma série de atividades condicionantes. Esta prática faz referência à diretriz \#18 (sistemas de alerta antecipado), a qual é também complementada com outras ferramentas de alerta relacionadas ao relatório gerencial mensal. No caso da figura, ilustrou-se uma das partes do cronograma, referente ao Auto de Vistoria do Corpo de Bombeiros (AVCB).

Já no caso do plano de vistorias, verifica-se um painel, compatibilizado de forma dinâmica com as negociações para entrega das unidades aos proprietários. 
Representa um sistema de priorização de liberações e consequente sequenciamento adequado à realidade do cliente, fatos alinhados de forma parcial às diretrizes \#19 (hierarquização de decisões) e \#21 (participação do cliente).

Figura 118 - Planejamento das vistorias de unidades

\begin{tabular}{|c|c|c|c|c|c|c|c|c|}
\hline PAV & \multicolumn{8}{|c|}{ Apartamentos Torre } \\
\hline $\mathbf{2 6}^{\circ}$ & $\begin{array}{c}261 \\
23 / 12 / 2015\end{array}$ & 262 & $\begin{array}{c}263 \\
23 / 12 / 2015 \\
\end{array}$ & $\begin{array}{c}264 \\
23 / 12 / 2015 \\
\end{array}$ & 265 & $\begin{array}{c}266 \\
23 / 12 / 2015\end{array}$ & $\begin{array}{c}267 \\
28 / 12 / 2015\end{array}$ & $\begin{array}{c}268 \\
23 / 12 / 2015\end{array}$ \\
\hline $\mathbf{2 5}^{\circ}$ & $\begin{array}{ll}251 \\
28 / 12 / 2015\end{array}$ & 252 & $\begin{array}{c}253 \\
28 / 12 / 2015\end{array}$ & 254 & $\begin{array}{c}255 \\
28 / 12 / 2015\end{array}$ & 256 & $\begin{array}{c}257 \\
28 / 12 / 2015\end{array}$ & $\begin{array}{c}258 \\
28 / 12 / 2015\end{array}$ \\
\hline $24^{\circ}$ & $\begin{array}{c}241 \\
30 / 11 / 2015\end{array}$ & 242 & 243 & $\begin{array}{c}244 \\
30 / 11 / 2015\end{array}$ & $\begin{array}{c}245 \\
30 / 11 / 2015\end{array}$ & $\begin{array}{c}246 \\
30 / 11 / 2015\end{array}$ & 247 & $\begin{array}{c}248 \\
30 / 11 / 2015\end{array}$ \\
\hline $\mathbf{2 3}^{\circ}$ & $\begin{array}{ll}231 \\
30 / 11 / 2015\end{array}$ & 232 & $\begin{array}{c}233 \\
30 / 11 / 2015\end{array}$ & $\begin{array}{c}234 \\
30 / 11 / 2015\end{array}$ & $\begin{array}{c}235 \\
01 / 12 / 2015\end{array}$ & $\begin{array}{c}236 \\
01 / 12 / 2015\end{array}$ & $\begin{array}{c}237 \\
28 / 12 / 2015\end{array}$ & $\begin{array}{c}238 \\
01 / 12 / 2015\end{array}$ \\
\hline $\mathbf{2 2}^{\circ}$ & $\begin{array}{c}221 \\
01 / 12 / 2015\end{array}$ & $\begin{array}{c}222 \\
01 / 12 / 2015 \\
\end{array}$ & $\begin{array}{c}223 \\
01 / 12 / 2015 \\
\end{array}$ & 224 & $\begin{array}{c}225 \\
01 / 12 / 2015\end{array}$ & $\begin{array}{c}226 \\
01 / 12 / 2015\end{array}$ & 227 & $\begin{array}{c}228 \\
02 / 12 / 2015 \\
\end{array}$ \\
\hline $21^{\circ}$ & $\begin{array}{c}211 \\
02 / 12 / 2015 \\
\end{array}$ & 212 & $\begin{array}{c}213 \\
02 / 12 / 2015 \\
\end{array}$ & $\overline{214}$ & $\begin{array}{c}215 \\
02 / 12 / 2015 \\
\end{array}$ & $\begin{array}{c}216 \\
02 / 12 / 2015\end{array}$ & $\begin{array}{c}217 \\
28 / 12 / 2015 \\
\end{array}$ & $\begin{array}{c}218 \\
02 / 12 / 2015 \\
\end{array}$ \\
\hline $20^{\circ}$ & 201 & $\begin{array}{c}202 \\
02 / 12 / 2015 \\
\end{array}$ & $\begin{array}{c}203 \\
02 / 12 / 2015 \\
\end{array}$ & $\begin{array}{c}204 \\
03 / 12 / 2015 \\
0\end{array}$ & $\begin{array}{c}205 \\
03 / 12 / 2015\end{array}$ & $\begin{array}{c}206 \\
03 / 12 / 2015\end{array}$ & $\begin{array}{c}207 \\
29 / 12 / 2015 \\
\end{array}$ & 208 \\
\hline $19^{\circ}$ & $\begin{array}{c}191 \\
03 / 12 / 2015\end{array}$ & 192 & $\begin{array}{c}193 \\
03 / 12 / 2015\end{array}$ & $\begin{array}{c}194 \\
03 / 12 / 2015\end{array}$ & $\begin{array}{c}195 \\
03 / 12 / 2015\end{array}$ & $\begin{array}{c}196 \\
03 / 12 / 2015\end{array}$ & $\begin{array}{c}197 \\
29 / 12 / 2015 \\
\end{array}$ & $\begin{array}{c}198 \\
04 / 12 / 2015\end{array}$ \\
\hline $18^{\circ}$ & $\begin{array}{c}181 \\
04 / 12 / 2015 \\
\end{array}$ & $\begin{array}{c}182 \\
04 / 12 / 2015 \\
\end{array}$ & $\begin{array}{c}183 \\
04 / 12 / 2015 \\
\end{array}$ & $\begin{array}{c}184 \\
04 / 12 / 2015 \\
\end{array}$ & $\begin{array}{c}185 \\
04 / 12 / 2015 \\
\end{array}$ & 186 & $\begin{array}{c}187 \\
29 / 12 / 2015 \\
\end{array}$ & $\begin{array}{c}188 \\
04 / 12 / 2015\end{array}$ \\
\hline $17^{\circ}$ & $\begin{array}{c}171 \\
04 / 12 / 2015\end{array}$ & $\begin{array}{c}172 \\
07 / 12 / 2015\end{array}$ & $\begin{array}{c}173 \\
07 / 12 / 2015\end{array}$ & $\begin{array}{c}174 \\
07 / 12 / 2015\end{array}$ & 175 & 176 & 177 & 178 \\
\hline $16^{\circ}$ & $\begin{array}{c}161 \\
07 / 2 / 2015\end{array}$ & $\begin{array}{c}162 \\
07 / 12 / 2015\end{array}$ & 163 & 164 & 0 & \multicolumn{3}{|c|}{ Vistorias Aceitas } \\
\hline $15^{\circ}$ & $\begin{array}{c}151 \\
08 / 12 / 2015\end{array}$ & $\begin{array}{c}152 \\
08 / 12 / 2015\end{array}$ & 153 & 154 & 0 & \multicolumn{3}{|c|}{ Revistoria } \\
\hline $14^{\circ}$ & 141 & 142 & 143 & 144 & 105 & \multicolumn{3}{|c|}{ Aguardando liberação } \\
\hline $13^{\circ}$ & 131 & 132 & 0,133 & $1 / 12 / 2015$ & 64 & \multicolumn{3}{|c|}{ Liberado para vistoria } \\
\hline $12^{\circ}$ & 121 & $\frac{10 / 12 / 2015}{122}$ & $\frac{10 / 12 / 2015}{123}$ & $\frac{10 / 12 / 2015}{124}$ & 39 & \multicolumn{3}{|c|}{ Incorporadora } \\
\hline $11^{\circ}$ & $\frac{10 / 12 / 2015}{111}$ & $\frac{11 / 12 / 2015}{112}$ & $\frac{11 / 12 / 2015}{1 / 113}$ & $\frac{11 / 12 / 2015}{114}$ & 208 & \multicolumn{3}{|c|}{ Total } \\
\hline 170 & $\frac{11 / 12 / 2015}{101}$ & $\frac{11 / 12 / 2015}{102}$ & $\frac{11 / 12 / 2015}{103}$ & 104 & \multicolumn{4}{|c|}{ Planilha atualizada em 03/12/2015 } \\
\hline
\end{tabular}

Fonte: O Autor (recorte de arquivo disponibilizado pela Construtora M)

\section{Cronogramas por tipologia de serviço}

Como descrito através de exemplos dos itens anteriores, verifica-se na obra o desenvolvimento de modelos de programação e controle aderentes à cada tipologia de serviço, fato aderente à diretriz \#24 (premissas por tipo de serviço).

Além dos itens relativos à entrega da obra, que diferem aos modelos padronizados para os serviços do tipo, outros cronogramas visuais são elaborados pela equipe da obra para o planejamento do térreo, o que tradicionalmente são complexos e geram risco à finalização global do empreendimento.

\section{$>$ Comentários gerais}

Algumas observações relativas ao que se verificou na obra:

- Evidenciadas, apenas no serviço de estrutura, durações evolutivas nos primeiros pavimentos (diretriz \#14 - curva de aprendizado, de forma parcial); 
- O cronograma de uso referencial não tinha folga, mas este fato não ocorreu por opção técnica ou prática alinhada à diretriz \#9 (metas realistas). O que levou a esta definição foi o fato do prazo contratual estar tão justo que não permitia a inclusão de folgas arbitrárias e nem buffers controlados;

- Foram discutidas com a equipe de planejamento algumas ações de análise de restrições, mas que não são realizadas de maneira formal;

- Verificou-se a participação do cliente final em reuniões de apresentação dos resultados da obra, mas a diretriz \#21 (participação do cliente) ficou longe de ser evidenciada. Nestas reuniões foi possível verificar que eram apresentados dados de referência com margens de segurança nos serviços parciais (para que os resultados reais previstos não fossem revelados de forma antecipada ao cliente até que todas as previsões se conformassem e assim gerar desgastes "desnecessários", pois não havia folga no cronograma contratual). Esta prática dificilmente alcança seus objetivos, mas essencialmente nesta obra, pelo fato dos desvios serem pequenos, mostrou-se bem sucedida.

\subsection{Compilação dos resultados da pesquisa aplicada}

\subsubsection{Análise de aderência das práticas ao objeto de pesquisa}

Como pode ser observado nas descrições das avaliações das obras, diversas ações, mesmo interessantes ou com objetivos positivos, acabam não apresentando resultados efetivos para se evitar problemas de planejamento ou ajudar nas ações de combate aos atrasos.

Conforme descrito no capítulo 2 e baseado nos conceitos de Hevner (2007), para que a pesquisa traga contribuição à base do conhecimento, durante a avaliação da construção de Artefatos e Processos na DSR, é importante que se busque a sinergia entre o ciclo da relevância e o ciclo do rigor.

Desta forma, para a proposição final da tese, levou-se em consideração a relevância de cada ação ou prática observada nos empreendimentos, classificando a aplicabilidade do conjunto de ações como evidência da respectiva diretriz ao qual se baseará a construção do método. 
Com objetivo de garantir o ciclo do rigor, caso as práticas fossem consideradas relevantes para a construção do método, estas foram classificadas como "Evidências Claras" e seriam utilizadas na composição do método de planejamento e gestão. Caso as práticas fossem consideradas irrelevantes, seja porque não atingiram o objetivo, seja por ainda não estarem efetivamente implantadas (e assim, rigorosamente não podem ser comprovadas), estas foram classificadas como "Ações Iniciais". Elas seriam estudadas de forma mais aprofundada para então, decidir se fariam parte da composição do método, de que forma e com quais restrições.

O resultado desta classificação é apresentado no quadro 15.

Quadro 15 - Resumo das avaliações das diretrizes orientativas nas obras

\begin{tabular}{|c|c|c|c|c|c|c|c|c|c|c|}
\hline \multirow[b]{2}{*}{$\mathbf{N}^{\circ}$} & \multirow{2}{*}{\multicolumn{2}{|c|}{ Descrição Genérica da Diretriz }} & \multicolumn{8}{|c|}{ Empreendimentos Pesquisados } \\
\hline & & & I & II & III & IV & V & VI & VII & VIII \\
\hline 1 & \multicolumn{2}{|c|}{ Definição clara de equipes, local e mobilização } & 1 & 1 & $E$ & 1 & $\mathrm{~N}$ & $E$ & 1 & $E$ \\
\hline 2 & \multicolumn{2}{|c|}{ Uso de premissas mensuráveis e monitoráveis } & I & $E$ & $E$ & $E$ & $\mathrm{~N}$ & $E$ & $\mathrm{~N}$ & $E$ \\
\hline 3 & \multicolumn{2}{|c|}{ Garantia de terminalidade de serviços } & 1 & $\mathrm{~N}$ & $E$ & $\mathrm{~N}$ & $E$ & $E$ & $\mathrm{~N}$ & $\mathrm{~N}$ \\
\hline 4 & \multicolumn{2}{|c|}{ Sistemas de produção puxada e que evitem disperdicios } & $\mathrm{N}$ & $\mathrm{N}$ & 1 & $\mathrm{~N}$ & $\mathrm{~N}$ & $\mathrm{~N}$ & $\mathrm{~N}$ & $\mathrm{~N}$ \\
\hline 5 & \multicolumn{2}{|c|}{ Gestão à vista (comunicação, transparência e sinalização) } & $E$ & 1 & $E$ & $\mathrm{~N}$ & $\mathrm{~N}$ & $\mathrm{~N}$ & $\mathrm{~N}$ & $\mathrm{~N}$ \\
\hline 6 & \multicolumn{2}{|r|}{ Foco em continuidade de serviços, cadência da obra } & 1 & $\mathrm{~N}$ & 1 & $\mathrm{~N}$ & $E$ & $E$ & $\mathrm{~N}$ & $E$ \\
\hline 7 & \multicolumn{2}{|c|}{ Planejamento formalizado } & E & $\mathrm{E}$ & $\mathrm{E}$ & $E$ & $E$ & $E$ & $\mathrm{E}$ & $\mathrm{E}$ \\
\hline 8 & \multicolumn{2}{|r|}{ Participação das equipes de produção na definição de metas } & $\mathrm{E}$ & 1 & $\mathrm{E}$ & $E$ & $\mathrm{~N}$ & $E$ & $\mathrm{E}$ & $E$ \\
\hline 9 & \multicolumn{2}{|r|}{ Definição de metas realistas (sem folgas arbitrárias) } & $\mathrm{E}$ & $\mathrm{E}$ & $E$ & $E$ & $\mathrm{~N}$ & 1 & $\mathrm{~N}$ & $E$ \\
\hline 10 & \multicolumn{2}{|c|}{ Métodos que melhorem a produtividade das equipes } & $\mathrm{E}$ & $\mathrm{N}$ & $E$ & $\mathrm{~N}$ & $\mathrm{E}$ & 1 & $\mathrm{E}$ & $\mathrm{N}$ \\
\hline 11 & \multicolumn{2}{|r|}{ Ambiente de trabalho organizado, sistema de incentivos } & $E$ & $\mathrm{~N}$ & 1 & $\mathrm{~N}$ & $E$ & $\mathrm{~N}$ & $E$ & $E$ \\
\hline 12 & \multicolumn{2}{|r|}{ Contratações conjuntas, transparência, qualificação fornecedores } & E & 1 & $\mathrm{E}$ & 1 & $\mathrm{~N}$ & 1 & $\mathrm{E}$ & 1 \\
\hline 13 & \multicolumn{2}{|r|}{ Planejamento de suprimentos (antecedências) } & $\mathrm{E}$ & $\mathrm{E}$ & $E$ & $E$ & $E$ & $\mathrm{E}$ & E & $\mathrm{E}$ \\
\hline 14 & \multicolumn{2}{|c|}{ Previsão de curvas de aprendizado } & E & 1 & $\mathrm{E}$ & 1 & 1 & $E$ & $\mathrm{~N}$ & $E$ \\
\hline 15 & \multicolumn{2}{|c|}{ Sistemas de controle da qualidade dos serviços } & 1 & $\mathrm{~N}$ & I & $E$ & $E$ & 1 & $E$ & $\mathrm{~N}$ \\
\hline 16 & \multicolumn{2}{|c|}{ Logística de canteiro com condições especiais } & $\mathrm{N}$ & $\mathrm{I}$ & $\mathrm{E}$ & $E$ & $\mathrm{E}$ & 1 & $\mathrm{E}$ & $E$ \\
\hline 17 & \multicolumn{2}{|c|}{ Análise de condições locais de abastecimento } & 1 & 1 & $E$ & $E$ & $E$ & 1 & $\mathrm{E}$ & $\mathrm{N}$ \\
\hline 18 & \multicolumn{2}{|c|}{ Sistemas de alertas antecipados } & E & 1 & 1 & $\mathrm{~N}$ & $\mathrm{~N}$ & $\mathrm{~N}$ & $\mathrm{E}$ & $\mathrm{N}$ \\
\hline 19 & \multicolumn{2}{|r|}{ Métodos de hierarquização de decisões (prioridades) } & $\mathrm{N}$ & $\mathrm{N}$ & 1 & 1 & 1 & $\mathrm{~N}$ & $\mathrm{E}$ & $\mathrm{N}$ \\
\hline 20 & \multicolumn{2}{|c|}{ Plano mestre mais detalhado (caminho crítico) } & E & 1 & $\mathrm{E}$ & 1 & $E$ & $E$ & $\mathrm{I}$ & $\mathrm{E}$ \\
\hline 21 & \multicolumn{2}{|r|}{ Envolvimento do cliente nos processos de planejamento e riscos } & $\mathrm{N}$ & $\mathrm{N}$ & $\mathrm{E}$ & I & $\mathrm{E}$ & $\mathrm{N}$ & $\mathrm{E}$ & I \\
\hline 22 & \multicolumn{2}{|c|}{ Métodos de gestão de escopo do projeto } & $\mathrm{N}$ & $\mathrm{N}$ & $\mathrm{E}$ & $E$ & $\mathrm{E}$ & $\mathrm{N}$ & $\mathrm{I}$ & $\mathrm{N}$ \\
\hline 23 & \multicolumn{2}{|c|}{ Sistemas de fiscalização independente } & I & 1 & $E$ & E & E & 1 & E & 1 \\
\hline 24 & \multicolumn{2}{|c|}{ Premissas por tipo de serviços } & E & $\mathrm{E}$ & $\mathrm{E}$ & $\mathrm{N}$ & $\mathrm{N}$ & $E$ & $\mathrm{~N}$ & $\mathrm{E}$ \\
\hline & \multicolumn{10}{|c|}{ Legenda } \\
\hline & \multicolumn{10}{|c|}{ E Evidenciadas práticas ou ações relevantes relacionadas à respectiva diretriz } \\
\hline & 1 & Ações iniciais ou previstas mas sem impacto ou comprovação c & tire & & & & & & & \\
\hline & $\mathrm{N}$ & Não há indicios de ações relacionadas à respectiva diretriz & & & & & & & & \\
\hline
\end{tabular}

Fonte: O Autor 
No quadro podem ser observadas as 2 classificações (Evidências Claras representadas pela letra "E" e Ações Iniciais por "A"), bem como diretrizes que não foram citadas ou observadas pela pesquisa de campo (representadas por "N").

\subsubsection{Práticas mais adotadas}

Como pode ser observado no quadro anterior, as diretrizes mais claramente adotadas pelos gestores destes empreendimentos relacionam-se com a formalização dos planejamentos (\#7 - formalização do planejamento), com o estabelecimento de ferramentas de planejamento específicas para o setor de suprimentos (\#13 planejamento de suprimentos) ou para serviços específicos (\#24 - premissas por tipo de serviço). Destacam-se ainda as diretrizes referentes ao monitoramento da obra, que indiquem as ações prioritárias e de forma antecipada, para a correção ágil do problema ou restrição para a execução do que foi planejado (\#18 - sistemas de alerta antecipado e \#19 - hierarquização de decisões).

Realmente, em todas as obras acompanhadas (100\%), verifica-se a importância de se estabelecer referências formais de planejamento, desde o planejamento de longo prazo até as programações de curto prazo, mesmo que estas últimas sejam realizadas de forma muito simples, como observado nos Empreendimentos II e VIII.

No caso do planejamento de longo prazo, uma formalização ou cronograma normalmente são exigidos por força de contrato. Mas este tipo de cronograma, muitas vezes é elaborado de forma muito abrangente, conservadora e sem elementos que garantam sua viabilidade operacional. Propositadamente ele deixa margens para ajustes ao longo da execução da obra, para que a construtora não seja punida no caso de não atendimento. Esta foi uma das razões pelas quais a diretriz foi proposta, já que em muitos projetos analisados na primeira pesquisa de campo, esta era uma causa recorrente dos problemas de não atendimento dos prazos.

$\mathrm{Na}$ análise realizada nesta pesquisa, o que se entendeu como necessário para se evidenciar a diretriz \#7 (formalização do planejamento) foi um planejamento operacional, de uso interno da equipe da obra (ou das áreas de apoio à obra), pois este sim está correlacionado às programações mensais, semanais, diárias, sendo 
revisado periodicamente, conforme andamento dos serviços. Trata-se de um referencial técnico (linha de base) onde todos devem estar comprometidos a cumprir.

Outra prática verificada em quase a totalidade de obras acompanhadas (apenas no Empreendimento VII não se verificou práticas similares alinhadas a diretriz \#13 planejamento de suprimentos) foi o estabelecimento de ferramentas específicas que garantissem um bom processo de suprimentos, com o detalhamento de etapas internas, datas, setores responsáveis e com variações em relação aos materiais, serviços ou equipamentos que eram considerados importantes para cada empresa. Alguns sistemas eram muito detalhados como no empreendimento IV, outros traziam apenas um cronograma dos serviços considerados críticos, como no empreendimento V. Independente disto, entende-se que é uma prática já consolidada no mercado, imprescindível para a garantia de eliminação de restrições de entrega e mobilização de recursos, e que será claramente inclusa no método. Talvez a contribuição maior desta pesquisa seja em se destacar possíveis detalhes para a elaboração deste cronograma que auxiliem ainda o processo de implantação desta ferramenta gerencial.

Analogamente ao processo de planejamento de suprimentos destacado acima, verificou-se que em quase a totalidade das obras pesquisadas (apenas no Empreendimento $\mathrm{V}$ isto não ocorreu) há diversas práticas que apoiam a equipe de planejamento em suas atividades cotidianas que estão alinhadas à diretriz \#24 (premissas por tipo de serviço). De acordo com este direcionamento, as obras realizam estudos mais específicos dos serviços (sempre os mais críticos) conforme projeto e condições de execução ou mobilização dos contratados. Estas práticas englobam a composição detalhada do que está inserido no pacote ou escopo a ser entregue, do uso do micro planejamento para detalhar operações mais complexas (ou que a equipe não tem experiência) e a utilização de ferramentas que trazem as especificidades como uma premissa obrigatória de geração do plano, como o uso de múltiplos calendários ou cronogramas de entrega.

Verificou-se ainda que duas diretrizes, embora distintas, ocorreram nas obras de forma correlacionada (\#18 - sistemas de alerta antecipado e \#19 - hierarquização de decisões). Em todos os empreendimentos foi possível a identificação de práticas alinhadas a estas diretrizes (em algumas poucas obras de forma parcial), que 
buscavam identificar, registrar, alertar e priorizar ações quando previsto o não cumprimento de algum serviço.

Neste aspecto, a pesquisa trouxe vários exemplos diferentes de ferramentas, e que desta forma evidenciam a sugestão desta tese no estabelecimento das diretrizes, muito mais do que ferramentas específicas, para o sucesso dos projetos do ponto de vista de prazos. Foram verificados painéis gerenciais, indicadores numéricos ou visuais, processos analíticos e descritivos, ou seja, modelos que demonstram a preocupação dos bons gestores em entender rapidamente o que está restringido a programação e agir nos fatores chaves destas restrições.

Outras seis diretrizes obtiveram destaque (\#1 - planejamento de equipes, \#2 premissas mensuráveis, \#8 - participação das equipes de produção, \#9 - metas realistas, \#11- ambiente de trabalho organizado e \#20 - plano mestre detalhado), e que foram identificadas de alguma forma, em mais da metade dos empreendimentos.

Todas elas relacionam-se, de certa forma, a estudos mais profundados dos ciclos das atividades, maior detalhamento do planejamento e o uso de dados de engenharia para a tomada de decisão em relação ao que será executado. Se estas práticas, ainda estiverem dentro de condições favoráveis de organização, bom ambiente de trabalho que incentivem o comprometimento das equipes com as programações, mais efetivas serão estas práticas.

Este tipo de enfoque traz uma diferenciação grande em relação a muitas obras onde se verifica a programação dos serviços baseada em sentimentos, experiência do planejador ou do engenheiro da obra, e pouco baseado em números, levantamentos mais precisos e estruturação de cenários.

Definir de forma clara e precisa as premissas de planejamento e realizar seu acompanhamento é talvez uma prática que a princípio pode parecer muito lógica e inteligente, mas sua efetiva aplicação dos canteiros é rara.

Observaram-se ganhos importantes para a condução das ações de readequação da produção nos empreendimentos que efetivamente mediram índices ligados às produtividades. Este monitoramento de premissas será abordado no método que a ser estruturado. 
Dentro destas mesmas diretrizes que se destacaram, o estudo da logística de abastecimento também mostrou-se importante na eliminação das restrições que impediam a execução das programações de obra. Independente do porte, esta prática é primordial para se caracterizar um bom planejamento.

Neste aspecto, uma consideração importante: o estudo desta logística não é simplesmente a elaboração de um projeto de canteiro. Foi verificado em algumas obras que o projeto pode auxiliar em uma orientação inicial e para dar uma primeira visão do canteiro, contribuindo sim favoravelmente ao planejamento. Todavia, como o processo de obra é muito dinâmico, a logística precisa ser adequada às fases ou prever as situações onde o pico de funcionários, entrega, estoque, transporte e acessos sejam adequadamente tratados. Isto pode ser feito com estudos de demanda, áreas, sinalizações e programações detalhadas, até então não contempladas em um projeto de canteiro.

\subsubsection{Práticas menos observadas}

Como destaque da pesquisa, observa-se que para algumas diretrizes especificadas, não foram implantadas práticas esperadas pela análise conceitual anterior.

Isto não quer dizer que tais orientações de conduta não sejam apropriadas e válidas para o método. Nem ao menos significa que não existam práticas sendo adotadas conforme estas diretrizes, uma vez que a amostragem utilizada é pequena nesta segunda pesquisa.

No entanto, pelo mesmo princípio de relevância e rigor descritos no Capitulo 2, estas práticas devem ser tratadas de forma diferenciada na estruturação do método, garantindo as premissas do DSR.

Uma das diretrizes onde este fato foi observado, por exemplo, relaciona-se com a implantação de sistemas de planejamento puxado e redução de desperdício (\#4 produção puxada), bem como a questão da garantia do término da atividade (\#3 terminalidade). Apesar de não observados exemplos claros desta diretriz nas obras visitadas, há uma extensa literatura sobre o assunto, com cases positivos e demonstrações de ganhos importantes na gestão de prazos. Logicamente foram muito relevantes na análise deste autor. 
Desta forma, a estruturação do método com tais elementos deve ser mais cautelosa e justificada, garantindo a aderência com os demais elementos respaldados pelos fatos concretos observados nesta pesquisa.

\subsection{Conclusões desta etapa da pesquisa}

Com base em todas as informações levantadas, entende-se que o objetivo desta segunda pesquisa de campo foi atingido.

Apesar de algumas limitações já destacadas, pôde-se verificar práticas e ferramentas descritas na bibliografia e ainda aderentes à grande parte das diretrizes propostas como orientativas para a estruturação do método.

A pesquisa trouxe uma base sólida de elementos que sustentarão as proposições finais da tese, seja para validação das premissas iniciais propostas, seja para adequação dos pontos que não ficaram claramente comprovados ou que devam ser tratados de maneira singular.

Outra contribuição para o estudo aprofundado dos empreendimentos foi a identificação também de algumas práticas que não agregaram valor ao planejamento físico da obra. Mesmo com o sucesso do projeto (fato que o levou a ser escolhido para a composição da amostra), verificam-se elementos que podem ser usados como contraexemplos às diretrizes propostas, seja porque ferem o objetivo proposto, seja, porque a ação não foi implantada de forma efetiva e não gerou os resultados pretendidos. 


\section{CONSOLIDAÇÃO DO MÉTODO E SUA VALIDAÇÃO}

\subsection{Consolidação dos resultados e estruturação do método}

Após a análise de todos os dados relativos à última pesquisa, verificou-se uma série de correlações entre as diversas práticas implantadas nas obras estudadas.

Além disso, muitas destas práticas também foram balizadas em modelos teóricos ou conceitos que foram discutidos na revisão bibliográfica.

Estas considerações impactaram de forma determinante nas conclusões de aplicabilidade das ações, bem como a estruturação das mesmas pelas 24 diretrizes referenciadas para análise na pesquisa de campo.

Observa-se que muitas das diretrizes são aplicáveis em diversos momentos da execução do planejamento da obra. Além disso, muitas delas são correlacionadas a uma mesma prática.

Desta forma, entendeu-se que a melhor forma de apresentação do método deveria ocorrer através da evolução do processo de planejamento, representado por etapas, e correlacionadas com as melhores práticas para aquele determinado momento.

Inicialmente, adotou-se um agrupamento com 3 grandes etapas:

- Práticas para a etapa preliminar ao início das atividades no canteiro, que estariam ligadas ao planejamento estratégico-tático do projeto (denominou-se de "planejamento preliminar ou estratégico");

- Práticas no início das atividades operacionais (denominou-se de "planejamento operacional"); e

- Prática relacionadas às rotinas de curto prazo da obra (denominou-se de "controle e reprogramação").

Neste momento, não foi objetivo do autor uma análise crítica muito pormenorizada da nomenclatura escolhida, uma vez que tanto estas estruturações, como suas denominações, seriam analisadas e validadas pelo grupo focal (conforme previsto na sequência do plano de pesquisa da tese). 
Estabeleceu-se também que cada grupo (etapa) seria composto por 4 grandes fases de planejamento, as quais apresentam de forma correlata 2 ou mais práticas julgadas como necessárias para se evitar problemas recorrentes de planejamento e que geram atrasos dos projetos.

Nesta proposta, não há modelos ou ferramentas específicas, uma vez que se entende que aquelas apresentadas nas diversas pesquisas estudas são suficientes. $O$ uso incorreto das mesmas é que podem gerar condições para a ocorrência dos problemas.

$\mathrm{Na}$ primeira fase (planejamento preliminar ou estratégico), o método foca no estabelecimento de condições exequíveis dos projetos, com cenários realistas e de como todas as premissas que compõe este cenário devem ser formalizadas e validadas, evitando-se estimativas sem bases técnicas confiáveis.

Na segunda fase (planejamento operacional), o método foca no estabelecimento dos detalhes de como o cenário será efetivamente executado, na definição das referências e dos critérios de controle que garantirão as correções de rota ao longo da evolução do projeto.

Por fim, na última fase (controle e reprogramação), o método foca no estabelecimento de sistemas de análise de restrições, registros dos problemas e orientação para soluções, retomando possíveis desvios do projeto. Esta fase é muito dinâmica e fatalmente afeta a fase anterior, que inicialmente não deveria ser revisada. Caso os desvios impactem os prazos finais, o cenário configura-se diferente do previsto, e deverá ser redesenhado, conforme práticas já anteriormente citadas no método.

O método foi descrito em detalhes e compôs parte do material que seria validado pelo grupo focal, como descrito no item a seguir.

\subsection{Planejamento do Grupo Focal}

Conforme descrito no item 2.5.5 desta pesquisa, a atividade do grupo focal foi desenvolvida através da realização de uma reunião de trabalho e discussão em um grupo seleto, que neste momento, sem uma preocupação conceitual do termo, chamou-se de workshop. Normalmente o termo workshop é utilizado para a realização 
de uma atividade com um grupo maior de pessoas, mas para o propósito do grupo focal esta quantidade foi julgada mais adequada.

Para a realização deste workshop, foram convidados profissionais do mercado que são responsáveis pelo planejamento de obras em suas empresas. Tais indivíduos são aqueles que efetivamente executam, monitoram e atuam na gestão dos prazos dos projetos de construção e assim controlam os atrasos que seus empreendimentos apresentam. Estes profissionais são aqueles que usualmente utilizam (ou não) as ferramentas descritas nesta pesquisa e têm condições de avaliar as práticas utilizadas em cada projeto que participaram.

Buscando-se atender às orientações de McDonagh-Philp e Bruseberg (2000) e Tremblay et al.(2010), estruturou-se um roteiro a ser aplicado no workshop, com as seguintes definições ou informações:

- Objetivos da sessão: contextualizar o problema de atrasos de obra, solicitar contribuições (livres) em relação às possíveis causas de atraso, sugestões para combatê-las (comparando-se com os dados já coletados até aquele momento na pesquisa), e principalmente, que os participantes criticassem o método de planejamento e gestão de prazos proposto pelo autor;

- Tópicos a serem abordados na atividade: (i) causas de atraso mais significativas na visão dos participantes; (ii) práticas para se evitar os atrasos; (iii) críticas em relação à metodologia de pesquisa adotada; (iv) itens considerados importantes em relação ao tema e que não foram abordados na pesquisa; e finalmente $(v)$ as críticas em relação ao método proposto (estrutura, conteúdo, nomenclatura, aplicação prática e restrições);

- Fluxo ou dinâmica das discussões: (i) exercício livre individual de cerca de 15 minutos para a identificação das principais causas de atraso vividas pelo participante; (ii) novo exercício livre durante 20 minutos, para a descrição de sugestões de práticas para combater das causas apontadas no exercício anterior; (iii) apresentação da pesquisa durante cerca de 25 minutos (objetivos, resultados das diversas etapas e destaque para o método proposto até aquele momento); (iv) 15 minutos de discussão em grupos mais restritos (de 3 pessoas) sobre as diretrizes ou práticas que são comumente utilizadas pelos profissionais em seus projetos; (v) mantendo-se nos mesmos grupos, mais 20 
minutos de discussão sobre o que cada um entendeu sobre o método e preparação de tópicos com dúvidas ou observações a serem discutidas em plenário; e (vi) a principal discussão entre todos os presentes, com cerca de 1 hora de duração, sobre os pontos abordados nos grupos, questionamentos ao autor, críticas à pesquisa e sugestões de melhoria do método;

- Recursos visuais e estímulos externos utilizados: sala de apoio e equipamento de apresentação (projetor, computador e software MS Power Point), mesas e cadeiras livres para agrupamento em forma de plenário ou discussão em grupos, roteiro do moderador (o autor), lista de perguntas e orientações, material de escritório para uso nos grupos (papel, canetas, dentre outros).

Seguindo-se os passos descritos na figura 5 desta pesquisa, após toda a preparação do evento, buscou-se o recrutamento dos participantes. O perfil daqueles profissionais que estiveram presentes no workshop pode ser observado no quadro 16.

Quadro 16 - Perfil dos participantes do grupo focal

\begin{tabular}{|c|c|c|c|}
\hline $\begin{array}{c}\text { Formação / } \\
\text { Especialização }\end{array}$ & Idade & $\begin{array}{l}\text { Tipos de empresa em que o } \\
\text { profissional trabalhou }\end{array}$ & $\begin{array}{c}\text { Experiência em } \\
\text { planejamento }\end{array}$ \\
\hline $\begin{array}{l}\text { Administrador / } \\
\text { Gerenciamento de Projetos } \\
\text { (PMP) }\end{array}$ & 34 & $\begin{array}{l}\text { - Empresa especializada em } \\
\text { planejamento (consultoria) } \\
\text { - Construtora de médio porte }\end{array}$ & 16 anos \\
\hline $\begin{array}{l}\text { Técnico de Edificações e } \\
\text { Engenheiro Civil }\end{array}$ & 32 & $\begin{array}{l}\text { - Construtora de grande porte } \\
\text { - Construtora de médio porte }\end{array}$ & 8 anos \\
\hline Engenheiro Civil & 40 & $\begin{array}{l}\text { - Gerenciadora e prestadora de serviços } \\
\text { - Empresa especializada em } \\
\text { planejamento (consultoria) }\end{array}$ & 8 anos \\
\hline $\begin{array}{l}\text { Engenheiro Civil / } \\
\text { Gerenciamento de Projetos }\end{array}$ & 34 & $\begin{array}{l}\text { - Indústria (fornecedor-grande porte) } \\
\text { - Construtora de grande porte }\end{array}$ & 13 anos \\
\hline Engenheiro Civil / Mestrado & 37 & $\begin{array}{l}\text { - Empresa especializada em gestão e } \\
\text { planejamento (consultoria) } \\
\text { - Construtora de médio porte }\end{array}$ & 4 anos \\
\hline $\begin{array}{l}\text { Engenheiro Civil / } \\
\text { Especialista Eng. Produção }\end{array}$ & 36 & $\begin{array}{l}\text { - Construtora de grande porte } \\
\text { - Incorporadora de médio porte }\end{array}$ & 7 anos \\
\hline Engenheiro Civil & 31 & - Construtora de grande porte & 5 anos \\
\hline
\end{tabular}




\subsection{Resultados do Grupo Focal}

Realizado o workshop, alguns resultados podem ser destacados, com base nos tópicos abordados.

\subsubsection{Identificação de causas dos atrasos}

Este primeiro tópico abordado no evento mostrou relativa aderência aos resultados da primeira pesquisa de campo (apresentados no capítulo 4). Algumas conclusões neste aspecto foram interessantes.

Neste grupo restrito, verificou-se que as causas apontadas pelos participantes após uma breve reflexão livre (sem direcionamento do moderador) foram muito abrangentes, mostrando que há grandes singularidades nos problemas de cada empresa ou profissional em seu ambiente de trabalho. Isto porque apenas neste pequeno grupo, foram listados 31 tipos diferentes de causas.

Buscar uma convergência daquelas que são as mais frequentes não foi difícil e conforme pode ser verificado na tabela 4 , a causa identificada como mais frequente (e determinante para o atraso das obras) relaciona-se aos constantes retrabalhos dos serviços no canteiro e que geram implicações nas sequências das atividades, principalmente postergação de início.

De uma certa forma, as causas mais votadas pelos participantes tiveram ordenação um pouco diferentes do ranking apresentado no capítulo 4 (ver tabela 3 ), embora as 10 causas mais frequentes sejam muito similares.

Tabela 4 - Resultados do workshop sobre as principais causas de atraso

\begin{tabular}{ll}
\hline \multicolumn{1}{c}{ Descrição da causa do atraso } & $\begin{array}{c}\text { Identificação como } \\
\text { causa determinante }\end{array}$ \\
\hline - Retrabalho devido a erros durante a construção & 5 de 7 participantes \\
- Demora na tomada de decisões internas (na produção) & 4 de 7 participantes \\
- Duração do contrato da obra irrealista (muito curta) & 4 de 7 participantes \\
- Demora na tomada de decisão pelo Empreendedor & 4 de 7 participantes \\
\hline
\end{tabular}




\subsubsection{Sugestões para tratamento das causas identificadas}

Este segundo tópico trouxe poucas contribuições dos participantes, após uma nova reflexão individual livre.

Pela forma como o tema foi abordado (explicações do moderador) ou pelas limitações de entendimento dos propósitos do trabalho naquele momento (uma vez que ainda tratava-se de uma atividade prévia, sem a apresentação da pesquisa pelo autor), percebeu-se que as sugestões foram muito superficiais. A maior parte delas foram muito mais comentários ou reafirmações do problema, do que efetivamente uma análise de como tratar a causa do problema.

Quando algumas das práticas ou recomendações sugeridas eram alinhadas com o efetivo tratamento da causa, estas já estavam contempladas na gama de sugestões estudadas pelo autor.

No entanto, exatamente por esta razão, pode-se então validar grande parte das diretrizes teóricas propostas pela pesquisa, como alinhadas ao entendimento dos profissionais de planejamento quanto à sua pertinência e/ou eficácia.

Um dos pontos mais destacados pelos participantes relaciona-se a falta de envolvimento da equipe de planejamento na definição dos prazos contratuais ou mesmo da participação nas discussões do estudo de viabilidade do projeto.

A diretriz proposta nesta pesquisa para este problema relacionava-se ao uso de prazos realistas e no desenvolvimento do um plano mestre mais detalhado ao menos nos caminhos críticos da obra. Assim, de forma indireta a prática estava dentro da diretriz, embora não de forma tão explícita como apresentada pelos participantes.

As outras diretrizes ou práticas propostas estavam mais alinhadas ao que pregava a pesquisa. Podem-se citar algumas destas sugestões:

- Estreitamento de relação com fornecedores, com a criação de prestadores mais fixos, garantindo transparência das negociações, parceria "ganha-ganha" e que permitam maior previsibilidade de atendimento;

- Ações que assegurem a terminalidade dos serviços, como liberações de frentes após avaliação e aceite do serviço, e sistemas de gestão de qualidade; 
- Estudo prévio do canteiro e plano logístico contemplando várias fases da obra;

- Uso de linhas de balanço para verificar incompatibilidades de progresso de serviços e definição de ritmo constante para a obra, ao menos nas atividades da torre.

Por fim, alguns pontos para melhoria foram citados mais de uma vez, porém sem configurar efetivamente uma diretriz que possa ser inclusa como método, como por exemplo, "investimento em compatibilização de projetos" ou a "contratação de profissionais com experiência". Estes itens são recomendações que não podem ser descartadas, mais estão ligadas à estratégia de atuação da empresa.

Se verificado, por exemplo, que a causa dos atrasos é a inexperiência dos profissionais, então o método deveria buscar mecanismos de auxiliassem os profissionais menos experientes em suas limitações, mas não descartá-los.

\subsubsection{Validação de diretrizes para a definição das práticas que evitem atrasos}

Este terceiro tópico buscou a contribuição dos participantes para se identificar, dentre as diretrizes propostas no capítulo 5 , aquelas consideradas mais importantes para o sucesso dos projetos em que os profissionais participaram.

O resultado foi comparado com os dados coletados na pesquisa descrita no capítulo 6 , gerando então duas referências importantes para a validação das práticas que serão inclusas no método, objetivo central desta pesquisa.

A identificação de quais foram as diretrizes mais citadas pelos participantes, após a atividade de discussão em grupo (com roteiro orientativo e lista com referências de diretrizes propostas) está apresentada na tabela 5.

Como pode ser observado, algumas das diretrizes mais citadas não foram as mesmas observadas nas obras da segunda pesquisa de campo. Isto demonstra que os resultados do grupo focal podem ser complementares e não apenas confirmatórios.

Diretrizes como a "formalização do planejamento" (\#7), o "plano de suprimentos" (\#13) e o "plano metre detalhado" (\#20) aparecem em ambos os resultados, garantindo assim a confirmação como determinantes e inclusão das mesmas no método. 
Tabela 5 - Resultados da identificação das diretrizes pelos participantes

\begin{tabular}{lc}
\hline $\begin{array}{c}\text { Descrição da diretrizes proposta inicialmente para se } \\
\text { evitar a ocorrência de atrasos }\end{array}$ & $\begin{array}{c}\text { Identificação como } \\
\text { diretriz determinante }\end{array}$ \\
\hline - Previsão de curvas de aprendizado (\#14) & 7 de 7 participantes \\
- Plano mestre detalhado, ao menos no caminho crítico (\#20) & 7 de 7 participantes \\
- Planejamento de suprimentos, antecipação de contratos (\#13) & 6 de 7 participantes \\
- Processos que assegurem a terminalidade de serviços (\#3) & 5 de 7 participantes \\
- Formalização dos planejamentos, conforme cada nível (\#7) & 5 de 7 participantes \\
- Participação das equipes de produção nas metas (\#8) & 5 de 7 participantes \\
\hline
\end{tabular}

Fonte: O Autor

Diretrizes como "hierarquização de decisões" (\#19) e "premissas específicas por serviço" (\#24), por sua vez, mesmo frequente nas obras pesquisadas, não foram citadas por nenhum participante. Assim, sua inclusão no método deverá ser avaliada antes da efetivação.

Também vinculadas às diretrizes elencadas como mais importantes, foi solicitado ao grupo descrever as práticas ou ferramentas que as exemplificassem nos projetos que já tivessem participado.

Analogamente ao item 7.3.2 anterior, não se verificou quantidade significativa de exemplos práticos mensuráveis ilustrativos, e que pudessem ser comparados ao que foi descrito no capítulo 6 . Aqueles mais relevantes são listados a seguir:

- Estabelecimento de banco de dados de premissas mensuráveis mais importantes ou referenciais (padrão interno da empresa);

- Auditorias recorrentes de qualidade do serviço visando garantia de terminalidade;

- Formalização de parcerias em suprimentos;

- Compatibilização de projetos e também do cronograma de desenvolvimento dos mesmos com o cronograma físico real e atualizado na obra. 


\subsubsection{Análise crítica ao método proposto}

Finalizando as atividades do workshop, este último tópico caracterizou-se como o mais importante dentro desta etapa da metodologia de pesquisa, contribuindo para o refinamento do artefato desenvolvido até aquele momento.

Após a discussão plenária de todo o grupo, troca de experiências e esclarecimentos do autor sobre o método que se pretende estruturar, buscou-se compilar as contribuições dos participantes, que verdadeiramente criticaram construtivamente o artefato.

Um dos pontos abordados com ênfase relaciona-se ao momento de decisões estratégicas de um projeto, onde há pouco envolvimento da equipe técnica da construtora. As decisões tomadas na fase de análise de viabilidade impactam em todo o posterior desenvolvimento do planejamento operacional. Muito frequentemente as referências utilizadas para aceitação de um projeto e comprometimento com o prazo contratual assumido são incoerentes com a realidade da construtora e das equipes internas. Os prazos são definidos referenciando-se apenas projetos similares, muitas vezes não sendo consideradas situações específicas sobre peculiaridades do local, terreno, necessidades do cliente (contratante), condições atuais dos fornecedores e diversos outros pontos que usualmente são de domínio da equipe técnica ou dos profissionais de planejamento da empresa.

Outro ponto de destaque apontado pelo grupo focal refere-se às questões de fluxo de caixa do empreendimento. Muitas vezes as ações planejadas não são cumpridas por insuficiência de recursos, e o método proposto não contempla de forma mais detalhada práticas específicas relacionadas a este problema usual em obra.

Ambos os pontos discutidos têm sua justificativa, embora especificamente para o objetivo desta tese, representam uma contribuição pouco efetiva. Como o foco do trabalho é estudar o planejamento da produção, parte das atividades relacionadas ao estudo de viabilidade e outras decisões estratégicas do negócio da construtora não são abordadas de forma detalhada, apenas citadas como fontes de impacto.

De fato, caso estas características fossem destacadas no momento da análise dos riscos em se assumir os prazos contratuais, a taxa de assertividade seria maior. 
Algumas críticas interessantes ao método não se sustentaram na discussão plenária, mas serviram de base para melhor descrever a apresentação da proposição e/ou destaque de suas limitações.

Uma delas, por exemplo, refere-se à manutenção de folgas no planejamento estratégico. Percebe-se que ao defender esta posição, um dos participantes pretendia preservar ações de proteção às falhas de planejamento e responsabilização dos problemas ao gestor da obra. No entanto, como destacado na revisão bibliográfica e no item 5.2.9 deste trabalho, estas folgas são usualmente consumidas sem o devido cuidado e trazem consequências muito ruins à gestão do projeto.

Estas e outras sugestões foram então descartadas, embora direcionaram discussões importantes para a defesa dos princípios do método, demandando embasamento teórico adequado, típico de uma tese de doutorado como esta.

Outro ponto discutido do workshop trouxe uma pequena alteração da descrição do método. Muito se destacou na estruturação das práticas de mitigação de atrasos, a necessidade de se buscar ferramentas que assegurassem a terminalidade dos serviços. Dentre estas ações destacam-se a medição dos serviços somente após a aceitação dos serviços. Esta seria feita com a garantia do atendimento de todos os critérios de recebimento e não apenas após o serviço efetivamente acabado (pois apesar de concluído, talvez ainda não atenda critérios específicos e seja necessário o retrabalho)

O mesmo ocorreu quando parte dos profissionais destacou as condições do mercado como forma de se justificar parte dos problemas de planejamento existentes em seus empreendimentos. Destacou-se que a pesquisa pouco referenciava estas justificativas ou ações específicas ligadas ao momento de mercado, seja aquecido, seja em crise.

Como relacionado ao logo do trabalho, as causas dos atrasos podem ser afetadas com as condições de mercado, mas não as ferramentas, práticas ou mesmo o método como um todo. Descreve-se um exemplo prático: se numa crise há uma reestruturação das equipes de projeto, com "enxugamento" da máquina produtiva e diminuição da estrutura organizacional e hierarquia na empresa, talvez a comunicação até melhore, pela facilidade de contato entre os integrantes do projeto. Nestes casos, as decisões podem ocorrer de forma mais rápida, a entrega dos materiais tenha menos atrasos ou 
a equipe responsável pela obra seja melhor qualificada do que quando a empresa era mais hierarquizada. Embora esta condição seja teoricamente favorável à gestão do projeto, as diretrizes propostas continuam as mesmas, como em relação ao ritmo constante das atividades, aos planos formais, aos controles que devem ser executados. Este aspecto é garantido exatamente pelo fato do método não detalhar funções específicas, responsabilidades e frequências de controle.

Outro ponto conceitual levantado e que foi aceito pelo autor, refere-se à nomenclatura de uma das etapas do método. Apesar de simples, esta constatação foi importante para que os futuros usuários do método pudessem entender melhor as razões pelas quais tais práticas foram agrupadas nestes grandes grupos.

Segundo parte dos participantes, a primeira etapa já traz elementos que impactam o planejamento operacional. $\mathrm{E}$ as práticas relacionadas têm menos enfoque estratégico do que estimativas mais alinhadas aos estudos de viabilidade, ou atividades mais características do plano estratégico da obra.

Assim, mesmo mantendo-se praticamente a mesma configuração, esta primeira etapa foi reescrita apenas com o título "Planejamento Preliminar", deixando em aberto se as ações estão focadas no planejamento estratégico ou apenas em um momento anterior do planejamento operacional clássico. 


\section{PROPOSIÇÃO FINAL DO MÉTODO}

Com tudo o que foi discutido até a etapa de validação, e considerando as críticas e sugestões de refinamento do artefato desenvolvido, este capítulo apresenta de forma detalhada o método de planejamento e gestão proposto pelo autor.

A descrição final do método manteve os quatro grandes grupos de atividades, representadas por etapas, e fases ordenadas que as compõem, conforme pode ser esquematicamente apresentado na figura 119.

Figura 119 - Resumo esquemático do método proposto

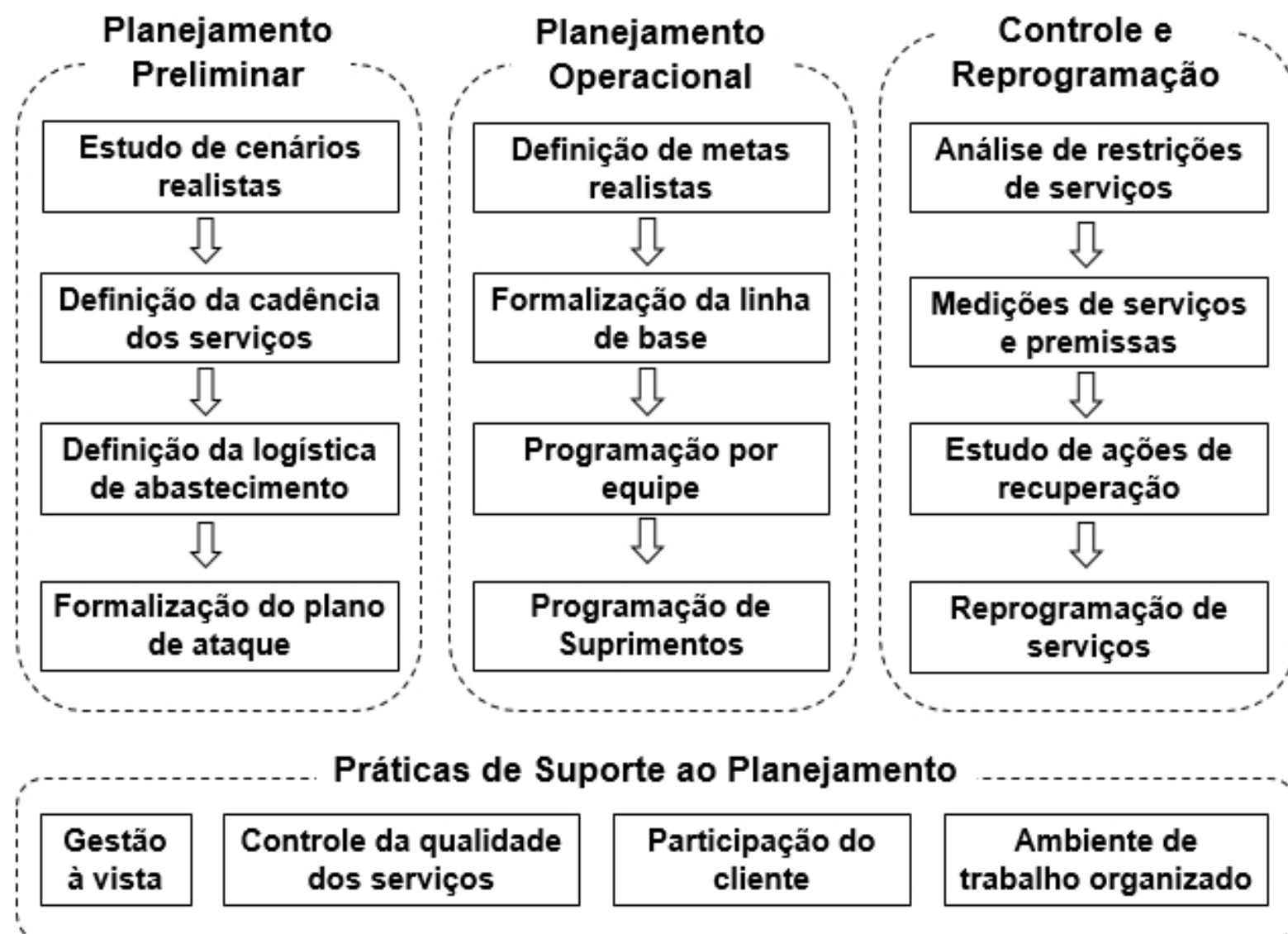

Fonte: O Autor

Todas as fases são detalhas nos itens a seguir. 


\subsection{Etapa de Planejamento Preliminar}

Nesta etapa, buscou-se detalhar as práticas relacionadas ao momento anterior ao início das atividades no canteiro de obras.

Como destacado pelo grupo focal e alterado posteriormente pelo autor, tratam-se de ações relacionadas à preparação das atividades operacionais que virão em seguida. Apesar do momento de realização ser anterior à obra, como já são estabelecidas premissas ligadas à produção e com teor ligeiramente detalhado, as decisões estão mais focadas ao plano operacional de longo prazo, do que no plano estratégico do projeto. É claro que muitas das decisões estabelecidas neste âmbito podem impactar a estratégia de execução do projeto, mas as ferramentas e práticas mais adequadas ao plano estratégico-tático são diferentes das previstas no método.

As quatro fases propostas para esta etapa e as práticas recomendadas são apresentadas de forma geral na figura 120 e detalhadas nos itens a seguir.

Figura 120 - Detalhe da etapa de planejamento preliminar do método proposto

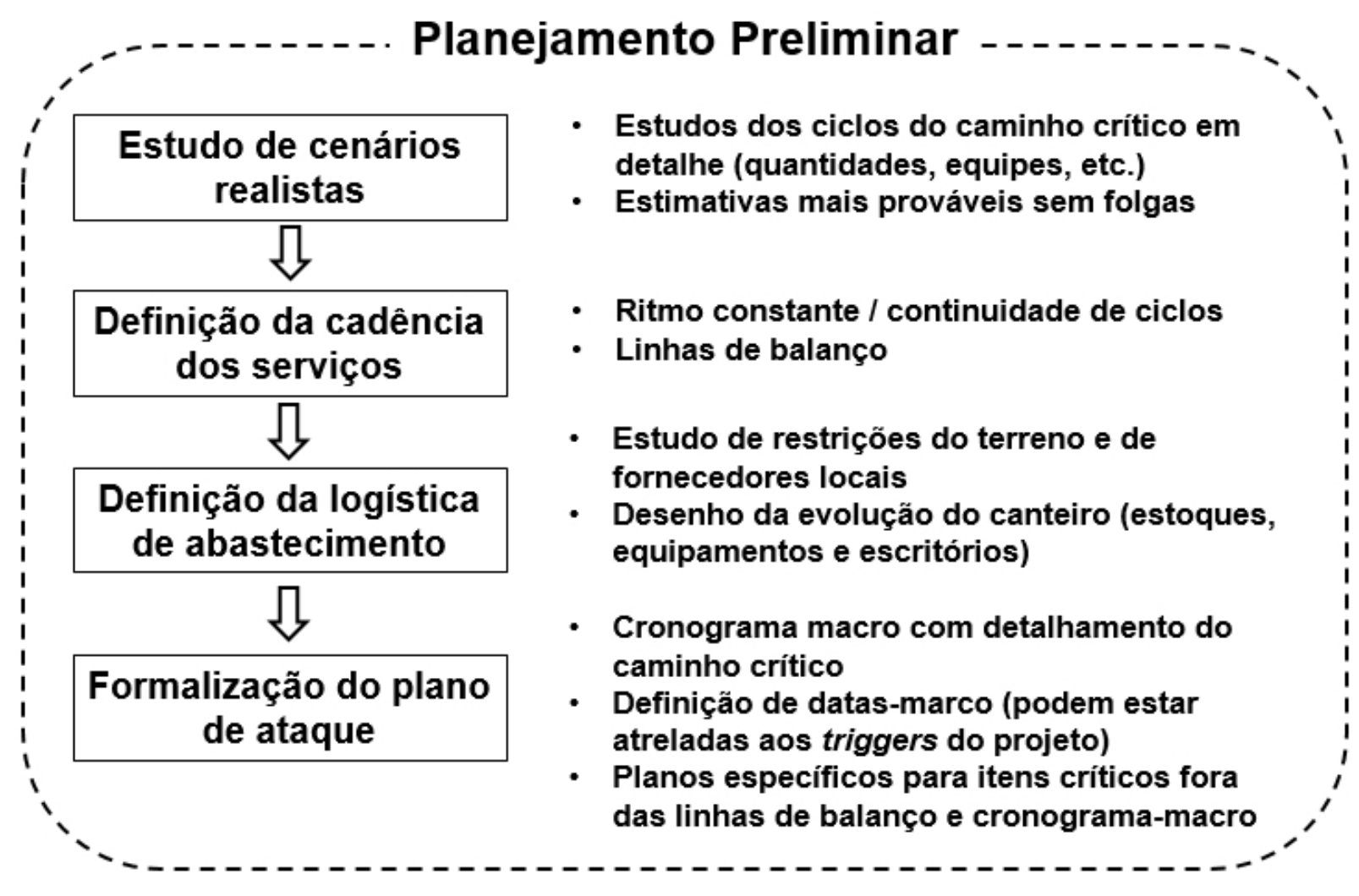

Fonte: O Autor 


\subsubsection{Fase I - Estudo de cenários realistas}

Nesta fase o objetivo é a estruturação das premissas iniciais das principais atividades do empreendimento, subsidiando a validação dos prazos de referência e estratégia de execução da obra.

Práticas orientativas desta fase:

- Estimativas de prazo mais prováveis (sem inclusão de folgas) dos serviços de referência do plano de ataque;

- Estudo com detalhes mínimos dos ciclos dos serviços do caminho crítico (quantidades, equipes, equipamentos, produtividade);

- Definição de premissas paramétricas para os demais serviços que compõem o plano de ataque.

Exemplo de ferramentas para esta fase: plano de ataque.

\subsubsection{Fase II - Definição da cadência dos serviços}

Nesta fase o objetivo é a definição do melhor ritmo dos serviços, que não necessariamente é o mais rápido possível, mas aquele que atenda aos prazos de referência do plano de ataque e ao mesmo tempo não sobrecarregue alguns dos serviços com cadências improváveis ou otimistas demais.

Práticas orientativas desta fase:

- Estabelecimento de um ritmo constante para os serviços do plano de ataque, buscando a continuidade dos ciclos;

- Revisão das premissas iniciais de planejamento, com base na necessidade de alinhamento das atividades com o ritmo da obra, incluindo alteração da quantidade de equipes por serviço ou procedimento de execução.

Exemplo de ferramentas para esta fase: diagrama tempo-caminho. 


\subsubsection{Fase III - Definição da logística de abastecimento}

Nesta fase o objetivo é a definição de como os serviços do plano de ataque serão executados no canteiro, evitando-se restrições de mobilização, transporte, disponibilização de insumos e esperas.

Práticas orientativas desta fase:

- Estudo de restrições do canteiro de obras (acessos, áreas de descarga, restrições de circulação, áreas de estoque);

- Estudo de localização e uso dos equipamentos de transporte, principalmente vertical, com a definição dos prazos de subida dos diversos materiais e capacidade de carga de cada um;

- Revisão das premissas iniciais de planejamento, com base na necessidade de abastecimento e possíveis alterações de modelos de fluxo, como alocação de ajudantes, posicionamento de equipamentos, uso de sistemas alternativos, dentre outros.

Exemplo de ferramentas para esta fase: projeto de canteiro / desenhos evolutivos.

\subsubsection{Fase IV - Formalização do plano mestre da obra}

Nesta fase o objetivo é a validação de todos os conceitos adotados anteriormente e a elaboração de documentos formais de planejamento (para que todos os envolvidos estejam comprometidos com as metas estabelecidas) e os controles que serão implementados no acompanhamento da obra.

Práticas orientativas desta fase:

- Elaboração do cronograma macro, com as principais atividades do plano mestre, mas com o detalhamento daquelas que constituem o caminho crítico;

- Inclusão de buffer de projeto no caminho crítico;

- Validação do cronograma macro com a equipe gerencial da obra, bem como realização dos ajustes necessários solicitados pelos responsáveis de cada equipe; 
- Definição das datas-marco da obra, que podem estar atreladas a triggers de projeto (alertas antecipados para ações mais rápidas);

- Elaboração de planos de execução globais para itens que não estão contemplados no plano de ataque, mas são considerados importantes para o atendimento das datas marco escolhidas.

Exemplo de ferramentas para esta fase: plano mestre.

\subsection{Etapa de Planejamento Operacional}

Nesta etapa, buscou-se detalhar as práticas relacionadas às fases que ocorrem no início das atividades no canteiro de obras e nas quais todas as atividades são referenciadas, uma vez que neste momento define-se a linha de base da obra.

As quatro fases propostas para esta etapa e as práticas recomendadas são apresentadas de forma geral na figura 121 e detalhadas nos itens a seguir.

Figura 121 - Detalhe da etapa de planejamento operacional do método proposto

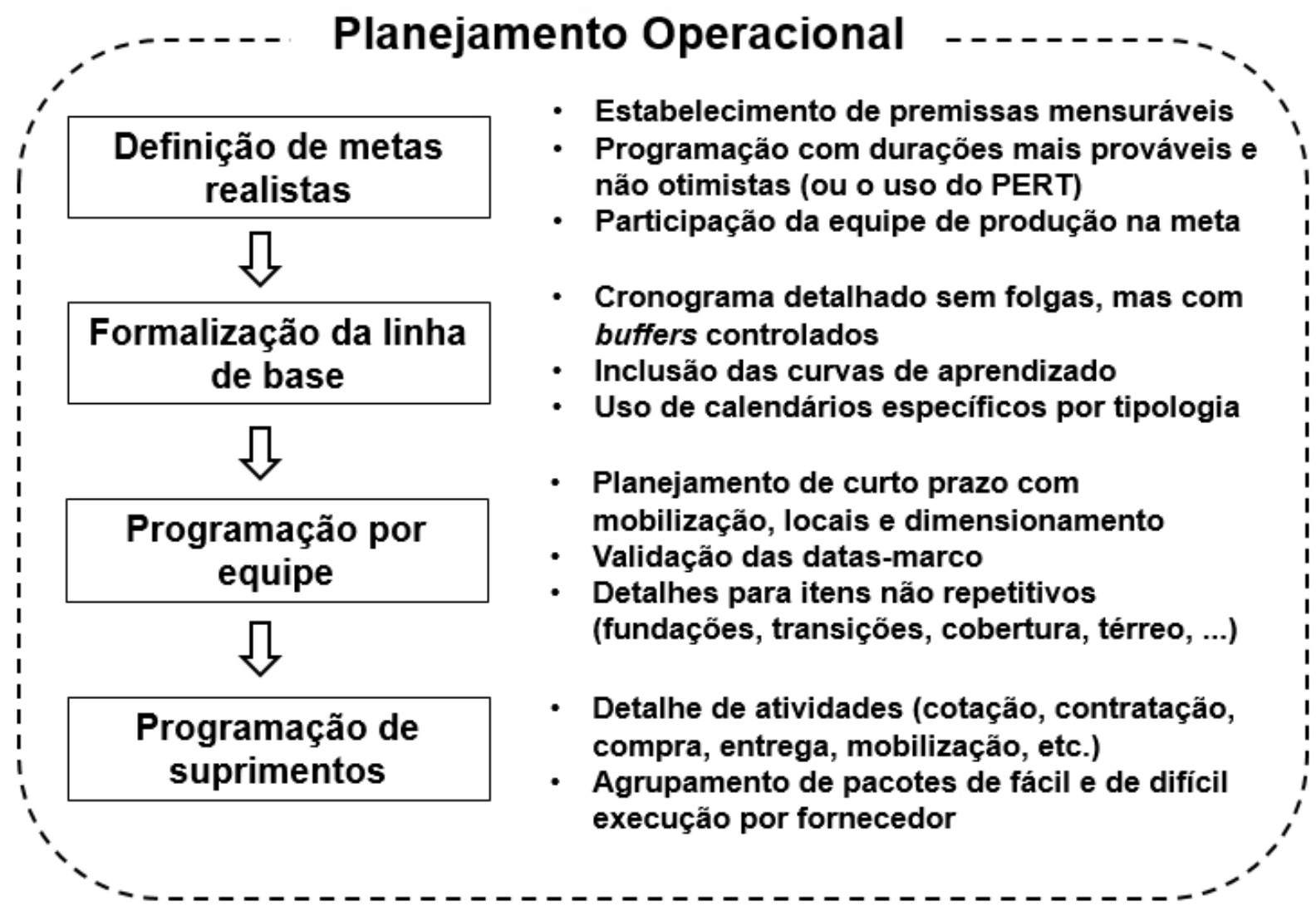

Fonte: O Autor 


\subsubsection{Fase V-Definição de metas de produção realistas}

Nesta fase o objetivo é o refinamento das premissas, detalhando-se os serviços para que seja possível a elaboração das programações de produção e garantindo que as premissas sejam gerenciáveis ao longo da obra.

Práticas orientativas desta fase:

- Estudo detalhado dos ciclos das atividades do caminho crítico, com atividades diárias e movimentação das equipes (micro planejamento);

- Elaboração do diagrama de rede, utilizando durações mais prováveis e não otimistas (ou a utilização da média ponderada do PERT para uma referência determinística mais próxima; ou ainda estudos de probabilidade utilizando verdadeiramente os conceitos do PERT);

- Estruturação do banco de dados com as premissas adotadas para a definição das durações dos ciclos, quantidades, equipes, produtividades, bem como precedências ou restrições de recursos.

Exemplo de ferramentas para esta fase: diagrama de rede / banco de dados.

\subsubsection{Fase VI - Formalização da linha de base}

Nesta fase o objetivo é a definição da referência de planejamento, pela qual as programações e ações de gestão serão desenvolvidas.

Práticas orientativas desta fase:

- Elaboração do cronograma detalhado com as atividades do diagrama e sem folgas, manutenção do buffer do projeto e a inclusão de buffers de alimentação;

- Inclusão de curvas de aprendizado para as atividades mais importantes, com a revisão de algumas durações de serviços nos primeiros pavimentos;

- Calendários específicos por serviço, no mínimo àqueles afetados por chuvas;

- Fixação da linha de base e ampla divulgação aos envolvidos;

- Validação de datas-marco do projeto e vinculação com plano de contratações.

Exemplo de ferramentas para esta fase: cronograma de longo prazo. 


\subsubsection{Fase VII - Programação por equipe}

Nesta fase o objetivo é a definição das metas de curto prazo e orientação de distribuição das equipes no canteiro.

Práticas orientativas desta fase:

- Elaboração do cronograma de médio prazo (trimestral ou bimestral), com foco na meta mensal e detalhando-se restrições a serem eliminadas, bem como quando a equipe deve ser mobilizada;

- Elaboração do cronograma de curto prazo e programação por equipe, com detalhes de locais e dimensionamento;

- Validação formal das programações com os líderes de equipe (ou participação dos mesmos na elaboração das próprias programações);

- Se possível, identificação de serviço por pavimento, no local de execução, organizando a mobilização das equipes de forma simples e visual;

- Elaboração de cronogramas ou plano específicos para itens ou setores não repetitivos e não detalhados no cronograma base ou nas linhas de balanço.

Exemplo de ferramentas para esta fase: cronogramas de médio e curto prazo.

\subsubsection{Fase VIII - Programação de suprimentos}

Nesta fase o objetivo é a definição das contratações e seus processos preliminares, garantindo que não ocorram restrições de abastecimentos e transporte na obra.

Práticas orientativas desta fase:

- Validação dos quantitativos (e premissas) e lista de fornecedores adequados às necessidades locais e da obra, compatível com as premissas de planejamento e transparência com os fornecedores (riscos e complexidades dos serviços);

- Elaboração do cronograma de contratações com as datas de início de cada serviço sempre atualizada (aderente ao cronograma físico atualizado da obra), e prazos a montante para cada atividade predecessora (editais, cotação, negociação, contratação, mobilização); 
- Contratação de pacotes de complexidade nivelada, ou seja, com serviços, etapas ou locais tanto de fácil, como de difícil execução, motivando continuidade de ciclos (por exemplo, evitar contratar os pavimentos tipos e trechos de periferia, que apresentam repetitividade, separadamente dos locais com menor possibilidade de produtividade, como térreo, cobertura e subsolos).

Exemplo de ferramentas para esta fase: cronogramas de contratações.

\subsection{Etapa de Controle e Reprogramação}

Nesta etapa, buscou-se detalhar as práticas relacionadas às fases que ocorrem durante toda a obra, quando são feitos os monitoramentos de todas as premissas definidas na etapa anterior. Quando as premissas não são atendidas, são necessárias ações de recuperação para se buscar a linha de referência acordada.

As quatro fases propostas para esta etapa e as práticas recomendadas são apresentadas de forma geral na figura 122 e detalhadas nos itens a seguir.

Figura 122 - Detalhe da etapa de controle e reprogramação do método proposto

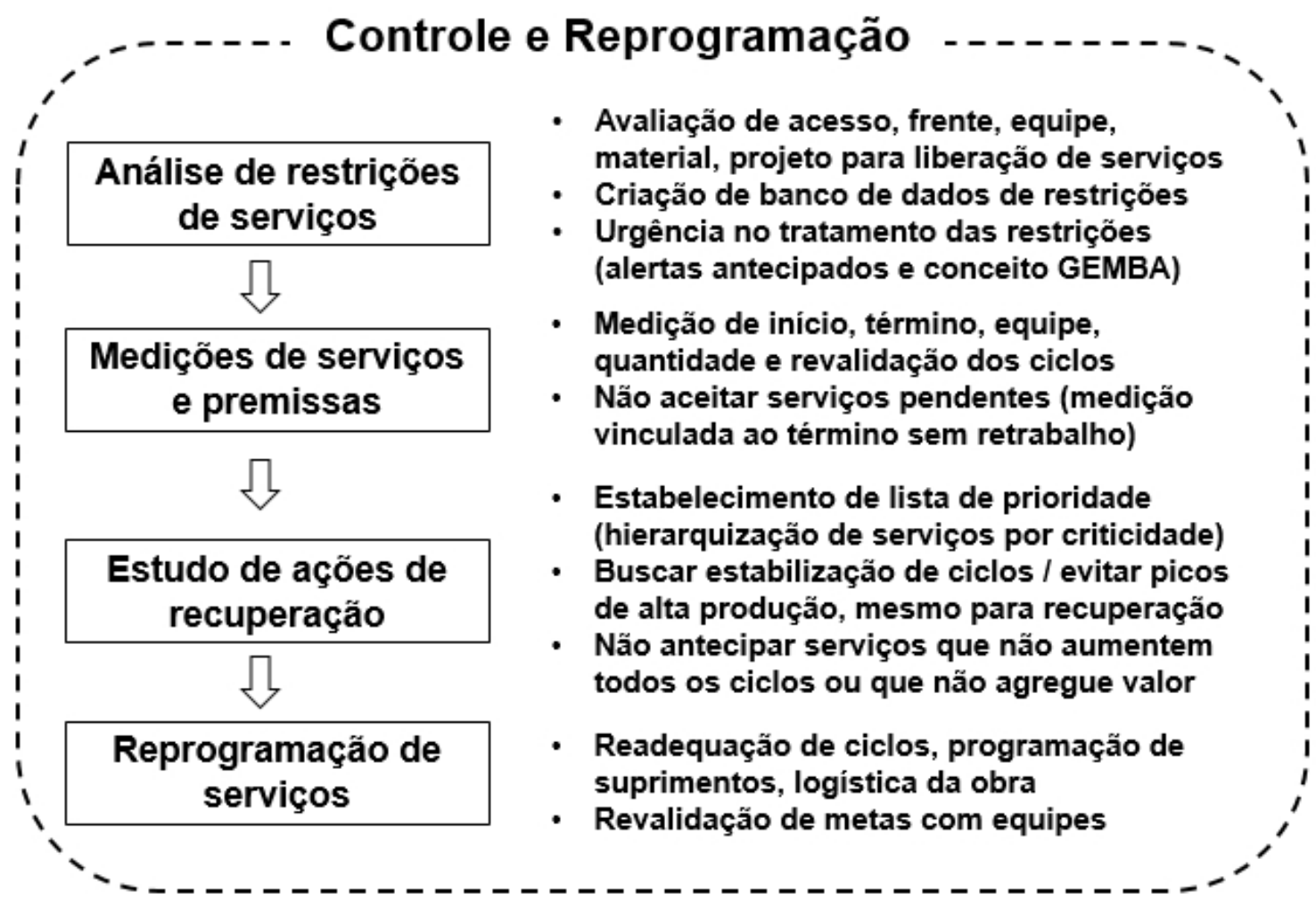

Fonte: O Autor 


\subsubsection{Fase IX - Análise de restrições de serviços}

Nesta fase o objetivo é garantir que não ocorram problemas para que a programação de médio e curto prazo sejam cumpridas e caso existam restrições a serem eliminadas, que isto seja feito de forma rápida e eficiente.

Práticas orientativas desta fase:

- Elaboração de lista de restrições mais comuns para a tipologia de obra da empresa, incluindo: indefinições de projeto, liberação de frente de serviço, material não entregue, equipe não mobilizada, equipamento quebrado, problema de acesso, insegurança, dentre outras;

- Análise de ocorrência de restrição e sua eliminação com uso do conceito GEMBA (foco na solução no "chão de fábrica" e o mais rápido possível, não afetando atraso de toda a linha de produção);

- Registro das ocorrências e indicadores de evolução (notas, \% eliminação, IRR, IDP ou SPI, PPC, \% riscos, dentre outros).

Exemplo de ferramentas para esta fase: lista de restrições e indicadores de evolução.

\subsubsection{Fase $X$ - Medição de serviços e análise de premissas}

Nesta fase o objetivo é gerar indicadores para a tomada de decisão e monitorar as premissas do planejamento operacional, para que a reprogramação seja aderente às tendências da obra.

Práticas orientativas desta fase:

- Definição clara de critérios de medição, que garantam transparência para a medição aderente ao realizado e compatibilidade com o entendimento das partes envolvidas;

- Medição apenas de serviços efetivamente acabados nos locais de referência dos planos, garantindo terminalidade;

- Vinculação do pagamento dos terceiros aos serviços efetivamente finalizados, dando pesos importantes quando os arremates forem inevitáveis; 
- Registrar datas de início e término reais das atividades, bem como índices de validação das premissas iniciais (equipe, produtividade, plano de ataque, quantidades).

Exemplo de ferramentas para esta fase: planilhas de medição.

\subsubsection{Fase $X I$ - Estudo de ações de recuperação}

Nesta fase o objetivo é gerar ações coordenadas que viabilizem a recuperação dos atrasos por incumprimento das premissas definidas e consequentemente das programações que estejam vigentes na obra.

Práticas orientativas desta fase:

- Envolvimento das equipes de produção para discussão de alternativas;

- Formalização das ações, com responsáveis e prazos, e destaque para aquelas que são prioritárias para se evitar atrasos do caminho crítico e da obra como um todo;

- Buscar estabilização de ciclos, evitando-se altos picos de produtividade, mesmo que seja para a recuperação dos atrasos (é mais importante um plano contínuo do que ações isoladas do tipo "apagar incêndio");

- Não antecipar serviços que não agreguem valor, evitando-se estoques, esperas, interferências;

- Revisão das datas-marco e avaliação dos impactos das ações de recuperação.

Exemplo de ferramentas para esta fase: planos de ação e programações de médio / curto prazo.

\subsubsection{Fase XII - Reprogramação de serviços}

Nesta fase o objetivo é revisar os planos de médio e curto prazo, de forma que estes sejam aderentes ao Plano Mestre e Linha de Base inicialmente definidas.

Práticas orientativas desta fase:

- Formalização de programações de recuperação, incluindo planos específicos para atividades não previstas (ou sub-etapas não detalhadas anteriormente), 
mas que necessitam ser realizadas para a estabilização do fluxo (planos de áreas especiais, requadros, shafts, taliscas, pisos especiais, dentre outros);

- Planos de ação específicos para arremates de serviços, cujas etapas não foram previstas no macro fluxo de processos e cujos pesos para avanço físico sejam pequenos ou imperceptíveis;

- Análise dos impactos das novas datas de programação ou metas de produção nos demais itens do planejamento, como no cronograma de suprimentos, programações de entrega, estruturação do canteiro de obras, cronograma de aprovações ou concessionárias, evitando-se estoques desnecessários ou estregas antecipadas que gerem novas restrições de execução.

> Exemplo de ferramentas para esta fase: programações de médio / curto prazo.

\subsection{Práticas de suporte às etapas de planejamento}

Algumas das práticas levantadas por esta pesquisa não estão relacionadas com momentos específicos dentro da execução de uma obra. Foram evidenciadas nos empreendimentos pesquisados em diversas ocasiões diferentes, embora claramente sejam avaliadas como condições importantes para melhorar a gestão dos prazos dos empreendimentos.

Desta forma, buscou-se destacá-las neste item, como práticas de apoio aos processos ordinários descritos nos três itens anteriores.

As práticas foram também agrupadas e apresentadas no método de forma similar ao proposto para os grupos descritos nos itens 8.1 a 8.3 , conforme pode ser observado na figura 123 e detalhado nos itens a seguir.

A única diferença estrutural nesta representação está no fato dos grupos de práticas não possuírem relação sequencial e por esta razão não foram definidos como "fases", mas simplesmente como "grupos". 
Figura 123 - Detalhe do grupo de práticas de suporte ao planejamento

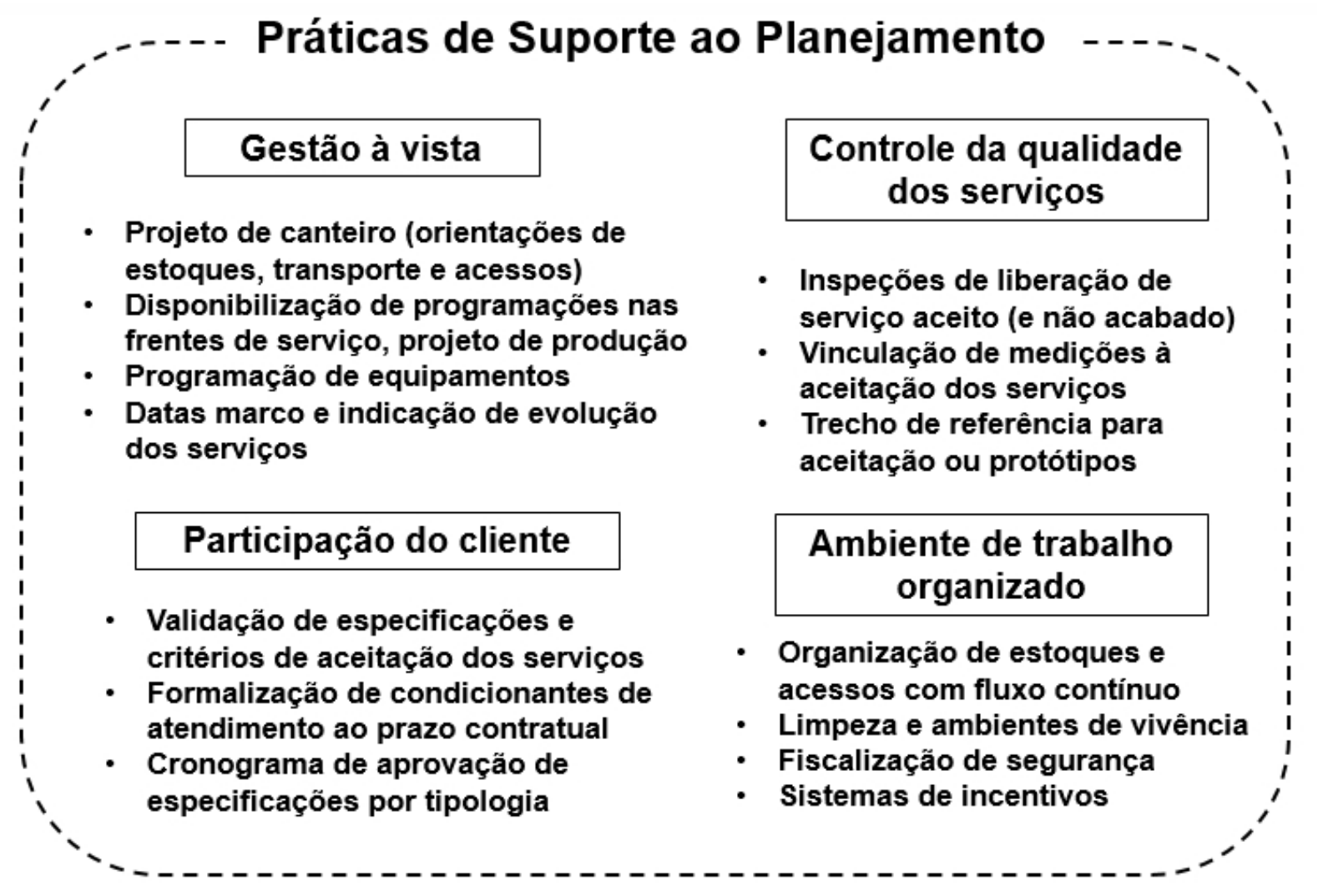

Fonte: O Autor

\subsubsection{Gestão à vista (comunicação)}

O objetivo das práticas deste grupo é garantir a transmissão rápida e precisa das informações relevantes ao completo entendimento das programações, bem como do desempenho das equipes ao longo da execução da obra.

Equipes bem informadas são mais facilmente gerenciadas, além de estimular o comprometimento das mesmas com suas metas de produção.

Assim, o foco das ferramentas de comunicação não está relacionado ao detalhamento ou conteúdo técnico. Isto é importante, mas estes dados são fornecidos como parte das atividades destacadas nos itens anteriores, tais como cronogramas e relatórios.

\section{Práticas orientativas deste grupo:}

- Quadro com o desenho do canteiro nas diversas etapas de evolução da obra, onde podem ser observados os locais apropriados de estocagem, escritórios, equipamentos de transporte, acessos e outros pontos que devem refletir a logística da obra; 
- Disponibilização das programações das equipes nos locais de produção, com a identificação dos líderes de cada uma, os quais serão cobrados pelo atendimento do que está previsto;

- Indicações dos locais definidos como frentes de serviço, ou seja, os nomes utilizados como referenciais e detalhados em cronogramas ou croquis (que usualmente aparecem apenas nos documentos dos líderes ou da equipe de planejamento). Trata-se de indicar não apenas andares ou apartamentos, mas também trechos de periferia, áreas futuras ainda não constituídas (normalmente futuros ambientes de áreas comuns), setores confinados ou de acesso restrito por motivos de preservação do serviço acabado;

- Fixação da programação dos equipamentos de transporte (grua, elevadores, cremalheira, dentre outros), próximo do local de embarque e/ou carregamento, garantindo o conhecimento de todas as equipes de quando será sua vez de transportar seus insumos, organizando os acessos e evitando-se paradas ou estoques intermediários indesejáveis;

- Quadro ou cartazes com as datas marco mais importantes que garantam atendimento da linha de base ou contrato, gerando metas comuns a todas as equipes (poucas datas podem ser fixadas no inconsciente das pessoas ou discutidas frequentemente por todos, gerando comprometimento do grupo);

- Indicação da evolução dos serviços por pavimento ou trecho, através de croquis esquemáticos ou cópias dos projetos que são pintados assim que as atividades são finalizadas. Destacam-se frentes de serviço liberadas ou atrasadas para todas as equipes da obra;

- Comunicações ou desenhos esquemáticos nos locais de início das atividades (normalmente o primeiro pavimento ou primeiros trechos onde ocorrem as chamadas curvas de aprendizagem) sobre o projeto de produção, ou desenhos com as etapas dos serviços não triviais, ou ainda detalhes construtivos que necessitem ser cumpridos em ordens específicas para se evitar retrabalhos.

Exemplo de ferramentas para esta fase: quadros, cartazes, placas, linhas ou outras marcações. 


\subsubsection{Controle da qualidade de serviços}

O objetivo das práticas deste grupo é garantir que ocorram as terminalidades dos serviços e com isso evitar retrabalhos ou desvios da programação.

Quando se generaliza a função qualidade, entende-se que não apenas é necessário verificar se os serviços foram executados de forma correta, dentro de tolerâncias dimensionais ou critérios visuais de especialistas. Mas também é importante garantir que o serviço foi executado conforme especificações de projeto, dentro da ordem prevista no fluxo de processo da empresa, e com a proteção dos serviços acabados que garantam que os mesmos não serão danificados posteriormente.

Este grupo complementa as práticas descritas no item 8.3.2, que também idealizam modelos de medição dos serviços, mas que focam o monitoramento das premissas de produtividade e não das premissas de aceitação dos serviços.

\section{Práticas orientativas deste grupo:}

- Inspeções frequentes da equipe da qualidade ou após o término de cada trecho, previamente treinadas, com foco na verificação da correta entrega do serviço contratado;

- Vinculação da medição do serviço (usualmente relacionado à liberação do faturamento do subcontratado ou parte dele) com a aprovação do serviço. Destaca-se que o objetivo é a medição do serviço aceito e não do serviço acabado;

- Execução de trecho de referência ou unidade protótipo, para validação das condições de aceitação dos serviços.

D Exemplo de ferramentas para esta fase: listas de verificação (check-lists) específicos por serviço e local / trecho.

\subsubsection{Participação do cliente e sua comunicação}

O objetivo das práticas deste grupo é evitar indefinições relacionadas à execução dos serviços (que afetam diretamente a correta programação das atividades) e garantir 
que as decisões a serem tomadas no processo produtivo sejam realizadas de forma rápida e direcionada.

$\mathrm{Na}$ verdade, todas as decisões dentro da obra devem ocorrer da forma mais rápida possível. As práticas descritas nos itens de 8.1 a 8.3 subsidiam a comunicação e as decisões entre as equipes de campo e também com as áreas de apoio à produção, como projetos, suprimentos e outros departamentos. No entanto, a forma como foi estruturado o método não contempla, nas fases ordinárias, ações focadas no envolvimento do cliente, sendo este um dos fatores levantados na pesquisa como causa frequente de atraso em obra e assim incluso neste grupo.

\section{Práticas orientativas deste grupo:}

- Validação formal dos projetos, especificações e critérios de aceitação dos serviços que não tenham normas ou outras referências claras para aceitação;

- Identificação e/ou destaque das condicionantes utilizadas para a definição do cronograma linha de base e das demais reprogramações necessárias (estejam elas definidas em contrato, projeto ou não), que serão utilizadas para negociação do contrato e impactos nos prazos, quando solicitadas alterações do escopo do projeto pelo cliente;

- Reuniões periódicas frequentes para apresentação dos resultados da obra e riscos de indefinições ou do não cumprimento das premissas de planejamento adotadas pela construtora;

- Cronograma de aprovação de especificações por tipologia de serviço, compatível com o cronograma físico e de suprimentos. As indefinições devem ser resolvidas até a data em que não afeta o processo de compra de materiais ou execução dos serviços, como opções de planta (antes dos processos de execução de alvenaria e instalações), acabamentos (antes do processo de execução dos revestimentos), dentre outros.

Exemplo de ferramentas para esta fase: relatórios gerenciais e programações específicas de itens que necessitam definições de cliente. 


\subsubsection{Ambiente de trabalho organizado}

O objetivo das práticas deste grupo é garantir que se obtenham condições adequadas para a implantação de todas as práticas descritas anteriormente.

Os pontos que caracterizam um bom ambiente de trabalho estão relacionados à organização do canteiro e possíveis sistemáticas de incentivos que garantam a manutenção das equipes no processo produtivo, bem como sua produtividade próxima das premissas adotadas para ao fechamento da linha de base.

Práticas orientativas deste grupo:

- Identificação dos locais de estoque, carga e descarga, vivência, escritórios e todas as áreas delimitadas no projeto de canteiro, garantindo que não ocorram improvisos quando do recebimento dos insumos, e que afetem a logística programada;

- Sinalizações em todo o canteiro delimitando trechos, níveis, pisos disponíveis, e orientando a melhor forma de acesso aos locais de produção, reuniões e áreas de vivência, sem necessidade de questionamentos ou apoio de terceiros, complementando o item 8.4.1 anterior;

- Fiscalização de segurança focando, não apenas o atendimento das normas regulamentadoras, mas a eliminação das restrições para execução dos serviços, complementando o item 8.3.1;

- Implantação de sistema de incentivos para a manutenção da conservação do canteiro e atendimento dos critérios de segurança, bem como sistema de avaliação de equipes (incluindo subcontratados) em relação à organização e limpeza.

Exemplo de ferramentas para esta fase: projeto de canteiro e programas de saúde e segurança do trabalho. 


\section{CONSIDERAÇÕES FINAIS}

\subsection{Conclusões}

O desenvolvimento deste trabalho buscou, conforme estabelecido nos objetivos descritos no capítulo 2, o aprofundamento dos estudos sobre um tema corrente na rotina dos profissionais responsáveis pela gestão de projetos: planejar e garantir o atendimento dos prazos.

Apesar de representar uma necessidade básica, facilmente compreendida como essencial pelas partes envolvidas no projeto, a complexidade de fatores que afetam a execução de um projeto, sobretudo de construção, torna o estudo fascinante e sempre atual.

Para alcançar o objetivo principal da pesquisa, ou seja, a criação de um método, foi necessário o desdobramento em outros objetivos complementares.

No primeiro desdobramento, com foco na organização da bibliografia referente ao tema, os levantamentos ajudaram a compreensão total do problema relativo aos atrasos, fato necessário para a aplicação adequada do DSR como método de pesquisa adotado.

Tal fato foi complementado com a realização da primeira pesquisa de campo e seus desdobramentos. Esta etapa garantiu a geração de informações relevantes que pudessem suportar a futura estruturação do artefato (método).

Com a proposição inicial e o estudo das diretrizes em uma nova pesquisa de campo, conseguiu-se uma avaliação da aplicabilidade dos conceitos estudados em projetos reais, consolidando grande parte das respostas às questões estabelecidas nos objetivos secundários.

Por fim, de maneira a refinar o método teórico, mas baseado nas experiências em campo, buscou-se uma validação externa do trabalho, apresentando a um grupo de especialistas, todos os conceitos envolvidos na estruturação do método de planejamento e gestão, objetivo principal desta tese. 
Desta forma, consolidando todos os desdobramentos e formalizando-se o artefato de maneira a contemplar todas as experiências obtidas em cada etapa da pesquisa, entende-se que a pesquisa atingiu seu objetivo principal.

Não apenas pelos relatos advindos do grupo focal, mas pela convicção do autor, acredita-se que o método proposto apresenta contribuições importantes para a Base do Conhecimento em gestão de projetos, embora claramente apresenta limitações, que serão destacadas no item a seguir.

\subsection{Limitações do método proposto}

Primeiramente, entende-se que o método proposto precisa ser avaliado em um número suficiente de empreendimentos para que seja ainda mais debatido e se transforme em uma ferramenta de aplicação prática efetiva.

Mesmo assim, uma vez que todo o trabalho utilizou-se de referências a projetos imobiliários, principalmente nas duas pesquisas de campo, provavelmente haverá limitações para a utilização em empreendimentos com características diferentes, tais como obras de infraestrutura e de base imobiliária (shoppings center, galpões, hospitais e outros).

Estas limitações estão concentradas em uma menor quantidade de tarefas que possam ser repetidas ou em conceitos relativos às características dos profissionais e empresas prestadoras de serviços (e subcontratados).

Outra tipologia que não foi abordada no trabalho relaciona-se a empreendimentos horizontais, mesmo que também imobiliários. Estas obras possuem características onde é possível a realização de diversas atividades em paralelo, ou seja, é possível a execução de uma quantidade de frentes de serviço maior, o que claramente traz consequências importantes na tipologia de planejamento. Espera-se que muitas das práticas citadas sejam claramente aplicadas, mas algumas outras causas de atrasos menos significativas para a tipologia pesquisada (vertical) devem trazer maior impacto na outra tipologia (horizontal).

Ainda sobre a tipologia de projetos, o método também apresenta limitações para aplicação em empreendimentos públicos. Este tipo de projeto apresenta uma 
quantidade muito maior de interferências externas, que podem ter sido levantadas na revisão bibliográfica, mas não foram tratadas nos estudos de caso prático.

Como o objetivo do trabalho foi criar um método abrangente, não houve uma preocupação para se identificar qual das causas de atraso é a mais impactante para o sucesso do projeto ou qual prática de planejamento apresenta resultados mais eficientes. Desta forma, pode-se citar como mais uma limitação da pesquisa a análise quantitativa de riscos ou impactos. Todas as causas frequentes foram tratadas com a mesma importância. O mesmo ocorre em relação às ações de mitigação.

Esta questão foi levantava pelos participantes do workshop, que inclusive discutiram sobre o grau de relevância dos problemas e das ações. Este fato sensibilizou o autor, que incluiu no planejamento de suas próximas pesquisas esta abordagem. Com isso, será possível no futuro, também destacar os pontos críticos do método descrito na tese.

Uma ponderação também destacada na avaliação do método relaciona-se à definição de responsabilidades por cada etapa do processo. Não foram avaliadas demandas de funções ou cargos dentro do processo de planejamento.

Isto porque a proposta da pesquisa preconiza um método que possa ser utilizado em todos os projetos da tipologia estudada, independente da estrutura organizacional defendida em cada empresa construtora. Não foi abordado, por exemplo, se o planejamento operacional é executado pela equipe da obra, se existe uma área de apoio na empresa que realiza tais tarefas (departamento técnico ou de planejamento) ou até mesmo que há fornecedores terceirizados para a execução das programações e controle das obras.

O mesmo pode ser descrito em relação aos detalhes das atividades de planejamento, tais como linguagem, periodicidade das ações, frequência dos controles, conteúdo de relatórios, dentre outros.

Outras limitações características da pesquisa estão relacionadas à forma de abordagem do problema e aos recortes de temáticas envolvidas nas causas dos atrasos. No entanto, entende-se que estas questões na verdade estão mais correlacionadas às premissas da pesquisa, do que a suas limitações efetivas. 
Pode-se citar estas premissas no item a seguir.

\subsection{Análise das premissas adotadas para a pesquisa}

Um dos pontos bastante discutidos, principalmente na última etapa de avaliação (grupo focal) relaciona-se às características da equipe do projeto. Segundo os participantes, uma das formas de se evitar a ocorrência de diversas causas de atraso seria a alocação de profissionais mais experientes.

Intuitivamente esta percepção é até justificável, mas academicamente seria necessário trazer dados ou evidências embasadas cientificamente para serem consideradas válidas.

Assim, este tipo de discussão, na verdade, estaria relacionado a se analisar quais as melhores competências ou qualificações dos profissionais envolvidos no projeto, incluindo certamente o item "experiência".

Infelizmente esta avaliação não foi considerada no plano de pesquisa desta tese. Caso o fosse, certamente traria elementos inspiradores, mas há de se considerar que mudaria muito o foco do trabalho, trazendo elementos relacionados à seleção e gestão de pessoas e a necessidade de se ampliar o universo dos levantamentos bibliográficos e das pesquisas de campo.

Além disso, caso fossem abordadas as competências dos envolvidos no projeto, outra discussão poderia gerar ainda mais complexidade ao estudo: a relação entre quais itens do processo de planejamento seriam mais afetados pela baixa qualificação dos profissionais, ou vice-versa. Por exemplo, será que problemas em relação ao planejamento de uma obra estariam sendo ocultados em uma investigação (ou pesquisa de campo), exatamente pelo fato de profissionais com qualificação acima da média estabelecerem ações não triviais para recuperar atrasos ou evitar maiores impactos das falhas dos processos de planejamento implantados?

A premissa utilizada na elaboração do método supõe um nível mínimo de conhecimento e qualificação dos profissionais envolvidos no projeto, que propicie a implantação das ferramentas e práticas sugeridas. 
Outra premissa que precisa ser destacada relaciona-se aos processos que ocorrem fora do ambiente do canteiro de obras, como projetos, suprimentos, aprovações e outros itens. Apesar dos problemas relacionados a estes itens impactarem diretamente a produção dentro do canteiro, o método limitou-se a destacar práticas que são desenvolvidas em conjunto com a equipe da obra para se evitar que estes processos influenciem os atrasos.

Assim, não foram tratadas práticas que melhorem as atividades específicas das demais partes da cadeia, como o desenvolvimento dos projetos, compatibilização, descrição das plantas e desenhos, formas de envio, métodos de contratação, detalhes de documentos de cotação e compra, entre outros. Mas sim, ferramentas que garantam à equipe da obra monitorar estes processos ou interagir positivamente para que apresentem melhores resultados, tais como os cronogramas de suprimentos ou formas de interação com fornecedores.

Um dos pontos abordados na etapa de avaliação e validação do método pelo grupo focal foi a necessidade de comunicação muito próxima entre as áreas de apoio à obra (orçamento, projeto, suprimentos, dentre outros), o que incluir também a área de planejamento. Este fato foi contemplado no método, através dos documentos e práticas relacionadas aos itens de apoio, embora com claras limitações.

\subsection{Propostas para continuidade de estudos sobre o tema}

Como anteriormente descrito, observou-se uma lacuna importante em pesquisas desta natureza no Brasil e espera-se que este trabalho incentive outros pesquisadores a desenvolverem o tema, tão presente nos projetos de construção.

Inicialmente, um enfoque mais detalhado nos tipos de serviço que fazem parte dos projetos estudados, pode contribuir com a identificação ou correlação de diversos problemas ou causas de atraso relativas apenas a parte dos serviços. Já existem registros de quais serviços (fundação, estrutura, alvenaria, fachadas, dentre outros) dentro de cada obra estudada, geraram atrasos ou problemas de início na data prevista, ou manutenção da produtividade prevista na linha de base. A grande quantidade de informações relativas aos empreendimentos estudados pode resultar em um estudo muito interessante, seja através de um artigo científico deste autor, seja 
através de pesquisas de iniciação científica ou mestrado de outros pesquisadores que se interessem pelo assunto.

Alguns pontos descritos anteriormente como limitações desta pesquisa são também fontes de inspiração para a continuidade dos estudos sobre o tema.

O primeiro que se pode destacar refere-se à aplicabilidade do método em outras tipologias de obra. Entende-se que estudos desta natureza seriam igualmente importantes. Uma das possibilidades seria a análise de aplicação do método em empreendimentos horizontais. Mesmo com características distintas, obras desta natureza apresentam necessidades similares quanto ao planejamento, como a definição de cenários, necessidade de cadenciamento dos serviços (talvez até maior do que em obras verticais), formalização de plano de ataque, garantia de terminalidade e muitos outros pontos abordados no método.

Outra necessidade verificada durante o desenvolvimento desta pesquisa diz respeito à possibilidade de avaliação das causas mais impactantes no atraso final de um empreendimento imobiliário. O trabalho identificou as causas mais frequentes, mas após definir um grupo restrito de fatores, a pesquisa tratou todas as causas com a mesma importância. Sabe-se que no entanto, em muitos casos, um único erro de planejamento ou previsão pode afetar de forma decisiva todo o prazo do projeto. Enquanto que outros problemas mais simples podem ser até mais frequentes e menos impactantes, ou ainda causar atrasos em parte pequena das programações de serviços, mas não no conjunto da obra como um todo. Assim, um estudo potencial, julgado importante pelo grupo focal que atuou nesta pesquisa, está na identificação de quais destas causas são as mais impactantes nas obras, como se houvesse um grupo crítico de causas a serem tratadas com maior ênfase, para o sucesso do projeto.

Mais uma possibilidade de pesquisa futura pode ser destacada a partir das limitações destacadas. Refere-se à avaliação das competências dos profissionais envolvidos no planejamento da obra. Este talvez seja um tema dos mais relevantes e pouco explorado em trabalhos acadêmicos voltados ao tema do planejamento.

Verificam-se muitas pesquisas na área de gerenciamento de projetos que estudam o tema da gestão de pessoas e a inter-relação de stakeholders. Até mesmo o PMI (2013) estabelece uma área de conhecimento inteira dentro das boas práticas de 
gestão de projetos, denominada "gerenciamento de recursos humanos" e que está diretamente atrelada ao grupo de processos de planejamento, como pode ser observado no quadro 8 no item 3.5 desta tese.

No entanto, estudar a correlação das atividades de planejamento e dos processos de gestão de pessoas, em especial a qualificação ou competência dos responsáveis pelo planejamento da obra, ainda não foi feito de forma direcionada. Pesquisas que tratem deste tipo de abordagem serão muito significativas e ajudarão a entender as dificuldades existentes na implantação do método proposto, bem como um possível refinamento das práticas sugeridas quanto estiver mais clara a responsabilidade de cada agente do processo de planejamento. 


\section{REFERÊNCIAS BIBLIOGRÁFICAS}

ABD EL-RAZEK, M.E.; BASSIONI, H.A.; MOBARAK, A.M. Causes of delay in building construction projects in Egypt. Journal of Construction Engineering and Management, 2008, Vol.134, No.11, pp.831-841.

ABDUL-RAHMAN, H.; BERAWI, M.A.; BERAWI, A.R.; MOHAMED, O. OTHMAN, M.; YAHYA, A. Delay mitigation in the malaysian construction industry. Journal of Construction Engineering and Management, 2006, Vol.132, No.2. pp. 125-132.

ACKOFF, R.L. Planejamento empresarial; tradução de Marco Túlio de Freitas. Rio de Janeiro, LTC, 1976. 126p.

AIBINU, A.A.; ODEYINKA, H.A. Construction delays and their causative factors in Nigeria. Journal of Construction Engineering and Management, 2006, Vol.132, No.7, pp.667-677.

AKKARI, A.M.P. A interligação entre o planejamento de longo, médio e curto prazo com o uso do pacote computacional MS Project. 2003. Dissertação (Mestrado) - Universidade Federal do Rio Grande do Sul, Porto Alegre/RS, 2003.

AKKARI, A.M.P. Proposição de um método de nivelamento de recursos a partir de princípios da teoria das restrições para o planejamento operacional. 2009. Tese (Doutorado) - Escola Politécnica da Universidade de São Paulo, São Paulo, 2009. 365p.

AL-MOUMANI, H.A. Construction delay: a quantitative analysis. International Journal of Project Management, 2000, Vol.18, No.1, pp.51-59.

ALVAREZ, R.R.; ANTUNES Jr., J.A.V. Takt-time: conceitos e contextualização dentro do sistema Toyota de produção. Gestão \& Produção, São Carlos, 2001, Vol. 8, No. 1, pp. 1-18.

ALWI, S.; HAMPSON, K. Identifying the importante causes of delays in building construction projects. In Proceedings The 9th East Asia-Pacific Conference on Structural Engineering and Construction, Bali, Indonesia, 2003.

AMOR, J. Scheduling programs with repetitive projects using composite curve learning approximations. Project Management Journal, 2002, Vol.33, No.3. pp.16-29.

ARDITI, D.; TOKDEMIR, O.B.; SUH, K. Challenges in line-of-balance scheduling. Journal of Construction Engineering and Management, 2002, Vol.128, No.6, pp. 545-556.

ASSAF, S.A.; AL-HEJJI, S. Causes of delay in large construction projects. International Journal of Project Management, 2006, Vol.24, No.4, pp.349-357.

ASSOCIAÇÃO BRASILEIRA DE NORMAS TÉCNICAS (ABNT). NBR ISO 10006: Sistemas de gestão da qualidade - Diretrizes para a gestão da qualidade em empreendimentos. Rio de Janeiro, 2006. 33p.

ASSUMPÇÃO, J.F.P. Gerenciamento de empreendimentos na construção civil: modelo para planejamento estratégico da produção de edifícios. 1996. 206p. Tese (Doutorado) - Escola Politécnica, Universidade de São Paulo, São Paulo, 1996.

ASSUMPÇÃO, J.F.P.; FUGAZZA, A.E. Uso de redes de precedências para planejamento da produção de edifícios. In: Encontro Nacional de Tecnologia do 
Ambiente Construído (7.:1998: Florianópolis) Qualidade no processo construtivo: Anais... Florianópolis,: NPC/ECV/CTC/UFSC, 1998, 2v. p.359-368.

BALLARD, G. Lookahead planning: the missing link in production control. In: Annual Conference of the Internacional Group for Lean Construction, 5, 1997, Australia. Proceedings... IGLC, 1997.

The last planner system of production control. 2000. Tese (Doutorado) - School of Civil Engineering, Faculty of Engineering, University of Birmingham, 2000.

BALLARD, G.; HOWELL, G.A. Shielding production: an essential step in production control. Technical Report No. 97-1, Construction Engineering and Management Program, Department of Civil and Environmental Engineering, University of California, 1997.

An update on last planner. In: Annual Conference of the International Group for Lean Construction, 11, 22-24 Jul, 2003. Blacksburg, Virginia, Proceedings...IGLC, 2003.

BARCAUI, A.B.; BORBA, D.; SILVA, I.M.; NEVES, R.B. Gerenciamento do tempo em projetos. 4ed. Rio de Janeiro: Editora FGV, 2013. 160p.

BARRAZA, G.A. Probabilistic estimation and allocation of project time contingency. Journal of Construction Engineering and Management, 2011, Vol.137, No.4. pp. 259-265.

BAYAZIT, N. Investigating design: a review of forty years of design research. Massachusetts Institute of Technology: Design Issues. 2004, Vol. 20, No. 1, pp.16-29.

BERNARDES, M.M.S. Desenvolvimento de um modelo de planejamento e controle da produção para micro e pequenas empresas de produção. 2001. 282p. Tese (Doutorado) - Universidade Federal do Rio Grande do Sul, Porto Alegre, 2001.

BRITISH STANDARD INSTITUTE (BSI). BS 6079-1: Project management Part 1 Principles and guidelines for the management of projects. BSI, 2010. 72p.

CARDIM, R.F.; PICCHI, F.A. Potencial de redução do prazo de empreendimentos através da aplicação de linha de balanço. In: Simpósio Brasileiro de Gestão e Economia da Construção (9.: 2015: São Carlos): Anais... São Carlos: SIBRAGEC ELAGEC, 2015. pp 91-99.

CHAN, D.W.M.; KUMARASWAMY, M.M. A comparative study of causes of time overruns in Hong Kong construction projects. International Journal of Project Management, 1997. Vol.15, No.1, pp.55-63.

CODINHOTO, R. Diretrizes para o planejamento e controle integrado dos processos de projeto e produção na construção civil. 2003. 176p. Dissertação (Mestrado) - Universidade Federal do Rio Grande do Sul. Porto Alegre: PPGEC/UFRGS, 2003.

COELHO, H.O. Diretrizes e requisitos para o planejamento e controle da produção em nível de médio prazo na construção civil. 2003. 134p. Dissertação (Mestrado) - Universidade Federal do Rio Grande do Sul. Porto Alegre: UFRGS/PPGEC, 2003. 
CONTE, A.S.I. Lean construction: from theory to practice. In: Annual Conference of the International Group for Lean Construction, 10, 6-8 Aug, 2002, Gramado, Brazil. Proceedings..., 2002 (pp. 553-561).

COUTO, J. P. Incumprimento dos prazos na construção. 2007. 486p. Tese (Doutorado) - Universidade do Minho, Braga, Portugal, 2007.

DE FILIPPI, G. A.; MELHADO, S. B. Um estudo sobre as causas de atrasos de obras de empreendimentos imobiliários na região Metropolitana de São Paulo. Ambiente Construído, Porto Alegre, 2015, Vol.15, No.3, pp.161-173. (jul./set. 2015).

DOLDIN, B. A practical and accurate alternative to PERT. In: Józefowska, J.; Weglarz, J. (org.). Perspectives in modern project scheduling. Poznan: Springer, 2006, Vol. 92. pp.3-23.

DOLOI, H.; SAWHNEY, A.; IYER, K.C.; RENTALA, S. Analysing factors affecting delays in Indian construction projects. International Journal of Project Management, 2012, Vol.30, No.4, pp.479-489.

DRESCH, A. Design Science e Design Science Research como artefatos metodológicos para engenharia de produção. 2013. 184p. Dissertação (Mestrado) - Universidade do Vale do Rio dos Sinos, São Leopoldo/RS, 2013.

ELDER, A. As cinco doenças do gerenciamento de projetos. No Limits Leadership Inc, 2006, 11p.

ELBELTAGI, E.; DAWOOD, M. Integrated visualized time control system for repetitive construction projects. Automation in Construction, 2011, Vol.20. pp. 940-963.

FABRÍCIO, M.; MELHADO, S. Desafios para integração do processo de projeto na construção de edifícios. São Carlos: Anais ...Workshop Nacional: Gestão do Processo de Projeto na Construção Civil, 2001.

FACHINI, A. C. Subsídios para a programação de estruturas de concreto armado no nível operacional. 2005. 215p. Dissertação (Mestrado) - Escola Politécnica, Universidade de São Paulo. São Paulo, 2005.

FAN, S.L.; TSERNG, H.P. Object-oriented scheduling for repetitive projects with soft logics. Journal of Construction Engineering and Management, 2006, Vol.132, No.1.pp.35-48.

FARIDI, A.S.; EL-SAYEGH, S.M. Significant factors causing delay in the UAE construction industry. Construction Management and Economics, 2006, Vol.24, No.11, pp.1167-1176.

FERREIRA, F.M.P.F.R. Benefícios da aplicação da ferramenta CPM no planejamento operacional e no controle físico da produção na indústria da construção civil: sub-setor de edificações. 2001. Dissertação (Mestrado) - Escola Politécnica, Universidade de São Paulo, São Paulo.

FORMOSO, C.T. Lean construction: princípios básicos e exemplos. Universidade Federal do Rio Grande do Sul. Porto Alegre: NORIE/UFRGS, 2002.

FORMOSO, C.T.; BERNARDES, M.M.S.; OLIVEIRA, L.F.M.; OLIVEIRA, K.A. Termo de referência para o processo de planejamento e controle da produção em empresas construtoras. Universidade Federal do Rio Grande do Sul. Porto Alegre: PPGEC/UFRGS, 1999. 
FORMOSO, C.T.; BERNARDES, M.M.S.; ALVES, T.C.L. Gestão da qualidade na construção civil: estratégias e melhorias de processos em empresas de pequeno porte. Porto Alegre: UFRGS/PPGEC/NORIE, 2001. 58 p. (Relatório de Pesquisa: Proposta de intervenção no sistema de planejamento da produção de empresas de construção civil, Volume 6).

FUGAR, F.D.K.; AGYAKWAH-BAAH, A.B. Delays in building construction projects in Ghana. Australasian Journal of Construction Economics and Building, 2010, Vol. 10, No.1-2, pp.128-141.

GIL, A.C. Como elaborar projetos de pesquisa. 4.ed. 11 reimpr. São Paulo: Atlas, 2008. 175 p.

GOLDRATT, E.M. Corrente crítica. São Paulo: Nobel, 1998. 268p.

GOLDRATT, E.M; FOX,R. A meta: um processo de melhoria contínua. 2ed. São Paulo: Nobel, 2002.

GÜNDUZ, M.; NIELSEN, Y.; ÖZDEMIR, M. Quantification of delay factors using the relative importance index method for construction projects in turkey. Journal of Management in Engineering, 2013, Vol.29, No.2. pp.133-139.

HALPIN, D.W. Construction Management. 3ed. USA: John Wiley e Sons, 2006. 416p.

HALPIN, D.W.; RIGGS, L.S. Planning and analysis of construction operations. New York: Wiley, 1992. 381p.

HAMZEH, F.R., BALLARD, G.; TOMMELEIN, I.D. Rethinking lookahead planning to optimize construction workflow. Lean Construction Journal, 2012, No.2, pp. 15-34.

HANNA, A.; TAYLOR, C.; SULLIVAN, K. Impact of extended overtime on construction labor productivity. Journal of Construction Engineering and Management, 2005, Vol. 131, No. 6. Pp.734-739.

HASEEB, M.; LU, X.; BIBI, A.; DYIAN, M.; RABBANI, W. Problems of projects and effects of delay in the construction industry of Pakistan. Australian Journal of Business and Management Research, 2011, Vol.1, No.5, pp.41-50.

HEGAZY, T.; MENESI, W. Critical path segments scheduling technique. Journal of Construction Engineering and Management, 2010, Vol. 136, No.10. pp.1078-1085.

HEVNER, A.R. A three cycle view of design science research. Scandinavian Journal of Information Systems, 2007, Vol.19, No.2, pp.87-92.

HEVNER, A. R.; MARCH, S.T.; PARK, J. Design Science in information systems research. MIS Quaterly, 2004, Vol.28, No.1, pp.75-105.

HOWELL, G.; BALLARD, G. (1994). Implementing Lean Construction: reducing inflow variation. In: Annual Conference of the International Group for Lean Construction, 2, Set, 1994, Santiago, Chile.. Proceedings... IGLC, 1994 (pp. 93-100).

Implementing Lean Construction: stabilizing workflow. In: Annual Conference of the International Group for Lean Construction, 2, Set, 1994, Santiago, Chile.. Proceedings... IGLC, 1994 (pp. 101-110).

. Implementing Lean Construction: improving downstream performance. In: Annual Conference of the International Group for Lean Construction, 2, Set, 1994, Santiago, Chile.. Proceedings..., 1994 (pp. 111-126). 
HUANG,R.; SUN,K. Non-unit-based planning and scheduling of repetitive construction projects. Journal of Construction Engineering and Management, 2006, Vol.132, No.6. pp. 585-597.

IBBS, W.; NGUYEN, L.D. Schedule analysis under the effect of resource allocation. Journal of Construction Engineering and Management, 2007, Vol.133, No. 2. pp 131-138.

JUNQUEIRA, L.E.J. Aplicação da Lean Construction para redução dos custos de produção da casa 1.0®. 2006 146p. Dissertação (Especialização) - Escola Politécnica, Universidade de São Paulo, Departamento de Engenharia de Produção. São Paulo, 2006.

KALLANTZIS, A.; SOLDATOS, J.; LAMBROPOULOS. Linear versus network scheduling: a critical path comparison. Journal of Construction Engineering and Management, 2007, Vol.133, No.7. pp.483-491.

KENLEY, R.; SEPPÄNEN, O. Location-based management of construction projects: part of a new typology for project scheduling methodologies. In: Winter Simulation Conference: Energy Alternatives, 13-16 December, 2009, Austin, TX, USA. Proceedings..., 2009.

KEMMER, S.L. Análise de diferentes tempos de ciclo na formulação de planos de ataque de edifícios de múltiplos pavimentos. 2006. 122p. Dissertação (Mestrado) - Universidade Federal do Santa Catarina, Florianópolis, 2006.

KEMMER, S.L.; SARAIVA, M.A.; HEINECK, L.F.M.; PACHECO, A.V.L.; NOVAES, M.V. The use of andon in high rise buiding. In: Annual Conference of the International Group for Lean Construction, 14, Jul, 2006, Santiago, Chile.. Proceedings..., 2006 (pp. 575-582).

KERZNER, H. Gestão de projetos: as melhores práticas. 2ed. Porto Alegre: Bookman, 2006. 821p.

KIM, K.; LA GARZA, J.M. Phantom float. Journal of Construction Engineering and Management, 2003, Vol.129, pp.507-517.

Critical path method with multiple calendars. Journal of Construction

Engineering and Management, 2005, Vol.131, No.3. pp.331-342.

KOSKELA, L. Application of the new production philosophy to construction. Technical Report, Filand: CIFE, 1992.

LA GARZA, J.M.; PRETEAPUSANOND, A.; AMBASI, N. Preallocation of total float in the application of a critical path method based construction contract. Journal of Construction Engineering and Management, 2007, Vol.133, No.11. pp.836-845.

LACERDA, D.P.; DRESCH, A.; PROENÇA, A.; ANTUNES Jr.,J.A.V. Design Science Research: método de pesquisa para a engenharia de produção. Gestão da Produção, São Carlos, 2013, Vol. 20, No. 4, pp. 741-761.

LAUFER, A.; TUCKER, R. L. Is construction project planning really doing its job? A critical examination of focus, role and process. Construction Management and Economics, 1987, Vol.5, No.3. pp.243-266.

LIMA Jr., J.R. Decisão e planejamento: fundamentos para a empresa e empreendimentos na construção civil. Texto Técnico TT/PPC/25. São Paulo: Escola Politécnica da Universidade de São Paulo, 2004. 54p. 
LIMMER, C.V. Planejamento, orçamentação e controle de projetos e obras. Rio de Janeiro, Livros Técnicos e Científicos Editora, 1996.

LO, T.Y.; FUNG, I.W. ; TUNG, K.C. Construction delays in Hong Kong civil engineering projects. Journal of Construction Engineering and Management, 2006, Vol.132, No.6, pp.636-649.

LUCKO, G. Productivity scheduling method compared to linear and repetitive project scheduling methods. Journal of Construction Engineering and Management, 2008, Vol.134, No.9. pp. 711-720.

MACHADO, R.L. A sistematização de antecipações gerenciais no planejamento da produção de sistemas da construção civil. 2003. Tese (Doutorado) Universidade Federal de Santa Catarina, Florianópolis/SC, 2003. 264p.

MACHADO, L.; FREITAS JR, J.C.S.; KLEIN, A.Z., FREITAS, A.S. A design research como método de pesquisa de administração: aplicações práticas e lições aprendidas. In: Encontro da ANPAD, 27, 7-11 Set, 2013, Rio de Janeiro/RJ. Anais...ANPAD, 2013.

MARSH, E.R. The harmonogram: an overlooked method of scheduling work. Project Management Quarterly, 1976, Vol. 7, No.1, pp. 21-25.

MARCONI, M.A.; LAKATOS, E.M. Fundamentos de metodologia científica. 6.ed. São Paulo: Atlas, 2008. 315 p.

MARZOUK, M.M.; EL-RASAS, T.I. Analyzing delay causes in Egyptian construction projects. Journal of Advanced Research, 2014, Vol.5, pp. 49-55.

MATTILA, K,G,; PARK, A. Comparison of linear scheduling model and repetitive scheduling method. Journal of Construction Engineering and Management, 2003, Vol.129, No.1. pp.56-64.

MATTOS, A.D. Porque os cronogramas "furam"? Mundo Project Management. Curitiba, Ano 3, No.17, out-nov 2007. pp. 32-37.

. Os 50 anos do PERT/CPM. Mundo Project Management. Curitiba, Ano 5, No.25, fev-mar 2009.

MCDONAGH-PHILP, D.; BRUSEBERG, A. Using focus groups to support new product development. Institution of Engineering Designers Journal, 2000, Vol.26, No.5, pp.4-9.

MELHADO, S.B. Gestão, cooperação e integração para um novo modelo voltado à qualidade do processo de projeto na construção de edifícios. 2001. 235p. Tese (Livre-Docência) - Escola Politécnica, Universidade de São Paulo, São Paulo. 2001.

MENDES, J.R.B.; VALLE, A.B.; FABRA, A.B. Gerenciamento de projetos. 2ed. Rio de Janeiro: Editora FGV, 2014. 218p.

MEREDITH, J.; MANTEL, S. Project management: a managerial approach. 8ed. New York: John Wiley e Sons, 2011. 589p.

MEZHER, T.M.; TAWIL, W. Causes of delays in the construction industry in Lebanon. Engineering, Construction and Architectural Management, 1998, Vol.5, No.3, pp.252-260.

MORAES; R.M.M.; SERRA, S.M.B. Análise e estrutruração do processo de planejamento da produção na construção civil. Revista INGEPRO, 2009, Vol.1, No. 2, pp.65-77. 
MOURA, R.S.L.M.; HEINECK, L.F. Linha de balanço: síntese dos princípios de produção enxuta aplicados à programação de obras? In: Encontro Nacional de Tecnologia do Ambiente Construído-XV ENTAC, 2014, Maceió. Anais..., 2014. pp.1358-1367.

MUBARAK, S. Construction project scheduling and control. 2ed. USA: John Wiley e Sons, 2010. 456p.

MUIANGA, E.A.D.; GRANJA, A.D.; RUIZ, J.A. Desvios de custos e prazos em empreendimentos da construção civil: categorização e fatores de influência. Ambiente Construído, Porto Alegre, 2015, Vol.15, No.1, pp.79-97. (jan./mar. 2015).

MYDIN, O.M.A.;SANI, M.N.;SALIM, A.N.A.;ALIAS, M.N. Assessment of Influential causes of construction project delay in Malaysian private housing from developer's viewpoint. In: Emerging Technology for Sustainable Development Congress (ETSDC 2014), Vol.3. 8p. Bangi, Malaysia, 2014.

NASSAR, K.; HEGAB, M. Developing a complexity measure for project schedules. Journal of Construction Engineering and Management, 2006, Vol. 132, No.6. pp.554-561.

NEPAL, M.P.; PARK, M.; SON, B. Effects of schedule pressure on construction performance. Journal of Construction Engineering and Management, 2006, Vol. 132, No.2. pp. 182-188.

OBERLENDER, G.D. Project management for engineers and construction. McGraw-Hill Science, 2000. 2ed. 384p.

ODEH, A.M.; BATTAINEH, H.T. Causes of construction delay: traditional contracts. International Journal of Project Management, 2002. Vol.20, No.1, pp.67-73.

OHNO, T. O sistema Toyota de produção: além da produção em larga escala. Porto Alegre: Bookman, 1997. 152p.

OLAWALE, Y. A.; SUN, M. Cost and time control of construction projects: inhibiting factors and mitigating measures in practice. Construction Management and Economics, 2010, Vol. 28, No. 5, pp. 509-526.

OLIVIERI, H.; GRANJA, A. D.; PICCHI, F. A. Planejamento tradicional, LocationBased Management System e Last Planner System: um modelo integrado. Ambiente Construído, Porto Alegre, 2016, Vol.16, No.1, pp.265-283. (jan./mar. 2016).

PEREIRA, E.S.S. Fatores associados ao atraso na entrega de edifícios residenciais. 2012. Dissertação (Mestrado) - Universidade Federal de Santa Catarina, Florianópolis/SC, 2003. 204p.

PRITSKER, A.A.B. GERT: graphical evaluation and review technique. Memorandum RM-4973-NASA. National Aeronautics and Space Administration. Santa Monica/CA: RAND Corporation, April 1966.

PROJECT MANAGEMENT INSTITUTE (PMI). Project management body of knowledge: PMBOK Guide. 5ed. Newton Square: PMI, 2013.

QUELHAS, O. BARCAUI, A.B. Corrente crítica: uma alternativa à gerência de projetos tradicional. Revista Pesquisa e Desenvolvimento Engenharia de Produção, 2004, No. 2. pp 1-21. 
REIS, P. Os custos do atraso. Construção Mercado. Set 2010. Ed.110. Disponível em <http://construcaomercado.pini.com.br/negocios-incorporacao-construcao/110> acesso em 26/08/2014.

RICARDINO, R.; SILVA, S.; ALENCAR, C. Causas frequentes de reivindicações contratuais. Revista Engenharia, São Paulo: IE, 2013, Vol.70, No.615, pp.90-94 (mai./jul. 2013).

ROGALSKA, M.; HEJDUCKI, Z. Time buffers in construction process scheduling. Journal of Civil Engineering and Management, 2007, Vol.13, No.2, pp.143-148.

RUSSELL, M.M.; HSIANG, S.M.; LIU, M.; WAMBEKE, B. Causes of time buffer and duration variation in construction project tasks: comparison of perception to reality. Journal of Construction Engineering and Management, 2014, Vol.140, No.6.

SAMBASIVAN, M.; SOON, Y.W. Causes and effects of delays in Malaysian construction industry. International Journal of Project Management, 2007, Vol. 25, No.5, pp. 517-526.

SANTOS, H.P.; STARLING, C.M.D.; ANDERY, P.R.P. Um estudo sobre as causas de aumentos de custos e de prazos em obras de edificações públicas municipais. Ambiente Construído, Porto Alegre, 2015, Vol.15, No.4, pp.225-242. (out./dez. 2015).

SCHÜRCH, H. Der Bau des Talüberganges Bei Langwies an der Elektrischen Bahn Chur-Arosa. Armierter Beton, 1915, No.8, Oktober, pp.229-238.

SERVIÇO BRASILEIRO DE APOIO ÀS MICRO E PEQUENAS EMPRESAS (SEBRAE). (Org.). Anuário do trabalho na micro e pequena empresa, 2013, 6ed, Brasília-DF: DIEESE, 2013. 284 p.

SILVA, E.L.; MENEZES, E.M. Metodologia da pesquisa e elaboração de dissertação. 3ed. Florianópolis: Laboratório de Ensino a Distância da UFSC, 2001.

SINDICATO DA INDUSTRIA DA CONSTRUÇÃO CIVIL DO ESTADO DE SÃO PAULO (SINDUSCON-SP). Indicadores da construção. Conjuntura da Construção, 2014, Ano XII, No. 3. pp.21-31.

SIMON, H. A. The Sciences of the artificial. 3ed. USA: MIT Press, 1996.

SOARES, A.C.; BERNARDES, M.M.S.; FORMOSO, C.T. Improving the production planning and control system in a building company: contributions after stabilization. In: 10th Annual Conference of the International Group for Lean Construction (IGLC-10). Gramado-RS, Aug 2002. Proceedings. pp.477-487.

SOUTO, R.G. Gestão do processo de planejamento da produção em empresas construtoras de edifícios: estudo de caso. 2006. 151p. Dissertação (Mestrado) Escola Politécnica, Universidade de São Paulo, São Paulo, 2006.

SWEIS, G.; SWEIS, R.; ABU HAMMAD, A.; SHBOUL, A. Delays in construction projects: the case of Jordan. International Journal of Project Management, 2008, Vol.26, No.6, pp.665-674.

TAKEDA, H.; VEERKAMP, P.; TOMIYAMA, T.; YOSHIKAWA, H. Modeling Design Processes. Al Magazine. American Association for Artificial Intelligence: 1990, Vol.11, No.4, pp.37-48. 
TAPAI ADVOGADOS. Ações contra construtoras disparam $2600 \%$ nos últimos cinco anos. Disponível em< http://www.tapaiadvogados.com.br/imprensa>em 03/05/2014. Release.

TREMBLAY, M.C.; HERVNER, A.R.; BERNDT, D.J. Focus groups for artifact refinament and evaluation in Design Research. Communications of the Association for Information Systems, 2010, Vol. 26, No.27, pp. 599-618.

UNIVERSIDADE DE SÃO PAULO. Sistema Integrado de Bibliotecas. Grupo DiTeses. Diretrizes para apresentação de dissertações e teses da USP: documento eletrônico e impresso. Coord. Funaro, V.M.B.O. ...[et al.] São Paulo : SIBi-USP, 2004. 115p. (Caderno de estudos;9).

VAISHNAVI, V.; KUECHLER, W. Design research in information systems. Portal Desrist - Design Science Research in Information Systems and Technology, Overview. Disponível em: <http://desrist.org/design-research-in-informationsystems>. Acesso em: 11 nov. 2015.

VANHOUCKE, M. Work continuity constraints in project scheduling. Journal of Construction Engineering and Management, 2006, Vol. 132, No. 1. pp. 14-25.

Project management with dynamic scheduling: baseline scheduling, risk analysis and project control. Berlin: Springer, 2012. 310p.

VARALLA, R. Planejamento e controle de obras. São Paulo: O Nome da Rosa, 2003.

WINCH, G.M.; NORTH, S. Project planning and design back to search results. Critical space analysis. Journal of Construction Engineering and Management, 2006, Vol.132, No.5. pp. 473-481.

YANG, J.B.; WEI, P. Causes of delay in the planning and design phases for construction projects. Journal of Architectural Engineering, 2010, Vol.16, No.2. pp.80-83.

YI, K.; LEE, H.; CHOI, Y. Network creation and development for repetitive-unit projects. Journal of Construction Engineering and Management, 2002, Vol.128, No. 3. pp 257-264.

YIN, R.K. Estudo de caso: planejamento e métodos. 4ed. Porto Alegre: Bookman, 2010. 248 p. 
APÊNDICE A - RESULTADO COMPLETO DA PRIMEIRA PESQUISA (50 OBRAS)

\begin{tabular}{|c|c|c|c|c|c|c|c|c|c|c|c|c|c|c|c|c|c|c|c|c|c|c|c|c|c|c|c|c|c|c|c|c|c|c|c|c|}
\hline \multicolumn{7}{|c|}{$\begin{array}{l}\text { 5. Contratado Principal / } \\
\text { Empreiteiro (continua) }\end{array}$} & \multicolumn{8}{|c|}{ 4. Projeto / Design } & \multicolumn{7}{|c|}{ 3. Consultores / Gestores } & \multicolumn{8}{|c|}{ 2. Empreendedor / Cliente } & \multicolumn{6}{|c|}{ 1. Escopo / Contrato } & 告 \\
\hline 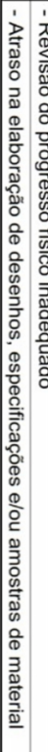 & 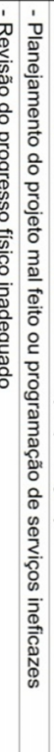 & 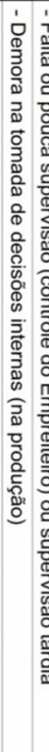 & 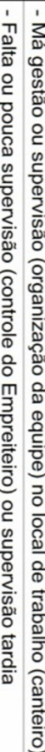 & & 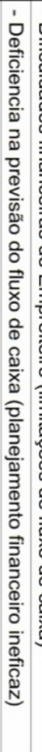 & 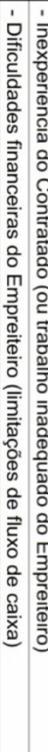 & & 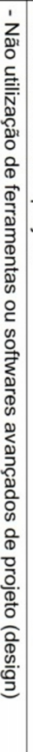 & 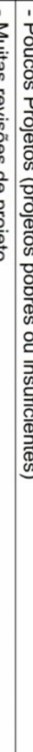 & & & 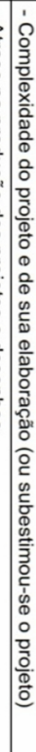 & 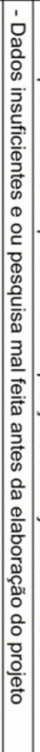 & & 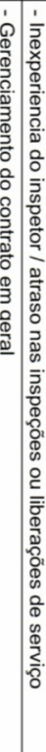 & & 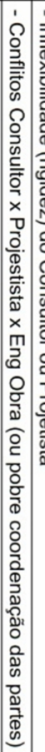 & 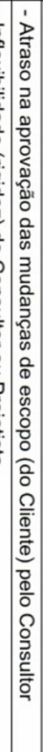 & 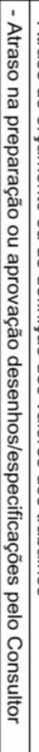 & 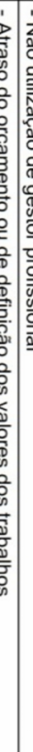 & 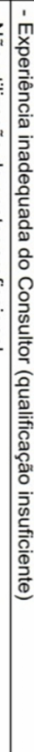 & & 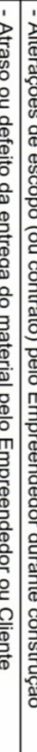 & 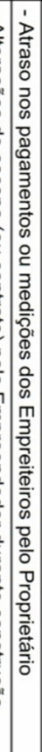 & & 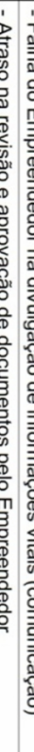 & & & & 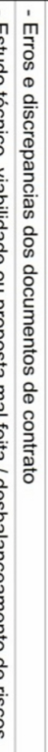 & 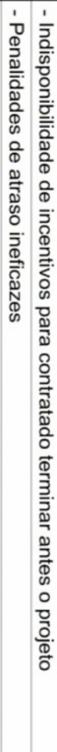 & & 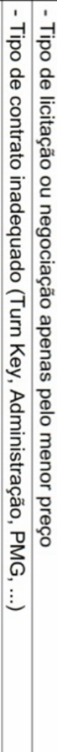 & 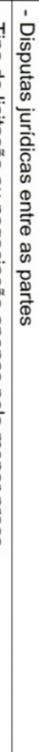 & 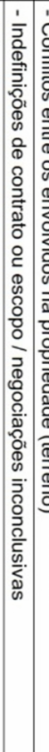 & 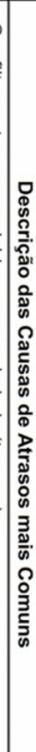 \\
\hline$\vec{\omega} \bumpeq$ & N. & & $\overrightarrow{\mathrm{v}}$ & 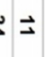 & or & $\infty \overrightarrow{+}$ & N & $\omega$ & - & $\vec{o}$ & & $=$ & N & & $ه-$ & $\vec{\Delta}$ & $v c$ & $\infty$ & $\bullet$ & & - & t & $\rightarrow$ & 0 & & $\overrightarrow{0} 0$ & & & & $+\infty$ & $\infty \sim$ & & $\vec{\omega}$ or & $n$ & & 豆 \\
\hline & $\times \times$ & $x>$ & $\times>$ & $x$ & $x$ & $x$ & & & & & & $x$ & $x$ & & $x$ & & $x$ & & & & & & & $x$ & & & & & $\times$ & $x$ & $\times$ & & $x$ & & & 1 \\
\hline$x$ & $x$ & & $x$ & & & & & & & & & & & & & & & & $x$ & & & & & & & $x$ & & $x_{0}$ & $\times$ & & & $x$ & & & & 2 \\
\hline & & $x$ & & & $x$ & $x$ & & & $x$ & & & $x$ & & & 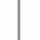 & & & $x$ & & $x$ & & & & & $x$ & & & $x$ & & & & $x$ & & & & 3 \\
\hline & $x$ & & $x$ & 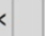 & & & & & & $x$ & $x$ & & & & $x$ & & & & & & & & & & & & & & & & & & & & & 4 \\
\hline$x$ & $x$ & $>$ & $x \times$ & & & & & & & & & & & & $x$ & $x$ & & & & & & & & & & & & & & & & & & & & 5 \\
\hline & & & $\times$ & 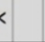 & & $x$ & & & & & & & & & & $\times$ & & $x$ & & & & & & & & $x$ & & $x$ & $x$ & $x$ & & & & & & 6 \\
\hline$\times$ & & & $x \times$ & & & $x$ & & & & $x$ & & $x$ & & & & & & & $x$ & & & & & & & & & & & & & & & & & 7 \\
\hline$>$ & $x$ & & $\times$ & & & & & & & & & $\times$ & & & & $\times$ & $x$ & $x$ & $\times$ & & & & $>$ & & & $x$ & & $x$ & & & & & & & & 8 \\
\hline$\times$ & $x$ & & $\times>$ & & $\times$ & & & & & $x$ & $\times$ & & & & $x$ & & & & $x$ & & & & & & & $x$ & & $x$ & $\times$ & $x \times$ & & & $\times$ & & $x$ & 9 \\
\hline & $x$ & $x$ & & & & & & & & & & & & & & & & & & & & & & $\times$ & $x$ & ${ }^{2}$ & $x$ & & $\times$ & & $\times$ & & & & & 10 \\
\hline & & & $x$ & $\mathrm{k}$ & & $>$ & & & & & & & & & & & & & & & & & & & & & $x$ & & & $x$ & $x \times$ & $x$ & & & & 11 \\
\hline & $x$ & & & & & $x$ & & & & $x$ & & & & & $x \times$ & & & & & $x$ & & & & & & & & & $x$ & $x \times$ & $x$ & & & & $\times$ & 12 \\
\hline & $\times$ & & & & & & & & & & & & & & & & & & $\times$ & & & & & $x$ & & & & & $\times$ & $\times$ & $\times$ & & & & & 13 \\
\hline & $x$ & & $\times$ & r & & & & & & & & & & & & & & & & & & & $\times$ & $x$ & & & & & $\times$ & & $x$ & & & & & 14 \\
\hline & & & $x$ & r & & & & & & & & $\times$ & & & $\times$ & & & & & & & & & & $x$ & & $>$ & & & & & $x$ & & & & 15 \\
\hline & $x$ & & $\times$ & $x \times$ & & $x$ & & & & $x$ & $\times$ & $\times$ & & & & & & & $\times$ & & & & $>$ & & & $?$ & $>$ & & & & $\times$ & & $\times$ & & & 16 \\
\hline & & & & & & & & & & & & & & & & & & & & & & & & & & & & & & & $\times$ & & $\times$ & & & 17 \\
\hline & & & & & & & & & & & & & & & & & & & $\times$ & & & $\times$ & $>$ & & & $\times$ & & & & & & & $\rtimes$ & & $\times$ & 18 \\
\hline & $x$ & $\times$ & & $x$ & & & $\times$ & & & $x$ & $\times$ & & & $x$ & & $\times$ & & $x$ & $\times$ & $\times$ & & & $>$ & $x$ & & r & & $\times$ & $\times$ & & & & $\times$ & & $\times$ & 19 \\
\hline$>$ & $x$ & $\times$ & & $x \times$ & & & & & & $\times$ & $x$ & & & & & $\times$ & & & & & & & & $\times$ & & ? & $>$ & & $\times$ & & & $\times$ & $\times$ & & $\times$ & 20 \\
\hline & $\times \times$ & & & & & $>$ & & & & & & & & & & & & & & & $x \times$ & & & $x$ & & 2 & & & & & $\times$ & & $\times$ & $x$ & & 21 \\
\hline & $\times \times$ & & $\times$ & k & & & & & & & & & & & & & & & & & & & & & & & & & 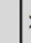 & $x$ & $x$ & $x$ & & & & 22 \\
\hline & & & $>$ & K & & & & & & & & & & & & $\times$ & & & & & & & & & & & & & & & & $\times$ & & & & 23 \\
\hline & $x$ & $\times$ & & & & $x$ & & & & & & $\times$ & & & $\times$ & & $\times$ & & & & & & $>$ & & & & $>$ & & & & & & & & & 24 \\
\hline & & & $\times$ & $k$ & & & & & & & & & & & & & & $\times$ & & & & & & $\times$ & & & & & & & & & & & & 25 \\
\hline
\end{tabular}




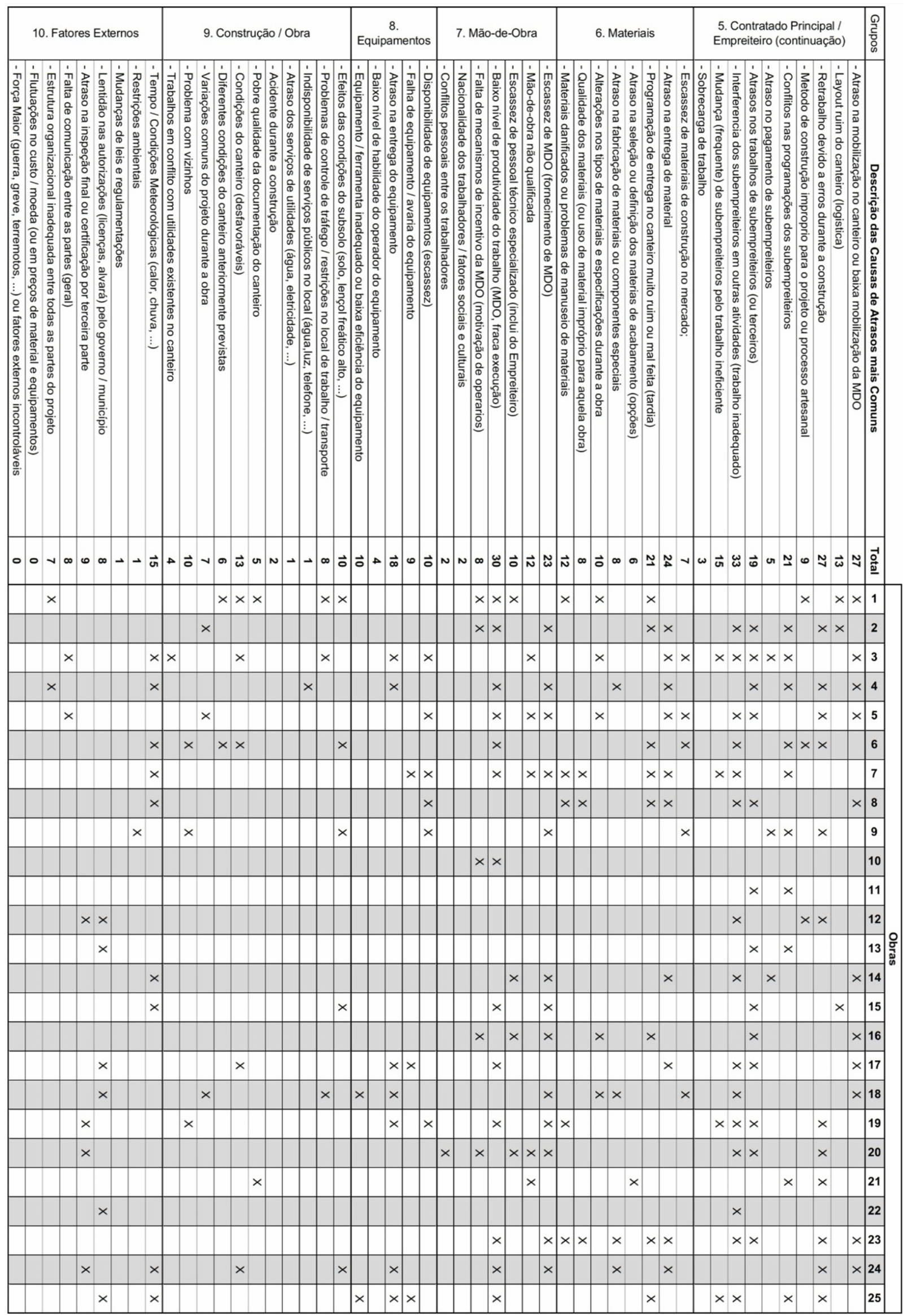




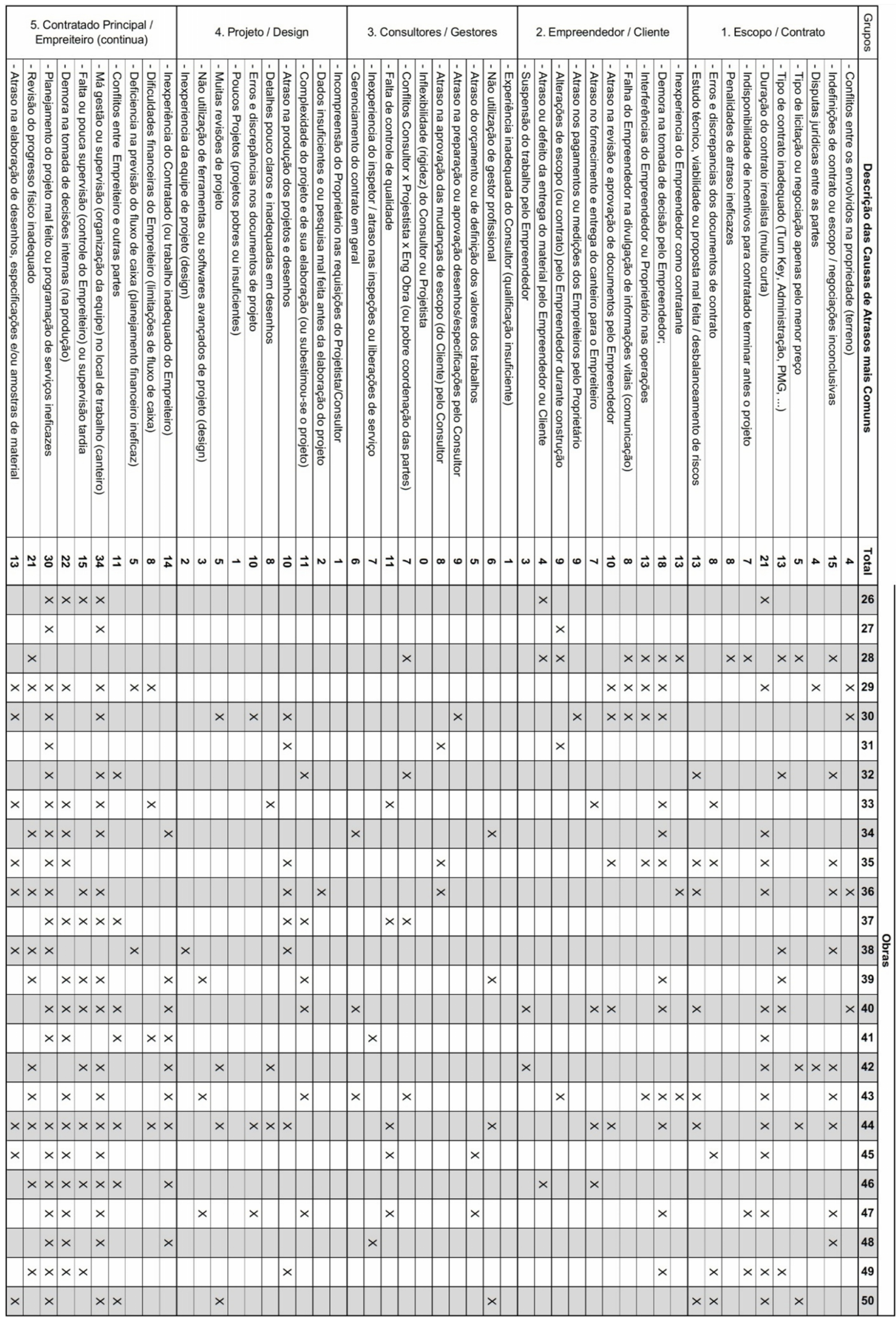




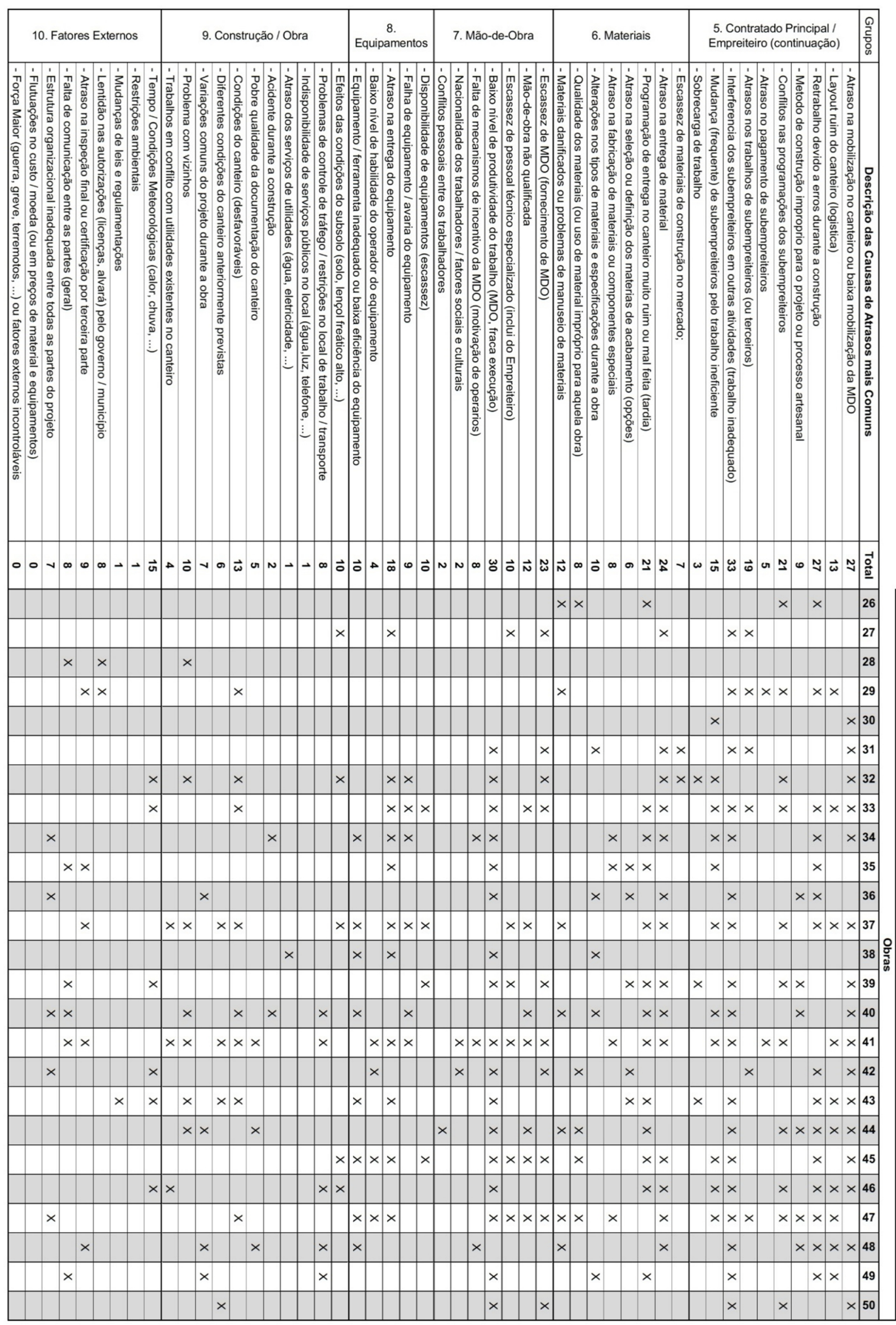




\section{APÊNDICE B - COMPILAÇÃO COMPLETA DA PRIMEIRA PESQUISA (ESTABELECIMENTO DO RANKING DE CAUSAS MAIS FREQUENTES)}

\begin{tabular}{|c|c|c|c|}
\hline № Obras & Grupo & Causa analisada em cada obra & Frequência \\
\hline 34 & 5 & - Má gestão ou supervisão (organização da equipe) no local de trabalho (canteiro) & $68,0 \%$ \\
\hline 33 & 5 & - Interferencia dos subempreiteiros em outras atividades (ou trabalho inadequado) & $66,0 \%$ \\
\hline 30 & 5 & - Planejamento do projeto mal feito ou programação de serviços ineficazes & $60,0 \%$ \\
\hline 30 & 7 & - Baixo nível de produtividade do trabalho (MDO, fraca execução) & $60,0 \%$ \\
\hline 27 & 5 & - Atraso na mobilização no canteiro ou baixa mobilização da MDO & $54,0 \%$ \\
\hline 27 & 5 & - Retrabalho devido a erros durante a construção & $54,0 \%$ \\
\hline 24 & 6 & - Atraso na entrega de material & $48,0 \%$ \\
\hline 23 & 7 & - Escassez de MDO (fornecimento de MDO) & $46,0 \%$ \\
\hline 22 & 5 & - Demora na tomada de decisões internas (na produção) & $44,0 \%$ \\
\hline 21 & 5 & - Revisão do progresso físico inadequado & $42,0 \%$ \\
\hline 21 & 5 & - Conflitos nas programações dos subempreiteiros & $42,0 \%$ \\
\hline 21 & 6 & - Programação de entrega no canteiro muito ruim ou mal feita (tardia) & $42,0 \%$ \\
\hline 21 & 1 & - Duração do contrato irrealista (muito curta) & $42,0 \%$ \\
\hline 19 & 5 & - Atrasos nos trabalhos de subempreiteiros (ou terceiros) & $38,0 \%$ \\
\hline 18 & 2 & - Demora na tomada de decisão pelo Empreendedor; & $36,0 \%$ \\
\hline 18 & 8 & - Atraso na entrega do equipamento & $36,0 \%$ \\
\hline 15 & 1 & - Indefinições de contrato ou escopo / negociações inconclusivas & $30,0 \%$ \\
\hline 15 & 5 & - Falta ou pouca supervisão (controle do Empreiteiro) ou supervisão tardia & $30,0 \%$ \\
\hline 15 & 5 & - Mudança (frequente) de subempreiteiros pelo trabalho ineficiente & $30,0 \%$ \\
\hline 15 & 10 & - Tempo / Condições Meteorológicas (calor, chuva, ...) & $30,0 \%$ \\
\hline 14 & 5 & - Inexperiência do Contratado (ou trabalho inadequado do Empreiteiro) & $28,0 \%$ \\
\hline 13 & 1 & - Tipo de contrato inadequado (Turn Key, Administração, PMG, ...) & $26,0 \%$ \\
\hline 13 & 1 & - Estudo técnico, viabilidade ou proposta mal feita / desbalanceamento de riscos & $26,0 \%$ \\
\hline 13 & 2 & - Inexperiencia do Empreendedor como contratante & $26,0 \%$ \\
\hline 13 & 2 & - Interferências do Empreendedor ou Proprietário nas operações & $26,0 \%$ \\
\hline 13 & 5 & - Atraso na elaboração de desenhos, especificações e/ou amostras de material & $26,0 \%$ \\
\hline 13 & 5 & - Layout ruim do canteiro (logistica) & $26,0 \%$ \\
\hline 13 & 9 & - Condições do canteiro (desfavoráveis) & $26,0 \%$ \\
\hline 12 & 6 & - Materiais danificados ou problemas de manuseio de materiais & $24,0 \%$ \\
\hline 12 & 7 & - Mão-de-obra não qualificada & $24,0 \%$ \\
\hline 11 & 3 & - Falta de controle de qualidade & $22,0 \%$ \\
\hline 11 & 4 & - Complexidade do projeto e de sua elaboração (ou subestimou-se o projeto) & $22,0 \%$ \\
\hline 11 & 5 & - Conflitos entre Empreiteiro e outras partes & $22,0 \%$ \\
\hline 10 & 2 & - Atraso na revisão e aprovação de documentos pelo Empreendedor & $20,0 \%$ \\
\hline 10 & 4 & - Atraso na produção dos projetos e desenhos & $20,0 \%$ \\
\hline 10 & 4 & - Erros e discrepâncias nos documentos de projeto & $20,0 \%$ \\
\hline 10 & 6 & - Alterações nos tipos de materiais e especificações durante a obra & $20,0 \%$ \\
\hline 10 & 7 & - Escassez de pessoal técnico especializado (inclui do Empreiteiro) & $20,0 \%$ \\
\hline 10 & 8 & - Disponibilidade de equipamentos (escassez) & $20,0 \%$ \\
\hline 10 & 8 & - Equipamento / ferramenta inadequado ou baixa eficiência do equipamento & $20,0 \%$ \\
\hline 10 & 9 & - Efeitos das condições do subsolo (solo, lençol freático alto, ...) & $20,0 \%$ \\
\hline 10 & 9 & - Problema com vizinhos & $20,0 \%$ \\
\hline 9 & 2 & - Atraso nos pagamentos ou medições dos Empreiteiros pelo Proprietário & $18,0 \%$ \\
\hline 9 & 2 & - Alterações de escopo (ou contrato) pelo Empreendedor durante construção & $18,0 \%$ \\
\hline 9 & 3 & - Atraso na preparação ou aprovação de desenhos/especificações pelo Consultor & $18,0 \%$ \\
\hline 9 & 5 & - Metodo de construção improprio para o projeto ou processo artesanal & $18,0 \%$ \\
\hline 9 & 8 & - Falha de equipamento / avaria do equipamento & $18,0 \%$ \\
\hline 9 & 10 & - Atraso na inspeção final ou certificação por terceira parte & $18,0 \%$ \\
\hline 8 & 1 & - Penalidades de atraso ineficazes & $16,0 \%$ \\
\hline 8 & 1 & - Erros e discrepancias dos documentos de contrato & $16,0 \%$ \\
\hline
\end{tabular}




\begin{tabular}{|c|c|c|c|}
\hline № Obras & Grupo & Causa analisada em cada obra & Frequência \\
\hline 8 & 2 & - Falha do Empreendedor na divulgação de informações vitais (comunicação) & $16,0 \%$ \\
\hline 8 & 3 & - Atraso na aprovação das mudanças de escopo (do Cliente) pelo Consultor & $16,0 \%$ \\
\hline 8 & 4 & - Detalhes pouco claros e inadequadas em desenhos & $16,0 \%$ \\
\hline 8 & 5 & - Dificuldades financeiras do Empreiteiro (limitações de fluxo de caixa) & $16,0 \%$ \\
\hline 8 & 6 & - Atraso na fabricação de materiais ou componentes especiais & $16,0 \%$ \\
\hline 8 & 6 & - Qualidade dos materiais (ou uso de material impróprio para aquela obra) & $16,0 \%$ \\
\hline 8 & 7 & - Falta de mecanismos de incentivo da MDO (motivação de operarios) & $16,0 \%$ \\
\hline 8 & 9 & - Problemas de controle de tráfego / restrições no local de trabalho / transporte & $16,0 \%$ \\
\hline 8 & 10 & - Lentidão nas autorizações (licenças, alvará) pelo governo / município & $16,0 \%$ \\
\hline 8 & 10 & - Falta de comunicação entre as partes (geral) & $16,0 \%$ \\
\hline 7 & 1 & - Indisponibilidade de incentivos para contratado terminar antes o projeto & $14,0 \%$ \\
\hline 7 & 2 & - Atraso no fornecimento e entrega do canteiro para o Empreiteiro & $14,0 \%$ \\
\hline 7 & 3 & - Conflitos Consultor x Projestista x Eng Obra (ou pobre coordenação das partes) & $14,0 \%$ \\
\hline 7 & 3 & - Inexperiencia do inspetor / atraso nas inspeções ou liberações de serviço & $14,0 \%$ \\
\hline 7 & 6 & - Escassez de materiais de construção no mercado; & $14,0 \%$ \\
\hline 7 & 9 & - Variações comuns do projeto durante a obra & $14,0 \%$ \\
\hline 7 & 10 & - Estrutura organizacional inadequada entre todas as partes do projeto & $14,0 \%$ \\
\hline 6 & 3 & - Não utilização de gestor profissional & $12,0 \%$ \\
\hline 6 & 3 & - Gerenciamento do contrato em geral & $12,0 \%$ \\
\hline 6 & 6 & - Atraso na seleção ou definição dos materias de acabamento (opções) & $12,0 \%$ \\
\hline 6 & 9 & - Diferentes condições do canteiro anteriormente previstas & $12,0 \%$ \\
\hline 5 & 1 & - Tipo de licitação ou negociação apenas pelo menor preço & $10,0 \%$ \\
\hline 5 & 3 & - Atraso do orçamento ou de definição dos valores dos trabalhos & $10,0 \%$ \\
\hline 5 & 4 & - Muitas revisões de projeto & $10,0 \%$ \\
\hline 5 & 5 & - Deficiencia na previsão do fluxo de caixa (planejamento financeiro ineficaz) & $10,0 \%$ \\
\hline 5 & 5 & - Atraso no pagamento de subempreiteiros & $10,0 \%$ \\
\hline 5 & 9 & - Pobre qualidade da documentação do canteiro & $10,0 \%$ \\
\hline 4 & 1 & - Conflitos entre os envolvidos na propriedade (terreno) & $8,0 \%$ \\
\hline 4 & 1 & - Disputas jurídicas entre as partes & $8,0 \%$ \\
\hline 4 & 2 & - Atraso ou defeito da entrega do material pelo Empreendedor ou Cliente & $8,0 \%$ \\
\hline 4 & 8 & - Baixo nível de habilidade do operador do equipamento & $8,0 \%$ \\
\hline 4 & 9 & - Trabalhos em conflito com utilidades existentes no canteiro & $8,0 \%$ \\
\hline 3 & 2 & - Suspensão do trabalho pelo Empreendedor & $6,0 \%$ \\
\hline 3 & 4 & - Não utilização de ferramentas ou softwares avançados de projeto (design) & $6,0 \%$ \\
\hline 3 & 5 & - Sobrecarga de trabalho & $6,0 \%$ \\
\hline 2 & 4 & - Dados insuficientes e ou pesquisa mal feita antes da elaboração do projeto & $4,0 \%$ \\
\hline 2 & 4 & - Inexperiencia da equipe de projeto (design) & $4,0 \%$ \\
\hline 2 & 7 & - Nacionalidade dos trabalhadores / fatores sociais e culturais & $4,0 \%$ \\
\hline 2 & 7 & - Conflitos pessoais entre os trabalhadores & $4,0 \%$ \\
\hline 2 & 9 & - Acidente durante a construção & $4,0 \%$ \\
\hline 1 & 3 & - Experiência inadequada do Consultor (qualificação insuficiente) & $2,0 \%$ \\
\hline 1 & 4 & - Incompreensão do Proprietário nas requisições do Projetista/Consultor & $2,0 \%$ \\
\hline 1 & 4 & - Poucos Projetos (projetos pobres ou insuficientes) & $2,0 \%$ \\
\hline 1 & 9 & - Indisponibilidade de serviços públicos no local (água,luz, telefone, ...) & $2,0 \%$ \\
\hline 1 & 9 & - Atraso dos serviços de utilidades (água, eletricidade, ...) & $2,0 \%$ \\
\hline 1 & 10 & - Restrições ambientais & $2,0 \%$ \\
\hline 1 & 10 & - Mudanças de leis e regulamentações & $2,0 \%$ \\
\hline 0 & 3 & - Inflexibilidade (rigidez) do Consultor ou Projetista & $0,0 \%$ \\
\hline 0 & 10 & - Flutuações no custo / moeda (ou em preços de material e equipamentos) & $0,0 \%$ \\
\hline 0 & 10 & - Força Maior (guerra, greve, terremotos, ...) ou fatores externos incontroláveis & $0,0 \%$ \\
\hline
\end{tabular}

